\title{
Biotic and abiotic controls on microbial activity, functionality and processes in soil hotspots
}

\author{
Dissertation \\ to attain the doctoral degree (Dr. rer. nat.) \\ of the Faculty of Agricultural Sciences \\ Georg-August-Universität Göttingen
}

Submitted by

Xuechen Zhang

Born on June 1992 in Hebei, China

Göttingen, August 2021 
$1^{\text {st }}$ Referee: Prof. Dr. Michaela Dippold

$2^{\text {nd }}$ Referee: Prof. Dr. Sandra Spielvogel

$3^{\text {rd }}$ Referee: Prof. Dr. Bahar S. Razavi

$4^{\text {th }}$ Referee: Prof. Dr. Andrea Polle

$5^{\text {th }}$ Referee: Prof. Dr. Magdalena Frąc

Date of the oral examination: 12 July 2021 


\section{Summary}

When a carbon $(\mathrm{C})$ source is added to a soil volume and causes microorganisms to thrive, a microbial hotspot is formed - a microsite with much higher process rates than the surrounding bulk soil. The formation, size, and lifetime of microbial hotspots in the vicinity of growing roots (rhizosphere) are governed by biotic and abiotic factors. Root exudation stimulates the production of extracellular enzymes and thus soil organic matter (SOM) decomposition. Nonetheless, we lack a mechanistic understanding of the enzymatic response of rhizosphere microorganisms to individual component of the root exudates. The extent and spatial distribution of rhizosphere depend on soil matrix (e.g. soil nutrient availability), plant properties (e.g. root morphology) and climate changes (e.g. warming and drought). The ongoing global change and the manipulation of exudate composition or root morphology often occur simutaneously, but the consequences of their interactive effects on microbial processes are poorly understood. For example, how the presence of root hairs regulates exudate input and microbial strategies in response to climate changes remains unknown. Therefore, this thesis coupled novel methods including high-throughout sequencing and in situ imaging approaches to demonstrate the effects of biotic or abiotic factors and their interactions on microbial localization, community structure, activity, strategy and efficiency. The objectives of this thesis are to investigate: 1) which component of root exudates plays the key role in stimulating microbial enzyme activities in the absence of living roots and how the presence of root hairs or the presence or absence of inhibitory substances within root exudates influences the formation of rhizosphere gradients; 2) the effect of soil nutrient availability on kinetic parameters in hotspots and bulk soil; 3) whether the response of enzyme activities to drought is driven by the selection of drought-resistant microorganisms; 4) how interactions of root hairs and warming or interactions of root hairs and drought affect the spatial distribution of enzyme activities and unravel strategies for plants and microorganisms to adapt to climate changes.

Using artificial roots in combination with specific exudate components, we identified that the spatial distribution of microbial-derived enzyme activities is enzyme- and componentspecific: 1) alanine had the overall strongest effect in this nitrogen (N)-limited soil; 2) the activities of phosphorus (P)-, N- and sulfur (S)-related enzymes showed clear gradients in the rhizosphere while the pattern for enzymes majorly involved in C-cycling was uniform and independent of the exudate composition. We also found benzoxazinoids presented in exudates suppressed $\beta$-glucosidase activity by $30 \%$ (mutant with reduced benzoxazinoid 
content in exudates ( $b x l) v s$. its corresponding wild type maize), but the presence of root hairs increased exudate release and expanded the spatial extent of $\beta$-glucosidase activity around the root axis by $35 \%$ (mutant with defective root hair prolongation (rth3) vs. its corresponding wild type maize).

Apart from biotic factors, abiotic factors have fundamental effects on microbial processes and microbial community structure. Effects of soil $\mathrm{C}$ and nutrients status on functional properties of microorganisms in soil hotspots were investigated by coupling zymography and measurements of kinetics of substrate-induced growth response and enzyme activities in two soils with contrasting soil nutrient availability. The result showed that: 1) differences in microbial growth strategy between rhizosphere hotspots and bulk soil were dependent on soil nutrient availability; 2) differences in enzyme activity and affinity were detected between hotspots and bulk soil in both soils but were enzyme-specific: the difference was significant for $\beta$-glucosidase, whereas it was insignificant for leucine aminopeptidase.

Drought (another abiotic factor) only induced minor changes in bacterial community structure in rhizosphere hotspots, instead, it increased relative abundance of genera belonging to Actinobacteria capable of leucine aminopeptidase and chitinase production and thus induced a 5.0 - 17\% increase in the number of gene copies encoded by Actinobacteria related to these two enzymes. This was reflected in a $35-70 \%$ increase in the activities of leucine aminopeptidase and chitinase under drought. This demonstrates that bacterial communities react to drought stress by increasing extracellular enzyme production and they achieve this by encoding more enzyme - genes.

Root hairs proliferation and warming strongly influence exudate release, enzyme activities and microbial substrate utilization. To reveal their interactions, mutant with defective root hair prolongation ( $r$ th 3 ) and its corresponding wild type maize were grown for 3 weeks at 20 and $30{ }^{\circ} \mathrm{C}$, respectively. Root hairs regulated enzyme expression, microbial growth strategies and thus substrate use efficiency, hence mediating the SOM stocks in response to warming. To clarify the relative importance of biotic and abiotic factors, we conducted an experiment considering the interactive effects of root hairs and drought. The result showed that both root hairs and soil moisture influenced spatial distribution of rhizosphere biochemical properties and processes, but soil water availability was more important than root exudates when the soil is limited by both water and C sources.

In summary, both biotic and abiotic factors could influence microbial processes in hotspots. The role of root hairs was diminished when interacting with drought even though it was of 
great importance in regulating enzyme systems and microbial growth to adapt to climate warming. Therefore, we suggest that predicting and modeling soil $\mathrm{C}$ and nutrient dynamics should not only incorporate the interactive effects of biotic and abiotic factors, but also consider which factor involved in the interaction. Overall, this thesis strongly contributes to the understanding of mechanisms involved in the hotspot's processes. This is particularly crucial for agro-ecosystems where many essential ecosystem services relevant to human well-being are linked to micro-scale processes occurring in hotspots. 


\section{Zusammenfassung}

Wenn einem Bodenvolumen eine Kohlenstoffquelle (C) zugesetzt wird und Mikroorganismen gedeihen, entsteht ein mikrobieller Hotspot - eine Microsite mit viel höheren Prozessraten als der umgebende Schüttboden. Die Bildung, Größe und Lebensdauer von mikrobiellen Hotspots in der Nähe wachsender Wurzeln (Rhizosphäre) wird von biotischen und abiotischen Faktoren bestimmt. Wurzelexsudation stimuliert die Produktion von extrazellulären Enzymen und damit die Zersetzung organischer Bodensubstanz (SOM). Dennoch fehlt uns ein mechanistisches Verständnis der enzymatischen Reaktion von Rhizosphären-Mikroorganismen auf einzelne Verbindungen von Wurzelexsudaten. Das Ausmaß und die räumliche Verteilung der Rhizosphäre hängen von der Bodenmatrix (z. B. Verfügbarkeit von Bodennährstoffen), den Pflanzeneigenschaften (z. B. Wurzelmorphologie) und den Klimaveränderungen (z. B. Erwärmung und Trockenheit) ab. Der anhaltende globale Wandel und die Manipulation der Exsudationszusammensetzung oder der Wurzelmorphologie treten häufig gleichzeitig auf, aber die Konsequenzen ihrer interaktiven Auswirkungen auf mikrobielle Prozesse sind kaum bekannt. Zum Beispiel ist unbekannt, wie das Vorhandensein von Wurzelhaaren den Exsudationseingang und mikrobielle Strategien als Reaktion auf den Klimawandel reguliert. In dieser Arbeit wurden daher neuartige Methoden gekoppelt, einschließlich hochgradiger Sequenzierungs- und In-situBildgebungsansätze, um die Auswirkungen biotischer oder abiotischer Faktoren und ihre Wechselwirkungen auf die mikrobielle Lokalisierung, die Gemeinschaftsstruktur, die Aktivität, die Strategie und die Effizienz zu demonstrieren.

Ziel dieser Arbeit ist es zu untersuchen: 1) welche Komponente von Wurzelexsudaten die Schlüsselrolle bei der Stimulierung mikrobieller Enzymaktivitäten in Abwesenheit lebender Wurzeln spielt und wie das Vorhandensein von Wurzelhaaren oder das Vorhandensein oder Fehlen von hemmenden Substanzen in Wurzelexsudaten die Bildung von Rhizosphärengradienten beeinflusst; 2) die Auswirkung der Nährstoffverfügbarkeit des Bodens auf die kinetischen Parameter in Hotspots und Schüttböden; 3) ob die Reaktion der Enzymaktivitäten auf Trockenheit von der Auswahl dürreresistenter Mikroorganismen abhängt; 4) wie Wechselwirkungen von Wurzelhaaren und Erwärmung oder Wechselwirkungen von Wurzelhaaren und Trockenheit die räumliche Verteilung von Enzymaktivitäten beeinflussen und Strategien für Pflanzen und Mikroorganismen zur Anpassung an den Klimawandel aufdecken. 
Unter Verwendung künstlicher Wurzeln in Kombination mit einer spezifischen Exsudatverbindung stellten wir fest, dass die räumliche Verteilung der von Mikroben abgeleiteten Enzymaktivitäten enzym- und komponentenspezifisch ist: 1) Alanin hatte die insgesamt stärkste Wirkung in diesem stickstoff (N) -begrenzten Boden; 2) die Aktivitäten von Phosphor (P)-, N- und Schwefel (S)-verwandten Enzymen zeigten klare Gradienten in der Rhizosphäre, während das Muster für Enzyme, die hauptsächlich am C-Zyklus beteiligt sind, einheitlich und unabhängig von der Exsudatzusammensetzung war. Wir fanden auch, dass in Exsudaten präsentierte Benzoxazinoide die $\beta$-Glucosidase-Aktivität um 30\% unterdrückten (Mutante mit reduziertem Benzoxazinoidgehalt in Exsudaten (bx1) gegenüber dem entsprechenden Wildtyp-Mais), aber das Vorhandensein von Wurzelhaaren erhöhte die Exsudatfreisetzung und erweiterte das räumliche Ausmaß von $\beta$-Glucosidase-Aktivität um die Wurzelachse um 35\% (Mutante mit defekter Wurzelhaarverlängerung (rth3) gegenüber dem entsprechenden Wildtyp-Mais).

Neben biotischen Faktoren haben abiotische Faktoren grundlegende Auswirkungen auf mikrobielle Prozesse und die Struktur der mikrobiellen Gemeinschaft. Die Auswirkungen von Boden C und Nährstoffstatus auf die funktionellen Eigenschaften von Mikroorganismen in Boden-Hotspots wurden durch Kopplungszymographie und Messungen der Kinetik der substratinduzierten Wachstumsreaktion und der Enzymaktivitäten in zwei Böden mit gegensätzlicher Bodennährstoffverfügbarkeit untersucht. Das Ergebnis zeigte, dass: 1) Unterschiede in der Strategie des mikrobiellen Wachstums zwischen Rhizosphären-Hotspots und Bulk-Boden von der Nährstoffverfügbarkeit des Bodens abhängen; 2) Unterschiede in der Enzymaktivität und -affinität wurden zwischen Hotspots und Bulk-Boden sowohl in fruchtbaren als auch in armen Böden festgestellt, waren jedoch enzymspezifisch: Der Unterschied war für $\beta$-Glucosidase signifikant, während er für Leucin-Aminopeptidase unbedeutend war.

Dürre (ein weiterer abiotischer Faktor) führte nur zu geringfügigen Veränderungen der Struktur der Bakteriengemeinschaft in Rhizosphären-Hotspots. Stattdessen erhöhte sie die relative Häufigkeit von Gattungen von Actinobakterien, die zur Produktion von Leucinaminopeptidase und Chitinase fähig sind, und damit die Anzahl der Genkopien um 5,0 bis $17 \%$ kodiert von Actinobakterien, die mit diesen beiden Enzymen verwandt sind. Dies spiegelte sich in einem Anstieg der Aktivitäten von Leucinaminopeptidase und Chitinase unter Dürre um 35 bis 70\% wider. Dies zeigt, dass Bakteriengemeinschaften auf Trockenstress reagieren, indem sie die extrazelluläre Enzymproduktion erhöhen und dies erreichen, indem sie mehr Enzym-Gene kodieren. 
Die Proliferation und Erwärmung der Wurzelhaare beeinflusst die Freisetzung von Exsudat, die Enzymaktivitäten und die Verwendung von mikrobiellem Substrat stark. Um ihre Wechselwirkungen aufzudecken, wurden Mutanten mit defekter Wurzelhaarverlängerung (rth3) und der entsprechende Wildtyp-Mais 3 Wochen lang bei 20 bzw. $30^{\circ} \mathrm{C}$ gezüchtet. Wurzelhaare regulierten die Enzymexpression, mikrobielle Wachstumsstrategien und damit die Effizienz der Substratnutzung und vermittelten so die SOM-Bestände als Reaktion auf die Erwärmung.

Um die relative Bedeutung biotischer und abiotischer Faktoren zu klären, haben wir ein Experiment durchgeführt, bei dem die interaktiven Auswirkungen von Wurzelhaaren und Trockenheit untersucht wurden. Das Ergebnis zeigte, dass sowohl Wurzelhaare als auch Bodenfeuchtigkeit die räumliche Verteilung der biochemischen Eigenschaften und Prozesse der Rhizosphäre beeinflussten, aber die Verfügbarkeit von Bodenwasser wichtiger war als Wurzelexsudate, wenn der Boden sowohl durch Wasser als auch durch C-Quellen begrenzt ist.

Zusammenfassend können sowohl biotische als auch abiotische Faktoren mikrobielle Prozesse in Hotspots beeinflussen. Die Rolle der Wurzelhaare wurde bei der Wechselwirkung mit Trockenheit verringert, obwohl es für die Regulierung der Enzymsysteme und des mikrobiellen Wachstums von großer Bedeutung ist, sich an die Klimaerwärmung anzupassen. Daher schlagen wir vor, dass die Vorhersage und Modellierung des Bodens $\mathrm{C}$ und der Nährstoffdynamik nicht nur die interaktiven Effekte biotischer und abiotischer Faktoren berücksichtigen, sondern auch berücksichtigen sollte, welcher Faktor an der Wechselwirkung beteiligt ist. Insgesamt trägt diese Arbeit stark zum Verständnis der Mechanismen bei, die an den Prozessen des Hotspots beteiligt sind. Dies ist besonders wichtig für Agrarökosysteme, bei denen viele wesentliche Ökosystemleistungen, die für das Wohlbefinden des Menschen relevant sind, mit Prozessen im Mikromaßstab in Hotspots verbunden sind. 


\section{Acknowledgements}

I am always thinking I was a new PhD student. However, time doesn't lie, it tells me the truth: it is time to end the $\mathrm{PhD}$ life. I would say these four years are enjoyable, memorable and beautiful. Before I started PhD, I thought four years were too long, but now I just thought it passed too fast. I still remember the first day when I met Prof. Michaela Dippold and Prof. Bahar S. Razavi at the Department of Biogeochemistry of Agroecosystems, University of Göttingen. I was attracted by their warm and peaceful smile and they became the most important supervisors during my $\mathrm{PhD}$ study.

First of all, I would like to thank Prof. Michaela Dippold for the possibility to study in her group. She gave me many opportunities and also flexibility as well as provided brilliant ideas and advices for my experiment and manuscripts. Very special thanks to Prof. Bahar S. Razavi. She is not like my supervisor, instead she is more like my friend and my sister. She surely supported me the most on the scientific work during these four years. In addition to this, she gave me love, happiness and encouragement. Whenever I felt confused, unhappy and not confident, she was always there encouraging me patiently, making me feel ease, hopeful and confident. I would like to appreciate Prof. Sandra Spielvogel, Prof. Andrea Polle, Dr. Kazem Zamanian and Prof. Dr. Yakov Kuzyakov for their insightful suggestions on my work. I also very appreciate that Prof. Dr. Magdalena Frąc can attend my defense.

I am very grateful to my colleagues and members in our group for all their help. I also want to thank the technical staff for their assistance in the lab work. Specific thank to my international and Chinese friends for their help and support during my $\mathrm{PhD}$.

I am very thankful to the China Scholarship Council (CSC) for the financial support.

Finally, I would like to thank my family for their support, love and understanding during these years. Especially thanks to my boyfriend Xiangtian Meng, who gave me encouragement, motivation and a lot of fun.

Thanks!

Xuechen Zhang

Göttingen, Germany 


\section{Table of contents}

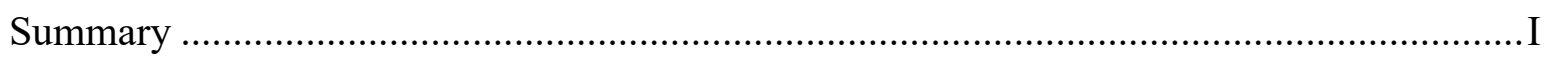

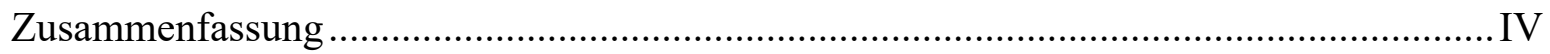

Acknowledgements ............................................................................................... VII

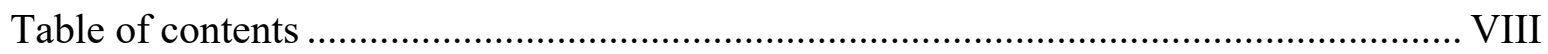

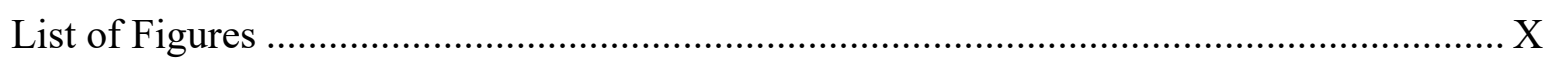

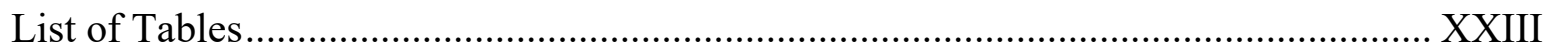

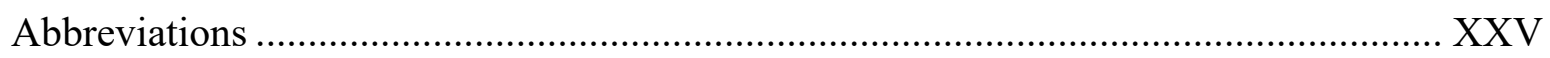

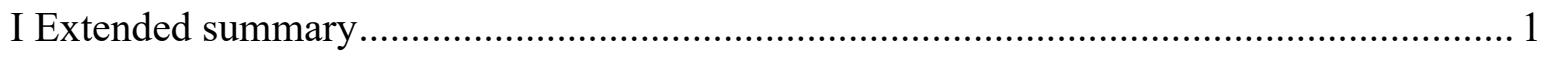

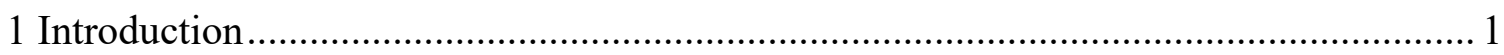

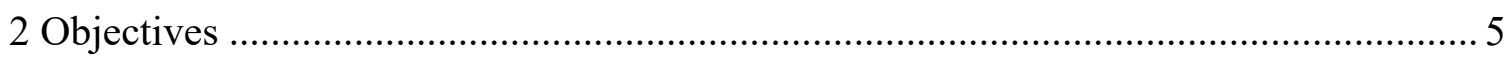

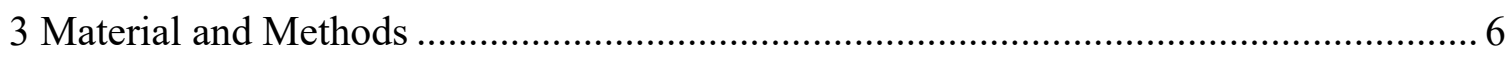

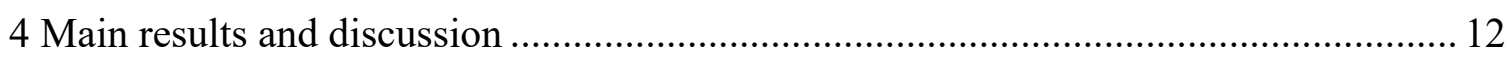

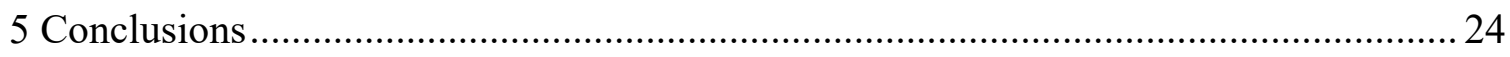

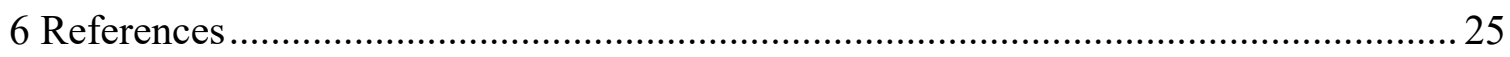

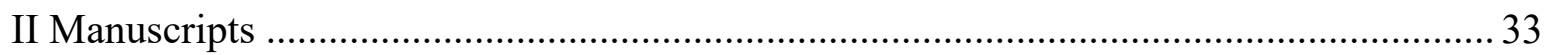

1 Study 1: Spatial pattern of enzyme activities depends on root exudate composition .... 33

2 Study 2: Maize genotype-specific strategies to increase microbial activity in the rhizosphere

3 Study 3: Microbial growth and enzyme kinetics in rhizosphere hotspots are modulated by soil organics and nutrient availability

4 Study 4: Resistance of microbial community and its functional sensitivity in the rhizosphere hotspots to drought

5 Study 5: Rhizosphere hotspots: root hairs and warming control microbial efficiency, carbon utilization and energy production

6 Study 6: Soil water content controls more than root exudation on the spatial distribution of $\beta$-glucosidase activities 
7 Study 7: Soil zymography: Simple and reliable? Review of current knowledge and

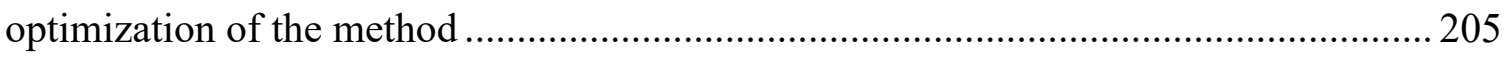

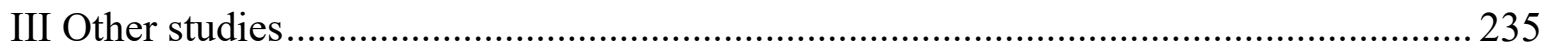

Study 8: Croplands conversion to cash crops in dry regions: consequences of nitrogen losses and decreasing nitrogen use efficiency for food chain system........................... 235

Study 9: Plant flavones enrich rhizosphere Oxalobacteraceae to improve maize performance under nitrogen deprivation

Study 10: Root hairs and protein addition to soil promote leucine aminopeptidase activity of Hordeum vulgare L... 238

Study 11: The geographical scale dependence of diazotroph assembly and activity: Effect of a decade fertilization. 239

Study 12: Effects of plastic and straw mulching on soil microbial P limitations in maize fields: Dependency on soil organic carbon demonstrated by ecoenzymatic stoichiometry 241

Study 13: Changes in nutrient balance, environmental effects, and green development after returning farmland to forests: A case study in Ningxia, China 242

Declarations 243 


\section{List of Figures}

\section{Extended Summary}

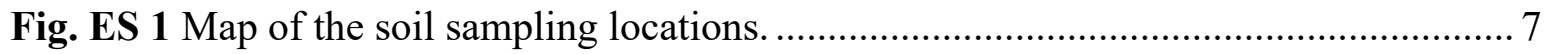

Fig. ES 2 Synthesis of main results of the studies. ........................................................... 13

Fig. ES 3 Zymography images in response to component additions. a. $\beta$-glucosidase, b. leucine aminopeptidase, c. phosphatase, d. sulfatase. Side color scale is proportional to enzyme activities $\left(\mathrm{nmol} \mathrm{cm} \mathrm{cm}^{-2} \mathrm{~h}^{-1}\right.$.

Fig. ES 4 The profile of enzyme activity distribution as a function of distance from the root center. Each line refers to the mean value of many lines of one part from each zymogram. 0 on the $\mathrm{X}$ axis shows the center of the artificial root. The $\mathrm{Y}$ axis is presented in relative units as enzyme activity $\left(\mathrm{nmol} \mathrm{cm} \mathrm{cm}^{-2} \mathrm{~h}^{-1}\right.$ ). For leucine aminopeptidase, the right axis is for purple line (methionine). Vertical dashed black lines on the curves: artificial rhizosphere extent for individual substances.

Fig. ES 5 General pattern of the effects of maize mutations (root defective $r$ th 3 and BX deficient $b x l$ as compared to wild type (WT) on the rhizosphere extent, hotspots, enzyme activity level and overlap of $\beta$-glucosidase with water and exudates. Significant increase and decrease indicated by $\uparrow$ and $\downarrow$ respectively.

Fig. ES $6 \mathrm{~V}_{\max }(\mathrm{a})$ and $\mathrm{K}_{\mathrm{m}}$ (b) values of $\beta$-glucosidase, and leucine aminopeptidase in the fertile and the poor soils. Values are means of three replicates $( \pm \mathrm{SE})$. Asterisks indicate significantly different from bulk soil. The inserts show the mean value of different samples.

Fig. ES 7 Glucose-induced respiratory responses of microbial community and their corresponding specific growth rates ( $\mu \mathrm{m}$; inset figures) after substrate addition into the (A) fertile and (B) poor soil. Experimental data are shown as symbols and model simulation (Equation (1)) as curves. Bars show standard errors of the means $( \pm \mathrm{SE})$. Lower-case letter indicates significant difference at a level of $\mathrm{P}<0.05$.

Fig. ES 8 Conceptual graph showing effects of drought on microbial community structure, activity and functionality. Activities of chitinase and leucine aminopeptidase were higher under drought conditions. Drought induced higher enzyme-related gene copies encoded by Actinobacteria controlling microbial roles in protein and chitin decomposition. 
Fig. ES $9 \beta$-glucosidase activity parameters: $V_{\max }(\mathrm{a})$ and $\mathrm{K}_{\mathrm{m}}(\mathrm{b})$ at 20 and $30{ }^{\circ} \mathrm{C}$ of root-hair wild and root-hairless mutant maize. $p$ values were obtained after two-way ANOVA. Genotype: wild type and mutant maize; Temperature: 20 and $30^{\circ} \mathrm{C}$. Lower case letters in (a): significant differences after two-way ANOVA and Tukey's HSD test at $p<0.05$; Lower case letters in (b): significant differences between wild type and mutant maize after two-way ANOVA and Student's $t$ test at $p<0.05$.

Fig. ES 10 (a) Specific growth rates $(\mu)$ of soil microorganisms during incubation at 20 and $30^{\circ} \mathrm{C}$ for the two maize genotypes estimated by substrate-induced respiration. (b) Substrate use efficiency expressed as calorespirometric ratios obtained from the $24 \mathrm{~h}$ incubation of soil samples after glucose addition. $p$ values were obtained after two-way ANOVA. Genotype: wild type and mutant maize; Temperature: 20 and $30^{\circ} \mathrm{C}$. Lower case letters in (a): significant differences after two-way ANOVA and Tukey's HSD test at $p<0.05$. Lower case letters (b): significant differences between wild type and mutant maize after two-way ANOVA and Student's $t$ test at $p<0.05$; Upper case letters in (b): significant differences between 20 and $30{ }^{\circ} \mathrm{C}$ after two-way ANOVA and Student's $t$ test at $p<0.05$. 20

Fig. ES 11 (a) Hotspot (\%) and (b) bidirectional rhizosphere extent of $\beta$-glucosidase activity for two maize genotypes (wild type and mutant $r$ th3) under drought and optimal water content. $p$ values were obtained after two-way ANOVA. genotype: wild type and mutant $r t h 3$; water: drought and optimal water content. Data is mean $(n=3)$ and error bars represent standard deviation (SD).

Fig. ES 12 Colocalization analysis for region of interest (ROIs) of (a) hotspots between $\beta$ glucosidase activity (Enzyme) and ${ }^{14} \mathrm{C}$ exudates (Exudates), or (b) hotspots between $\beta$ glucosidase activity (Enzyme) and water (Water). M1: Manders' coefficient, the fraction of Enzyme overlapping with Exudates or Water; M2: Manders' coefficient, the fraction of Exudates or Water overlapping with Enzyme; $p$ values were obtained after two-way ANOVA. genotype: wild type and mutant $r t h 3$; water: drought and optimal water content. Upper case letters in (a): significant differences for M1 between optimal and drought conditions after two-way ANOVA and Student's t-test at $p<0.05$. Upper case letters in (b): significant differences for M1 among four treatments after two-way ANOVA analysis and Tukey's HSD test at $p<0.05$. Lower case letters in (a) and (b): significant differences for M2 between optimal and drought conditions after two-way ANOVA and Student's t-test at $p<0.05 \ldots 23$

\section{Study 1}


Fig. 1 Mechanisms of formation of enzyme activity gradient in the rhizosphere: a) Secretes such as enzymes and root exudate are released by roots and show clear spatial distribution; b) Enzymes will be released by microorganisms, whose activities directly depend on root functions. Root exudates increase microbial activities, thus microbial enzyme activities in the rhizosphere. Theoretically stimulated microbial activity should form a gradient of microbial enzyme activity. However, the key compounds for stimulating microbial enzyme activities and formation of gradients in the rhizosphere remain unknown.

Fig. 2 Zymography images in response to component additions. a. $\beta$-glucosidase, b. leucine aminopeptidase, c. phosphatase, d. sulfatase. Side color scale is proportional to enzyme activities $\left(\mathrm{nmol} \mathrm{cm} \mathrm{cm}^{-2} \mathrm{~h}^{-1}\right)$.

Fig. 3 The profile of enzyme activity distribution as a function of distance from the root center. Each line refers to the mean value of many lines of one part from each zymogram. 0 on the $\mathrm{X}$ axis shows the center of the artificial root. The $\mathrm{Y}$ axis is presented in relative units as enzyme activity $\left(\mathrm{nmol} \mathrm{cm} \mathrm{cm}^{-2} \mathrm{~h}^{-1}\right.$ ). For leucine aminopeptidase, the right axis is for purple line (methionine). Vertical dashed black lines on the curves: artificial rhizosphere extent for individual substances

Fig. 4 Relative effects of components to water: $\log _{10}$ (ratio of percentage of hotspot between components and water). Below zero shows that percentage of hotspot in respond to each component is less than water addition while above zero demonstrates increment of percentage of hotspot compared to water addition. Subfigure shows hotspots (with area exceeding $20 \%$ of average grey values of the whole image), as a percentage of total area for (a) $\beta$-glucosidase, (b) leucine aminopeptidase, (c) phosphatase, and (d) sulfatase (left axis is for green color; right axis is for blue color treatments) in the artificial rhizosphere of six substances. Small letters: significant differences $(p<0.05$ after Tukey HSD test). 44

Fig. 5 Relative effects of components to water: $\log _{10}$ (ratio of enzyme activities between components and water). Below zero shows that enzyme activity in respond to each component is less than water addition while above zero demonstrates increment of enzyme activity compared to water addition. Subfigure shows enzyme activity as a function of substrate concentration for (a) $\beta$-glucosidase, (b) leucine aminopeptidase, (c) phosphatase and (d) sulfatase in response to component additions. Values are means of four replicates ( \pm SE). Small letters: significant differences $(p<0.05$ after Tukey HSD test) between components. 45 
Fig. 6 Ratios of (a) log-transformed ( $\beta$-glucosidase + cellobiohydrolase) and leucine aminopeptidase activities; the $\mathrm{C}: \mathrm{N}$ regression is $\ln ($ leucine aminopeptidase $)=-1.266+1.295$ $\times \ln (\beta$-glucosidase + cellobiohydrolase $), \mathrm{R}^{2}=0.44, p=0.0021$ (b) log-transformed $(\beta$ glucosidase + cellobiohydrolase) and phosphatase activities, the C:P regression is $\ln ($ phosphatase $)=0.347+0.997 \times \ln (\beta$-glucosidase + cellobiohydrolase $), \mathrm{R}^{2}=0.64, p<0.001$. Red dash line is with a slope of 1.0.

Fig. $7 \ln -K_{m}$ values of $\beta$-glucosidase, cellobiohydrolase, leucine aminopeptidase, phosphatase and sulfatase when adding substrates.

Fig. 8 Relative effects of components to water: $\log _{10}$ (ratio of turnover time between components and water). Below zero shows that turnover time in respond to each component is less than water addition while above zero demonstrates increment of turnover time compared to water addition. Subfigure shows substrate turnover times of (a) $\beta$-glucosidase, (b) leucine aminopeptidase, (c) phosphatase and (d) sulfatase when adding substrates. Small letters: significant differences ( $p<0.05$ after Tukey HSD test) of turnover time between each substance.

Fig. 9 Relative effects of components to water: $\log _{10}$ (ratio of catalytic efficiency between components and water). Below zero shows that catalytic efficiency in respond to each component is less than water addition while above zero demonstrates increment of catalytic efficiency compared to water addition. Subfigure shows catalytic efficiency $\left(V_{\max } / K_{m}\right)$ of (a) $\beta$-glucosidase, (b) leucine aminopeptidase, (c) phosphatase and (d) sulfatase. Small letters indicate significant differences between substances $p<0.05$ after Tukey HSD test. 48

Appendix 1 Example of spatial distribution of enzyme activity around the maize root. .... 59

Fig. S1 An example of rhizobox (dotted line is the area where we took soil samples); And zymography images of cellobiohydrolase in response to component additions. Side color scale is proportional to enzyme activities $\left(\mathrm{nmol} \mathrm{cm} \mathrm{cm}^{-2} \mathrm{~h}^{-1}\right)$.

Fig. S2 The profile of cellobiohydrolase distribution as a function of distance from the root center. Each line refers to the mean value of many lines of one part from each zymogram. 0 on the $\mathrm{X}$ axis shows the center of the artificial root. The $\mathrm{Y}$ axis is presented in relative units as enzyme activity $\left(\mathrm{nmol} \mathrm{cm} \mathrm{cm}^{-2} \mathrm{~h}^{-1}\right)$.

Fig. S3 Hotspots (with area exceeding $20 \%$ of average grey values of the whole image), as a percentage of total area for cellobiohydrolase in the artificial rhizosphere of six substances. Small letters: significant differences ( $p<0.05$ after Tukey HSD test). 60 
Fig. S4 Enzyme activity as a function of substrate concentration for cellobiohydrolase in response to component additions. Values are means of four replicates $( \pm \mathrm{SE})$. Small letters: significant differences ( $p<0.05$ after Tukey HSD test) between components.

Fig. S5 Substrate turnover times of cellobiohydrolase when adding substrates. Small letters: significant differences ( $p<0.05$ after Tukey HSD test) of turnover time between each substance.

Fig. S6 Catalytic efficiency $\left(V_{\max } / K_{m}\right)$ of cellobiohydrolase. Small letters indicate significant differences between substances $p<0.05$ after Tukey HSD test.

Fig. S7 Michaelis-Menten kinetics (enzyme activity as a function of substrate concentration) for $\beta$-glucosidase, leucine aminopeptidase, phosphatase and sulfatase in response to methionine addition.

\section{Study 2}

Figure 1. Root images (real light photos) (a,b,c), zymograms of $\beta$-glucosidase activity (d,e,f), ${ }^{14} \mathrm{C}$ phosphor images $(\mathrm{g}, \mathrm{h}, \mathrm{i})$, and neutron radiographs $(\mathrm{j}, \mathrm{k}, \mathrm{l})$ of three maize genotypes (WT, $r$ th 3 and $b x 1$ ). Side color or gray scales are proportional to $\beta$-glucosidase activity (pmol $\mathrm{cm}^{-}$ $\left.{ }^{2} \mathrm{~h}^{-1}\right),{ }^{14} \mathrm{C}$ activity (MBq) and to volumetric water content. Always one representative replicate out of four was chosen. WT: wild type maize, rth3: root hair defective mutant; $b x 1$ : mutant with reduced benzoxazinoids in root exudates.

Figure 2. The rhizosphere extent for $\beta$-glucosidase activity (a) and ${ }^{14} \mathrm{C}$-labeled root exudates (b). Data are means for each genotype (WT, rth3 and $b x 1)(\mathrm{n}=4)$, error bars indicate standard deviations. Letters within one root type mark significant differences among the genotypes at $P<0.05$. Asterisks on the bracket at the right side indicate significant differences between root sections ('***' $P<0.001$; ‘**' $P<0.01$; ' ${ }^{*}$ ' $P<0.05$ ).

Figure 3. Mean of $\beta$-glucosidase activity in bulk soil (shaded) and in the rhizosphere along the mature root and root tips. Data are means for each genotype (WT, rth3 and $b x 1)(\mathrm{n}=4)$, error bars indicate standard deviations. Letters within one root section mark significant differences among the genotypes at $P<0.05$. Capital letters refer to bulk soil, while lower case letters refer to rhizosphere soil. Relative increase (fold, times) in $\beta$-glucosidase activity along mature root and at root tip compared to bulk soil is marked over arrow at each column. The vertical thin dashed line separates the bars for bulk and rhizosphere activities. .78 
Figure 4. Hotspots for $\beta$-glucosidase activity and ${ }^{14} \mathrm{C}$ exudation. Data are means for each genotype (WT, rth3 and $b \times l)(\mathrm{n}=4)$, error bars indicate standard deviations. Letters within one hotspot type marks significant differences among the genotypes at $P<0.05$.

Figure 5. Region of interest (ROIs) images of hotspots for exudates and $\beta$-glucosidase activity, and their overlap image for three maize genotypes (WT, rth3, bxl). The results of co-localization analysis are given as means of four replicates and presented by overlap coefficient (r) and two Manders coefficients (M1 and M2, see detailed explanation in Fig. $\mathrm{S} 3$ ). Asterisks on the values indicate significant difference between genotypes ('*, $P<0.05$;

‘**’ $\mathrm{P}<0.01$; ‘***’ $P<0.001)$

Figure 6. General pattern of the effects of maize mutations (root defective $r$ th 3 and BX deficient $b x 1$ as compared to wild type (WT) on the rhizosphere extent, hotspots, enzyme activity level and overlap of $\beta$-glucosidase with water and exudates. Significant increase and decrease indicated by $\uparrow$ and $\downarrow$ respectively.

Figure S1. Sketch of rhizosphere thresholding methodology: a) an example of zymogram with five rectangles (B1-B5) which represent the areas of background $\beta$-glucosidase activity; b) gray values plotted against the distance. 98

Figure S2 Linear correlation between the gray values of the calibration membranes incubated for one hour and methylumbelliferone (MUF) concentrations. .99

Figure S3. Schematic illustration of quantitative co-localization of activities/hotspots on two images A (Hotspot 1 - red) and B (Hotspot 2 - green) hotspots. Yellow part indicates 48\% of overlap between two hotspot images ( $\mathrm{r}=0.48)$; Manders coefficient 1 indicates that $44 \%$ of Hotspot 1 (yellow fraction of red hotspot) is considered as co-localized with Hotspot 2 (M1=0.44); Manders coefficient 2 indicates that $65 \%$ of Hotspot 2 (yellow fraction of green hotspot) is considered as co-localized with Hotspot 1 (red hotspot) $(\mathrm{M} 2=0.65)$. 99

\section{$\underline{\text { Study } 3}$}

Fig. 1 Examples of maize roots grown in rhizoboxes (center) and zymographs; showing spatial distribution of enzyme activities: (a) $\beta$-glucosidase, and (b) leucine aminopeptidase in the fertile soil; (c) $\beta$-glucosidase, and (d) leucine aminopeptidase in the poor soil, and (e) the sampling scenario using wet needle. 106

Fig. 2 Glucose-induced respiratory responses of microbial community and their corresponding specific growth rates ( $\mu_{\mathrm{m}}$; inset figures) after substrate addition into the (A) fertile and (B) poor soil. Experimental data are shown as symbols and model simulation 
(Equation (1)) as curves. Bars show standard errors of the means ( \pm SE). Lower-case letter indicates significant difference at a level of $\mathrm{P}<0.05$.

Fig. $3 \mathrm{~V}_{\max }$ (a) and $\mathrm{K}_{\mathrm{m}}$ (b) values of $\beta$-glucosidase, and leucine aminopeptidase in the fertile and the poor soils. Values are means of three replicates $( \pm \mathrm{SE})$. Asterisks indicate significantly different from bulk soil. The inserts show the mean value of different samples.

Fig. 4 The relationship between the $V_{\max }$ of $\beta$-glucosidase and the growing microbial biomass $(\mathrm{P}<0.05)$

Fig. 5 The turnover time (a) at excess of substrate and (b) lack of substrate, and (c) the catalytic efficiency of enzymes (ratio of $V_{\max } / K_{m}$ ) in the fertile and the poor soils. Values are means of three replicates $( \pm \mathrm{SE})$. Asterisks indicate significantly different from bulk soil. The inserts show the mean value of different samples.

Fig. 6 Conceptual graph showing changes of microbial activities and functions in the hotspots as affected by soil fertility. Vertical and horizontal red arrow indicate increase and no change of microbial kinetics and functions in the hotspots compared to bulk soil, respectively. Red gradient arrow indicates increasing trend, blue gradient arrow indicates decreasing trend, gray arrow indicates no change along soil fertility.

\section{Study 4}

Fig. 1 Example of soil sampling from rhizosphere hotspots and coldspots based on zymography images of leucine aminopeptidase. Here, hotspots were defined as areas with gray values higher than mean +2 standard deviation (SD); coldspots were considered as activities in the range of bulk soil within the rhizosphere. Color bar represents enzyme activity (nmol cm $\mathrm{ch}^{-1}$ ) in soil with maize roots (21 days) under drought (20\% of WHC) and optimal moisture $(70 \%$ of $\mathrm{WHC})$.

Fig. $2 V_{\max }(a, b)$ and $K_{m}(c, d)$ of leucine aminopeptidase and chitinase in soil from the rhizosphere hot- and coldspot under drought (20\% of WHC) and optimal moisture $(70 \%$ of WHC), respectively. Microsites: hotspots and coldspots. Lower case letters: significant differences between hot- and coldspots at $p<0.05$; Upper case letters: significant differences between drought and optimal moisture at $p<0.05$.

Fig. 3 The resistance of enzyme activity to drought (i.e. resistance $=1-\left(2\left|\mathrm{D}_{0}\right| /\left(\mathrm{C}_{0}+\left|\mathrm{D}_{0}\right|\right)\right)$. $\mathrm{D}_{0}$ is the difference in a biological function between the control soil $\left(\mathrm{C}_{0}\right)$ and the drought soil $\left(\mathrm{P}_{0}\right)$ at the end of disturbance $\left(\mathrm{t}_{0}\right)$. Letters indicate significant differences between hot- and coldspots. 135 
Fig. 4 Relative abundance of soil bacterial community members at the genus level in soil from rhizosphere hot- and coldspots under drought (20\% of WHC) and optimal moisture (70\% of WHC); (b) Relative abundance of Nocardioides and Streptomyces which were significant higher under drought than optimal conditions based on the merged dataset $(n=6)$ from both microsites. The Shapiro-Wilk test was used to check normality, and Levene tests were performed to check the homogeneity of variances. The normality or homogeneity was not proved, and the Wilcoxon test was performed at $\mathrm{p}<0.05$. Asterisks indicate significant differences between drought and optimal conditions.

Fig. 5 The number of gene copies encoding (a) leucine aminopeptidase (EC 3.4.11.1) and (b) chitinase (EC 3.2.1.52) analyzed by PICRUSt2 for the soil from rhizosphere hot- and coldspots under drought (20\% of WHC) and optimal moisture (70\% of WHC), respectively. Values are means of three replicates \pm standard deviation (SD). Star $(*)$ beside the legends indicates significant difference $(p<0.05)$ between drought and optimal moisture.

Fig. 6 Networks of top 100 genera for the soil from rhizosphere hot- and coldspots (a), and (b) under drought (20\% of WHC) and optimal moisture (70\% of WHC), based on Spearman correlation analysis. Red and green lines: strong positive relationships $(r>0.85, p<0.05)$ and strong negative relationships $(r<-0.85, p<0.05)$, respectively. Colored nodes represent corresponding genera assigned to major phyla. The size of each node is proportional to the relative abundance.

Fig. 7 ZP-plot showing distributions of genera on their network roles. Each node represents a genus (a) in rhizosphere hot- and coldspots, and (b) under drought (20\% of WHC) and optimal moisture $(70 \%$ of $\mathrm{WHC})$. Zi: within-module connectivity, Pi: among-module connectivity. Note: norank_c_OLB14, norank_c_Gitt-GS-136: unidentified genera belonging to phylum Chloroflexi; norank_fXXanthobacteraceae, norank_f_Methyloligellaceae, norank_o_Azospirillales, norank_o_Rhizobiales, unclassified_f_Rhizobiaceae, norank_f_Steroidobacteraceae: unidentified genera belonging to phylum Proteobacteria; norank_c_Subgroup_6: a norank genus belonging to phylum Acidobacteria; unclassified_c_Actinobacteria, norank_o_Gaiellales, unclassified_f_Propionibacteriaceae: unidentified genera belonging to phylum Actinobacteria.

Fig. 8 Degree distribution pattern for the bacterial communities (a) in rhizosphere hot- and coldspots, and (b) under drought ( $20 \%$ of WHC) and optimal moisture ( $70 \%$ of WHC). The 
degree of a node is the number of connections it has. Count means the number of the node with that degree.

Fig. S1 Water content of soils during drying cycle. The soil water content was measured gravimetrically by weighing the rhizoboxes. The points represent the average of 3 replicates.

Fig. S2 Rarefaction curves of Sobs index on OTU level against the number of sequence reads for soils from rhizosphere hot- and coldspots under drought (20\% of WHC) and optimal moisture $(70 \%$ of $\mathrm{WHC})$, respectively.

Fig. S3 Principal Coordinates Analysis (PCoA) of bacterial communities in soils from rhizosphere hot- and coldspots under drought $(20 \%$ of WHC) and optimal moisture $(70 \%$ of WHC), respectively.

Fig. S4 (a) Metabolic functions related to leucine aminopeptidase and chitinase using Tax4Fun2 at level 3 displayed as normalization of relative abundance by $\mathrm{Z}$ score. (b) Functional profiles of selected metabolisms (relative abundance $>1 \%$ ) based on KEGG categories (level 3) displayed as normalization of relative abundance by $\mathrm{Z}$ score. Lower case letters: significant differences between drought and optimal moisture after two-way ANOVA and Student's $t$ test at $p<0.05$.

Fig. S5 Network stability analysis. The decrease of natural connectivity when attacking nodes in the static network in the soil of (a) hotspot and coldspot, and (b) drought and optimal moisture.

Fig. S6 The relative abundance of the genus Luedemannella, which was detected as module hubs in the network under drought conditions. 154

\section{Study 5}

Fig. 1 Schematic microbial response to the input of root exudates in the rhizosphere. Substrate limitation shifts gene expression to the production of enzyme systems with a higher binding affinity. Production of multiple forms of key enzymes under low $\mathrm{C}$ availability reduces metabolic efficiency. This investment would impose a tradeoff by reducing the allocation of available energy to growth (left). Under high C input, however, microorganisms increase enzyme expression and maximize the fraction of resources for biosynthesis (right). Thus, the substrate availability as affected by root hair proliferation and warming may control the optimal strategy of thermoregulation. 
Fig. 2 Examples of soil sampling from hotspots of $\beta$-glucosidase activity $\left(\mathrm{nmol} \mathrm{cm} \mathrm{cm}^{-1}\right.$ ) for further analyses (enzyme kinetics (Fig. 3), kinetics of substrate-induced respiration (Fig. 4) and heat production (Fig. S1)). Small circles: the hotspot soil sampled for further analyses. Left: wild maize type; right: hairless mutant

Fig. $3 \beta$-glucosidase activity parameters: $V_{\max }(a)$ and $K_{m}(b)$ at 20 and $30{ }^{\circ} \mathrm{C}$ of root-hair wild and root-hairless mutant maize. $p$ values were obtained after two-way ANOVA. Genotype: wild type and mutant maize; Temperature: 20 and $30^{\circ} \mathrm{C}$. Lower case letters in (a): significant differences after two-way ANOVA and Tukey's HSD test at $p<0.05$; Lower case letters in (b): significant differences between wild type and mutant maize after two-way ANOVA and Student's $t$ test at $p<0.05$.

Fig. 4 Specific growth rates $(\mu)$ of soil microorganisms (a), actively growing microbial biomass (b), and the ratio of growing to total microbial biomass (c) during incubation at 20 and $30^{\circ} \mathrm{C}$ for the two maize genotypes estimated by substrate-induced respiration. $p$ values were obtained after two-way ANOVA. Genotype: wild type and mutant maize; Temperature: 20 and $30^{\circ} \mathrm{C}$. Lower case letters in (a): significant differences after two-way ANOVA and Tukey's HSD test at $p<0.05$; Lower case letters in (b) and (c): significant differences between wild type and mutant maize after two-way ANOVA and Student's $t$ test at $p<0.05$; Upper case letters in (b): significant differences between 20 and $30{ }^{\circ} \mathrm{C}$ after two-way ANOVA and Student's $t$ test at $p<0.05$. 166

Fig. 5 Substrate use efficiency expressed as calorespirometric ratios obtained from the $24 \mathrm{~h}$ incubation of soil samples after glucose addition. $p$ values were obtained after two-way ANOVA. Genotype: wild type and mutant maize; Temperature: 20 and $30{ }^{\circ} \mathrm{C}$. Lower case letters: significant differences between wild type and mutant maize after two-way ANOVA and Student's $t$ test at $p<0.05$; Upper case letters: significant differences between 20 and $30{ }^{\circ} \mathrm{C}$ after two-way ANOVA and Student's $t$ test at $p<0.05$.

Fig. 6 Generalized effects of temperature and root hairs on microbial and enzyme activities. The effects of root hairs are more pronounced at higher temperature. Temperature shifted microbial growth strategy towards a higher abundance of fast-growing microorganisms. Root hairs induced higher enzyme activity and larger fraction of actively growing microbial biomass (GMB) under higher temperature, whereas was coincided with lower enzyme efficiency. Changes in enzymatic properties and in microbial functioning offset the exudateinduced promotion of microbial activities in the presence of root hairs (wild type) and could compensate for the reduced exudate effect in the absence of root hairs (mutant) in a warmer 
world. $\mathrm{V}_{\max }$ : $\beta$-glucosidase activity; $\mathrm{E}_{\mathrm{a}}-\mathrm{V}_{\max }$ : the activation energy for $\beta$-glucosidase activity; $\mu$ : specific growth rate; GMB: growing microbial biomass. 170

Fig. S1 Cumulative heat production after glucose addition subtract from no glucose addition with 3 replicates for the two maize genotypes at 20 and $30^{\circ} \mathrm{C}$, respectively. $p$ values were obtained after two-way ANOVA. Genotype: wild type and mutant maize; Temperature: 20 and $30^{\circ} \mathrm{C}$. Upper case letters: significant differences between 20 and $30{ }^{\circ} \mathrm{C}$ after two-way ANOVA and Student's $t$ test at $p<0.05$. 177

\section{Study 6}

Fig. 1 Spatial distribution of $\beta$-glucosidase activity for two maize genotypes (wild type and mutant $r$ th3) under drought (a \& b) and optimal water content (c \& d). The color scale is proportional to $\beta$-glucosidase activity $\left(\mathrm{nmol} \mathrm{cm}^{-2} \mathrm{~h}^{-1}\right)$.

Fig. 2 (a) Hotspot (\%) and (b) bidirectional rhizosphere extent of $\beta$-glucosidase activity for two maize genotypes (wild type and mutant $r t h 3$ ) under drought and optimal water content. $p$ values were obtained after two-way ANOVA. genotype: wild type and mutant $r$ th 3 ; water: drought and optimal water content. Data is mean $(n=3)$ and error bars represent standard deviation (SD).

Fig. 3 Michaelis-Menten kinetic parameters, i.e. (a) $V_{\max }\left(n m o l g^{-1} h^{-1}\right)$ and (b) $K_{m}\left(\mu m o l g^{-}\right.$ ${ }^{1}$ soil), of rhizosphere soil for two maize genotypes (wild type and mutant $r t h 3$ ) under drought and optimal water content. Data is mean $(n=3)$ and error bars represent standard deviation (SD).

Fig. 4 Spatial distribution of root exudates for two maize genotypes (wild type and mutant rth3) under drought (a \& b) and optimal water content (c \& d).

Fig. 5 (a) Percentage of hotspot and (b) bidirectional rhizosphere extent of root exudates for two maize genotypes (wild type and $r$ th 3 mutant) under drought and optimal water content. $p$ values were obtained after two-way ANOVA. $\eta^{2}$ : effect size; genotype: wild type and mutant $r$ th3; water: drought and optimal water content. Data is mean $(\mathrm{n}=3)$ and error bars represent standard deviation $(\mathrm{SD})$.

Fig. 6 Region of interest (ROIs) of soil water spatial distribution for two maize genotypes (wild type and mutant $r$ th3) under drought (a \& b) and optimal water content (c \& d). Side color scale is proportional to volumetric water content.

Fig. 7 Bidirectional rhizosphere extent of soil water content for two maize genotypes (wild type and mutant $r$ th 3 ) under drought and optimal water content. $p$ values were obtained after 
two-way ANOVA. $\eta^{2}$ : effect size; genotype: wild type and mutant $r$ th3; water: drought and optimal water content. Data is mean $(n=3)$ and error bars represent standard deviation (SD).

Fig. 8 Colocalization analysis for region of interest (ROIs) of (a) hotspots between $\beta$ glucosidase activity (Enzyme) and ${ }^{14} \mathrm{C}$ exudates (Exudates), or (b) hotspots between $\beta$ glucosidase activity (Enzyme) and water (Water). M1: Manders' coefficient, the fraction of Enzyme overlapping with Exudates or Water; M2: Manders' coefficient, the fraction of Exudates or Water overlapping with Enzyme; $p$ values were obtained after two-way ANOVA. genotype: wild type and mutant $r$ th3; water: drought and optimal water content. Upper case letters in (a): significant differences for M1 between optimal and drought conditions after two-way ANOVA and Student's t-test at $p<0.05$. Upper case letters in (b): significant differences for M1 among four treatments after two-way ANOVA analysis and Tukey's HSD test at $p<0.05$. Lower case letters in (a) and (b): significant differences for M2 between optimal and drought conditions after two-way ANOVA and Student's t-test at $p<0.05 .195$

\section{Study 7}

Fig. 1. Schematic illustration of soil zymography setup and its main steps: a. shows root position and membrane attachment. The inset shows laser scanning for soil surface topography; b. Performance of soil zymography under the initial environmental conditions of the samples; c. Balance between saturating substrate concentration of soil and selected substrate concentration; d. Proper calibration standards; e. Fixed camera settings and photography conditions. Art work: Tahoora Emam. 208

Fig. 2. Examples of calibration line: a) when the correlation of gray values and concentrations are linear; b) when the correlation is not linear. When the calibration line shows non-linear behavior, the safe zone of the curve according to the concentration and gray values should be identified.

Fig. 3. Intensity of MUF and AMC standard curves with and without $\mathrm{NaOH}$, as well as trend of leucine aminopeptidase activity with and without buffer.

Fig. 4. Four possible positions of root in soil: i) completely out of the soil surface, ii) partly buried in soil and positioned partly outside of the soil surface, iii) partly buried in soil and positioned at the same level as the soil surface, iv) completely buried in the soil. The eliminated zones around the lupine root (a) corresponding to the similar root position as position (i). (b), shows eliminated zones around the maize root covered by $1 \mathrm{~mm}$ gel plate 
when the root is at a similar position as (i). A clear imprint of enzyme activity on the root and surrounding soil (c) corresponding to the similar root position as (iii). All images are in true color without image processing.

Fig. 5. Top: a, b and c presenting three different load levels around a soil column. The sub figure of a, shows real soil column. All images are in true color without image processing. Bottom: four incubation durations. The radial diffusion on the membrane after $26 \mathrm{~h}$ is clearly detectable

Fig. 6. Detected false signals on membrane saturated by sterile water under UV light. Not a single pixel refers to spot with enzyme activity. (a) Shows the original zymogram in true color and (b) shows the same zymogram after image processing.

Fig. 7. (a) Example of zymogram (true color), and (b) shows segmented root in green, while blue is root and noise which should be excluded from the analysis (when the whole root is not visible or the contrast between root and background is not sufficient).

Fig. 8. a) Example of detecting the boundaries of different categories of enzyme activities in the specific gradient (biopores). Percentage of the area of MUF/AMC concentration in the total image is considered as a function of color intensity. Asterisks indicate significant differences between the mean values (modified from Hoang et al., 2016). b) Example of spatial distribution of hotspots in soil treated with and without fertilizer. Long-term $\mathrm{N}$ fertilization leads to formation of aggregate hotspots while no fertilization caused dispersed distribution of hotspots. The dotted quadrates represent symbolic applied quadrat counts method on images.

Fig. 9. a: an example of overlapped ${ }^{14} \mathrm{C}$ image and zymography. The red color corresponds to $\beta$-glucosidase activity and white represents ${ }^{14} \mathrm{C}$ release (root exudate). $\mathrm{b}$ : An illustrative example of phosphatase activity (blue) and changes of $\mathrm{pH}$ (red) along the maize root. In (a) and (b) background (soil) is converted to black to improve the visibility. c: an example of three overlapped images: real root, zymogram, and $\mathrm{CO}_{2}$ changes. The green color represents the area where leucine-aminopeptidase activity and $\mathrm{CO}_{2}$ release overlapped. Sub-figures shows: i. roots, ii. leucine-aminopeptidase imprint, and iii. $\mathrm{CO}_{2}$ release. There are areas where microbial respiration is visible while imprint of enzyme activity is not detectable (or the activity is low). 225 


\section{List of Tables}

\section{Study 1}

Table 1 Basic soil physiochemical properties 38

Table S1 $\mathrm{R}^{2}$ after 3-, 4- and 5-parameters logistic curve fitted to enzyme activities as a function of distance from the artificial root center in response to various components

\section{Study 2}

Table S1. Degrees of colocalization as fuzzy linguistic variables and the respective ranges of values of popular coefficients used to estimate colocalization, such as PC, r, and M1(M2) (Zinchuk et al., 2013) 100

Table S2. Result of co-localization analysis for the whole image of water content at neutron image (Water), ${ }^{14} \mathrm{C}$ exudates (Exudates) and $\beta$-glucosidase activity (Enzyme). The colocalization parameters are overlay coefficient (r), Mander's coefficient 1 (M1) and 2 (M2). Data are means for each genotype and parameter $(n=4) \pm$ standard deviations. Capital letters mark significant differences among the genotypes at $P<0.1$ and small letters mark significant differences among interactions within genotype at $P<0.05$ and $P<0.1$. Asterisks on the $\mathrm{p}-$ values indicate significant differences between root type $\left({ }^{\prime}{ }^{(*)}{ }^{\prime} P<0.1 ;\right.$ ' $*$ ' $P<0.05$; '**' $P<0.01$; ‘***' $P<0.001)$. 100

\section{$\underline{\text { Study } 3}$}

Table 1 Stand parameters at two research sites in Germany. Data taken from relevant German forest authority (Haußmann and Lux, 1997; Lang et al., 2017). 104

Table 2 Growing microbial biomass and its proportion of total biomass, lag-period and generation time of actively growing microbial community consuming substrate during incubation of soils with glucose and nutrients. 109

\section{$\underline{\text { Study } 4}$}

Table S1 PERMANOVA analysis at the OTU level based on Bray-Curtis distances 154

Table S2 Alpha diversity indices at the OTU level in soil from rhizosphere hot- and coldspots under drought (20\% of WHC) and optimal moisture ( $70 \%$ of WHC)..... 154

Table S3 The relative abundance ( $>1 \%$ under drought) of the total and 5 most increased genera belonging to Actinobacteria related to leucine aminopeptidase under drought (20\% of 
WHC) compared with optimal moisture (70\% of WHC). Note: g_norank_c_Actinobacteria: a norank genus belonging to the phylum Actinobacteria. 155

Table S4 The relative abundance ( $>1 \%$ under drought) of the total and 5 most increased genera belonging to Actinobacteria related to chitinase under drought ( $20 \%$ of WHC) compared with optimal moisture (70\% of WHC). Note: $g \_$norank_c_Actinobacteria: a norank genus belonging to the phylum Actinobacteria...... 155

\section{Study 5}

Table 1 The activation energy for $\beta$-glucosidase activity $\left(E_{a}-V_{\max }\right)$ as obtained by fitting the Arrhenius equation (Eq. 2) based on the $\mathrm{V}_{\max }$ of $\beta$-glucosidase at 20 and $30^{\circ} \mathrm{C}$. Small letters: significant differences after Student's $t$ test at $p<0.05$. 166

Table S1 Actively growing and total microbial biomass during incubation for substrateinduced respiration at 20 and $30^{\circ} \mathrm{C}$ for the two maize genotypes. Two-way ANOVA analysis of the influences of maize genotype, temperature and their interactions on microbial biomass.

\section{Study 7}

Table 1 Enzymes commonly imaged in environmental samples, and their organic matter constituents and substrates. 210

Table 2 Summary of abiotic and biotic factors which may distort results. 226 


\section{Abbreviations}

$\begin{array}{ll}\mathrm{C} & \text { Carbon } \\ \mathrm{N} & \text { Nitrogen } \\ \mathrm{P} & \text { Phosphorus } \\ \mathrm{S} & \text { Sulfur } \\ \mathrm{K} & \text { Potassium } \\ \mathrm{SOM} & \text { Soil organic matter } \\ \text { LMWOS } & \text { Low-molecular weight organic substances } \\ \mathrm{CO}_{2} & \text { Carbon dioxide } \\ \text { DOC } & \text { Dissolved organic carbon } \\ \text { WHC } & \text { Water holding capacity } \\ \text { TMB } & \text { Total microbial biomass } \\ \text { GMB } & \text { Growing microbial biomass } \\ \mu & \text { Specific growth rates } \\ \text { RS } & \text { resistance } \\ \eta^{2} & \text { Effect size } \\ \text { RABIT } & \text { Rapid automated bacterial impedance technique } \\ \text { SIGR } & \text { Substrate Induced Growth Respiration } \\ \text { PC } & \text { Pearson's correlation coefficient } \\ \text { M1 and M2 } & \text { Manders' coefficient }\end{array}$




\section{Extended summary}

\section{Introduction}

Localization of active microorganisms in a small soil volume forms microbial hotspot microsites with much higher biogeochemical process rates than the bulk soil (Kuzyakov, 2010). The formation, spatial organization and lifetime of microbial hotspots depend not only on biotic (e.g. root exudates and root morphology) but also on abiotic (e.g. warming and drought) factors (Ge et al., 2017; Kuzyakov, 2002). Detailed knowledge about the effects of these factors on microbial processes is a prerequisite for deciphering the complex biogeochemical processes in the rhizosphere. Especially, our knowledge is very limited on how multiple factors control enzyme systems, microbial activity and community in hotspots. Despite their very smallscale occurrence, the cumulative effects of exudate-driven rhizosphere processes are of global importance (e.g. C and nutrient cycling) (Hinsinger et al., 2009; Spohn et al., 2013).

\subsection{Biotic factors: root exudates and root morphology}

The input of root exudates boosts the abundance and activity of soil microorganisms and produces microbial hotspots in the rhizosphere. Exudate properties depend on root morphology such as the presence of root hairs (Kuzyakov and Razavi, 2019). Most prominently, root hairs increase the substrate availability for microorganisms (Jones et al., 2009; Mishra et al., 2009), which in turn stimulates the production of extracellular enzymes (Asmar et al., 1994) and hence, soil organic matter (SOM) decomposition (Cheng and Coleman, 1990). Thus, interactions between roots and their microbiome may fundamentally affect C turnover in hotspots (Paterson et al., 2009; Blagodatskaya et al., 2011).

Herbaceous plants release $20 \%$ and $50 \%$ of their photosynthesized $\mathrm{C}$ which are in the form of low or high molecular weight organic substances (Badri and Vivanco, 2009), through their roots into soil (Kuzyakov et al., 2003; Kuzyakov and Domanski, 2000) via various mechanisms including secretion, diffusion and cell lysis (Jones et al., 2009). Thus, microorganisms are more active and produce more enzymes in the rhizosphere due to the large input of easily degradable low-molecular weight organic substances (LMWOS) (Burns, 1982; Dennis et al., 2010). In most plants, the dominating forms of LMWOS are sugars, amino acids and carboxylic acids (Oburger and Jones, 2018). Glucose is the most abundant sugars, accounting about $40-50 \%$ of the root exudates (Hutsch et al., 2002), and is one of the most important energy sources for microorganisms. Following sugars, the concentration of 
amino acids is the second highest and they are key sources of both $\mathrm{C}$ and nitrogen $(\mathrm{N})$ to microorganisms. Alanine makes up 15\% of amio acid recoverd in dissolved organic carbon (DOC) (Fischer et al., 2007) and methionine is another major amino acid of root exudates, containing sulfur (S). Organic acids with low concetration in soil involed in many processes, such as nutrient mineralizaion and metal detoxification (Jones, 1998). Along with primary metabolites, plant roots exudate secondary metabolites such as benzoxazinoids (Dick et al., 2012) which induce herbivore resistance (Frey et al., 1997; Maag et al., 2016), and have strong fungicidal and less pronounced antibacterial effect (Cotton et al., 2019; Kudjordjie et al., 2019). Apart from plant protective functions (Erb and Kliebenstein, 2020), benzoxazinoids can cause plant biomass decrease (Hu et al., 2018). Such a negative effect of benzoxazinoids on crop productivity is mainly attributed to the inhibition of beneficial microorganisms belonging to phylum Glomeromycota or to Flavobacteriaceae (Cadot et al., 2020; $\mathrm{Hu}$ et al., 2018), which also release less $\beta$-glucosidase (Ahmad et al., 2011; Okamoto et al., 2000). Decrease in $\beta$-glucosidase activity induces less hydrolyzed available $C$, which is required to maintain higher microbial activity including microorganisms responsible for nutrients mining. Furthermore, decomposition of benzoxazinoids by microorganisms with a high degradation capacity (i.e., Pseudomonas putida, Neal et al., 2012) requires time and energy (Schütz et al., 2019). Accordingly, low or no benzoxazinoids in the exudates may be advantageous for rhizosphere microorganisms. Finally, microorganisms activated at root tips and other root parts with intensive exudation may decompose benzoxazinoids, thus reducing their inhibiting effects. The quantity, composition and spatial distribution of these released exudates strongly depend on root morphology (Kaiser et al., 2015; McCully and Canny, 1985; Peterson and Farquhar, 1996). For example, the presence of root hairs in barley increased root exudation up to threefold, traced by ${ }^{14} \mathrm{C}$ (Holz et al., 2018b), supposedly due to larger root surface area (Haling et al., 2013). Increased amount of root exudates activates microorganisms (Bertin et al., 2003; Liu et al., 2020), and thus, may expand the enzymatic rhizosphere extent (Ma et al., 2018a). Many previous studies have focused on enzyme activities in the rhizosphere (Tarafdar and Jungk, 1987; George et al., 2006) or have illuminated gradients of enzyme activities as a function of distance from the root surface to the soil (Razavi et al., 2016; Ge et al., 2017; Ma et al., 2018b). Nonetheless, knowledge about the dependence of enzyme activities and their spatial distributions in the rhizosphere on individual component or on the composition and quantity (reflected by root hairs) of root exudates remains unclear. Therefore, we combined soil zymography with Rhizon ${ }^{\circledR}$ samplers (artificial roots) to investigate whether spatial patterns of microbial enzyme activities in the 
rhizosphere are component-specific or not (Study 1). Three maize genotypes - wild type, mutant with defective root hair prolongation (rth3), and mutant with reduced benzoxazinoid content in exudates $(b x l)$ - were chosen to investigate the effects of root hairs and exudate composition on the spatial distribution of enzyme activities in the rhizosphere (Study 2).

\subsection{Abiotic factors: drought and soil nutrient availability}

Apart from biotic factors, the abiotic factor, e.g. drought - sub consequences of climate change (Hasibeder et al., 2015; Davidson and Janssens, 2006) — directly imposes osmotic pressure on both root and microbial cells, disconnects enzymes from substrate as well as microorganisms from nutrients, which would lead to microbial death and thus impair enzyme activities (Holz et al., 2019a; Turner et al., 2003). In addition, drought commonly alters the quantity and allocation of root exudates (Preece and Peñuelas, 2016; Wei et al., 2019), and thus affects microbial activity and enzyme production. The plant is likely to up-regulate the allocation of assimilated $\mathrm{C}$ to belowground in response to drought, to compensate for negative effects of drought (Preece and Peñuelas, 2016). For example, an increase in the release of mucilage can facilitate root water uptake and ease the root movement in the dry soil environment (Ahmed et al., 2014; Holz et al., 2018a). However, the amount of root exudates is also projected to decline under severe drought, probably due to the lower photosynthesis rate and the $\mathrm{C}$ redirection to other vital processes (Gargallo-Garriga et al., 2018). This will affect the quantity and quality of plant inputs of available organic compounds (Bardgett et al., 2008; Jones et al., 2009) and thus probably change the pattern of substrate distribution in soil. Heterogeneity in substrate localization is the primary reason for the existence of microbial hotspots in soil (Kuzyakov and Razavi, 2019). Previous studies have shown similar functions between or within hotspots despite dissimilarities in their microbial community structure (Kuzyakov and Blagodatskaya, 2015; Sanaullah et al., 2011). Although various communities may carry out similar functions, they may not be equivalent in other respects, such as in the efficiencies with which they express these functions in hotspots and their sensitivity to abiotic factors (e.g. drought). The degradation of high molecular organic matter depends on the microbial community's repertoire of genes encoding for the required enzymes (Bach et al., 2001). Changes in the abundance of enzymeencoding genes reveal alteration of the microbial potential to respond to external disturbances, such as drought, but can also provide information on the source organisms of a particular enzyme (Nannipieri et al., 2018, 2012). Thus, analyzing and quantifying microbial gene abundance as well as gene expression enables determining whether a response in enzyme expression is driven by the selection of drought-resistant microorganisms. An improved 
understanding of drought consequences on the micro-scale (i.e., hotspots), and of the mechanisms involved, would help assess impacts on ecosystem (e.g., macro-scale) processes and functioning. Hence, we coupled soil zymography with high-throughput sequencing to test whether specific bacterial taxa have individual responses to drought in enzymatic hotspots (Study 4).

Soil nutrient availability is another factor affecting the structure of rhizosphere community (i.e., species dominance and activity) (reviewed by Kuzyakov and Razavi, 2019). Microbial and enzyme activities should be higher in the hotspots with higher soil quality due to more available nutrients and organic substances. Therefore, the research question is that how the difference between the hotspots and bulk soil is impacted by soil nutrient availability, which dramatically changes soil $\mathrm{C}$ and nutrient status. This question needs to be addressed considering that microbial communities in the hotspots and bulk soil are functionally different in terms of their life strategies and enzyme kinetic properties due to different qualities and quantities of organic substrates (Blagodatskaya et al., 2009; Hoang et al., 2016) (Study 3).

\subsection{Interactive effects of biotic and abiotic factors (root hairs * temperature, root hairs * drought) on microbial processes in the hotspots}

Both biotic and abiotic factors strongly influence microbial processes in hotspots. However, studies that have explored their interactive effects are extremely scarce.

Root hairs are developed from epidermal cells (Peterson and Farquhar, 1996), and play a critical role in resource exchanges between soil, plants and soil microorganisms. One of the key contributions of root hairs is to increase the amount of available substrate for microorganisms (Jones et al., 2009; Mishra et al., 2009). This fundamentally affects C turnover and carbon dioxide $\left(\mathrm{CO}_{2}\right)$ emissions from the hotspots (Paterson et al., 2009; Blagodatskaya et al., 2011).

The increased amount of $\mathrm{C}$ released from roots also could be induced by elevated air temperature (Wei et al., 2019). However, the stimulated microbial respiration and functionality may be ephemeral responses to warming, either due to thermal acclimation or to substrate depletion (Allison et al., 2010; Bradford et al., 2019, 2008). Considering warming and root traits, it is far from clear whether root hairs increase the activity of the decomposer community through higher exudation rates or decrease it due to temperature acclimation. To answer these questions, we coupled soil zymography with enzyme kinetics, microbial growth kinetics and heat flow to assess the response of microbial community 
structure and functionality to warming depending on the root morphology in enzymatic hotspots (Study 5).

Drought not only alters root exudate pattern mentioned in section 1.2, water depletion also directly imposes osmotic pressure on both root and microbial cells, disconnects enzymes from substrates as well as microorganisms from nutrients, which would lead to microbial death and thus impair enzyme activities (Holz et al., 2019; Turner et al., 2003). This suggest that the spatial distribution of enzyme activities may also shift based on the pattern of water content, especially under drought. The presence of root hairs (e.g. more C input) may also magnify the uncertainty in our understanding on drought effects on root exudates and microbial functionality (e.g. enzyme activities). Therefore, a better understanding is urgently needed to identify the role of root exudates and water content in characterizing enzymatic distribution, especially at the root-soil interface. It is still unknown whether more root exudates (reflected by root hairs) can offset the direct negative impacts of water stress. Such knowledge is vital as it not only defines the soil volume actively used by plant and microorganisms, but also determine the soil volume where rhizosphere priming i.e. SOM decomposition as an important process in C cycling occurs (Kumar et al., 2018). Hence, as the enzymatic decomposition of SOM is the rate-limiting step in $\mathrm{C}$ and nutrient cycling, its spatial respond to the drought stress in a world with changing climate is essential (Kuzyakov and Razavi, 2019). Thus, we combined zymography, ${ }^{14} \mathrm{C}$ imaging and neutron radiograph to estimate how enzyme activities and its spatial dependence on root exudates or on water content are affected by root hairs and soil moisture (Study 6).

\section{Objectives}

To address the above listed knowledge gaps, the objectives of this thesis were to:

1) assess the effect of biotic factors on enzyme properties and microbial processes in hotspots: - evaluate effects of various components of root exudates on gradients and spatial distribution of microbial enzyme activities in the absence of further influencing factors related to real roots (Study 1);

- to test how root hairs and exudate composition affect the spatial distribution of $\beta$ glucosidase activities (Study 2).

2) investigate the effect of abiotic factors on enzyme properties and microbial processes:

- investigate the effect of soil nutrient availability on the difference in kinetic parameters between hotspots and bulk soil (Study 3) 
- determine whether a response of enzyme expression in hotspots to drought is driven by the changes in enzyme-related genes (Study 4).

3) determine the interactive effect of biotic and abiotic factors on enzyme properties and microbial processes:

- assess how root hairs regulate microbial growth strategy and enzyme systems to adapt to warming in rhizosphere hotspots (Study 5).

- estimate how root hairs and soil water content affect spatial dependence of $\beta$-glucosidase activities on root exudates and soil water (Study 6).

\section{Material and Methods}

\subsection{Sampling sites}

Soil for study 1 was taken from four plots at the Campus Klein-Altendorf ( $50^{\circ} 37^{\prime} \mathrm{N}, 6^{\circ} 59^{\prime}$ E), south-west of Bonn, Germany. The site has been used for cropping for more than 100 years.

The soil for study 2, 5 and 6 was collected from a Haplic Phaeozem close to Schladebach in Saxony Anhalt, Germany.

Study 3: Mitterfels (fertile soil) is located in the Central German Uplands. The samples of Mitterfels soil were taken from loamy Ap horizon (Lang et al., 2017) with high $\mathrm{C}$ and $\mathrm{N}$ content. Unterlüss (poor soil) is located in Lower Saxony, Germany. The samples taken from Ap horizon of Unterlüss silty loam soil were relatively barren with respectively, 1.6, 2.0 and 4.1 times lower $\mathrm{C}, \mathrm{N}$ and $\mathrm{P}$ content as compared with Mitterfels soil.

Soil for study 4 was collected from the Ap horizon of an arable loamy Haplic Luvisol, located on a terrace plain of the river Leine in the north-west of Göttingen, Germany. The site was for long-term organic farming with high $\mathrm{N}$ content but in organic form -unavailable for plant. 


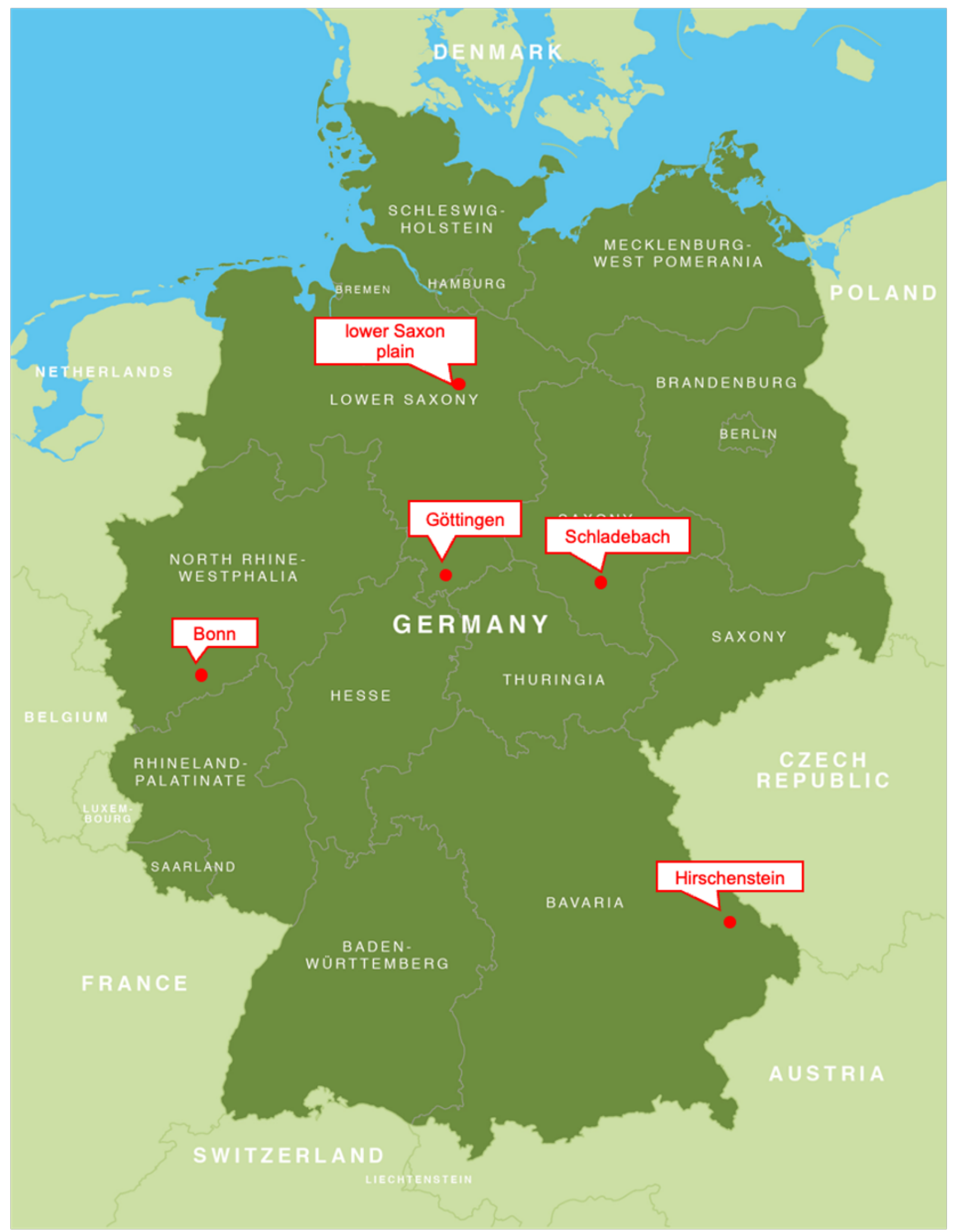

Fig. ES 1 Map of the soil sampling locations.

\subsection{Experimental layout}

\subsubsection{Study 1}

To test the effects of root exudates on microbial enzyme activities in the absence of real roots, we used a 100-mm-long Rhizon samplers as a simulated root. Organic substances - glucose, 
alanine, methionine, citrate and malate- were separately injected from the Rhizon in each rhizobox. During 14 days of incubation, rhizoboxes were kept in the climate chamber at 20 $\pm 1{ }^{\circ} \mathrm{C}$.

\subsubsection{Study 2}

Three maize (Zea mays L.) genotypes - wild type (WT, B73), root-hair defective ( $>90 \%)$ mutant (rth3) (Hochholdinger et al., 2018, 2008; Wen and Schnable, 1994) and benzoxazinoids (BX) deficit (>90\%) mutant (bxl) (Frey et al., 1997) - were grown in the rhizoboxes. After 3 days of germination, the pre-germinated seedlings of each genotype were planted in four replicates into separate rhizoboxes and all plants were cultivated for 21 days. The rhizoboxes were placed at an angle of approximately $45^{\circ}$ to ensure roots growing towards the wall of the rhizoboxes. About $20-22 \%$ of volumetric water content (VWC) was kept by watering the soil regularly from the top. Plants were grown in the climate chamber with a controlled temperature of $22{ }^{\circ} \mathrm{C}$ during the day and $18{ }^{\circ} \mathrm{C}$ during the night, a photoperiod of $12 \mathrm{~h}$, relative air humidity of $65 \%$ and a light intensity of $350 \mu \mathrm{mol} \mathrm{m}^{-2} \mathrm{~s}^{-1}$ of photosynthetically active radiation at the top of the rhizobox (LED Grow Light, GrowLED, France).

\subsubsection{Study 3}

Individual maize plants (Zea mays L., KWS, Germany) were grown in separate rhizoboxes in two soils with similar $\mathrm{pH}$ but contrasting texture and fertilization. During growth, the rhizoboxes were kept inclined at an angle of $45^{\circ}$ so that the roots grew at the vicinity of the lower wall of the rhizobox due to gravitropism. After cultivating maize plants for 2 weeks, soil zymography was applied to identify the spatial distribution of $\beta$-glucosidase and leucine aminopeptidase hotspots around the roots (Razavi et al., 2019).

\subsubsection{Study 4}

Maize seeds (Zea mays L.) were germinated on the filter paper in a dark environment for 3 days. Then one seedling was transplanted to each rhizobox $(12.3 \times 12.5 \times 2.3 \mathrm{~cm})$, which was filled with soil to a final bulk density of $1.4 \mathrm{~g} \mathrm{~cm}^{-3}$. The plants were kept in a climate chamber with a controlled temperature of $22 \pm 1{ }^{\circ} \mathrm{C}$ and a photo-period of $16 \mathrm{~h}$ light (photosynthetically active radiation intensity of $300 \mu \mathrm{mol} \mathrm{m} \mathrm{m}^{-2} \mathrm{~s}^{-1}$ ) and $8 \mathrm{~h}$ night for 3 weeks. During the growth period, the rhizoboxes' surfaces were covered completely to avoid algal growth, and they were put inclined at an angle of $45^{\circ}$ to ensure roots growth along the lower wall of the rhizobox. 
Two treatments (drought and optimum) with three replicates were established. One group of maize was grown in soil with an optimal water content $(70 \%$ of water holding capacity (WHC)) for 3 weeks. Another group of maize was under water limitation conditions, where soil water content was maintained at $70 \%$ of WHC for the first week, dried to $20 \%$ of WHC for one week and then kept at $20 \%$ of WHC for the last week.

\subsubsection{Study 5}

Two maize genotypes (Zea mays L.) - the root hair defective mutant $r$ th3 (showing root hair initiation but disturbed root hair elongation) (Hochholdinger et al. 2008; 2018), and the corresponding wild type - were germinated for 3 days. Each seedling was transplanted to a separate rhizobox with inner dimensions of $12.3 \times 12.5 \times 2.3 \mathrm{~cm}$. Two genotypes with 3 replicates were incubated in a climate chamber at $20 \pm 1{ }^{\circ} \mathrm{C}$ or $30 \pm 1{ }^{\circ} \mathrm{C}$ for 3 weeks. The daily light period of that climate chamber was $12 \mathrm{~h}$ with a photosynthetically active radiation intensity of $350 \mu \mathrm{mol} \mathrm{m} \mathrm{m}^{-2} \mathrm{~s}^{-1}$ and the relative air humidity was $65 \%$. During the growth period, these rhizoboxes were covered to avoid algal growth on the surface and kept inclined at an angle of $45^{\circ}$ to ensure that the roots grew along the lower wall. Each rhizobox was weighed and irrigated with distilled water to maintain the soil water content at $60 \% \mathrm{WHC}$.

\subsubsection{Study 6}

Two maize (Zea mays L.) genotypes, the root hair defective mutant $r$ th3 (showing root hair initiation but disturbed root hair elongation) (Hochholdinger et al. 2008; 2018), and the corresponding wild-type sibling were grown for 3 weeks in the rhizoboxes with the inner size of $10 \times 21 \times 0.6 \mathrm{~cm}$.

Before transplanting plants to the rhizoboxes, seeds were germinated on the filter paper for $72 \mathrm{~h}$. The rhizoboxes were kept at an angle of $45^{\circ}$ to make sure the roots grow along the lower side. The soil water content was maintained at $70 \%$ WHC in the first 2 weeks. In the $3^{\text {rd }}$ weeks, the water content was kept at either $70 \%$ of WHC (optimal water content) or adjusted to $30 \%$ of WHC (drought). Therefore, there were in total 12 rhizoboxes: two genotypes of maize, two water content conditions, and 3 replicates for each treatment. All of the plants were grown in a controlled climate chamber with a constant temperature of $22 \pm$ $1^{\circ} \mathrm{C}$ with the photoperiod was $12 \mathrm{~h}$ and the light intensity was $350 \mu \mathrm{M} \mathrm{m}^{-2} \mathrm{~s}^{-1}$.

\subsection{Methods}

Enzyme kinetics, kinetics of the substrate-induced growth response and heat production were measured to unravel enzyme and microbial strategies in response to biotic and abiotic factors. 
Microbial analysis (high-throughput sequencing) was conducted to reveal the response of bacterial community structure and functional groups related to enzymes to drought stress. Soil zymography was used to visualize and localize enzymatic hotspots. We also employed imaging methods - soil zymography, ${ }^{14} \mathrm{C}$ imaging and neutron radiography to elucidate the linkage between enzyme and rhizodeposition or between enzyme and water.

\subsubsection{Soil zymography (Study 1, 2, 3, 4, 5 and 6)}

After incubation, soil zymography was applied to visualize spatial distributions and localize hotspots of maximal enzyme activities (Razavi et al., 2019). Polyamide membrane filters (Tao Yuan, China) (diameter: $20 \mathrm{~cm}$, pore size: $0.45 \mu \mathrm{m}$ ) were saturated with fluorogenic substrates based on 4-methylumbelliferone (MUF) and 7-amino-4-methylcoumarin (AMC). The saturated membrane was placed on the soil surface. After $1 \mathrm{~h}$ incubation, membranes were carefully lifted off the soil surfaces and any attached soil particles were gently removed using a small brush. Then, the membranes were photographed under ultraviolet (UV) light in a dark room with a Canon EOS 6D camera. A calibration line with a series of increasing concentration of MUF or AMC was used to transformed gray values to enzyme activities.

\subsubsection{Enzyme kinetics (Study 1, 3, 4, 5 and 6)}

$0.5 \mathrm{~g}$ soil was mixed with $50 \mathrm{ml}$ sterile water. After $2 \mathrm{~min}$ low-energy sonification, $50 \mu \mathrm{l}$ soil suspension, $100 \mu \mathrm{l}$ substrate with different concentrations and $50 \mu \mathrm{l}$ buffer (MES, TRIZMA or Na-acetate) were added into a 96-well black microplate. The fluorescence was measured by a Victor 1420-050 Multi label counter (PerkinElmer, USA) after 0, $30 \mathrm{~min}, 1 \mathrm{~h}$ and $2 \mathrm{~h}$. The Michaelis-Menten equation was used to determine $\mathrm{V}_{\max }$ and $\mathrm{K}_{\mathrm{m}}$ :

$$
v=\frac{V_{\max } \times[S]}{K_{m}+[S]}
$$

where $\mathrm{V}$ is the reaction rate, $[\mathrm{S}]$ is the substrate concentration, $\mathrm{K}_{\mathrm{m}}$ is the substrate concentration at the half-maximal rate, and $\mathrm{V}_{\max }$ is the maximum reaction rate. The substrate turnover time (hours) $=\left(\mathrm{K}_{\mathrm{m}}+[\mathrm{S}]\right) / \mathrm{V}_{\max }$ (Panikov et al., 1992), where $\mathrm{S}$ is the substrate concentration regarding to the $\mathrm{V}_{\max }$. The catalytic efficiency of enzymes was determined by catalytic efficiency $\left(\mathrm{K}_{\mathrm{a}}\right)=\mathrm{V}_{\max } / \mathrm{K}_{\mathrm{m}}$ (Razavi et al., 2016)

\subsubsection{Kinetics of the substrate-induced growth response (Study 5)}

$0.5 \mathrm{~g}$ fresh soil in a tube was amended with a mixture containing glucose $\left(10 \mathrm{mg} \mathrm{g}^{-1}\right)$ and mineral salts (1.9 $\mathrm{mg} \mathrm{g}^{-1}\left(\mathrm{NH}_{4}\right)_{2} \mathrm{SO}_{4}, 2.25 \mathrm{mg} \mathrm{g}^{-1} \mathrm{~K}_{2} \mathrm{HPO}_{4}$, and $\left.3.8 \mathrm{mg} \mathrm{g}^{-1} \mathrm{MgSO}_{4} \cdot 7 \mathrm{H}_{2} \mathrm{O}\right)$ (Blagodatskaya et al., 2009). Soil samples were incubated in the modified rapid automated 
bacterial impedance technique (RABIT) system and the $\mathrm{CO}_{2}$ production rate was monitored every $20 \mathrm{~min}$. The theory of the microbial growth kinetics has been presented in detail earlier (Panikov, 1995).

\subsubsection{Microbial energy response to substrates (Study 5)}

$0.5 \mathrm{~g}$ soil from each rhizobox was used for incubation. Sand $\left(\mathrm{SiO}_{2}\right)$ were used as references for each treatment. The treatment and the reference should have the same heat capacity at the beginning. All the samples containing soil or sand were placed into airtight glass containers and incubated at $20{ }^{\circ} \mathrm{C}$ and $30{ }^{\circ} \mathrm{C}$, accordingly in the TAM Air Thermostat SN 548. Heat flow rate and heat production were monitored continuously every $10 \mathrm{~s}$ over $1 \mathrm{~h}$.

\subsubsection{Plant labeling and ${ }^{14} \mathrm{C}$ imaging (Study 2 and 6)}

After 3 weeks of maize growth, each plant was labeled with $0.5 \mathrm{MBq}{ }^{14} \mathrm{CO}_{2}$ in an airtight chamber for 6 hours. The detailed procedures were referred to Kuzyakov et al., (2006). Briefly, before labeling, $\mathrm{NaOH}$ was put in a glass vial connected with the chamber via a pipe to trap $\mathrm{CO}_{2}$ in the chamber for $8 \mathrm{~h}$. NaOH solution was then replaced by ${ }^{14} \mathrm{C}_{\text {as }} \mathrm{Na}_{2}{ }^{14} \mathrm{CO}_{3}$ solution dissolved by $1 \mathrm{M} \mathrm{H}_{3} \mathrm{PO}_{4}$. The released ${ }^{14} \mathrm{CO}_{2}$ was pumped into the chamber for $6 \mathrm{~h}$. After labeling, the remaining ${ }^{14} \mathrm{CO}_{2}$ in the chamber was trapped with $1 \mathrm{M} \mathrm{NaOH}$ for $2 \mathrm{~h}$.

Directly after labeling, the rhizoboxes were transferred to a dark room. The rooted soil surfaces were exposed to storage phosphor screens (BAS-IP MS 2040 E, GE Healthcare, U.S.A.). All screens were erased for $10 \mathrm{~min}$ under the strong bright light before use, and were protected from moisture by transparent plastic bags (polypropylene, $40 \mu \mathrm{m}$ thickness, density $0.95 \mathrm{~g} \mathrm{~cm}^{-3}$, MDF Verpackungen GmbH, Bergisch Gladbach, Germany). The plate with plastic bag was attached to the rooted soil surface for $20 \mathrm{~h}$ in a totally dark room. Thereafter, the plates were scanned with a laser scanner for phosphor-imaging (650 nm excitation, FLA7000, GE Healthcare, U.S.A.) with a spatial resolution of $25 \mu \mathrm{m}$ (Banfield et al., 2017) .

\subsubsection{Neutron radiography (Study 2 and 6)}

Neutron radiography is a non-destructive method which is sensitive to hydrous materials (Ahmed et al., 2016; Moradi et al., 2009b), and thus can quantify present water distribution in the rhizosphere (Holz et al., 2018a; Zarebanadkouki et al., 2018). The experiments were conducted at the ICON beam line at the Paul Scherrer Institute (PSI) in Switzerland. We used a CCD camera detector with an array of 1260 by 1260 pixels, a field of view of $15.75 \mathrm{~cm}$ by $15.75 \mathrm{~cm}$, and a spatial resolution of $0.2 \mathrm{~mm}$. 4 radiographs with marginal overlaps were scanned to cover the entire sample. 


\subsubsection{Microbial analysis (Study 4)}

DNA was extracted from frozen hot- and coldspot samples ( $c a .0 .5 \mathrm{~g})$ using the Quick Soil Isolation Kit (Omega, USA), according to the manufacturer's instructions. The V3-V4 region of $16 \mathrm{~S}$ rRNA was amplified with the primers 338F: 5'-ATGCAGGGACTA CHVGGGTWTCTAAT-3' and 806R: 5'-ACTCCTACGGGAGGCAGCA-3' (Jiang et al., 2019). Each sample had an eight-base Barcode at the $5^{\prime}$ end of the primers. PCR for amplification was carried out under the following conditions: at $95^{\circ} \mathrm{C}$ for $3 \mathrm{~min}$ followed by 27 cycles for $30 \mathrm{~s}$ at $95^{\circ} \mathrm{C}$, annealing for $30 \mathrm{~s}$ at $55^{\circ} \mathrm{C}$, an extension for $45 \mathrm{~s}$ at $72{ }^{\circ} \mathrm{C}$ and a final extension for $5 \mathrm{~min}$ at $72{ }^{\circ} \mathrm{C}$. The PCR products after purifying with AxyPrep DNA Gel Extraction Kit (Axygen Biosciences. USA) were quantified using a QuantiFluor ${ }^{\text {TM}}-\mathrm{ST}$ fluorometer (Promega, USA). The products were then pooled, and the paired-end sequencing $(2 \times 300 \mathrm{bp})$ was conducted on an Illumina MiSeq sequencer.

\section{Main results and discussion}

\subsection{Synthesis of main results of the studies}

1) The rhizosphere extent of microbial-derived enzyme activities is component- and enzyme-specific.

2) The presence of root hairs in wild type maize increased $\beta$-glucosidase activity, whereas benzoxazinoids in root exudates suppressed microorganisms.

3) The differences in microbial growth strategy between rhizosphere hotspots and bulk soil were dependent on soil fertility; a difference in enzyme activity and affinity was detected between the hotspots and bulk soil in the fertile and the poor soils but was enzymespecific.

4) Drought induced minor changes in rhizosphere bacterial community composition, which had great implications for the number of functional gene copies related to leucine aminopeptidase and chitinase.

5) Root hair effects on enzyme activities and microbial growth strategy were more pronounced at the elevated temperature: i) $\beta$-glucosidase activity of the wild type at $30{ }^{\circ} \mathrm{C}$ was $21 \%$ higher than that of mutant $r t h 3$; ii) temperature shifted the microbial growth strategy, whereas root hairs promoted the fraction of growing microbial biomass; iii) $\mathrm{K}_{\mathrm{m}}$ and the activation energy for $\beta$-glucosidase under the mutant $r$ th 3 was lower than that under wild maize. 
6) Both root hairs and soil moisture influenced spatial distribution of rhizosphere properties and processes, while soil moisture contributed more to the spatial correlation between hotspots of enzyme and root exudates/soil water content.

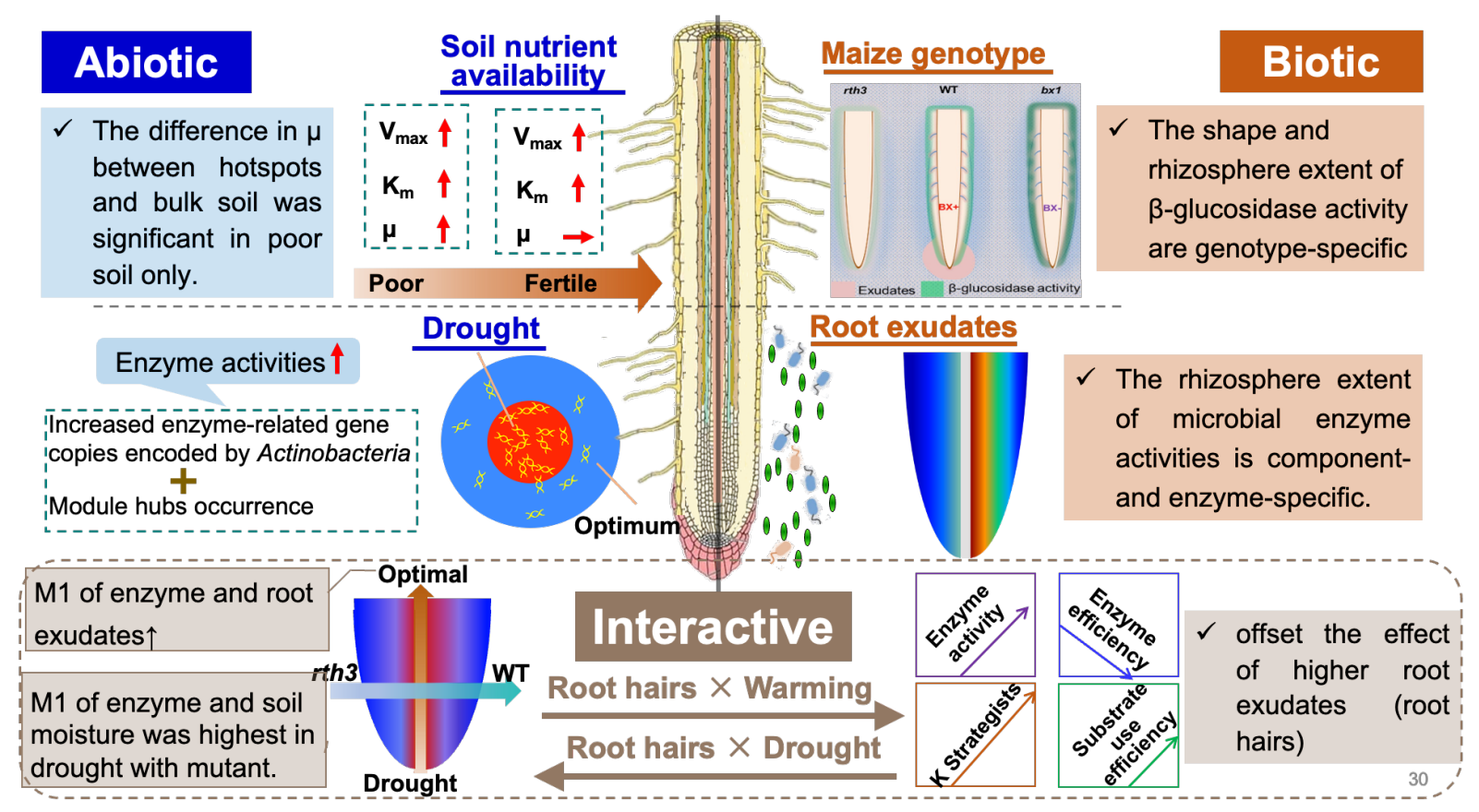

Fig. ES 2 Synthesis of main results of the studies.

\subsection{Effects of biotic factors (root exudates and root morphology) on the spatial} distribution of enzyme activities
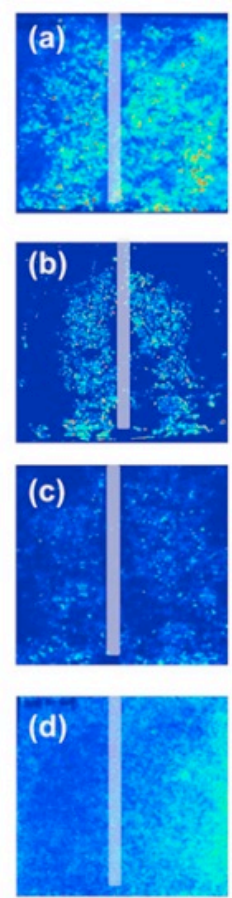

water
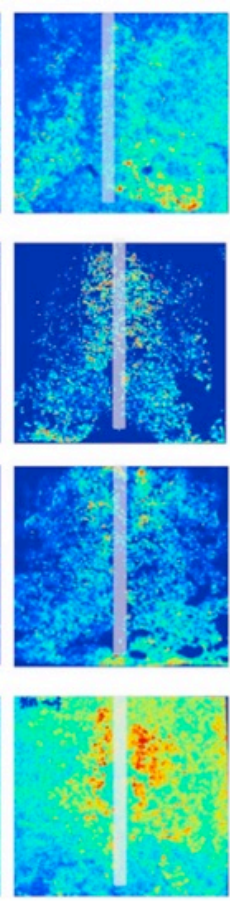

glucose
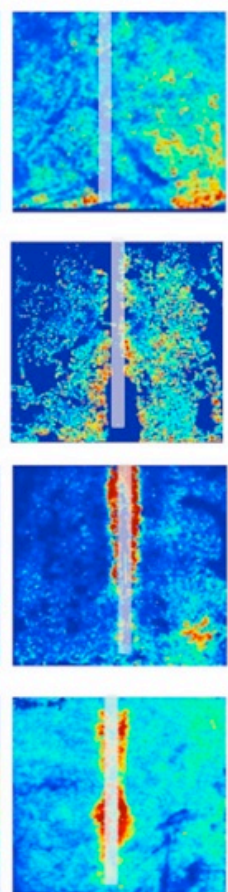

alanine
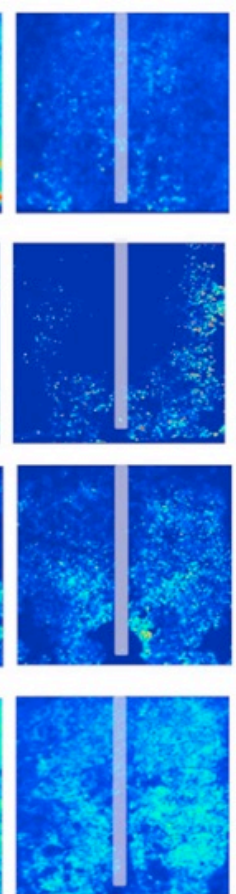

methionine
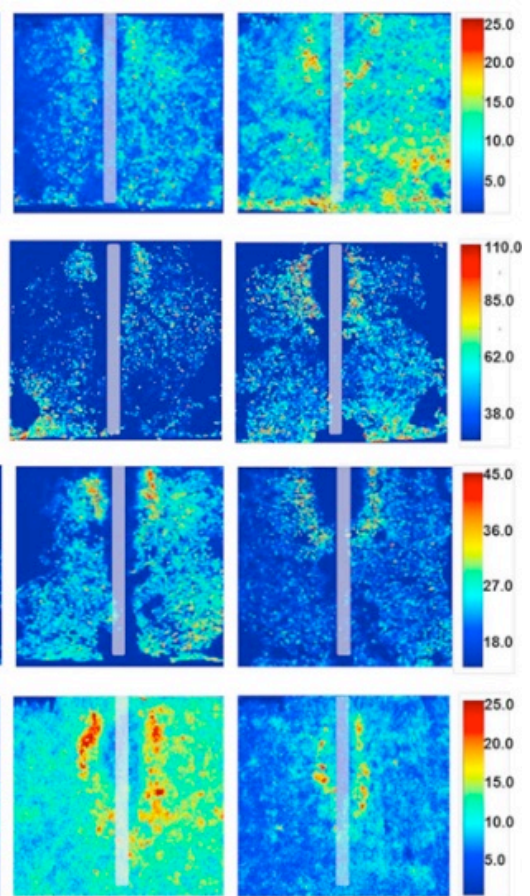

citrate

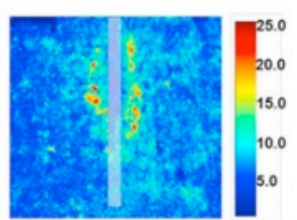

malate 
Fig. ES 3 Zymography images in response to component additions. a. $\beta$-glucosidase, b. leucine aminopeptidase, c. phosphatase, d. sulfatase. Side color scale is proportional to enzyme activities $\left(\mathrm{nmol} \mathrm{cm} \mathrm{ch}^{-2} \mathrm{~h}^{-1}\right)$.
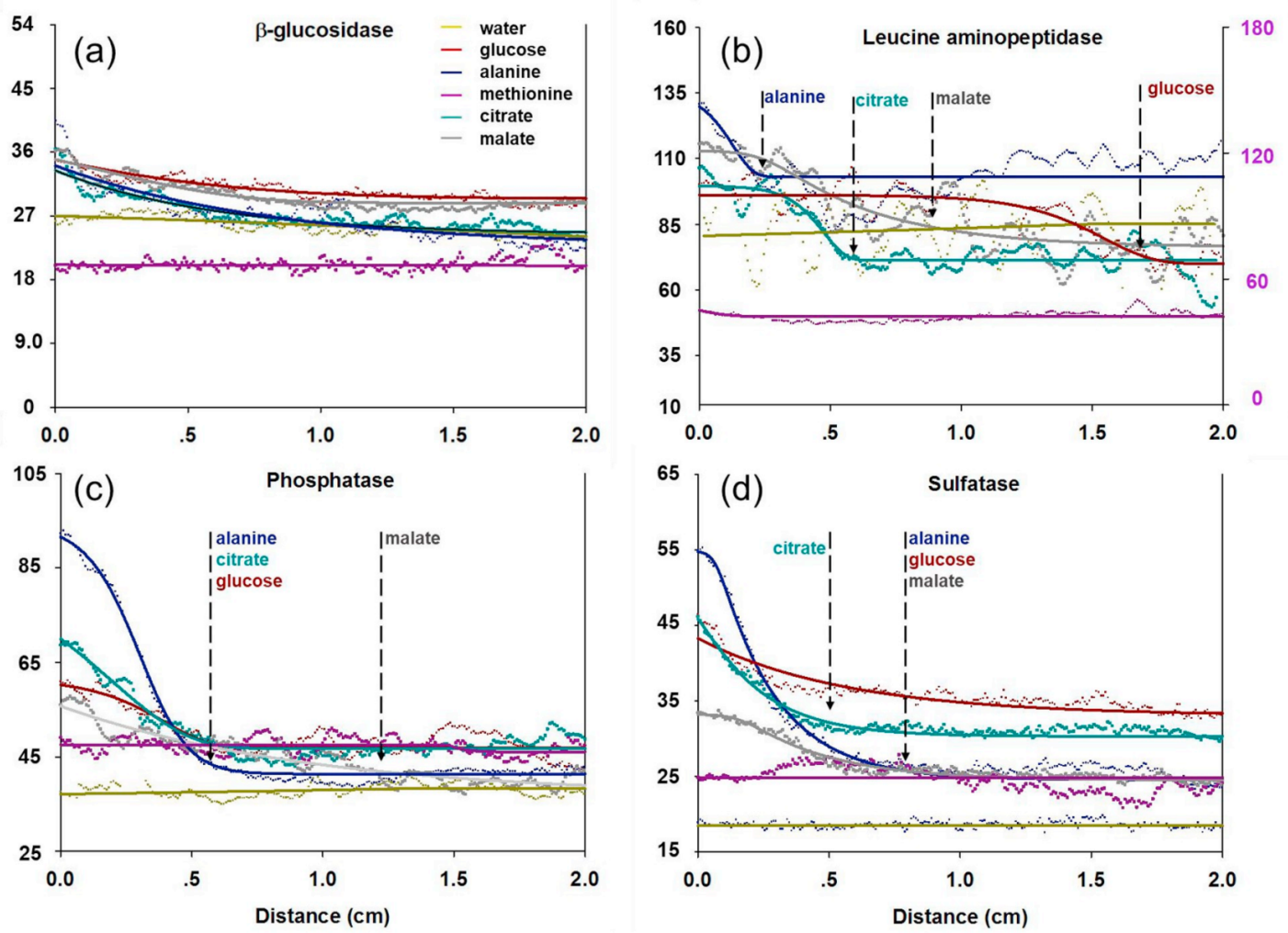

Fig. ES 4 The profile of enzyme activity distribution as a function of distance from the root center. Each line refers to the mean value of many lines of one part from each zymogram. 0 on the $\mathrm{X}$ axis shows the center of the artificial root. The $\mathrm{Y}$ axis is presented in relative units as enzyme activity $\left(\mathrm{nmol} \mathrm{cm} \mathrm{cm}^{-2} \mathrm{~h}^{-1}\right)$. For leucine aminopeptidase, the right axis is for purple line (methionine). Vertical dashed black lines on the curves: artificial rhizosphere extent for individual substances.

The spatial distribution of $\beta$-glucosidase did not change strongly after component additions and there was no clear rhizosphere extent (boundary) for $\beta$-glucosidase (Fig. ES3). This homogeneous spatial pattern of $\beta$-glucosidase involved in the carbohydrate decomposition might be mainly because microorganisms use some of the carbohydrate directly as an energy source. In contrast, artificial exudates stimulate microorganisms for production of phosphatase, leucine aminopeptidase and sulfatase and form spatial gradients from artificial roots to the bulk soil (Fig. ES3). Such higher enzyme activities in the rhizosphere are traditionally related to inputs of labile organic substances, which activate microorganisms (Kuzyakov and Blagodatskaya, 2015). 
Individual component had a specific effect on the spatial extent of rhizosphere enzyme activities. Alanine increased the rhizosphere extent much stronger than other substances, while methionine had no effect on the spatial distribution of enzyme activities (Fig. ES4). As the soil we used is $\mathrm{N}$ limited, the $\mathrm{N}$ source provided by alanine most likely explains why the activities of all enzymes were more strongly increased by alanine than by any other substances. The lower effect of methionine on the enzyme activity was due to the C-S bond, which impedes its rapid mineralization (Spohn et al., 2013).

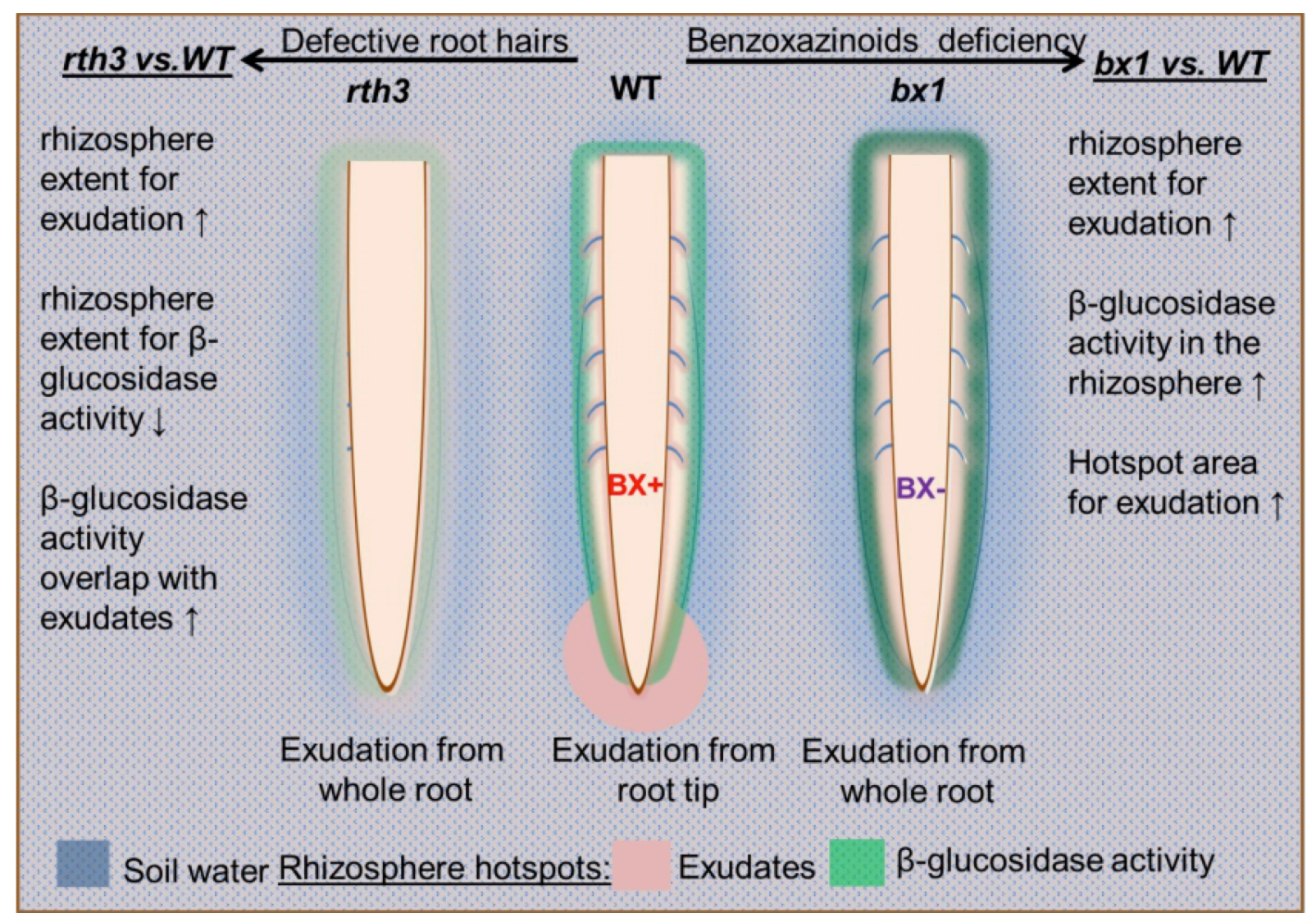

Fig. ES 5 General pattern of the effects of maize mutations (root defective $r$ th 3 and BX deficient $b x l$ as compared to wild type (WT) on the rhizosphere extent, hotspots, enzyme activity level and overlap of $\beta$-glucosidase with water and exudates. Significant increase and decrease indicated by $\uparrow$ and $\downarrow$ respectively.

The WT released exudates primarily from root tips, while the $r t h 3$ and $b x 1$ mutants released ${ }^{14} \mathrm{C}$ exudates along the whole roots (Fig. ES 5). The change in spatial distribution of exudates in $r$ th 3 and $b x l$ is presumably a plant strategy to maintain high microbial activity and thus 
enzyme activity (including $\beta$-glucosidase) by releasing easily available $\mathrm{C}$ into the entire rhizosphere (McDougall \& Rovira, 1970; Voothuluru et al., 2018; Cotton et al., 2019).

Root hair rhizodeposits, along with the released exudates, increase the active portion of microbial biomass in the rhizosphere (Zhang et al., 2020) and therefore stimulate $\beta$ glucosidase production (Wang \& Lu, 2006). Therefore, the presence of root hairs enlarged the enzymatic rhizosphere for $\beta$-glucosidase activity ( $+35 \%$ of rhizosphere extent). In contrast, the absence of root hairs (rth3) induces an increased exudation of primary metabolites and $\beta$-glucosidase (Gramss et al., 1999) from the mature root zone in $r$ th3. The substrate limitation for microorganisms can stimulate exudation by roots (Williams and Vries, 2020) and increase the spatial extent of the ${ }^{14} \mathrm{C}$ exudation patterns along the mature root section (Fig. ES 5).

The $b x 1$ maize plant did not need to invest high energy into synthesizing benzoxazinoids and therefore probably produced more primary metabolites (Pott et al., 2019). The larger ${ }^{14} \mathrm{C}$ accumulation area in the soil in $b x 1$ is because the ${ }^{14} \mathrm{C}$ is localized along the whole root, not only at the root tip as in WT. The result was 2.5 -fold larger ${ }^{14} \mathrm{C}$ exudate hotspot areas. The release of benzoxazinoids by roots suppressed the activities of rhizosphere microorganisms, which led to $30 \%$ lower $\beta$-glucosidase activity but did not change the rhizosphere extent (Fig. ES 5). 
4.3 Effects of abiotic factors (soil nutrient availability and drought) on microbial processes

\subsubsection{Soil nutrient availability}
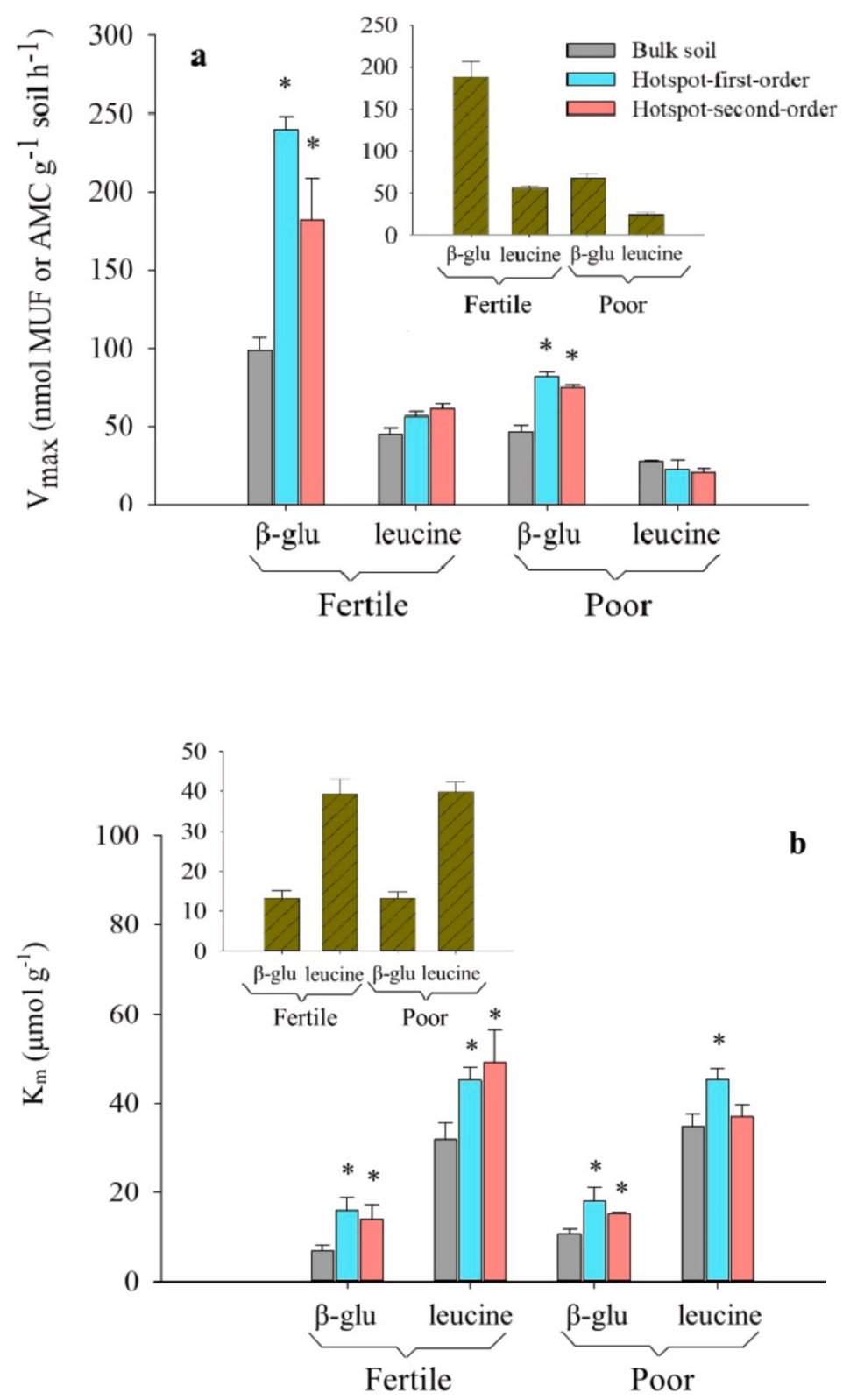

Fig. ES $6 \mathrm{~V}_{\max }(\mathrm{a})$ and $\mathrm{K}_{\mathrm{m}}(\mathrm{b})$ values of $\beta$-glucosidase, and leucine aminopeptidase in the fertile and the poor soils. Values are means of three replicates $( \pm \mathrm{SE}) . \quad$ Asterisks indicate significantly different from bulk soil. The inserts show the mean value of different samples.

Generally, greater $V_{\max }$ values in the fertile soil versus poor soil (Fig. ES 6a) was a result of more growing biomass in the former (Table 2 in study 3 ). Growing microorganisms produce larger amount of active enzymes $\left(\mathrm{E}_{0}\right)$ and the $\mathrm{V}_{\max }$ is a function of $\mathrm{E}_{0}$ (Nannipieri and Gianfreda, 1998; Allison et al., 2010; Blagodatskaya et al., 2016).

The higher $\mathrm{V}_{\max }$ in hotspots than bulk soil only occurred for $\beta$-glucosidase (Fig. ES 6a), which indicated that the activity of $\beta$-glucosidase was also a function of the amount of available substrate (Allison and Vitousek, 2005). However, the difference of $V_{\max }$ of leucine 
aminopeptidase between hotspots and bulk soil was negligible. Given the $\mathrm{C} / \mathrm{N}$ ratio around and above 20 in both soils (Table 1 in study 3), the microbial acquisition of $\mathrm{N}$ was strongly restricted by nutrient supply capacity according to stoichiometric constraints (Sinsabaugh et al., 2009). As root exudates and rhizodeposits were generally depleted in $\mathrm{N}$ content, the $\mathrm{N}$ supply capacity was even lower in the hotspots than in bulk soil, thus restricting mobilization of organic N by microorganisms (Tarafdar and Jungk, 1987; Badalucco and Nannipieri, 2007; Kuzyakov and $\mathrm{Xu}, 2013)$. In accordance with ecological principles, the $\mathrm{K}_{\mathrm{m}}$ increased in rhizosphere hotspots compared to bulk soil (Fig. ES 6b), indicating decreased affinity of enzymes as an effect of root exudates and rhizodeposits (Blagodatskaya et al., 2009). The higher $\mathrm{K}_{\mathrm{m}}$ values in the hotspots versus bulk soil indicated altered enzyme systems by rhizomicrobial interactions.
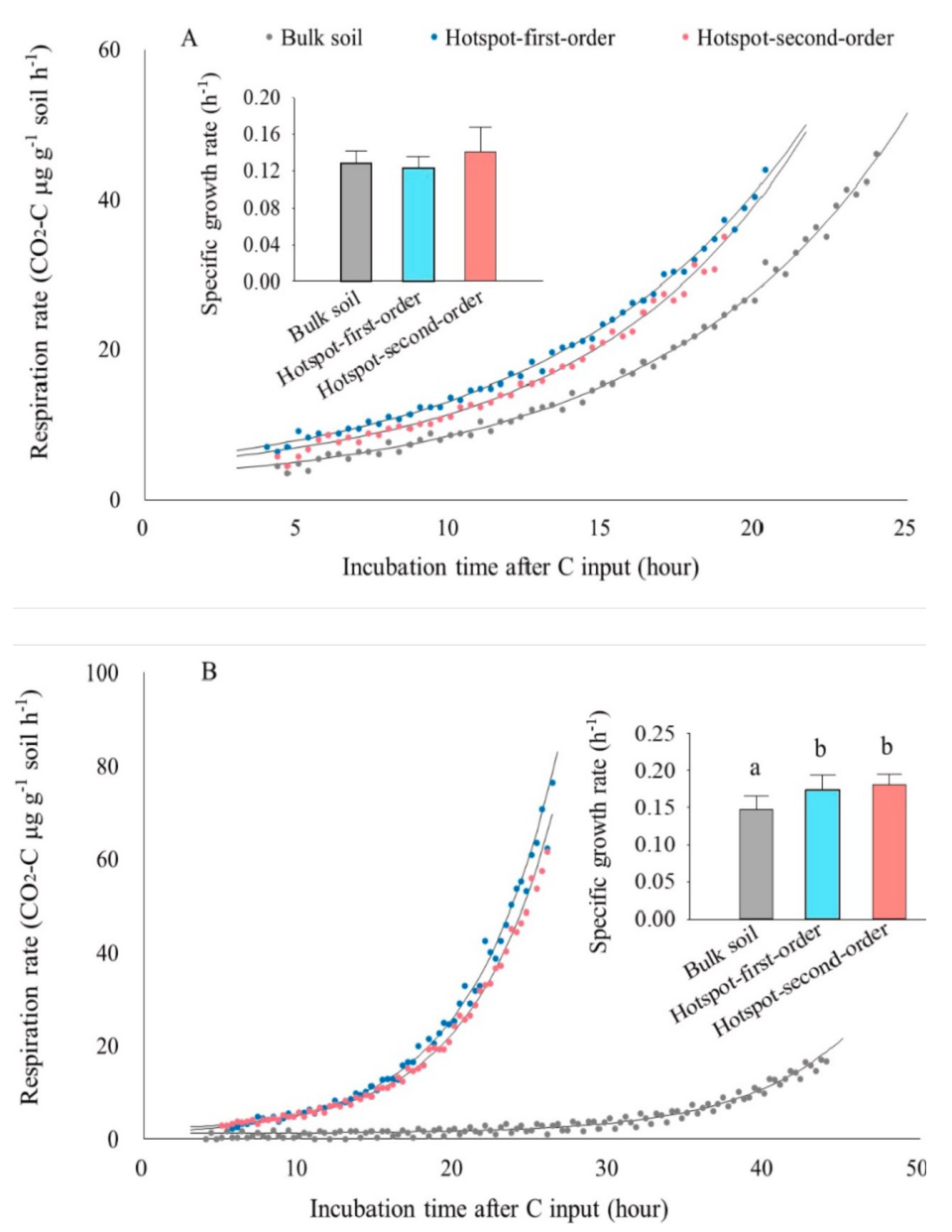

Fig. $\quad$ ES 7 Glucose-induced respiratory responses of microbial community and their corresponding specific growth rates ( $\mu \mathrm{m}$; inset figures) after substrate addition into the (A) fertile and (B) poor soil. Experimental data are shown as symbols and model simulation (Equation (1)) as curves. Bars show standard errors of the means $( \pm \mathrm{SE})$. Lower-case letter indicates significant difference at a level of $\mathrm{P}<0.05$.

Differences in the microbial growth response to substrate addition between rhizosphere hotspots and bulk soil were dependent on soil nutrient availability and were detected only in the poor soil (Fig. ES 7). Equal microbial specific growth rates $\left(\mu_{\mathrm{m}}\right)$ in the hotspots and bulk 
soil from the fertile soil might be associated with the availability of soil organics (German et al., 2011). Due to abundant organics in soil, the energy limitation and dependence of the microbial community on labile $\mathrm{C}$ input by roots are weak. In contrast, substrate addition to hotspots of the poor soil induced strong stimulation of microbial growth compared to bulk soil.

\subsubsection{Drought}

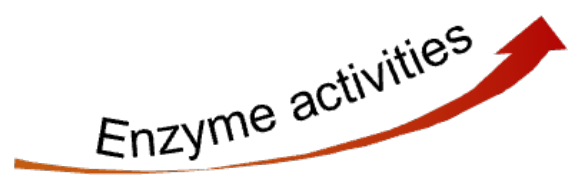

\section{Optimum Drought}
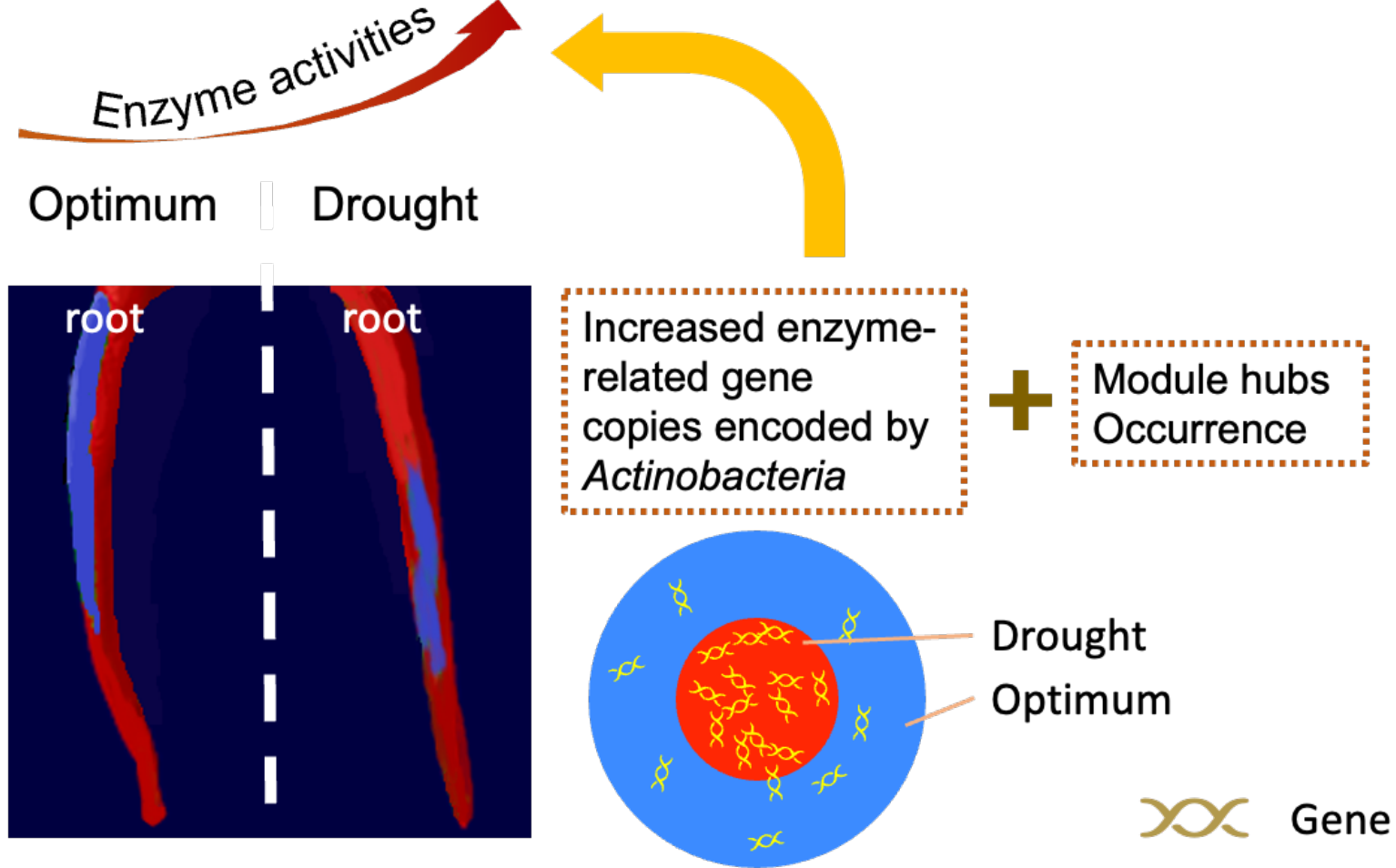

Fig. ES 8 Conceptual graph showing effects of drought on microbial community structure, activity and functionality. Activities of chitinase and leucine aminopeptidase were higher under drought conditions. Drought induced higher enzyme-related gene copies encoded by Actinobacteria controlling microbial roles in protein and chitin decomposition.

The higher enzyme activities under drought were due to the increased number of functional genes copies encoded by the Actinobacteria for both leucine aminopeptidase and chitinase (Fig. ES8). Moreover, the interactions between bacteria were less equal under drought (Fig $8 \mathrm{~b}$ in study 4 ), which indicated the adaptation of keystone bacteria to drought stress. The genus Luedemannella (Actinobacteria) is probably one of the keystone bacteria that acting as module hubs to mediate energy and substance exchanges within modules to maintain the interactions between bacterial populations. 
4.4 Interactive effects of biotic and abiotic factors (root hairs * temperature, root hairs * drought) on microbial processes

\subsubsection{Root hairs * temperature}

(a)

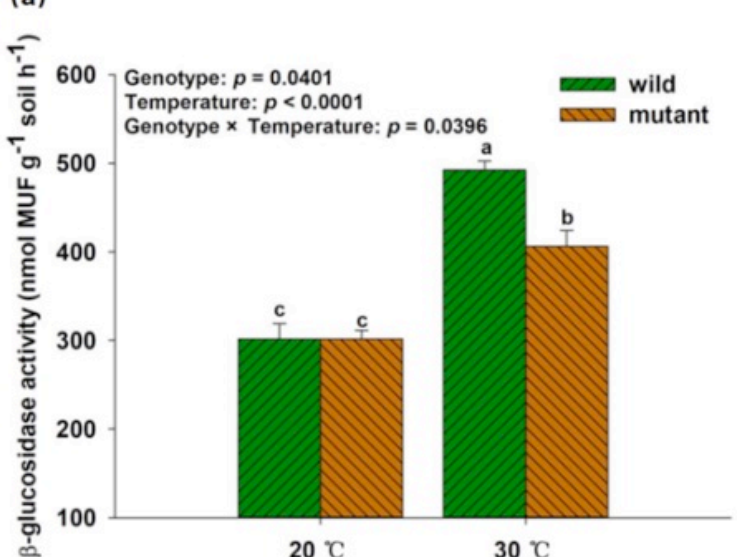

(b)

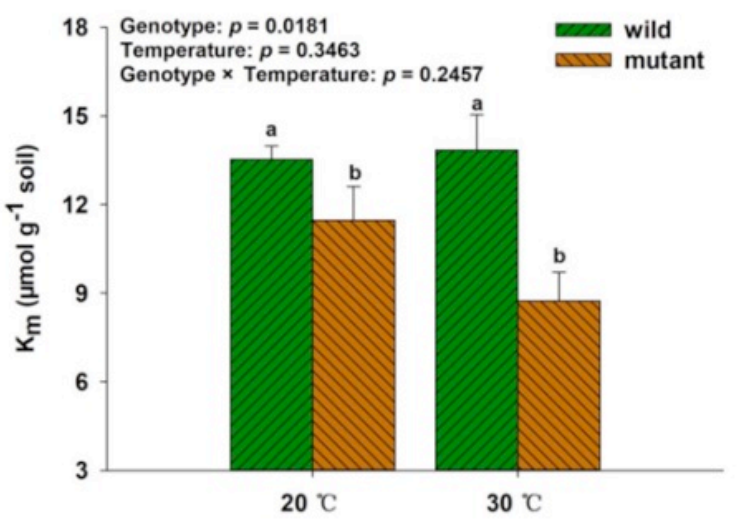

Fig. ES $9 \beta$-glucosidase activity parameters: $V_{\max }(\mathrm{a})$ and $\mathrm{K}_{\mathrm{m}}(\mathrm{b})$ at 20 and $30^{\circ} \mathrm{C}$ of root-hair wild and root-hairless mutant maize. $p$ values were obtained after two-way ANOVA. Genotype: wild type and mutant maize; Temperature: 20 and $30^{\circ} \mathrm{C}$. Lower case letters in (a): significant differences after two-way ANOVA and Tukey's HSD test at $p<0.05$; Lower case letters in (b): significant differences between wild type and mutant maize after two-way ANOVA and Student's $t$ test at $p<0.05$.
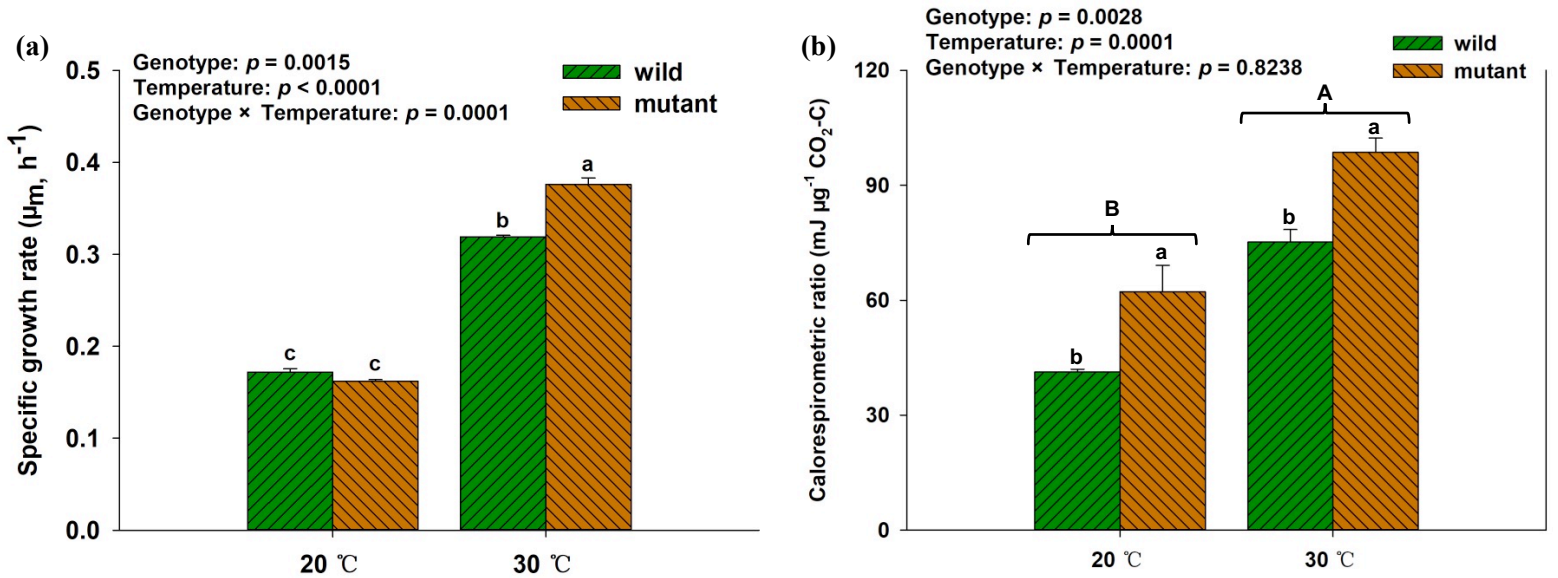

Fig. ES 10 (a) Specific growth rates $(\mu)$ of soil microorganisms during incubation at 20 and $30{ }^{\circ} \mathrm{C}$ for the two maize genotypes estimated by substrate-induced respiration. (b) Substrate use efficiency expressed as calorespirometric ratios obtained from the $24 \mathrm{~h}$ incubation of soil samples after glucose addition. $p$ values were obtained after two-way ANOVA. Genotype: wild type and mutant maize; Temperature: 20 and $30^{\circ} \mathrm{C}$. Lower case letters in (a): significant 
differences after two-way ANOVA and Tukey's HSD test at $p<0.05$. Lower case letters (b): significant differences between wild type and mutant maize after two-way ANOVA and Student's $t$ test at $p<0.05$; Upper case letters in (b): significant differences between 20 and $30{ }^{\circ} \mathrm{C}$ after two-way ANOVA and Student's $t$ test at $p<0.05$.

$\beta$-Glucosidase activities at $30{ }^{\circ} \mathrm{C}$ were $63 \%$ and $35 \%$ higher than at $20{ }^{\circ} \mathrm{C}$ in the soil from hotspots of root-hair wild type and mutant $r$ th3, respectively (Fig. ES 9a). $V_{\max }$ and $\mathrm{K}_{\mathrm{m}}$ of $\beta$ glucosidase activity for wild type was higher than that of the mutant $r \operatorname{th} 3$ at $30{ }^{\circ} \mathrm{C}$ (Fig. ES 9). Temperature accelerated the specific growth rates and increased the calorespirometric ratios. The rates and ratios were higher in the hotspots of mutant $r$ th 3 versus wild type at $30{ }^{\circ} \mathrm{C}$ (Fig. ES 10).

The higher $\beta$-glucosidase activity at $30{ }^{\circ} \mathrm{C}$ was probably related to the higher root exudate release due to the effect of warming on the membrane permeability of root cells (Steinweg et al., 2008; Allison et al., 2010). At $30^{\circ} \mathrm{C}$, root hairs released large amounts of compounds (Badri and Vivanco, 2009; Jones et al., 2009; Holz et al., 2018b), and thus increased enzyme activities compared to mutant $r$ th 3 . However, selecting enzymes with lower substrate affinity (i.e. higher $\mathrm{K}_{\mathrm{m}}$ ) in the presence of root hairs will restrain the enzyme-mediated reactions at higher temperature (Bradford et al., 2019). This means the increased $\beta$-glucosidase production in the presence of root hairs was sufficient to gain enough energy for microbial activity. In addition, the higher relative abundance of slow-growing microorganisms in the soil of wild type could induce a lower calorespirometric ratio compared with the mutant $r$ th 3 . Such a higher ratio of $\mathrm{C}$ incorporated into microbial biomass meant higher SOM formation rates and retarded soil $\mathrm{C}$ losses (Bölscher, 2016; Bradford et al., 2019). In comparison, the lower $\mathrm{K}_{\mathrm{m}}$ of $\beta$-glucosidase in the hotspots of mutant $r$ th 3 maize at higher temperature indicated the selection of efficient enzyme systems to compensate for the less amount of exudate. The higher abundance of fast-growing microorganisms in the soil of mutant $r$ th 3 at $30{ }^{\circ} \mathrm{C}$ responded faster to the available substrates and maximized their growth by increasing the calorespirometric ratio (Fierer et al., 2007), leading to a large energy loss as heat (Herrmann et al., 2014). 


\subsubsection{Root hairs * drought}
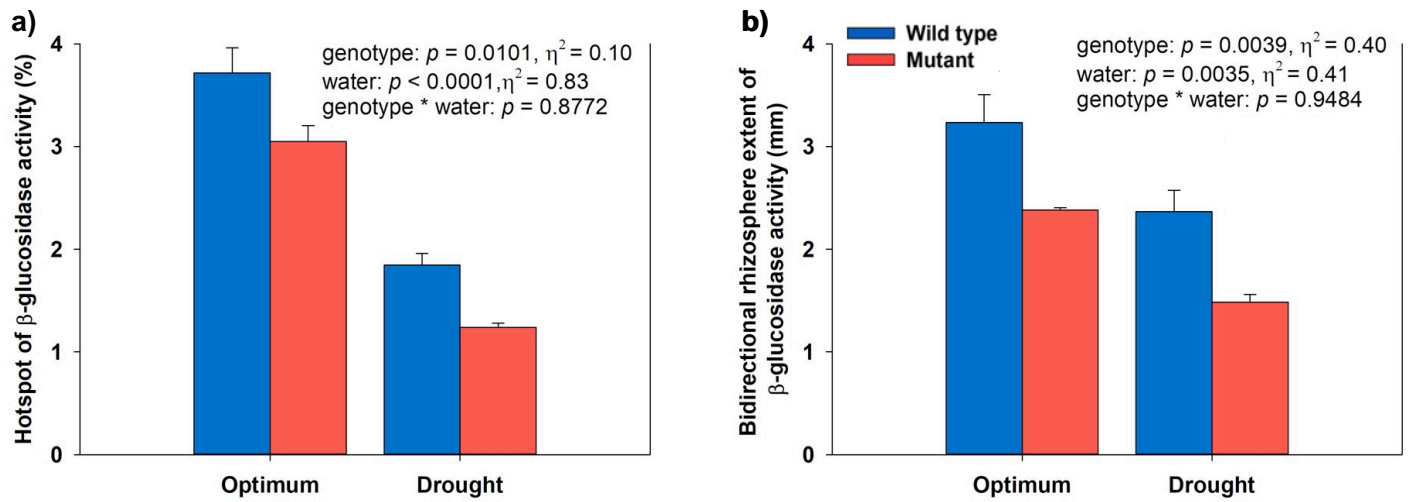

Fig. ES 11 (a) Hotspot (\%) and (b) bidirectional rhizosphere extent of $\beta$-glucosidase activity for two maize genotypes (wild type and mutant $r$ th3) under drought and optimal water content. $p$ values were obtained after two-way ANOVA. genotype: wild type and mutant $r t h 3$; water: drought and optimal water content. Data is mean $(n=3)$ and error bars represent standard deviation (SD).

(a) Enzyme $\times$ Exudates

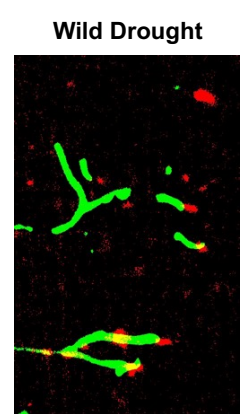

M1: 0.09B

M2: $0.09 \mathrm{~b}$

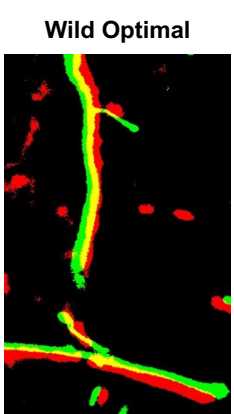

M1: $0.36 \mathrm{~A}$

M2: $0.44 \mathrm{a}$

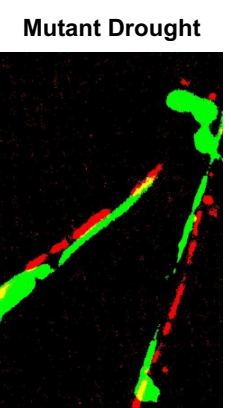

M1: 0.18B

M2: $0.08 \mathrm{~b}$

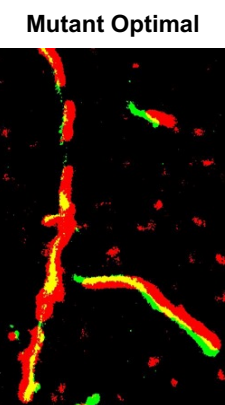

M1: 0.43A

M2: $0.52 \mathrm{a}$
Two-way ANOVA for M1:

Genotype: $p=0.4768$

Water: $p=0.0329$

Genotype ${ }^{*}$ Water: $p=0.9011$

Two-way ANOVA for M2:

Genotype: $p=0.5908$

Water: $p=0.0007$

Genotype ${ }^{*}$ Water: $p=0.5647$ 
(b) Enzyme $\times$ Water

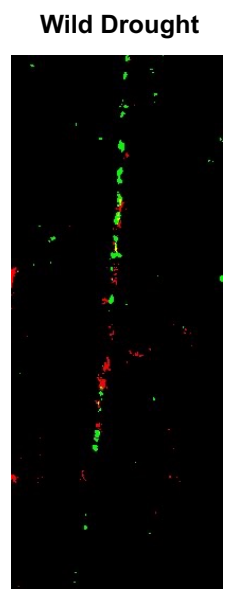

M1: 0.07B

M2: $0.04 \mathrm{~b}$

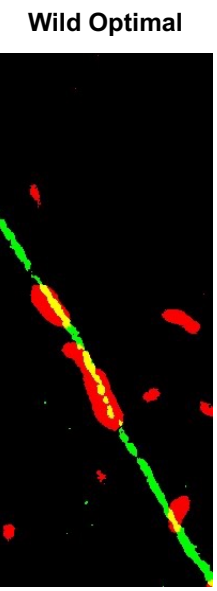

M1: 0.12B

M2: $0.29 a$

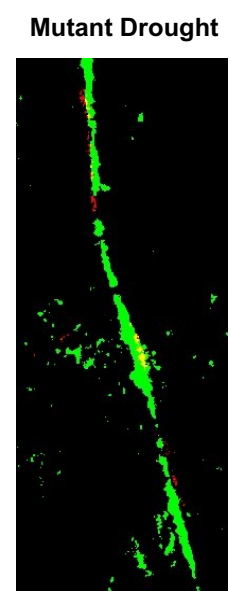

M1: $0.45 \mathrm{~A}$

M2: $0.04 \mathrm{~b}$

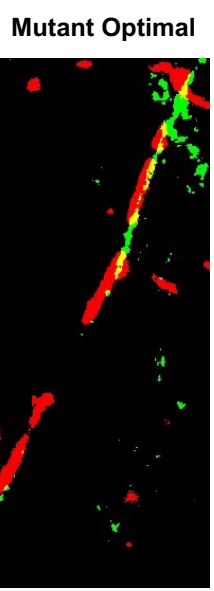

M1: 0.09B

M2: $0.23 a$

Two-way ANOVA for M1:

Genotype: $p=0.0170$

Drought: $p=0.0251$

Genotype*Drought: $p=0.0077$

Two-way ANOVA for M2:

Genotype: $p=0.5649$

Drought: $p=0.0032$

Genotype*Drought: $p=0.6018$

Fig. ES 12 Colocalization analysis for region of interest (ROIs) of (a) hotspots between $\beta$ glucosidase activity (Enzyme) and ${ }^{14} \mathrm{C}$ exudates (Exudates), or (b) hotspots between $\beta$ glucosidase activity (Enzyme) and water (Water). M1: Manders' coefficient, the fraction of Enzyme overlapping with Exudates or Water; M2: Manders' coefficient, the fraction of Exudates or Water overlapping with Enzyme; $p$ values were obtained after two-way ANOVA. genotype: wild type and mutant $r$ th3; water: drought and optimal water content. Upper case letters in (a): significant differences for M1 between optimal and drought conditions after two-way ANOVA and Student's t-test at $p<0.05$. Upper case letters in (b): significant differences for M1 among four treatments after two-way ANOVA analysis and Tukey's HSD test at $p<0.05$. Lower case letters in (a) and (b): significant differences for M2 between optimal and drought conditions after two-way ANOVA and Student's t-test at $p<0.05$.

Root hairs, which released more root exudates (Pausch et al., 2016), enlarged the enzymatic hotspot area and extended the rhizosphere size (Fig. ES 11). Although root exudates directly relieved microbial $\mathrm{C}$ limitation, the importance of soil moisture outweighed root hairs in regulating the occurrence of enzyme hotspots. Drought reduced the hotspot area (Fig. ES 11a) and narrowed the rhizosphere extent of $\beta$-glucosidase activity (Fig. ES 11b). The larger hotspots area and wider rhizosphere extent of $\beta$-glucosidase activity were concurrent with optimal water content because the proper soil moisture is a prerequisite for higher root biomass. It has been strongly suggested as a compelling explanation for higher rhizodeposition (Preece and Peñuelas, 2016). Additionally, the optimal water content provided a suitable growth environment for microorganisms, and increased microbial access to nutrients and energy (Ahmed et al., 2018), as well as enhanced the diffusion of both 
enzymes and substrate (Holz et al., 2019). Consequently, $\beta$-glucosidase activities in wet soil were most pronounced. In addition, colocalization between enzymatic hotspots and root exudates were only pronounced under optimal soil moisture, while lower soil water availability limits the enzymatic hotspot areas when occurring co-limitation of available $\mathrm{C}$ and water (Fig. ES 12).

\section{Conclusions}

Both biotic (e.g. root exudates and root hairs) and abiotic (e.g. soil nutrient availability and climate changes) factors play the key role in enzyme activities and their spatial distributions, as well as in microbial functionality. Generally, global changes often occur simultaneously with the manipulation of exudate composition or root morphology. For example, the lower soil enzyme efficiency and higher substrate use efficiency could offset the exudate-induced increase of microbial activity and hence maintain SOM stocks in the presence of root hairs under warming. However, the role of root hairs was diminished when drought occurred. Soil moisture contributed more to microbial processes and enzymatic distributions in the rhizosphere. Accordingly, practices which retain soil water effectively should be implemented into arid and semiarid areas. In addition, we found minor changes in bacterial community abundance had strong implications for functional gene abundances controlling microbial roles in proteins and chitin decomposition in response to drought. This proves the importance of microbial functional gene abundance in its function in $\mathrm{N}$ cycles. Together, these results indicate the necessity of incorporating functional genes and multi-factor interactive effects into models for better prediction of biogeochemical cycles. This would require interdisciplinary cooperation from soil scientists, microbiologists, ecologists, statistician and computer expert. 


\section{References}

Ahmed, M.A., Kroener, E., Holz, M., Zarebanadkouki, M., Carminati, A., 2014. Mucilage exudation facilitates root water uptake in dry soils. Functional Plant Biology 41, 1129. doi:10.1071/FP13330.

Ahmed, M.A., Sanaullah, M., Blagodatskaya, E., Mason-Jones, K., Jawad, H., Kuzyakov, Y., Dippold, M.A., 2018. Soil microorganisms exhibit enzymatic and priming response to root mucilage under drought. Soil Biology and Biochemistry 116, 410-418. doi:10.1016/j.soilbio.2017.10.041.

Ahmad, S., Veyrat, N., Gordon-Weeks, R., Zhang, Y., Martin, J., Smart, L., Glauser, G., Erb, M., Flors, V., Frey, M., Ton, J., 2011. Benzoxazinoid Metabolites Regulate Innate Immunity against Aphids and Fungi in Maize. Plant Physiology 157, 317-327. doi:10.1104/pp.111.180224.

Allison, S., Vitousek, P., 2005. Responses of extracellular enzymes to simple and complex nutrient inputs. Soil Biology and Biochemistry 37, 937-944.

Allison, S.D., Wallenstein, M.D., Bradford, M.A., 2010. Soil-carbon response to warming dependent on microbial physiology. Nature Geoscience 3, 336-340. doi:10.1038/ngeo846.

Asmar, F., Eiland, F., Nielsen, N.E., 1994. Effect of extracellular enzyme activities on solubilization rate of soil organic nitrogen. Biology and Fertility of Soils 17, 32-38.

Badalucco, L., Nannipieri, P., 2007. Nutrient transformation in the rhizosphere. In: Pinton, R., Varanini, Z., Nannipieri, P. (Eds.), The Rhizosphere: Biochenistry and Organic Substrates at the Soil-Plant Interface. CRC Prss, Boca Raton, FL, pp. 111-133.

Badri, D.V., Vivanco, J.M., 2009. Regulation and function of root exudates. Plant, Cell \& Environment 32, 666-681. doi:10.1111/j.1365-3040.2009.01926.x.

Banfield, C.C., Zarebanadkouki, M., Kopka, B., Kuzyakov, Y., 2017. Labelling plants in the Chernobyl way: A new 137Cs and 14C foliar application approach to investigate rhizodeposition and biopore reuse. Plant and Soil 417, 301-315. doi:10.1007/s11104-017-3260-7.

Bardgett, R.D., Freeman, C., Ostle, N.J., 2008. Microbial contributions to climate change through carbon cycle feedbacks. The ISME Journal 2, 805-814. doi:10.1038/ismej.2008.58.

Bertin, C., Yang, X., Weston, L.A., 2003. The role of root exudates and allelochemicals in the rhizosphere. Plant and Soil 256, 67-83. doi:10.1023/A:1026290508166.

Blagodatskaya, E., Yuyukina, T., Blagodatsky, S., Kuzyakov, Y., 2011. Three-source-partitioning of microbial biomass and of $\mathrm{CO} 2$ efflux from soil to evaluate mechanisms of priming effects. Soil Biology and Biochemistry 43, 778-786. doi:10.1016/j.soilbio.2010.12.011.

Blagodatskaya, E.V., Blagodatsky, S.A., Anderson, T.H., Kuzyakov, Y., 2009. Contrasting effects of glucose, living roots and maize straw on microbial growth kinetics and substrate availability in soil. European Journal of Soil Science 60, 186-197. doi:10.1111/j.1365-2389.2008.01103.x.

Blagodatskaya, E., Blagodatsky, S., Khomyakov, N., Myachina, O., Kuzyakov, Y., 2016. Temperature sensitivity and enzymatic mechanisms of soil organic matter decomposition along an altitudinal gradient on Mount Kilimanjaro. Scientific Reports 6, 22240. 
Bölscher, T., Wadsö, L., Börjesson, G., Herrmann, A.M., 2016. Differences in substrate use efficiency: impacts of microbial community composition, land use management, and substrate complexity. Biology and Fertility of Soils 52, 547-559. https://doi.org/10.1007/s00374-0161097-5.

Bradford, M.A., Davies, C.A., Frey, S.D., Maddox, T.R., Melillo, J.M., Mohan, J.E., Reynolds, J.F., Treseder, K.K., Wallenstein, M.D., 2008. Thermal adaptation of soil microbial respiration to elevated temperature. Ecol Lett 11, 1316-27. doi:10.1111/j.1461-0248.2008.01251.x.

Bradford, M.A., McCulley, R.L., Crowther, Thomas.W., Oldfield, E.E., Wood, S.A., Fierer, N., 2019. Cross-biome patterns in soil microbial respiration predictable from evolutionary theory on thermal adaptation. Nature Ecology \& Evolution 3, 223-231. doi:10.1038/s41559-018-0771-4.

Burns, R.G., 1982. Enzyme activity in soil: location and a possible role in microbial ecology. Soil Biology and Biochemistry 14, 423-427.

Cadot, S., Guan, H., Bigalke, M., Walser, J.C., Jander, G., Erb, M., van der Heijden, M., Schlaeppi, K., 2020. Specific and conserved patterns of microbiota-structuring by maize benzoxazinoids in the field. BioRxiv. doi:10.1101/2020.05.03.075135.

Cheng, W., Coleman, D.C., 1990. Effect of living roots on soil organic matter decomposition. Soil Biology and Biochemistry 22, 781-787.

Cotton, T.E.A., Pétriacq, P., Cameron, D.D., Meselmani, M. Al, Schwarzenbacher, R., Rolfe, S.A., Ton, J., 2019. Metabolic regulation of the maize rhizobiome by benzoxazinoids. The ISME Journal 13, 1647-1658. doi:10.1038/s41396-019-0375-2.

Davidson, E.A., Janssens, I.A., 2006. Temperature sensitivity of soil carbon decomposition and feedbacks to climate change. Nature 440, 165-173. doi:10.1038/nature04514.

Dennis, P.G., Miller, A.J., Hirsch, P.R., 2010. Are root exudates more important than other sources of rhizodeposits in structuring rhizosphere bacterial communities? FEMS Microbial Ecology 72 , $313-327$.

Dick, R., Rattei, T., Haslbeck, M., Schwab, W., Gierl, A., Frey, M., 2012. Comparative analysis of benzoxazinoid biosynthesis in monocots and dicots: Independent recruitment of Stabilization and activation functions. Plant Cell 24, 915-928. doi:10.1105/tpc.112.096461.

Erb, M., Kliebenstein, D.J., 2020. Plant Secondary Metabolites as Defenses, Regulators, and Primary Metabolites: The Blurred Functional Trichotomy. Plant Physiology 184, 39-52. doi:10.1104/pp.20.00433.

Fierer, N., Bradford, M.A., Jackson, R.B., 2007. Toward an ecological classification of soil bacteria. Ecology 88, 1354-1364.

Fischer, H., Meyer, A., Fischer, K., Kuzyakov, Y., 2007. Carbohydrate and amino acid composition of dissolved organic matter leached from soil. Soil Biology and Biochemistry 39, 2926-2935. 
Frey, M., Chomet, P., Glawischnig, E., Stettner, C., Grün, S., Winklmair, A., Eisenreich, W., Bacher, A., Meeley, R.B., Briggs, S.P., Simcox, K., Gierl, A., 1997. Analysis of a chemical plant defense mechanism in grasses. Science 277, 696-699. doi:10.1126/science.277.5326.696.

Gargallo-Garriga, A., Preece, C., Sardans, J., Oravec, M., Urban, O., Peñuelas, J., 2018. Root exudate metabolomes change under drought and show limited capacity for recovery. Scientific Reports 8 , 12696. doi:10.1038/s41598-018-30150-0.

Ge, T., Wei, X., Razavi, B.S., Zhu, Z., Hu, Y., Kuzyakov, Y., Jones, D.L., Wu, J., 2017. Stability and dynamics of enzyme activity patterns in the rice rhizosphere: Effects of plant growth and temperature. Soil Biology \& Biochemistry 113, 108-115. doi:10.1016/j.soilbio.2017.06.005.

George, T.S., Turner, B.L., Gregory, P.J., Cade-menun, B.J., Richardson, A.E., 2006. Depletion oforganic phosphorusfrom Oxisols in relation to phosphatase activities in the rhizosphere. European Journal of Soil Science 57, 47-57.

German, D.P., Chacon, S.S., Allison, S.D., 2011. Substrate concentration and enzyme allocation can affect rates of microbial decomposition. Ecology 98, 1471-1480.

Gramss, G., Voigt, K-D., Kirsche, B., 1999. Oxidoreductase enzymes liberated by plant roots and their effects on soil humic material. Chemosphere 38: 1481-1494.

Haling, R.E., Brown, L.K., Bengough, A.G., Young, I.M., Hallett, P.D., White, P.J., George, T.S., 2013. Root hairs improve root penetration, root-soil contact, and phosphorus acquisition in soils of different strength. Journal of Experimental Botany 64, 3711-3721. doi:10.1093/jxb/ert200.

Hasibeder, R., Fuchslueger, L., Richter, A., Bahn, M., 2015. Summer drought alters carbon allocation to roots and root respiration in mountain grassland. New Phytologist 205, 1117-1127. doi:10.1111/nph.13146.

Herrmann, A.M., Coucheney, E., Nunan, N., 2014. Isothermal microcalorimetry provides new insight into terrestrial carbon cycling. Environmental Science \& Technology 48, 4344-4352. https://doi.org/10.1021/es403941h.

Hinsinger, P., Bengough, A., Vetterlein, D., Young, I., 2009. Rhizosphere: biophysics, biogeochemistry and ecological relevance. Plant and Soil 321, 117-152.

Hoang, D.T.T., Pausch, J., Razavi, B.S., Kuzyakova, I., Banfield, C.C., Kuzyakov, Y., 2016. Hotspots of microbial activity induced by earthworm burrows, old root channels, and their combination in subsoil. Biology and Fertility of Soils 52, 1105-1119.

Hochholdinger, F., Wen, T.-J., Zimmermann, R., Chimot-Marolle, P., da Costa e Silva, O., Bruce, W., Lamkey, K.R., Wienand, U., Schnable, P.S., 2008. The maize (Zea mays L.) roothairless3 gene encodes a putative GPI-anchored, monocot-specific, COBRA-like protein that significantly affects grain yield. The Plant Journal 54, 888-898. doi:10.1111/j.1365-313X.2008.03459.x.

Hochholdinger, F., Yu, P., Marcon, C., 2018. Genetic Control of Root System Development in Maize. Trends in Plant Science 23, 79-88. doi:10.1016/j.tplants.2017.10.004. 
Holz, M., Zarebanadkouki, M., Carminati, A., Hovind, J., Kaestner, A., Spohn, M., 2019. Increased water retention in the rhizosphere allows for high phosphatase activity in drying soil. Plant and Soil 443, 259-271. doi:10.1007/s11104-019-04234-3.

Holz, M., Zarebanadkouki, M., Kaestner, A., Kuzyakov, Y., Carminati, A., 2018a. Rhizodeposition under drought is controlled by root growth rate and rhizosphere water content. Plant Soil 423, 429-442. doi:10.1007/s11104-017-3522-4.

Holz, M., Zarebanadkouki, M., Kuzyakov, Y., Pausch, J., Carminati, A., 2018b. Root hairs increase rhizosphere extension and carbon input to soil. Annals of Botany 121, 61-69. doi:10.1093/aob/mcx127.

Hu, L., Robert, C.A.M., Cadot, S., Zhang, X., Ye, M., Li, B., Manzo, D., Chervet, N., Steinger, T., Van Der Heijden, M.G.A., Schlaeppi, K., Erb, M., 2018. Root exudate metabolites drive plantsoil feedbacks on growth and defense by shaping the rhizosphere microbiota. Nature Communications 9, 1-13. doi:10.1038/s41467-018-05122-7.

Hutsch, B.W., Augustin, J., Merbach, W., 2002. Plant rhizodeposition - an important source for carbon turnover in soils. Journal of Plant Nutrition and Soil Science 165, 397-407.

Jiang, J., Wang, Y., Liu, J., Yang, X., Ren, Y., Miao, H., Pan, Y., Lv, J., Yan, G., Ding, L., Li, Y., 2019. Exploring the mechanisms of organic matter degradation and methane emission during sewage sludge composting with added vesuvianite: Insights into the prediction of microbial metabolic function and enzymatic activity. Bioresource Technology 286, 121397. doi:10.1016/j.biortech.2019.121397.

Jones, D.L., 1998. Organic acids in the rhizosphere - a critical review. Plant and soil 205, 25-44.

Jones, D.L., Nguyen, C., Finlay, R.D., 2009. Carbon flow in the rhizosphere: carbon trading at the soil-root interface. Plant and Soil 321, 5-33. doi:10.1007/s11104-009-9925-0.

Kaiser, C., Kilburn, M.R., Clode, P.L., Fuchslueger, L., Koranda, M., Cliff, J.B., Solaiman, Z.M., Murphy, D. V., 2015. Exploring the transfer of recent plant photosynthates to soil microbes: Mycorrhizal pathway vs direct root exudation. New Phytologist 205, 1537-1551. doi:10.1111/nph.13138.

Kudjordjie, E.N., Sapkota, R., Steffensen, S.K., Fomsgaard, I.S., Nicolaisen, M., 2019. Maize synthesized benzoxazinoids affect the host associated microbiome. Microbiome 7, 1-17. doi:10.1186/s40168-019-0677-7.

Kumar, A., Shahbaz, M., Blagodatskaya, E., Kuzyakov, Y., Pausch, J., 2018. Maize phenology alters the distribution of enzyme activities in soil: Field estimates. Applied Soil Ecology. doi:10.1016/j.apsoil.2018.02.001.

Kuzyakov, Y., 2002. Review: Factors affecting rhizosphere priming effects. Journal of Plant Nutrition and Soil Science 165, 382-396.

Kuzyakov, Y., 2010. Priming effects: Interactions between living and dead organic matter. Soil Biology and Biochemistry 42, 1363-1371. doi:10.1016/j.soilbio.2010.04.003. 
Kuzyakov, Y., Blagodatskaya, E., 2015. Microbial hotspots and hot moments in soil: Concept \& review. Soil Biology \& Biochemistry 83, 184-199. doi:10.1016/j.soilbio.2015.01.025.

Kuzyakov, Y., Domanski, G., 2000. Carbon input by plants into the soil. Review. Journal of Plant Nutrition and Soil Science 163, 421-431. doi:10.1002/1522-2624(200008)163:4<421::AIDJPLN421>3.0.CO;2-R.

Kuzyakov, Y., Razavi, B.S., 2019. Rhizosphere size and shape: Temporal dynamics and spatial stationarity. Soil Biology and Biochemistry S0038071719301452. doi:10.1016/j.soilbio.2019.05.011.

Kuzyakov, Y., Raskatov, A., Kaupenjohann, M., 2003. Turnover and distribution of root exudates of Zea mays. Plant and Soil 254, 317-327.

Kuzyakov, Y., Shevtzova, E., Pustovoytov, K., 2006. Carbonate re-crystallization in soil revealed by 14C labeling: Experiment, model and significance for paleo-environmental reconstructions. Geoderma 131, 45-58. doi:10.1016/j.geoderma.2005.03.002.

Kuzyakov, Y., Xu, X.L., 2013. Competition between roots and microorganisms for nitrogen: mechanisms and ecological relevance. New Phytologist 198, 656-669.

Lang, F., Krüger, J., Amelung, W., Willbold, S., Frossard, E., Bünemann, E.K., Bauhus, J., Nitschke, R., Kandeler, E., Marhan, S., Schulz, S., Bergkemper, F., Schloter, M., Luster, J., Guggisberg, F., Kaiser, K., Mikutta, R., Guggenberger, G., Polle, A., Pena, R., Prietzel, J., Rodionov, A., Talkner, U., Meesenburg, H., von Wilpert, K., Holscher, € A., Dietrich, H.P., Chmara, I., 2017. Soil phosphorus supply controls $\mathrm{P}$ nutrition strategies of beech forest ecosystems in Central Europe. Biogeochemistry 136, 5-29.

Liu, Y., Shahbaz, M., Ge, T., Zhu, Z., Liu, S., Chen, L., Wu, X., Deng, Y., Lu, S., Wu, J., 2020. European Journal of Soil Biology Effects of root exudate stoichiometry on $\mathrm{CO}_{2}$ emission from paddy soil. European Journal of Soil Biology 101, 103247. doi:10.1016/j.ejsobi.2020.103247.

Ma, X., Liu, Y., Zarebanadkouki, M., Razavi, B.S., Blagodatskaya, E., Kuzyakov, Y., 2018a. Spatiotemporal patterns of enzyme activities in the rhizosphere: effects of plant growth and root morphology. Biology and Fertility of Soils 54, 819-828. doi:10.1007/s00374-018-1305-6.

Ma, X.M., Zarebanadkouki, M., Kuzyakova, Y., Blagodatskaya, E., Pausch, J., Razavi, B.S., 2018b. Spatial patterns of enzyme activities in the rhizosphere: Effects of root hairs and root radius. Soil Biology and Biochemistry 118, 69-78.

Maag, D., Köhler, A., Robert, C.A.M., Frey, M., Wolfender, J.L., Turlings, T.C.J., Glauser, G., Erb, M., 2016. Highly localized and persistent induction of Bx1-dependent herbivore resistance factors in maize. Plant Journal 88, 976-991. doi:10.1111/tpj.13308.

McCully, M.E., Canny, M.J., 1985. Localisation of translocated 14C in roots and root exudates of field-grown maize. Physiologia Plantarum 65, 380-392. doi:10.1111/j.13993054.1985.tb08661.x. 
McDougall, B.M., Rovira, A.D., 1970. Sites of exudation of 14C-labelled compounds from wheat roots. New Phytologist 69: 999-1003.

Mishra, B.S., Singh, M., Aggrawal, P., Laxmi, A., 2009. Glucose and Auxin Signaling Interaction in Controlling Arabidopsis thaliana Seedlings Root Growth and Development. PLoS ONE 4, e4502. doi:10.1371/journal.pone.0004502.

Nannipieri, P., Gianfreda, L., 1998. Kinetics of enzyme reactions in soil environments. In: Huang, P.M., Senesi, N., Buffle, J. (Eds.), Structure and Surface Reactions. John Wiley \& Sons, New York, pp. 449-479.

Neal, A.L., Ahmad, S., Gordon-Weeks, R., Ton, J., 2012. Benzoxazinoids in root exudates of maize attract pseudomonas putida to the rhizosphere. PLoS ONE 7. doi:10.1371/journal.pone.0035498.

Oburger, E., Jones, D.L., 2018. Sampling root exudates - Mission impossible? Rhizosphere 6, 116133.

Okamoto, K., Nakano, H., Yatake, T., Kiso, T., Kitahata, S., 2000. Purification and Some Properties of a $\beta$-Glucosidase from Flavobacterium johnsonae. Bioscience, Biotechnology, and Biochemistry 64, 333-340. doi:10.1271/bbb.64.333.

Panikov, N., 1995. Microbial Growth Kinetics. Chapman \& Hall Ltd, London.

Panikov, N., Blagodatsky, S., Blagodatskaya, J., Glagolev, M., 1992. Determination of microbial mineralization activity in soil by modified Wright and Hobbie method. Biology and Fertility of Soils 14, 280-287.

Paterson, E., Midwood, A.J., Millard, P., 2009. Through the eye of the needle: a review of isotope approaches to quantify microbial processes mediating soil carbon balance: Tansley review. New Phytologist 184, 19-33. doi:10.1111/j.1469-8137.2009.03001.x.

Pausch, J., Loeppmann, S., Kühnel, A., Forbush, K., Kuzyakov, Y., Cheng, W., 2016. Rhizosphere priming of barley with and without root hairs. Soil Biology and Biochemistry 100, 74-82. doi:10.1016/j.soilbio.2016.05.009.

Peterson, R.L., Farquhar, M.L., 1996. Root hairs: Specialized tubular cells extending root surfaces. The Botanical Review 62, 1-40. doi:10.1007/BF02868919.

Pott, D.M, Osorio, S., Vallarino, J.G., 2019. From Central to Specialized Metabolism: An Overview of Some Secondary Compounds Derived From the Primary Metabolism for Their Role in Conferring Nutritional and Organoleptic Characteristics to Fruit. Frontiers in Plant Science 10.

Preece, C., Peñuelas, J., 2016. Rhizodeposition under drought and consequences for soil communities and ecosystem resilience. Plant and Soil 409, 1-17. doi:10.1007/s11104-016-3090-z.

Razavi, B.S., Zarebanadkouki, M., Blagodatskaya, E., Kuzyakov, Y., 2016. Rhizosphere shape of lentil and maize: spatial distribution of enzyme activities. Soil Biology and Biochemistry 96, 229237. 
Razavi, B.S., Zhang, X.C., Bilyera, N., Guber, A., Zarebanadkouki, M., 2019. Soil zymography: simple and reliable? Review of current knowledge and optimization of method. Rhizosphere 11. Article 100161.

Sanaullah, M., Blagodatskaya, E., Chabbi, A., Rumpel, C., Kuzyakov, Y., 2011. Drought effects on microbial biomass and enzyme activities in the rhizosphere of grasses depend on plant community composition. Applied Soil Ecology 48, 38-44. doi:10.1016/j.apsoil.2011.02.004.

Schütz, V., Bigler, L., Girel, S., Laschke, L., Sicker, D., Schulz, M., 2019. Conversions of Benzoxazinoids and Downstream Metabolites by Soil Microorganisms. Frontiers in Ecology and Evolution 7. doi:10.3389/fevo.2019.00238.

Shi, Y., Delgado-Baquerizo, M., Li, Y., Yang, Y., Zhu, Y.-G., Peñuelas, J., Chu, H., 2020. Abundance of kinless hubs within soil microbial networks are associated with high functional potential in $\begin{array}{lllll}\text { agricultural ecosystems. } & \text { Environment } & \text { International } & 142, & 105869 .\end{array}$ doi:10.1016/j.envint.2020.105869.

Sinsabaugh, R.L., Hill, B.H., Shah, J.J.F., 2009. Ecoenzymatic stoichiometry of microbial organic nutrient acquisition in soil and sediment. Nature 462, 795.

Spohn, M., Ermak, A., Kuzyakov, Y., 2013. Microbial gross organic phosphorus mineralization can be stimulated by root exudates $-\mathrm{A}{ }^{33} \mathrm{P}$ isotopic dilution study. Soil Biology and Biochemistry 65 , 254-263.

Steinweg, J.M., Plante, A.F., Conant, R.T., Paul, E.A., Tanaka, D.L., 2008. Patterns of substrate utilization during long-term incubations at different temperatures. Soil Biology and Biochemistry 40, 2722-2728. https://doi.org/10.1016/j. soilbio.2008.07.002.

Tarafdar, J.C., Jungk, A., 1987. Phosphatase activity in the rhizosphere and its relation to the depletion of soil organic phosphorus. Biology and Fertility of Soils 3, 199-204.

Turner, B.L., Driessen, J.P., Haygarth, P.M., Mckelvie, I.D., 2003. Potential contribution of lysed bacterial cells to phosphorus solubilisation in two rewetted Australian pasture soils. Soil Biology and Biochemistry 35, 187-189. doi:10.1016/S0038-0717(02)00244-4.

Voothuluru, P., Braun, D.M., Boyer, J.S., 2018. An in vivo imaging assay detects spatial variability in glucose release from plant roots. Plant Physiology 178: 1002-1010.

Wang, X.C., Lu, Q., 2006. Beta-glucosidase activity in paddy soils of the Taihu Lake region, China. Pedosphere 16: 118-124.

Wei, L., Razavi, B.S., Wang, W., Zhu, Z., Liu, S., Wu, J., Kuzyakov, Y., Ge, T., 2019. Labile carbon matters more than temperature for enzyme activity in paddy soil. Soil Biology and Biochemistry 135, 134-143. doi:10.1016/j.soilbio.2019.04.016.

Williams, A., Vries, F.T., 2020. Plant root exudation under drought: implications for ecosystem functioning. New Phytologist 225: 1899-1905. 
Zarebanadkouki, M., Ahmed, M., Hedwig, C., Benard, P., Kostka, S.J., Kastner, A., Carminati, A., 2018. Rhizosphere hydrophobicity limits root water uptake after drying and subsequent rewetting. Plant and Soil 428, 265-277. doi:10.1007/s11104-018-3677-.

Zhang, X., Kuzyakov, Y., Zang, H., Dippold, M.A., Shi, L., Spielvogel, S., Razavi, B.S., 2020. Rhizosphere hotspots: Root hairs and warming control microbial efficiency, carbon utilization and energy production. Soil Biology and Biochemistry: 107872. 


\title{
II Manuscripts
}

\section{Study 1: Spatial pattern of enzyme activities depends on root exudate composition}

Xuechen Zhang ${ }^{\mathrm{a}, \mathrm{b}^{*}}$, Michaela A. Dippold ${ }^{\mathrm{a}}$, Yakov Kuzyakov ${ }^{\mathrm{b}, \mathrm{d}, \mathrm{e}}$, Bahar S. Razavi ${ }^{\mathrm{c}, \mathrm{f}}$

\section{Status: Published in Soil Biology \& Biochemistry}

a Department of Biogeochemistry of Agroecosystem, University of Göttingen, Göttingen, Germany

${ }^{b}$ Department of Agricultural Soil Science, University of Göttingen, Göttingen, Germany

${ }^{c}$ Institute of Plant Nutrition and Soil Science, University of Kiel, Kiel, Germany

${ }^{d}$ Institute of Physicochemical and Biological Problems in Soil Science, Russian Academy of Sciences, 142290 Pushchino, Russia

${ }^{e}$ Soil Science Consulting, 37077 Göttingen, Germany

${ }^{f}$ Institute of Phytopathology, University of Kiel, Kiel, Germany

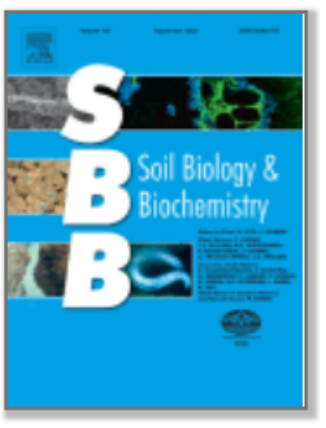

\begin{abstract}
Roots increase microbial activities depending on exudate composition, especially on the ratios of sugars, carboxylic and amino acids, and thus structure enzyme activities in the rhizosphere. We introduce a new approach combining soil zymography and simulated exudates released from Rhizon ${ }^{\circledR}$ samplers to stimulate microbial activities but avoid the direct release of enzymes by living roots. This enabled visualizing, localizing and analyzing the effects of simulated root exudates on activity of five microbial enzymes involved in carbon (C) ( $\beta$-glucosidase, cellobiohydrolase), nitrogen $(\mathrm{N})$ (leucine aminopeptidase), phosphorus (P) (phosphatase) and sulfur (S) (sulfatase) cycles. We tested the hypotheses that 1) artificial exudates stimulate microorganisms for enzyme production and form spatial gradients around roots, and 2) the extent of microbial enzyme activities in the rhizosphere is component-specific. In line with these hypotheses, the activities of P-, N- and S-related enzymes were higher near the artificial root and gradually decreased as a function of distance from the root. The pattern for $\mathrm{C}$-cycle enzymes was uniform and independent of the exudate composition. Among all components, alanine increased the rhizosphere extent much stronger than other substances, while methionine had no effect on the spatial distribution of enzyme activities. $V_{\max }$ of all enzymes increased with alanine addition, but decreased after adding citrate. The ratios of enzyme activities demonstrated that rhizosphere microorganisms release more leucine aminopeptidase than other enzymes to meet their $\mathrm{N}$ demand. Glucose increased the $K_{m}$ of cellobiohydrolase and $\beta$-glucosidase, while alanine had the greatest effect on the $\mathrm{K}_{\mathrm{m}}$ of protease and sulfatase. Phosphatase is the enzyme most sensitive to the composition of root exudates; consequently, any factor influencing root exudate composition can strongly affect the $\mathrm{P}$ cycle. We conclude that the rhizosphere extent of microbial-derived enzyme activities is component- and enzyme-specific and that this extent depends on the substrate stoichiometry and microbial nutrient demand.
\end{abstract}

Keywords: Artificial root, microbial hotspots, microbial enzymes, rhizosphere extent, soil zymography 
"Corresponding author: Xueczhang@hotmail.com

\section{Graphical abstract}

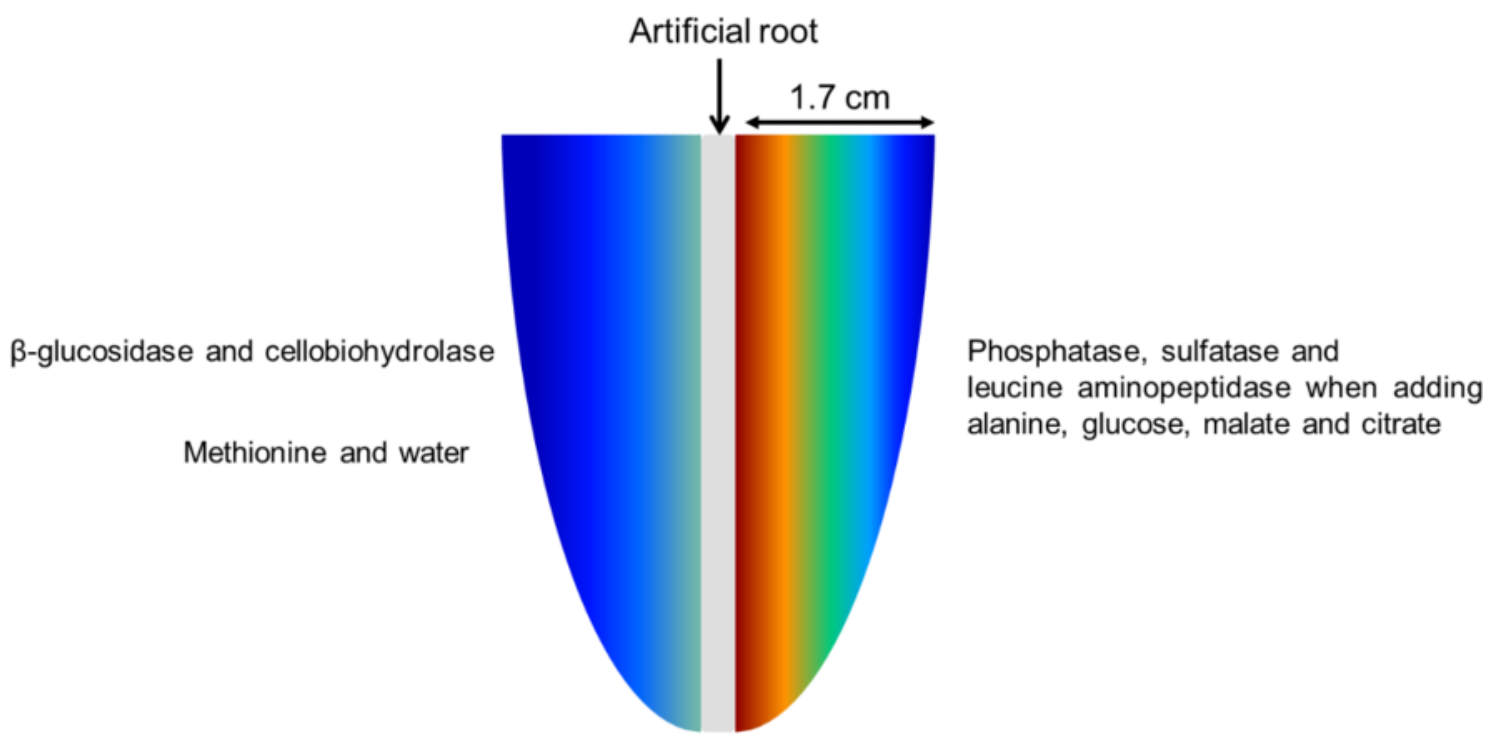




\subsection{Introduction}

Root exudates and rhizodeposits prompt a dynamic interplay between roots, the associated microbiome and soil particles. Microorganisms are more active and produce more enzymes in the rhizosphere due to the large input of easily degradable low-molecular weight organic substances (LMWOS) (Burns, 1982; Dennis et al., 2010). In most plants, the dominating forms of LMWOS are sugars, amino acids and carboxylic acids (Oburger et al., 2018). These substances are typically present in high concentrations in the cytoplasm (0.1$10 \mathrm{mM}$ ) and the vacuoles (up to $50 \mathrm{mM}$ ) (Lohaus et al., 1994) compared with the soil solution and thus tend to control exudation in quantitative carbon (C) terms. Sugars form the most abundant exudate pool (Derrien et al., 2004), with glucose constituting a significant portion (ca $40-50 \%$ of the root exudates; Hutsch et al., 2002). Following sugars, the amino acid content is the second highest pool, providing important sources of both $\mathrm{C}$ and nitrogen $(\mathrm{N})$ to microorganisms. Alanine makes up 15\% of amino acids recovered in dissolved organic carbon (DOC) (Fischer et al., 2007), and methionine is another major amino acid of root exudates, containing sulfur (S). Carboxylic acids are frequently present in lower concentrations than sugars and amino acids but are involved in many processes including nutrient mineralization (Jones, 1998). LMWOS are incorporated and used by microorganisms rapidly and efficiently, which is the main process removing them from soil solution. This process takes only a few minutes for glucose (Hill et al., 2008; Fischer et al., 2010), several hours of half-life times for amino acids (Jones et al., 2005), to much longer half-life time for carboxylic acids due to their fast adsorption to sesquioxides (Jones and Brassington, 1998; Fischer et al., 2010). The duration and the rates of microbial utilization of LMWOS are the main factors affecting the duration of microbial hot moments, which are defined as short-term events or sequences of events that accelerate microbial processes as compared to the average rates, and are typically located in the rhizosphere (Kuzyakov and Blagodatskaya, 2015).

Root exudation stimulates the production of extracellular enzymes (Asmar et al., 1994) and, thus, SOM decomposition (Cheng and Coleman, 1990). However, the higher enzyme activity of the rhizosphere versus root-free soil depends not only on microbial activity but also on the direct release of enzymes by roots, the root secretion, consisting of high molecular weight compounds (> 1000 Da; e.g. enzymes) or by lysis of root cells (Oburger et al., 2018). Enzymes are valuable tools for plants and microbiomes to degrade complex organic substances and make nutrients/C available for plant/microbial uptake. Many previous studies have focused on enzyme activities in the rhizosphere (Tarafdar and Jungk, 1987; George et 
al., 2006) or have illuminated gradients of enzyme activities as a function of distance from the root surface to the soil (Razavi et al., 2016a; Ge et al., 2017; Ma et al., 2018; Fig. 1a). Nonetheless, we lack a mechanistic understanding of the enzymatic response of rhizosphere microorganisms to root exudates, in the absence of direct release of enzymes by roots (Fig. 1b). More specifically, carboxylic acids from roots mobilize nutrients by chemical processes (Jones, 1998) and, conversely, affect the microbial decomposability of SOM (Kuzyakov et al., 2000). Amino acids or monosaccharides can stimulate microorganisms to switch from a dormant state (Blagodatskaya and Kuzyakov, 2013) to an active stage, promoting the release of enzymes and thus boosting soil organic matter (SOM) mineralization. The root exudate compounds that play the key role in stimulating microbial enzyme activities and formation of gradients in the rhizosphere remain unknown. Despite their very small-scale occurrence, the cumulative effect of exudate-driven rhizosphere processes such as enzymatic activities are of global importance (e.g. C and nutrient cycling). Detailed knowledge about the effect of the different quality and quantity of root exudates released around roots is therefore a prerequisite for deciphering the complex biogeochemical processes in the rhizosphere and their feedback loops. This includes microbial function, changes in enzyme systems and catalytic properties, or even the optimal $\mathrm{C}$ : nutrients ratio to meet microorganism demand. The amount of nutrients released by enzymes can be determined by the above ratio, and also by the nutrient content in SOM (Sinsabaugh et al., 2008; Mooshammer et al., 2014). Ratios of enzyme activities involved in SOM decomposition can be used as an indicator of microbial resource allocation to nutrient acquisition (Waring et al., 2014). Therefore, the stoichiometry of enzymes represents a relative nutrient limitation (Hill et al., 2012), and enzyme activities are indicators of microbial nutrient demand (Schimel and Weintraub, 2003; Caldwell, 2005; Moorhead and Sinsabaugh, 2006).

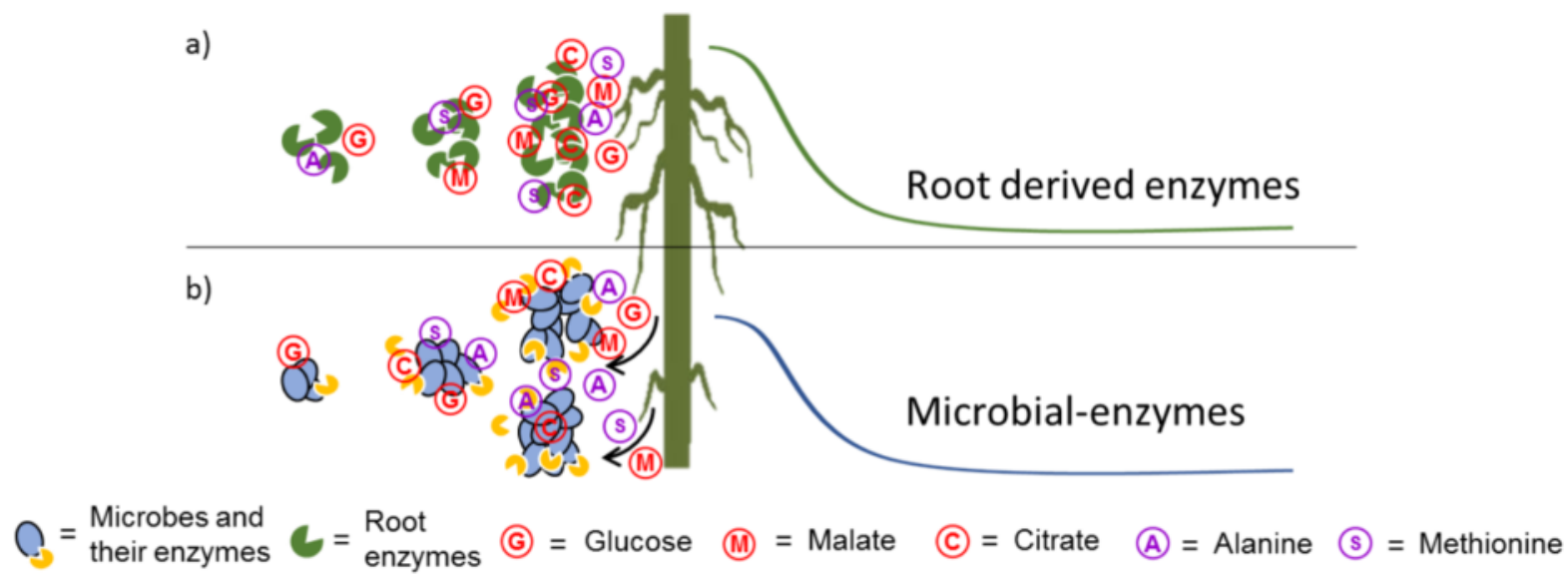


Fig. 1 Mechanisms of formation of enzyme activity gradient in the rhizosphere: a) Secretes such as enzymes and root exudate are released by roots and show clear spatial distribution; b) Enzymes will be released by microorganisms, whose activities directly depend on root functions. Root exudates increase microbial activities, thus microbial enzyme activities in the rhizosphere. Theoretically stimulated microbial activity should form a gradient of microbial enzyme activity. However, the key compounds for stimulating microbial enzyme activities and formation of gradients in the rhizosphere remain unknown.

The rhizosphere and root system architecture are complex, as are the many simultaneously ongoing processes when $\mathrm{C}$ compounds are released into the soil by the root (i.e. changes in $\mathrm{pH}$, microbial decomposition, microbial growth). This makes the identification of mobilized nutrients, enzymatic rates and gradients maintained solely by microorganisms (and not by plants, e.g. direct release of enzymes by roots) nearly impossible.

Soil zymography, a novel in situ method, enables determining the two-dimensional spatial distribution of enzyme activities in soil (Spohn and Kuzyakov, 2013; Razavi et al., 2016a). Combining this technique with Rhizon ${ }^{\circledR}$ samplers (artificial roots) would help to localize hotspots of various microbial enzyme activities and mark their correlation with substrate turnover. It would also enable testing whether the spatial patterns of enzyme activities in rhizosphere are component-specific or not.

Here, we selected glucose as a representative of sugars; alanine and methionine as representatives of amino acids; and citrate and malate as representatives of carboxylic acids in order to simulate root exudates but avoid the direct release of enzymes by roots. We measured enzymes involved in the terminal reactions of $\mathrm{C}, \mathrm{N}, \mathrm{P}$ and $\mathrm{S}$ cycles. These included two enzymes in the C-cycle: $\beta$-glucosidase and cellobiohydrolase, which are responsible for consecutive stages of cellulose degradation; one enzyme in the N-cycle: leucine aminopeptidase, which is involved in protein degradation; one enzyme in the P-cycle: phosphatase, which catalyzes the hydrolysis of organic P compounds to phosphate esters; and one enzyme in the S-cycle: sulfatase, which hydrolyzes ester sulfate. This study was designed to 1) investigate the mechanisms of microbial enzymatic response to root exudates, in the absence of real roots; 2) evaluate the effects of various components of artificial root exudates on the gradients and spatial distribution of microbial enzyme activities; and 3) to describe the stoichiometry of enzyme activities in the rhizosphere, where individual root exudate compounds have effects on the stoichiometry of available resources. We hypothesized that 1) artificial exudates stimulate microorganisms for enzyme production and 
form spatial gradients; 2) the spatial distribution of microbial enzyme activities in the rhizosphere is component-specific, and gradients are maximal for exudates with the longest turnover, e.g. carboxylic acids; 3) such stimulation depends on the substrate stoichiometry.

\subsection{Materials and methods}

\subsubsection{Soil preparation}

Soil for the incubation experiment was taken from 75-105 cm depth at four plots at the Campus Klein-Altendorf (50 $\left.37^{\prime} \mathrm{N}, 6^{\circ} 59^{\prime} \mathrm{E}\right)$, south-west of Bonn, Germany. After collecting, the soil was mixed by hand; at the same time, roots and stones were removed and the soil was placed in ziplock bags and kept cold $\left(\sim 4{ }^{\circ} \mathrm{C}\right)$. Basic soil physiochemical properties were shown in Table 1. Before the incubation, soil was passed through a $2 \mathrm{~mm}$ sieve. The soil is a Haplic Luvisol (WRB). Detailed soil properties are given in Vetterlein et al. (2013) and Hoang et al. (2016).

Table 1 Basic soil physiochemical properties

\begin{tabular}{llll}
\hline $\mathrm{pH}$ & $\begin{array}{l}\text { Soil organic carbon } \\
\left(\mathrm{mg} \mathrm{C} \mathrm{g}^{-1}\right)\end{array}$ & $\begin{array}{l}\text { Total nitrogen } \\
\left.(\mu \mathrm{g} \mathrm{N} \mathrm{g})^{-1}\right)\end{array}$ & $\begin{array}{l}\text { Total phosphorous } \\
\left(\mathrm{mg} \mathrm{P} \mathrm{g}^{-1}\right)\end{array}$ \\
\hline 6.6 & 3.2 & 0.5 & 0.6 \\
\hline
\end{tabular}

\subsubsection{Experimental layout}

100-mm-long Rhizon ${ }^{\circledR}$ samplers (Rhizosphere Research Products, Wageningen) were used to simulate the exudation of organic substances from the root into the soil. The rhizobox $(12 \times 14 \times 1 \mathrm{~cm})$ is a transparent plastic box with a removable front panel enabled opening without affecting artificial root (Rhizon) (Fig. S1). When filling in the soil, the rhizoboxes were placed horizontally with one side open, and then the sieved soil was slowly put in. After a little soil was poured into the rhizobox, the open side was closed and the sample was reoriented vertically, after which it was shaken gently to be homogeneous. The above steps were repeated until the rhizobox was full with a stable soil packing.

Five organic substances - glucose, alanine, methionine, citrate and malate - were chosen to estimate the effects of simulated root exudation on microbial enzyme activities. These substances, at a concentration of $200 \mu \mathrm{mol} \mathrm{C} \mathrm{ml} \mathrm{Cl}^{-1}$, were added to the rhizoboxes during 14 days of the experiment at a rate of $1.0 \mathrm{ml} \mathrm{d}^{-1} .14$ days were considered to ensure that the gradients will form around the entire artificial root (Keiluweit et al., 2015). The selected concentrations correspond to estimated released exudates by plant per day $\left(\sim 2400 \mu \mathrm{g} \mathrm{C}\right.$ day $^{-}$ ${ }^{1}$ ) (Oburger et al., 2013). The same volume of distilled water was added to the control soil. 
For each substance, four replicates were incubated. During 14 days of incubation, the rhizoboxes were kept in the climate chamber at $20 \pm 1{ }^{\circ} \mathrm{C}$.

\subsubsection{Soil zymography}

Soil zymography - following the protocol proposed by Razavi et al. (2016a) - was applied to determine the spatial distribution of soil enzymes around the Rhizon ${ }^{\circledR}$ after adding organic substances. Membranes saturated with 4-methylumbelliferone (MUF)-substrates and 7-amino-4-methylcoumarin (AMC)-substrates were used to visualize enzyme activities. After hydrolyzing by the specific enzyme, substrates become fluorescent. $\beta$-glucosidase, cellobiohydrolase, phosphatase, leucine-aminopeptidase and sulfatase activities were detected by 4-methylumbelliferyl- $\beta$-D-glucoside; 4-methylumbelliferyl- $\beta$-D-cellobioside; 4methylumbelliferyl-phosphate; L-leucine-7-amido-4-methylcoumarin hydrochloride and sulfate potassium salt, respectively. Each of these substrates was dissolved to a concentration of $1 \mathrm{mM}$ in MES buffer (for MUF substrate, $\mathrm{pH} \approx 6.5$ ), TRIZMA buffer (for AMC substrate, $\mathrm{pH} \approx 7.2$ ), and Na-acetate buffer for sulfatase (Sigma Aldrich, Germany, $\mathrm{pH} \approx$ 6). Polyamide membrane filters (Tao Yuan, China) (diameter: $20 \mathrm{~cm}$, pore size: $0.45 \mu \mathrm{m}$ ) were cut into sizes adjusted to the rhizobox and saturated with the substrates for each enzyme. After 14 days, the rhizoboxes were opened from the lower side and the saturated membranes were put directly on the soil surface. After incubation for $1 \mathrm{~h}$, the membranes were carefully lifted off the soil surfaces and any attached soil particles were gently removed using a small brush. Then, the membranes were placed under ultraviolet (UV) light with an excitation wavelength of $355 \mathrm{~nm}$ in a dark room. In order to compare the enzyme activities of the images, the distance between samples, UV light and the camera were standardized (Razavi et al., 2016). We used a Canon EOS 6D camera with a Canon lens EF 24-105 mm 1: 4L IS, with the best results at $\mathrm{f}=24 \mathrm{~mm} \& \mathrm{f} / 3.5$. Camera settings were defined experimentally (Razavi et al., 2017a; Guber et al., 2018) and provided images with a view field of $105 \times 3576 \mathrm{~mm}$, at a resolution of 20.2 megapixel and flat field non-uniformity of 0.099 , assessed as a coefficient of grayscale variation measured in a dry polyamide membrane filter. Focal length, aperture and shutter speed were set to $250 \mathrm{~mm}, \mathrm{f} / 6.3$ and 1/125 sec, respectively.

The gray values of the images were transferred to enzyme activity using a standard calibration. The calibration line was obtained from zymography of saturated membranes (2 $\left.\times 2 \mathrm{~cm}^{2}\right)$ with increasing concentration of $\operatorname{MUF}(0,0.01,0.02,0.05,0.1,0.2,0.4,0.6,1 \mathrm{mM})$ and AMC $(0,0.01,0.2,0.5,1,2,3,4,5,6,10 \mathrm{mM})$. The amount of MUF and AMC on an area basis was calculated from the solution volume taken up by the membrane and its size 
(Razavi et al., 2016a). These membranes were imaged under UV light in the same manner as the zymograms.

\subsubsection{Image processing and analysis}

Image processing included 3 steps: 1) convert the signal (fluorescence) on images to gray values, 2) adjust the background, 3) transfer gray values to enzyme activities based on standardization.

Fluorescence on the images shows that the substrate has been hydrolyzed by a specific enzyme. The signal intensity is proportional to enzyme activity (Razavi et al., 2016a). The zymograms were quantified using Matlab. Zymograms were transformed to 16-bit grayscale images as matrices and corrected for light variations and camera noise. The gray value received from the blank sides of the sample served as the referencing point. Then the background gray value was subtracted from all the zymograms. The gray values on all the images were converted to enzyme activity using the calibration standard line.

Gray values exceeding 20\% of mean gray values of the whole image were defined as hotspots (Liu et al., 2017). The total hotspot areas were calculated as a percentage of the whole image.

\subsubsection{Enzyme kinetic parameters and substrate turnover time}

After incubation for 14 days, soil was collected near the Rhizon ${ }^{\circledR}$ (dotted line in Fig. S1) from each rhizobox. Enzyme kinetics were measured for four replicates of each substance. $50 \mathrm{ml}$ sterile water was added to $0.5 \mathrm{~g}$ soil used for enzyme kinetics. Soil suspension was made using low-energy sonication ( $40 \mathrm{~J} \mathrm{~s}^{-1}$ output energy) for $2 \mathrm{~min} .50 \mu \mathrm{L}$ of soil suspension, $100 \mu \mathrm{L}$ substrate and $50 \mu \mathrm{L}$ of buffer (MES, TRIZMA or Na-acetate) were added to a 96well microplate. To ensure the saturation concentrations of fluorogenic substrates, preliminary experiments were performed. Fluorescence was measured at an excitation wavelength of $355 \mathrm{~nm}$ and an emission wavelength of $460 \mathrm{~nm}$, and a split width of $25 \mathrm{~nm}$, with a Victor 1420-050 Multi label Counter (Perkin Elmer, USA). Measurements were taken after 0, $30 \mathrm{~min}, 1 \mathrm{~h}$ and $2 \mathrm{~h}$. Enzyme activity was expressed as nmol MUF or AMC $\mathrm{g}^{-1}$ soil $\mathrm{h}^{-1}$. The Michaelis-Menten equation was used to determine $\mathrm{V}_{\max }$ and $\mathrm{K}_{\mathrm{m}}$ :

$$
\mathrm{v}=\frac{V_{\max } \times[S]}{K_{m}+[S]}
$$

where $\mathrm{v}$ is the reaction rate, $[\mathrm{S}]$ is the substrate concentration, $\mathrm{K}_{\mathrm{m}}$ is the substrate concentration at half-maximal rate, and $\mathrm{V}_{\max }$ is the maximum reaction rate. 
The substrate turnover time was calculated by turnover time (hours) $=\left(\mathrm{K}_{\mathrm{m}}+[\mathrm{S}]\right) / \mathrm{V}_{\max }$ (Panikov et al., 1992), where $\mathrm{S}$ is the substrate concentration regarding to the $\mathrm{V}_{\max }$. In specific, for $\beta$-glucosidase, cellobiohydrolase and leucine-aminopeptidase, $\mathrm{S}=200 \mu \mathrm{mol} \mathrm{g}{ }^{-1}$, for phosphatase, $\mathrm{S}=100 \mu \mathrm{mol} \mathrm{g}{ }^{-1}$, and for sulfatase, $\mathrm{S}=400 \mu \mathrm{mol} \mathrm{g} \mathrm{g}^{-1}$ (Fig. S7).

The catalytic efficiency of enzymes was determined by catalytic efficiency $\left(K_{a}\right)=V_{\max }$ / $\mathrm{K}_{\mathrm{m}}$ (Razavi et al., 2016b). The $\mathrm{K}_{\mathrm{a}}$ characterizes the enzyme catalytic properties and is used as an indicator to reflect the shift of microbial communities (Tischer et al., 2015). The higher $\mathrm{K}_{\mathrm{a}}$ shows better catalytic properties (Moscatelli et al., 2012).

\subsubsection{Statistical analyses}

Significance of maximal enzyme activity, $\mathrm{K}_{\mathrm{m}}$, turnover time, percentage of hotspot, and catalytic efficiency was tested by ANOVA followed by the Tukey HSD test using the software JMP, at $\alpha<0.05$.

To represent the extension of enzyme activities, a horizontal line was drawn through the image from the artificial root center to the image boundary. The gray values of all the pixels on this line were extracted. In total, about 60 separate lines were randomly selected from each image, and the average gray values of these replicates were plotted against the distance from Rhizon ${ }^{\circledR}$ center using Sigmaplot 12.5 (detailed information was shown in Table S1).

Activities of cellobiohydrolase, $\beta$-glucosidase, leucine aminopeptidase and phosphatase were $\log _{\mathrm{e}}$ transformed prior to stoichiometry analysis. Ratios of $\ln$ ( $\beta$-glucosidase + cellobiohydrolase): $\ln$ (leucine aminopeptidase) and $\ln (\beta$-glucosidase + cellobiohydrolase) : $\ln$ (phosphatase) represent the acquisition of organic $\mathrm{N}$ and $\mathrm{P}$ relative to $\mathrm{C}$ (Sinsabaugh et al., 2008).

\subsection{Results}

\subsubsection{Spatial distributions of enzyme activities around artificial roots}

The enzyme activity spatial distributions were component- and enzyme-specific (Figs 2, S1). For all enzymes, when water and methionine were added to the artificial roots, the spatial distributions of enzyme activities remained constant from the artificial root surface to bulk soil. Alanine, citrate, glucose and malate addition caused a radial gradient of enzyme activity around the artificial root, whereby alanine inputs had the greatest effects (Figs 2,3). The spatial distributions of cellobiohydrolase and $\beta$-glucosidase were uniform and homogeneous within the whole rhizoboxes (Figs 2a, S1). Leucine aminopeptidase, phosphatase and sulfatase showed clear radial gradients from the artificial root to bulk soil, with higher 
activities near the artificial roots and a significant decrease with increasing distance (except when adding methionine; Figs 2 b, c, d).

The artificial rhizosphere extension was enzyme-specific: it was maximal for leucine aminopeptidase $(0.25-1.7 \mathrm{~cm})$, followed by phosphatase $(0.6-1.2 \mathrm{~cm})$ and sulfatase $(0.5-0.75$ $\mathrm{cm}$ ), while there was no clear extent (boundary) for cellobiohydrolase and $\beta$-glucosidase (Fig. $3, \mathrm{~S} 2)$.
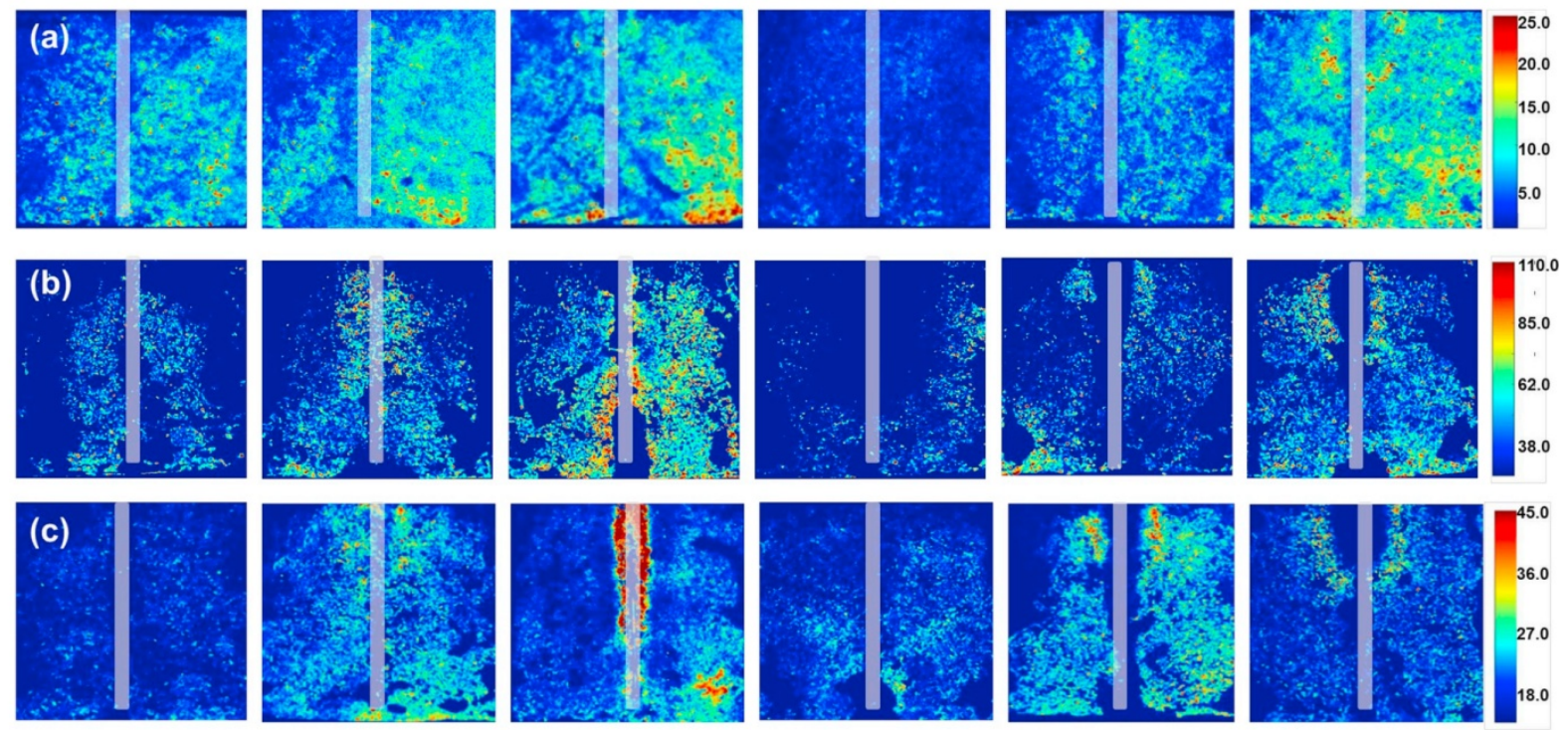

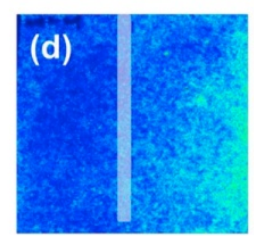

water

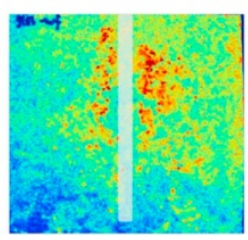

glucose

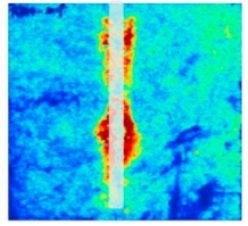

alanine

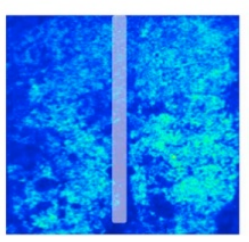

methionine

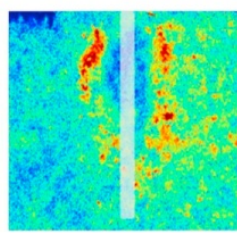

citrate

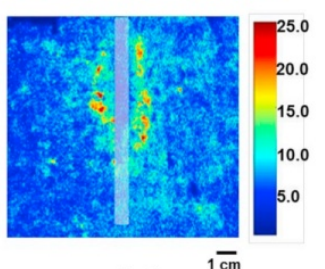

malate

Fig. 2 Zymography images in response to component additions. a. $\beta$-glucosidase, b. leucine aminopeptidase, c. phosphatase, d. sulfatase. Side color scale is proportional to enzyme activities $\left(\mathrm{nmol} \mathrm{cm} \mathrm{cm}^{-2} \mathrm{~h}^{-1}\right)$. 

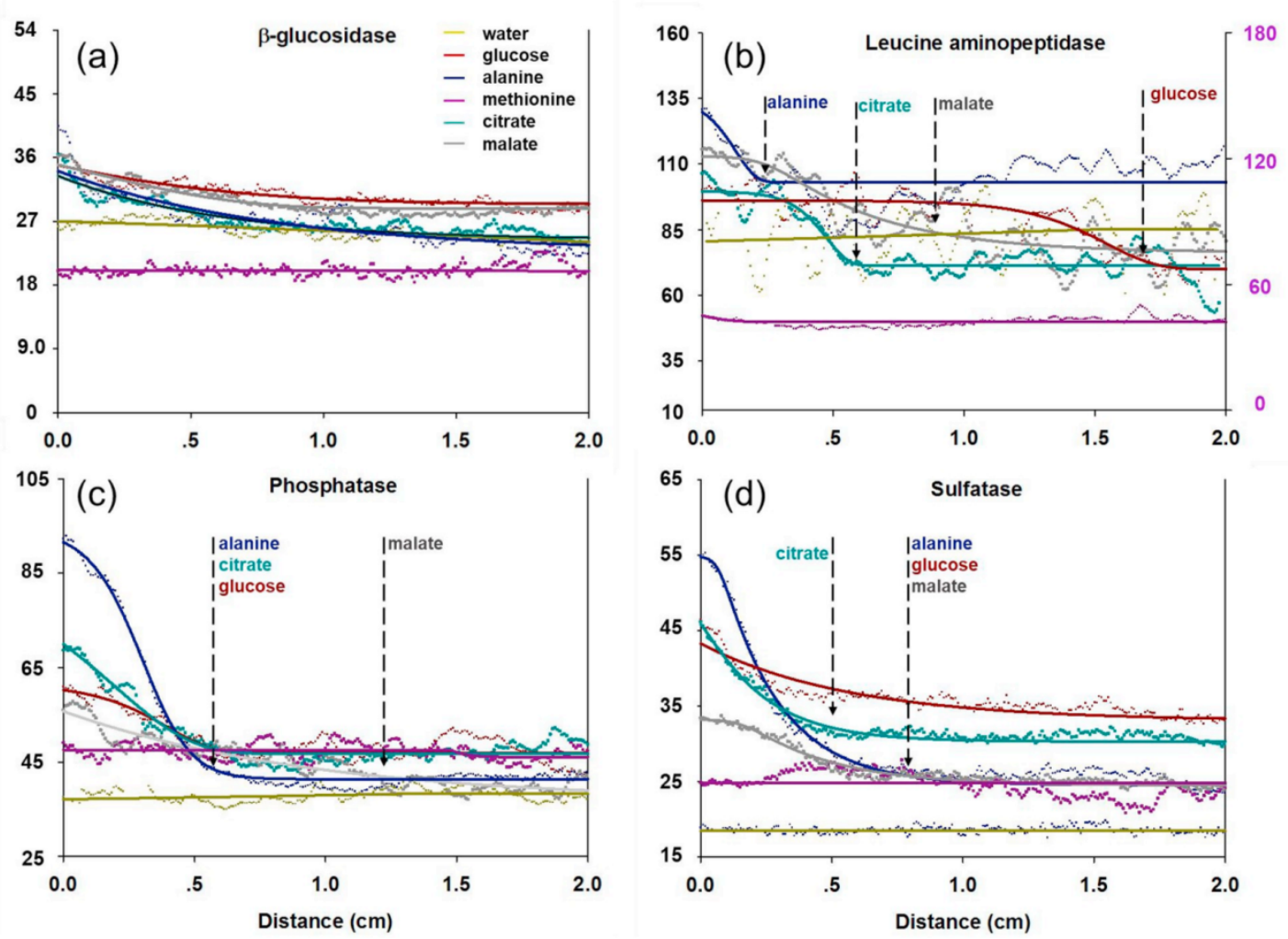

Fig. 3 The profile of enzyme activity distribution as a function of distance from the root center. Each line refers to the mean value of many lines of one part from each zymogram. 0 on the $\mathrm{X}$ axis shows the center of the artificial root. The $\mathrm{Y}$ axis is presented in relative units as enzyme activity $\left(\mathrm{nmol} \mathrm{cm} \mathrm{cm}^{-2} \mathrm{~h}^{-1}\right.$ ). For leucine aminopeptidase, the right axis is for purple line (methionine). Vertical dashed black lines on the curves: artificial rhizosphere extent for individual substances.

The total hotspot area of $\beta$-glucosidase after adding alanine was 2.8 times greater than after adding water (Subfig. 4a). For leucine aminopeptidase, the percentage of hotspot area increased by $84.4 \%$ at glucose addition, but decreased by $34.6 \%$ at methionine addition (Subfig. 4b). All the substances increased the total hotspot area of phosphatase by 13.1 to 26.2 times (Subfig. 4c). After adding alanine, sulfatase increased strongly, while methionine had no effects (Fig. 4). 


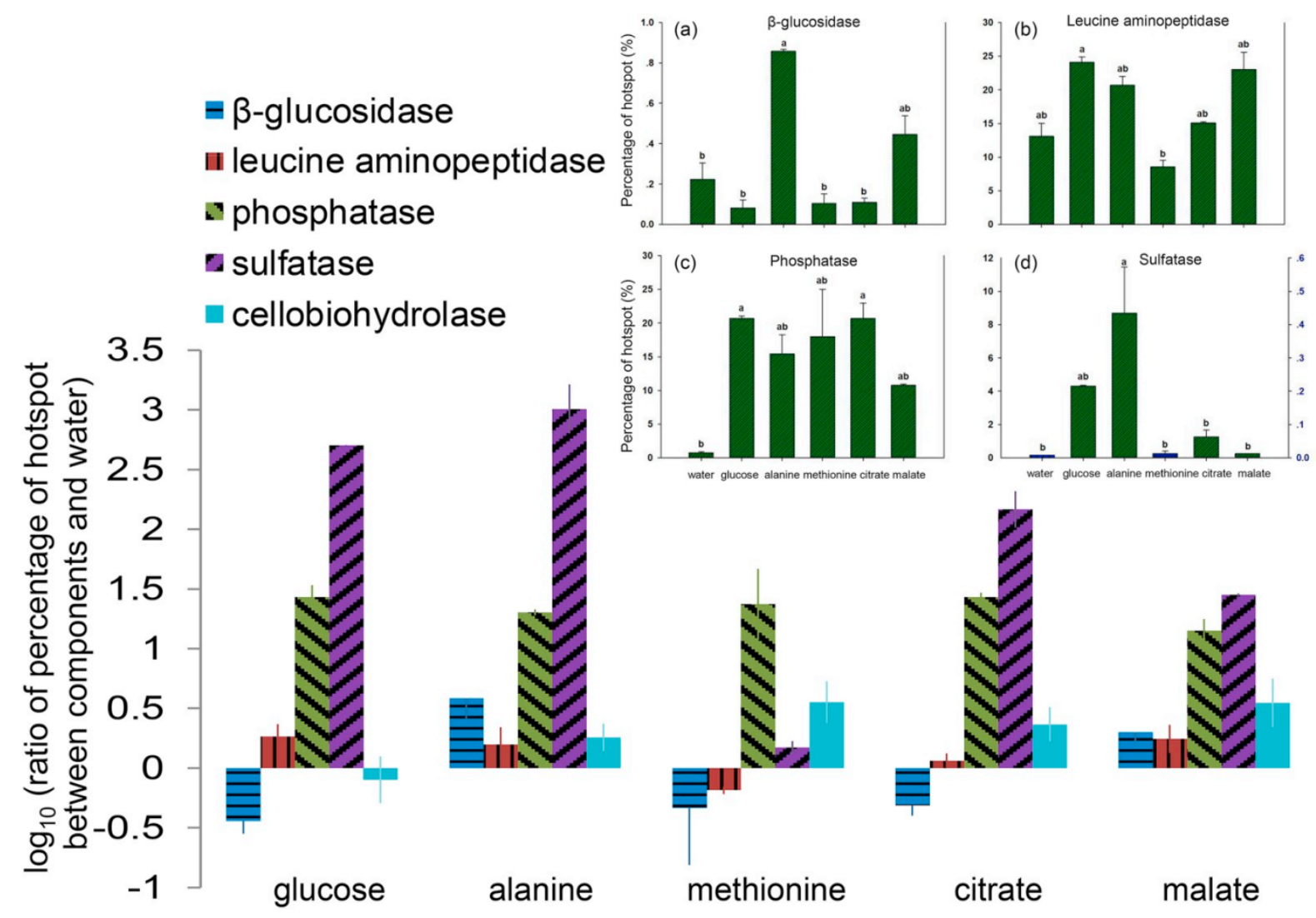

Fig. 4 Relative effects of components to water: $\log _{10}$ (ratio of percentage of hotspot between components and water). Below zero shows that percentage of hotspot in respond to each component is less than water addition while above zero demonstrates increment of percentage of hotspot compared to water addition. Subfigure shows hotspots (with area exceeding $20 \%$ of average grey values of the whole image), as a percentage of total area for (a) $\beta$-glucosidase, (b) leucine aminopeptidase, (c) phosphatase, and (d) sulfatase (left axis is for green color; right axis is for blue color treatments) in the artificial rhizosphere of six substances. Small letters: significant differences $(p<0.05$ after Tukey HSD test).

Thus, the spatial distribution of cellobiohydrolase and $\beta$-glucosidase did not change strongly after component additions. In contrast, the spatial patterns of phosphatase, leucine aminopeptidase and sulfatase were higher near the artificial root, and were componentspecific.

\subsubsection{Response of enzyme kinetics and substrate turnover to exudate components}

Alanine addition increased $\mathrm{V}_{\max }$ of all enzymes, which were similar with the zymogram results. $V_{\max }$ values of all the enzymes decreased $(p<0.05)$ when citrate was added to the soil (Fig. 5; S4), in contrast to the zymogram results which show enzyme activities of soil surface. 
The slopes of $\ln (\beta$-glucosidase + cellobiohydrolase): ln (leucine aminopeptidase), an indicator of potential $\mathrm{C}: \mathrm{N}$ acquisition, was 0.77 . The corresponding ratio of $\mathrm{C}: \mathrm{P}$, shown by $\ln (\beta$-glucosidase + cellobiohydrolase) $: \ln$ (phosphatase), was 1.00 (Fig. 6). Although Scontaining organic substances are decomposed to meet $\mathrm{S}$ deficiencies, they are not main carbon sources for soil microorganisms, so sulfatase was not included in the stoichiometry analysis.

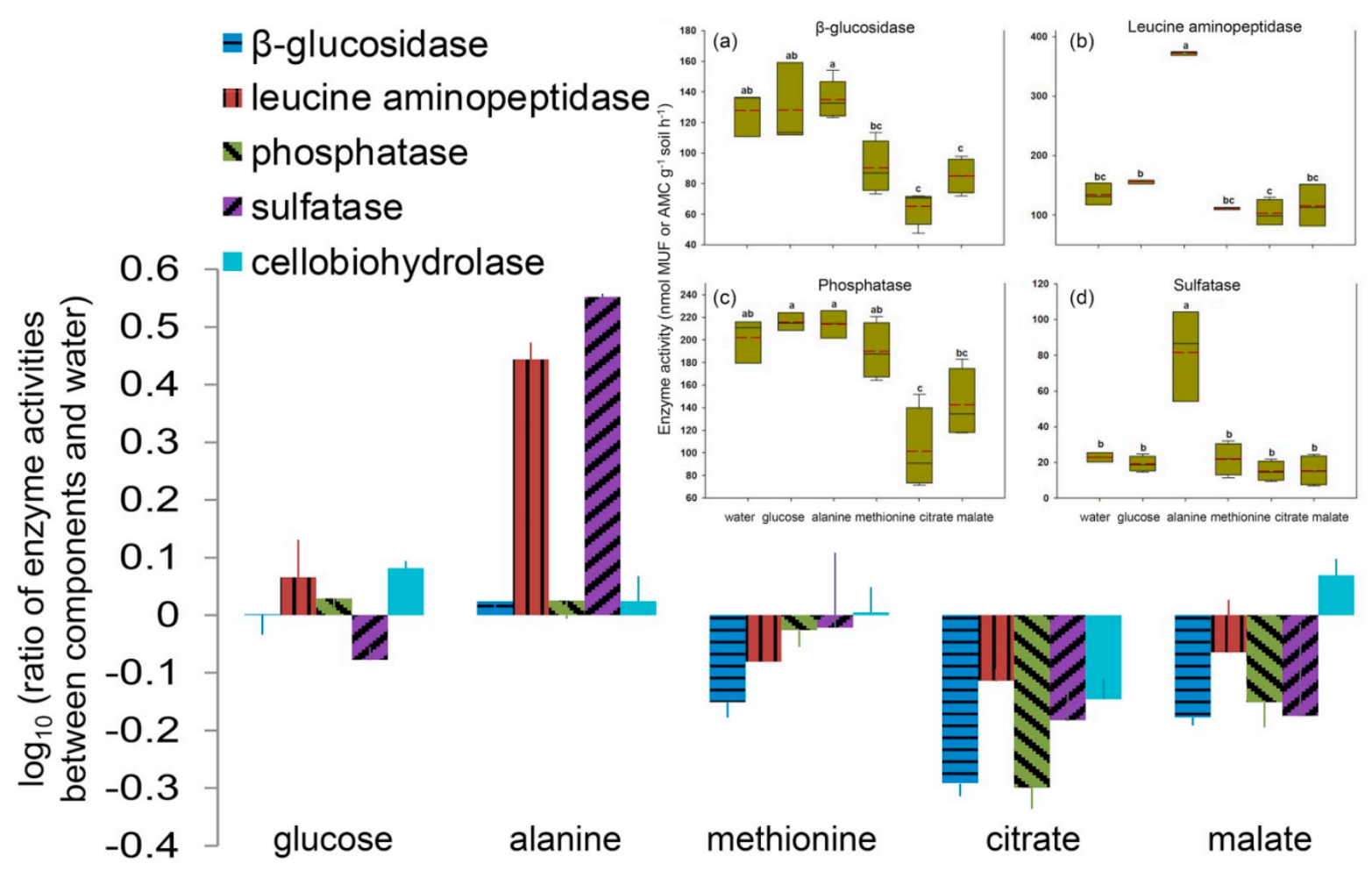

Fig. 5 Relative effects of components to water: $\log _{10}$ (ratio of enzyme activities between components and water). Below zero shows that enzyme activity in respond to each component is less than water addition while above zero demonstrates increment of enzyme activity compared to water addition. Subfigure shows enzyme activity as a function of substrate concentration for (a) $\beta$-glucosidase, (b) leucine aminopeptidase, (c) phosphatase and (d) sulfatase in response to component additions. Values are means of four replicates $( \pm \mathrm{SE})$. Small letters: significant differences $(p<0.05$ after Tukey HSD test) between components. 

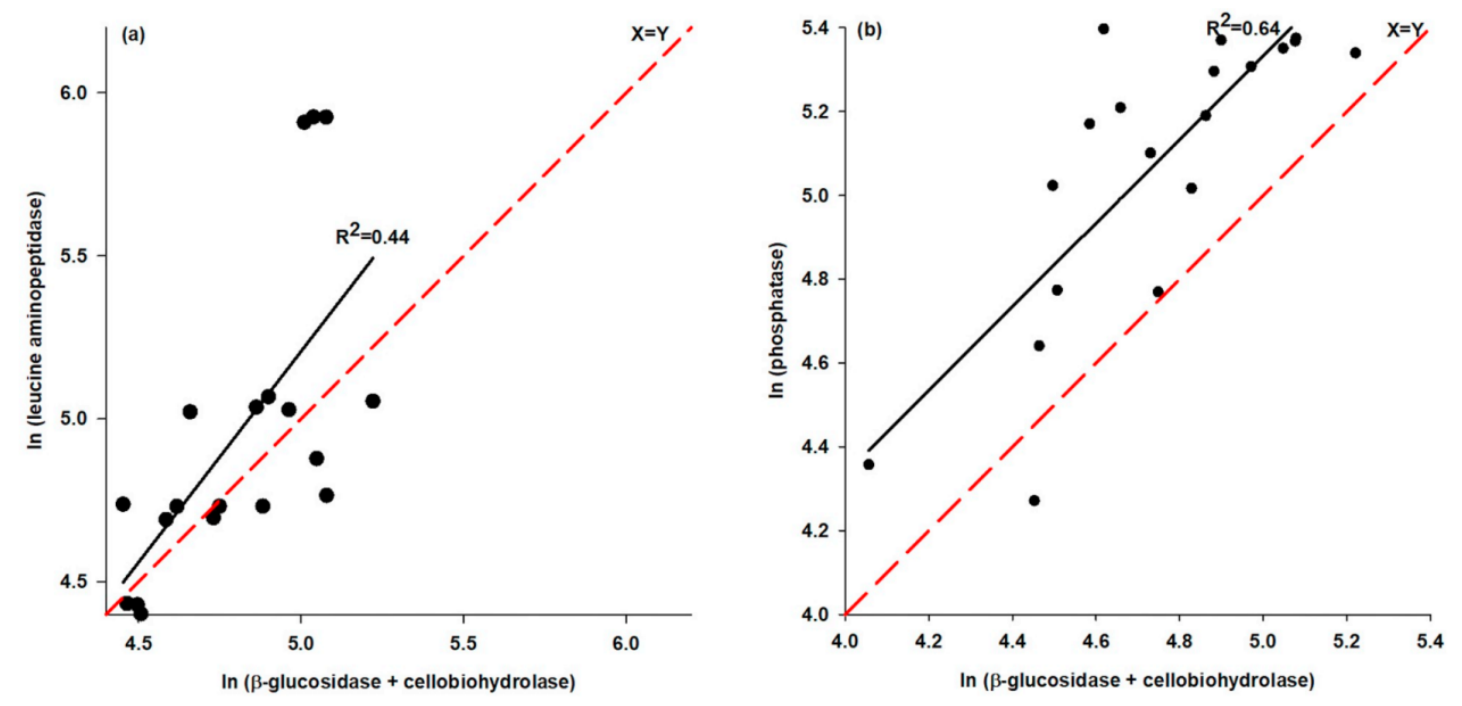

Fig. 6 Ratios of (a) log-transformed ( $\beta$-glucosidase + cellobiohydrolase) and leucine aminopeptidase activities; the $\mathrm{C}: \mathrm{N}$ regression is $\ln ($ leucine aminopeptidase $)=-1.266+1.295$ $\times \ln (\beta$-glucosidase + cellobiohydrolase $), \mathrm{R}^{2}=0.44, p=0.0021$ (b) log-transformed $(\beta$ glucosidase + cellobiohydrolase) and phosphatase activities, the C:P regression is $\ln ($ phosphatase $)=0.347+0.997 \times \ln (\beta$-glucosidase + cellobiohydrolase $), \mathrm{R}^{2}=0.64, p$ $<0.001$. Red dash line is with a slope of 1.0 .

The $K_{m}$ values of cellobiohydrolase and $\beta$-glucosidase when adding glucose were about two or four times higher than in soil with water addition. For leucine aminopeptidase and sulfatase, the $\mathrm{K}_{\mathrm{m}}$ values were higher when alanine was added in compare with the other substance additions. Phosphatase was the most sensitive to component additions compared with other enzymes: the $\mathrm{K}_{\mathrm{m}}$ values decreased $(p<0.05)$ when adding all the components (Fig. 7). The turnover times of all substrates in response to alanine input were shorter than in response to other components. In contrast, citrate addition prolonged the substrate turnover times regarding to all the enzymes (Fig. 8; S5).

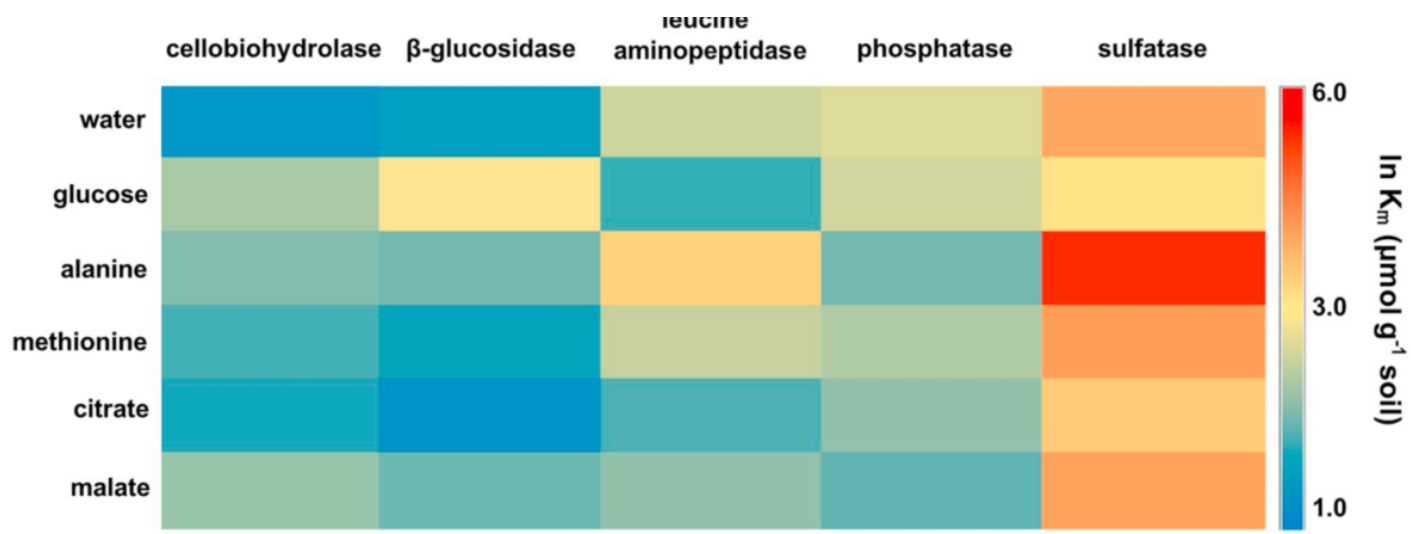


Fig. $7 \ln -K_{m}$ values of $\beta$-glucosidase, cellobiohydrolase, leucine aminopeptidase, phosphatase and sulfatase when adding substrates.
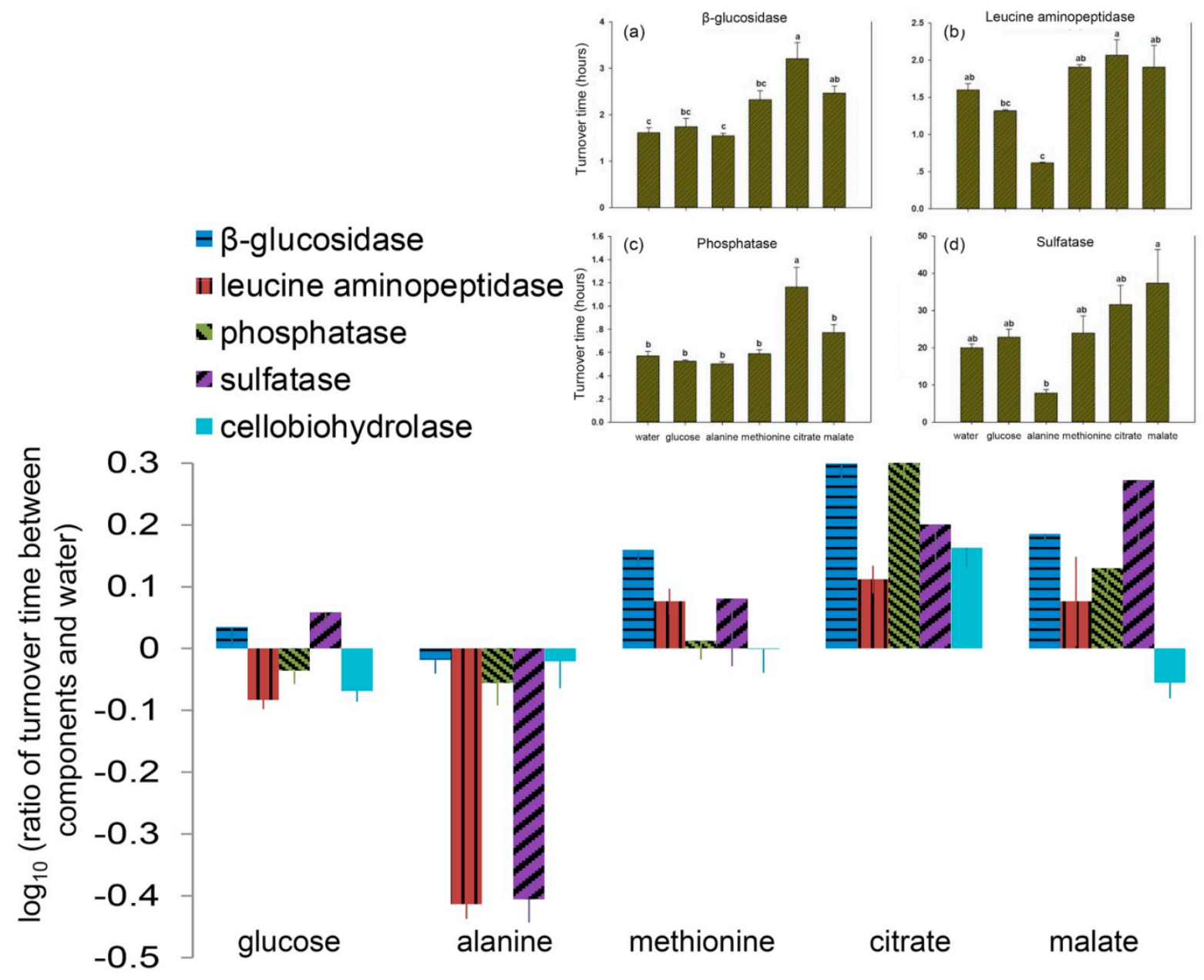

Fig. 8 Relative effects of components to water: $\log _{10}$ (ratio of turnover time between components and water). Below zero shows that turnover time in respond to each component is less than water addition while above zero demonstrates increment of turnover time compared to water addition. Subfigure shows substrate turnover times of (a) $\beta$-glucosidase, (b) leucine aminopeptidase, (c) phosphatase and (d) sulfatase when adding substrates. Small letters: significant differences ( $p<0.05$ after Tukey HSD test) of turnover time between each substance.

Glucose reduced the catalytic efficiency $\left(V_{\max } / K_{m}\right)$ of $\beta$-glucosidase (77.2\%, Subfig. 9a) and cellobiohydrolase (48.7\%, Fig. S6). The catalytic efficiencies of phosphatase after alanine additions were 2.18 times higher than after water addition (Subfig. 9c). In contrast, the catalytic efficiencies under other conditions remained stable (Fig. 9). In summary, the 
addition of components by artificial roots showed great effects on enzymes, and were specific for added components and individual enzymes.

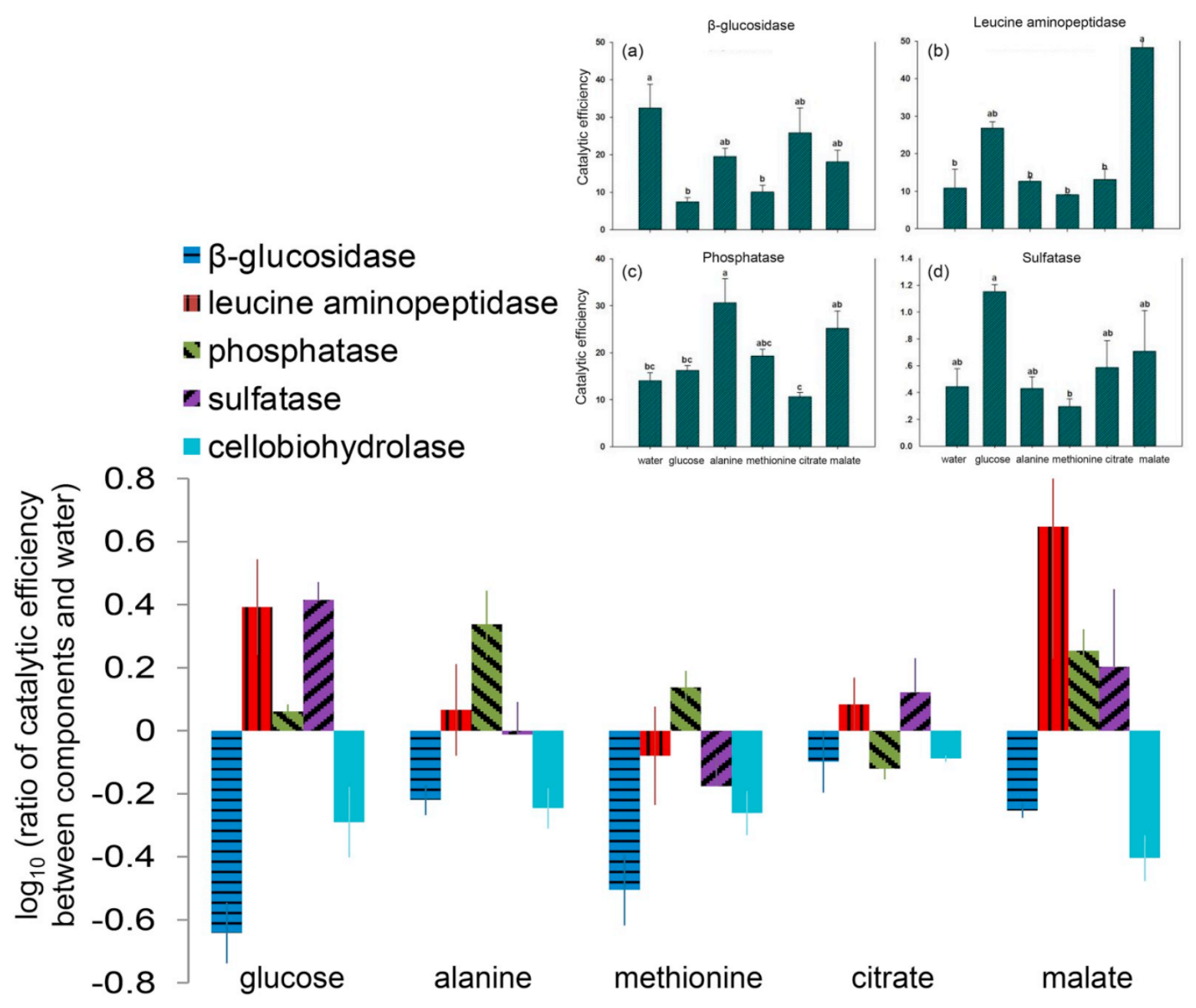

Fig. 9 Relative effects of components to water: $\log _{10}$ (ratio of catalytic efficiency between components and water). Below zero shows that catalytic efficiency in respond to each component is less than water addition while above zero demonstrates increment of catalytic efficiency compared to water addition. Subfigure shows catalytic efficiency $\left(V_{\max } / K_{m}\right)$ of (a) $\beta$-glucosidase, (b) leucine aminopeptidase, (c) phosphatase and (d) sulfatase. Small letters indicate significant differences between substances $p<0.05$ after Tukey HSD test.

\subsection{Discussion}

\subsubsection{Spatial distributions of enzyme activities in artificial rhizosphere}

Individual compounds had a specific effect on the spatial extent of rhizosphere enzyme activities (Figs. 2, 3). Nonetheless, the hypothesis that the presence of substances would always form radial gradients of enzyme activities around the artificial root was not generally supported, especially not for the C-related enzymes: $\beta$-glucosidase and cellobiohydrolase. 
The enzymes involved in carbohydrate decomposition revealed homogeneous spatial patterns. This might be mainly because microorganisms use some of the carbohydrate directly as an energy source, whereas amino acids serve as a $\mathrm{C}$ and, more importantly, also as an $\mathrm{N}$ source (Hamer and Marschner, 2005). As the soil we used soil is $\mathrm{N}$ limited, the $\mathrm{N}$ source provided by alanine most likely explains why the activities of all enzymes were more strongly increased by alanine than by any other substances. Increased phosphatase activities have been observed after atmospheric $\mathrm{N}$ depositions (Saiya-Cork et al., 2002) or alanine application (Spohn et al., 2013). Methionine, in contrast, had a low or no effect on enzyme activity (Figs. 2, 3). This probably reflects the C-S bond, which impedes its rapid mineralization (Spohn et al., 2013). For instance, applying ${ }^{35} \mathrm{~S}$-labeled methionine and cysteine to investigate the decomposition of S-containing amino acids in forest soils showed that methionine was mostly incorporated into the organic matter instead of being mineralized (Fitzgerald and Hale, 1988; Fitzgerald and Hale, 1990).

In line with our hypothesis 1, N-, P- and S-related enzymes were mostly localized around the artificial root. Similar results (higher enzyme activities) were obtained in association with the presence of living roots (Appendix. 1). Such higher enzyme activities in the rhizosphere are traditionally related to inputs of labile organic substances, which activate microorganisms (Kuzyakov and Blagodatskaya, 2015).

The extent of enzyme activity in the rhizosphere varied between various LMWOS exuded (Fig. 3). The spatial distribution of enzyme activities showed clear gradients when adding glucose, alanine, citrate or malate. This is probably due to the fast incorporation and use of LMWOS by microorganisms (Jones et al., 2003; Fischer et al., 2010). Accordingly, microorganisms near the artificial root took the opportunity to uptake the organic substances, forming microbial hotspots there (Kuzyakov and Blagodatskaya, 2015).

The rhizosphere extents along the artificial root were broader than those around real roots (e. g., Fig. 3, Appendix 1). In the artificial rhizosphere, water and organic substances go from the root to the bulk soil. In the real rhizosphere, however, the water is transported by mass flow to the root, but the exudates are exuded from the root. Therefore, the real rhizosphere (with opposite fluxes) has a much smaller extent than the artificial rhizosphere. Another reason is that enzyme extension is associated with the distance over which the root exudates diffuse. For real roots, the gradients of di- and tricarboxylic in the rhizosphere are 0.2-1.0 mm, depending on soil type, organic acid type and time (Darrah, 1991a; Jones et al., 1996a). In contrast, the extension of non-adsorbing components such as glucose and 
monocarboxylic acids can be larger ( $>5 \mathrm{~mm}$, Darrah, 1991b). Accordingly, the rhizosphere extension of lentil, maize and rice, based on enzyme activity, is between 1 and $3.5 \mathrm{~mm}$ (Razavi et al., 2016a; Ge et al., 2017). For artificial roots, however, the diffusion of simulated exudates was wider and faster. This is because the exudate components for one-day requirements were added to the soil at one time, in contrast to living plants, which slowly release root exudates from the main roots as well as additionally from root hairs (Pausch and Kuzyakov, 2018) and fine roots during the photosynthetically active period of the day (Kuzyakov and Gavrichkova, 2010). Consequently, the wider rhizosphere extension is associated with a wider distribution of organic components, which stimulates microorganisms and increases enzyme activity (Gianfreda and Rao, 2014).

\subsubsection{Enzyme kinetic parameters and substrate turnover}

The addition of components via artificial roots had dissimilar effects on $V_{\max }$ and $\mathrm{K}_{\mathrm{m}}$ (Fig. 5, 7). Alanine, as the $\mathrm{C}$ and $\mathrm{N}$ source, increased the $\mathrm{V}_{\max }$ values of C-, P-and $\mathrm{S}$ - related enzymes and decreased substrate turnover time depending on the substrate stoichiometry. Moreover, alanine also increased the activity of leucine aminopeptidase due to the enzyme production process, which is N- and energy intensive (Allison and Vitousek, 2005). Contrary to our hypothesis, adding glucose did not pronouncedly increase $\mathrm{V}_{\max }$, possibly because the glucose was very likely incorporated in microorganisms, but the energy and $\mathrm{C}$ might have been insufficient to meet the demands for expression of enzymes. From another point of view, glucose is a very ubiquitous substrate and can be distributed over nearly the entire microbial community and this could be the reason that the amount of glucose might have been insufficient to cause a strong activation of any of the glucose-based microbial groups. Quite simply, as the mineralization rate of organic $\mathrm{C}$ in soil is concentration dependent (German et al., 2011a), constrained decomposition at low concentration may be particularly important for substrates that only induce increased enzyme expression at relatively high ( $>10 \%$ of SOM) concentrations. It means that glucose addition might have stimulated microbial activity (e.g. respiration) (Keiluweit et al., 2015) but did not alter enzyme production. Citrate and malate, representing other $\mathrm{C}$ sources, caused a strong decrease (13.9-49.9\%) in $\mathrm{V}_{\max }$, which subsequently increased the substrate turnover time. Indeed, malate and citrate are favorable for a small portion of microbial communities (Jones, 1998; Fig. 2). Nonetheless, with regard to the total potential enzyme activities, they showed similar decreasing trends compared with water addition. The extreme decrease possibly reflects the importance of the $\mathrm{H}^{+}$release on nutrient mobilization (Jones et al., 2003). Additionally, in contrast to glucose and amino acids, 
malate and citrate are easily sorbed to the solid phase of soils (Ström et al., 2001), reducing the availability of their $\mathrm{C}$ for microbial uptake.

Enzyme production is an energy-intensive process for microorganisms. Soil microbes prefer cost-efficient strategies for survival, thus allocating their resources to synthesize enzymes that facilitate the acquisition of the most limited elements (Allison and Vitousek, 2005). Moreover, enzyme activities regulate microbial nutrient acquisition from SOM and plant litter. These activities therefore reflect the microbial nutrient demand (Sinsabaugh et al., 2008). The ratio of C-, N- and P-acquiring enzyme activities is near 1.0 in the natural environment, with similar supply rates of C, N and P from substrates (Sinsabaugh et al., 2008, 2012). Here, the $\mathrm{C} / \mathrm{P}$ acquisition ratio $\sim 1$ showed equivalent activities of $\mathrm{C}$ - and $\mathrm{P}$-acquiring enzymes in all treatments, whereas the $\mathrm{C} / \mathrm{N}$ acquisition ratio $<1$ suggested $\mathrm{N}$ limitation for microorganisms (Fig. 6). Based on the resource allocation theory, microorganisms allocate resources to the production of enzymes related to limited nutrients (Allison et al., 2011). The input of labile $\mathrm{C}$ such as glucose boosted the activities of phosphatase and leucine aminopeptidase, while in some cases the labile $\mathrm{C}$ inputs did not show similar trends (Hernandez and Hobbie, 2010). Glucose addition decreased the catalytic efficiency of $\beta$ glucosidase (Fig. 9) and cellobiohydrolase (Fig. S6) probably due to the end-product (glucose) inhibitory effects (Xiao et al., 2004). As glucose does not contain N, P or S, microorganisms are strained to produce corresponding enzymes to degrade other sources to acquire these nutrients. This leads to hotspots of leucine aminopeptidase and phosphatase activity (Fig. 4) and an increased catalytic efficiency of sulfatase (Fig. 9). The presence of malate and citrate strongly accelerated phosphatase dissolution, leading to 10-1000-fold higher $\mathrm{P}$ concentrations depending on soil type and speciation and the concentration of organic acids (Jones, 1998). Based on this phenomenon, i.e. the high mobilization of inorganic P, phosphatase activity did not increase (Fig. 5) even though citrate and malate are C sources for microorganisms. At the same time, this also demonstrated that organic acids strongly interacted with the mineral phase of the soil and might thus be much less microbially available than other LMWOS added in identical amounts. Alanine addition increased N availability, causing $\mathrm{C}$ and $\mathrm{P}$ limitation for microorganisms. This, in turn, enhanced $\mathrm{C}$ mobilizing enzymes (Allison and Vitousek, 2005) and phosphatase activity to mobilize recalcitrant organic matter (Geisseler and Horwath, 2009; Marklein and Houlton, 2012). This increased the proportion of hotspot areas of $\beta$-glucosidase and phosphatase. Methionine, which contains S, induced hotspot formation less than did alanine (Fig. 4) according to the stoichiometric constraints. We therefore conclude that the increase of nutrient-acquiring 
enzyme activities and $\mathrm{C}$ supply resulted from an overall specific nutrient limitation of the microbial community. This interpretation was supported by $\mathrm{C} / \mathrm{N}$ acquisition ratio $<1$, suggesting $\mathrm{N}$ limitation of microorganisms feeding on substrates with high $\mathrm{C} / \mathrm{N}$ stoichiometry.

Note that enzymes measurements in this study were assayed under $\mathrm{pH}$ close to soil original pH (6.6). Enzyme assay protocols for soil and litter samples usually call for the use of an aqueous buffer to control assay $\mathrm{pH}$ and dilute the sample (German, et al., 2011b). However, application of different buffer would cause fluctuation in enzyme activity and result in driven of contrasting conclusions. Thus, due to effect of $\mathrm{pH}$ on enzyme activity, further studies considering various ranges of $\mathrm{pH}$ on single isolated enzyme or enzymes in soil would improve our understanding on the enzymatic activity in response to range of substances.

The response of $\mathrm{K}_{\mathrm{m}}$ values to artificial root exudates varied between enzymes and components (Fig. 7). The increases of $\mathrm{K}_{\mathrm{m}}$ values for C-cycle enzymes when adding glucose (two- to threefold) and for leucine aminopeptidase and sulfatase when adding alanine (twoto fourfold) indicated that the enzyme systems were changed to lower affinity to their substrate (Razavi et al., 2017b). In fact, such a strong decrease in substrate affinity is in line with the stoichiometry theory that microbes regulate enzyme activities in response to soil resource availability to fulfill their nutrient requirements (Sinsabaugh and Follstad Shah, 2012). The major drop in $K_{m}$ for phosphatase means high reaction rates already present at very low substrate concentrations (Tischer et al., 2015). Thus, maintaining the stability of soil enzyme systems might have ensured efficient enzymatic functioning. Indeed, the activities of extracellular enzymes are mainly a function of the amount of available substrate and of the microbial biomass present to potentially synthesize them (Blagodatskaya et al., 2014). The catalytic efficiency $\left(\mathrm{K}_{\mathrm{a}}\right)$ of enzymes (ratio of $\left.V_{\max } / K_{m}\right)$ also suggested the possible shift in microbial community structure due to the changes in substrate availability. The relative changes of $K_{a}$ for phosphatase under alanine and malate addition (Fig. 9) and for sulfatase under glucose addition compared to water (Fig. 9) revealed that $\mathrm{K}_{\mathrm{a}}$ increased consistently due to lower substrate availability (Hausmann et al., 2016). Except for the above results, the $\mathrm{K}_{\mathrm{m}}$ values of these enzymes were unaffected by other components, likely indicating that these enzyme systems are relatively well conserved. This means that the production of enzymes with higher stability and efficiency was a preferred microbial strategy in the studied soil (Stone et al., 2012; Razavi et al., 2016b). From another point of view, we 
assumed that the adaptive modifications to carry out protein and cellulose catalysis at sufficient substrate availability are unnecessary in this soil.

\subsection{Conclusions}

For the first time, we showed which compounds of root exudates play the key role in stimulating microbial enzyme activities and formation of rhizosphere gradients in the absence of living roots. According to the principles of stoichiometry, enzyme activities and hotspot areas are partly related to the $\mathrm{C}$ and to nutrient availability: i) Alanine increased the percentage of hotspot area of $\beta$-glucosidase, phosphatase and sulfatase; ii) Methionine caused no strong effects on the hotspot area of sulfatase; iii) The hotspot area of leucine aminopeptidase and phosphatase was increased greatly by adding glucose; iv) Alanine had the overall strongest effect in this N-limited soil. In conclusion, the rhizosphere shape formed by microbial activities is enzyme- and component-specific. Within all tested enzymes, phosphatase is the most sensitive enzyme to the composition of exuded compounds. This shows that those abiotic and biotic factors affecting root exudate composition may strongly affect the P cycle. Accordingly, we suggest that predicting and modeling the consequences of abiotic and biotic factors that affect root exudate composition for $\mathrm{C}$ and nutrient cycles in the rhizosphere could assume dissimilarity of enzyme-based processes. It would be appropriate that they consider possible factors triggering strong changes in root exudate composition, which are reflected in the enzyme systems and thus in the enzyme process rates in the rhizosphere - the most diverse hotspots in the biosphere.

\section{Acknowledgments}

We gratefully acknowledge the China Scholarship Council (CSC) for financial support for XZ. The contribution of YK was supported by the Russian Science Foundation (project No. 18-14-00362), and MD was supported by the Robert-Bosch Foundation. This study was supported by the DFG grant RA-3062/3-1 and KU-1184/33-1. We thank Soil Science Consulting (https://soilscicon.wordpress.com) for help in manuscript preparation.

\section{References}

Allison, S.D., Vitousek, P.M., 2005. Responses of extracellular enzymes to simple and complex nutrient inputs. Soil Biology and Biochemistry 37, 937-944.

Allison, S.D., Weintraub, M.N., Gartner, T.B., Waldrop, M.P., 2011. Evolutionary-economic principles as regulators of soil enzyme production and ecosystem function. Soil Enzymology 22, 229-243. 
Asmar, F., Eiland, F., Nielsen, N.E., 1994. Effect of extracellular enzyme activities on solubilization rate of soil organic nitrogen. Biology and Fertility of Soils 17, 32-38.

Bastian, F., Bouziri, L., Nicolardot, B., Ranjard, L., 2009. Impact of wheat straw decomposition on successional patterns of soil microbial community structure. Soil Biology and Biochemistry 41 , $262-275$.

Blagodatskaya, E.V., Blagodatsky, S.A., Anderson, T.H., Kuzyakov, Y., 2009. Contrasting effects of glucose, living roots and maize straw on microbial growth kinetics and substrate availability in soil. European Journal of Soil Science 60, 186-197.

Blagodatskaya, E., Kuzyakov, Y., 2013. Active microorganisms in soil: critical review of estimation criteria and approaches. Soil Biology and Biochemistry 67, 192-211.

Blagodatskaya, E., Khomyakov, N., Myachina, O., Bogomolova, I., Blagodatsky, S., Kuzyakov, Y., 2014. Microbial interactions affect sources of priming induced by cellulose. Soil Biology and Biochemistry 74, 39-49.

Burns, R.G., 1982. Enzyme activity in soil: location and a possible role in microbial ecology. Soil Biology and Biochemistry 14, 423-427.

Caldwell, B., 2005. Enzyme activities as a component of soil biodiversity: a review. Pedobiologia 49, $637-644$

Cheng, W., Coleman, D.C., 1990. Effect of living roots on soil organic matter decomposition. Soil Biology and Biochemistry 22, 781-787.

Darrah, P.R., 1991. Measuring the diffusion-coefficient of rhizosphere exudates in soil. I. The diffusion of non-sorbing compounds. Journal of Soil Science 42, 413-420.

Dennis, P.G., Miller, A.J., Hirsch, P.R., 2010. Are root exudates more important than other sources of rhizodeposits in structuring rhizosphere bacterial communities? FEMS Microbial Ecology 72 , 313-327.

Derrien, D., Marol, C., Balesdent, J., 2004. The dynamics of neutral sugars in the rhizosphere of wheat. An approach by ${ }^{13} \mathrm{C}$ pulse-labelling and GC/C/IRMS. Plant and Soil 267, 243-253.

Fischer, H., Ingwersen, J., Kuzyakov, Y., 2010. Microbial uptake of low-molecular weight organic substances out-competes sorption in soil. European Journal of Soil Science 61, 504-513.

Fischer, H., Meyer, A., Fischer, K., Kuzyakov, Y., 2007. Carbohydrate and amino acid composition of dissolved organic matter leached from soil. Soil Biology and Biochemistry 39, 2926-2935.

Fitzgerald, J.W., Hale, D.D., 1988. Sulphur-containing amino acid metabolism in surface horizons of a hardwood forest. Soil Biology and Biochemistry 20, 825- 831.

Fontaine, S., Barot, S., 2005. Size and functional diversity of microbe populations control plant persistence and long-term soil carbon accumulation. Ecology Letters 8, 1075-1087.

Ge, T.D., Wei, X.M., Razavi, B.S., Zhu, Z.K., Hu, Y.J., Kuzyakov, Y., Jones D.L., Wu. J.S., Stability and dynamics of enzyme activity patterns in the rice rhizosphere: Effects of plant growth and temperature. Soil Biology and Biochemistry 113, 108-115. 
Geisseler, D., Horwath, W.R., 2009. Relationship between carbon and nitrogen availability and extracellular enzyme activities in soil. Pedobiologia 53, 87-98.

George, T.S., Turner, B.L., Gregory, P.J., Cade-menun, B.J., Richardson, A.E., 2006. Depletion oforganic phosphorusfrom Oxisols in relation to phosphatase activities in the rhizosphere. European Journal of Soil Science 57, 47-57.

German, D.P., Chacon, S.S., Allison, S.D., 2011a. Substrate concentration and enzyme allocation can affect rates of microbial decomposition. Ecology 98, 1471-1480.

German, D.P., Weintraub, M.N., Grandy, A.S., Lauber, C.L., Rinkes, Z.L., Allison, S.D., 2011 b. Optimization of hydrolytic and oxidative enzyme methods for ecosystem studies. Soil Biology and Biochemistry 43, 1387-1397.

Gianfreda, L., Rao, A.A., 2014. Enzymes in Agricultural Sciences. Published by OMICS Group eBooks, Gull Ave, Foster City. CA94404, USA.

Hale, D.D., Fitzgerald, J.W., 1990. Generation of sulphate from cysteine in forest soil and litter. Soil Biology and Biochemistry 22, 427-429.

Hamer, U., Marschner, B., 2005. Priming effects in soils after combined and repeated substrate additions. Geoderma 128, 38- 51.

Hausmann, B., Knorr, K.H., Schreck, K., Tringe, S.G., Glavina del Rio, T., Loy, A., Pester, M., 2016. Consortia of low-abundance bacteria drive sulfate reduction-dependent degradation of fermentation products in peat soil microcosms. The Isme Journal 10: 2365-2375.

Hernandez, D.L., Hobbie, S.E., 2010. The effects of substrate composition, quantity, and diversity on microbial activity. Plant and Soil 335, 397-411.

Hertenberger, G., Zampach, P., Bachmann, G., 2002. Plant species affect the concentration of free sugars and free amino acids in different types of soil. Journal of Plant Nutrition and Soil Science $165,557-565$.

Hill, B.H., Elonen, C.M., Seifert, L.R., May, A.A., Tarquinio, E., 2012. Microbial enzyme stoichiometry and nutrient limitation in US streams and rivers. Ecological Indicators 18, 540551.

Hill, P., Farrar, J., Jones, D.L., 2008. Decoupling of microbial glucose uptake and mineralization in soil. Soil Biology and Biochemistry 40, 616-624.

Hoang, D.T.T., Pausch, J., Razavi, B.S., Kuzyakova, I., Banfield, C.C., Kuzyakov, Y., 2016. Hotspots of microbial activity induced by earthworm burrows, old root channels, and their combination in subsoil. Biology and Fertility of Soils 52, 1105-1119.

Högberg, P., Read, D.J., 2006. Towards a more plant physiological perspective on soil ecology. TRENDS in Ecology and Evolution 21, 548-554.

Hutsch, B.W., Augustin, J., Merbach, W., 2002. Plant rhizodeposition - an important source for carbon turnover in soils. Journal of Plant Nutrition and Soil Science 165, 397-407.

Jones, D.L., 1998. Organic acids in the rhizosphere - a critical review. Plant and soil 205, 25-44. 
Jones, D.L., Brassington, D.S., 1998. Sorption of organic acids in acid soils and its implications in the rhizosphere. European Journal of Soil Science 49, 447-455.

Jones, D.L., Darrah, P.R., 1994. Role of root derived organic acids in the mobilization of nutrients from the rhizosphere. Plant and Soil 166, 247-257.

Jones, D.L., Darrah, P.R., Kochian, L.V., 1996. Critical-evaluation of organic-acid mediated iron dissolution in the rhizosphere and its potential role in root iron uptake. Plant and Soil 180, 5766.

Jones, D.L., Dennis, P.G., Owen, A.G., van Hees, P.A.W., 2003. Organic acid behavior in soils misconceptions and knowledge gaps. Plant and Soil 248, 31-41.

Jones, D.L., Edwards, A., 1998. Influence of sorption on the biological utilization of two simple carbon substrates. Soil Biology and Biochemistry 30, 1895-1902.

Keiluweit, M., Bougoure, J.J., Nico, P.S., Pett-Ridge, J.,Weber, P.K., Kleber, M., Mineral protection of soil carbon counteracted by root exudates. Nature Climate Change 5, 588-595.

Kuzyakov, Y., Blagodatskaya, E., 2015. Microbial hotspots and hot moments in soil: Concept \& review. Soil Biology and Biochemistry 83, 184-199.

Kuzyakov, Y., Demin, V., 1998. $\mathrm{CO}_{2}$ efflux by rapid decomposition of low molecular organic substances in soils. Sciences of Soils 3, 11-22.

Kuzyakov, Y., Friedel, J. K., Stahr, K., 2000. Review of mechanisms and quantification of priming effects. Soil Biology and Biochemistry 32, 1485-1498.

Kuzyakov, Y., Gavrichkova, O., 2010. REVIEW: Time lag between photosynthesis and carbon dioxide efflux from soil: a review of mechanisms and controls. Global Change Biology 16, 33863406.

Lohaus, G., Burba, M., Held, H.W., 1994. Comparison of the contents of sucrose and amino acids in the leaves, phloem sap and taproots of high and low sugar-producing hybrids of sugar beet (Beta vulgaris L.). Journal of Experimental Botany 45, 1097- 1101.

Luster, J., Göttlein, A., Nowack, B., Sarret, G., 2009. Sampling, defining, characterising and modeling the rhizosphere - the soil science tool box. Plant and Soil 321, 457-482.

Ma, X.M., Zarebanadkouki, M., Kuzyakova, Y., Blagodatskaya, E., Pausch, J., Razavi, B.S., 2018. Spatial patterns of enzyme activities in the rhizosphere: Effects of root hairs and root radius. Soil Biology and Biochemistry 118, 69-78.

Marklein, A.R., Houlton, B.Z., 2012. Nitrogen inputs accelerate phosphorus cycling rates across a wide variety of terrestrial ecosystems. New Phytologist 193, 696-704.

Marschner, P., Marhan, S., Kandeler, E., 2012. Microscale distribution and function of soil microorganisms in the interface between rhizosphere and detritusphere. Soil Biology and Biochemistry 49, 174-183. 
Mooshammer, M., Wanek, W., Zechmeister-Boltenstern, S., Richter, A., 2014. Stoichiometric imbalances between terrestrial decomposer communities and their resources: mechanisms and implications of microbial adaptations to their resources. Frontiers in Microbiology 5, 1-10.

Moorhead, D.L., Sinsabaugh, R.L., 2006. A theoretical model of litter decay and microbial interaction. Ecological Monographs 76, 151-174.

Moscatelli, M.C., Lagomarsino, A., Garzillo, A.M.V., Pignataro, A., Grego, S., 2012. $\beta$-Glucosidase kinetic parameters as indicators of soil quality under conventional and organic cropping systems applying two analytical approaches. Ecological Indicators 13, 322-327.

Oburger, E., Dell'mour, M., Hann, S., Wieshammer, G., Puschenreiter, M., Wenzel, W.W., 2013. Evaluation of a novel tool for sampling root exudates from soil-grown plants compared to conventional techniques. Environmental and Experimental Botany 87, 235-247.

Oburger, E., Jones, D.L., 2018. Sampling root exudates - Mission impossible? Rhizosphere 6, 116133.

Panikov, N., Blagodatsky, S., Blagodatskaya, J., Glagolev, M., 1992. Determination of microbial mineralization activity in soil by modified Wright and Hobbie method. Biology and Fertility of Soils 14, 280-287.

Pausch, J., Kuzyakov, Y., 2018. Carbon input by roots into the soil: Quantification of rhizodeposition from root to ecosystem scale. Global Change Biology 24, 1-12.

Razavi, B.S., Blagodatskaya, E., Kuzyakov, Y., 2016b. Temperature selects for static soil enzyme systems to maintain high catalytic efficiency. Soil Biology and Biochemistry 97, 15-22.

Razavi, B.S., Hoang, D.T.T., Blagodatskaya, E., Kuzyakov, Y., 2017a. Mapping the footprint of nematodes in the rhizosphere: Cluster root formation and spatial distribution of enzyme activities. Soil Biology and Biochemistry 115, 213-220.

Razavi, B.S., Liu, S.B., Kuzyakov, Y., 2017b. Hot experience for cold-adapted microorganisms: Temperature sensitivity of soil enzymes. Soil Biology and Biochemistry 105, 236-243.

Razavi, B.S., Zarebanadkouki, M., Blagodatskaya, E., Kuzyakov, Y., 2016a. Rhizosphere shape of lentil and maize: spatial distribution of enzyme activities. Soil Biology and Biochemistry 96, 229-237.

Saiya-Cork, K.R., Sinsabaugh, R.L., Zak, D.R., 2002. The effects of long term nitrogen deposition on extracellular enzyme activity in an Acer saccharum forest soil. Soil Biology and Biochemistry 34, 1309-1315.

Schimel, J.P., Weintraub, M.N., 2003. The implications of exoenzyme activity on microbial carbon and nitrogen limitation in soil: a theoretical model. Soil Biology and Biochemistry 35, 549-563.

Sinsabaugh, R.L., Follstad Shah, J.J., 2012. Ecoenzymatic stoichiometry and ecological theory. Annual Review of Ecology, Evolution, and Systematics 43, 313-343.

Sinsabaugh, R.L., Lauber, C.L., Weintraub, M.N., Ahmed, B., Allison, S.D., Crenshaw, C., Contosta, A.R., Cusack, D., Frey, S., Gallo, M.E., Gartner, T.B., Hobbie, S.E., Holland, K., Keeler, B.L., 
Powers, J.S., Stursova, M., Takacs-Vesbach, C., Waldrop, M.P., Wallenstein, M.D., Zak, D.R., Zeglin, L.H., 2008. Stoichiometry of soil enzyme activity at global scale. Ecology Letters 11, 1252-1264.

Spohn, M., Ermak, A., Kuzyakov, Y., 2013. Microbial gross organic phosphorus mineralization can be stimulated by root exudates - A ${ }^{33} \mathrm{P}$ isotopic dilution study. Soil Biology and Biochemistry $65,254-263$.

Spohn, M., Kuzyakov, Y., 2013. Distribution of microbial- and root-derived phosphatase activities in the rhizosphere depending on $\mathrm{P}$ availability and $\mathrm{C}$ allocation - Coupling soil zymography with ${ }^{14} \mathrm{C}$ imaging. Soil Biology and Biochemistry 67,106-113.Ström, L., Owen, A.G., Godbold, D.L., Jones, D.L., 2001. Organic acid behaviour in a calcareous soil: sorption reactions and biodegredation rates. Soil Biology and Biochemistry 33, 2125-2133.

Ström, L., Owen, A.G., Godbold, D.L., Jones, D.L., 2005. Organic acid behaviour in a calcareous soil implications for rhizosphere nutrient cycling. Soil Biology and Biochemistry 37, 2046-2054.

Tarafdar, J.C., Jungk, A., 1987. Phosphatase activity in the rhizosphere and its relation to the depletion of soil organic phosphorus. Biology and Fertility of Soils 3, 199-204.

Tischer, A., Blagodatskaya, E., Hamer, U., 2015. Microbial community structure and resource availability drive the catalytic efficiency of soil enzymes under land-use change conditions. Soil Biology and Biochemistry 89, 226-237.

Vetterlein, D., Kühn, T., Kaiser, K., Jahn, R., 2013. Illite transformation and potassium release upon changes in composition of the rhizosphere soil solution. Plant and Soil 371, 267-279.

Waring, B.G., Weintraub, S.R., Sinsabaugh, R.L., 2014. Ecoenzymatic stoichiometry of microbial nutrient acquisition in tropical soils. Biogeochemistry 117, 101-113.

Watt, M., Wendy, K.S., Passioura, J.B., 2006. Rates of root and rganism growth, soil conditions, and temporal and spatial development of the rhizosphere. Annals of Botany 97, 839-855.

Xiao, Z., Zhang, X., Gregg, D.J., Saddler, J.N., 2004. Effects of sugar inhibition on cellulases and beta-glucosidase during enzymatic hydrolysis of softwood substrates. Applied Biochemistry and Biotechnology, 113-116:1115-26. 


\section{Appendix}

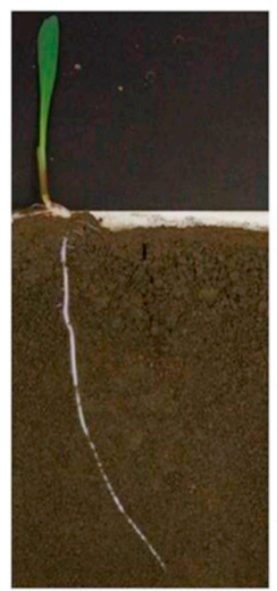

Enzyme activity (pmol mm-2 $\left.\mathrm{h}^{-1}\right)$
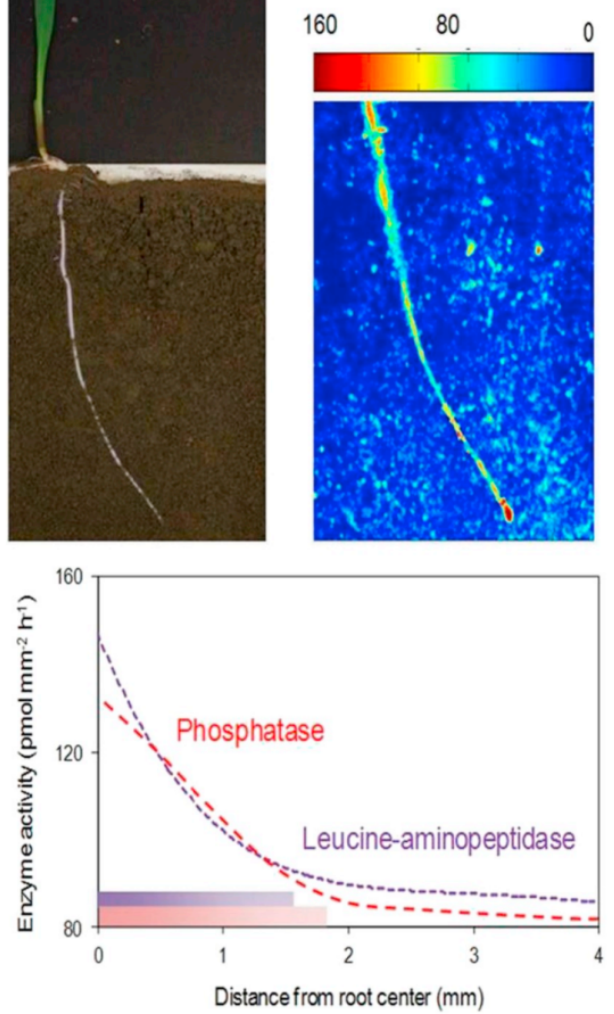

Appendix 1 Example of spatial distribution of enzyme activity around the maize root.

\section{Supplementary}

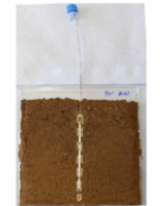

Rhizobox

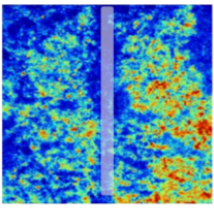

water

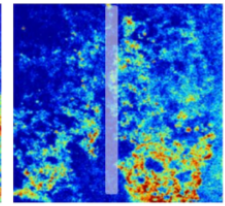

glucose

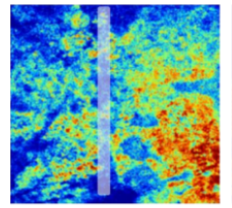

alanine

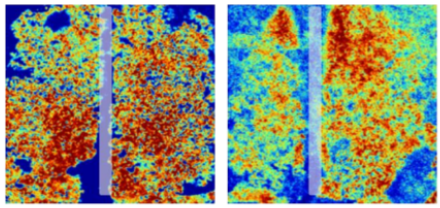

citrate

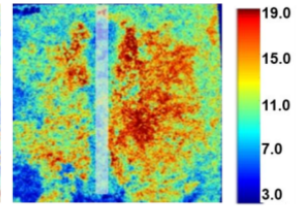

malate

Fig. S1 An example of rhizobox (dotted line is the area where we took soil samples); And zymography images of cellobiohydrolase in response to component additions. Side color scale is proportional to enzyme activities $\left(\mathrm{nmol} \mathrm{cm}^{-2} \mathrm{~h}^{-1}\right)$. 


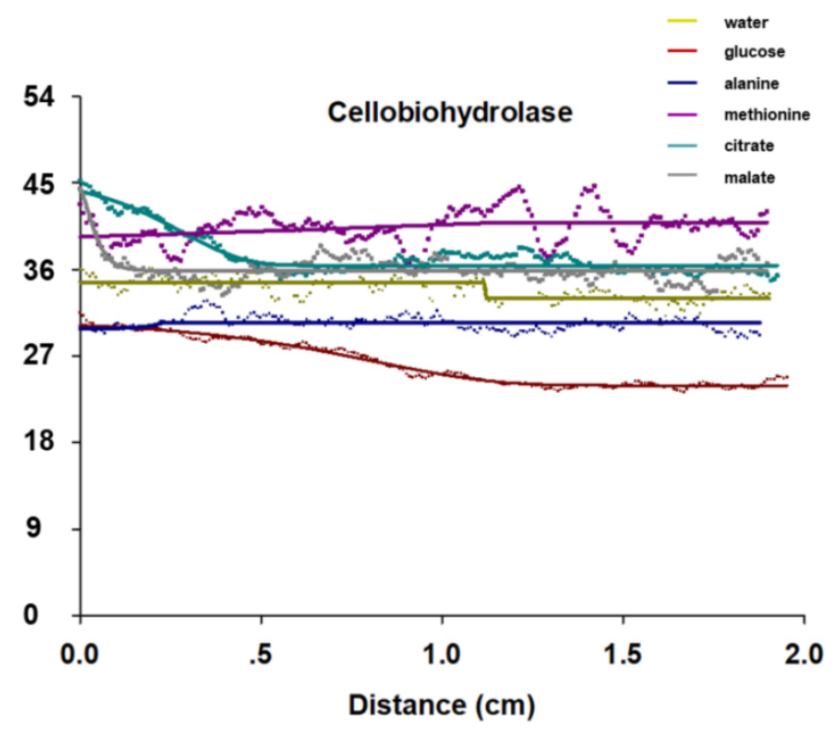

Fig. S2 The profile of cellobiohydrolase distribution as a function of distance from the root center. Each line refers to the mean value of many lines of one part from each zymogram. 0 on the $\mathrm{X}$ axis shows the center of the artificial root. The $\mathrm{Y}$ axis is presented in relative units as enzyme activity $\left(\mathrm{nmol} \mathrm{cm} \mathrm{cm}^{-2} \mathrm{~h}^{-1}\right)$.

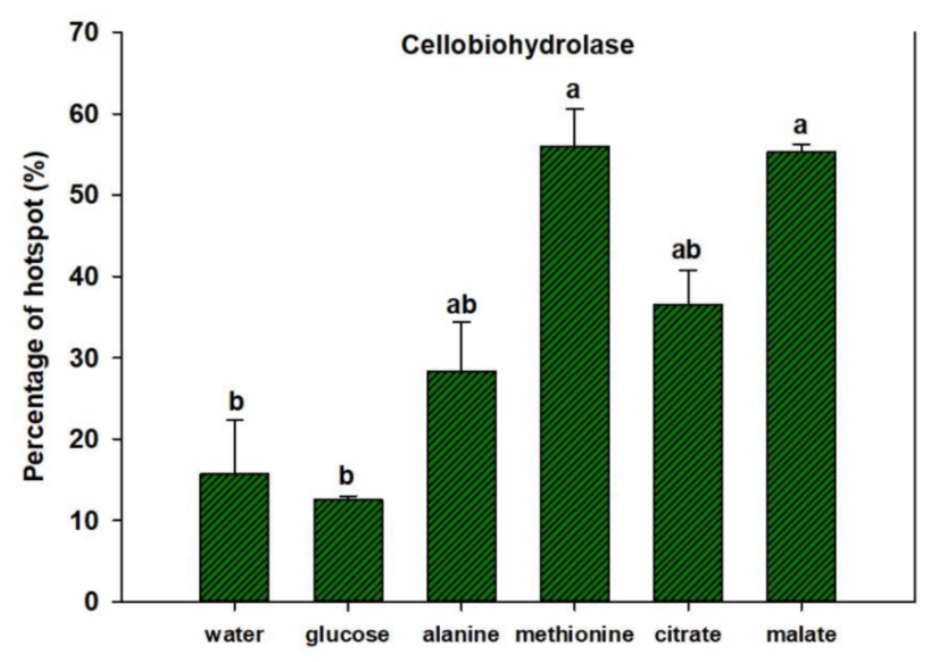

Fig. S3 Hotspots (with area exceeding 20\% of average grey values of the whole image), as a percentage of total area for cellobiohydrolase in the artificial rhizosphere of six substances. Small letters: significant differences $(p<0.05$ after Tukey HSD test). 


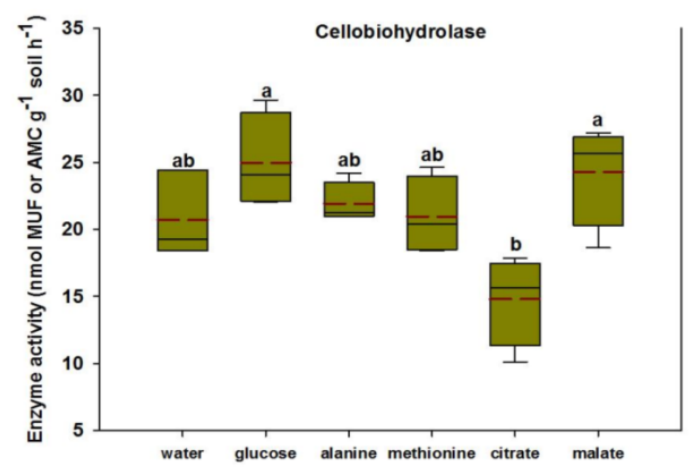

Fig. S4 Enzyme activity as a function of substrate concentration for cellobiohydrolase in response to component additions. Values are means of four replicates $( \pm \mathrm{SE})$. Small letters: significant differences ( $p<0.05$ after Tukey HSD test) between components.

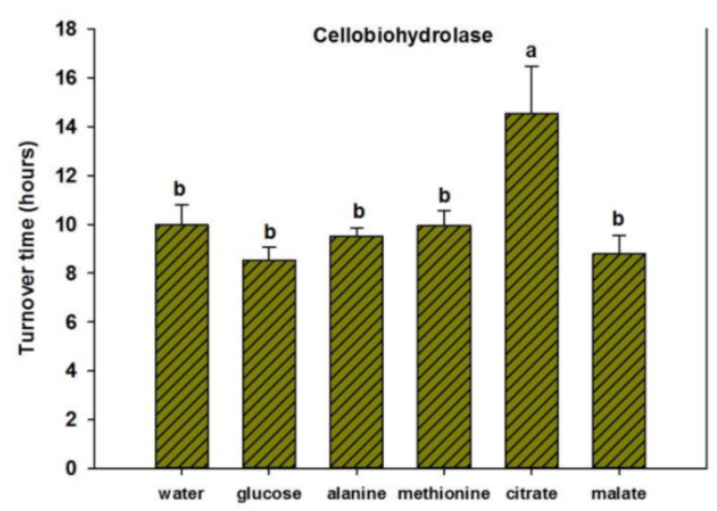

Fig. S5 Substrate turnover times of cellobiohydrolase when adding substrates. Small letters: significant differences ( $p<0.05$ after Tukey HSD test) of turnover time between each substance.

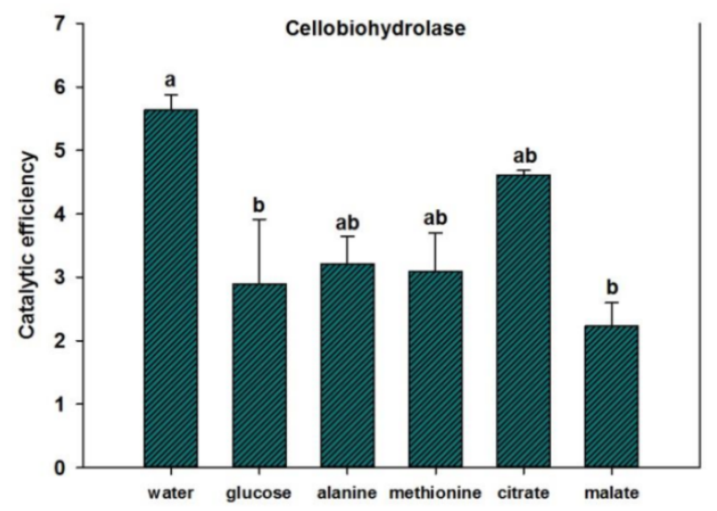

Fig. S6 Catalytic efficiency $\left(V_{\max } / K_{m}\right)$ of cellobiohydrolase. Small letters indicate significant differences between substances $p<0.05$ after Tukey HSD test. 

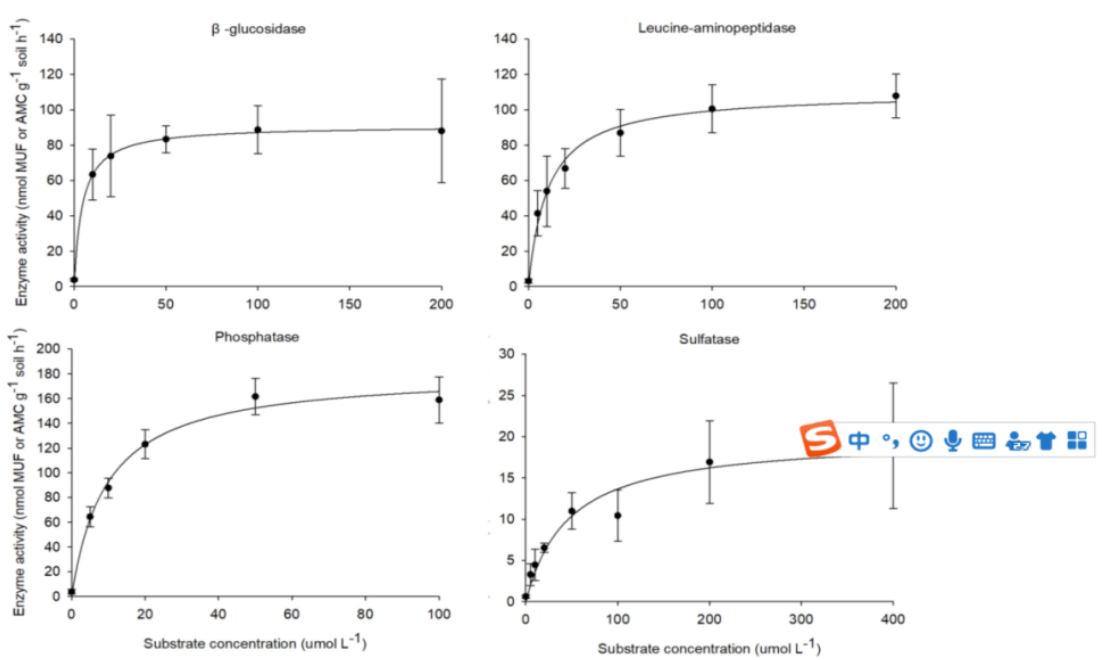

Fig. S7 Michaelis-Menten kinetics (enzyme activity as a function of substrate concentration) for $\beta$-glucosidase, leucine aminopeptidase, phosphatase and sulfatase in response to methionine addition.

A five-parameter logistic curve was fitted to enzyme activity as a function of distance from the center of Rhizon ${ }^{\circledR}$ to the soil, using the same form of equation for all enzymes and substances:

$$
\mathrm{y}=\min +\frac{(\max -\min )}{\left[1+\left({ }^{x} / E C\right)^{-H i l l s l o p e}\right]^{c}}
$$

where, $\mathrm{y}$ is enzyme activity for each substance; min and max are minimum and maximum horizontal asymptote (the lowest and the highest activity) and $\mathrm{x}$ is the independent value (distance from the Rhizon center to the soil); EC and Hillslope, respectively, are the point of inflection (the point on the S shaped curve halfway between min and max) and Hill's slope of the curve (which reflects curve steepness at point EC); $\mathrm{c}$ is asymmetry factor and when $\mathrm{c}=1$ we have a symmetrical curve around inflection point and so we have a four-parameters logistic equation, in the Sigmaplot (v. 12.5) environment. The five parameters logistic cure is characterized by the classic "S" or sigmoidal shape that fits the bottom and top plateaus of the curve. The criterion was an equation which gives the highest correlation with the obtained results and best describes the observed pattern. 
Table S1 R ${ }^{2}$ after 3-, 4- and 5-parameters logistic curve fitted to enzyme activities as a function of distance from the artificial root center in response to various components

\begin{tabular}{|c|c|c|c|c|}
\hline \multirow{4}{*}{ Enzymes } & \multirow{4}{*}{$\begin{array}{l}\text { Component } \\
\text { s }\end{array}$} & \multicolumn{3}{|l|}{$\mathbf{R}^{2}$} \\
\hline & & 3 & 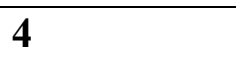 & 5 Parameters \\
\hline & & Parameter & Parameters & \\
\hline & & $\mathbf{s}$ & & \\
\hline \multirow{6}{*}{$\beta$-glucosidase } & water & 0.9118 & 0.9119 & 0.9119 \\
\hline & glucose & 0.3049 & 0.6558 & 0.6607 \\
\hline & alanine & 0.6223 & 0.7783 & 0.7783 \\
\hline & methionine & 0.3041 & 0.3041 & 0.3041 \\
\hline & citrate & 0.5928 & 0.8657 & 0.8657 \\
\hline & malate & 0.2582 & 0.7878 & 0.799 \\
\hline \multirow{6}{*}{$\begin{array}{l}\text { leucine } \\
\text { aminopeptidase }\end{array}$} & water & 0.016 & 0.0371 & 0.0178 \\
\hline & glucose & 0.7703 & 0.7955 & 0.8007 \\
\hline & alanine & NAN & 0.3045 & 0.3085 \\
\hline & methionine & NAN & 0.0443 & 0.045 \\
\hline & citrate & 0.5547 & 0.8159 & 0.818 \\
\hline & malate & 0.6395 & 0.741 & 0.7441 \\
\hline \multirow{6}{*}{ phosphatase } & water & 0.0199 & 0.1873 & 0.0687 \\
\hline & glucose & 0.5643 & 0.7354 & 0.7387 \\
\hline & alanine & 0.476 & 0.9927 & 0.9928 \\
\hline & methionine & 0.0778 & 0.171 & 0.158 \\
\hline & citrate & 0.3312 & 0.9124 & 0.9163 \\
\hline & malate & 0.8123 & 0.8768 & 0.8772 \\
\hline \multirow{6}{*}{ sulfatase } & water & 0.0228 & 0.2337 & 0.2348 \\
\hline & glucose & 0.6165 & 0.871 & 0.8713 \\
\hline & alanine & 0.3807 & 0.954 & 0.9583 \\
\hline & methionine & 0.3473 & 0.4047 & 0.4034 \\
\hline & citrate & 0.4434 & 0.9278 & 0.9282 \\
\hline & malate & 0.5566 & 0.9102 & 0.9176 \\
\hline \multirow{3}{*}{$\begin{array}{l}\text { cellobiohydrolas } \\
\text { e }\end{array}$} & water & 0.4311 & 0.5063 & 0.5063 \\
\hline & glucose & 0.8803 & 0.9726 & 0.9778 \\
\hline & alanine & 0.0372 & 0.0594 & 0.0593 \\
\hline
\end{tabular}




$\begin{array}{llll}\text { methionine } & 0.0717 & 0.1264 & 0.0861 \\ \text { citrate } & 0.4921 & 0.8878 & 0.8965 \\ \text { malate } & 0.0585 & 0.5131 & 0.5133\end{array}$




\title{
2 Study 2: Maize genotype-specific strategies to increase microbial activity in the rhizosphere
}

Nataliya Bilyera ${ }^{\mathrm{a}, \mathrm{b}, *}$, Xuechen Zhang ${ }^{\mathrm{c}}$, Patrick Duddek ${ }^{\mathrm{d}, \mathrm{e}}$, Lichao Fan ${ }^{\mathrm{f}}$, Callum C. Banfield ${ }^{\mathrm{c}}$, Steffen Schlüter ${ }^{\mathrm{g}}$, Andrea Carminati ${ }^{\mathrm{d}}$, Anders Kaestner ${ }^{\mathrm{h}}$, Mutez A. Ahmed ${ }^{\mathrm{e}}$, Yakov Kuzyakov $^{\mathrm{f}}$, Michaela A. Dippold ${ }^{\mathrm{c}}$, Sandra Spielvogel ${ }^{\mathrm{b}}$, Bahar S. Razavi ${ }^{\mathrm{a}}$

\section{Status: Submitted to Soil Biology \& Biochemistry}

a - Dept. Soil and Plant Microbiome, Institute of Phytopathology, Christian-AlbrechtsUniversity of Kiel, 24118 Kiel, Germany

b - Dept. of Soil Science, Institute for Plant Nutrition and Soil Science, ChristianAlbrechts-University Kiel, 24118 Kiel, Germany

${ }^{c}$ - Dept. of Biogeochemistry of Agroecosystems, University of Göttingen, Göttingen, Germany

${ }^{d}$ - Department of Environmental Systems Science, Physics of Soils and Terrestrial Ecosystems, ETH Zürich, Switzerland

e - Chair of Soil Physics, Bayreuth Center of Ecology and Environmental Research (BayCEER), Bayreuth, Germany

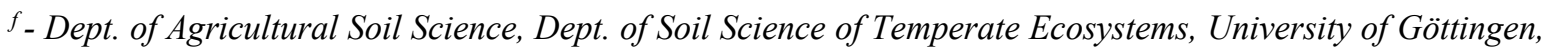
37077, Göttingen, Germany

g - Department Soil System Science, Helmholtz Centre for Environmental Research - UFZ, 06120 Halle, Germany

${ }^{h}$ - Laboratory for Neutron Scattering and Imaging, Paul Scherrer Institute, 5232 Villigen, Switzerland.

\begin{abstract}
Plants stimulate microbial enzyme production in the rhizosphere, regulating soil organic matter decomposition and nutrient cycling. Root morphology (i.e., root hairs) and exudate composition define the spatial distribution of properties and functions in the rhizosphere, but their influence on rhizosphere self-organization remains unknown. We coupled three in situ imaging approaches: ${ }^{14} \mathrm{C}$ imaging to localize exudates, soil zymography to analyze enzyme activity distribution, and neutron radiography for water fluxes to trace the spatial structure of the rhizosphere of three maize genotypes (wild type, mutant with defective root hair prolongation (rth3), and mutant with reduced benzoxazinoid content in exudates (bxl)). Colocalization analysis revealed the pivotal role of both optimal water content and root exudation for $\beta$-glucosidase production by the rhizosphere microbiome and its hydrolytic activity. Root hairs increased the exudate release and expanded the spatial extent of $\beta$ glucosidase activity around the root axis by $35 \%$, yielding a two-fold faster ${ }^{14} \mathrm{C}$ exudate decomposition compared to the rth 3 mutant. In contrast, benzoxazinoids suppressed $\beta$ glucosidase activity by $30 \%$, reflecting decreased microbial activity, whereas their absence broadened the rhizosphere. Overall, root hairs in wild type maize increased microbial activity (i.e. $\beta$-glucosidase production), whereas benzoxazinoids in root exudates suppressed microorganisms.
\end{abstract}

Keywords: microbial activity, primary metabolites, secondary metabolites, soil imaging methods, spatial rhizosphere functioning *Corresponding author: n.bilyera@soils.uni-kiel.de 


\subsection{Introduction}

The rhizosphere is a microbial hotspot in soil where roots and microorganisms interact (Berg \& Smalla, 2009; Philippot et al., 2013; Yang et al., 2017; Pett-Ridge et al., 2021) and accelerate process rates beyond that in bulk soil (Koranda et al., 2011). To overcome nutrient and water limitations, plants have developed various rhizosphere-related strategies such as root morphological adaptations (Hinsinger et al., 2009; Vetterlein et al., 2020; Ahmed et al., 2021), beneficial associations with microorganisms (Smith et al., 2001; Bucher et al., 2014), and release of exudates and enzymes (Farrar et al., 2003; Jones et al., 2009; Gianfreda, 2015; Vives-Peris et al., 2020). Despite many efforts to study each of these rhizosphere strategies (Downie et al., 2015; Canarini et al., 2019; Vetterlein et al., 2020; Watt et al., 2020), the spatial organization of the rhizosphere and its functioning remain poorly understood (Vetterlein et al., 2020).

Enzyme activity is crucial for the decomposition of soil organic matter (SOM) and nutrient cycling. Enzymes are released into the soil by roots and microorganisms (Sinsabaugh et al., 1992; Waring, 2013). Plants produce $\beta$-glucosidase, an enzyme important for the first step of organic compound degradation; this step releases the easily available monomer glucose from any oligo- and polysaccharides or glycosylated compounds, to which $\beta$ glycosidic binds. $\beta$-glucosidase is released directly from the roots into the soil (Cairns \& Esen, 2010; Gómez-Anduro et al., 2011), but plants also facilitate $\beta$-glucosidase production in microorganisms by releasing easily available organic substances they can access (Kandeler et al., 2002). Thus, soil microorganisms synthesize $\beta$-glucosidase in response to the presence of suitable substrate that must be degraded (Turner et al., 2002; Veres et al., 2015). The extent of $\beta$-glucosidase activities is one measure to define the soil volume in which SOM decomposition is altered by root activity (Huo et al., 2017). The process of SOM decomposition is also responsible for $\mathrm{C}$ (i.e., glucose) mining by microorganisms in the rhizosphere. Beyond substrate availability, optimal abiotic conditions such as soil water content are key prerequisites for microbial activity (Masciandaro et al., 2004; Collins et al., 2008; Henry, 2012). Up to $80 \%$ higher $\beta$-glucosidase activity was reported in soils with optimal moisture content compared to dry soils (Sardans \& Peñuelas, 2005; Boeddinghaus et al., 2015). Soil water is essential for $\beta$-glucosidase activity and serves as a medium for diffusion of labile $\mathrm{C}$. Therefore, maintaining a greater enzymatic rhizosphere volume (or extent in $2 \mathrm{D}$ images) along with higher $\beta$-glucosidase activities and optimal water contents are necessary for plants to acquire nutrients from organic sources (i.e., SOM) when available 
and mobile inorganic forms are limited. The extent to which $\beta$-glucosidase activity is controlled by spatial patterns of exudation and soil water content, however, remains unknown.

The spatial distribution of released exudates strongly depends on root morphology because organic substances are released along the root axis (mainly at the root tips, elongation zones, and root hairs) (McCully \& Canny, 1985; Peterson \& Farquhar, 1996; Kaiser et al., 2015). For example, the presence of root hairs increased root ${ }^{14} \mathrm{C}$ exudation up to three-fold (Holz et al., 2018), supposedly due to a larger root surface area (Silberbush \& Barber, 1983; Haling et al., 2013). An increased amount of root exudates - forming more readily available C (e.g. sugars, amino acids) - activates microorganisms (Bertin et al., 2003; Liu et al., 2020) and can thus expand the enzymatic rhizosphere extent by up to 1.5 times (Ma et al., 2018a) in root-hair zones.

Along with primary metabolites, plant roots exudate secondary metabolites such as benzoxazinoids (Dick et al., 2012) which induce herbivore resistance (Frey et al., 1997; Maag et al., 2016), and have strong fungicidal and less pronounced antibacterial effects (Kudjordjie et al., 2019; Cotton et al., 2019). Apart from plant protective functions (Erb \& Kliebenstein, 2020), benzoxazinoids can reduce plant biomass (Hu et al., 2018). Such a negative effect on crop productivity is mainly attributed to the inhibition of beneficial microorganisms belonging to the phylum Glomeromycota or to Flavobacteriaceae (Hu et al., 2018; Cadot et al., 2020), which also release less $\beta$-glucosidase (Okamoto et al., 2000; Ahmad et al., 2011; Sørensen et al., 2013). Less $\beta$-glucosidase activity induces less hydrolyzed available $\mathrm{C}$, which is required to maintain higher microbial activity, including microorganisms responsible for nutrient mining. Furthermore, benzoxazinoids decomposition by microorganisms with a high degradation capacity (i.e., Pseudomonas putida (Neal et al., 2012)) requires time and energy (Schütz et al., 2019). Accordingly, low or no benzoxazinoids in the exudates may be advantageous for rhizosphere microorganisms. Finally, microorganisms activated at root tips and other root parts with intensive exudation may decompose benzoxazinoids, thus reducing their inhibitory effects. This calls for investigating the influence of root hairs and benzoxazinoids on the spatial distribution of root exudates along and across the roots, and ultimately on the rhizosphere extent and $\beta$ glucosidase activity.

Imaging methods per se provide the advantage of non-destructively visualizing the distribution of compounds or activities in the root-soil continuum. In the case of the rhizosphere, unique relations can thus be co-localized, such as effects of the water content 
and the exudation of labile compounds - two prerequisites for high exoenzymatic activity. The spatial distribution of enzyme activity can be detected by soil zymography (Spohn et al., 2013; Razavi et al., 2019), the release of recently assimilated carbon as root exudates visualized with ${ }^{14} \mathrm{C}$ imaging (Holz et al., 2018), and water content localized with neutron radiography (Zarebanadkouki et al., 2012). Soil zymography and neutron radiography (Holz et al., 2019a) have been successfully coupled, as have soil zymography and ${ }^{14} \mathrm{C}$ imaging (Spohn \& Kuzyakov, 2013). The combination of the three approaches, however, promises to link two spatially highly variable factors - the newly released photoassimilates and the water content - to elucidate their separate and combined effects on enzyme activity.

In this respect, using genotypes with contrasting rhizosphere morphology (i.e. root hair defective) (Wen \& Schnable, 1994) and exudate profiles (i.e. benzoxazinoids deficit) (Hu et $a l ., 2018)$ will induce varying interactions in the rhizosphere.

We investigate how the spatial distribution of $\beta$-glucosidase activity in the rhizosphere of maize depends on the localization of the newly released organic substances via the roots and on the soil water content. For this purpose, we compare two maize mutants with the corresponding wild type. We hypothesized that: (i) the gradients of $\beta$-glucosidase activity in the rhizosphere depend on both labile $\mathrm{C}$ and soil water availability (H1); (ii) the presence of root hairs expands the rhizosphere extent as well as the maximal activity of $\beta$-glucosidase (H2); (iii) the presence of benzoxazinoids in root exudates suppresses microbial activity, reducing $\beta$-glucosidase activity (H3). To test these hypotheses, we applied three imaging methods (soil zymography, ${ }^{14} \mathrm{C}$ imaging, neutron radiography) to three maize genotypes (wild type, mutant with defective root hair prolongation (rth3), mutant with reduced benzoxazinoids content in root exudates $(b x l))$.

\subsection{Materials and Methods}

\subsubsection{Experimental setup}

We used a Haplic Phaeozem soil substrate with a loam texture consisting of sand $-33 \%$, silt $-48 \%$, and clay $-19 \%$ (Vetterlein et al., 2021). The soil $\mathrm{pH}\left(\mathrm{CaCl}_{2}\right)$ was 6.21 , total $\mathrm{C}$ and $\mathrm{N}$ were 8.5 and $0.8 \mathrm{~g} \mathrm{~kg}^{-1}$, respectively; mineral $\mathrm{N}$, available $\mathrm{P}$ and $\mathrm{K}$ were $1.4,32.7$, and $28.5 \mathrm{mg} \mathrm{kg}^{-1}$, respectively (Vetterlein et al., 2021). The following nutrients were added to the soil before filling the rhizoboxes $(10 \times 21.2 \times 0.6 \mathrm{~cm}): 50 \mathrm{mg} \mathrm{kg}-1 \mathrm{~N}^{-} \mathrm{NH}_{4} \mathrm{NO}_{3}, 50 \mathrm{mg} \mathrm{kg}^{-}$ ${ }^{1} \mathrm{~K}_{\text {as }} \mathrm{K}_{2} \mathrm{SO}_{4}, 25 \mathrm{mg} \mathrm{kg}^{-1} \mathrm{Mg}$ as $\mathrm{MgCl}_{2} 6 \mathrm{H}_{2} \mathrm{O}$, and $40 \mathrm{mg} \mathrm{kg}^{-1} \mathrm{P}$ as $\mathrm{CaHPO}_{4}$. The $1 \mathrm{~mm}$ sieved soil was homogeneously filled into rhizoboxes, avoiding the formation of layers. The mass 
of soil was about 161-162 g per rhizobox, assuring a homogeneous bulk density of $1.27 \mathrm{~g}$ $\mathrm{cm}^{-3}$.

Three maize (Zea mays L.) genotypes - wild type (WT, B73), root-hair defective ( $>90 \%)$ mutant (rth3) (Wen \& Schnable, 1994; Hochholdinger et al., 2008, 2018) and benzoxazinoids (BX) deficit (>90\%) mutant (bxl) (Frey et al., 1997) - were grown in the rhizoboxes. After 3 days of germination, the pre-germinated seedlings of each genotype were planted in four replicates into separate rhizoboxes and all plants were cultivated for 21 days. The rhizoboxes were placed at an angle of approximately $45^{\circ}$ to ensure roots growing towards the wall of the rhizoboxes. About $20-22 \%$ of volumetric water content (VWC) was maintained by watering the soil regularly from the top. The spatial distribution of water was visualized by neutron radiography (details below). Plants were grown in a climate chamber with a controlled temperature of $22{ }^{\circ} \mathrm{C}$ during the day and $18{ }^{\circ} \mathrm{C}$ during the night, a photoperiod of $12 \mathrm{~h}$, relative air humidity of $65 \%$, and a light intensity of $350 \mu \mathrm{mol} \mathrm{m}^{-2} \mathrm{~s}^{-1}$ of photosynthetically active radiation at the top of the rhizobox (LED Grow Light, GrowLED, France).

\subsubsection{Imaging methods}

\subsubsection{Plant labeling and ${ }^{14} \mathrm{C}$ imaging}

After 21 days of growth, each plant was labeled with about $0.5 \mathrm{MBq}^{14} \mathrm{CO}_{2}$ at a target $\mathrm{CO}_{2}$ concentration of $500 \mathrm{ppm}$, following the procedure described by Kuzyakov et al. (2006). Briefly, six plants (two replicates of each of three genotypes) were put in an airtight chamber (120 L volume) during two days. Before labeling, the $\mathrm{CO}_{2}$ inside the labeling chamber was reduced by cycling the air through $1 \mathrm{M} \mathrm{NaOH}$ for $8 \mathrm{~h}$ with the grow light off. For the labeling, $\mathrm{Na}_{2} \mathrm{CO}_{3}$ solution containing $3 \mathrm{MBq}$ of $\mathrm{Na}_{2}{ }^{14} \mathrm{CO}_{3}$ was dissolved in $10 \mathrm{ml}$ phosphoric acid (100\%). During the labeling, all plants were kept under a grow light $\left(350 \mu \mathrm{mol} \mathrm{m}^{-2} \mathrm{~s}^{-1}\right)$ to enable maximum photosynthetic activity. After $6 \mathrm{~h}$, not assimilated $\mathrm{CO}_{2}$ in the chamber was trapped by pumping the air through $1 \mathrm{M} \mathrm{NaOH}$ for $2 \mathrm{~h} .{ }^{14} \mathrm{C}$ activities were determined by liquid scintillation counting using a Hidex 300SL Automatic Liquid Scintillation Counter (Hidex, Turku, Finland). $0.5 \mathrm{ml}$ of $\mathrm{NaOH}$ were added to the $8 \mathrm{ml}$ scintillation cocktail Rotiszint Eco plus (Carl Roth, Karlsruhe, Germany) and kept in the dark for $24 \mathrm{~h}$ for chemiluminescence to cease.

The ${ }^{14} \mathrm{C}$ imaging was done as described in Holz et al. (2018). Briefly, directly after labeling, the rhizoboxes were transferred to a dark room. The rooted soil surfaces were exposed to storage phosphor screens (BAS-IP MS 2040 E, GE Healthcare, U.S.A.). All screens were erased for $10 \mathrm{~min}$ under a strong bright light before use, and were protected 
from moisture by transparent plastic bags (polypropylene, $40 \mu \mathrm{m}$ thickness, density $0.95 \mathrm{~g} \mathrm{~cm}^{-3}$, MDF Verpackungen $\mathrm{GmbH}$, Bergisch Gladbach, Germany). After $20 \mathrm{~h}$ exposure in the dark, the screens were removed from the soil-root surface and scanned by a laser scanner for phosphorimaging (650 nm excitation, FLA-7000, GE Healthcare, U.S.A.) with a spatial resolution of $25 \mu \mathrm{m}$. The duration of $20 \mathrm{~h}$ was recommended by previous studies (Holz et al., 2018; Thu Hoang et al., 2020) to best visualize the ${ }^{14} \mathrm{C}$ signal.

The ${ }^{14} \mathrm{C}$ images were calibrated by preparing a series of smooth soils with activities ranging from 0 to $1.55 \mathrm{MBq}$ at $\mathrm{cm}^{-2}$. The same procedure of ${ }^{14} \mathrm{C}$ imaging and image processing procedure was applied. The details are described in Thu Hoang et al. (2020).

Due to the short time $\left(20 \mathrm{~h}\right.$ ) between labeling and imaging, almost all of the ${ }^{14} \mathrm{C}$ detected can be attributed to exudates and secretion - and a negligible proportion to root cell/tissue turnover, which requires longer observation times ( $>5$ days).

\subsubsection{Soil zymography}

Direct soil zymography (Razavi et al., 2016) was used to study the spatial distribution of enzyme activities immediately after removing the ${ }^{14} \mathrm{C}$ imaging plates. Enzyme activity was visualized using polyamide membranes $(0.45 \mu \mathrm{m}$ mesh size, Tao Yuan, China) saturated with 4-methylumbelliferone (MUF)-labeled substrates. The $\beta$-glucosidase activity was detected with 4-methylumbelliferyl- $\beta$-D-glucoside (Sigma-Aldrich, Germany). The substrate was completely dissolved in MES buffer $\left(\mathrm{C}_{6} \mathrm{H}_{13} \mathrm{NO}_{4} \mathrm{SNa}_{0.5}\right)$ (pH: 6.5) (Sigma-Aldrich, Germany) by shaking to reach the concentration of $1 \mathrm{~g} \mathrm{~L}^{-1}$ (Sanaullah et al., 2016), which corresponds to $3.5 \mathrm{mM}$. Polyamide membrane filters $(20 \times 20 \mathrm{~cm})$ and a pore size of $0.45 \mu \mathrm{m}$ were cut to $10 \times 20 \mathrm{~cm}$ to fit the size of the rhizobox. Each membrane was saturated with $5 \mathrm{ml}$ of the substrate solution by covering it completely with the solution in a flat box for $10 \mathrm{~s}$. The rhizoboxes were opened from the rooted side, and the saturated membranes were applied directly to the soil surface (Razavi et al., 2016). After $1 \mathrm{~h}$ incubation at the root-soil interface, the membranes were carefully lifted off, and the few attached soil particles were gently removed using tweezers and a soft-thin paintbrush.

The membranes were placed in a dark room under ultraviolet (UV) light with an excitation wavelength of $355 \mathrm{~nm}$. Photos were taken with a digital camera Canon EOS 6D with a Canon lens EF $94 \mathrm{~mm} \mathrm{1:} \mathrm{4L} \mathrm{IS.} \mathrm{The} \mathrm{aperture} \mathrm{and} \mathrm{shutter} \mathrm{speed} \mathrm{were} \mathrm{set} \mathrm{to} \mathrm{f/5.6} \mathrm{and}$ $1 / 30 \mathrm{~s}$, respectively.

A standard calibration that relates the enzyme activities to the gray values of zymogram fluorescence (i.e. of the membrane) was performed. The calibration function (Fig. S1) was 
obtained by zymography of $4 \mathrm{~cm}^{2}$ membranes soaked in a solution of MUF with concentrations of $0,0.01,0.2,0.5,1,2,4,6$ and $10 \mathrm{mM}$. The amount of MUF on an area basis was preliminarily determined to ensure complete membrane saturation but no excess liquid that may drip. The membranes used for calibration were imaged under UV light and analyzed with identical light conditions and camera settings as the samples.

\subsubsection{Neutron radiography}

Neutron radiography was used to create images of the water content in the sample and to identify differences in the water content of rhizosphere and bulk soil.

Neutron radiography is highly sensitive to hydrous materials and therefore visualizes the water distribution along the roots in the soil (Moradi et al., 2009; Ahmed et al., 2016). A parallel neutron beam propagates through the sample, and the transmitted neutrons behind the sample are detected using a scintillator. The scintillator converts the neutrons into visible light captured by a CCD camera. The exposed image carries information on sample thickness and composition according to the Beer-Lambert's law (Zarebanadkouki et al., 2012):

$$
\frac{I-d c}{f f-d c}=\exp \left[-\sum_{i=1}^{i=n}\left(\mu_{i} d_{i}\right)\right] \quad(\text { Eq. } 1)
$$

where $I$ is the transmitted neutron beam intensity $\left[\mathrm{cm}^{-2} \mathrm{~s}^{-1}\right], f f$ is the flat field (i.e. the transmitted beam without sample) $\left[\mathrm{cm}^{-2} \mathrm{~s}^{-1}\right], d c$ is the dark current (i.e. transmitted beam when the beam is off) $\left[\mathrm{cm}^{-2} \mathrm{~s}^{-1}\right], \mu_{i}$ is the neutron attenuation coefficient $\left[\mathrm{cm}^{-1}\right]$, and $d_{i}$ is the thickness $[\mathrm{cm}]$ of material $i$. The materials composing our samples were: aluminum, dry soil, root, and water. The attenuation contribution of aluminum and dry soil were obtained from radiographs of empty and dry samples, respectively. The attenuation coefficient of water was derived from images of step wedge samples of known thickness filled with water. The measurements were performed within 0.5-1 h after zymography at the ICON beamline at the Paul Scherrer Institute (PSI), Villigen, Switzerland (Kaestner et al., 2011). We used a sCMOS camera detector (Andor NEO, Andor Technologies) with an array of 1260 by 1260 pixels, a field of view of 15.75 by $15.75 \mathrm{~cm}$, and an effective spatial resolution of $0.2 \mathrm{~mm}$ (or $2160 \times 2560$ pixels, yielding a field of view of $13.3 \times 16 \mathrm{~cm}$ and pixel size of $0.062 \mathrm{~mm}$ ). With this field of view, a $2 \times 2$ matrix radiography scan with overlapping marginally was needed to fully cover the rhizobox sample. 


\subsubsection{Image processing and co-localization}

\subsubsection{Image processing}

All images were processed in ImageJ (version 1.52p) (Abràmoff et al., 2004). Zymograms, neutron radiographs, and ${ }^{14} \mathrm{C}$ images were transformed into 8-bit grayscale images. The backgrounds were calculated and subtracted based on the calibration line at concentration of zero added MUF for zymogram, no ${ }^{14} \mathrm{C}$ activity added for ${ }^{14} \mathrm{C}$ images, and intensity attenuations values of aluminum and dry soil for neutron images.

For each treatment the mean values of $\beta$-glucosidase activity were measured from calibrated zymograms (Fig. S2) at three locations (bulk soil, mature root, root tips) using ImageJ. $\beta$-glucosidase activity for bulk soil was estimated at 5-7 locations $\left(\sim 2-6 \mathrm{~cm}^{2}\right)$ away from all adjacent roots. $\beta$-glucosidase activity along the mature root and root tip areas was measured at 5-7 root compartments with a good visibility to avoid bias related to attachment issues, as described in Razavi et al. (2019).

Rhizosphere hotspots for $\beta$-glucosidase activity, ${ }^{14} \mathrm{C}$ exudates, and water content were thresholded by a previously developed statistical approach of Mean+2SD (or $\mu+2 \sigma)($ Bilyera et al., 2020).

\subsubsection{Rhizosphere thresholding procedure}

The rhizosphere extent was determined for root segments $>3 \mathrm{~cm}$ from the tip and root tip regions 0-2 cm from the tip (Yu et al., 2016), irrespective of root type and order, for the following parameters: 1) ${ }^{14} \mathrm{C}$ in exudates $\left({ }^{14} \mathrm{C}\right.$ images); and 2) $\beta$-glucosidase activity (soil zymograms). To measure the rhizosphere extent, five horizontal transects (angle to the root $\sim 90^{\circ}$ ) were randomly drawn across five randomly selected roots for each ${ }^{14} \mathrm{C}$ image and zymogram using ImageJ. In total, this yielded 25 lines per image as pseudo-replicates, and their mean was used for each rhizobox (as a true replicate).

The pixelwise gray values along each section were plotted against their distance from the starting point at the root-soil interface. A minimum of five locations $\left(\sim 2-6 \mathrm{~cm}^{2}\right)$ of the background activities (bulk soil) per image were manually selected, and their mean pixel intensities were determined (Fig. S2) (Hummel et al., 2021). The threshold value (here lower limit of the rhizosphere activities) for the rhizosphere was taken from the $\mu+2 \sigma$ of the pixel intensity distribution, as was mentioned above. Then, in the cross sections, the distance between the points where the threshold was first / last exceeded from both sides of each root was calculated and used as the rhizosphere bidirectional extent (Fig. S2). Root diameters at 
the same segments of the root system were manually measured in individual photos. Based on the assumption that the rhizosphere is symmetrically distributed around the root (Hinsinger et al., 2005), the rhizosphere extent was calculated as the difference between rhizosphere bidirectional extent and root diameter divided by two.

\subsubsection{Co-localization analysis}

Prior to co-localization analysis, all three images from each replicate were cropped to the same dimensions and manually registered by spatial alignment with the TrackEM2 plugin (Cardona et al., 2012; Saalfeld et al., 2012) in ImageJ. The co-localization of three parameters $\left({ }^{14} \mathrm{C}\right.$ intensity, $\beta$-glucosidase activity, soil water content distributions) enables to detect if they spatially overlap / coincidence. The co-localization was analyzed using JACoP (Just another co-localization plug-in) (Bolte \& Cordelières, 2006) in ImageJ. We did not correct images for root growth during the imaging processes because soil zymography was conducted maximally 10-15 min after the ${ }^{14} \mathrm{C}$ image plate was removed; thus, following $1 \mathrm{~h}$ of exposure time for zymography, the samples in rhizoboxes were measured for water content by neutron radiography $1.5-2 \mathrm{~h}$ after ${ }^{14} \mathrm{C}$ imaging. The co-localization analysis was conducted for two sets: (1) normalized images of ${ }^{14} \mathrm{C}$ intensity, $\beta$-glucosidase activity, and soil water content distributions; and (2) thresholded hotspot areas of $\beta$-glucosidase activity, ${ }^{14} \mathrm{C}$ exudates, and water content (binary images of rhizosphere).

We calculated the following co-localization coefficients: (1) Pearson correlation coefficient (PC) - to characterize the correlations of the pixel intensity distribution between two images; (2) overlap coefficient (Fig. S3) (r) - to distinguish if the pixel intensity distribution of two signals overlap with positive values between two images; (3) Mander's or co-occurrence coefficients (Fig. S3): M1 - the co-localization of parameter A with parameter B; M2 - the co-localization of parameter B with parameter A. This image analysis produced two coefficients that represent the fraction of co-localizing objects in each component of a dual-channel image (Manders et al., 1993). The co-localization coefficients were calculated for original images for the whole rhizobox area (bulk and rhizosphere soil). Binary images of thresholded rhizosphere were applied for calculation coefficients $r$, M1 and M2 of the rhizosphere.

Pearson correlation coefficient: $P C=\frac{\sum_{i}\left(A_{i}-a\right) \cdot\left(B_{i}-b\right)}{\sqrt{\sum_{i}\left(A_{i}-a\right)^{2} \sum_{i}\left(B_{i}-b\right)^{2}}}$. 


$$
\text { Overlap coefficient: } r=\frac{\sum_{i} A_{i} \cdot B_{i}}{\sqrt{\sum_{i} A_{i}^{2} \cdot \sum_{i} B_{i}^{2}}}
$$

$$
\begin{array}{rr}
\text { Manders' coefficients: } M 1=\frac{\sum_{i} A_{i, \text { coloc }}}{\Sigma_{i} A_{i}} \quad \text { with } A_{i, \text { coloc }}=A_{i} \text { if } B_{i}>0 \\
M 2=\frac{\Sigma_{i} B_{i, c o l o c}}{\Sigma_{i} B_{i}} \quad \text { with } B_{i, \text { coloc }}=B_{i} \text { if } A_{i}>0
\end{array}
$$

where $A_{i}$ is the intensity at each pixel of image $A, B_{i}$ is the intensity at each pixel of image $\mathrm{B}$, and $\mathrm{a}$ and $\mathrm{b}$ are the mean intensities of images $\mathrm{A}$ and $\mathrm{B}$, respectively.

The qualitative interpretation of the quantitative co-localization results is provided according to Zinchuk et al. (2013) in five linguistic variables - very weak, weak, moderate, strong, very strong (Table S1).

\subsubsection{Statistical analysis}

All data are presented as mean \pm standard deviation of four replicate rhizoboxes. The Nalimov outlier test was performed to check the reliability of data sets. The Shapiro-Wilk test was performed for residues of means to check for normality, and the Bartlett test was applied to check the homogeneity of variances. If data meet normality and homogeneity, oneway ANOVA and Tukey's HSD post hoc test were performed; if homogeneity was not proved, the Welch test and Games-Howell post-hoc test were performed; if normality was not met, the Kruskal-Wallis test was applied. All analyses were performed using R software, Version 3.6.1 (R Development Core Team, 2011) at a significance level of $\alpha=0.05$.

\subsection{Results}

\subsubsection{Spatial distribution of ${ }^{14} \mathrm{C}$ from root exudation, $\beta$-glucosidase activity and soil water content}

Visual analysis of the ${ }^{14} \mathrm{C}$ images showed contrasting exudation patterns for the three maize genotypes: 1) stronger exudation at root tip regions in wild type (WT) (Fig. 1d); 2) rather homogeneous exudation along the whole root system of mutants' rth3 (Fig. 1e) and $b x 1$ (Fig. 1f). Overall, exudation was higher for $b x 1$ than for $r t h 3$. $\beta$-glucosidase activities on zymograms were higher at root tips and young roots in WT (Fig. 1g) but mainly on young roots in $r$ th 3 (Fig. 1h) and rather homogeneous along the root axis in $b x 1$ (Fig. 1i). Neutron images clearly showed the roots themselves due to their high tissue water content $(\sim 0.2 \%)$ and a very variable water content in close proximity to the root $(0-1 \mathrm{~mm})($ Fig. $1 \mathrm{j}-1)$. 

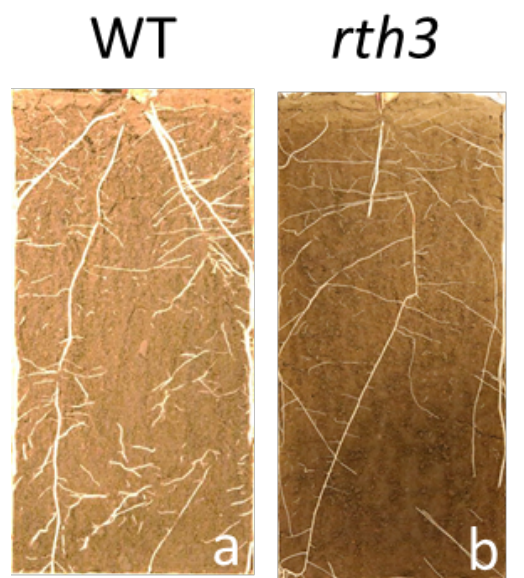

$b \times 1$
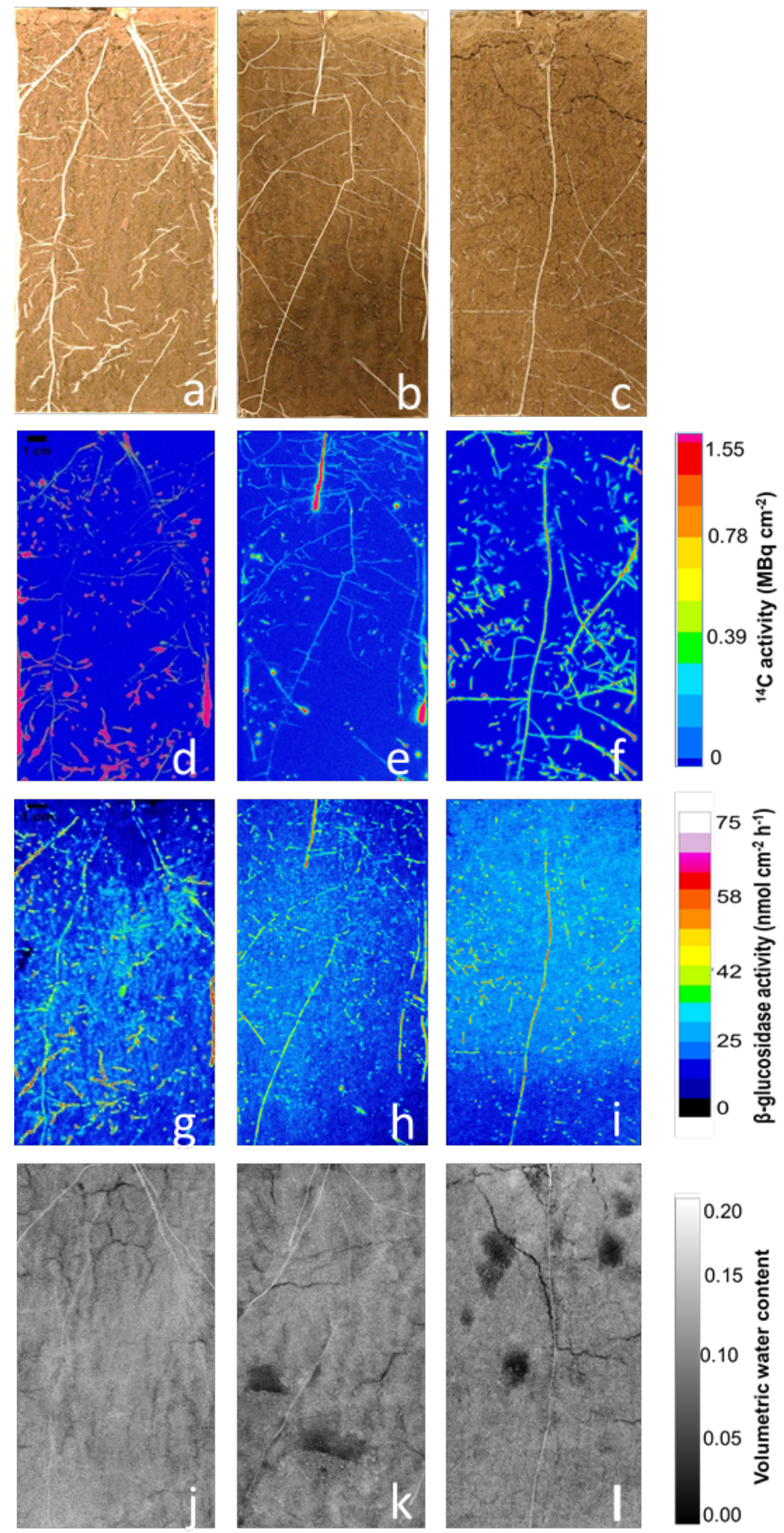

Figure 1. Root images (real light photos) (a,b,c), zymograms of $\beta$-glucosidase activity (d,e,f), ${ }^{14} \mathrm{C}$ phosphor images $(\mathrm{g}, \mathrm{h}, \mathrm{i})$, and neutron radiographs $(\mathrm{j}, \mathrm{k}, \mathrm{l})$ of three maize genotypes (WT, $r t h 3$ and $b x 1$ ). Side color or gray scales are proportional to $\beta$-glucosidase activity (pmol $\mathrm{cm}^{-}$ $\left.{ }^{2} \mathrm{~h}^{-1}\right),{ }^{14} \mathrm{C}$ activity (MBq) and to volumetric water content. Always one representative replicate out of four was chosen. WT: wild type maize, $r t h 3$ : root hair defective mutant; $b x 1$ : mutant with reduced benzoxazinoids in root exudates. 


\subsubsection{Rhizosphere extent}

The rhizosphere extent of $\beta$-glucosidase activity of $r$ th 3 was $30-35 \%$ smaller for the mature root $(P<0.05)$ and root tip region $(P<0.001)$ than for the corresponding regions of WT, but there was no difference between $b x 1$ and WT (Fig. 2a). The mean rhizosphere extent with respect to $\beta$-glucosidase activity was $\sim 50 \%$ greater $(P<0.001)$ at the root tip region than along mature roots over all genotypes (Fig. 2a).

The rhizosphere extent of exudation along mature roots was about 2.5 times smaller $(P<$ 0.001 ) in the WT versus both mutants (Fig. 2b). In contrast, there was no genotype effect $(P=0.31)$ on the spatial ${ }^{14} \mathrm{C}$ extent around the root tips (Fig. $\left.2 b\right)$. Generally, the exudation distance increased 2-6 fold at the root tip versus mature root for all genotypes $(P<0.001)$.

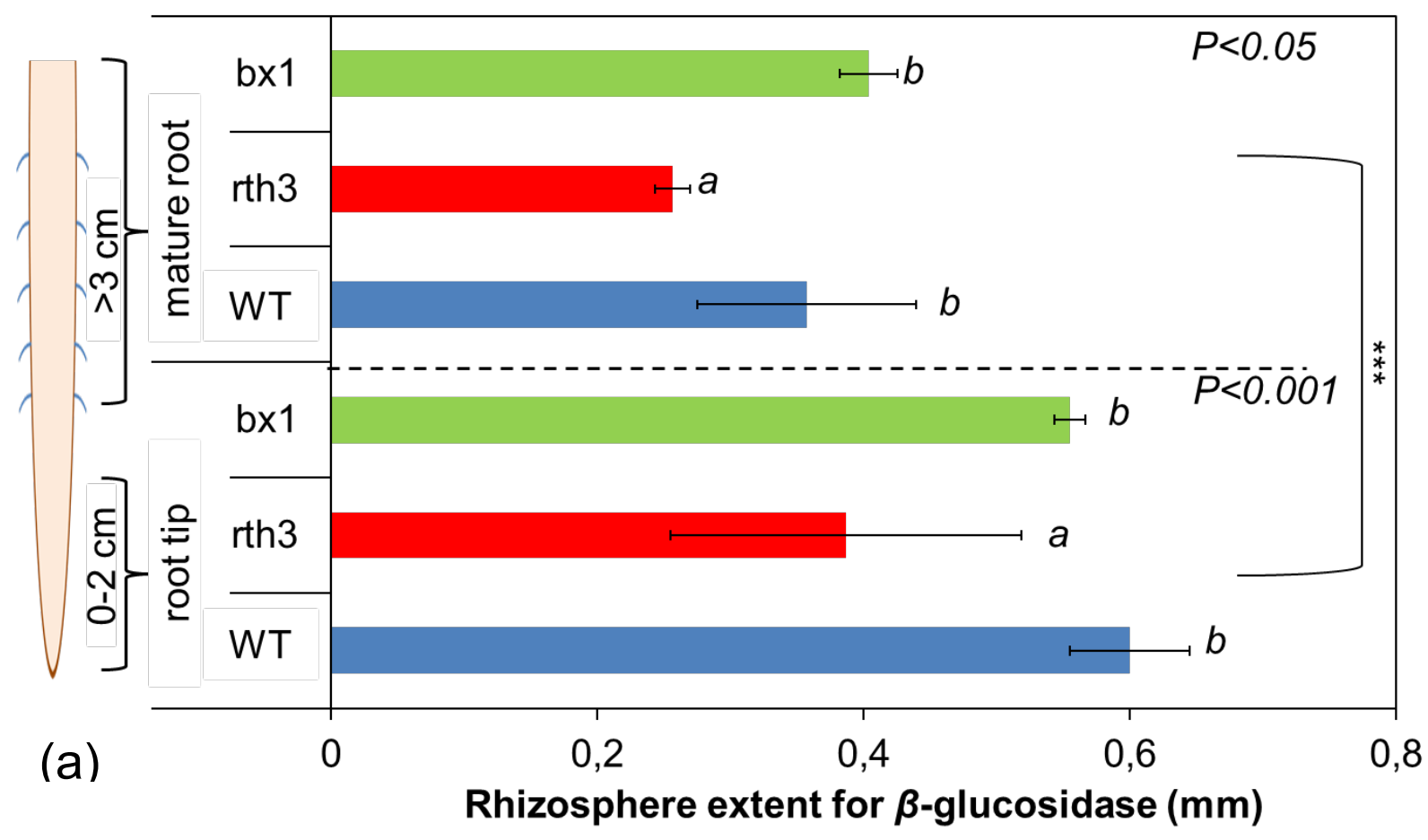




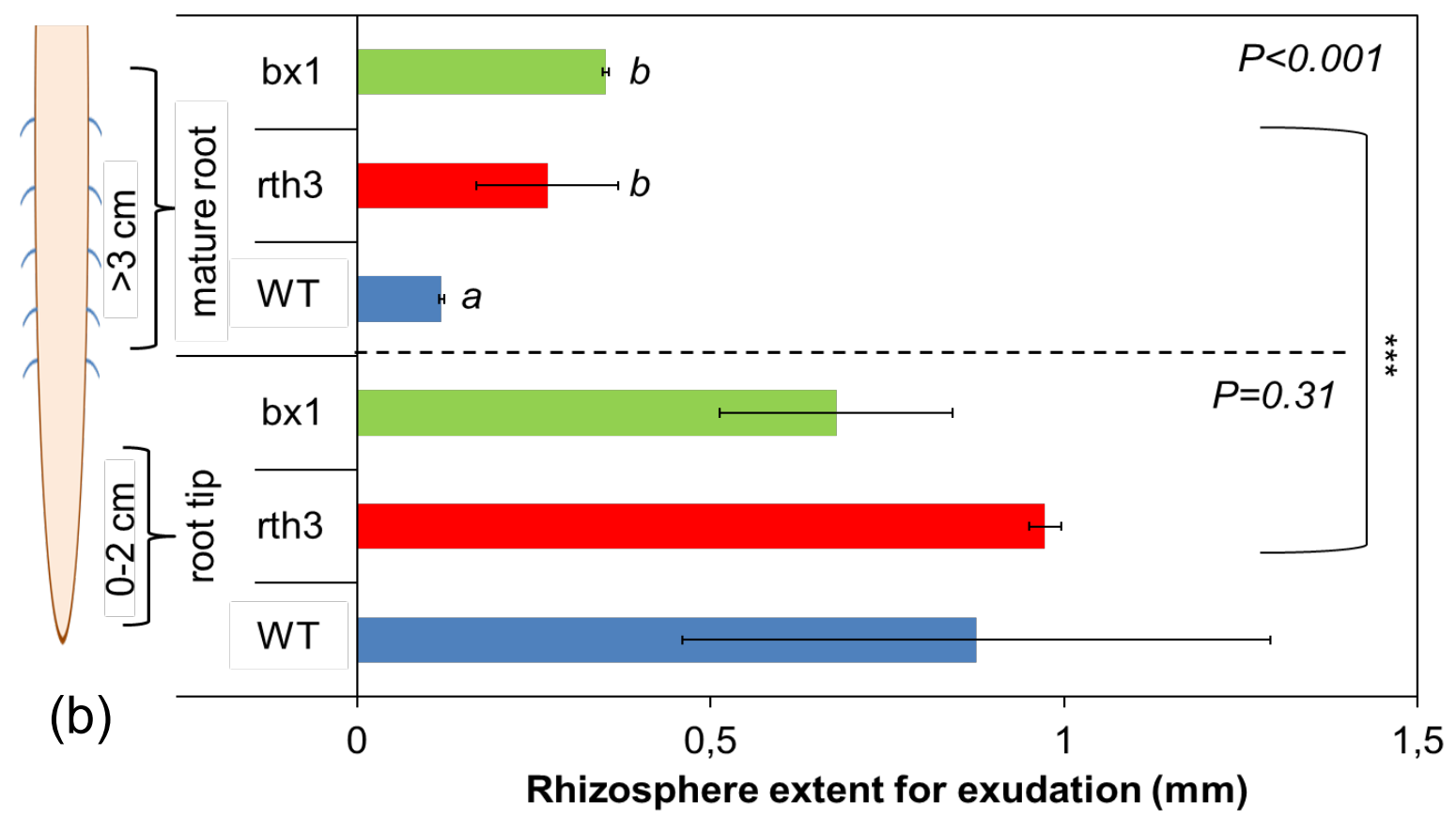

Figure 2. The rhizosphere extent for $\beta$-glucosidase activity (a) and ${ }^{14} \mathrm{C}$-labeled root exudates (b). Data are means for each genotype (WT, rth3 and $b x 1)(\mathrm{n}=4)$, error bars indicate standard deviations. Letters within one root type mark significant differences among the genotypes at $P<0.05$. Asterisks on the bracket at the right side indicate significant differences between root sections ('***' $P<0.001$; ‘**' $P<0.01$; ' '*' $P<0.05$ ).

\subsubsection{Mean $\beta$-glucosidase activity}

Mean $\beta$-glucosidase activity in the bulk soil was $\sim 20 \%(P<0.001)$ higher for $r$ th 3 than $b x l$ and WT (Fig. 3). The mean values along mature roots (Fig. 3) increased to 554 pmol cm${ }^{2} \mathrm{~h}^{-1}(P<0.01)$ in $b x 1$ compared to $436 \mathrm{pmol} \mathrm{cm}^{-2} \mathrm{~h}^{-1}$ in WT, whereas they were within the same range (550-571 pmol cm $\mathrm{ch}^{-1}, P=0.34$ ) for all genotypes at the root tip region (Fig. 3). 


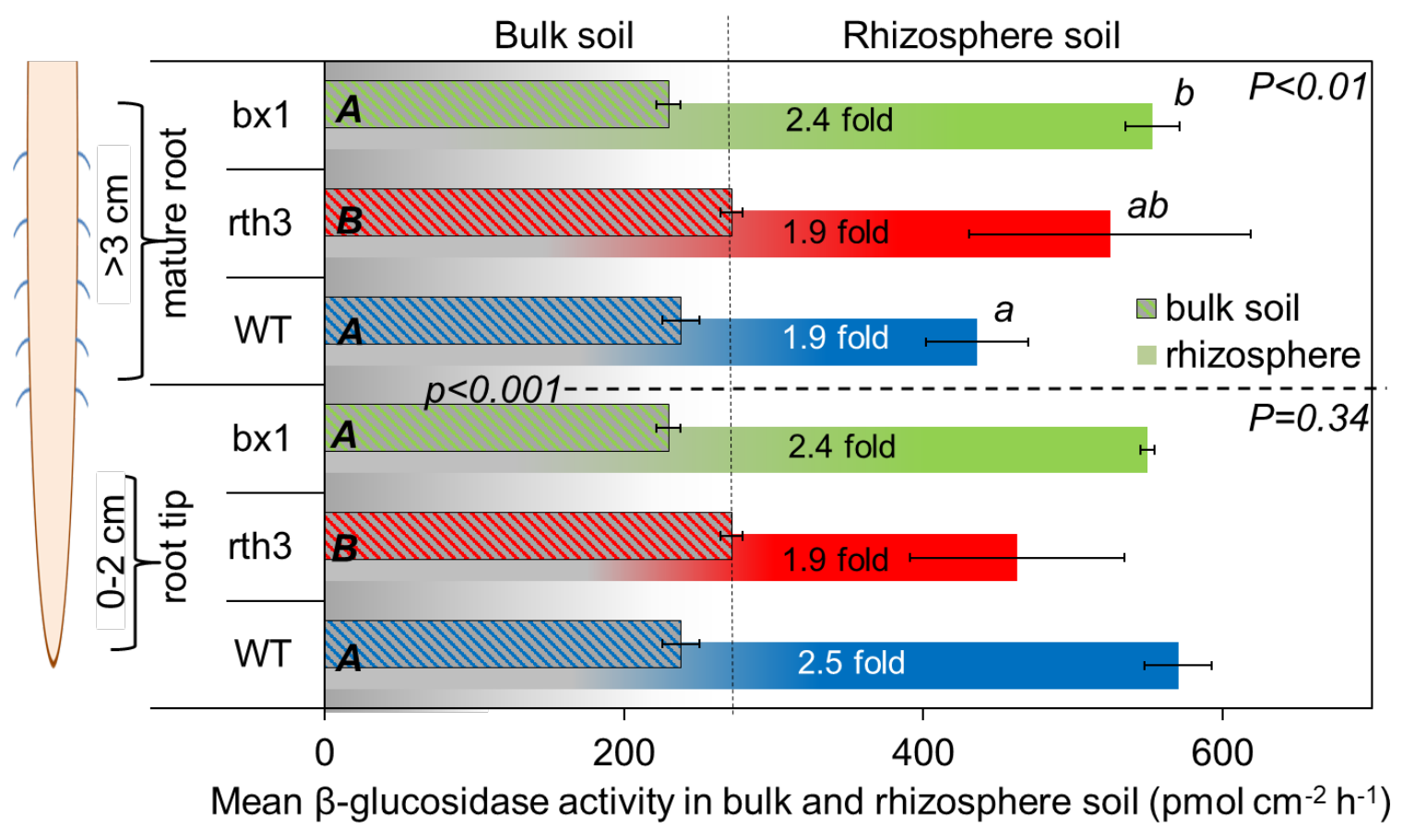

Figure 3. Mean of $\beta$-glucosidase activity in bulk soil (shaded) and in the rhizosphere along the mature root and root tips. Data are means for each genotype (WT, rth3 and $b x l)(\mathrm{n}=4)$, error bars indicate standard deviations. Letters within one root section mark significant differences among the genotypes at $P<0.05$. Capital letters refer to bulk soil, while lower case letters refer to rhizosphere soil. Relative increase (fold, times) in $\beta$-glucosidase activity along mature root and at root tip compared to bulk soil is marked over arrow at each column. The vertical thin dashed line separates the bars for bulk and rhizosphere activities.

\subsubsection{Hotspots areas}

The percentage of hotspot areas for $\beta$-glucosidase activity did not differ $(P=0.24)$ among the genotypes (Fig. 4a). Mutant $b x 1$ had the highest percentage (27\% of the total rhizobox area) of the hotspot area for exudation (Fig. 4b), which was 3.5 -fold greater $(P<0.05)$ than for WT or $r$ th3. 


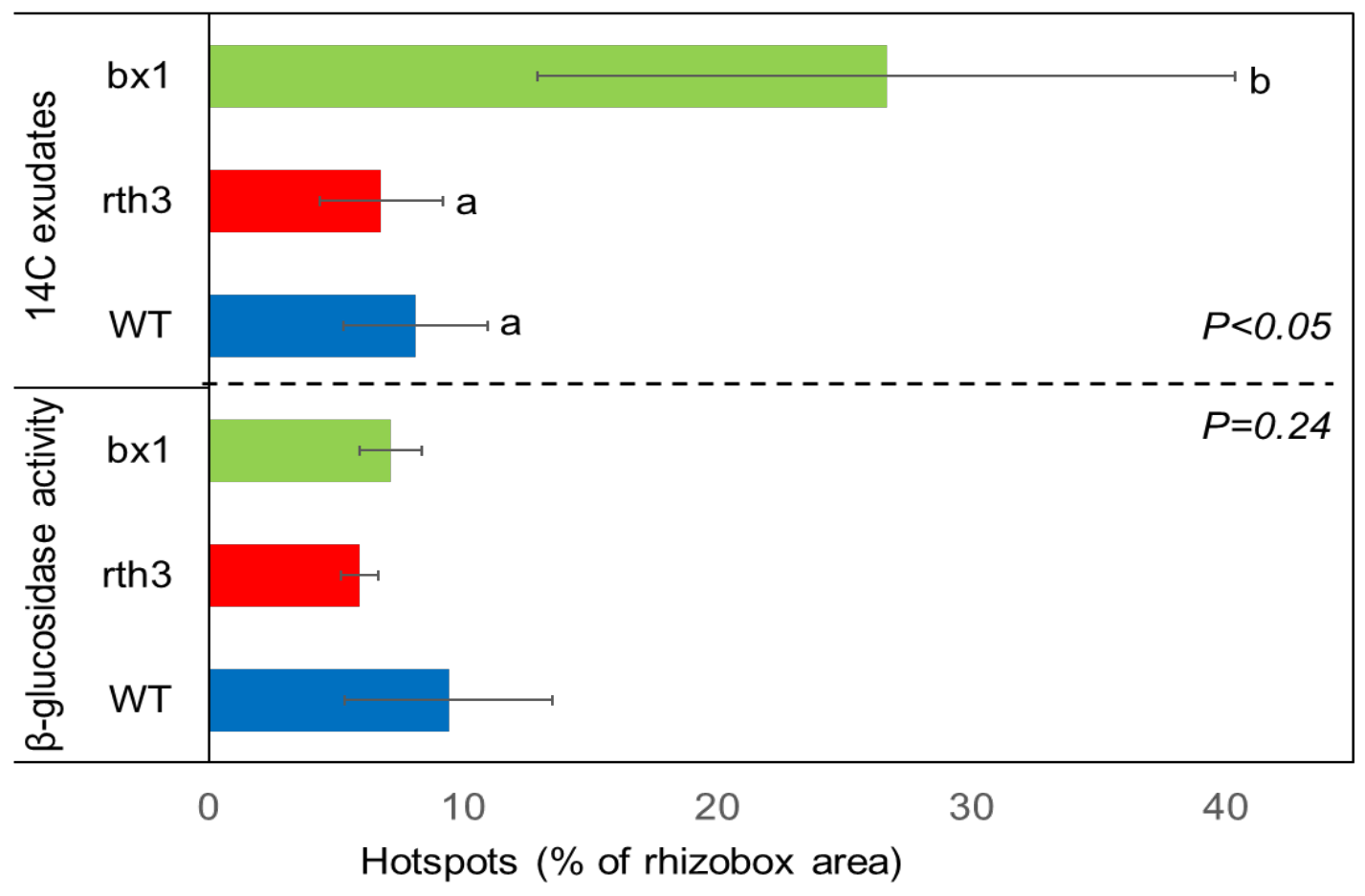

Figure 4. Hotspots for $\beta$-glucosidase activity and ${ }^{14} \mathrm{C}$ exudation. Data are means for each genotype (WT, rth3 and $b x 1)(\mathrm{n}=4)$, error bars indicate standard deviations. Letters within one hotspot type marks significant differences among the genotypes at $P<0.05$.

\subsubsection{Co-localization}

The co-localization analysis of the whole image revealed a moderate Pearson coefficient (PC) (in the order $r t h 3(0.14)<\mathrm{WT}(0.18)<b x 1(0.24)$ ) for the dependence of $\beta$-glucosidase activity on the newly released ${ }^{14} \mathrm{C}$ exudates (Table S2). ${ }^{14} \mathrm{C}$ root exudates strongly induced $\beta$-glucosidase activity in $r$ th $3(\mathrm{r}=0.85$, Table $\mathrm{S} 2)$, but much less pronounced in WT and $b x 1$ $(\mathrm{r}=0.26-0.31)$. The area of enhanced $\beta$-glucosidase activity, which co-occurred with ${ }^{14} \mathrm{C}$ exudates (represented here by Mander's coefficient (M1)), increased $(P<0.001)$ from 0.26 in WT and 0.39 in $b x 1$ to 0.99 in $r t h 3$ (Table S2). $\beta$-glucosidase activity co-localized strongly $(\mathrm{r}=0.89-0.96$, Table S2) with soil water content for all three genotypes. In contrast, PC for the water*enzyme interaction was dependent on genotype $(P<0.01)$, from very weak in $r t h 3$ $(-0.02)$ to moderate in both WT (0.19) and bxl (0.23) (Table S2).

Restricting the co-localization analysis to the rhizosphere hotspot area defined by highest $\beta$-glucosidase activity resulted in similar overlap coefficients within genotypes for ${ }^{14} \mathrm{C}$ exudate hotspots (0.37-0.50) and rhizosphere water hotspots (0.39-0.43) (Fig. 5). The area of the $\beta$-glucosidase activity hotspot co-occurring with ${ }^{14} \mathrm{C}$ exudates in hotspots (M2) was about two times larger in mutant $b x 1$ than WT (Fig. 5). The area of $\beta$-glucosidase activity co- 
occurring with the rhizosphere water hotspot (or wet rhizosphere) (M1) was similar for all genotypes (0.30-0.39).

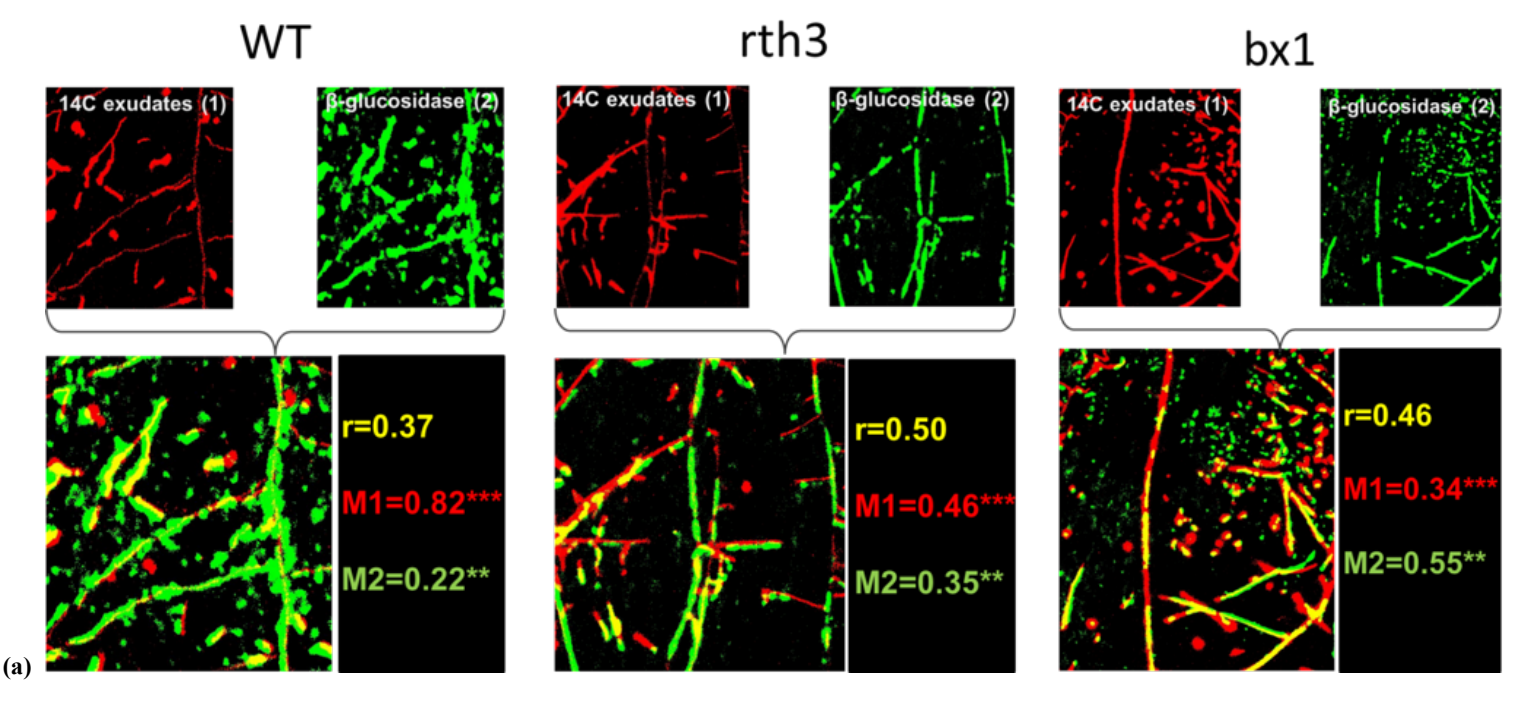




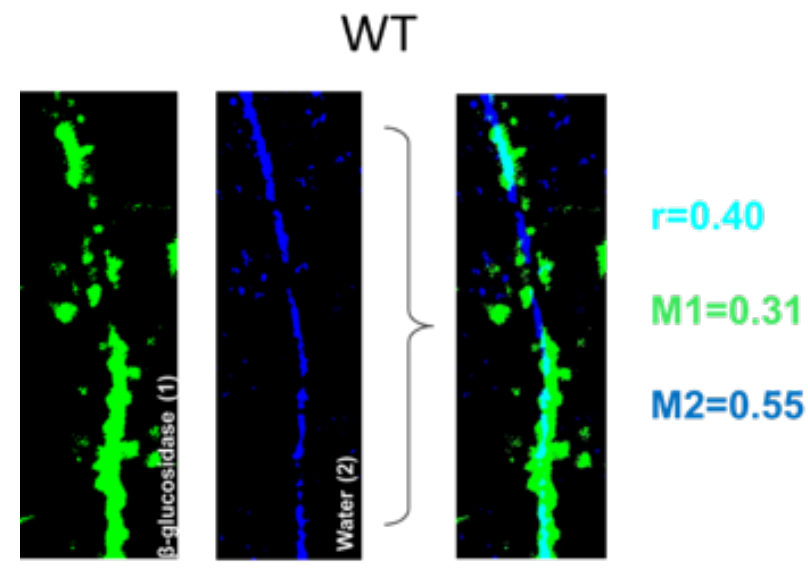

rth3
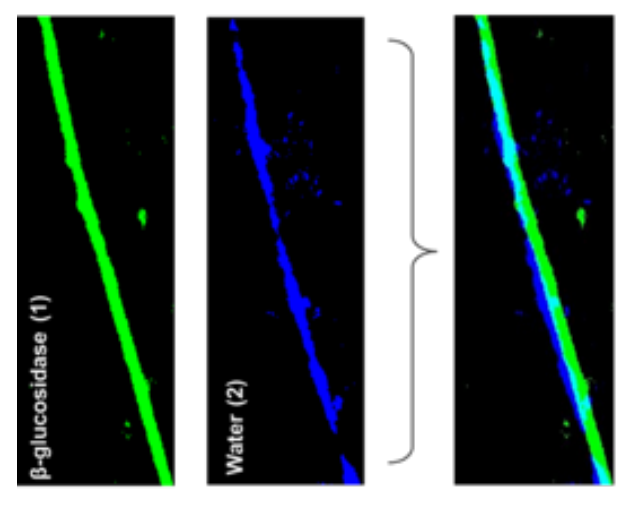

$r=0.43$

$\mathrm{M} 1=0.39$

M2 $=0.53$

bx1
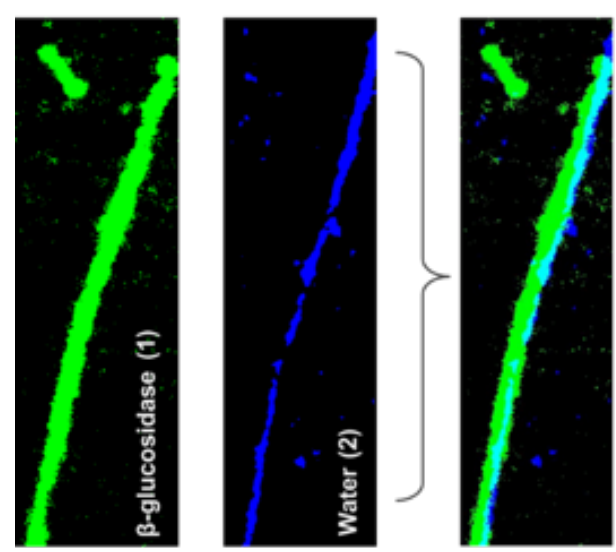

$r=0.39$

M1 $=0.30$

M2 $=0.55$

(b) 
Figure 5. Region of interest (ROIs) images of hotspots for exudates and $\beta$-glucosidase activity, and their overlap image for three maize genotypes (WT, rth $3, b x l$ ). The results of co-localization analysis are given as means of four replicates and presented by overlap coefficient (r) and two Manders coefficients (M1 and M2, see detailed explanation in Fig. $\mathrm{S} 3$ ). Asterisks on the values indicate significant difference between genotypes ( ${ }^{*}, P<0.05$; ‘**’ $\mathrm{P}<0.01$; “***’ $P<0.001)$.

\subsection{Discussion}

\subsubsection{Role of root exudation and water distribution on $\beta$-glucosidase activity}

The WT released exudates primarily from root tips (Fig. 1, Fig. S4), as already previously identified by ${ }^{14} \mathrm{C}$ labeling (Rovira, 1973; McCully \& Canny, 1985). In contrast, the rth 3 and $b x 1$ mutants released ${ }^{14} \mathrm{C}$ exudates along the whole roots (Fig. 1d-f), i.e. not restricted to root tips. The change in spatial distribution of exudates in rth 3 and $b x 1$ is presumably a plant strategy to maintain high microbial activity and thus enzyme activity (including $\beta$-glucosidase) by releasing easily available $\mathrm{C}$ into the entire rhizosphere (McDougall \& Rovira, 1970; Voothuluru et al., 2018; Cotton et al., 2019). The rth3 mutant could compensate for its up to $70 \%$ smaller root surface area (Tachibana \& Ohta, 1983; Raghothama \& Karthikeyan, 2005; Segal et al., 2008) by increasing the total amount of exudates distributed longitudinally along the roots (Lagos et al., 2015). Similarly, the deficit of benzoxazinoids in $b x \mathrm{l}$ induces not only an altered exudate composition (Hu et al., 2018), with a higher labile $\mathrm{C}$ content, but also distributed the exudates along longer segments of its root system (Fig. 1).

Water is crucial not only for microbial functions, but especially for substance diffusion. Microorganisms in bulk soil, being at least $12-14 \mathrm{~mm}$ away from ${ }^{14} \mathrm{C}$ exudation hotspots, rely mainly on SOM as a C source (Vedere et al., 2020). SOM is sparsely and patchily distributed a few mm away from roots, and the long diffusion pathways between nondiffusible enzymes and substrate require closed water films. (Hobley et al., 2018; Benard et al., 2019a; Vedere et al., 2020). Low water content reduces the continuity of such substrate diffusion paths and increases the probability of enzyme sorption and inactivation (Kandeler, 1990; Allison, 2006; Guber et al., 2019; Vedere et al., 2020). Accordingly, the dependence of enzyme activity on soil moisture is supported by the high correlation $(r=0.89-0.96)$ between $\beta$-glucosidase activity and water content (Table S2).

Because enzyme diffusion in soil in nearly absent (Kandeler, 1990; Guber et al., 2019; Vedere et al., 2020), the high co-localization of $\beta$-glucosidase activities (zymography) with 
exudate distribution $\left({ }^{14} \mathrm{C}\right)$ outside the root surface clearly shows that rhizosphere microorganisms use root exudates to produce enzymes. Thus, much $(65-78 \%)$ of the $\beta$ glucosidase activity in the rhizosphere is produced by microorganisms, not by roots (only $22-35 \%)$.

Enzyme activity in the rhizosphere is controlled by environmental conditions favorable for microorganisms. Such conditions are present in a biofilm-like environment, which stabilizes abiotic conditions and provides a buffer of $\mathrm{C}$ availability (Flemming et al., 2016). Consequently, root exudates (visible by ${ }^{14} \mathrm{C}$ imaging) with high $\mathrm{C}$ availability, which are close to the root surface $(0-2 \mathrm{~mm})$, create ideal conditions for maximum microbial activity (Paterson et al., 2008).

${ }^{14} \mathrm{C}$ shows the spatial distribution of exudates, and mucilage distribution determines the rhizosphere water content (Carminati et al., 2010). Mucilage in the rhizosphere increases microbial activity by providing favorable conditions for $\mathrm{C}$ diffusion and enzyme production (Ahmed et al., 2018; Holz et al., 2019a). The higher $\beta$-glucosidase activities and enhanced rhizosphere extension of the WT are attributable to mucilage production at the root tips rather than along older root sections (Guinel and McCully, 1986; Horst et al., 1982, this study Figs. 2 and 3). Generally, the distinct rhizosphere extent for enzyme activity and exudation, along with the increased $\beta$-glucosidase activities at root tips compared to mature roots, support a bimodal distribution of rhizosphere properties (Carminati \& Vetterlein, 2013). This concept reflects different age-based properties at the root tip and mature root zone (root tips lack fully developed functional tissues). This determines their respective functions and hence their ability to acquire water and nutrients. Our findings clearly support the bimodal nature of the rhizosphere in WT, but this was less pronounced in $b x 1$ and $r t h 3$ (Figs. 2, 3).

Overall, unlike in a bulk soil, enzyme activity (here $\beta$-glucosidase) in the rhizosphere was equally co-localized with optimal water content $(\mathrm{r}=0.39-0.43)$ and ${ }^{14} \mathrm{C}$ exudates $(\mathrm{r}=0.37$ 0.50) (Fig. 5). This supports our hypothesis (H1) on the important role of soil water and C availability in enzyme activity gradients.

\subsubsection{Role of root hairs for spatial distribution of exudates and $\beta$-glucosidase activity}

Root hairs are usually abundant only 1-5 cm above the root tip (Jungk, 2001), but the rhizodeposits formed when such hairs break and lyse promote microbial activity in the rhizosphere of the root region above 5-6 $\mathrm{cm}$ from the root tip, as the root continues growing. These root hair rhizodeposits, along with the released exudates, increase the active portion of microbial biomass in the rhizosphere (Zhang et al., 2020) and therefore stimulate $\beta$ - 
glucosidase production (Wang \& Lu, 2006). Generally, the presence of root hairs enlarged the enzymatic rhizosphere by up to 50\% (Ma et al. 2018b), which our study also confirmed for $\beta$-glucosidase activity ( $+35 \%$ of rhizosphere extent) (Fig. 2). The rhizosphere radius $(\sim 0.36 \mathrm{~mm})$ of maize with root hairs is equivalent to the average length of root hairs alone ( 0.4 mm) (Ma et al., 2018b). The root hair regions (Gilroy \& Jones, 2000; Haling et al., 2013) could belong to nutrient-depletion zones (Kreuzeder et al., 2018; Hummel et al., 2021). When experiencing nutrient limitation, active microorganisms induce higher enzyme activity generally and $\beta$-glucosidase activity in particular. This expands the rhizosphere radius of maize at least within the length of root hairs. Thus, the expanded rhizosphere enzymatic zone along the root axis in WT maize (Fig. 1g-1) proves that gradients of $\beta$-glucosidase activity strongly depend on root hair presence $(\mathrm{H} 2)$.

In contrast, the absence of root hairs ( $r$ th 3 ) induces an increased exudation of primary metabolites and $\beta$-glucosidase (Gramss et al., 1999) from the mature root zone in $r$ th3. This might reflect the higher membrane permeability in the absence of root hairs. The substrate limitation for microorganisms can stimulate exudation by roots (Williams and Vries, 2020) and increase the spatial extent of the ${ }^{14} \mathrm{C}$ exudation patterns along the mature root section (Fig. 2). Nonetheless, we cannot exclude methodological issues of ${ }^{14} \mathrm{C}$ imaging (i.e. detection limits) due to root hair presence: such hairs may result in a more fuzzy distributions of ${ }^{14} \mathrm{C}$ images (Holz et al., 2019b). Assuming the same amount of released root exudates from WT and $r t h 3$, then the much smaller root surface area in $r$ th 3 due to the deficient root hairs (Tachibana \& Ohta, 1983; Segal et al., 2008) will probably yield a larger and/or faster exudation rate per root area. Some exudates are decomposed by microorganisms within $24 \mathrm{~h}$ of ${ }^{14} \mathrm{C}$ imaging (Holz et al., 2019b), and this portion is expected to be larger along the root hairs colonized by bacteria (Mercado-blanco \& Prieto, 2012). Higher decomposition in WT was confirmed by the almost two-fold larger overlap coefficient for ${ }^{14} \mathrm{C}$ exudates $(82 \%$ vs. $46 \%$ in the $b x 1$ and $r t h 3$ mutants) and by the formed $\beta$-glucosidase hotspot due to the presence of root hairs (Fig. 5). Nonetheless, we cannot reject the effect of patchiness along the root axis (active and inactive segments/patterns) in the rhizosphere, which may contribute to the co-localization results.

\subsubsection{Role of benzoxazinoids for spatial distribution of exudates and $\beta$-glucosidase activity}

The $b x 1$ maize plant did not need to invest high energy into synthesizing benzoxazinoids and therefore probably produced more primary metabolites (Pott et al., 2019). Consequently, microbes very close to the root are less inhibited by defensive secondary metabolites $(10-40 \%$ 
lower amount) but instead have $20-30 \%$ more primary (soluble protein, amino acids, sugars) metabolites (Hu et al., 2018). (Fig. 2). The larger ${ }^{14} \mathrm{C}$ accumulation area in the soil in $b x 1$ is because the ${ }^{14} \mathrm{C}$ is localized along the whole root, not only at the root tip as in WT. Due to the $25 \%$ stronger concentration gradients of sugars (Hu et al., 2018), ${ }^{14} \mathrm{C}$ exudates from $b x 1$ diffused faster than from WT. Favorable $(\sim 15-20 \%)$ soil water contents facilitate the diffusion of primary and secondary metabolites from the rhizosphere into the bulk soil, especially if this diffusion is induced by the presence of mucilage, ensuring continuous water films (Benard et al., 2018, 2019b). Nevertheless, due to their short ( $<24$ h) half-life in the soil (Macías et al., 2005) benzoxazinoids can diffuse no more than $1 \mathrm{~cm}$ from the root surface (Rice et al., 2012). This means they will not directly affect microbial activity in the bulk soil of WT. In contrast, primary exudation metabolites diffuse over larger distances from the whole root surface, but not from root tips as in WT. (Fig. 2). More available C further from the root surface presumably enlarges the rhizosphere extent for $\beta$-glucosidase activity in $b x l$, but this was not demonstrated in our results. Instead, excluding benzoxazinoids from exudates resulted in a sharp gradient of $\beta$-glucosidase activity (2.4-fold) between the rhizosphere and bulk soil (Fig. 3). Moreover, the two-times larger area of non-rhizosphere $\beta$ glucosidase hotspots away from the root surface in $b x 1$ supports the indirect influence of the inhibitory effect of benzoxazinoids ( $\mathrm{Hu}$ et al., 2018) or other secondary metabolites (Banerjee et al., 2018). Some $\beta$-glucosidase hotspots may belong to the rhizosphere of roots covered by soil particles and not visible on Fig. 1a-c, but detected by neutron images (Fig. 1j1). Even if the influence on bulk soil remains speculative, the lower benzoxazinoid content increases microbial functionality in the rhizosphere (Das \& Varma, 2010; Igalavithana et al., 2017) and induces higher microbial activation. Thus, the $30 \%$ higher $\beta$-glucosidase activity in the rhizosphere along the root axis of $b x l$ (Fig. 3) reflects the absence of the fungicidal effect of benzoxazinoids (Kudjordjie et al., 2019). In contrast, the presence of benzoxazinoids in exudates of WT probably reduces the production rate of $\beta$-glucosidase by microorganisms (Turner et al., 2002). These findings support our hypothesis (H3) that microbial activity in the rhizosphere is inhibited by the presence of benzoxazinoids in root exudates.

\subsection{Conclusions}

Coupling three in situ imaging approaches $-{ }^{14} \mathrm{C}$ imaging for root exudate localization, soil zymography for analysis of enzyme activity distribution, and neutron radiography for tracing water fluxes - yielded insights into the spatial structure of biochemical gradients and functioning in the rhizosphere. This is the first study to provide evidence of maize genotypespecific exudation strategies, including their implications for microbial functions. Beyond 
the previously confirmed preferable exudation via the root tip regions in wild type maize, maize mutants with defective root hairs ( $r$ th 3$)$ and secondary metabolism (bxl) released considerable amounts of exudates including enzymes from the entire root. The colocalization analysis of zymograms, ${ }^{14} \mathrm{C}$ exudates, and neutron radiography images revealed an equal dependence of $\beta$-glucosidase activity on water and ${ }^{14} \mathrm{C}$ exudate availability in the rhizosphere. The greater role of water over ${ }^{14} \mathrm{C}$ exudate availability in the bulk soil underlines the pivotal role of water availability for the functioning of the soil microbiome and its hydrolytic activity.

We conclude that the shape and extent of the rhizosphere for $\beta$-glucosidase activity are genotype-specific and depend on the released rhizodeposits. This study shows that gene knock-out often substantially alters the process-network in the rhizosphere, including its spatial localization along and across the roots. Intensive exudation by root hairs and the resulting microbial activity increased the utilization of ${ }^{14} \mathrm{C}$ exudates up to two-fold. This, in turn, induced a broader rhizosphere extent for $\beta$-glucosidase activity.

Altered exudation of defensive compounds (i.e., reduced benzoxazinoids), along with a strong additional influence of abiotic factors such as water content, lead to a spatial reorganization of rhizomicrobial activities in mutants compared to maize wild type. The release of benzoxazinoids by roots suppressed the activities of rhizosphere microorganisms, which led to $30 \%$ lower $\beta$-glucosidase activity but did not change the rhizosphere extent. The absence of benzoxazinoids induced root exudation along the whole root, but not at the root tip as in the wild type. The result was 2.5 -fold larger ${ }^{14} \mathrm{C}$ exudate hotspot areas.

Overall, our findings confirm the contrasting exudation strategies of maize (Fig. 6) to ensure beneficial (i.e. producing $\beta$-glucosidase) microbial activity in the rhizosphere 1) to overcome energy and nutrient limitations due to the absence of root hairs, and 2) to compensate for the altered exudation composition and a shift from secondary to primary exudates in the profile. 


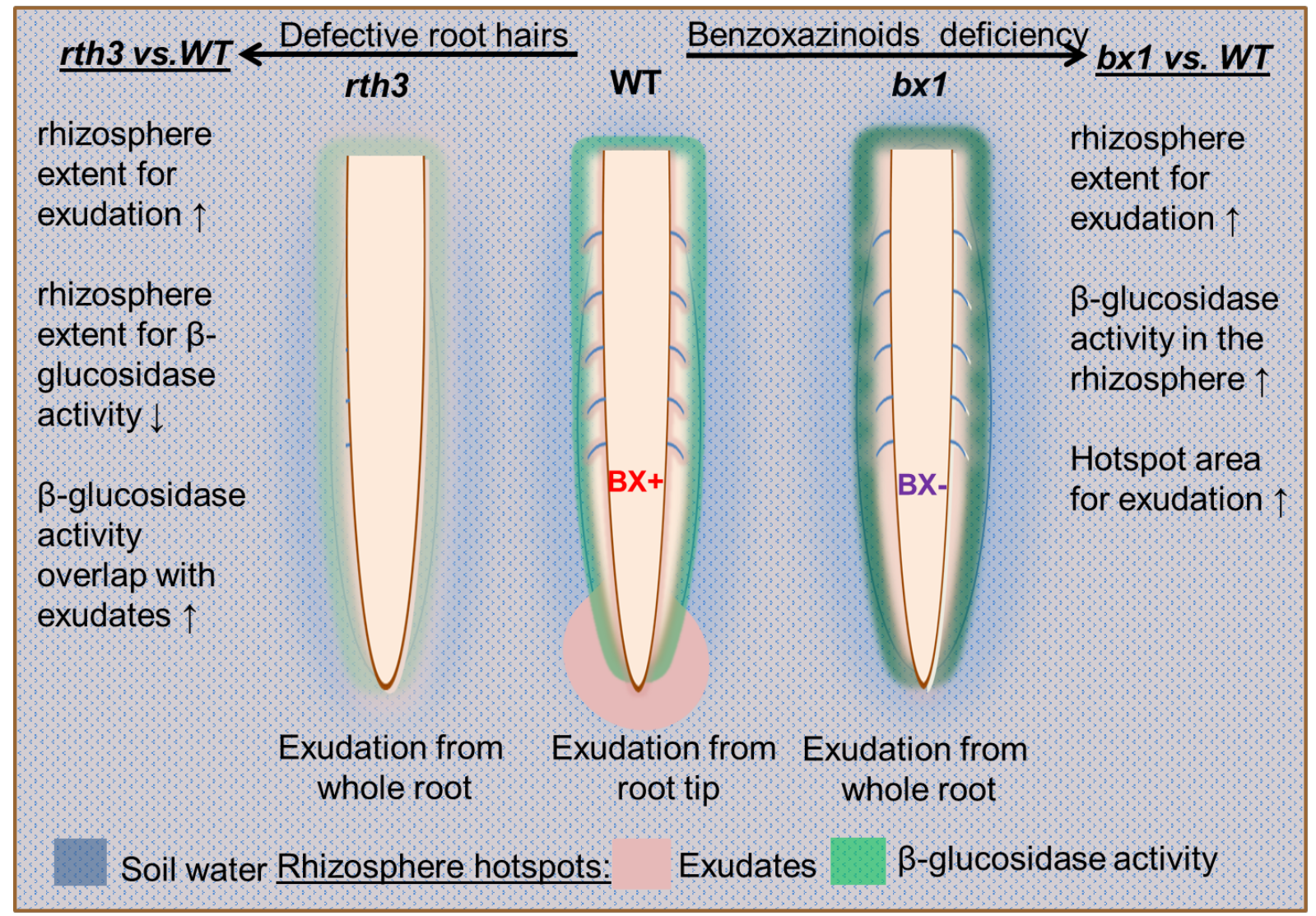

Figure 6. General pattern of the effects of maize mutations (root defective rth3 and BX deficient $b x 1$ as compared to wild type (WT) on the rhizosphere extent, hotspots, enzyme activity level and overlap of $\beta$-glucosidase with water and exudates. Significant increase and decrease indicated by $\uparrow$ and $\downarrow$ respectively.

\subsection{Acknowledgments}

We deeply grateful Doris Vetterlein for her valuable comments and helpful suggestions on the earlier draft of this manuscript. We gratefully acknowledge Jan Hovind from the ICON imaging station of the Paul Scherrer Institute (PSI), Villigen, Switzerland for their facilities and excellent technical support during the measurements with neutron radiography and providing us an imager (FLA-7000), and facilities for zymography installations. We acknowledge Caroline Marcon and Frank Hochholdinger (University of Bonn) for kindly providing seeds of maize mutant $r$ th3. This project was carried out in the framework of the priority programme 2089 "Rhizosphere spatiotemporal organization - a key to rhizosphere functions" funded by DFG (RA-3062/3-1 and SP 943/6-1). The work was funded by the Interfaculty Research Cooperation (IRC) “One Health” at University of Bern, Sub-Project 4. We gratefully acknowledge the China Scholarship Council (CSC) for the financial support 
of Xuechen Zhang and Lichao Fan, and the Robert Bosch Foundation for supporting Michaela Dippold and this study via the Robert Bosch Junior Professorship 2017.

\subsection{Author contributions}

BR developed research concept and designed the experiment. NB, XZ, LF and BR conducted laboratory experiments and perform the ${ }^{14} \mathrm{C}$ imaging and zymography analysis with inputs from SS and MD. CB and SS contributed to image analysis and co-localization. PD, AK, MA and AC conducted neutron imaging. NB performed all statistical analysis and data evaluation with inputs of YK. NB wrote the manuscript. All authors contributed to writing and revising the manuscript.

\subsection{Data Availability}

The data that support the findings of this study are available from the corresponding author upon reasonable request.

\subsection{References}

Abràmoff MD, Magalhães PJ, Ram SJ. 2004. Image processing with imageJ. Biophotonics International 11: 36-41.

Ahmad S, Veyrat N, Gordon-Weeks R, Zhang Y, Martin J, Smart L, Glauser G, Erb M, Flors V, Frey M, et al. 2011. Benzoxazinoid Metabolites Regulate Innate Immunity against Aphids and Fungi in Maize. Plant Physiology 157: 317-327.

Ahmed MA, Sanaullah M, Blagodatskaya E, Mason-Jones K, Jawad H, Kuzyakov Y, Dippold MA. 2018. Soil microorganisms exhibit enzymatic and priming response to root mucilage under drought. Soil Biology and Biochemistry 116: 410-418.

Ahmed MA, Vetterlein D, Carminati A. 2021. Advances in understanding plant root water uptake. In: 373-392.

Ahmed MA, Zarebanadkouki M, Kaestner A, Carminati A. 2016. Measurements of water uptake of maize roots: the key function of lateral roots. Plant and Soil 398: 59-77.

Allison SD. 2006. Soil minerals and humic acids alter enzyme stability: implications for ecosystem processes. Biogeochemistry 81: 361-373.

Banerjee S, Schlaeppi K, van der Heijden MGA. 2018. Keystone taxa as drivers of microbiome structure and functioning. Nature Reviews Microbiology 16: 567-576.

Benard P, Zarebanadkouki M, Brax M, Kaltenbach R, Jerjen I, Marone F, Couradeau E, Felde VJMNL, Kaestner A, Carminati A. 2019a. Microhydrological Niches in Soils: 
How Mucilage and EPS Alter the Biophysical Properties of the Rhizosphere and Other Biological Hotspots. Vadose Zone Journal 18: 1-10.

Benard P, Zarebanadkouki M, Carminati A. 2019b. Physics and hydraulics of the rhizosphere network. Journal of Plant Nutrition and Soil Science 182: 5-8.

Benard P, Zarebanadkouki M, Hedwig C, Holz M, Ahmed MA, Carminati A. 2018. Pore-Scale Distribution of Mucilage Affecting Water Repellency in the Rhizosphere. Vadose Zone Journal 17: 170013.

Berg G, Smalla K. 2009. Plant species and soil type cooperatively shape the structure and function of microbial communities in the rhizosphere. FEMS Microbiology Ecology 68: 113.

Bertin C, Yang X, Weston LA. 2003. The role of root exudates and allelochemicals in the rhizosphere. Plant and Soil 256: 67-83.

Bilyera N, Kuzyakova I, Guber A, Razavi BS, Kuzyakov Y. 2020. How "hot" are hotspots: Statistically localizing the high-activity areas on soil and rhizosphere images. Rhizosphere 16: 100259 .

Boeddinghaus RS, Nunan N, Berner D, Marhan S, Kandeler E. 2015. Do general spatial relationships for microbial biomass and soil enzyme activities exist in temperate grassland soils? Soil Biology and Biochemistry 88: 430-440.

Bolte S, Cordelières FP. 2006. A guided tour into subcellular colocalization analysis in light microscopy. Journal of Microscopy 224: 213-232.

Bucher M, Hause B, Krajinski F, Küster H. 2014. Through the doors of perception to function in arbuscular mycorrhizal symbioses. New Phytologist 204: 833-840.

Cadot S, Guan H, Bigalke M, Walser JC, Jander G, Erb M, van der Heijden M, Schlaeppi K. 2020. Specific and conserved patterns of microbiota-structuring by maize benzoxazinoids in the field. bioRxiv.

Cairns JRK, Esen A. 2010. $\beta$-Glucosidases. Cellular and Molecular Life Sciences 67: 3389-3405.

Canarini A, Kaiser C, Merchant A, Richter A, Wanek W. 2019. Root exudation of primary metabolites: Mechanisms and their roles in plant responses to environmental stimuli. Frontiers in Plant Science $\mathbf{1 0 .}$

Cardona A, Saalfeld S, Schindelin J, Arganda-Carreras I, Preibisch S, Longair M, 
Tomancak P, Hartenstein V, Douglas RJ. 2012. TrakEM2 software for neural circuit reconstruction. PLOS ONE 7.

Carminati A, Moradi AB, Vetterlein D, Vontobel P, Lehmann E, Weller U, Vogel HJ, Oswald SE. 2010. Dynamics of soil water content in the rhizosphere. Plant and Soil 332: $163-176$.

Carminati A, Vetterlein D. 2013. Plasticity of rhizosphere hydraulic properties as a key for efficient utilization of scarce resources. Annals of Botany 112: 277-290.

Collins SL, Sinsabaugh RL, Crenshaw C, Green L, Porras-Alfaro A, Stursova M, Zeglin LH. 2008. Pulse dynamics and microbial processes in aridland ecosystems. Journal of Ecology 96: 413-420.

Cotton TEA, Pétriacq P, Cameron DD, Meselmani M Al, Schwarzenbacher R, Rolfe SA, Ton J. 2019. Metabolic regulation of the maize rhizobiome by benzoxazinoids. The ISME Journal 13: 1647-1658.

Das SK, Varma A. 2010. Soil enzymology. Soil Enzymology 22: 275-285.

Dick R, Rattei T, Haslbeck M, Schwab W, Gierl A, Frey M. 2012. Comparative analysis of benzoxazinoid biosynthesis in monocots and dicots: Independent recruitment of Stabilization and activation functions. Plant Cell 24: 915-928.

Downie HF, Adu MO, Schmidt S, Otten W, Dupuy LX, White PJ, Valentine TA. 2015. Challenges and opportunities for quantifying roots and rhizosphere interactions through imaging and image analysis. Plant, Cell and Environment 38: 1213-1232.

Erb M, Kliebenstein DJ. 2020. Plant Secondary Metabolites as Defenses, Regulators, and Primary Metabolites: The Blurred Functional Trichotomy. Plant Physiology 184: 39-52.

Farrar J, Hawes M, Jones D, Lindow S. 2003. How roots control the flux of carbon to the rhizosphere. Ecology 84: 827-837.

Flemming HC, Wingender J, Szewzyk U, Steinberg P, Rice SA, Kjelleberg S. 2016. Biofilms: An emergent form of bacterial life. Nature Reviews Microbiology 14: 563-575.

Frey M, Chomet P, Glawischnig E, Stettner C, Grün S, Winklmair A, Eisenreich W, Bacher A, Meeley RB, Briggs SP, et al. 1997. Analysis of a chemical plant defense mechanism in grasses. Science 277: 696-699.

Gianfreda L. 2015. Enzymes of importance to rhizosphere processes. Journal of soil science and plant nutrition: $0-0$. 
Gilroy S, Jones DL. 2000. Through form to function: root hair development and nutrient uptake. Trends in Plant Science 5: 56-60.

Gómez-Anduro G, Ceniceros-Ojeda EA, Casados-Vázquez LE, Bencivenni C, SierraBeltrán A, Murillo-Amador B, Tiessen A. 2011. Genome-wide analysis of the betaglucosidase gene family in maize (Zea mays L. var B73). Plant Molecular Biology 77: 159183.

Gramss G, Voigt K-D, Kirsche B. 1999. Oxidoreductase enzymes liberated by plant roots and their effects on soil humic material. Chemosphere 38: 1481-1494.

Guber AK, Kravchenko AN, Razavi BS, Blagodatskaya E, Kuzyakov Y. 2019. Calibration of 2-D soil zymography for correct analysis of enzyme distribution. European Journal of Soil Science 70: 715-726.

Haling RE, Brown LK, Bengough AG, Young IM, Hallett PD, White PJ, George TS. 2013. Root hairs improve root penetration, root-soil contact, and phosphorus acquisition in soils of different strength. Journal of Experimental Botany 64: 3711-3721.

Henry HAL. 2012. Soil extracellular enzyme dynamics in a changing climate. Soil Biology and Biochemistry 47: 53-59.

Hinsinger P, Bengough AG, Vetterlein D, Young IM. 2009. Rhizosphere: Biophysics, biogeochemistry and ecological relevance. Plant and Soil 321: 117-152.

Hinsinger P, Gobran GR, Gregory PJ, Wenzel WW. 2005. Rhizosphere geometry and heterogeneity arising from root-mediated physical and chemical processes. New Phytologist 168: $293-303$.

Hobley E, Steffens M, Bauke SL, Kögel-Knabner I. 2018. Hotspots of soil organic carbon storage revealed by laboratory hyperspectral imaging. Scientific Reports 8: 13900.

Hochholdinger F, Wen T-J, Zimmermann R, Chimot-Marolle P, da Costa e Silva O, Bruce W, Lamkey KR, Wienand U, Schnable PS. 2008. The maize (Zea mays L.) roothairless 3 gene encodes a putative GPI-anchored, monocot-specific, COBRA-like protein that significantly affects grain yield. The Plant Journal 54: 888-898.

Hochholdinger F, Yu P, Marcon C. 2018. Genetic Control of Root System Development in Maize. Trends in Plant Science 23: 79-88.

Holz M, Zarebanadkouki M, Carminati A, Hovind J, Kaestner A, Spohn M. 2019a. Increased water retention in the rhizosphere allows for high phosphatase activity in drying 
soil. Plant and Soil 443: 259-271.

Holz M, Zarebanadkouki M, Carminati A, Kuzyakov Y. 2019b. Visualization and quantification of root exudation using 14C imaging: challenges and uncertainties. Plant and Soil 437: 473-485.

Holz M, Zarebanadkouki M, Kuzyakov Y, Pausch J, Carminati A. 2018. Root hairs increase rhizosphere extension and carbon input to soil. Annals of Botany 121: 61-69.

Hu L, Robert CAM, Cadot S, Zhang X, Ye M, Li B, Manzo D, Chervet N, Steinger T, Van Der Heijden MGA, et al. 2018. Root exudate metabolites drive plant-soil feedbacks on growth and defense by shaping the rhizosphere microbiota. Nature Communications 9: 1-13.

Hummel C, Boitt G, Santner J, Lehto NJ, Condron L, Wenzel WW. 2021. Co-occurring increased phosphatase activity and labile $\mathrm{P}$ depletion in the rhizosphere of Lupinus angustifolius assessed with a novel, combined 2D-imaging approach. Soil Biology and Biochemistry 153.

Huo C, Luo Y, Cheng W. 2017. Rhizosphere priming effect: A meta-analysis. Soil Biology and Biochemistry 111: 78-84.

Igalavithana AD, Lee SS, Niazi NK, Lee YH, Kim KH, Park JH, Moon DH, Ok YS. 2017. Assessment of soil health in urban agriculture: Soil enzymes and microbial properties. Sustainability (Switzerland) 9.

Jones DL, Nguyen C, Finlay RD. 2009. Carbon flow in the rhizosphere: carbon trading at the soil-root interface. Plant and Soil 321: 5-33.

Jungk A. 2001. Root hairs and the acquisition of plant nutrients from soil. Journal of Plant Nutrition and Soil Science 164: 121-129.

Kaestner AP, Hartmann S, Kühne G, Frei G, Grünzweig C, Josic L, Schmid F, Lehmann EH. 2011. The ICON beamline A facility for cold neutron imaging at SINQ. Nuclear Instruments and Methods in Physics Research, Section A: Accelerators, Spectrometers, Detectors and Associated Equipment 659: 387-393.

Kaiser C, Kilburn MR, Clode PL, Fuchslueger L, Koranda M, Cliff JB, Solaiman ZM, Murphy D V. 2015. Exploring the transfer of recent plant photosynthates to soil microbes: Mycorrhizal pathway vs direct root exudation. New Phytologist 205: 1537-1551.

Kandeler E. 1990. Characterization of free and adsorbed phosphatases in soils. Biology and Fertility of Soils 9: 199-202. 
Kandeler E, Marschner P, Tscherko D, Singh Gahoonia T, Nielsen NE. 2002. Microbial community composition and functional diversity in the rhizosphere of maize. Plant and Soil 238: $301-312$.

Koranda M, Schnecker J, Kaiser C, Fuchslueger L, Kitzler B, Stange CF, Sessitsch A, Zechmeister-Boltenstern S, Richter A. 2011. Microbial processes and community composition in the rhizosphere of European beech - The influence of plant C exudates. Soil Biology and Biochemistry 43: 551-558.

Kreuzeder A, Santner J, Scharsching V, Oburger E, Hoefer C, Hann S, Wenzel WW. 2018. In situ observation of localized, sub-mm scale changes of phosphorus biogeochemistry in the rhizosphere. Plant and Soil 424: 573-589.

Kudjordjie EN, Sapkota R, Steffensen SK, Fomsgaard IS, Nicolaisen M. 2019. Maize synthesized benzoxazinoids affect the host associated microbiome. Microbiome 7: 1-17.

Kuzyakov Y, Shevtzova E, Pustovoytov K. 2006. Carbonate re-crystallization in soil revealed by $14 \mathrm{C}$ labeling: Experiment, model and significance for paleo-environmental reconstructions. Geoderma 131: 45-58.

Lagos ML, Maruyama F, Nannipieri P, Mora ML, Ogram A, Jorquera MA. 2015. Current overview on the study of bacteria in the rhizosphere by modern molecular techniques: A mini-review. Journal of Soil Science and Plant Nutrition 15: 504-523.

Liu Y, Shahbaz M, Ge T, Zhu Z, Liu S, Chen L, Wu X, Deng Y, Lu S, Wu J. 2020. European Journal of Soil Biology Effects of root exudate stoichiometry on CO 2 emission from paddy soil. European Journal of Soil Biology 101: 103247.

Ma X, Liu Y, Zarebanadkouki M, Razavi BS, Blagodatskaya E, Kuzyakov Y. 2018a. Spatiotemporal patterns of enzyme activities in the rhizosphere: effects of plant growth and root morphology. Biology and Fertility of Soils 54: 819-828.

Ma X, Zarebanadkouki M, Kuzyakov Y, Blagodatskaya E, Pausch J, Razavi BS. $2018 b$. Spatial patterns of enzyme activities in the rhizosphere: Effects of root hairs and root radius. Soil Biology and Biochemistry 118: 69-78.

Maag D, Köhler A, Robert CAM, Frey M, Wolfender JL, Turlings TCJ, Glauser G, Erb M. 2016. Highly localized and persistent induction of Bx1-dependent herbivore resistance factors in maize. Plant Journal 88: 976-991.

Macías FA, Oliveros-Bastidas A, Marín D, Castellano D, Simonet AM, Molinillo JMG. 
2005. Degradation studies on benzoxazinoids. Soil degradation dynamics of (2R)-2-O- $\beta-D-$ glucopyranosyl-4-hydroxy-(2H)-1,4-benzoxazin-3(4H)-one (DIBOA-Glc) and its degradation products, phytotoxic allelochemicals from gramineae. Journal of Agricultural and Food Chemistry 53: 554-561.

Manders EMM, Verbeek, F. J., Aten JA. 1993. Measurement of co-localization of objects in dual-colour confocal images. Journal of Microscopy 169: 375-382.

Masciandaro G, Ceccanti B, Benedicto S, Lee HC, Cook HF. 2004. Enzyme activity and $\mathrm{C}$ and $\mathrm{N}$ pools in soil following application of mulches. Canadian Journal of Soil Science 84: 19-30.

McCully ME, Canny MJ. 1985. Localisation of translocated 14C in roots and root exudates of field-grown maize. Physiologia Plantarum 65: 380-392.

McDougall BM, Rovira AD. 1970. Sites of exudation of 14C-labelled compounds from wheat roots. New Phytologist 69: 999-1003.

Mercado-blanco J, Prieto P. 2012. Bacterial endophytes and root hairs. Plant and Soil: 301-306.

Moradi AB, Conesa HM, Robinson B, Lehmann E, Kuehne G, Kaestner A, Oswald S, Schulin R. 2009. Neutron radiography as a tool for revealing root development in soil: capabilities and limitations. Plant and Soil 318: 243-255.

Neal AL, Ahmad S, Gordon-Weeks R, Ton J. 2012. Benzoxazinoids in root exudates of maize attract pseudomonas putida to the rhizosphere. PLOS ONE 7.

Okamoto K, Nakano H, Yatake T, Kiso T, Kitahata S. 2000. Purification and Some Properties of a $\beta$-Glucosidase from Flavobacterium johnsonae. Bioscience, Biotechnology, and Biochemistry 64: 333-340.

Paterson E, Osler G, Dawson LA, Gebbing T, Sim A, Ord B. 2008. Labile and recalcitrant plant fractions are utilised by distinct microbial communities in soil : Independent of the presence of roots and mycorrhizal fungi. Soil Biology and Biochemistry 40: 1103-1113.

Peterson RL, Farquhar ML. 1996. Root hairs: Specialized tubular cells extending root surfaces. The Botanical Review 62: 1-40.

Pett-Ridge J, Shi S, Estera-Molina K, Nuccio E, Yuan M, Rijkers R, Swenson T, Zhalnina K, Northen T, Zhou J, et al. 2021. Rhizosphere Carbon Turnover from Cradle to Grave: The Role of Microbe-Plant Interactions. In: 51-73. 
Philippot L, Raaijmakers JM, Lemanceau P, van der Putten WH. 2013. Going back to the roots: the microbial ecology of the rhizosphere. Nature Reviews Microbiology 11: 789799.

Pott DM, Osorio S, Vallarino JG. 2019. From Central to Specialized Metabolism: An Overview of Some Secondary Compounds Derived From the Primary Metabolism for Their Role in Conferring Nutritional and Organoleptic Characteristics to Fruit. Frontiers in Plant Science 10.

R Development Core Team R. 2011. R: A Language and Environment for Statistical Computing (RDC Team, Ed.). R Foundation for Statistical Computing 1: 409.

Raghothama KG, Karthikeyan AS. 2005. Phosphate Acquisition. Plant and Soil 274: 3749.

Razavi BS, Zarebanadkouki M, Blagodatskaya E, Kuzyakov Y. 2016. Rhizosphere shape of lentil and maize: Spatial distribution of enzyme activities. Soil Biology and Biochemistry 79: 229-237.

Razavi BS, Zhang X, Bilyera N, Guber A, Zarebanadkouki M. 2019. Soil zymography: Simple and reliable? Review of current knowledge and optimization of the method. Rhizosphere 11.

Rice CP, Cai G, Teasdale JR. 2012. Concentrations and allelopathic effects of benzoxazinoid compounds in soil treated with rye (secale cereale) cover crop. Journal of Agricultural and Food Chemistry 60: 4471-4479.

Rovira AD. 1973. Zones of exudation along plant roots and spatial distribution of microorganisms in the rhizosphere. Pesticide Science 4: 361-366.

Saalfeld S, Fetter R, Cardona A, Tomancak P. 2012. Elastic volume reconstruction from series of ultra-thin microscopy sections. Nature Methods 9: 717-720.

Sanaullah M, Razavi BS, Blagodatskaya E, Kuzyakov Y. 2016. Spatial distribution and catalytic mechanisms of $\beta$-glucosidase activity at the root-soil interface. Biology and Fertility of Soils 52: 505-514.

Sardans J, Peñuelas J. 2005. Drought decreases soil enzyme activity in a Mediterranean Quercus ilex L. forest. Soil Biology and Biochemistry 37: 455-461.

Schütz V, Bigler L, Girel S, Laschke L, Sicker D, Schulz M. 2019. Conversions of Benzoxazinoids and Downstream Metabolites by Soil Microorganisms. Frontiers in Ecology 
and Evolution 7.

Segal E, Kushnir T, Mualem Y, Shani U. 2008. Water Uptake and Hydraulics of the Root Hair Rhizosphere. Vadose Zone Journal 7: 1027-1034.

Silberbush M, Barber SA. 1983. Sensitivity of simulated phosphorus uptake to parameters used by a mechanistic-mathematical model. Plant and Soil 74: 93-100.

Sinsabaugh RL, Antibus RK, Linkins AE, McClaugherty CA, Rayburn L, Repert D, Weiland T. 1992. Wood decomposition over a first-order watershed: Mass loss as a function of lignocellulase activity. Soil Biology and Biochemistry 24: 743-749.

Smith SE, Dickson S, Smith FA. 2001. Nutrient transfer in arbuscular mycorrhizas: how are fungal and plant processes integrated? Functional Plant Biology 28: 685.

Sørensen A, Lübeck M, Lübeck PS, Ahring BK. 2013. Fungal beta-glucosidases: A bottleneck in industrial use of lignocellulosic materials. Biomolecules 3: 612-631.

Spohn M, Carminati A, Kuzyakov Y. 2013. Soil zymography - A novel in situ method for mapping distribution of enzyme activity in soil. Soil Biology and Biochemistry 58: 275-280.

Spohn M, Kuzyakov Y. 2013. Distribution of microbial- and root-derived phosphatase activities in the rhizosphere depending on $\mathrm{P}$ availability and $\mathrm{C}$ allocation - Coupling soil zymography with 14C imaging. Soil Biology and Biochemistry 67: 106-113.

Tachibana Y, Ohta Y. 1983. Root surface area, as a parameter in relation to water and nutrient uptake by cucumber plant. Soil Science and Plant Nutrition 29: 387-392.

Thu Hoang DT, Maranguit D, Kuzyakov Y, Razavi BS. 2020. Accelerated microbial activity, turnover and efficiency in the drilosphere is depth dependent. Soil Biology and Biochemistry 147: 107852.

Turner BL, Hopkins DW, Haygarth PM, Ostle N. 2002. B-Glucosidase Activity in Pasture Soils. Applied Soil Ecology 20: 157-162.

Vedere C, Harlote, Vieubl L, Girardin C, Chenu C. 2020. Spatial and temporal evolution of detritusphere hotspots at different soil moistures. Soil Biology and Biochemistry 150: 107975.

Veres Z, Kotroczó Z, Fekete I, Tóth JA, Lajtha K, Townsend K, Tóthmérész B. 2015. Soil extracellular enzyme activities are sensitive indicators of detrital inputs and carbon availability. Applied Soil Ecology 92: 18-23.

Vetterlein D, Carminati A, Kögel-Knabner I, Bienert GP, Smalla K, Oburger E, 
Schnepf A, Banitz T, Tarkka MT, Schlüter S. 2020. Rhizosphere spatiotemporal organisation - a key to rhizosphere functions. Frontiers in Agronomy 2: 8.

Vetterlein D, Lippold E, Schreiter S, Phalempin M, Fahrenkampf T, Hochholdinger F, Marcon C, Tarkka M, Oburger E, Ahmed M, et al. 2021. Experimental platforms for the investigation of spatiotemporal patterns in the rhizosphere-Laboratory and field scale. Journal of Plant Nutrition and Soil Science 184: 35-50.

Vives-Peris V, de Ollas C, Gómez-Cadenas A, Pérez-Clemente RM. 2020. Root exudates: from plant to rhizosphere and beyond. Plant Cell Reports 39: 3-17.

Voothuluru P, Braun DM, Boyer JS. 2018. An in vivo imaging assay detects spatial variability in glucose release from plant roots. Plant Physiology 178: 1002-1010.

Wang XC, Lu Q. 2006. Beta-glucosidase activity in paddy soils of the Taihu Lake region, China. Pedosphere 16: 118-124.

Waring BG. 2013. Exploring relationships between enzyme activities and leaf litter decomposition in a wet tropical forest. Soil Biology and Biochemistry 64: 89-95.

Watt M, Fiorani F, Usadel B, Rascher U, Muller O, Schurr U. 2020. Phenotyping: New Windows into the Plant for Breeders. Annual Review of Plant Biology 71: 689-712.

Wen T-J, Schnable PS. 1994. Analyses of Mutants of Three Genes that Influence Root Hair Development in Zea mays (Gramineae) Suggest that Root Hairs are Dispensable. American Journal of Botany 81: 833.

Williams A, Vries FT. 2020. Plant root exudation under drought: implications for ecosystem functioning. New Phytologist 225: 1899-1905.

Yang Y, Wang N, Guo X, Zhang Y, Ye B. 2017. Comparative analysis of bacterial community structure in the rhizosphere of maize by highthroughput pyrosequencing. PLoS ONE 12: 1-11.

Yu P, Baldauf JA, Lithio A, Marcon C, Nettleton D, Li C, Hochholdinger F. 2016. Root Type-Specific Reprogramming of Maize Pericycle Transcriptomes by Local High Nitrate Results in Disparate Lateral Root Branching Patterns. Plant Physiology 170: 1783-1798.

Zarebanadkouki M, Kim YX, Moradi AB, Vogel H-J, Kaestner A, Carminati A. 2012. Quantification and Modeling of Local Root Water Uptake Using Neutron Radiography and Deuterated Water. Vadose Zone Journal 11: vzj2011.0196.

Zhang X, Kuzyakov Y, Zang H, Dippold MA, Shi L, Spielvogel S, Razavi BS. 2020. 
Rhizosphere hotspots: Root hairs and warming control microbial efficiency, carbon utilization and energy production. Soil Biology and Biochemistry: 107872.

Zinchuk V, Wu Y, Grossenbacher-Zinchuk O. 2013. Bridging the gap between qualitative and quantitative colocalization results in fluorescence microscopy studies. Scientific Reports 3: $1-5$.

\section{Supplementary}

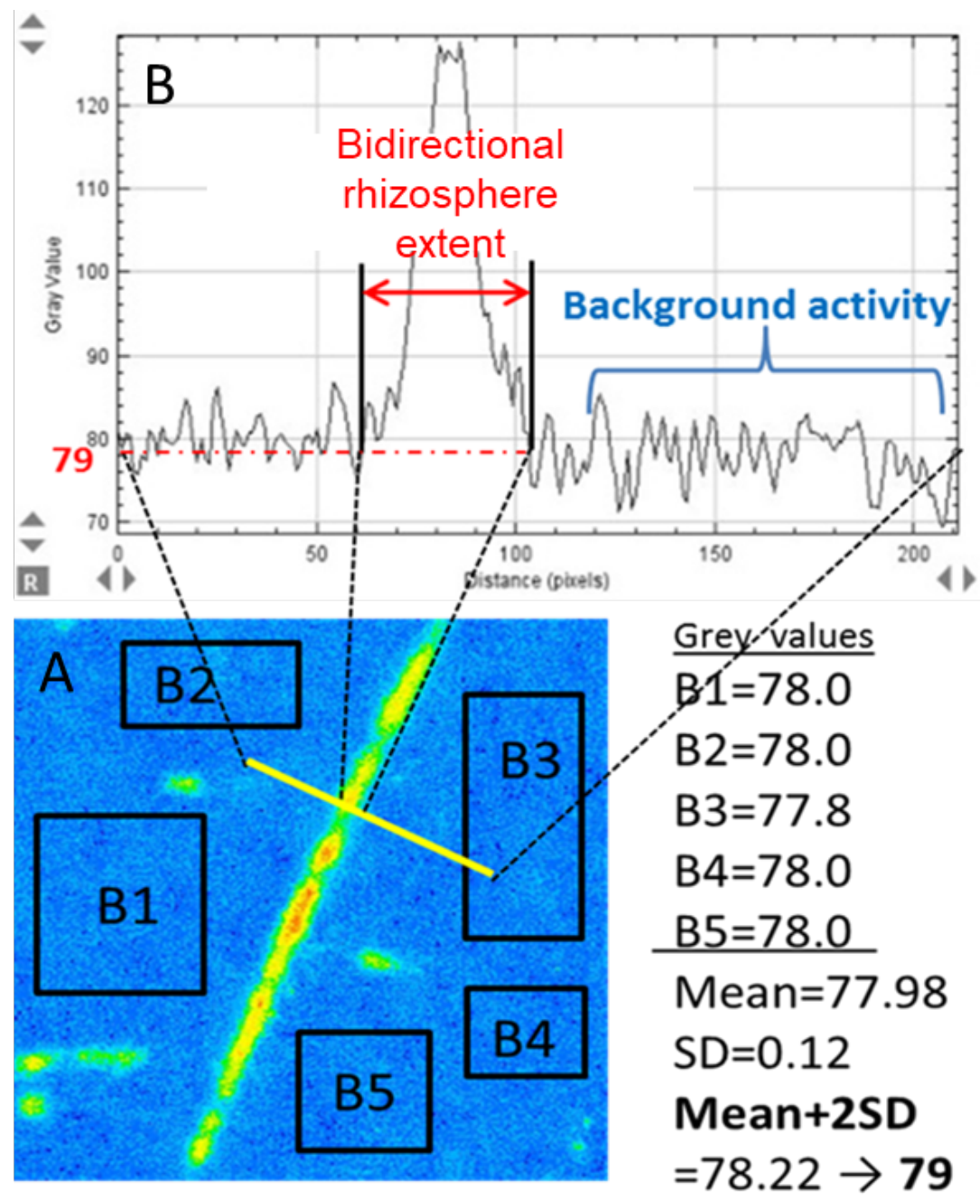

Figure S1. Sketch of rhizosphere thresholding methodology: a) an example of zymogram with five rectangles (B1-B5) which represent the areas of background $\beta$-glucosidase activity; b) gray values plotted against the distance. 


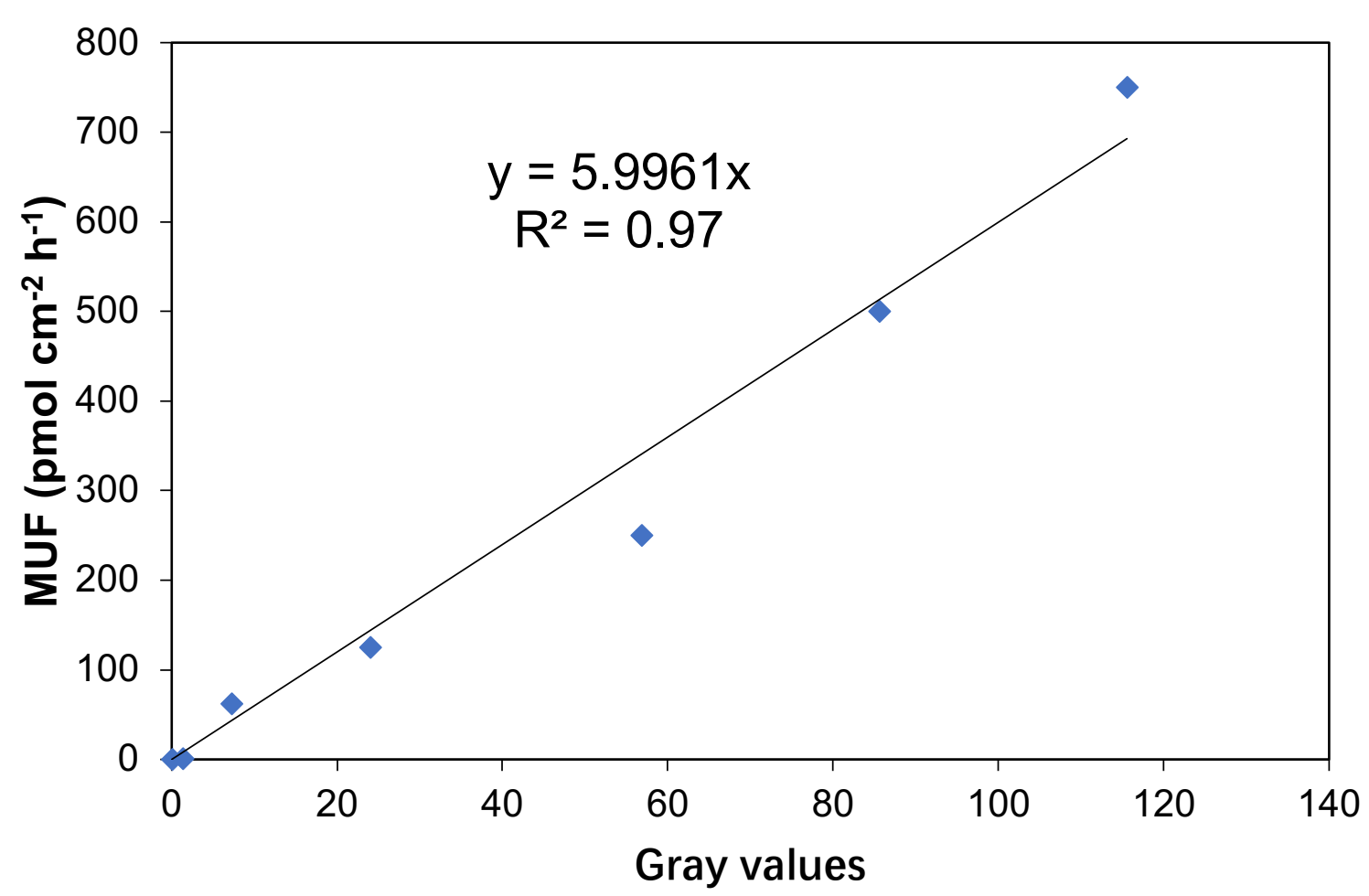

Figure S2 Linear correlation between the gray values of the calibration membranes incubated for one hour and methylumbelliferone (MUF) concentrations.
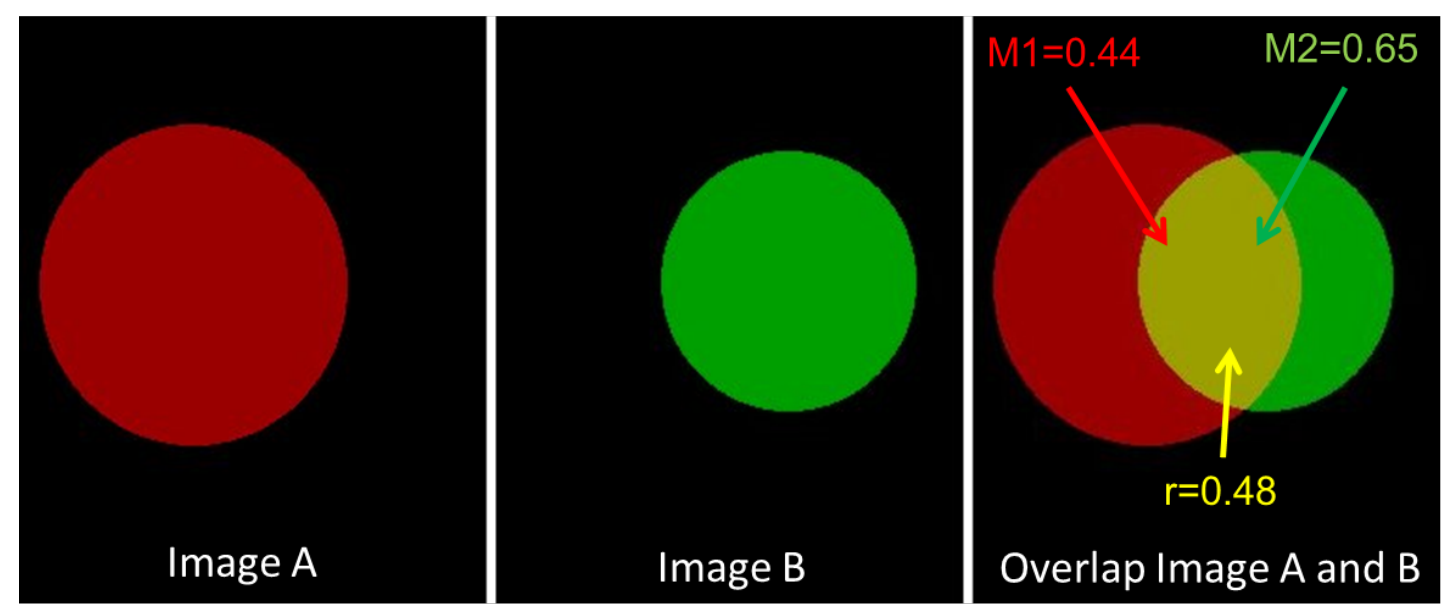

Figure S3. Schematic illustration of quantitative co-localization of activities/hotspots on two images A (Hotspot 1 - red) and B (Hotspot 2 - green) hotspots. Yellow part indicates 48\% of overlap between two hotspot images ( $\mathrm{r}=0.48)$; Manders coefficient 1 indicates that $44 \%$ of Hotspot 1 (yellow fraction of red hotspot) is considered as co-localized with Hotspot 2 $(\mathrm{M} 1=0.44)$; Manders coefficient 2 indicates that $65 \%$ of Hotspot 2 (yellow fraction of green hotspot) is considered as co-localized with Hotspot 1 (red hotspot) (M2=0.65). 
Table S1. Degrees of colocalization as fuzzy linguistic variables and the respective ranges of values of popular coefficients used to estimate colocalization, such as PC, r, and M1(M2) (Zinchuk et al., 2013)

\begin{tabular}{llll}
\hline $\begin{array}{l}\text { Degree of colocalization } \\
\text { (Fuzzy linguistic variables) }\end{array}$ & $\begin{array}{l}\text { Pearson coefficient } \\
(\mathrm{PC})\end{array}$ & $\begin{array}{l}\text { Overlap } \\
\text { coefficient (r) }\end{array}$ & $\begin{array}{l}\text { Manders } \\
\text { coefficien } \\
\text { ts M1or } \\
\text { M2 }\end{array}$ \\
\hline Very weak & $(-1)-(-0.27)$ & $0-0.49$ & $0-0.54$ \\
Weak & $(-0.26)-0.09$ & $0.50-0.70$ & $0.55-0.77$ \\
Moderate & $0.1-0.48$ & $0.71-0.88$ & $0.78-0.94$ \\
Strong & $0.49-0.84$ & $0.89-0.97$ & $0.96-0.98$ \\
Very strong & $0.85-1$ & $0.98-1.0$ & $0.99-1.0$ \\
\hline
\end{tabular}

Table S2. Result of co-localization analysis for the whole image of water content at neutron image (Water), ${ }^{14} \mathrm{C}$ exudates (Exudates) and $\beta$-glucosidase activity (Enzyme). The colocalization parameters are overlay coefficient (r), Mander's coefficient 1 (M1) and 2 (M2). Data are means for each genotype and parameter $(n=4) \pm$ standard deviations. Capital letters mark significant differences among the genotypes at $P<0.1$ and small letters mark significant differences among interactions within genotype at $P<0.05$ and $P<0.1$. Asterisks on the $\mathrm{p}$ values indicate significant differences between root type $\left({ }^{(*)}{ }^{*} P<0.1\right.$; '*,$P<0.05$; ‘**, $P<0.01$; ' “**' $P<0.001)$.

\begin{tabular}{|c|c|c|c|c|c|c|c|c|c|c|c|c|}
\hline \multirow[t]{3}{*}{ Genotype } & \multicolumn{12}{|c|}{ Co-localization coefficients } \\
\hline & \multicolumn{4}{|c|}{ Water $(1)^{\star}$ Exudates(2) } & \multicolumn{4}{|c|}{ Water $(1)^{\star}$ Enzyme(2) } & \multicolumn{4}{|c|}{ Enzyme (1)^Exudates(2) } \\
\hline & PC & $r$ & M1 & M2 & PC & $\mathrm{r}$ & M1 & M2 & PC & $\mathrm{r}$ & M1 & M2 \\
\hline \multirow[t]{2}{*}{ WT } & $0.03 \mathrm{AB}$ & $0.22 \mathrm{~A}$ & $0.24 \mathrm{~A}$ & 1.0 & $0.19 \mathrm{~B}$ & 0.89 & $0.99 \mathrm{~B}$ & 0.99 & 0.18 & $0.26 \mathrm{~A}$ & $0.26 \mathrm{~A}$ & 0.992 \\
\hline & \pm 0.01 & \pm 0.06 & \pm 0.11 & \pm 0.001 & \pm 0.10 & \pm 0.09 & \pm 0.007 & \pm 0.001 & \pm 0.08 & \pm 0.04 & \pm 0.17 & \pm 0.009 \\
\hline \multirow[t]{2}{*}{ rth3 } & $0.07 \mathrm{~B}$ & $0.89 \mathrm{~B}$ & $0.99 \mathrm{C}$ & 0.99 & $-0.02 \mathrm{~A}$ & 0.96 & $0.99 \mathrm{~B}$ & 0.99 & 0.14 & $0.85 B$ & $0.999 B$ & 0.995 \\
\hline & \pm 0.06 & \pm 0.05 & \pm 0.001 & \pm 0.001 & \pm 0.01 & \pm 0.01 & \pm 0.009 & \pm 0.001 & \pm 0.007 & \pm 0.09 & \pm 0.001 & \pm 0.008 \\
\hline \multirow[t]{2}{*}{$b \times 1$} & $0.002 \mathrm{~A}$ & $0.26 \mathrm{~A}$ & $0.38 \mathrm{~B}$ & 0.99 & $0.23 \mathrm{~B}$ & 0.93 & $0.972 \mathrm{~A}$ & 0.99 & 0.24 & $0.31 \mathrm{~A}$ & $0.39 \mathrm{~A}$ & 0.977 \\
\hline & \pm 0.006 & \pm 0.11 & \pm 0.14 & \pm 0.01 & \pm 0.01 & \pm 0.04 & \pm 0.031 & \pm 0.002 & \pm 0.04 & \pm 0.08 & \pm 0.12 & \pm 0.026 \\
\hline$p$ value & $<0.01$ & $<0.001$ & $<0.001$ & 0.41 & $<0.01$ & 0.15 & $<0.001$ & 0.19 & 0.14 & $<0.001$ & $<0.001$ & 0.30 \\
\hline
\end{tabular}




\title{
3 Study 3: Microbial growth and enzyme kinetics in rhizosphere hotspots are modulated by soil organics and nutrient availability
}

Peng Tian ${ }^{\mathrm{a}, \mathrm{b}}$, Bahar S. Razavic, Xuechen Zhang ${ }^{\mathrm{d}}$, Qingkui Wang, ${ }^{\mathrm{a}, \mathrm{e}^{*}}$, Evgenia Blagodatskaya ${ }^{\mathrm{f}, \mathrm{g}}$

\section{Status: Published in Soil Biology \& Biochemistry}

${ }^{a}$ Huitong Experimental Station of Forest Ecology, CAS Key Laboratory of Forest Ecology and Management, Institute of Applied Ecology, Shenyang, 110164, PR China

${ }^{b}$ University of Chinese Academy of Sciences, Beijing, 100049, PR China

${ }^{c}$ Department of Soil and Plant microbiome, Institute of Phytopathology, University of Kiel, Kiel, Germany

d Department of Biogeochemistry of Agroecosystem, University of Göttingen,

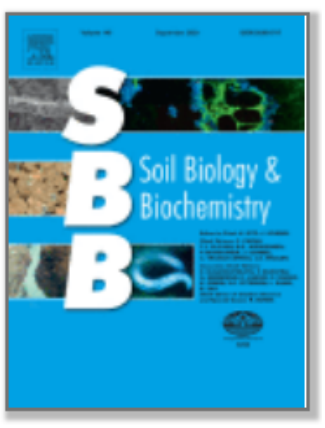
Göttingen, Germany

${ }^{e}$ Huitong National Research Station of Forest Ecosystem, Huitong, 418307, PR China

${ }^{f}$ Department of Soil Ecology, Helmholtz Centre for Environmental Research - UFZ, Halle (Saale), Germany $g$ Peoples Friendship University of Russia (RUDN University), Moscow, 117198, Russian Federation

\author{
Abstract
}

The input of labile organics by plant roots stimulates microbial activity and therefore facilitates biochemical process rates in the rhizosphere compared to bulk soil, forming microbial hotspots. However, the extent to which the functional properties of soil microorganisms are different in the hotspots formed in soils with contrasting fertility remains unclear. We identified the hotspots related to different levels of Zea mays L. root architecture by zymography of leucine aminopeptidase in two soils with contrasting fertility. The hotspots localized by tiny wet- needle approach around first- and second-order roots were compared for parameters of microbial growth and enzyme kinetics. The pattern of hotspot distribution was more dispersed and the hotspot area was one order of magnitude smaller around firstversus second-order roots. The specific microbial growth rate $\left(\mu_{\mathrm{m}}\right)$ and biomass of active microorganisms were soil-specific, with no difference between the hotspots and bulk soil in the fertile soil. In contrast, in the soil poor in organic matter and nutrients, 1.2-fold higher $\mu_{\mathrm{m}}$ and greater growing biomass were found in the hotspots versus bulk soil. Lower enzyme affinity (1.3-2.2 times higher $\mathrm{K}_{\mathrm{m}}$ value) of $\beta$-glucosidase and leucine aminopeptidase to the substrate was detected in the hotspots versus bulk soil, whereas only $\beta$-glucosidase showed higher potential enzyme activity $\left(\mathrm{V}_{\max }\right)$ in the hotspots, being 1.7-2.1 times greater than that in bulk soil. Notably, the activity of $\mathrm{C}$-acquiring enzyme, $\beta$-glucosidase positively correlated with the biomass of actively growing microorganisms. The fertile soil, on the whole, showed greater $\mathrm{V}_{\max }$ and catalytic efficiency $\left(\mathrm{V}_{\max } / \mathrm{K}_{\mathrm{m}}\right)$ and an approximately 2.5 times shorter substrate turnover time as compared to the poor soil. Therefore, we conclude that i) the differences in microbial growth strategy between rhizosphere hotspots and bulk soil were dependent on soil fertility; ii) affinity of hydrolytic enzyme systems to substrate was mainly modulated by plant, whereas potential enzymatic activity was driven by both plant and soil quality.

Keywords: Microbial hotspots, Soil zymography, Microbial growth, Enzyme kinetics *Corresponding author: qwang@iae.ac.cn 


\subsection{Introduction}

The input of root exudates and rhizodeposits, mainly easily degradable low-molecular weight organic substances, stimulates microbial growth and activity in the rhizosphere, which is defined as one of the most dynamic microbial hotspots (Kuzyakov and Blagodatskaya, 2015; Kuzyakov and Razavi, 2019). The peculiarity of the rhizosphere as a root-soil interface is that the microbial community composition is generally linked to the soil microbial community, which is determined by basic soil properties (de Ridder-Duine et al., 2005). The structure of rhizosphere community (i.e., species dominance and activity), however, is strongly modulated by the plant strategy for the nutrient acquisition, which is also dependent on basic soil properties, e.g., soil nutrition state (reviewed by Kuzyakov and Razavi, 2019). Therefore, the research question: how the difference between the hotspots and bulk soil is impacted by soil fertility, which dramatically changes soil $\mathrm{C}$ and nutrient status, is very relevant. This question needs to be addressed considering that microbial communities in the hotspots and bulk soil are functionally different in terms of their life strategies and enzyme kinetic properties due to different qualities and quantities of organic substrates (Blagodatskaya et al., 2009; Hoang et al., 2016).

Microbial activity is limited by various environmental factors and especially by carbon (C) availability (Hodge et al., 2000; German et al., 2011). Microbial hotspots are formed with the input of fresh carbon sources (Hodge et al., 2000; Schimel and Weintraub, 2003). Accordingly, soil with higher quality, i.e., the availability of organic substances and nutrients, should represent higher microbial and enzyme activity. On the other hand, the relative fraction of the hotspots induced by root exudates and rhizodeposits may be lower if soil inherent substrate availability is sufficient for microbial metabolism. We hypothesize, therefore, that the differences in microbial functional parameters between the hotspots and surrounding soil will be smoothed in rich compared to the poor soil.

In the rhizosphere, root exudation and rhizodeposits stimulate the activities of extracellular enzymes (Ge et al., 2017; Ma et al., 2018), which are valuable tools for microorganisms to degrade complex polymeric organic substances for acquiring energy and nutrients from surrounding soil. However, artificially labeled fluorogenic substrates applied in soil studies for determination of extracellular enzymes activity (Marx et al., 2001) are much less than natural organic polymers. Despite it is generally assumed that fluorogenic substrates are decomposed by extracellular enzymes; this assumption still needs to be proven experimentally. Furthermore, application of sonicated soil suspension cannot distinguish the 
activity of enzymes released by microorganisms in response to substrate addition and earlier secreted enzymes immobilized within soil matrix (Nannipieri et al., 2018). Therefore, the cumulative activity of enzymes presented in soil suspension is determined by this approach.

The gradients of enzyme activities as a function of distance from the root surface to the soil have been clearly related to nutrients availability (Tarafdar and Jungk, 1987; Badalucco and Nannipieri, 2007) and the spatial patterns of such gradients have been recently visualized (Sanaullah et al., 2016; Zhang et al., 2019). However, the inhomogeneous distribution of microbial hotspots along the roots has also been observed (Pausch and Kuzyakov, 2011; Razavi et al., 2016a), which might be due to soil heterogeneity (Webster, 2000; Heuvelink and Webster, 2001) or variation and distribution of exudation along the roots. Therefore, careful localization of the hotspots is necessary for precise soil sampling from microbial hotspots. Soil zymography, a novel in situ method, enables determining the two-dimensional spatial distribution of enzyme activities in soil (Spohn et al., 2013; Razavi et al., 2019; Heitkötter and Marschner, 2018) and localizing hotspots of various enzyme activities.

The most ecologically relevant biogeochemical processes in soils are microbially mediated, and microbial functions depend on active microbial pools in soil because only the active microorganisms drive biogeochemical processes (Blagodatsky et al., 2000; Nannipieri et al., 2003). The rate of biomass-specific respiration is 10-100 times greater when it is based on the active than on the total microbial pool (Salazar-Villegas et al., 2016). Additionally, the fraction of active microorganisms in the hotspots is up to 2 times higher than that in bulk soil (Blagodatskaya et al., 2014). Consequently, the simultaneous occurrence of numerous hotspots at the micro-scale level determines the microbial functions at higher scales (Blagodatsky and Smith, 2012; Kuzyakov and Blagodatskaya, 2015). In turn, the effect of hotspots can be quantified by their relevance to functional parameters, such as respiration, microbial growth and enzyme activities (Blagodatskaya and Kuzyakov, 2013). Kinetic approaches, based on product formation, e.g., respiration, are successful for assessment of the active biomass and for relating it to basic soil processes (Blagodatsky et al., 2000). Kinetic parameters of microbial growth as well as the dominant strategy can be detected using the substrate-induced growth response (SIGR) method (Panikov, 1995). The correspondence between microbial growth and functional parameters of enzymes hydrolyzing polymeric organic compounds in soil remains to be studied in the precisely localized hotspots (Razavi et al., 2015; Ma et al., 2017). 
Here, two types of soil with contrasting fertility were used to grow maize plants. The application of soil zymography enabled accurate localization of the microbial hotspots and successful collection of the micro-samples by tiny wet-needle approach. This study was designed to i) investigate the potential effect of rhizosphere hotspots on microbial growth and enzyme activities; ii) evaluate the effect of soil type on the difference in kinetic parameters between the hotspots and bulk soil. We hypothesized that 1) rhizosphere hotspots contain a high fraction of stimulated microorganisms (with a high growth rate and enzyme activity) compared to bulk soil independently of soil fertility; 2) the difference in kinetic parameters between the hotspots and bulk soil are stronger in the poor soil; 3) the enzyme activity in soil with higher fertility is higher than in the poor soil.

\subsection{Materials and Methods}

\subsubsection{Hotspot identification and sampling}

Individual maize plants (Zea mays L., KWS, Germany) were grown in separate rhizoboxes (30 plants in total) in two soils with similar $\mathrm{pH}$ but contrasting texture and fertilization. Mitterfels (fertile soil) is located in the Central German Uplands. The soil type is Hyperdystric Chromic Folic Cambisol (WRB, 2015). The samples of Mitterfels soil were taken from loamy Ap horizon (Lang et al., 2017) with high $\mathrm{C}$ and $\mathrm{N}$ content. Unterlüss (poor soil) is located in Lower Saxony, Germany. The soil type is Hyperdystric Folic Cambisol (WRB, 2015). The samples taken from Ap horizon of Unterlüss silty loam soil were relatively barren, with respectively, 1.6, 2.0 and 4.1 times lower $\mathrm{C}, \mathrm{N}$ and $\mathrm{P}$ content as compared with Mitterfels soil (Table 1). Further details on the sites, soil profiles and soil properties can be found in Lang et al. (2017). During growth, the rhizoboxes were kept inclined at an angle of $45^{\circ}$ so that the roots grew at the vicinity of the lower wall of the rhizobox due to gravitropism. After cultivating maize plants for 2 weeks, soil zymography was applied to identify the spatial distribution of $\beta$-glucosidase and leucine aminopeptidase hotspots around the roots (Razavi et al., 2019).

Table 1 Stand parameters at two research sites in Germany. Data taken from relevant German forest authority (Haußmann and Lux, 1997; Lang et al., 2017) 


\begin{tabular}{lll}
\hline Stand parameters & Mitterfels & Unterlüss \\
\hline Locations & $48^{\circ} 97^{\prime} \mathrm{N}, 12^{\circ} 87^{\prime} \mathrm{E}$ & $52^{\circ} 83^{\prime} \mathrm{N}, 10^{\circ} 36^{\prime} \mathrm{E}$ \\
Elevation $(\mathrm{m})$ & 1023 & 115 \\
Precipitation (mm) & 1229 & 779 \\
Mean annual temperature $\left(^{\circ} \mathrm{C}\right)$ & 4.9 & 8 \\
Texture & Loam & Silty sand \\
$\mathrm{P}_{\text {tot }}\left(\mathrm{g} \mathrm{m}^{-2}\right)$ & 1375 & 164 \\
$\mathrm{~N}_{\text {tot }}\left(\mathrm{kg} \mathrm{m}^{-2}\right)$ & 1.4 & 0.7 \\
$\mathrm{C}_{\text {tot }}\left(\mathrm{kg} \mathrm{m}^{-2}\right)$ & 26 & 16 \\
$\mathrm{C} / \mathrm{N}$ & 18.6 & 22.9 \\
$\mathrm{C} / \mathrm{P}$ & 127 & 493 \\
$\mathrm{pH}\left(\mathrm{H}_{2} \mathrm{O}\right)$ & 3.6 & 3.5 \\
$\mathrm{Clay} \%$ & 24 & 6 \\
Sand $\%$ & 32 & 19 \\
Silt $\%$ & 44 & 75 \\
\hline
\end{tabular}

Two types of fluorogenic substrates based on 4-methylumbelliferone (MUF) and 7amino-4-methylcoumarin (AMC) were used: 4-methylumbelliferyl- $\beta$-D-glucoside (MUF-G) for $\beta$-glucosidase; L-Leucine-7- amino-4-methylcoumarin (AMC-L) for leucine aminopeptidase. After fitting the substrate-saturated membrane to the soil surface for $1 \mathrm{~h}$, enzyme activity was detectable by the appearance of fluorescent products on the membrane visible under UV light (Fig. 1a-d). The estimation of fluorescence intensity proportional to the activity of the enzyme was calibrated by the range of concentrations of corresponding products: either MUF or AMC. In order to transform zymogram images to graphical representation, digital image histograms were developed as barcharts, which showed the distribution of pixel values according to the color map. These histogram graphs show the number of pixels of the zymogram images at each 0.01 color intensity value occurring in that image. Numbers of pixels as well as area of whole image were calculated based on these histograms. All pixels with the color intensity exceeding average value (i.e., $>0.75$ ) were assigned to the hotspots for enzyme activities (Sanaullah et al., 2016).

For both soils, we found higher resolution for the hotspots identified by leucine aminopeptidase compared to $\beta$-glucosidase. In addition, we found that the hotspots around new-developed first-order roots of maize were very small in size and can be considered as dots, in comparison with large hotspot areas around second-order root. The zymography images of leucine aminopeptidase activity were treated for the hotspots sampling around first- and second-order roots, separately. For precisely localized sampling, soil particles were carefully collected using wet needle (tip $1.5 \mathrm{~mm}$ ) of a syringe directly from the hotspots identified by zymography (Fig. 1e). No hotspots were detected at the distance exceeding 1.5 $\mathrm{mm}$ from the roots. About $0.1 \mathrm{~g}$ soil was collected from large number of hotspots and was pooled to form a composite sample for each plant replicate. Bulk soil was collected in a similar way from root- free soil. 

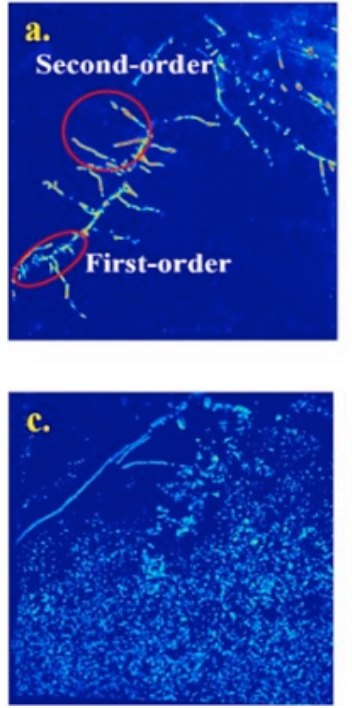
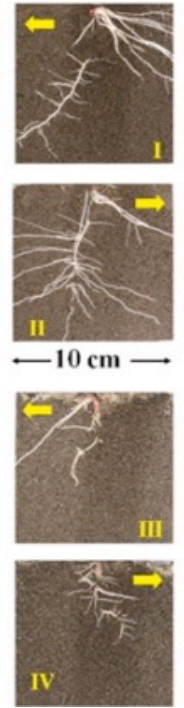
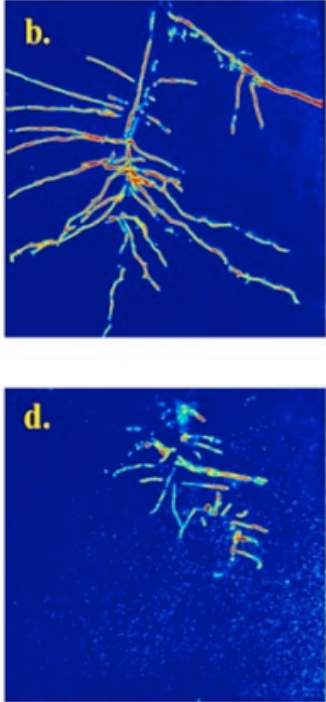

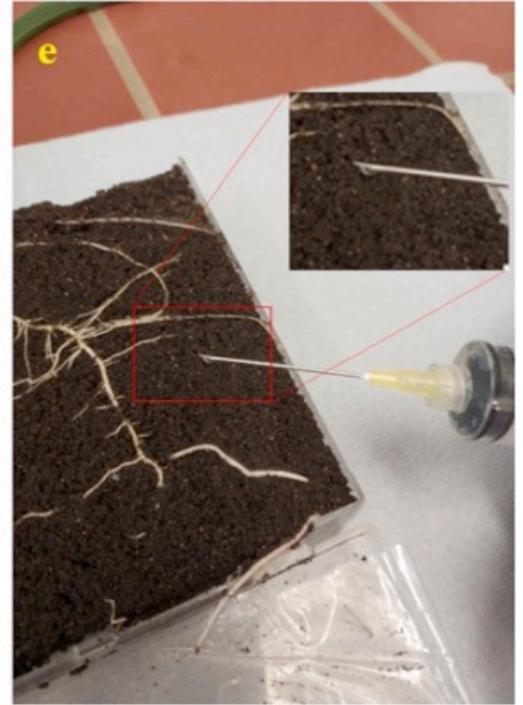

Fig. 1 Examples of maize roots grown in rhizoboxes (center) and zymographs; showing spatial distribution of enzyme activities: (a) $\beta$-glucosidase, and (b) leucine aminopeptidase in the fertile soil; (c) $\beta$-glucosidase, and (d) leucine aminopeptidase in the poor soil, and (e) the sampling scenario using wet needle.

\subsubsection{Kinetics of substrate-induced growth response}

The kinetic parameters of substrate-induced growth response were estimated by the dynamics of $\mathrm{CO}_{2}$ emission from soil amended with glucose and nutrients (Panikov, 1995), taking advantage of the rapid automated bacterial impedance technique (RABIT) system in a climate chamber enabling to work with reduced (up to $0.5-1 \mathrm{~g}$ ) soil sample size. Briefly, soil sample was incubated in a tube after solution addition with glucose $\left(10 \mathrm{mg} \mathrm{g}^{-1}\right)$ and mineral salts: $\left(\mathrm{NH}_{4}\right)_{2} \mathrm{SO}_{4}-1.9 \mathrm{mg} \mathrm{g}^{-1}, \mathrm{~K}_{2} \mathrm{HPO}_{4}-2.25 \mathrm{mg} \mathrm{g}^{-1}$, and $\mathrm{MgSO}_{4} \cdot 7 \mathrm{H}_{2} \mathrm{O}-3.8 \mathrm{mg} \mathrm{g}^{-1}$ (Blagodatsky et al., 2000). Soil water content was adjusted to $60 \%$ of water holding capacity by adding distilled water. The $\mathrm{CO}_{2}$ production rate was measured hourly at $22{ }^{\circ} \mathrm{C}$ using RABIT.

Specific growth rate $\left(\mu_{\mathrm{m}}\right)$ was determined by fitting of equation parameters to the experimental data on $\mathrm{CO}_{2}$ evolution rate ( $v$; Fig. 2) according to the following equation:

$$
v(t)=A+B \times \exp \left(\mu_{m} t\right)
$$

where $A$ is the initial rate of uncoupled (no growth) respiration, $B$ is the initial rate of coupled (growth) respiration, $t$ is the time (Panikov and Sizova, 1996; Blagodatsky et al., 2000); $r_{0}$, the so-called physiological state index of microorganisms at time zero (before substrate addition), is calculated from the ratio between $A$ and $B$. The total glucosemetabolizing microbial biomass (sustaining + growing) is 


$$
x_{0}=B \cdot \lambda \cdot Y_{\mathrm{CO}_{2}} / r_{0} \cdot u_{m}
$$

Biomass yield per unit of $\mathrm{CO}_{2}-\mathrm{C}\left(\mathrm{Y}_{\mathrm{CO} 2}\right)$ is assumed to be constant during the experiment and equals 1.5 , corresponding to a mean value of 0.6 for the microbial yield per unit of glucose-C consumed. $\lambda=0.9$ may be accepted as a basic stoichiometric constant (Panikov and Sizova, 1996). The growing (active) microbial biomass at time zero is given by

$$
x_{0}^{\prime}=x_{0} \cdot r_{0}
$$

The duration of the lag period $\left(t_{\text {lag }}\right)$ was determined as the time interval between the moment of glucose addition and the moment when the increasing rate of growth-related respiration $B \quad \times \exp \left(\mu_{\mathrm{m}} t\right)$ becomes as high as the rate of respiration uncoupled from ATP generation; it was calculated using the parameters of the approximated curve of the respiration rate of microorganisms by the equation:

$$
t_{\text {lag }}=\frac{\ln \left(\frac{A}{B}\right)}{\mu m}
$$

In addition, the kinetic approach allowed the assessment of generation time $\left(T_{g}\right)$ of both actively growing and total microbial population consuming glucose. The estimation of $T_{g}$ for actively growing biomass is based on specific growth rates, i.e:

$$
T_{g}=\frac{\ln (2)}{\mu m}
$$

\subsubsection{Enzyme kinetics}

Activities of $\beta$-glucosidase and leucine aminopeptidase for the hotspots and bulk soil were measured using the same fluorogenic substrates as for zymography with seven concentrations ranging from 0 to $400 \mu \mathrm{mol} \mathrm{L} \mathrm{L}^{-1}$. The extraction and determination were carried out according to German et al. (2011) and Razavi et al. (2015). Suspensions of $0.5 \mathrm{~g}$ soil (dry weight equivalent) with $50 \mathrm{~mL}$ deionized water were prepared using low-energy sonication ( $40 \mathrm{~J} \mathrm{~s}^{=1}$ output energy) for $2 \mathrm{~min}$.

Thereafter, $50 \mu \mathrm{L}$ of soil suspension was added to $100 \mu \mathrm{L}$ substrate solution and $50 \mu \mathrm{L}$ of buffer [MES $\left(\mathrm{C}_{6} \mathrm{H}_{13} \mathrm{NO}_{4} \mathrm{SNa}_{0.5}\right),(\mathrm{pH}: 6.5)$ for MUF substrate and TRIZMA $\left(\mathrm{C}_{4} \mathrm{H}_{11} \mathrm{NO}_{3}\right.$. $\left.\mathrm{HCl}, \mathrm{C}_{4} \mathrm{H}_{11} \mathrm{NO}_{3}\right),(\mathrm{pH}: 7.2)$ for AMC substrate] in a 96-well microplate. At 0 min, $1 \mathrm{~h}$ and 2 $\mathrm{h}$ after mixing, a fluorescence in microplates was measured at an excitation wavelength of $355 \mathrm{~nm}$ and an emission wavelength of $460 \mathrm{~nm}$, slit width of $25 \mathrm{~nm}$, with a Victor3 1420050 Multi label Counter (Perkin Elmer, USA). Enzyme activity was expressed as MUF or AMC release in nmol per $\mathrm{g}$ dry soil per hour (nmol g $\left.\mathrm{g}^{-1} \mathrm{soil} \mathrm{h}^{-1}\right)$. 
The parameters of Michaelis-Menten kinetics for enzyme activities were determined using the equation:

$$
\mathrm{V}=\frac{\mathrm{V}_{\max } \times[\mathrm{S}]}{K_{m}+[S]}
$$

where $V$ is the reaction rate, $[S]$ is the substrate concentration. $K_{m}$ (the substrate concentration at half-maximal rate) is related to the enzyme affinity to the substrate. $V_{\max }$ refers to decomposition rates at saturating substrate concentration.

The substrate turnover time $\left(T_{t}\right)$ was calculated according to the following equation: $T_{t}$ (hours) $=\left(K_{m}+S\right) / V_{\max }$ (Panikov et al., 1992), where $\mathrm{S}$ is the substrate concentration. The substrate turnover time was calculated at substrate concentration for the situations corresponding to the lack and excess of substrate, as $S=K_{m} / 10$ and $\mathrm{S}=10^{*} K_{m}$, respectively.

The catalytic efficiency of enzymes $\left(K_{a}\right)$ was determined as $K_{a}=V_{\max } / K_{m}$ (Hoang et al., 2016). The $K_{a}$ characterizes the enzyme catalytic properties and is used as an indicator to reflect the functional changes of microbial communities (Tischer et al., 2015). The higher $K_{a}$ shows better catalytic properties (Moscatelli et al., 2012).

\subsubsection{Statistical analysis}

One-way analysis of variance followed by the Tukey HSD $(P<0.05)$ was used to test the effect of hotspots on microbial and enzyme kinetic parameters, e.g., specific growth rate, $\mathrm{V}_{\max }, \mathrm{K}_{\mathrm{m}}, \mathrm{T}_{\mathrm{t}}$ and $\mathrm{K}_{\mathrm{a}}$. All the statistical analyses were performed using SPSS version 22.0 for Windows (SPSS Inc. Chicago).

\subsection{Results}

\subsubsection{Kinetics of substrate-induced growth response}

Different kinetic responses of microbial growth to substrate addition between the hotspots and bulk soil were detected in low fertile soil (Fig. 2 and Table 2). Glucose and nutrient input into the poor soil induced stronger stimulation of microbial growth with a 1.2-fold higher microbial specific growth rate $\left(\mu_{\mathrm{m}}\right)$ in the hotspots compared to bulk soil. In contrast, $\mu_{\mathrm{m}}$ values were similar between the hotspots and bulk soil of the fertile soil. The lag time $\left(t_{\text {lag }}\right)$ in the fertile soil was estimated as negligible, demonstrating immediate microbial growth after substrate input. Furthermore, a very high fraction of active microorganisms exceeding $10 \%$ of total biomass was observed in the fertile soil (Table 2). In contrast, a long lag time of $25.4 \mathrm{~h}$ was detected in bulk soil of the poor soil, accompanied by a low abundance of growing microbial biomass (Table 2). The growing microbial biomass $\left(x^{\prime}\right)$ ) was at least 4.8 -fold higher in the fertile than in the poor soil. Despite the strong 
difference in size, no difference in growth kinetic parameters was detected between the hotspots of first- and second-order roots.
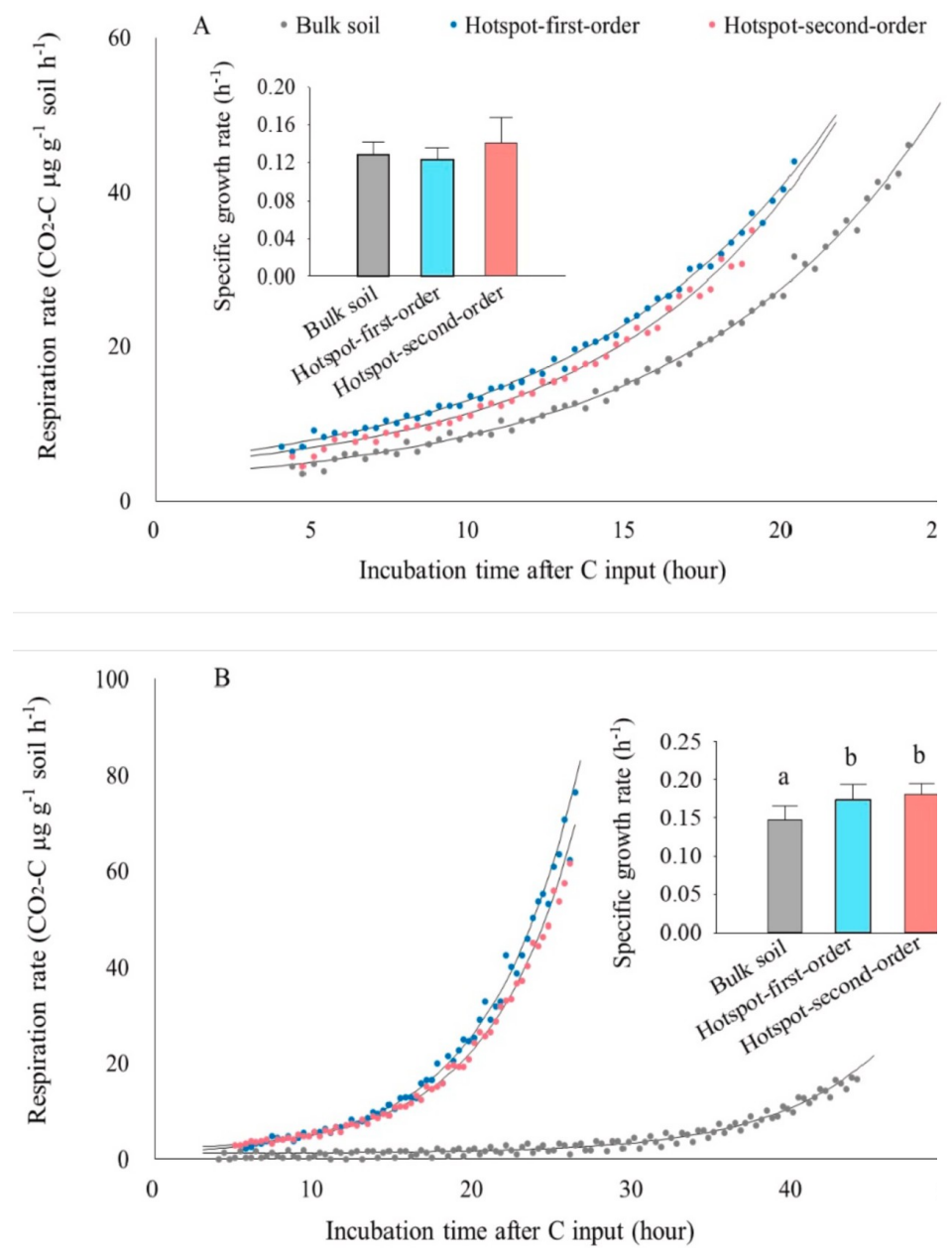

Fig. 2 Glucose-induced respiratory responses of microbial community and their corresponding specific growth rates $\left(\mu_{\mathrm{m}}\right.$; inset figures) after substrate addition into the (A) fertile and (B) poor soil. Experimental data are shown as symbols and model simulation (Equation (1)) as curves. Bars show standard errors of the means $( \pm \mathrm{SE})$. Lower-case letter indicates significant difference at a level of $\mathrm{P}<0.05$.

Table 2 Growing microbial biomass and its proportion of total biomass, lag-period and generation time of actively growing microbial community consuming substrate during incubation of soils with glucose and nutrients.

\begin{tabular}{|c|c|c|c|c|c|}
\hline \multirow[t]{2}{*}{ Soil } & \multirow[t]{2}{*}{ Treatment } & \multirow[t]{2}{*}{$\begin{array}{l}\text { Lag time } \\
\text { (hours) }\end{array}$} & \multicolumn{2}{|c|}{$\begin{array}{l}\text { Microbial biomass } \\
\left(\mu \mathrm{g} \mathrm{C}^{-1}\right)\end{array}$} & \multirow{2}{*}{$\begin{array}{l}\text { Generation } \\
\text { Time } \\
\text { (hours) }\end{array}$} \\
\hline & & & Growing & $\begin{array}{l}\% \text { of } \\
\text { total }\end{array}$ & \\
\hline \multirow[t]{3}{*}{ Fertile } & Bulk soil & 0 & 16.0 & 16.4 & 5.4 \\
\hline & $\begin{array}{l}\text { Hotspots-first- } \\
\text { order }\end{array}$ & 0 & 27.6 & 17.7 & 5.7 \\
\hline & $\begin{array}{l}\text { Hotspots- } \\
\text { second-order }\end{array}$ & 0.7 & 15.5 & 8.4 & 4.9 \\
\hline \multirow[t]{3}{*}{ Poor } & Bulk soil & 25.4 & 0.2 & 0.2 & 4.7 \\
\hline & $\begin{array}{l}\text { Hotspots-first- } \\
\text { order }\end{array}$ & 0 & 4.5 & 11.4 & 4.0 \\
\hline & $\begin{array}{l}\text { Hotspots- } \\
\text { second-order }\end{array}$ & 5.44 & 3.2 & 3.6 & 3.8 \\
\hline
\end{tabular}




\subsubsection{Enzyme kinetics and substrate turnover}

The maximum potential enzyme activity $\left(V_{\max }\right)$ was $1.7-2.1$ times higher in the hotspots than in bulk soil for $\beta$-glucosidase, whereas no difference was detected for leucine aminopeptidase (Fig. 3a). Interestingly, the difference in $V_{\max }$ of $\beta$-glucosidase between the hotspots and bulk soil showed a close dependence on the amount of growing microbial biomass $\left(R^{2}=0.85\right.$; Fig. 4$)$. Remarkably, $V_{\max }$ was approximately 2 times higher in the fertile than in the poor soil, whereas the $K_{m}$ showed no difference between the fertile and the poor soil. Overall, the $K_{m}$ values of $\beta$-glucosidase and leucine aminopeptidase were 1.3-2.2 times higher in the hotspots than in bulk soil $(P<0.05$; Fig. 3b). Consistent with microbial growth kinetics, no difference in enzyme kinetics was detected between the hotspots of first- and second-order roots.

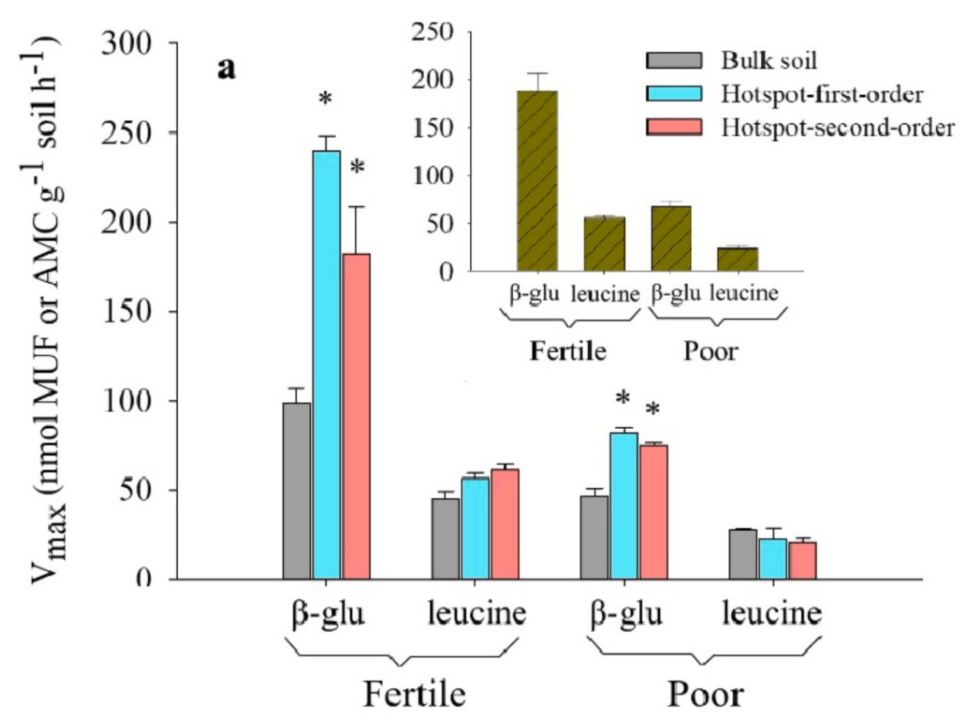

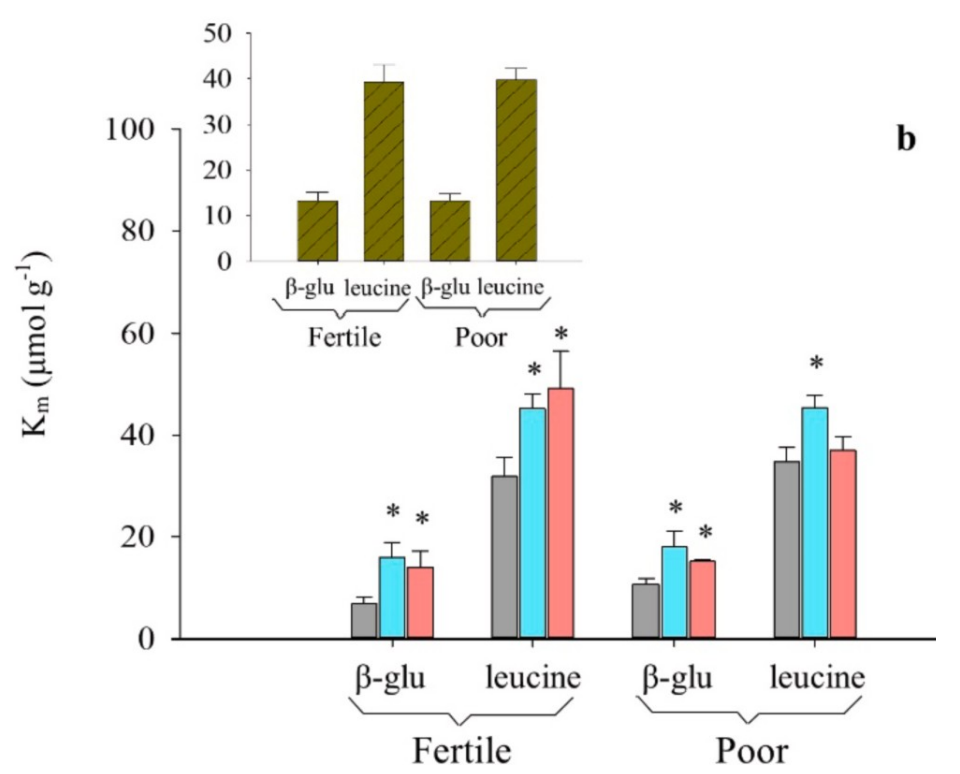

Fig. $3 V_{\max }$ (a) and $K_{m}$ (b) values of $\beta$-glucosidase, and leucine aminopeptidase in the fertile and the poor soils. Values are means of three replicates $( \pm \mathrm{SE})$. Asterisks indicate significantly different from bulk soil. The inserts show the mean value of different samples. 
The turnover time for enzymes showed no difference between the hotspots and bulk soil except the leucine aminopeptidase in the poor soil in which the turnover time in the hotspots around the first-order roots was $40 \%$ longer than that in bulk soil (Fig. 5a and b). The same pattern in the turnover time was detected under a lack of substrate as under an excess of substrate. Furthermore, the turnover time was approximately 2.4-2.9 times as long in the poor as in the fertile soil. No change in the catalytic efficiency $\left(V_{\max } / K_{m}\right)$ was detected in the hotspots for $\beta$-glucosidase or leucine aminopeptidase (Fig. 5c). However, the catalytic efficiency was approximately 3 times higher in the fertile versus the poor soil.

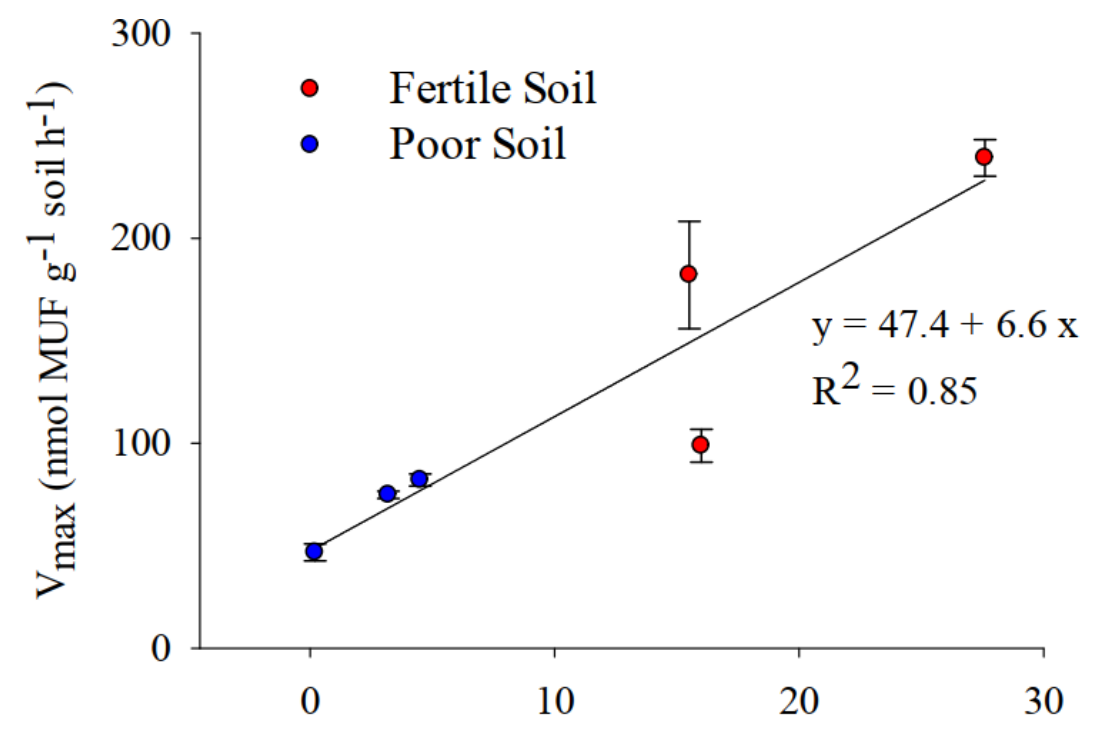

Growing microbial biomass $\left(\mu \mathrm{g} \mathrm{C} \mathrm{g} \mathrm{g}^{-1}\right)$
Fig. 4 The relationship between the $\mathrm{V}_{\max }$ of $\beta$ glucosidase and the growing microbial biomass $(\mathrm{P}<0.05)$. 

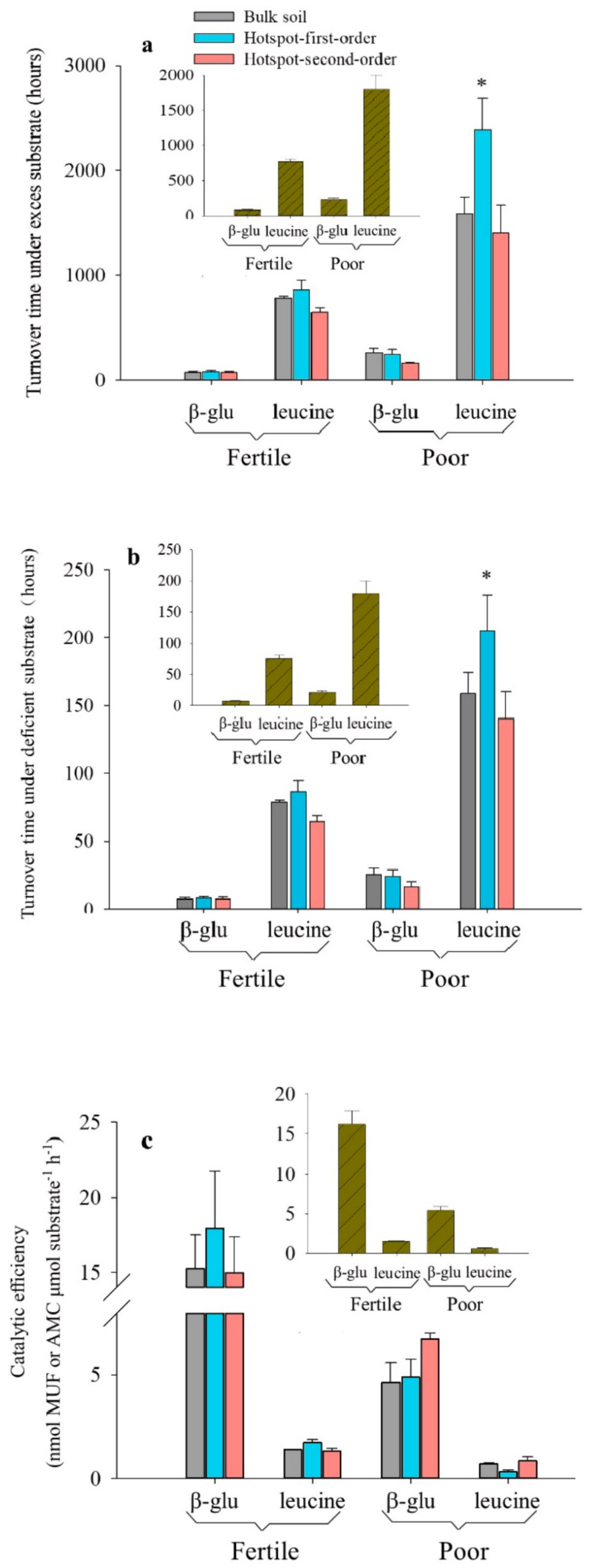

Fig. 5 The turnover time (a) at excess of substrate and (b) lack of substrate, and (c) the catalytic efficiency of enzymes (ratio of $V_{\max } / K_{m}$ ) in the fertile and the poor soils. Values are means of three replicates $( \pm \mathrm{SE})$. Asterisks indicate significantly different from bulk soil. The inserts show the mean value of different samples. 


\subsection{Discussion}

\subsubsection{Microbial growth response to substrate addition}

Differences in the microbial growth response to substrate addition between rhizosphere hotspots and bulk soil were soil fertility dependent and were detected only in the poor soil (Fig. 2), which partly rejects our first hypothesis that microbial hotspots always stimulate microbial growth compared with bulk soil. Equal microbial specific growth rates $\left(\mu_{\mathrm{m}}\right)$ in the hotspots and bulk soil from the fertile soil might be associated with the availability of soil organics (German et al., 2011). Due to abundant organics in soil, the energy limitation and dependence of the microbial community on labile $\mathrm{C}$ input by roots are weak. In contrast, substrate addition to hotspots of the poor soil induced strong stimulation of microbial growth compared to bulk soil, confirming our second hypothesis that the difference in microbial growth between the hotspots and bulk soil is stronger in the poor soil. Thus, a greater fraction of fast-growing microorganisms with r-strategy in the hotspots was selectively stimulated by the input of labile C from roots (Grayston et al., 1998; Goddard et al., 2001; Cheng, 2009; Philippot et al., 2013).

Based on the microbial respiration rate, a negligible lag time (tlag) was estimated in the fertile soil (Table 2), which was closely associated with the active microbial pool. In the fertile soil, growing microorganisms can take up the added substrate immediately for their growth (Blagodatskaya et al., 2014). In contrast, a long lag time in the bulk poor soil indicated dormancy of microbial community located far from roots and limited by labile $\mathrm{C}$, when the very tiny fraction of growing microorganisms was able to maintain activity state (Blagodatskaya and Kuzyakov, 2013). In the poor bulk soil, neither inherent soil C source nor labile $\mathrm{C}$ input from roots could support the activation of microorganisms. Overall, the lag time showed a negative correlation with the amount of active biomass, indicating that the state of microbial activity is responsible for the duration of $t_{\text {lag }}$ (Blagodatskaya et al., 2014). Therefore, the hotspot effect on microbial activity was not consistent among soils and was largely regulated by soil fertility.

Last, similar kinetics of the substrate-induced growth response between the hotspots associated with either first- or second-order roots suggest the same functional groups and activity of microorganisms. Different area and distribution patterns of the hotspots do not necessarily mean functional differences, i.e., microorganisms in individual hotspots are not fully separated. The size of hotspots is governed by metabolic pathways, which strongly depend on the amount of substrate (Dippold and Kuzyakov, 2013). Therefore, different 
magnitudes of labile $\mathrm{C}$ input by first- and second-order roots would be the fundamental cause of the various shapes of rhizosphere hotspots (Pausch and Kuzyakov, 2011).

\subsubsection{Enzyme kinetics and substrate turnover}

Generally, greater than doubled $V_{\max }$ values in the fertile soil versus poor soil is a result of more growing biomass in the former (Table 2). Growing microorganisms produce larger amount of active enzymes $\left(\mathrm{E}_{0}\right)$ and the $V_{\max }$ is a function of $\mathrm{E}_{0}$ (Nannipieri and Gianfreda, 1998; Allison et al., 2010; Blagodatskaya et al., 2016).

The difference in $V_{\max }$ between the hotspots and bulk soil was specific for individual enzymes, with higher $V_{\max }$ of $\beta$-glucosidase in thehotspots compared to bulk soil (Fig. 3). This observation partly rejected our first hypothesis again. It is necessary to underline that the activity of the enzymes was used here as an example of single enzyme-mediated processes (e.g., decomposition of cellulose-like oligosaccharides or hydrolysis of amino acid residues of polypeptides), which contributed to the decomposition of soil organics along with a large number of other processes and corresponding enzymes. Despite some empirical relationships observed (Sinsabaugh et al., 2008), neither $\beta$-glucosidase nor leucine aminopeptidase can be considered as an indicator of the heterogeneous process of $\mathrm{C}$ - or Ncycling. It is conceptually wrong to use the activity of single enzyme (for example, leucine aminopeptidase) as an indicator of general microbial $\mathrm{N}$ acquisition, which depends on the activity of many various enzymes and physiological factors conjointly (Nannipieri et al., 2018).

The higher $V_{\max }$ of $\beta$-glucosidase in the hotspots indicates that the activity of enzymes is also a function of the amount of available substrate (Allison and Vitousek, 2005). The easily available $\mathrm{C}$ input by roots triggers microbial activity and thus drives the fast microbial metabolism (mainly by r-strategists) on the substrate, which could favor counter- balancing the high C inputs (Kuzyakov and Blagodatskaya, 2015), resulting in the higher $V_{\max }$ in the hotspots versus bulk soil (Jones et al., 2003; Fischer et al., 2010). Supporting our interpretation, we found a good correspondence of growing microbial biomass and $V_{\max }$ of $\beta$-glucosidase (Fig. 4), indicating the strong association between microbial growth and functions (Dorodnikov et al., 2009). Thus, the fast-growing microorganisms with r-strategy in the hotspots are characterized by production of C-hydrolytic enzyme, which helps to consume the continuous input of labile $\mathrm{C}$ from roots (Sanaullah et al., 2016). However, the activity of the N-hydrolytic enzyme showed no significant correlation with the growing microbial biomass due to the insignificant difference in $V_{\max }$ of leucine aminopeptidase 
between the hotspots and bulk soil. Given the $\mathrm{C} / \mathrm{N}$ ratio around and above 20 in both soils (Table 1), the microbial acquisition of $\mathrm{N}$ was strongly restricted by nutrient supply capacity according to stoichiometric constraints (Sinsabaugh et al., 2009). As root exudates and rhizodeposits are generally depleted in $\mathrm{N}$ content, the $\mathrm{N}$ supply capacity was even lower in the hotspots than in bulk soil, thus restricting mobilization of organic $\mathrm{N}$ by microorganisms (Tarafdar and Jungk, 1987; Badalucco and Nannipieri, 2007; Kuzyakov and Xu, 2013).

In accordance with ecological principles, the $K_{m}$ increased in rhizosphere hotspots compared to bulk soil (Fig. 3b), indicating decreased affinity of enzymes as an effect of root exudates and rhizodeposits (Blagodatskaya et al., 2009). It is important to note that enzyme activity determined in situ in soil is a cumulative action of the entire microbial community, which produced a set of isoenzymes with similar functions but different environmental optima (Nannipieri et al., 1982; Nannipieri and Gianfreda, 1998). Therefore, the apparent $V_{\max }$ and $K_{m}$ represent average values of kinetic constants, reflecting simultaneous activity of a suite of isoenzymes catalyzing the same reactions (Nannipieri and Gianfreda, 1998; Razavi et al., 2016a). The higher $K_{m}$ values in the hotspots versus bulk soil indicated altered enzyme systems by rhizo-microbial interactions. Such changes resulted in a strong increase in $V_{\max }$ of $\mathrm{C}$-acquiring $\beta$-glucosidase due to high availability of oligosaccharides in the rhizosphere hotspots; while they were insufficient to increase the $V_{\max }$ of leucine aminopeptidase due to lack of oligopeptides and other N-containing substrates, again indicating the possible re- striction of $V_{\max }$ by basic soil properties.

Low enzyme affinity to substrate observed in the rhizosphere is typical for fastgrowing r-strategists, showing higher $K_{m}$ values (Fierer et al., 2007). The slow-growing K-strategists with enzymes of high substrate affinity are better adapted for growth on poorly available substrates, and they are uncompetitive against the r-strategists in rhizosphere hotspots (Dorodnikov et al., 2009). In fact, the decrease of substrate affinity is in line with the stoichiometric theory postulating that microbes regulate enzyme activities in response to soil resource availability to match their nutrient requirements (Sinsabaugh and Follstad Shah, 2012). Therefore, the shift in enzyme intrinsic properties $\left(K_{\mathrm{m}}\right)$ under different substrate availability was presumably associated with changes in microbial species domination, accompanying with the expression of isoenzymes with the same function but different conformations and structures (Somero, 1978). Thus, the $K_{m}$ values were independent on basic soil properties, demonstrating that enzyme affinity to substrate was mainly modulated by roots. In contrast, $V_{\max }$ was affected by both soil quality and plant-microbial interactions. 
Rhizosphere hotspots contain a stimulated microbial community with a greater enzyme activity and a lower affinity for the substrate compared to bulk soil. However, no difference in the catalytic efficiency $\left(K_{a}\right)$ of enzymes or turnover time of the substrate was detected between the hotspots and bulk soil due to simultaneous increases in $V_{\max }$ and $K_{m}$ (Fig. 5). This finding was inconsistent with the results of Sanaullah et al. (2016) who found that higher $K_{a}$ was detected in bulk soil, however, we found the same trend: both $V_{\max }$ and $K_{m}$ increased in the hotspots. Thus, our study revealed strong changes in enzyme systems in the hotspots versus bulk soil (as indicated by altered activity and affinity); as a result, an increased $K_{m}$ counterbalanced an increase in $V_{\max }$ resulting in similar catalytic efficiency in soil microhabitats. Furthermore, much shorter turnover time of substrate and higher catalytic efficiency in the fertile versus the poor soil suggest that microbial communities change the intrinsic properties of hydrolytic enzymes to adapt to different environments (Razavi et al., 2016b).

\subsection{Conclusions}

Microbial hotspots and bulk soil were successfully distinguished by soil zymography and were precisely sampled by tiny wet-needle approach with the goal of comparing the effects of hotspots on microbial growth and enzyme kinetic parameters. Overall, the differences in microbial growth between the hotspots and bulk soil were significant in the poor soil only, i.e., they were regulated by inherent soil substrate availability (Fig. 6). A difference in enzyme activity and affinity was detected between the hotspots and bulk soil in the fertile and the poor soils but was enzyme-specific: the difference was significant for $\beta$-glucosidase (one of enzymes involved in the decomposition of oligosaccharides), whereas it was insignificant for leucine aminopeptidase (enzyme contributing to the decomposition of proteins). In both soils, enzyme systems changed towards decreased affinity for the substrate to maintain similar catalytic efficiency in the hotspots versus bulk soil, which was the preferred microbial strategy in the tested soils. 
Poor soil hotspots

Fertile soil hotspots

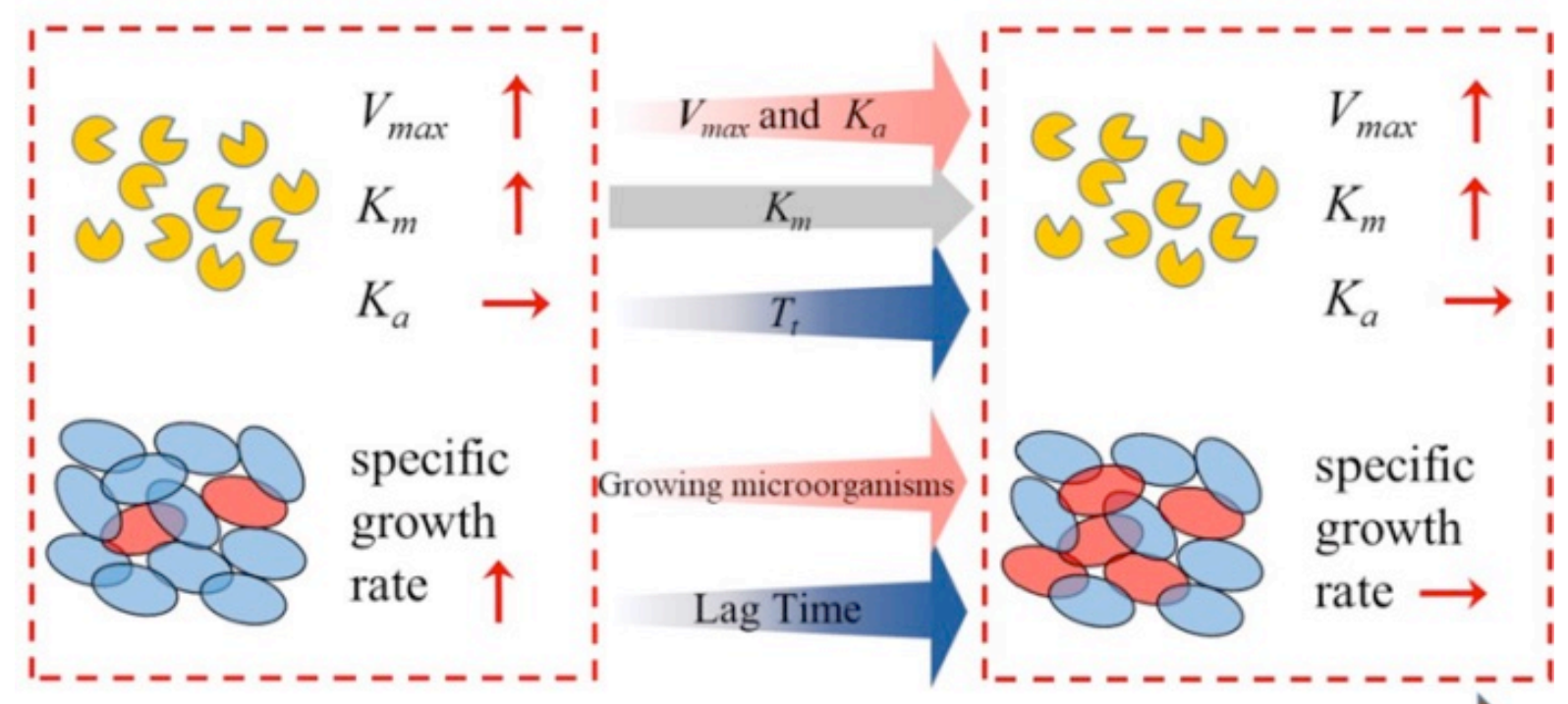

\section{Soil fertility}

Sustaining

microorganisms
Growing

microorganisms
Enzymes

Fig. 6 Conceptual graph showing changes of microbial activities and functions in the hotspots as affected by soil fertility. Vertical and horizontal red arrow indicate increase and no change of microbial kinetics and functions in the hotspots compared to bulk soil, respectively. Red gradient arrow indicates increasing trend, blue gradient arrow indicates decreasing trend, gray arrow indicates no change along soil fertility.

\section{Declaration of competing interest}

The authors declare that they have no known competing financial interests or personal relationships that could have appeared to influence the work reported in this paper.

\section{Acknowledgements}

We would like to thank Xiaona Song for her help with the laboratory work. This research was supported by the National Natural Science Foundation of China (grant No.31830015), National Key Research and Development Program of China (grant No. 2016YFA0600801). Contribution of BSR and EB was motivated and supported within the framework of the priority program 2089, funded by the DFG- Projects Nr. RA3062/3-1 and Nr. 403664478, respectively. The publication was financially supported by the "RUDN University Program 5-100". The authors appreciate very much the contribution of the reviewer and the editor, who identified and suggested to address several very important methodological and conceptual issues, improving the clarity and scientific value of the manuscript. 


\section{References}

Allison, S., Vitousek, P., 2005. Responses of extracellular enzymes to simple and complex nutrient inputs. Soil Biology and Biochemistry 37, 937-944.

Allison, S.D., Wallenstein, M.D., Bradford, M.A., 2010. Soil-carbon response to warming dependent on microbial physiology. Nature Geoscience 3, 336-340.

Badalucco, L., Nannipieri, P., 2007. Nutrient transformation in the rhizosphere. In: Pinton, R., Varanini, Z., Nannipieri, P. (Eds.), The Rhizosphere: Biochenistry and Organic Substrates at the Soil-Plant Interface. CRC Prss, Boca Raton, FL, pp. 111-133.

Blagodatskaya, E.V., Blagodatsky, S.A., Anderson, T.H., Kuzyakov, Y., 2009. Contrasting effects of glucose, living roots and maize straw on microbial growth kinetics and substrate availability in soil. European Journal of Soil Science 60, 186-197.

Blagodatskaya, E., Kuzyakov, Y., 2013. Active microorganisms in soil: critical review of estimation criteria and approaches. Soil Biology and Biochemistry 67, 192-211.

Blagodatskaya, E., Blagodatsky, S., Anderson, T.H., Kuzyakov, Y., 2014. Microbial growth and carbon use efficiency in the rhizosphere and root-free soil. PLoS One 9, e93282.

Blagodatskaya, E., Blagodatsky, S., Khomyakov, N., Myachina, O., Kuzyakov, Y., 2016. Temperature sensitivity and enzymatic mechanisms of soil organic matter decomposition along an altitudinal gradient on Mount Kilimanjaro. Scientific Reports 6, 22240.

Blagodatsky, S.A., Heinemeyer, O., Richter, J., 2000. Estimating the active and total soil microbial biomass by kinetic respiration analysis. Biology and Fertility of Soils 32, 73-81.

Blagodatsky, S.A., Smith, P., 2012. Soil physics meets soil biology: towards better mechanistic prediction of greenhouse gas emissions from soil. Soil Biology and Biochemistry 47, 78-92.

Cheng, W.X., 2009. Rhizosphere priming effect: its functional relationships with microbial turnover, evapotranspiration, and C-N budgets. Soil Biology and Biochemistry 41, 1795-1801.

de Ridder-Duine, A.S., Kowalchuk, G.A., Klein Gunnewiek, P.J.A., Smant, W., van Veen, J.A., de Boer, W., 2005. Rhizosphere bacterial community composition in natural stands of Carexarenaria (sand sedge) is determined by bulk soil community composition. Soil Biology and Biochemistry 37, 349-357.

Dippold, M.A., Kuzyakov, Y., 2013. Biogeochemical transformations of amino acids in soil assessed by position-specific labelling. Plant and Soil 373, 385-401.

Dorodnikov, M., Blagodatskaya, E., Blagodatsky, S., Marhan, S., Fangmeier, A., Kuzyakov, Y., 2009. Stimulation of microbial extracellular enzyme activities by elevated $\mathrm{CO} 2$ depends on aggregate size. Global Change Biology 15, 1603-1614.

Fierer, N., Bradford, M.A., Jackson, R.B., 2007. Toward an ecological classification of soil bacteria. Ecology 88, 1354-1364.

Fischer, H., Ingwersen, J., Kuzyakov, Y., 2010. Microbial uptake of low-molecularweight organic substances out-competes sorption in soil. European Journal of Soil Science 61, 504-513. 
Ge, T.D., Wei, X.M., Razavi, B.S., Zhu, Z.K., Hu, Y.J., Kuzyakov, Y., Jones, D.L., Wu, J.S., 2017. Stability and dynamics of enzyme activity patterns in the rice rhizosphere: effects of plant growth and temperature. Soil Biology and Biochemistry 113, 108-115.

German, D.P., Chacon, S.S., Allison, S.D., 2011. Substrate concentration and enzyme allocation can affect rates of microbial decomposition. Ecology 98, 1471-1480.

Goddard, V.J., Bailey, M.J., Darrah, P., Lilley, A.K., Thompson, I.P., 2001. Monitoring temporal and spatial variation in rhizosphere bacterial population diversity: a community approach for the improved selection of rhizosphere competent bacteria. Plant and Soil 232, 181-193.

Grayston, S.J., Wang, S., Campbell, C.D., Edwards, A.C., 1998. Selective influence of plant species on microbial diversity in the rhizosphere. Soil Biology and Biochemistry 30, 369-378.

Haußmann, T., Lux, W., 1997. Dauerbeobachtungsflächen zur Umweltkontrolle im Wald: Level II. BMELF. Erste Ergebnisse, Bonn 148.

Heitkötter, J., Marschner, B., 2018. Soil zymography as a powerful tool for exploring hotspots and substrate limitation in undisturbed subsoil. Soil Biology and Biochemistry 124, 210-217.

Heuvelink, G.B.M., Webster, R., 2001. Modelling soil variation: past, present, and future. Geoderma 100, 269-301.

Hoang, D.T.T., Pausch, J., Razavi, B.S., Kuzyakova, I., Banfield, C.C., Kuzyakov, Y., 2016. Hotspots of microbial activity induced by earthworm burrows, old root channels, and their combination in subsoil. Biology and Fertility of Soils 52, 1105-1119.

Hodge, A., Robinson, D., Filter, A., 2000. Are microorganisms more effective than plants at competing for nitrogen? Trends in Plant Science 5, 304-308.

Jones, D.L., Dennis, P.G., Owen, A.G., van Hees, P.A.W., 2003. Organic acid behavior in soils misconceptions and knowledge gaps. Plant and Soil 248, 31-41.

Kuzyakov, Y., Blagodatskaya, E., 2015. Microbial hotspots and hot moments in soil: concept \& review. Soil Biology and Biochemistry 83, 184-199.

Kuzyakov, Y., Razavi, B.S., 2019. Rhizosphere size and shape: temporal dynamics and spatial stationarity. Soil Biology and Biochemistry 135, 343-360.

Kuzyakov, Y., Xu, X.L., 2013. Competition between roots and microorganisms for nitrogen: mechanisms and ecological relevance. New Phytologist 198, 656-669.

Lang, F., Krüger, J., Amelung, W., Willbold, S., Frossard, E., Bünemann, E.K., Bauhus, J., Nitschke, R., Kandeler, E., Marhan, S., Schulz, S., Bergkemper, F., Schloter, M., Luster, J., Guggisberg, F., Kaiser, K., Mikutta, R., Guggenberger, G., Polle, A., Pena, R., Prietzel, J., Rodionov, A., Talkner, U., Meesenburg, H., von Wilpert, K., Hölscher, A., Dietrich, H.P., Chmara, I., 2017. Soil phosphorus supply controls $\mathrm{P}$ nutrition strategies of beech forest ecosystems in Central Europe. Biogeochemistry 136, 5-29. 
Ma, X.M., Zarebanadkouki, M., Kuzyakov, Y., Blagodatskaya, E., Pausch, J., Razavi, B.S., 2018. Spatial patterns of enzyme activities in the rhizosphere: effects of root hairs and root radius. Soil Biology and Biochemistry 118, 69-78.

Ma, X.M., Razavi, B.S., Holz, M., Blagodatskaya, E., Kuzyakov, Y., 2017. Warming increases hotspot areas of enzyme activity and shortens the duration of hot moments in the root-detritusphere. Soil Biology and Biochemistry 107, 226-233.

Marx, M.C., Wood, M., Jarvis, S.C., 2001. A microplate fluorimetric assay for the study of enzyme diversity in soils. Soil Biology and Biochemistry 33, 1633-1640.

Moscatelli, M.C., Lagomarsino, A., Garzillo, A.M.V., Pignataro, A., Grego, S., 2012. $\beta$-Glucosidase kinetic parameters as indicators of soil quality under conventional and organic cropping systems applying two analytical approaches. Ecological Indicators 13, 322-327.

Nannipieri, P., Ascher, J., Ceccherini, M.T., Landi, L., Pietramellara, G., Renella, G., 2003. Microbial diversity and soil functions. European Journal of Soil Science 54, 655-670.

Nannipieri, P., Ceccanti, B., Cervelli, S., Conti, C., 1982. Hydrolases extracted from soil: kinetic parameters of several enzymes catalysing the same reaction. Soil Biology and Biochemistry 14, 429-432.

Nannipieri, P., Gianfreda, L., 1998. Kinetics of enzyme reactions in soil environments. In: Huang, P.M., Senesi, N., Buffle, J. (Eds.), Structure and Surface Reactions. John Wiley \& Sons, New York, pp. 449-479.

Nannipieri, P., Trasar-Cepeda, C., Dick, R.P., 2018. Soil enzyme activity: a brief history and biochemistry as a basis for appropriate interpretations and meta-analysis. Biology and Fertility of Soils 54, 11-19.

Panikov, N.S., 1995. Microbial Growth Kinetics. Chapman \& Hall, London, UK.

Panikov, N., Blagodatsky, S., Blagodatskaya, J., Glagolev, M., 1992. Determination of microbial mineralization activity in soil by modified Wright and Hobbie method. Biology and Fertility of Soils 14, 280-287.

Panikov, N.S., Sizova, M.V., 1996. A kinetic method for estimating the biomass of microbial functional groups in soil. Journal of Microbiological Methods 24, 219-230.

Pausch, J., Kuzyakov, Y., 2011. Photoassimilate allocation and dynamics of hotspots in roots visualized by $14 \mathrm{C}$ phosphor imaging. Journal of Plant Nutrition and Soil Science 174, 12-19.

Philippot, L., Raaijmakers, J.M., Lemanceau, P., van der Putten, W.H., 2013. Going back to the roots: the microbial ecology of the rhizosphere. Nature Reviews Microbiology 11, 789-799.

Razavi, B.S., Blagodatskaya, E., Kuzyakov, Y., 2015. Nonlinear temperature sensitivity of enzyme kinetics explains canceling effect-a case study on loamy haplic Luvisol. Frontiers in Microbiology $6,1126$.

Razavi, B.S., Blagodatskaya, E., Kuzyakov, Y., 2016. Temperature selects for static soil enzyme systems to maintain high catalytic efficiency. Soil Biology and Biochemistry 97, 15-22. 
Razavi, B.S., Zarebanadkouki, M., Blagodatskaya, E., Kuzyakov, Y., 2016. Rhizosphere shape of lentil and maize: spatial distribution of enzyme activities. Soil Biology and Biochemistry 96, 229-237.

Razavi, B.S., Zhang, X.C., Bilyera, N., Guber, A., Zarebanadkouki, M., 2019. Soil zymography: simple and reliable? Review of current knowledge and optimization of method. Rhizosphere 11. Article 100161.

Sanaullah, M., Razavi, B.S., Blagodatskaya, E., Kuzyakov, Y., 2016. Spatial distribution and catalytic mechanisms of $\beta$-glucosidase activity at the root-soil interface. Biology and Fertility of Soils 52 , $505-514$.

Sinsabaugh, R.L., Follstad Shah, J.J., 2012. Ecoenzymatic stoichiometry and ecological theory. Annual Review of Ecology, Evolution, and Systematics 43, 313-343.

Sinsabaugh, R.L., Hill, B.H., Shah, J.J.F., 2009. Ecoenzymatic stoichiometry of microbial organic nutrient acquisition in soil and sediment. Nature 462, 795.

Sinsabaugh, R.L., Lauber, C.L., Weintraub, M.N., Ahmed, B., Allison, S.D., Crenshaw, C., Contosta, A.R., Cusack, D., Frey, S., Gallo, M.E., Gartner, T.B., Hobbie, S.E., Holland, K., Keeler, B.L., Powers, J.S., Stursova, M., Takacs-Vesbach, C., Waldrop, M. P., Wallenstein, M.D., Zak, D.R., Zeglin, L.H., 2008. Stoichiometry of soil enzyme activity at global scale. Ecology Letters $11,1252-1264$.

Salazar-Villegas, A., Blagodatskaya, E., Dukes, J.S., 2016. Changes in the size of the active microbial pool explain short-term soil respiratory responses to temperature and moisture. Frontiers in Microbiology 7, 524.

Schimel, J.P., Weintraub, M.N., 2003. The implications of exoenzyme activity on microbial carbon and nitrogen limitation in soil: a theoretical model. Soil Biology and Biochemistry 35, 549-563.

Somero, G., 1978. Temperature adaptation of enzymes- biological optimization through structurefunction compromises. Annual Review of Ecology and Systematics 9, 1-29.

Spohn, M., Ermak, A., Kuzyakov, Y., 2013. Microbial gross organic phosphorus mineralization can be stimulated by root exudates - a 33P isotopic dilution study. Soil Biology and Biochemistry 65, 254-263.

Tarafdar, J.C., Jungk, A., 1987. Phosphatase activity in the rhizosphere and its relation to the depletion of soil organic phosphorus. Biology and Fertility of Soils 3, 199-204.

Tischer, A., Blagodatskaya, E., Hamer, U., 2015. Microbial community structure and resource availability drive the catalytic efficiency of soil enzymes under land-use change conditions. Soil Biology and Biochemistry 89, 226-237. Webster, R., 2000. Is soil variation random? Geoderma 97, 149-163.

WRB, 2015. World Reference Base for Soil Resources 2014, Update 2015. International Soil Classification System for Naming Soils and Creating Legends for Soil Maps. World Soil Resources Reports. FAO, Rome. 
Zhang, X.C., Dippold, M.A., Kuzyakov, Y., Razavi, B.S., 2019. Spatial pattern of enzyme activities depends on root exudate composition. Soil Biology and Biochemistry 133, 83-93. 


\title{
4 Study 4: Resistance of microbial community and its functional sensitivity in the rhizosphere hotspots to drought
}

Xuechen Zhang ${ }^{\mathrm{a}, \mathrm{b}, \mathrm{c}}$, David D. Myrold ${ }^{\mathrm{d}}$, Lingling Shi ${ }^{\mathrm{b}, \mathrm{e}, \mathrm{f}}$, Yakov Kuzyakov ${ }^{\mathrm{g}, \mathrm{k}}$, Hongcui Dai ${ }^{\mathrm{a}, \mathrm{b} *}$, Duyen Thi Thu Hoang ${ }^{\mathrm{h}}$, Michaela A. Dippold ${ }^{\mathrm{b}}$, Xiangtian Mengi, Xiaona Song ${ }^{\mathrm{b}}$, Ziyan Li ${ }^{\mathrm{j}}$, Jie Zhou ${ }^{\mathrm{b}}$, Bahar S. Razavic

\section{Status: Published in Soil Biology \& Biochemistry}

${ }^{a}$ Crop Research Institute, Shandong Academy of Agricultural Sciences, Jinan 250100, PR China

${ }^{b}$ Department of Biogeochemistry of Agroecosystems, University of Göttingen, Göttingen, Germany

${ }^{\mathrm{c}}$ Department of Soil and Plant microbiome, Institute of Phytopathology, ChristianAlbrecht-University of Kiel, Kiel, Germany

${ }^{d}$ Department of Crop and Soil Science, Oregon State University, Corvallis, OR 97331

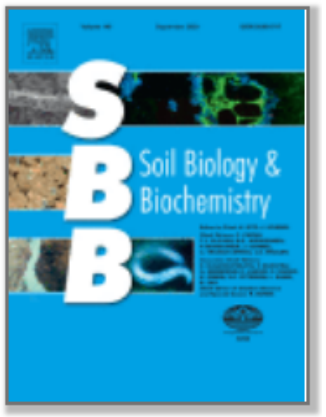
USA

${ }^{e}$ Key Laboratory of Economic Plants and Biotechnology, Kunming Institute of Botany, Chinese Academy of Sciences, 132 Lanhei Road, Kunming 650201, China

${ }^{f}$ World Agroforestry Centre, China \& East-Asia Office, 132 Lanhei Road, Kunming 650201, China

${ }^{g}$ Department of Agricultural Soil Science, Department of Soil Science of Temperate Ecosystems, University of Göttingen, Göttingen, Germany

${ }^{h}$ Master of Climate Change and Development Program, Vietnam-Japan University, Vietnam National University, Hanoi

${ }^{i}$ University of Chinese Academy of Sciences, Beijing 100049, China

${ }^{j}$ College of Resources and Environment, Northwest A\&F University, Yangling, 712100, China

${ }^{k}$ Agro-Technological Institute, RUDN University, 117198 Moscow, Russia

\begin{abstract}
Climate change impacts soil microbial communities, activities and functionality. Nonetheless, the responses of the microbiome in soil microenvironments with contrasting substrate availability in the rhizosphere to climatic stresses such as drought are largely unknown. To fill this knowledge gap, we coupled soil zymography with site-specific micro-sampling of the soil and subsequent high-throughput sequencing. This helped identify how the bacterial community structure and the genes encoding N-cycling enzymes (leucine aminopeptidase and chitinase) in rhizosphere hotspots and coldspots (microsites with activities in the range of bulk soil but localized within the rhizosphere) of maize respond to drought $(20 \% \mathrm{WHC}$, two weeks).

The elevated activities of leucine aminopeptidase and chitinase in rhizosphere hotspots were caused by the tight collaborative relationships between bacteria and their stable network structure rather than by any significant shift in bacterial community structure or enzymeencoding gene copies. Despite the similarity in bacterial community structure in soil under drought and optimal moisture, functional predictions indicated the increased relative abundance of genera belonging to Actinobacteria capable of leucine aminopeptidase and chitinase production, especially Streptomyces, Nocardioides, Marmoricola, and Knoellia.
\end{abstract}


Accordingly, the number of gene copies encoded by Actinobacteria for these two enzymes increased by 5.0 - 17\% under drought. Among the bacteria with increased relative abundance under drought, Luedemannella played a crucial role in mediating nutrients and energy fluxes between bacteria under drought. This was reflected in a $35-70 \%$ increase in leucine aminopeptidase and chitinase activities under drought. The resistance of enzyme activities to drought was higher in hotpots than that in coldspots. These results revealed that rhizosphere bacterial community composition remained stable, and that the number of gene copies encoded by Actinobacteria responsible for N-cycling enzymes increased under drought. The expected reduction of processes of $\mathrm{N}$ cycle was absent. Instead, bacteria increased $\mathrm{N}$ mining rate in those hotspots remaining active despite water scarcity.

Keywords: Drought, rhizosphere hotspots and coldspots, functional genes, resistance ${ }^{*}$ Corresponding author: daihongcui2013@163.com 


\section{Graphical abstract}

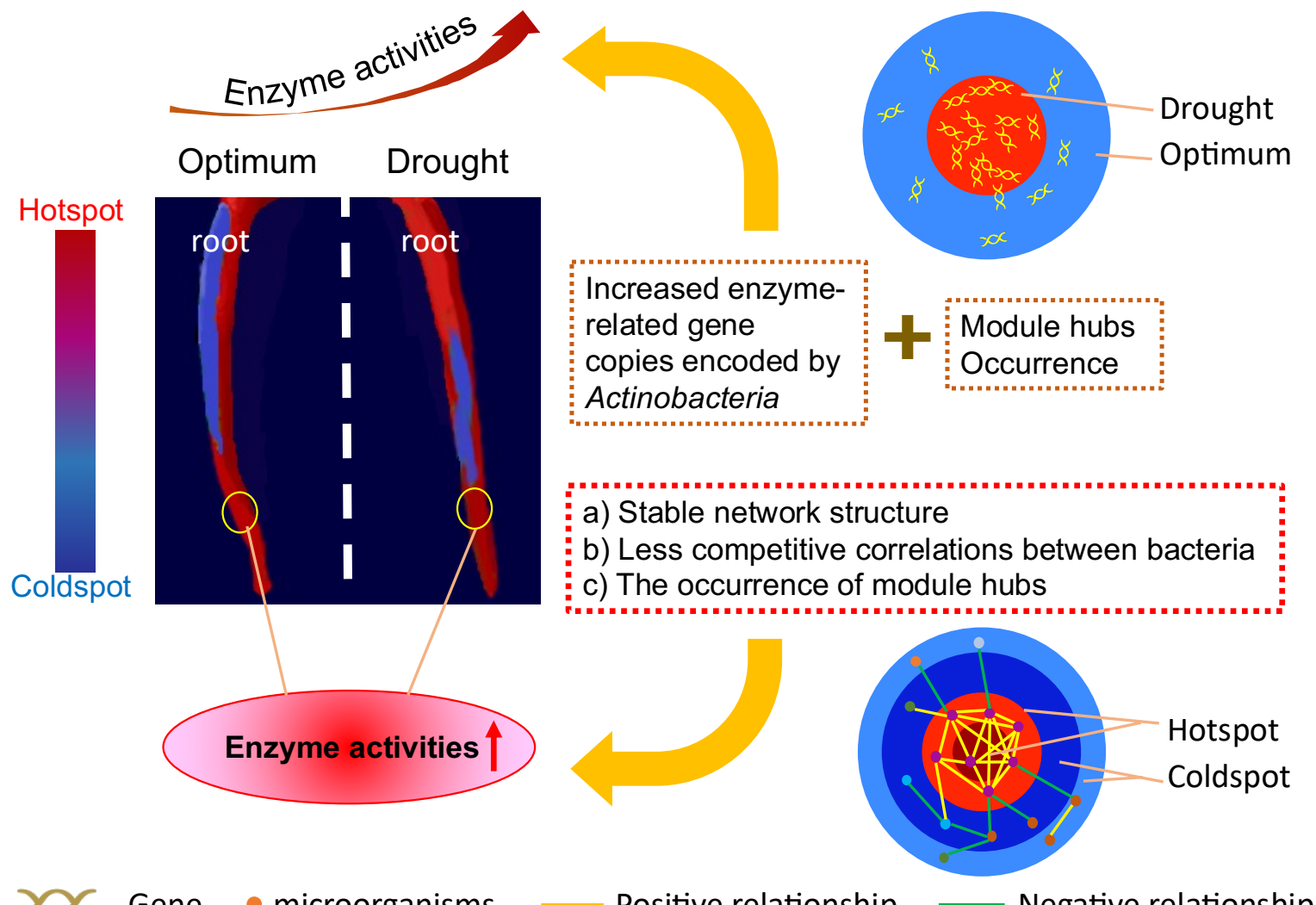




\subsection{Introduction}

One of the critical questions at the forefront of research in ecology is: "how will climate change alter the structure and functions of ecosystems across scales of space and time?" (Creamer et al., 2015; Sheik et al., 2011). One of the most frequently predicted effects of climate change on a broad set of ecosystems worldwide is an increased frequency and severity of droughts (Hasibeder et al., 2015). This will affect the quantity and quality of plant inputs of available organic compounds (Bardgett et al., 2008; Jones et al., 2009), thus probably changing the pattern of substrate distribution in soil. Heterogeneity in substrate localization is the primary reason for the existence of microbial hot- and coldspots in soil with significantly increased or decreased biological activity, respectively (Kuzyakov and Razavi, 2019). Hotspots are locations in soil, such as the rhizosphere, with increased microbial abundance, activities and faster process rates (Kuzyakov and Blagodatskaya, 2015). The heterogeneous soil environment forms microsites within the rhizosphere characterized by activities that are in the range of bulk soil (here defined as coldspots, Fig. 1). Previous studies have shown similar functions between or within hotspots despite dissimilarities in their microbial community structure (Kuzyakov and Blagodatskaya, 2015; Sanaullah et al., 2011). Although various communities may carry out similar functions, they may not be equivalent in other respects, such as in the efficiencies with which they express these functions in hotspots and their sensitivity to abiotic factors (e.g. drought). An improved understanding of drought consequences on the micro-scale (i.e., on hot- versus coldspots), and of the mechanisms involved, would help assess impacts on ecosystem (e.g., macro-scale) processes and functioning. This is particularly crucial for agro-ecosystems, where many essential ecosystem services relevant to human well-being are linked to micro-scale processes in hot- or coldspots. For instance, diverse plant communities - unlike monoculture agro-ecosystems - favor the development of micropores $(30-150 \mu \mathrm{m})$. These pores are the micro-environments associated with enzymatic hotspots. More such pores mean a greater spatial footprint that microorganisms make on the soil and consequently a greater soil $\mathrm{C}$ storage capacity (Kravchenko et al., 2019; 2021). Moreover, the faster decomposition rates of soil organic matter (SOM) in the hotspots than bulk soil, and thus the associated increased $\mathrm{CO}_{2}$ release, would provide feedbacks to global warming (Cheng et al., 2014).

Microorganisms modify the availability of most nutrients (Sheik et al., 2011). Recent studies suggest direct effects of soil bacterial community structure on the nitrogen $(\mathrm{N})$ cycle (e.g., Cookson et al., 2006; Ollivier et al., 2011). To meet their $\mathrm{N}$ demand, microorganisms produce a variety of $\mathrm{N}$-cycle related enzymes, such as chitinases and peptidases, to break 
down complex organic compounds into available forms (Kuzyakov and $\mathrm{Xu}, 2013$ ). A reduction in soil water content can impair microbial metabolic capabilities (Carbone et al., 2011) and enzyme activities (Ahmed et al., 2018; Chaves et al., 2003), and thus slow down N mobilization from SOM (Fuchslueger et al., 2014; Manzoni et al., 2012). Drought - the reduction of soil water content - impedes the diffusion of nutrients, substrates and enzymes (Davidson and Janssens, 2006), and increases osmotic stress for microbial cells. This induces a stress situation for microbial communities, at least in those microhabitats affected by drought (Navarro-García et al., 2012; Parker and Schimel, 2011).

A shift in community structure towards an increase of more tolerant soil biota is one of the most common responses to drought. Microbial functions (e.g., enzyme production) can also be affected (Bouskill et al., 2013). For instance, Gram-positive bacteria are more tolerant to drought because their cell walls are stronger compared with Gram-negative bacteria $(\mathrm{Bu}$ et al., 2018). The resistance of distinct microbial groups (i.e., their insensitivity to a disturbance) helps the whole system to maintain its ecosystem services even in disturbed environments (Shade et al., 2012). To "pay" for this resistance, energetically luxurious adaptation mechanisms divert resources from growth to survival processes (Schimel et al., 2007). Accordingly, microsites with abundant resources - microbial hotspots - may enhance the resistance of soil ecosystems. Those organisms that fail to cope with environmental stresses will die or become inactive, thus altering the composition of the microbial community (Placella et al., 2012).

Intensive discussion has been focused on microbial activity, diversity, and abundance in the rhizosphere and bulk soil. Little, however, is known about the spatial dissimilarity in microbial dynamics within the rhizosphere, where microorganisms are exposed to similar stochastic and temporal environmental changes. In particular, to what extent does drought stress determine the shift in initial microbiome community composition and functioning within the rhizosphere?

The degradation of high molecular organic matter depends on the microbial community's repertoire of genes encoding for the required enzymes (Bach et al., 2001). Changes in the abundance of enzyme-encoding genes reveal alteration of the microbial potential to respond to external disturbances, such as drought, but can also provide information on the source organisms of a particular enzyme (Nannipieri et al., 2018, 2012). Thus, analyzing and quantifying microbial gene abundance as well as gene expression enables determining whether a response in enzyme expression is driven by the selection of 
drought-resistant microorganisms or by altered regulation of the metabolism. Here, coupling high-throughput sequencing of $16 \mathrm{~S}$ rRNA with soil zymography (used as a map to localize the enzymatic hot- and coldspots, Zhang et al., 2019),-we tested the following hypotheses: 1) microbial community structure governs the higher enzyme activities in hotspots versus coldspot (H1); 2) specific bacterial taxa have individual responses to drought in enzymatic hot- and coldspots (H2);3) the resistance of enzyme activities to drought is higher in hotspots than in coldspots due to the high substrate availability (H3).

\subsection{Materials and Methods}

\subsubsection{Soil}

Soil samples were taken from the top $10 \mathrm{~cm}$ of the Ap horizon of an arable loamy Haplic Luvisol located on a terrace plain of the Leine River in the north-west of Göttingen, Germany. The soil consisted of $7 \%$ sand, $87 \%$ silt, $6 \%$ clay, with a bulk density of $1.4 \mathrm{~g} \mathrm{~cm}^{-3}$, a pH of 6.5 , total carbon of $11.6 \mathrm{~g} \mathrm{C} \mathrm{kg}^{-1}$, and total nitrogen of $1.2 \mathrm{~g} \mathrm{~N} \mathrm{~kg}^{-1}$. Total soil organic $\mathrm{C}$ and $\mathrm{N}$ content was determined by dry combustion (Elementar Analysensysteme GmbH, Hanau, Germany). The soil $\mathrm{pH}$ value was measured at room temperature in $\mathrm{H}_{2} \mathrm{O}$. For detailed information on the soil properties and methodology of measurement refer to Kramer et al. (2012).

\subsubsection{Experiment design}

Maize seeds (Zea mays L.) were germinated on filter paper in a dark environment for 3 days. Then one seedling was transplanted to each rhizobox $(12.3 \times 12.5 \times 2.3 \mathrm{~cm})$, which was filled with soil to a final bulk density of $1.4 \mathrm{~g} \mathrm{~cm}^{-3}$. The plants were kept in a climate chamber at a controlled temperature of $22 \pm 1{ }^{\circ} \mathrm{C}$ and a photo-period of $16 \mathrm{~h}$ light (photosynthetically active radiation intensity of $300 \mu \mathrm{mol} \mathrm{m} \mathrm{m}^{-2} \mathrm{~s}^{-1}$ ) and $8 \mathrm{~h}$ night for 3 weeks. During the growth period, the rhizobox surfaces were covered completely to avoid algal growth, and they were put inclined at an angle of $45^{\circ}$ to ensure root growth along the lower wall of the rhizobox.

Two treatments (drought and optimum) with three replicates were established. We irrigated the rhizoboxes with distilled water using capillary rise by immersing the boxes in water (with the water table $5 \mathrm{~cm}$ above the bottom of the rhizoboxes) for half an hour. During the first week's growth, the soil water content of all the rhizoboxes was maintained at $70 \%$ of water holding capacity (WHC). Thereafter, the drying stress was initiated (based on preliminary experiment, the drying takes 6 - 7 days). Half of the samples were dried (by plant transpiration) to $20 \%$ of WHC. The water content was measured gravimetrically by weighing 
the rhizoboxes and subtracting the dry weight (Fig S1). Thus, one group of maize was grown in soil with an optimal water content ( $70 \%$ of WHC) for 3 weeks. Another group of maize was kept under water limitation conditions, where soil water content was maintained at $70 \%$ of WHC for the first week, dried to $20 \%$ of WHC for one week and then kept at $20 \%$ of WHC for the last week.

After maize cultivation, soil zymography - an in situ technique - was applied to visualize hot- and coldspots of each enzyme: leucine aminopeptidase (EC 3.4.11.1) and chitinase (EC 3.2.1.52). Soil zymography was conducted using polyamide membranes (pore size: $0.45 \mu \mathrm{m}$, Tao Yuan, China) saturated with 4-methylumbelliferone (MUF)-substrates and 7-amino-4methylcoumarin (AMC)-substrates. These substrates become fluorescent when hydrolyzed by a corresponding enzyme (Razavi et al., 2016b). Leucine aminopeptidase activity was determined using L-leucine-7-amido-4-methylcoumarin hydrochloride. 4Methylumbelliferyl-N-acetyl-beta-D-glucosamine (MUF-NAG) (Sigma-Aldrich Co.) was used to detect chitinase activity - an enzyme that catalyzes the hydrolysis of terminal nonreducing $\mathrm{N}$-acetylglucosamine (NAG) residues in chitin oligomers. Detailed information can be found in Razavi et al. (2019). The zymographic image was used as a map to localize hotspots and coldspots of chitinase and leucine aminopeptidase activities (Fig. 1). Hotspots were defined as areas with intensities 2 standard deviation (SD) above the mean (Zhang et al., 2020); coldspots were considered as activities in the range of bulk soil but localized within the rhizosphere. For both drought and optimal conditions, the rhizosphere hot- and coldspot areas of leucine aminopeptidase were higher and clearer than that of chitinase. Therefore, due to the limited soil amount and to ensure the localization of enzymatic hot- and coldspots, the zymograms of leucine aminopeptidase were used for hotspot and coldspot sampling (Tian et al., 2020). About $1 \mathrm{~g}$ of soil from multiple hotspots or coldspots of each rhizobox were collected with a sterile needle and micro-spatula and pooled as one composite sample. This yielded a total of 12 samples ( 2 water conditions $\times 2$ microsites $\times 3$ replicates). Each soil sample was then divided into two portions for follow-up analysis (enzyme kinetics) or frozen at $-80^{\circ} \mathrm{C}$ (for molecular biology analysis) immediately. 

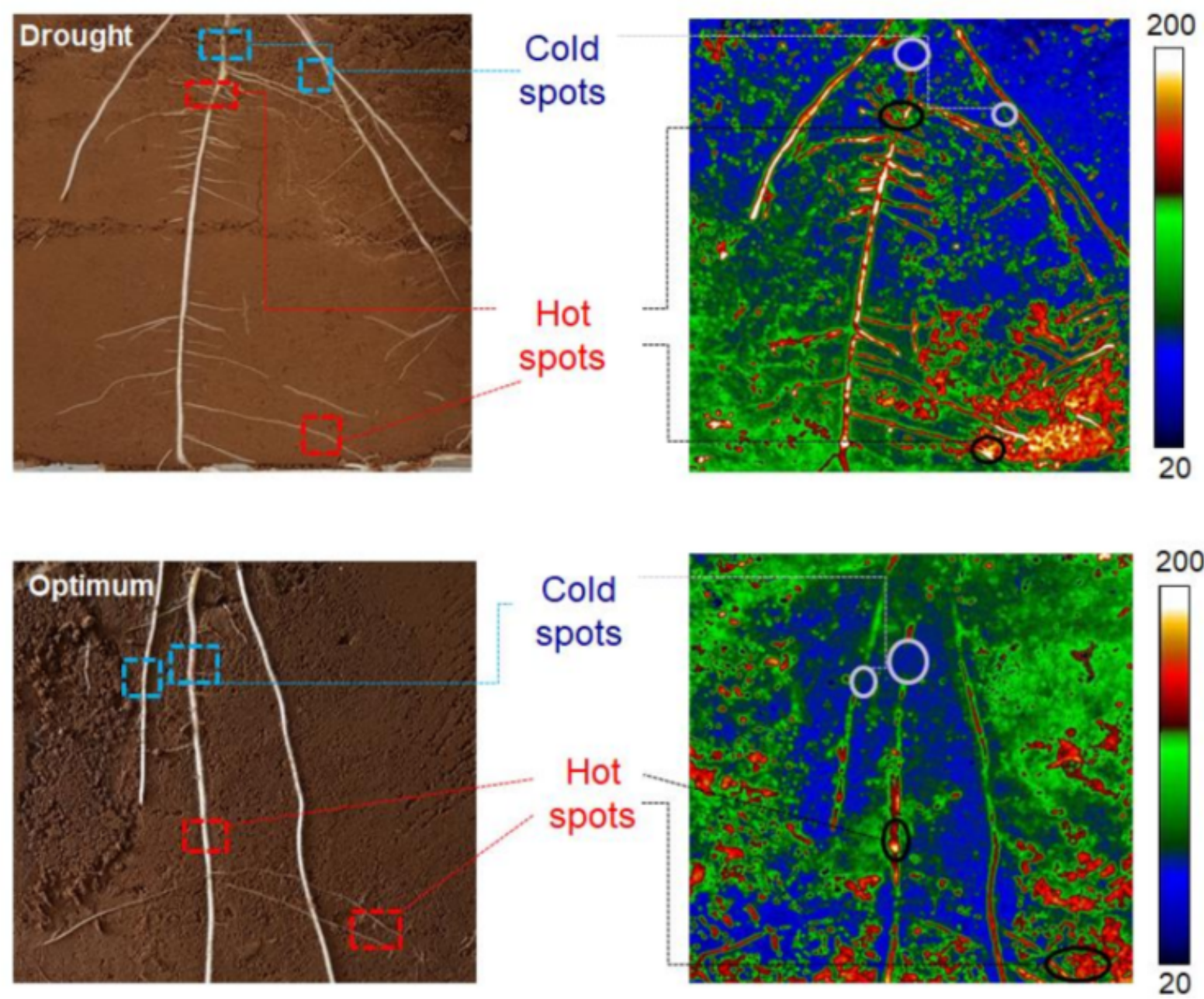

Fig. 1 Example of soil sampling from rhizosphere hotspots and coldspots based on zymography images of leucine aminopeptidase. Here, hotspots were defined as areas with gray values higher than mean +2 standard deviation (SD); coldspots were considered as activities in the range of bulk soil within the rhizosphere. Color bar represents enzyme activity (nmol cm $\mathrm{ch}^{-1}$ ) in soil with maize roots (21 days) under drought (20\% of WHC) and optimal moisture $(70 \%$ of $\mathrm{WHC})$.

\subsubsection{Enzyme kinetics and resistance}

The soil collected from rhizosphere hot- and coldspots was used to measure the kinetics of leucine aminopeptidase and chitinase. We determined enzyme activities in a range of substrate concentrations from low to high $\left(0,10,20,30,40,50,100,200 \mu \mathrm{mol} \mathrm{L}^{-1}\right)$. Saturation concentrations of fluorogenic substrates were determined in preliminary experiments. A soil suspension of $0.5 \mathrm{~g}$ soil and $50 \mathrm{~mL}$ deionized water was prepared after low-energy sonication (40 $\mathrm{J} \mathrm{s}^{-1}$ output energy) for 2 min. $50 \mu \mathrm{L}$ soil suspension, $100 \mu \mathrm{L}$ substrate and $50 \mu \mathrm{L}$ buffer (TRIZMA for leucine aminopeptidase, MES for chitinase) were added to a 96-well microplate (Koch et al., 2007; German et al., 2011). A Victor 1420-050 
Multi label Counter (Perkin Elmer, USA) was used to measure the fluorescence at an excitation wavelength of $355 \mathrm{~nm}$ and an emission wavelength of $460 \mathrm{~nm}$, and a split width of $25 \mathrm{~nm}$. Enzyme activities were recorded at 4 times $(0,30 \mathrm{~min}, 1 \mathrm{~h}$ and $2 \mathrm{~h})$ and were expressed as nmol MUF or AMC g ${ }^{-1}$ soil $^{-1}$. $\mathrm{V}_{\max }$ and $\mathrm{K}_{\mathrm{m}}$ were calculated with the MichaelisMenten equation:

$$
\mathrm{V}=\frac{\mathrm{V}_{\max } \times[\mathrm{S}]}{K_{m}+[S]}
$$

where $\mathrm{V}$ is the reaction rate, $[\mathrm{S}]$ is the substrate concentration, $\mathrm{K}_{\mathrm{m}}$ is the substrate concentration at the half-maximum reaction rate, and $\mathrm{V}_{\max }$ is the maximum reaction rate.

The resistance (RS) index of enzyme activity to drought was calculated by the following equation (Orwin and Wardle, 2004):

$$
R S\left(t_{0}\right)=1-\frac{2\left|D_{0}\right|}{C_{0}+\left|D_{0}\right|}
$$

where $\mathrm{D}_{0}$ is the difference in a biological function between the control soil $\left(C_{0}\right)$ and the drought soil $\left(P_{0}\right)$ at the end of disturbance $\left(t_{0}\right)$. This resistance index is between -1 and +1 , where +1 indicates no effects of disturbance (maximum resistance) and -1 indicates strongest effects (minimum resistance).

\subsubsection{Microbial analysis}

DNA was extracted from frozen hot- and coldspot samples (ca. $0.5 \mathrm{~g}$ ) using the Quick Soil Isolation Kit (Omega, USA), according to the manufacturer' s instructions. The V3-V4 region of $16 \mathrm{~S}$ rRNA was amplified with the primers 338F: 5'-ATGCAGGGACTA CHVGGGTWTCTAAT-3' and 806R: 5'-ACTCCTACGGGAGGCAGCA-3' (Jiang et al., 2019). Each sample had an eight-base Barcode at the 5' end of the primers. PCR for amplification was carried out under the following conditions: at $95{ }^{\circ} \mathrm{C}$ for $3 \mathrm{~min}$ followed by 27 cycles for $30 \mathrm{~s}$ at $95{ }^{\circ} \mathrm{C}$, annealing for $30 \mathrm{~s}$ at $55^{\circ} \mathrm{C}$, an extension for $45 \mathrm{~s}$ at $72{ }^{\circ} \mathrm{C}$ and a final extension for $5 \mathrm{~min}$ at $72{ }^{\circ} \mathrm{C}$. The PCR products after purifying with AxyPrep DNA Gel Extraction Kit (Axygen Biosciences. USA) were quantified using a QuantiFluor ${ }^{\mathrm{TM}_{-} \mathrm{ST}}$ fluorometer (Promega, USA). The products were then pooled, and the paired-end sequencing $(2 \times 300 \mathrm{bp})$ was conducted on an Illumina MiSeq sequencer. Sequencing data were processed using Quantitative Insights Into Microbial Ecology QIIME software (version 1.9.1) whereby the raw fastq files were quality filtered by Fastp0.19.6 and merged by FLASH1.2.11 based on the following workflow: i) discard the truncated sequences with $<50 \mathrm{bp}$ base if the average quality score was lower than 20; ii) Barcode sequences were also removed after 
sample sequences were sorted according to the barcodes which required no base mismatches. The maximum mismatch frequency per primer was $<2$ nucleotides. Remove all the sequences containing ambiguous bases; iii) sequences with an overlap of at least $10 \mathrm{bp}$ were assembled. Singletons were discarded prior to dereplication. Operational taxonomic units (OTUs) were clustered at $97 \%$ similarity cutoff while simultaneously removing chimera sequences (Uparse 7.0.1090). Then, clean data were mapped to the representative OTU to get the abundance table. Taxonomic annotation was assigned to OTU representative sequences based on the Silva 16S rRNA database by RDP classifier (2.11) with a confidence threshold of 70\% (Quast et al., 2012). All samples were normalized to rarefy sequences to the minimum number $(24,628$ sequences per sample). A total of 554,081 reads with an average length of 468 bp were detected. The rarefaction curves (Fig. S2) were asymptotic, indicating a nearcomplete sampling of the community.

The number of gene copies responsible for leucine aminopeptidase and chitinase was predicted by the Phylogenetic Investigation of Communities by Reconstruction of Unobserved States 2 (PICRUSt2) with reference to the Kyoto Encyclopedia of Genes and Genomes (KEGG) database (Langille et al., 2013; Wang et al., 2016). PICRUSt2 is freely available at https://github.com/picrust/picrust2 (Douglas et al., 2019). To further investigate the functional potential of the bacterial community, Tax4Fun2 was used to predict the functional profiles based on SILVA database. Tax4Fun2 is available at https://sourceforge.net/projects/tax4fun2/ (Wemheuer et al., 2020). The relative abundances of all the functions selected were then normalized by z-score.

\subsubsection{Statistical analysis}

All data were presented as mean \pm standard deviation (SD) of three replicates. The Shapiro-Wilk test was used to check normality, and Levene tests were performed to check the homogeneity of variances. If data met normality and homogeneity, the differences of enzyme kinetics $\left(\mathrm{V}_{\max }\right.$ and $\left.\mathrm{K}_{\mathrm{m}}\right)$ and all the microbial parameters were analyzed by two-way ANOVA using the software JMP, at $p<0.05$. The data of the resistance index met normality and homogeneity, and thus differences were analyzed by $t$-tests using the software JMP, at $p$ $<0.05$. If normality or homogeneity was not proved, the Scheirer-Ray-Hare test was performed in $\mathrm{R}$ (version 3.6.3), at $p<0.05$.

Principal coordinate analyses (PCoA) at the OTU level were applied to visualize the dissimilarity of bacterial communities among samples based on Bray-Curtis distance. PERMANOVA was used to assess whether drought, microsite and their interactions affected 
the bacterial community structure. PERMANOVA at the OTU level was conducted based on Bray-Curtis distance with the default 999 permutations. As the interactions of drought and microsite had no effect on enzyme kinetics (Fig. 2) or on bacterial community structure (Table S1), we performed network analysis based on the merged dataset $(n=6)$ from both moisture for hot- or coldspots or from both microsites for drought or optimal conditions. The network analysis was constructed to estimate the difference of bacterial relationships between coldspots and hotspots independent of water content, or only between drought and optimal conditions independent of microsites. The networks at the genus level were generated using Gephi (version 0.9.2), based on Spearman correlations. Only the top 100 genera were selected for network analysis. The cutoff value for the correlation coefficients was chosen as 0.85 with significance of $p<0.05$ (Dai et al., 2019). The natural connectivity was used to evaluate the stability of the network and it was estimated by removing nodes in the static network (Peng and $\mathrm{Wu}, 2016$ ).

The roles of individual nodes in the networks were determined by within-module connectivity $(\mathrm{Zi})$ and among-module connectivity $(\mathrm{Pi})$. The topological roles of nodes in the network were classified into: module hubs (well-connected nodes in the module, $\mathrm{Zi}>2$ ), network hubs (nodes highly connected both within and between modules, $\mathrm{Zi}>2$ and $\mathrm{Pi}>0.6$ ), connectors (highly connected nodes between modules, Pi $>0.6$ ), and peripherals (few connection nodes with other nodes, $\mathrm{Zi}<2$ and $\mathrm{Pi}<0.6$ ), according to nodes' within-module connectivity (Zi) and between-module links (Pi) (Deng et al., 2012; Guimerà and Nunes Amaral, 2005). The degree-distribution plot was generated based on network analysis.

\subsection{Results}

\subsubsection{Kinetics of leucine aminopeptidase and chitinase}

The $\mathrm{V}_{\max }$ values were higher in hotspots than in coldspots for both leucine aminopeptidase and chitinase (Fig. 2 a \& b). Accordingly, the results of zymography and enzyme kinetics after destructive sampling are in agreement, and our selection of enzymatic hot- and coldspots is confirmed. The $\mathrm{K}_{\mathrm{m}}$ values of cold- and hotspots were similar (Fig. 2 c $\& d)$.

Water content had a substantial impact on the catalytic characteristics of the enzymes (Fig. 2): the maximum activities $\left(\mathrm{V}_{\max }\right)$ of leucine aminopeptidase and chitinase under drought were 35 - 70\% higher (Fig. 2 a \& b) than under optimal moisture; $\mathrm{K}_{\mathrm{m}}$ under drought were $10-96 \%$ higher than under optimal moisture (Fig. 2 c \& d). The enzyme activities in hotspots were more resistant to drought than those in coldspots (Fig. 3). 

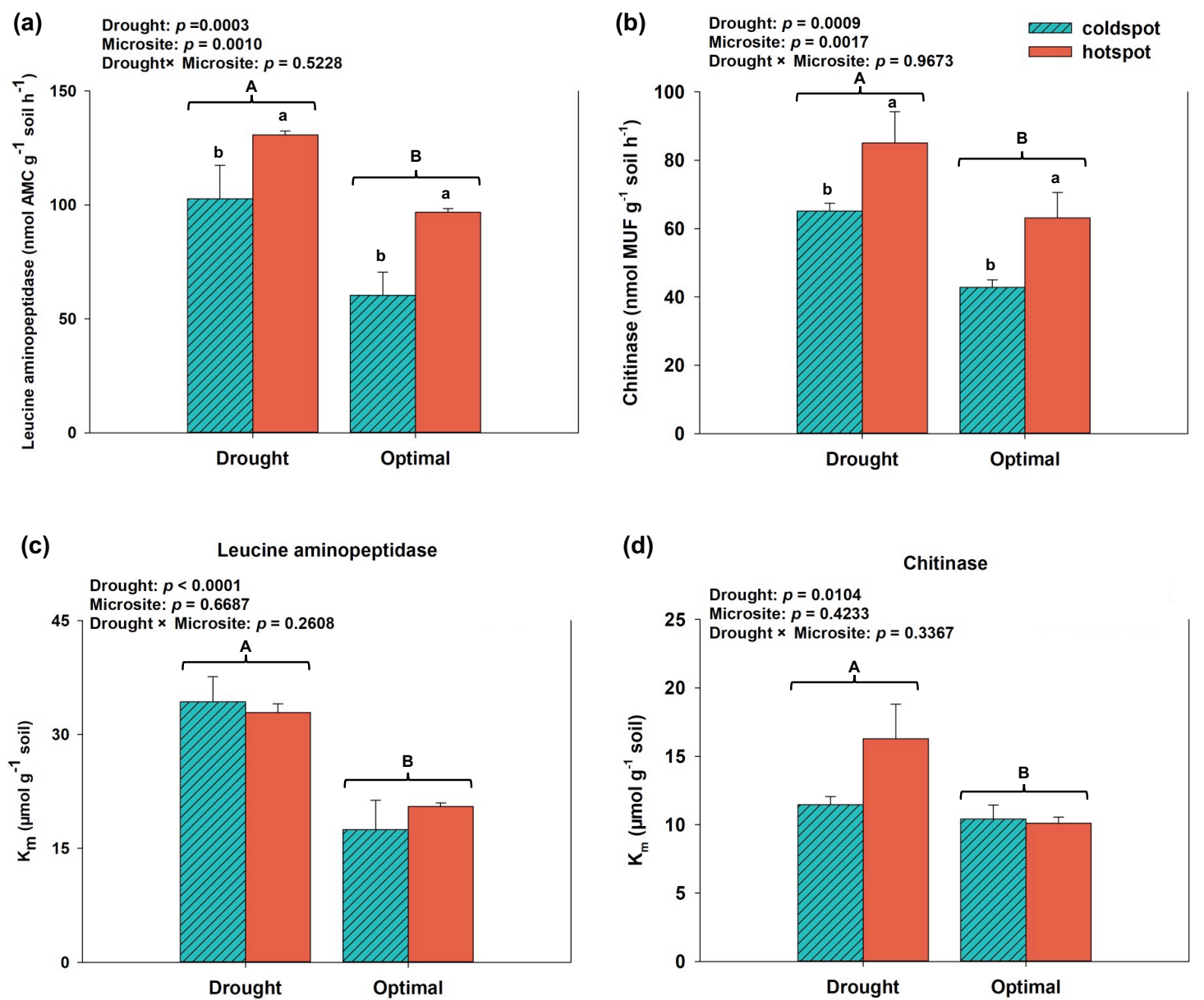

Fig. $2 V_{\max }(a, b)$ and $K_{m}(c, d)$ of leucine aminopeptidase and chitinase in soil from the rhizosphere hot- and coldspot under drought (20\% of WHC) and optimal moisture $(70 \%$ of WHC), respectively. Microsites: hotspots and coldspots. Lower case letters: significant differences between hot- and coldspots at $p<0.05$; Upper case letters: significant differences between drought and optimal moisture at $p<0.05$. 


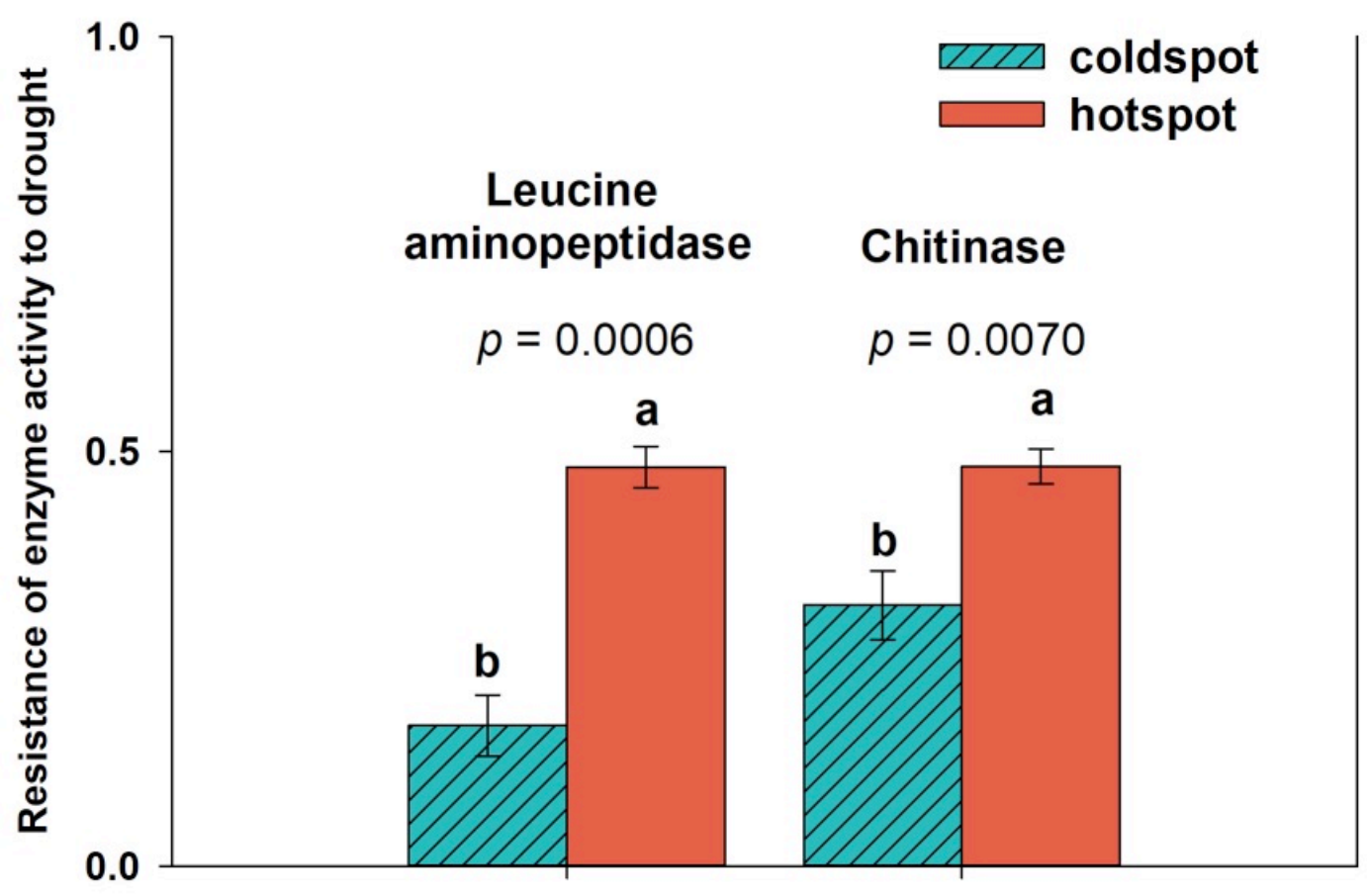

Fig. 3 The resistance of enzyme activity to drought (i.e. resistance $=1-\left(2\left|\mathrm{D}_{0}\right| /\left(\mathrm{C}_{0}+\left|\mathrm{D}_{0}\right|\right)\right)$. $\mathrm{D}_{0}$ is the difference in a biological function between the control soil $\left(\mathrm{C}_{0}\right)$ and the drought soil $\left(\mathrm{P}_{0}\right)$ at the end of disturbance $\left(\mathrm{t}_{0}\right)$. Letters indicate significant differences between hot- and coldspots.

\subsubsection{Soil bacterial community composition}

At the genus level, the dominant genera with a relative abundance $>1 \%$ were Gaiella, Arthrobacter, Nocardioides, Knoellia, Sphingomonas, Mycobacterium, Streptomyces, Microvirga, Marmoricola and Iamia in all samples (Fig. 4a). Nocardioides and Streptomyces, belonging to Actinobacteria, were more abundant in the soil under drought than that under optimal moisture $(p<0.05)$ (Fig. $4 b)$.

Drought, microsite and their interactions had no effect on alpha-diversity of the bacterial compositions (Table S2) and bacterial community structure (Fig. S3 and Table S1). 
(a)

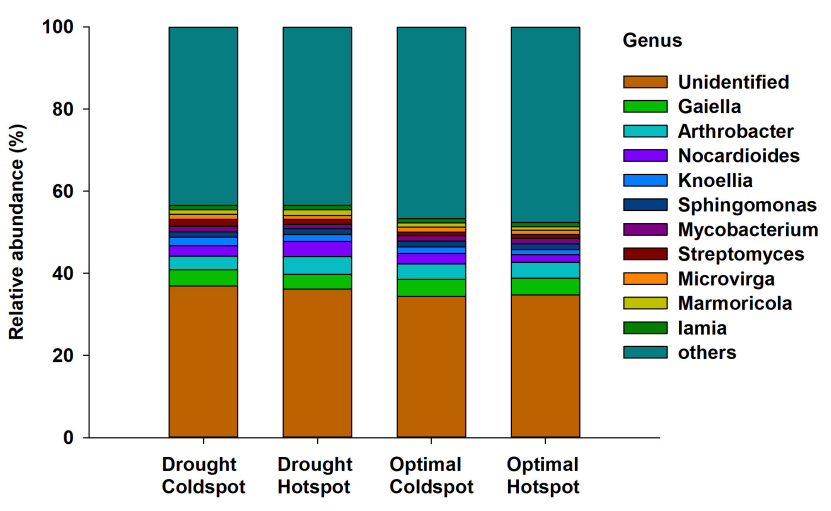

(b)

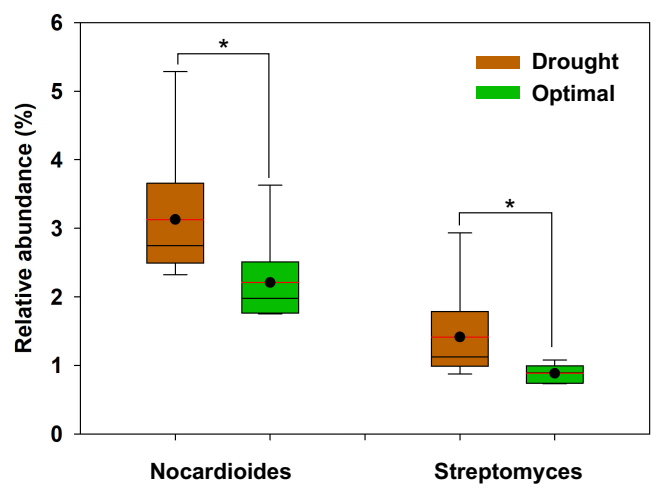

Fig. 4 Relative abundance of soil bacterial community members at the genus level in soil from rhizosphere hot- and coldspots under drought (20\% of WHC) and optimal moisture (70\% of WHC); (b) Relative abundance of Nocardioides and Streptomyces which were significant higher under drought than optimal conditions based on the merged dataset $(n=6)$ from both microsites. The Shapiro-Wilk test was used to check normality, and Levene tests were performed to check the homogeneity of variances. The normality or homogeneity was not proved, and the Wilcoxon test was performed at $p<0.05$. Asterisks indicate significant differences between drought and optimal conditions.

\subsubsection{The number of gene copies relevant to leucine aminopeptidase and chitinase}

At the phylum level, Actinobacteria was the only dominant phylum significantly affected by drought in contributing to the genetic potential for expressing leucine aminopeptidase and chitinase (Fig. 5). The number of Actinobacteria gene copies encoding leucine aminopeptidase was considerably increased $(5.0 \%$ for coldspots and $16.7 \%$ for hotspots) under drought compared to optimal moisture (Fig. 5a). Similarly, drought increased Actinobacteria gene copies encoding chitinase compared to optimal soil water content (Fig. $5 b)$. The number of gene copies encoding those N-related enzymes were similar between cold- and hotspots (Fig. 5). In order to explore the contribution of the bacteria relative abundance to the difference in the number of gene copies between drought and optimal moisture, we specifically calculated the relative abundance of genera that belong to the phylum Actinobacteria and have genes encoding leucine aminopeptidase and chitinase under two different water treatments. The relative abundance of all the genera that have genes encoding leucine aminopeptidase and chitinase increased $6.7 \%$ and $10.5 \%$ under drought compared to optimal moisture, respectively. The relative abundance ( $>1 \%$ under drought) of the 5 most increased genera belonging to Actinobacteria with genes encoding these 
enzymes under drought were Streptomyces, Nocardioides, Marmoricola, Knoellia and an unclassified genus of that phylum (Table S3 and S4).

Overall, water limitation increased the Actinobacteria gene copies of leucine aminopeptidase and chitinase, but the effects of cold- and hotspots were negligible.
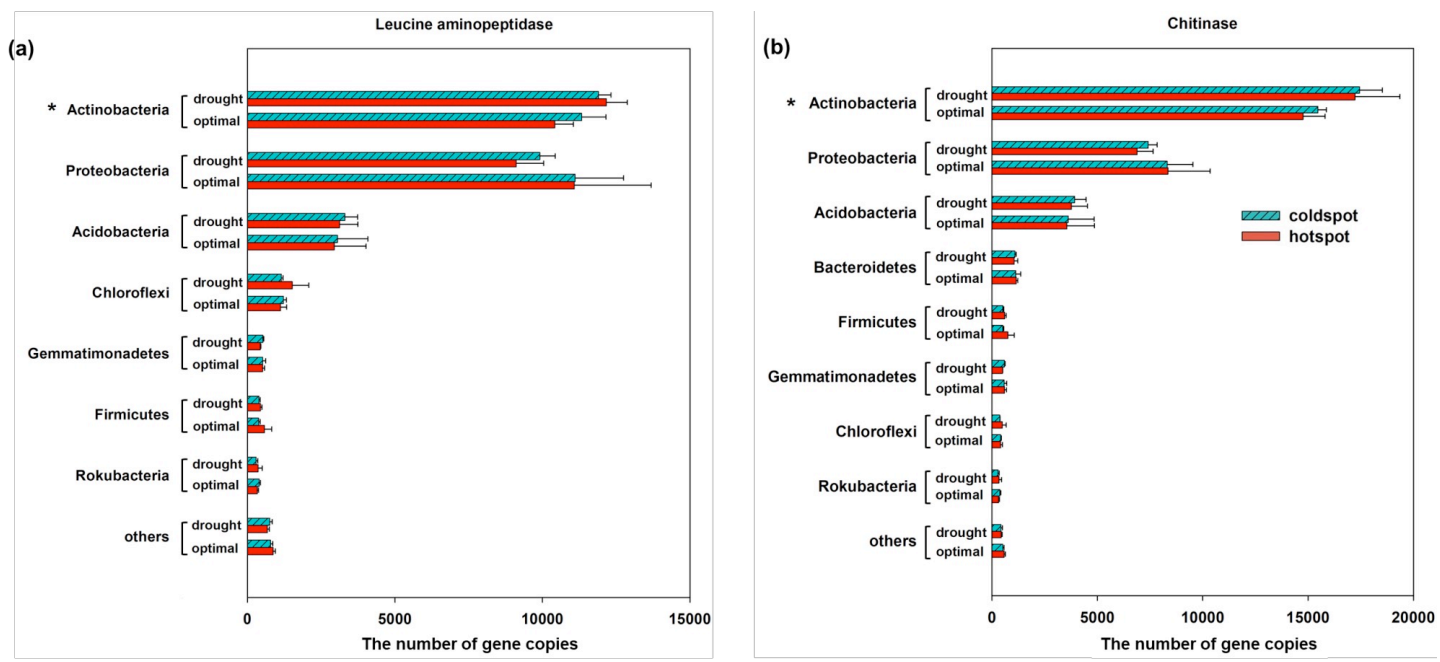

Fig. 5 The number of gene copies encoding (a) leucine aminopeptidase (EC 3.4.11.1) and (b) chitinase (EC 3.2.1.52) analyzed by PICRUSt2 for the soil from rhizosphere hot- and coldspots under drought (20\% of WHC) and optimal moisture ( $70 \%$ of WHC), respectively. Values are means of three replicates \pm standard deviation (SD). Star $(*)$ beside the legends indicates significant difference $(p<0.05)$ between drought and optimal moisture.

\subsubsection{Metabolic functions relevant to leucine aminopeptidase and chitinase activities}

Tax4Fun2 was used to evaluate the functional potential at the level 3 of the KEGG pathway hierarchy. Leucine aminopeptidase is involved in metabolic pathways and glutathione metabolism. The genes involved in glutathione metabolism were sensitive to drought (Fig. S4a). The relative abundance of genes for the pathways chitinase involving in: other glycan degradation, various types of $\mathrm{N}$-glycan biosynthesis, glycosaminoglycan degradation, and glycosphingolipid biosynthesis - ganglio series were increased under drought condition. (Fig. S4a). All these pathways belong to the category of metabolism at level 1 .

In addition to the pathways related to enzymes, we selected the functions with gene abundance $>1 \%$. Among them, the relative abundance of genes for biosynthesis of antibiotics, fatty acid metabolism, valine, leucine and isoleucine degradation, propanoate metabolism and fatty acid degradation increased $(p<0.05)$ under drought (Fig. S4b). 


\subsubsection{Network analysis of the bacterial community}

The number of positively correlated edges in hotspots (edge number $=546$ ) was greater than that in coldspots (edge number $=227$ ), and the ratio of positive to negative correlations in hotspots were 1.4 times higher than that in coldspots (Fig. 6a). Although there were far fewer significant correlations in the bacterial networks under drought (edge number $=357$ ) than that under optimal moisture (edge number $=946$ ) at the genus level, the ratios of positive to negative correlations were similar in both (drought 1.86, optimal moisture 1.80; Fig. 6b). The network structure in the soil of hotspots and of optimal moisture was more stable than that of coldspots and drought condition, respectively (Fig. S5).

(a)

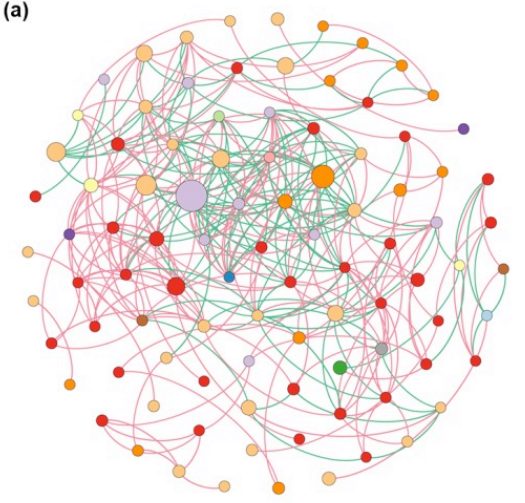

Coldspot

(b)

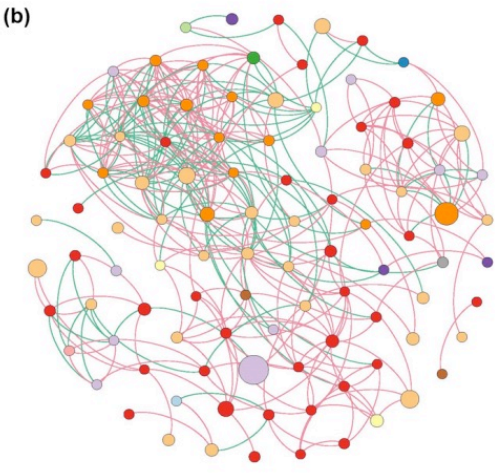

Drought

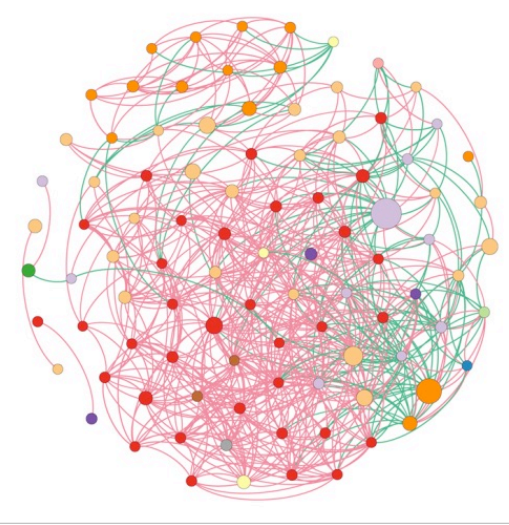

Hotspot

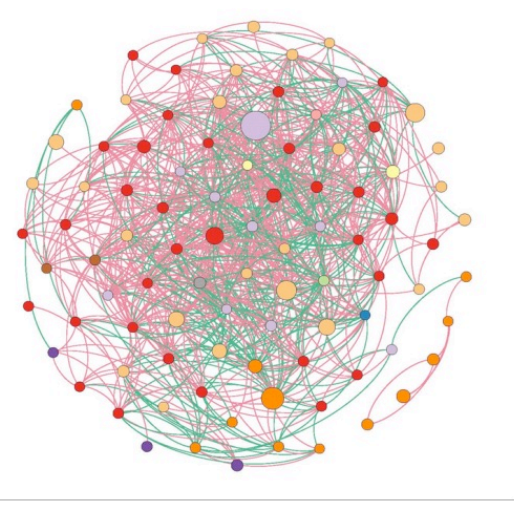

Optimum
Phylum

Proteobacteria

Actinobacteria

Chloroflexi

Acidobacteria

Firmicutes

Gemmatimonadetes

Bacteroidetes

Latescibacteria

Rokubacteria

$\bigcirc$ Verrucomicrobia

Planctomycetes

Patescibacteria

Nitrospirae

Fig. 6 Networks of top 100 genera for the soil from rhizosphere hot- and coldspots (a), and (b) under drought (20\% of WHC) and optimal moisture (70\% of WHC), based on Spearman correlation analysis. Red and green lines: strong positive relationships $(r>0.85, p<0.05)$ and strong negative relationships $(r<-0.85, p<0.05)$, respectively. Colored nodes represent corresponding genera assigned to major phyla. The size of each node is proportional to the relative abundance. 
Most nodes (genera) were classified as peripherals, and no genus was assigned as network hubs (Fig. 7). In coldspots, nine genera belonging to Proteobacteria, Actinobacteria, Acidobacteria and Chloroflexi were identified as connectors. In hotspots, four genera that serve as connectors belong to the phylum Proteobacteria, and one genus from the phylum Chloroflexi was identified as module hubs (Fig. 7a). Under drought, Luedemannella (Actinobacteria) was module hubs (Fig. 7b) and its relative abundance under drought increased $16.9 \%$ compared with optimal moisture (Fig. S6). Another unclassified genus in the phylum Proteobacteria was identified as module hubs. The genera Paenibacillus (Firmicutes), Nordella (Proteobacteria) and one unclassified genus belonging to Proteobacteria were connectors. Under optimal water content, seven genera belonging to Proteobacteria and Actinobacteria were designated as connectors (Fig. 7b).
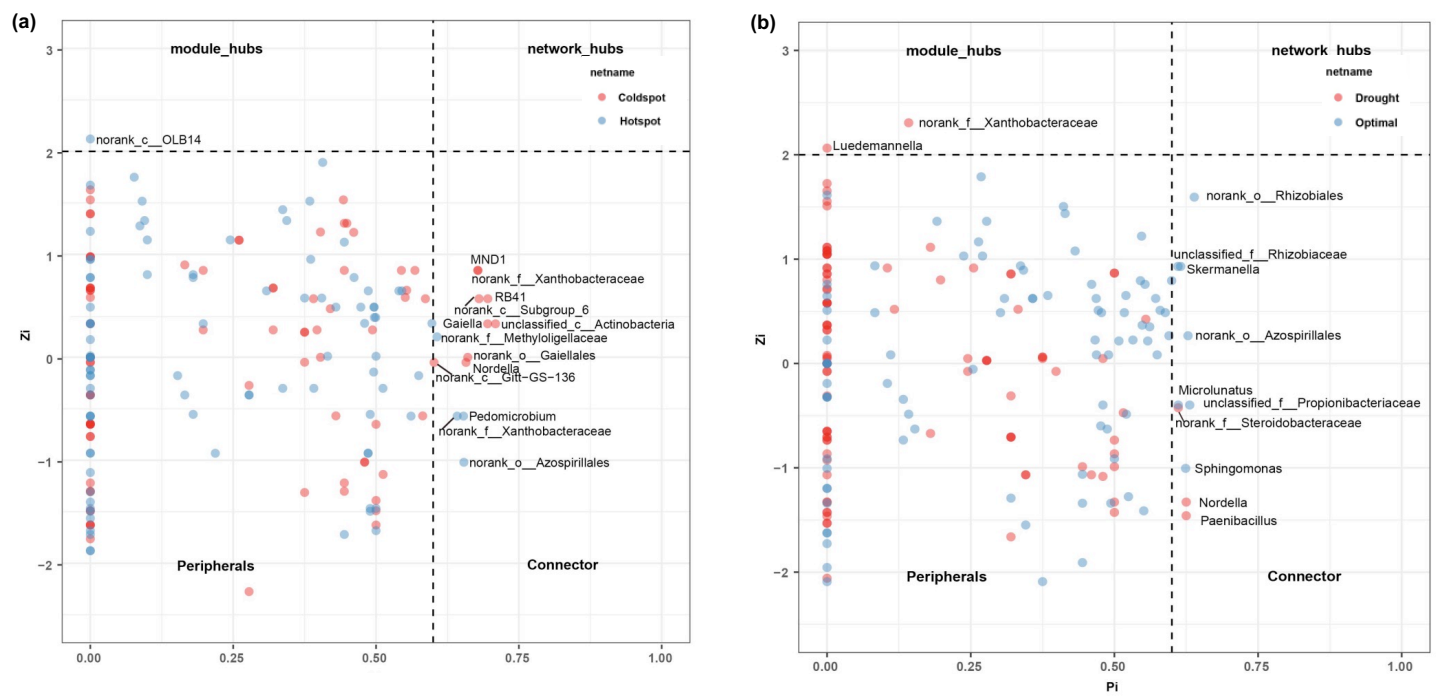

Fig. 7 ZP-plot showing distributions of genera on their network roles. Each node represents a genus (a) in rhizosphere hot- and coldspots, and (b) under drought (20\% of WHC) and optimal moisture (70\% of WHC). Zi: within-module connectivity, Pi: among-module connectivity. Note: norank_c_OLB14, norank_c_Gitt-GS-136: unidentified genera belonging to phylum Chloroflexi; norank_f_Xanthobacteraceae, norank_f_Methyloligellaceae, norank_o_Azospirillales, norank_o_Rhizobiales, unclassified_f_Rhizobiaceae, norank_f_Steroidobacteraceae: unidentified genera belonging to phylum Proteobacteria; norank_c_Subgroup_6: a norank genus belonging to phylum Acidobacteria; unclassified_c_Actinobacteria, norank_o_Gaiellales, unclassified_f_Propionibacteriaceae: unidentified genera belonging to phylum Actinobacteria. 
Topological patterns of degree distribution demonstrated that the genera in hotspots were randomly distributed $\left(\mathrm{R}_{\mathrm{adj}}{ }^{2}=0.019, p=0.219\right)$, whereas they followed a power-law distribution pattern in coldspots $\left(\mathrm{R}_{\mathrm{adj}}{ }^{2}=0.427, p \leq 0.001\right)$ (Fig. 8a). Considering water content, the degree distribution showed that the absolute value of the power in the powerlaw distribution under drought (0.745) was higher than that under optimal moisture $(0.241)$ (Fig. 8b).

(a)

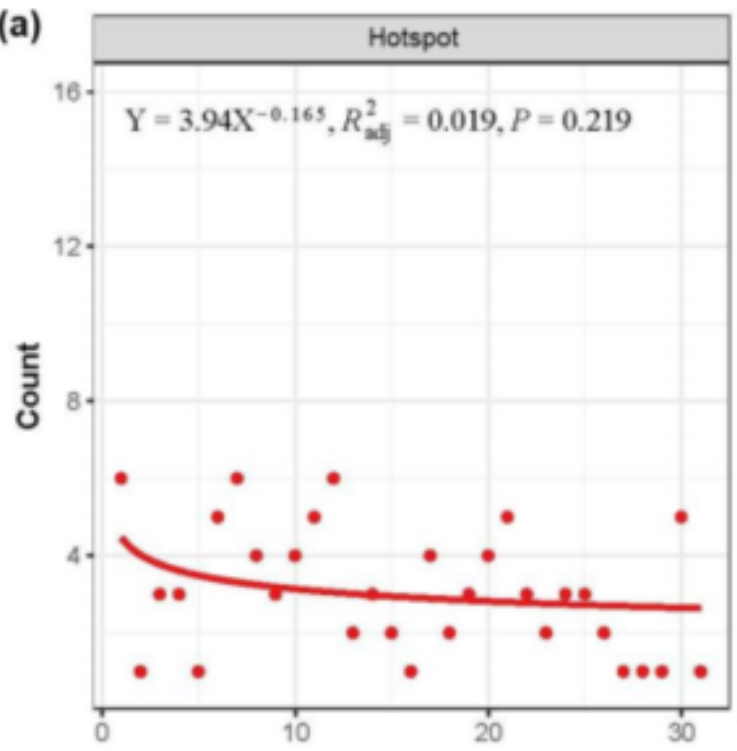

(b)
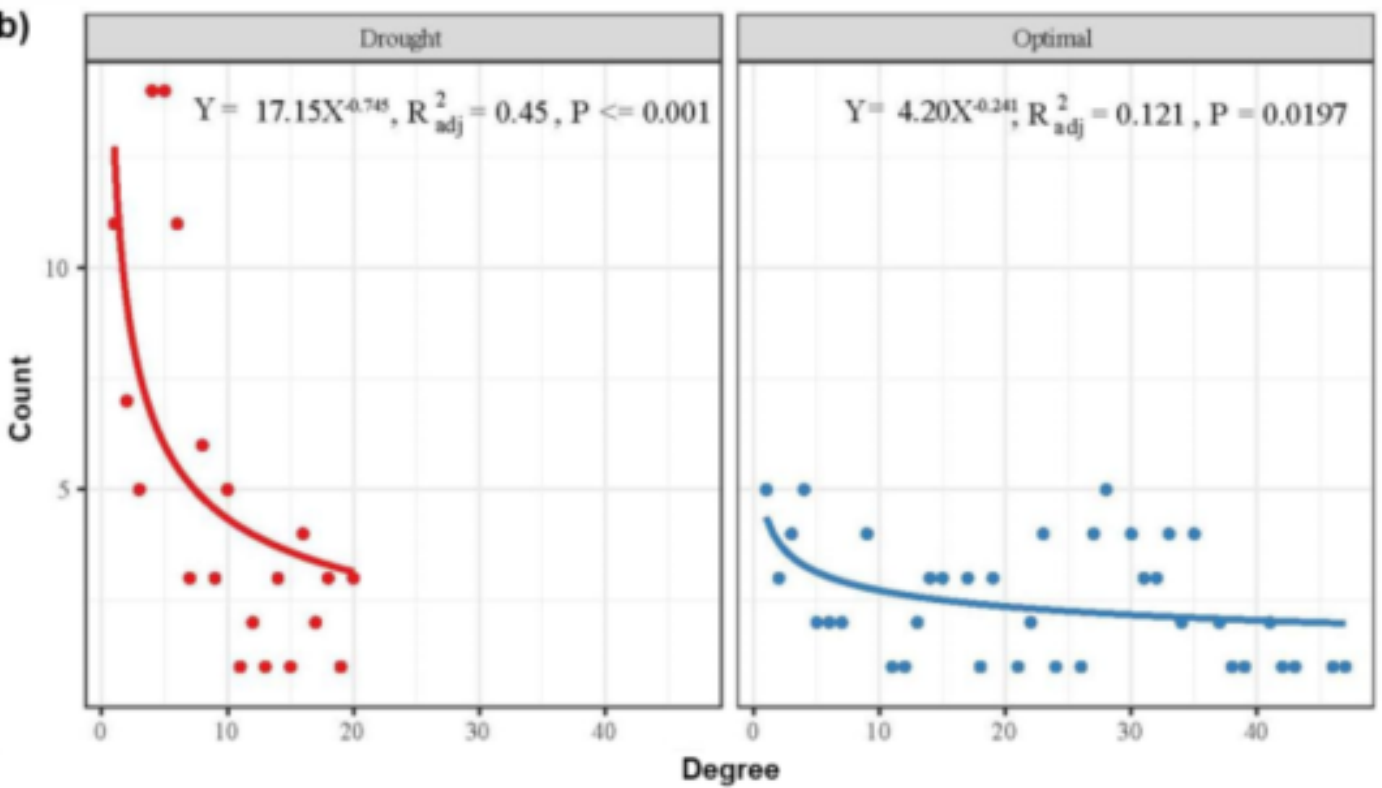

Fig. 8 Degree distribution pattern for the bacterial communities (a) in rhizosphere hot- and coldspots, and (b) under drought (20\% of WHC) and optimal moisture (70\% of WHC). The 
degree of a node is the number of connections it has. Count means the number of the node with that degree.

Overall, the bacterial genera in hotspots were more positively correlated with each other and presented a more stable network topological structure than those in coldspots. The interactions of bacterial communities under optimal water content were more complex and stable than under drought, but the bacterial communities under drought still maintained relatively tight positive correlations. Drought and microsites substantially affected the microbial roles in the networks.

\subsection{Discussion}

\subsubsection{Similarity of microbial communities between hot- and coldspots in the rhizosphere}

The similarity of bacterial communities between hot- and coldspots (Fig. 4a, Fig. S3 and Table S1) was in contrast with our first hypothesis (H1). Such homogeneous bacteria community composition was confirmed by their functionality: the same $\mathrm{K}_{\mathrm{m}}$ values between rhizosphere hot- and coldspots (Fig. 2c \& d) indicated stability of the expressed enzyme systems. Similarly, the number of functional gene copies (Fig. 5) and metabolic functions (Fig. S4) relevant to these two enzymes was similar between hot- and coldspots under both drought and optimal moisture. The consistency of these results suggests that the occurrence of enzymatic hot- and coldspots in close proximity to the roots did not shift the microbial community composition. Even though no changes in microbial community composition were detected, we attributed the higher enzyme activities in the hotspot soil to: i) a more complexed and stable network structure compared to the coldspot soil (Fig. 6a \& S5a); ii) less competitive relationships among bacteria (Fig. 6a) because probably more root exudates were released there (Zhang et al., unpublished); and iii) larger microbial biomass, as common in hotspots (Blagodatskaya et al., 2014). Also, the shift of bacterial roles to module hubs (Fig. 7a) strengthened the fluxes of energy and materials within an ecological module (Shi et al., 2020). Other sources of increased enzymatic activity are i) the direct secretion of enzymes by roots, ii) their release by the root cell lysis, and iii) the production of chitinase by fungi (Marinari et al., 2014; Burns, 1982; Tischer et al., 2015). However, such an altered exoenzyme secretion along the root axis must be triggered by an altered nutrient availability. This altered $\mathrm{N}$ supply would trigger microbial enzyme systems towards $\mathrm{N}$ mining (Li et al., 2017), suggesting a coaction of plant-derived and microbial-derived enzyme activities. The higher root exudates in the hotspots (Zhang et al., unpublished) and the increased SOM 
decomposition due to higher enzyme activity provided energy and nutrients to microorganisms. Thus, N-releasing enzyme activities were more resistant to drought in hotspots than in coldspots (Fig. 3), in line with our H3.

Consequently, the differentiation of enzymatic hot- and coldspots did not trigger shifts in the bacterial community structure. In contrast, microhabitats along the root axis with strongly differing microbial activities were likely associated with the stable network structure and stronger connections within modules.

\subsubsection{Drought impact on microbial communities and their contribution to $N$ cycle}

Both leucine aminopeptidase and chitinase activities in hot- and coldspots were higher under drought than under optimal soil moisture (Fig. 2a \& b), similar to the results reported by Sanaullah et al. (2011). Nonetheless, this is unexpected compared with some previous studies showing that drought decreased enzyme activities because of the negative effects of drought on soil biochemical properties, such as reduced diffusion of substrates, the suppressed microbial activities and lower microbial biomass (Hueso et al., 2012; Sardans and Peñuelas, 2018). However, in our study, one of the probable explanations for this enhanced enzymatic response lies in the increased release of root exudates (Preece and Peñuelas, 2016) to support microorganisms in compensating for soil water shortage (Bastida et al., 2017). For example, plants released more mucilage, which increased the soil water holding capacity and simplified the growth of roots in the dry soil (Gargallo-Garriga et al., 2018; Preece and Peñuelas, 2016). This, in turn, helped the microbial community to offset the reduced diffusion of organic substances to microbial cells and stimulated their activities. The increased rhizodeposition also included extracellular enzymes (Preece et al., 2018), which promoted the growth and survival of roots and microorganisms. Moreover, lower solute mobility most likely triggers an increase in enzyme activities. Water limitation slowed down the diffusion of substrate and the movement of microorganisms because the water films along the soil pores shrank (Burns et al., 2013; Manzoni et al., 2012; Or et al., 2007). This disconnection stimulated microorganisms to produce more enzymes to obtain required substrates (Acosta-Martinez et al., 2014). Other likely explanations for higher enzyme activities under drought were i) the release of enzymes upon the cell lysis (Berard et al., 2011); and ii) lower microbial competition with plants that are more sensitive to drought (Ochoa-Hueso et al., 2018). The altered amount/type of enzymes produced by the microbiome and the conformational changes during the two-week drought in comparison with optimal moisture could impair the enzyme affinity to the substrate (higher $\mathrm{K}_{\mathrm{m}}$ values, 
Fig. 2 c \& d). In soil with water limitation, microorganisms need more energy to retain water by producing extracellular polymeric substances (EPS) to keep their habitats moist (Schimel, 2018). The drought-tolerant microorganisms, however, must release more enzymes to break down organic matter to survive and maintain their functions (Steinweg, 2011). Such a process is most-likely promoted by the plant. This is because microbial $\mathrm{N}$ mobilization helps to overcome the reduced nutrient diffusion under drought and allows sufficient plant nutrient uptake. Higher peptidase and chitinase released by roots or indirectly by microbial stimulation via increased exudation is thus a strategy against drought when nutrient and exoenzyme diffusion is restricted. The energy and $\mathrm{N}$ required to produce these enzymes were probably supported by metabolic pathways in which the number of involved genes copies increased under drought (Fig. S4). For example, carbohydrate metabolism and amino acid metabolism could provide various compounds and energy for microorganisms (Wei et al., 2018).

The higher enzyme activities under drought due to the increase of the number of functional genes copies encoded by the Actinobacteria for both investigated enzymes (Fig. 5) was in line with our H2. The functional gene copies encoded by Actinobacteria were enriched probably because: i) drought increased the relative abundance of genera belonging to Actinobacteria capable of leucine aminopeptidase and chitinase production, such as Nocardioides, Streptomyces, Marmoricola and Knoellia (Table S3 and S4); ii) Although the relationships of bacteria under drought were less complex, bacteria still kept relatively tight positive correlations (Fig. 6b). Moreover, the interactions between bacteria were less equal under drought (Fig. 8b) (Fan et al., 2018), which indicated the adaptation of keystone bacteria to drought stress. The genus Luedemannella (Actinobacteria) is probably one of the keystone bacteria that acted as module hubs to mediate energy and substance exchanges within modules (Fig. 7b) to maintain the interactions between bacterial populations. Furthermore, this genus encoded genes for leucine aminopeptidase and chitinase, and its relative abundance under drought was $17 \%$ higher than in optimal moisture (Fig. S6). All these results combined suggested that the higher relative abundance of the bacteria that possess genes encoding leucine aminopeptidase and chitinase under drought contributed to the increased production of these enzymes. However, it is important to acknowledge that the functional differences detected by PICRUSt 2 and Tax4Fun2 might be of an artefact of the low percentage of functional assignments that these two methods can assign to different taxa.

Overall, the bacterial community composition and specific enzyme-related bacterial groups were similar in rhizosphere hotspots and coldspots. Instead, the stable network 
structure and less competitive correlations of the bacterial community played a crucial role in the high enzyme activities in the rhizosphere hotspots. The more root exudates and faster SOM decomposition caused by higher enzyme activities in hotspots contributed to the stronger resistance of enzyme activities to drought stress than in coldspots. Drought induced minor changes in bacterial community structure, which had strong implications for the potential number of functional gene copies controlling microbial decomposition of proteins and chitin and, thus, controlling $\mathrm{N}$ cycling. This demonstrates that bacterial communities react to drought stress by increasing extracellular enzyme production and they achieve this by encoding more enzyme- genes regardless of microhabitats (i.e., hotspots or coldspots). Note that the functional analysis done here is based on predicted functions. Future studies based on metagenomics or transcriptomic data would be necessary to confirm the predicted pattern.

\section{Acknowledgments}

This paper is dedicated to the memory of David Myrold, whose devotion to understanding of soil microbiology was unsurpassed. This study was supported by National Natural Science Foundation of China (32001487), National Key R\&D Program of China (2018YFD0300606) and the DAAD Research Mobility PPP Programme, Project Nr. 57386747 (to Bahar S. Razavi). The contribution of Michaela Dippold was supported by the Norddeutsche Wissenschaftspreis and the Robert-Bosch Foundation. We gratefully acknowledge the China Scholarship Council (CSC) for financial support for Xuechen Zhang, and Funding for Study Abroad Program by the Government of Shandong Province for financial support of Hongcui Dai. The contribution of Yakov Kuzyakov was supported by the "RUDN University Strategic Academic Leadership Program" and Government Program of Competitive Growth of Kazan Federal University.

\section{References}

Ahmed, M.A., Sanaullah, M., Blagodatskaya, E., Mason-Jones, K., Jawad, H., Kuzyakov, Y., Dippold, M.A., 2018. Soil microorganisms exhibit enzymatic and priming response to root mucilage under drought. Soil Biology and Biochemistry 116, 410-418. doi:10.1016/j.soilbio.2017.10.041

Bach, H.-J., Hartmann, A., Schloter, M., Munch, J.C., 2001. PCR primers and functional probes for amplification and detection of bacterial genes for extracellular peptidases in single strains and in soil. Journal of Microbiological Methods 44, 173-182. doi:10.1016/S0167-7012(00)00239-6

Bardgett, R.D., Freeman, C., Ostle, N.J., 2008. Microbial contributions to climate change through carbon cycle feedbacks. The ISME Journal 2, 805-814. doi:10.1038/ismej.2008.58

Bastida, F., Torres, I.F., Hernández, T., García, C., 2017. The impacts of organic amendments: Do 
they confer stability against drought on the soil microbial community? Soil Biology and Biochemistry 113, 173-183. doi:10.1016/j.soilbio.2017.06.012

Bouskill, N.J., Lim, H.C., Borglin, S., Salve, R., Wood, T.E., Silver, W.L., Brodie, E.L., 2013. Preexposure to drought increases the resistance of tropical forest soil bacterial communities to extended drought. The ISME Journal 7, 384-394. doi:10.1038/ismej.2012.113

Bu, X., Gu, X., Zhou, Xiaoqi, Zhang, M., Guo, Z., Zhang, J., Zhou, Xuhui, Chen, X., Wang, X., 2018. Extreme drought slightly decreased soil labile organic $\mathrm{C}$ and $\mathrm{N}$ contents and altered microbial community structure in a subtropical evergreen forest. Forest Ecology and Management 429, 18-27. doi:10.1016/j.foreco.2018.06.036

Burns, R.G., 1982. Enzyme activity in soil: Location and a possible role in microbial ecology. Soil Biology and Biochemistry 14, 423-427. doi:10.1016/0038-0717(82)90099-2

Burns, R.G., DeForest, J.L., Marxsen, J., Sinsabaugh, R.L., Stromberger, M.E., Wallenstein, M.D., Weintraub, M.N., Zoppini, A., 2013. Soil enzymes in a changing environment: Current knowledge and future directions. Soil Biology and Biochemistry 58, 216-234. doi:10.1016/j.soilbio.2012.11.009

Carbone, M.S., Still, C.J., Ambrose, A.R., Dawson, T.E., Williams, A.P., Boot, C.M., Schaeffer, S.M., Schimel, J.P., 2011. Seasonal and episodic moisture controls on plant and microbial contributions to soil respiration. Oecologia 167, 265-278. doi:10.1007/s00442-011-1975-3

Cheng, W.X., Parton, W.J., Gonzalez-Meler, M.A., Phillips, R., Asao, S., McNickle, G.G., Brzostek, E., Jastrow, J.D., 2014. Synthesis and modeling perspectives of rhizosphere priming. New Phytologist 201, 31-44. doi: 10.1111/nph.12440

Chaves, M.M., Maroco, J.P., Pereira, J.S., 2003. Understanding plant responses to drought - from genes to the whole plant. Functional Plant Biology 30, 239. doi:10.1071/FP02076

Cookson, W.R., Marschner, P., Clark, I.M., Milton, N., Smirk, M.N., Murphy, D.V., Osman, M., Stockdale, E.A., Hirsch, P.R., 2006. The influence of season, agricultural management, and soil properties on gross nitrogen transformations and bacterial community structure. Soil Research 44, 453-465. doi:10.1071/SR05042

Creamer, C.A., de Menezes, A.B., Krull, E.S., Sanderman, J., Newton-Walters, R., Farrell, M., 2015. Microbial community structure mediates response of soil $\mathrm{C}$ decomposition to litter addition and warming. Soil Biology and Biochemistry 80, 175-188. doi:10.1016/j.soilbio.2014.10.008

Dai, H., Zang, H., Zhao, Y., Qian, X., Liu, K., Wang, D., Hao, J., Chen, Y., Sui, P., 2019. Linking bacterial community to aggregate fractions with organic amendments in a sandy soil. Land Degradation \& Development 30, 1828-1839. doi:10.1002/ldr.3383

Davidson, E.A., Janssens, I.A., 2006. Temperature sensitivity of soil carbon decomposition and feedbacks to climate change. Nature 440, 165-173. doi:10.1038/nature04514

Deng, Y., Jiang, Y.-H., Yang, Y., He, Z., Luo, F., Zhou, J., 2012. Molecular ecological network analyses. BMC Bioinformatics 13, 113. doi:10.1186/1471-2105-13-113 
Douglas, G.M., Maffei, V.J., Zaneveld, J., Yurgel, S.N., Brown, J.R., Taylor, C.M., Huttenhower, C., Langille, M.G.I., 2019. PICRUSt2: An improved and customizable approach for metagenome inference (preprint). Bioinformatics. doi:10.1101/672295

Fan, K., Weisenhorn, P., Gilbert, J.A., Shi, Y., Bai, Y., Chu, H., 2018. Soil pH correlates with the cooccurrence and assemblage process of diazotrophic communities in rhizosphere and bulk soils of wheat fields. Soil Biology and Biochemistry 121, 185-192. doi:10.1016/j.soilbio.2018.03.017

Fuchslueger, L., Kastl, E.-M., Bauer, F., Kienzl, S., Hasibeder, R., Ladreiter-Knauss, T., Schmitt, M., Bahn, M., Schloter, M., Richter, A., Szukics, U., 2014. Effects of drought on nitrogen turnover and abundances of ammonia-oxidizers in mountain grassland. Biogeosciences 11, 6003-6015. doi:10.5194/bg-11-6003-2014

German, D.P., Weintraub, M.N., Grandy, A.S., Lauber, C.L., Rinkes, Z.L., Allison, S.D., 2011. Optimization of hydrolytic and oxidative enzyme methods for ecosystem studies. Soil Biology \& Biochemistry 43, 1387-1397. doi: 10.1016/j.soilbio.2011.03.017

Guimerà, R., Nunes Amaral, L.A., 2005. Functional cartography of complex metabolic networks. Nature 433, 895-900. doi:10.1038/nature03288

Gargallo-Garriga, A., Preece, C., Sardans, J., Oravec, M., Urban, O., Peñuelas, J., 2018. Root exudate metabolomes change under drought and show limited capacity for recovery. Scientific Reports 8, 12696. doi: 10.1038/s41598-018-30150-0

Hasibeder, R., Fuchslueger, L., Richter, A., Bahn, M., 2015. Summer drought alters carbon allocation to roots and root respiration in mountain grassland. New Phytologist 205, 1117-1127. doi:10.1111/nph.13146

Jiang, J., Wang, Y., Liu, J., Yang, X., Ren, Y., Miao, H., Pan, Y., Lv, J., Yan, G., Ding, L., Li, Y., 2019. Exploring the mechanisms of organic matter degradation and methane emission during sewage sludge composting with added vesuvianite: Insights into the prediction of microbial metabolic function and enzymatic activity. Bioresource Technology 286, 121397. doi:10.1016/j.biortech.2019.121397

Jones, D.L., Nguyen, C., Finlay, R.D., 2009. Carbon flow in the rhizosphere: carbon trading at the soil-root interface. Plant and Soil 321, 5-33. doi:10.1007/s11104-009-9925-0

Koch, O., Tscherko, D., Kandeler, E., 2007. Temperature sensitivity of microbial respiration, nitrogen mineralization, and potential soil enzyme activities in organic alpine soils. Global Biogeochemical Cycles 21, GB4017. doi: 10.1029/2007gb002983

Kramer, S., Marhan, S., Ruess, L., Armbruster, W., Butenschoen, O., Haslwimmer, H., Kuzyakov, Y., Pausch, J., Scheunemann, N., Schoene, J., Schmalwasser, A., Totsche, K.U., Walker, F., Scheu, S., Kandeler, E., 2012. Carbon flow into microbial and fungal biomass as a basis for the belowground food web of agroecosystems. Pedobiologia 55, 111-119. doi:10.1016/j.pedobi.2011.12.001

Kravchenko, A.N., Guber, A.K., Gunina, A., Dippold, M., Kuzyakov, Y., 2021. Pore-scale view of 
microbial turnover: Combining ${ }^{14} \mathrm{C}$ imaging, $\mu \mathrm{CT}$ and zymography after adding soluble carbon to soil pores of specific sizes. European Journal of Soil Science 72, 593-607. doi: 10.1111/ejss.13001

Kravchenko, A.N., Guber, A.K., Razavi, B.S., Koestel, J., Quigley, M.Y., Robertson, G.P., Kuzyakov, Y., 2019. Microbial spatial footprint as a driver of soil carbon stabilization. Nature Communication 10, 3121. doi: 10.1038/s41467-019-11057-4

Kuzyakov, Y., Blagodatskaya, E., 2015. Microbial hotspots and hot moments in soil: Concept \& review. Soil Biology \& Biochemistry 83, 184-199. doi:10.1016/j.soilbio.2015.01.025

Kuzyakov, Y., Razavi, B.S., 2019. Rhizosphere size and shape: Temporal dynamics and spatial stationarity. Soil Biology and Biochemistry S0038071719301452. doi:10.1016/j.soilbio.2019.05.011

Kuzyakov, Y., Xu, X.L., 2013. Competition between roots and microorganisms for nitrogen: mechanisms and ecological relevance. New Phytologist 198, 656-669. doi:10.1111/nph.12235

Li, X.G., Jia, B., Lv, J., Ma, Q., Kuzyakov, Y., Li, F., 2017. Nitrogen fertilization decreases the decomposition of soil organic matter and plant residues in planted soils. Soil Biology and Biochemistry 112, 47-55. doi:10.1016/j.soilbio.2017.04.018

Ma, X., Razavi, B.S., Holz, M., Blagodatskaya, E., Kuzyakov, Y., 2017. Warming increases hotspot areas of enzyme activity and shortens the duration of hot moments in the root-detritusphere. Soil Biology and Biochemistry 107, 226-233. doi:10.1016/j.soilbio.2017.01.009

Manzoni, S., Schimel, J.P., Porporato, A., 2012. Responses of soil microbial communities to water stress: results from a meta-analysis. Ecology 93, 930-938. doi:10.1890/11-0026.1

Marinari, S., Moscatelli, C., Grego, S., 2014. Enzymes at plant-soil interface. In: Gianfreda, L., Rao, M.A. (Eds.), Enzymes in Agricultural Sciences. OMICS Group eBooks, USA, pp. 94-109.

Nannipieri, P., Giagnoni, L., Renella, G., Puglisi, E., Ceccanti, B., Masciandaro, G., Fornasier, F., Moscatelli, M.C., Marinari, S., 2012. Soil enzymology: classical and molecular approaches. Biology and Fertility of Soils 48, 743-762. doi:10.1007/s00374-012-0723-0

Nannipieri, P., Trasar-Cepeda, C., Dick, R.P., 2018. Soil enzyme activity: a brief history and biochemistry as a basis for appropriate interpretations and meta-analysis. Biology and Fertility of Soils 54, 11-19. doi:10.1007/s00374-017-1245-6

Navarro-García, F., Casermeiro, M.Á., Schimel, J.P., 2012. When structure means conservation: Effect of aggregate structure in controlling microbial responses to rewetting events. Soil Biology and Biochemistry 44, 1-8. doi:10.1016/j.soilbio.2011.09.019

Ollivier, J., Töwe, S., Bannert, A., Hai, B., Kastl, E.-M., Meyer, A., Su, M.X., Kleineidam, K., Schloter, M., 2011. Nitrogen turnover in soil and global change. FEMS Microbiology Ecology 78, 3-16. doi:10.1111/j.1574-6941.2011.01165.x

Or, D., Smets, B.F., Wraith, J.M., Dechesne, A., Friedman, S.P., 2007. Physical constraints affecting bacterial habitats and activity in unsaturated porous media - a review. Advances in Water 
Resources 30, 1505-1527. doi:10.1016/j.advwatres.2006.05.025

Orwin, K.H., Wardle, D.A., 2004. New indices for quantifying the resistance and resilience of soil biota to exogenous disturbances. Soil Biology and Biochemistry 36, 1907-1912. doi:10.1016/j.soilbio.2004.04.036

Parker, S.S., Schimel, J.P., 2011. Soil nitrogen availability and transformations differ between the summer and the growing season in a California grassland. Applied Soil Ecology 48, 185-192. doi:10.1016/j.apsoil.2011.03.007

Peng, G.S., Wu, J., 2016. Optimal network topology for structural robustness based on natural connectivity. Physica A: Statistical Mechanics and its Applications 443, 212-220.

Placella, S.A., Brodie, E.L., Firestone, M.K., 2012. Rainfall-induced carbon dioxide pulses result from sequential resuscitation of phylogenetically clustered microbial groups. Proceedings of the National Academy of Sciences 109, 10931-10936. doi:10.1073/pnas.1204306109

Preece, C., Farré-Armengol, G., Llusià, J., Peñuelas, J., Thirsty tree roots exude more carbon, Tree Physiology 38, 690-695. doi:10.1093/treephys/tpx163

Preece, C., Peñuelas, J., 2016. Rhizodeposition under drought and consequences for soil communities and ecosystem resilience. Plant and Soil 409, 1-17. doi:10.1007/s11104-016-3090-z

Quast, C., Pruesse, E., Yilmaz, P., Gerken, J., Schweer, T.,Yarza, P., Glöckner, F.O., 2012. The SILVA ribosomal RNA gene database project: improved data processing and web-based tools. Nucleic Acids Res 41:D590-D596

Razavi, B.S., Blagodatskaya, E., Kuzyakov, Y., 2016a. Temperature selects for static soil enzyme systems to maintain high catalytic efficiency. Soil Biology and Biochemistry 97, 15-22. doi:10.1016/j.soilbio.2016.02.018

Razavi, B.S., Zarebanadkouki, M., Blagodatskaya, E., Kuzyakov, Y., 2016b. Rhizosphere shape of lentil and maize: Spatial distribution of enzyme activities. Soil Biology and Biochemistry 96, 229-237. doi:http://dx.doi.org/10.1016/j.soilbio.2016.02.020

Razavi, B.S., Zhang, X., Bilyera, N., Guber, A., Zarebanadkouki, M., 2019. Soil zymography: Simple and reliable? Review of current knowledge and optimization of the method. Rhizosphere 100161. doi:10.1016/j.rhisph.2019.100161

Sanaullah, M., Blagodatskaya, E., Chabbi, A., Rumpel, C., Kuzyakov, Y., 2011. Drought effects on microbial biomass and enzyme activities in the rhizosphere of grasses depend on plant community composition. Applied Soil Ecology 48, 38-44. doi:10.1016/j.apsoil.2011.02.004

Schimel, J., Balser, T.C., Wallenstein, M., 2007. Microbial Stress-Response Physiology and Its Implications for Ecosystem Function. Ecology 88, 1386-1394.

Schimel, J.P., 2018. Life in Dry Soils: Effects of Drought on Soil Microbial Communities and Processes. Annual Review of Ecology, Evolution, and Systematics 49, 409-432. doi:10.1146/annurev-ecolsys-110617-062614

Shade, A., Peter, H., Allison, S.D., Baho, D.L., Berga, M., Bürgmann, H., Huber, D.H., Langenheder, 
S., Lennon, J.T., Martiny, J.B.H., Matulich, K.L., Schmidt, T.M., Handelsman, J., 2012. Fundamentals of Microbial Community Resistance and Resilience. Frontiers in Microbiology 3. doi:10.3389/fmicb.2012.00417

Sheik, C.S., Beasley, W.H., Elshahed, M.S., Zhou, X., Luo, Y., Krumholz, L.R., 2011. Effect of warming and drought on grassland microbial communities. The ISME Journal 5, 1692-1700. doi:10.1038/ismej.2011.32

Shi, Y., Delgado-Baquerizo, M., Li, Y., Yang, Y., Zhu, Y.-G., Peñuelas, J., Chu, H., 2020. Abundance of kinless hubs within soil microbial networks are associated with high functional potential in $\begin{array}{lllll}\text { agricultural } & \text { ecosystems. } & \text { Environment } & \text { International } & 142,\end{array}$ doi:10.1016/j.envint.2020.105869

Song, F., Han, X., Zhu, X., Herbert, S.J., Response to water stress of soil enzymes and root exudates from drought and non-drought tolerant corn hybrids at different growth stages. Canadian Journal of Soil Science 92, 501-507. doi: 10.4141/cjss2010-057

Steinweg, J.M., 2011. Sensitivity of Microbial Community Physiology to Soil Moisture and Temperature in an Old Field Ecosystem, Graduate Degree Program in Ecology. Colorado State University, Fort Collins.

Tian, P., Razavi, B.S., Zhang, X., Wang, Q., Blagodatskaya, E., 2020. Microbial growth and enzyme kinetics in rhizosphere hotspots are modulated by soil organics and nutrient availability. Soil Biology and Biochemistry 141, 107662. doi:10.1016/j.soilbio.2019.107662

Tischer, A., Blagodatskaya, E., Hamer, U., 2015. Microbial community structure and resource availability drive the catalytic efficiency of soil enzymes under land-use change conditions. Soil Biology and Biochemistry 89, 226-237. doi:10.1016/j.soilbio.2015.07.011

Wei, H., Wang, L., Hassan, M., Xie, B., 2018. Succession of the functional microbial communities and the metabolic functions in maize straw composting process. Bioresource Technology 256, 333-341. doi: 10.1016/j.biortech.2018.02.050

Wemheuer, F., Taylor, J.A., Daniel, R., Johnston, E., Meinicke, P., Thomas, T., Wemheuer, B., 2020. Tax4Fun2: prediction of habitat-specific functional profiles and functional redundancy based on 16S rRNA gene sequences. Environmental Microbiome 15, 11. doi:10.1186/s40793-020-003587

Zhang, X., Dippold, M.A., Kuzyakov, Y., Razavi, B.S., 2019. Spatial pattern of enzyme activities depends on root exudate composition. Soil Biology and Biochemistry 133, 83-93. doi:10.1016/j.soilbio.2019.02.010

Zhang, X., Kuzyakov, Y., Zang, H., Dippold, M.A., Shi, L., Spielvogel, S., Razavi, B.S., 2020. Rhizosphere hotspots: Root hairs and warming control microbial efficiency, carbon utilization and energy production. Soil Biology and Biochemistry 107872. doi:10.1016/j.soilbio.2020.107872 


\section{Supplementary}

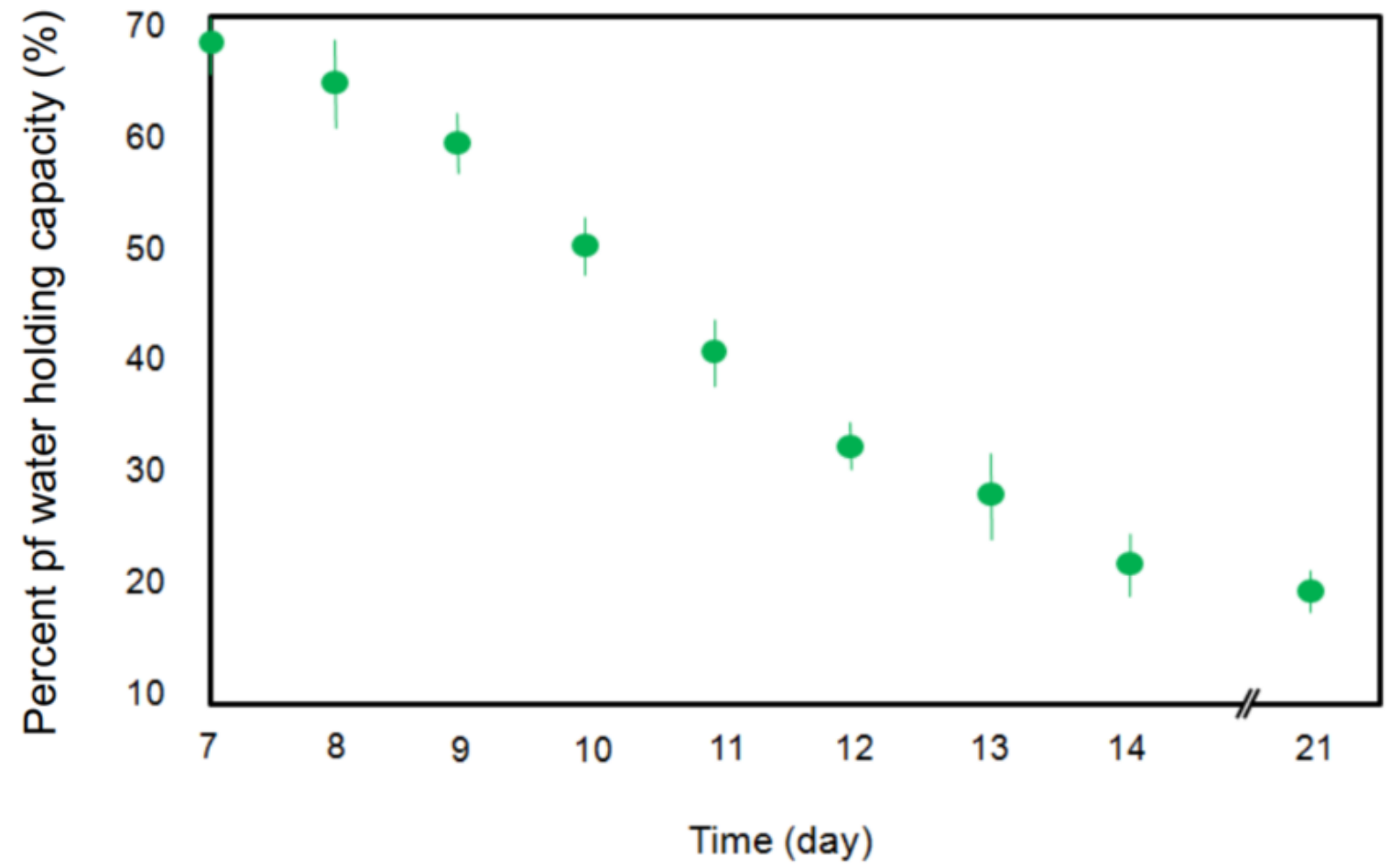

Fig. S1 Water content of soils during drying cycle. The soil water content was measured gravimetrically by weighing the rhizoboxes. The points represent the average of 3 replicates. 


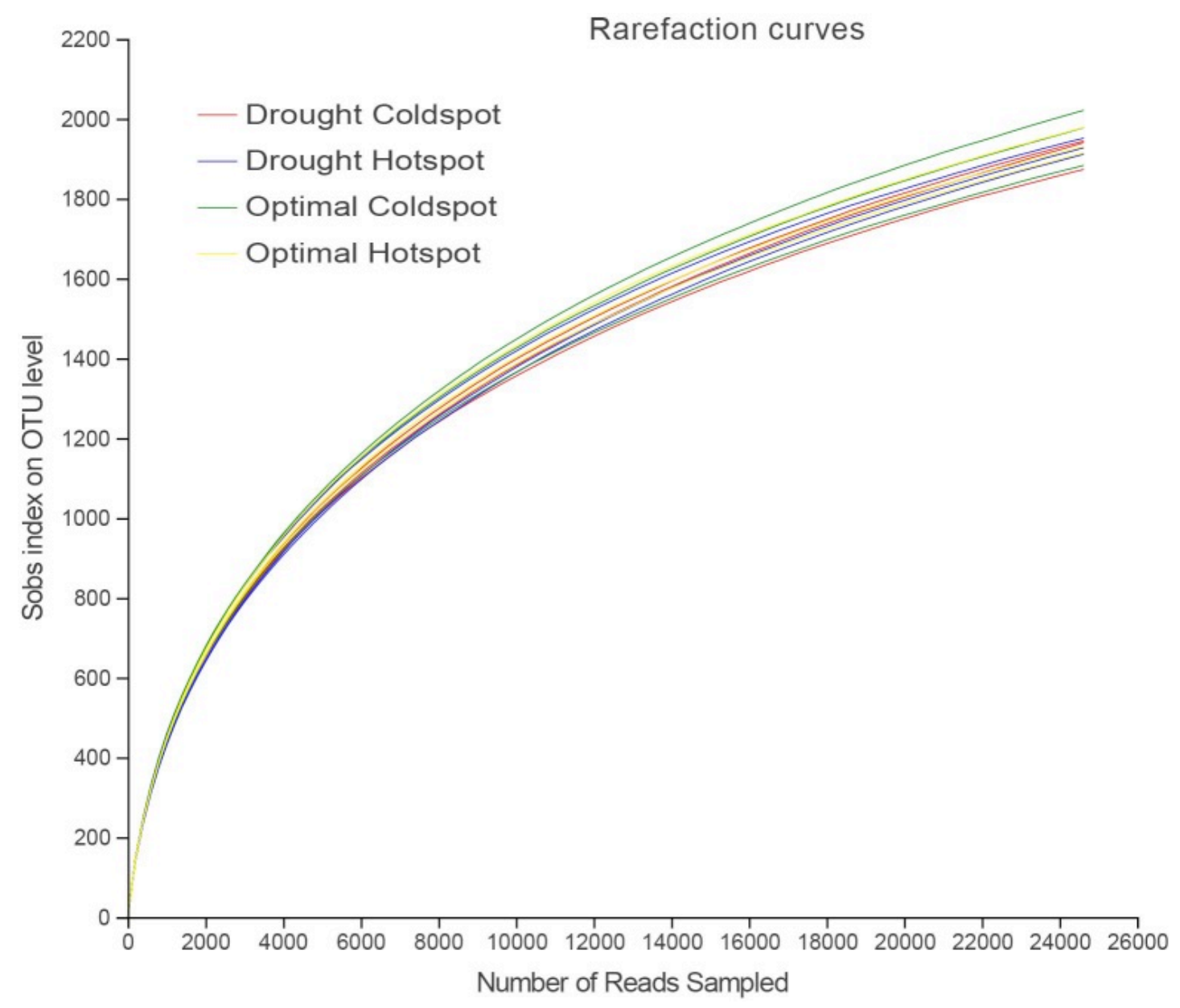

Fig. S2 Rarefaction curves of Sobs index on OTU level against the number of sequence reads for soils from rhizosphere hot- and coldspots under drought $(20 \%$ of WHC) and optimal moisture $(70 \%$ of $\mathrm{WHC})$, respectively. 


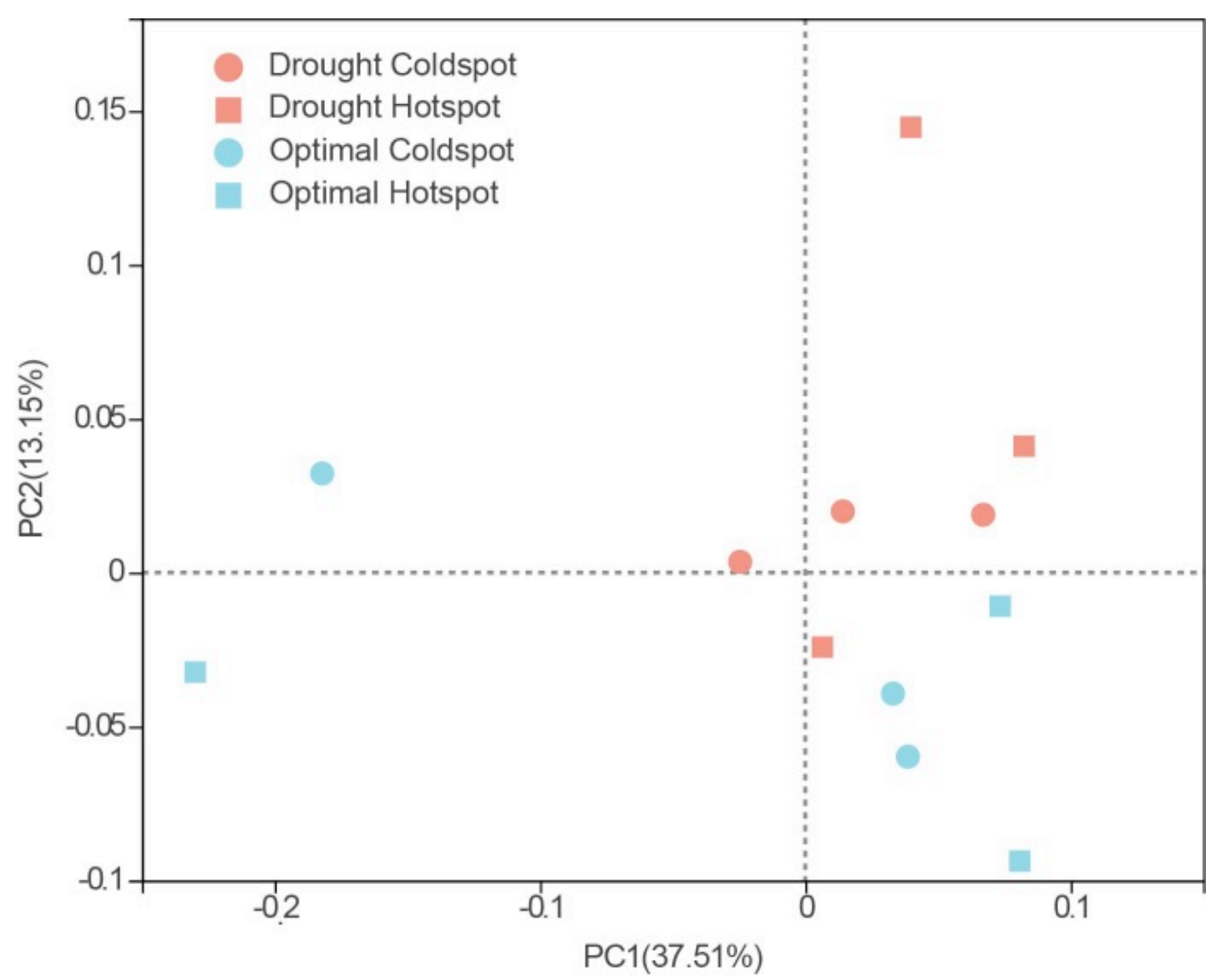

Fig. S3 Principal Coordinates Analysis (PCoA) of bacterial communities in soils from rhizosphere hot- and coldspots under drought $(20 \%$ of WHC) and optimal moisture $(70 \%$ of WHC), respectively. 


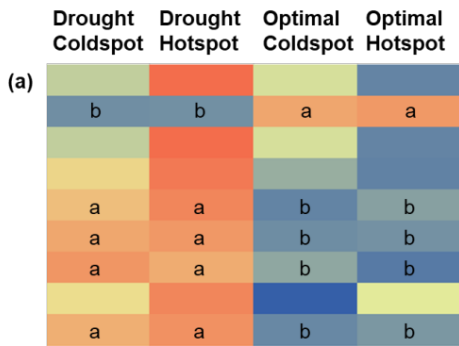

(b)
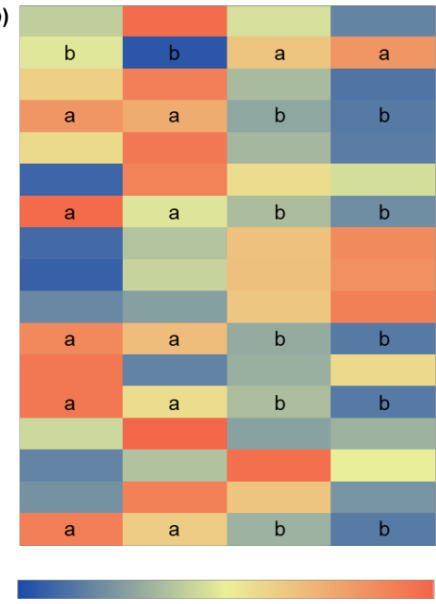

$-1.7$

0
Metabolic pathways

Glutathione metabolism

Metabolic pathways

Amino sugar and nucleotide sugar metabolism

Other glycan degradation

Various types of $\mathrm{N}$-glycan biosynthesis

Glycosaminoglycan degradation

Glycosphingolipid biosynthesis - globo and isoglobo series

Glycosphingolipid biosynthesis - ganglio series

Metabolic pathways

Microbial metabolism in diverse environments

Biosynthesis of secondary metabolites

Biosynthesis of antibiotics

Carbon metabolism

Biosynthesis of amino acids

Fatty acid metabolism

ABC transporters

Two-component system

Quorum sensing

Valine, leucine and isoleucine degradation

Butanoate metabolism

Propanoate metabolism

Pyruvate metabolism

Glyoxylate and dicarboxylate metabolism

Purine metabolism

Fatty acid degradation

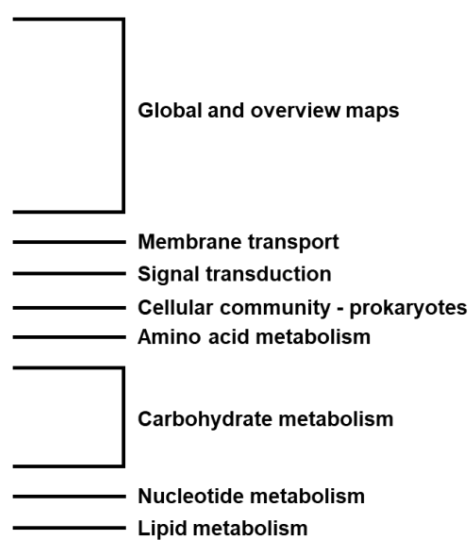

1.7

Normalization of relative abundance by $\mathbf{Z}$ score

Fig. S4 (a) Metabolic functions related to leucine aminopeptidase and chitinase using Tax4Fun2 at level 3 displayed as normalization of relative abundance by $\mathrm{Z}$ score. (b) Functional profiles of selected metabolisms (relative abundance $>1 \%$ ) based on KEGG categories (level 3) displayed as normalization of relative abundance by $\mathrm{Z}$ score. Lower case letters: significant differences between drought and optimal moisture after two-way ANOVA and Student's $t$ test at $p<0.05$.

(a)

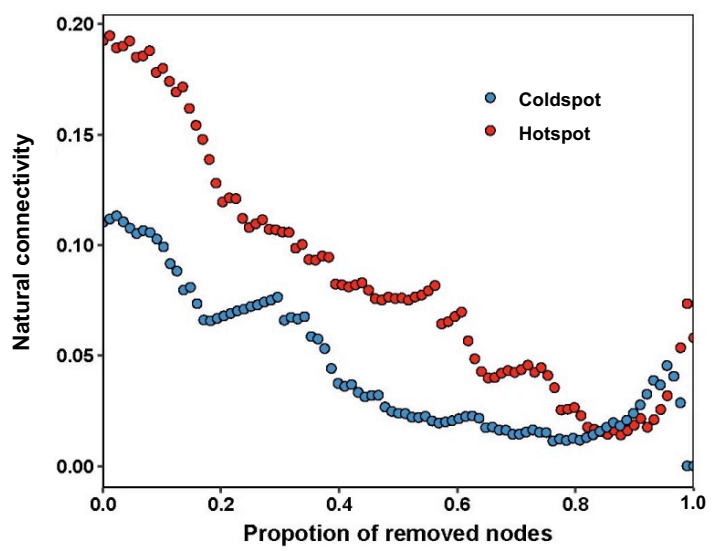

(b)

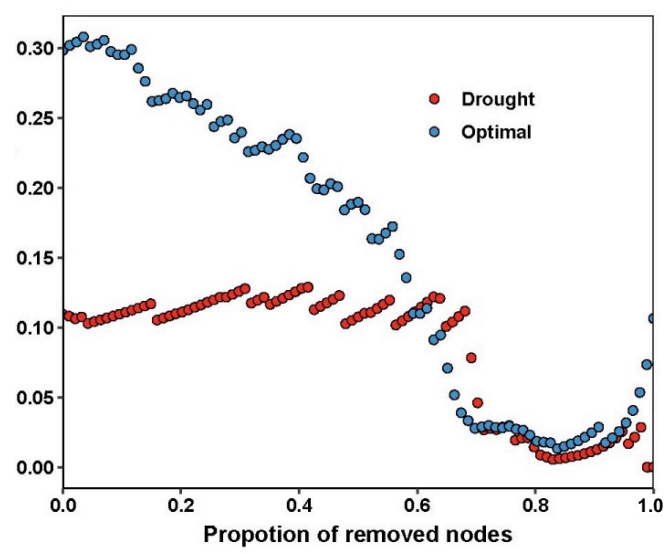


Fig. S5 Network stability analysis. The decrease of natural connectivity when attacking nodes in the static network in the soil of (a) hotspot and coldspot, and (b) drought and optimal moisture.

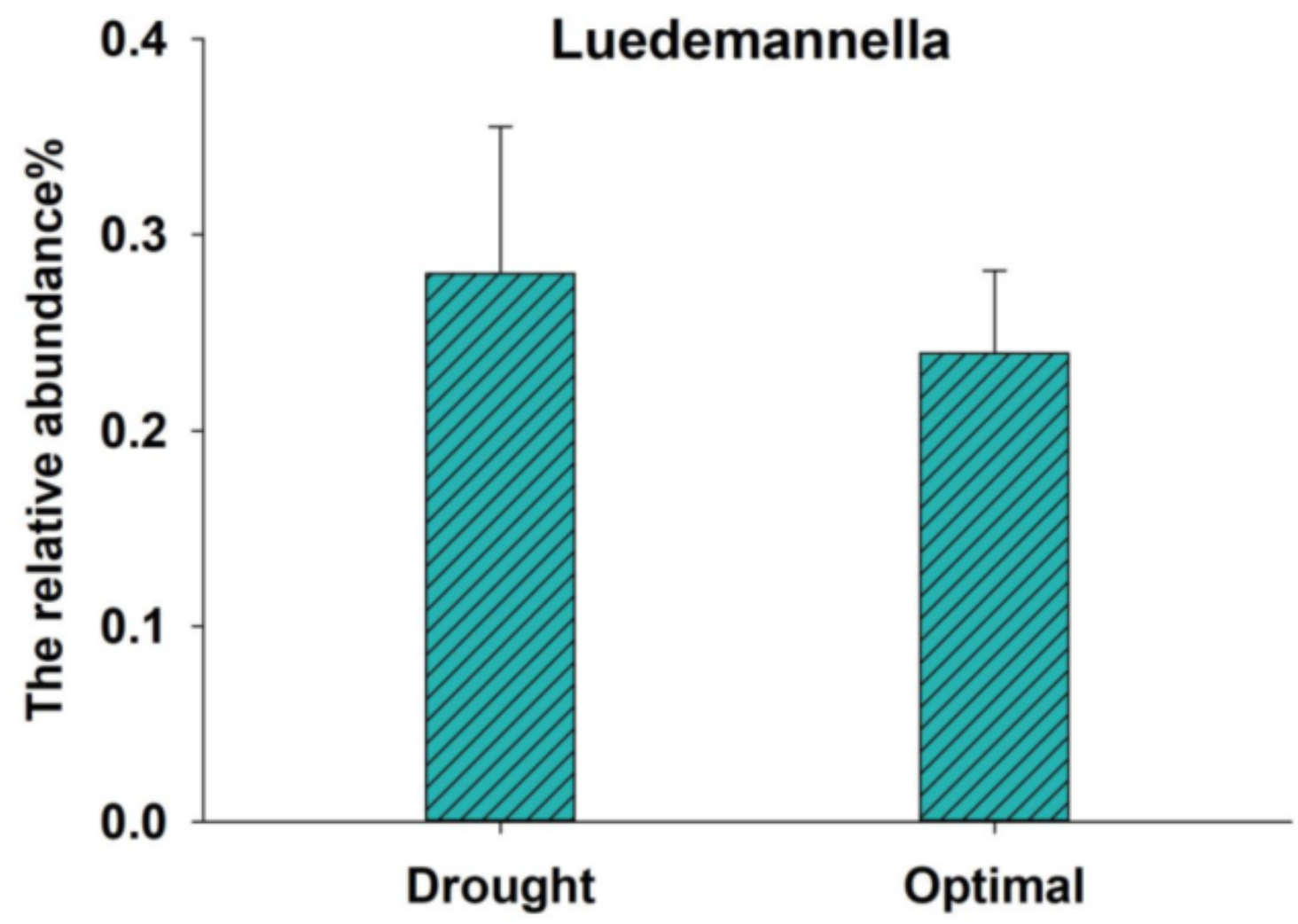

Fig. S6 The relative abundance of the genus Luedemannella, which was detected as module hubs in the network under drought conditions.

Table S1 PERMANOVA analysis at the OTU level based on Bray-Curtis distances

\begin{tabular}{lllllll}
\hline & Df & $\begin{array}{l}\text { Sums of } \\
\text { squares }\end{array}$ & Mean squares & F.Model & Variation (R2) & $\begin{array}{l}\text { Pr } \\
(>\mathbf{F})\end{array}$ \\
\hline Water content & 1 & 0.040 & 0.040 & 1.414 & 0.132615 & 0.229 \\
Microsite & 1 & 0.019 & 0.019 & 0.656 & 0.061557 & 0.795 \\
Water content * Microsite & 1 & 0.017 & 0.017 & 0.591 & 0.055422 & 0.868 \\
Residual & 8 & 0.229 & 0.029 & & 0.750406 & \\
Total & 11 & 0.305 & & & 1 & \\
\hline
\end{tabular}

Table S2 Alpha diversity indices at the OTU level in soil from rhizosphere hot- and coldspots under drought (20\% of WHC) and optimal moisture (70\% of WHC) 


\begin{tabular}{llll}
\hline Samples & Shannon & ACE & Chao 1 \\
\hline Drought coldspot & $6.20 \pm 0.01 \mathrm{a}$ & $2.60^{*} 10^{3} \pm 67.5 \mathrm{a}$ & $2.60^{*} 10^{3} \pm 108.3 \mathrm{a}$ \\
Drought hotspot & $6.17 \pm 0.10 \mathrm{a}$ & $2.61^{*} 10^{3} \pm 24.3 \mathrm{a}$ & $2.59^{*} 10^{3} \pm 32.6 \mathrm{a}$ \\
Optimal coldspot & $6.23 \pm 0.02 \mathrm{a}$ & $2.65^{*} 10^{3} \pm 93.5 \mathrm{a}$ & $2.65^{*} 10^{3} \pm 92.0 \mathrm{a}$ \\
Optimal hotspot & $6.19 \pm 0.05 \mathrm{a}$ & $2.56^{*} 10^{3} \pm 38.1 \mathrm{a}$ & $2.56^{*} 10^{3} \pm 55.6 \mathrm{a}$ \\
\hline
\end{tabular}

Note: Values are means of three replicates \pm SD. Letters indicate significant differences after two-way ANOVA at $p<0.05$.

Table S3 The relative abundance ( $>1 \%$ under drought) of the total and 5 most increased genera belonging to Actinobacteria related to leucine aminopeptidase under drought $(20 \%$ of WHC) compared with optimal moisture $(70 \%$ of WHC). Note: g_norank_c_Actinobacteria: a norank genus belonging to the phylum Actinobacteria.

\begin{tabular}{lllllll}
\hline & $\begin{array}{l}\text { Tota } \\
\text { l }\end{array}$ & $\begin{array}{l}\text { Streptomyc } \\
\text { es }\end{array}$ & $\begin{array}{l}\text { Nocardioid } \\
\text { es }\end{array}$ & $\begin{array}{l}\text { Marmoricol } \\
\text { a }\end{array}$ & $\begin{array}{l}\text { g_norank_c_Acti } \\
\text { nobacteria }\end{array}$ & $\begin{array}{l}\text { Knoell } \\
\text { ia }\end{array}$ \\
\hline Drought & $\begin{array}{l}38.1 \\
7\end{array}$ & 1.41 & 3.13 & 1.25 & 2.67 & 1.93 \\
Optimal & $\begin{array}{l}35.7 \\
6\end{array}$ & 0.88 & 2.21 & 0.94 & 2.04 & 1.49 \\
\hline
\end{tabular}

Table S4 The relative abundance ( $>1 \%$ under drought) of the total and 5 most increased genera belonging to Actinobacteria related to chitinase under drought ( $20 \%$ of WHC) compared with optimal moisture (70\% of WHC). Note: g_norank_c_Actinobacteria: a norank genus belonging to the phylum Actinobacteria.

\begin{tabular}{lllllll}
\hline & Total & $\begin{array}{l}\text { Streptomyc } \\
\text { es }\end{array}$ & $\begin{array}{l}\text { Nocardioid } \\
\text { es }\end{array}$ & $\begin{array}{l}\text { Marmoricol } \\
\text { a }\end{array}$ & $\begin{array}{l}\text { g_norank_c_A } \\
\text { ctinobacteria }\end{array}$ & $\begin{array}{l}\text { Knoelli } \\
\text { a }\end{array}$ \\
\hline Drought & $\begin{array}{l}31.7 \\
1\end{array}$ & 1.41 & 3.13 & 1.25 & 2.58 & 1.93 \\
Optimal & $\begin{array}{l}28.7 \\
0\end{array}$ & 0.88 & 2.21 & 0.94 & 1.95 & 1.49 \\
\hline
\end{tabular}




\title{
5 Study 5: Rhizosphere hotspots: root hairs and warming control microbial efficiency, carbon utilization and energy production
}

Xuechen Zhang, ${ }^{\mathrm{a}, \mathrm{b}}$, Yakov Kuzyakov ${ }^{\mathrm{c}, \mathrm{d}}$, Huadong Zang ${ }^{\mathrm{a}}$, Michaela A. Dippold ${ }^{\mathrm{b}}$, Lingling Shi ${ }^{\text {be,f, }}$, Sandra Spielvogel ${ }^{\mathrm{g}}$, Bahar S. Razavi ${ }^{\text {h }}$

\section{Status: Published in Soil Biology \& Biochemistry}

${ }^{a}$ College of Agronomy and Biotechnology, China Agricultural University, Beijing, China

${ }^{b}$ Department of Biogeochemistry of Agroecosystems, University of Göttingen, Göttingen, Germany

c Department of Agricultural Soil Science, University of Göttingen, Göttingen, Germany

${ }^{d}$ Institute of Physicochemical and Biological Problems in Soil Science, Russian Academy of Sciences, 142290 Pushchino, Russia

${ }^{e}$ Key Laboratory of Economic Plants and Biotechnology, Kunming Institute of Botany, Chinese Academy of Sciences, 132 Lanhei Road, Kunming 650201, China.

${ }^{f}$ World Agroforestry Centre, China \& East-Asia Office, 132 Lanhei Road, Kunming 650201, China.

${ }^{g}$ Institute of Plant Nutrition and Soil Science, Christian-Albrecht-University of Kiel, Kiel, Germany

${ }^{h}$ Department of Soil and Plant microbiome, Institute of Phytopathology, Christian-Albrecht-University of Kiel, Kiel, Germany

\begin{abstract}
Root hairs proliferation and warming strongly influence exudate release, enzyme activities and microbial substrate utilization. However, how the presence of root hairs regulates those processes in the rhizosphere under elevated temperature is poorly known. To clarify these interactions, a wild type maize (with root hairs) and its hairless mutant were grown for 3 weeks at 20 and $30{ }^{\circ} \mathrm{C}$, respectively. We combined zymography (localize hotspots of $\beta$ glucosidase) with substrate-induced respiration and microcalorimetry to monitor exudate effects on enzyme kinetics, microbial growth and heat production in the rhizosphere hotspots in response to warming.

Root hairs effects were more pronounced at the elevated temperature: i) $\beta$-glucosidase activity of the wild type at $30{ }^{\circ} \mathrm{C}$ was $21 \%$ higher than that of the hairless maize; ii) temperature shifted the microbial growth strategy, whereas root hairs promoted the fraction of growing microbial biomass; iii) $\mathrm{K}_{\mathrm{m}}$ and the activation energy for $\beta$-glucosidase under the hairless mutant was lower than that under wild maize. These results suggest that microorganisms inhabiting hotspots of the wild type synthesized more enzymes to fulfill their higher energy and nutrient demands than those of the hairless mutant. In contrast, at higher temperature the hairless maize produced an enzyme pool with higher efficiencies rather than higher enzyme production, enabling metabolic needs to be met at lower cost. We therefore conclude that root hairs play an important role in regulating enzyme systems and microbial growth to adapt to climate warming.
\end{abstract}


Keywords: microbial hotspots, enzyme kinetics, activation energy, microbial growth kinetics, $\mathrm{r}$ and $\mathrm{K}$ strategists, soil microcalorimetry

*Corresponding author: zanghuadong@,cau.edu.cn

\section{Graphical abstract}

\section{$20{ }^{\circ} \mathrm{C} \quad$ Enzyme activity $\quad 30{ }^{\circ} \mathrm{C}$}
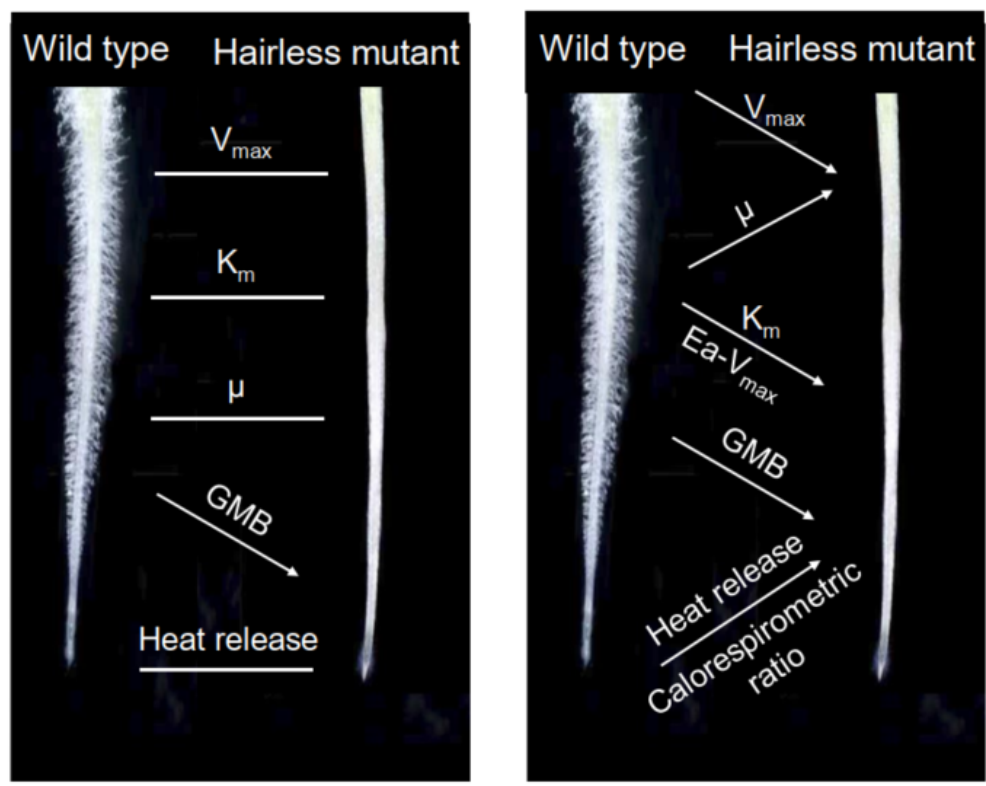


\subsection{Introduction}

When a carbon $(\mathrm{C})$ source is added to a small soil volume and causes microorganisms to thrive, a microbial hotspot is formed - a microsite with much higher process rates than the surrounding bulk soil (Kuzyakov, 2010). The formation, size, and lifetime of microbial hotspots in the vicinity of growing roots (rhizosphere) are governed by the quantity, frequency and quality of root exudate inputs (Zhang et al., 2019; Kuzyakov and Blagodatskaya, 2015; Tian et al., 2020). Exudate properties depend on root traits such as the presence of root hairs (Kuzyakov and Razavi, 2019). Most prominently, root hairs increase the substrate availability for microorganisms (Jones et al., 2009; Mishra et al., 2009), which in turn play a vital role in modulating plant responses to stress (Datta et al., 2011; Poirier et al., 2018). Thus, interactions between roots and their microbiome may fundamentally affect C turnover in hotspots (Paterson et al., 2009; Blagodatskaya et al., 2011). Root hair-less mutants have been previously used to test the relevance of root hairs for a range of rhizosphere-related phenomena (Bates and Lynch, 2000; Pausch et al., 2016).

Apart from root hairs, elevated air temperatures stimulate root exudation and thereby microbial activity (Wei et al., 2019; Zang et al., 2019) — caused by global warming. Increased microbial respiration may be a transient response to warming, either due to thermal acclimation of the community or substrate depletion (Allison et al., 2010; Bradford et al., 2019). Here, acclimation is defined as the individually physiological adjustments in response to an experimentally environmental factor (Bradford, 2013).

Considering warming and root traits, do root hairs increase soil respiration rates, or do they weaken soil organic matter (SOM) losses under warming? It is far from clear whether root hairs increase the activity of the decomposer community through higher exudation rates or decrease it due to temperature acclimation.

For example, enzyme expressions are shifted to higher binding affinities when substrates are limited (Steinweg et al., 2008). Microorganisms stimulated by warming produce more enzymes but with lower efficiency (higher $\mathrm{K}_{\mathrm{m}}$ ) since the microbial energy and nutrient demands may be met by more and higher $\mathrm{K}_{\mathrm{m}}$ enzymes (Razavi et al., 2016a). Such trade-offs between enzyme structure and functions can help compensate the less available substrate by highly flexible enzyme selections (Crowther and Bradford, 2013) or diminish the effects of warming on soil C losses by selecting stable enzymes (Razavi et al., 2016a).

Accordingly, substrate availability may indirectly control the optimal thermo regulation strategy (Fig. 1). In pure cultures, for example, microorganisms can produce enzyme pools 
which enable utilization of a wider range of amino acids, which may pose a survival advantage under substrate limitation (Zinser and Kolter, 1999; Finkel, 2006). This production of multiple forms of key enzymes under low $\mathrm{C}$ availability may be at the cost of decreasing metabolic efficiency (Fig. 1). However, substrate limitation may also enable a shift in microbial growth strategy: from fast-growing r-strategists to slow-growing K-strategists (Panikov and Sizova, 1996). Importantly, this theoretical prediction has never been tested in complex matrices such as soil hotspots.

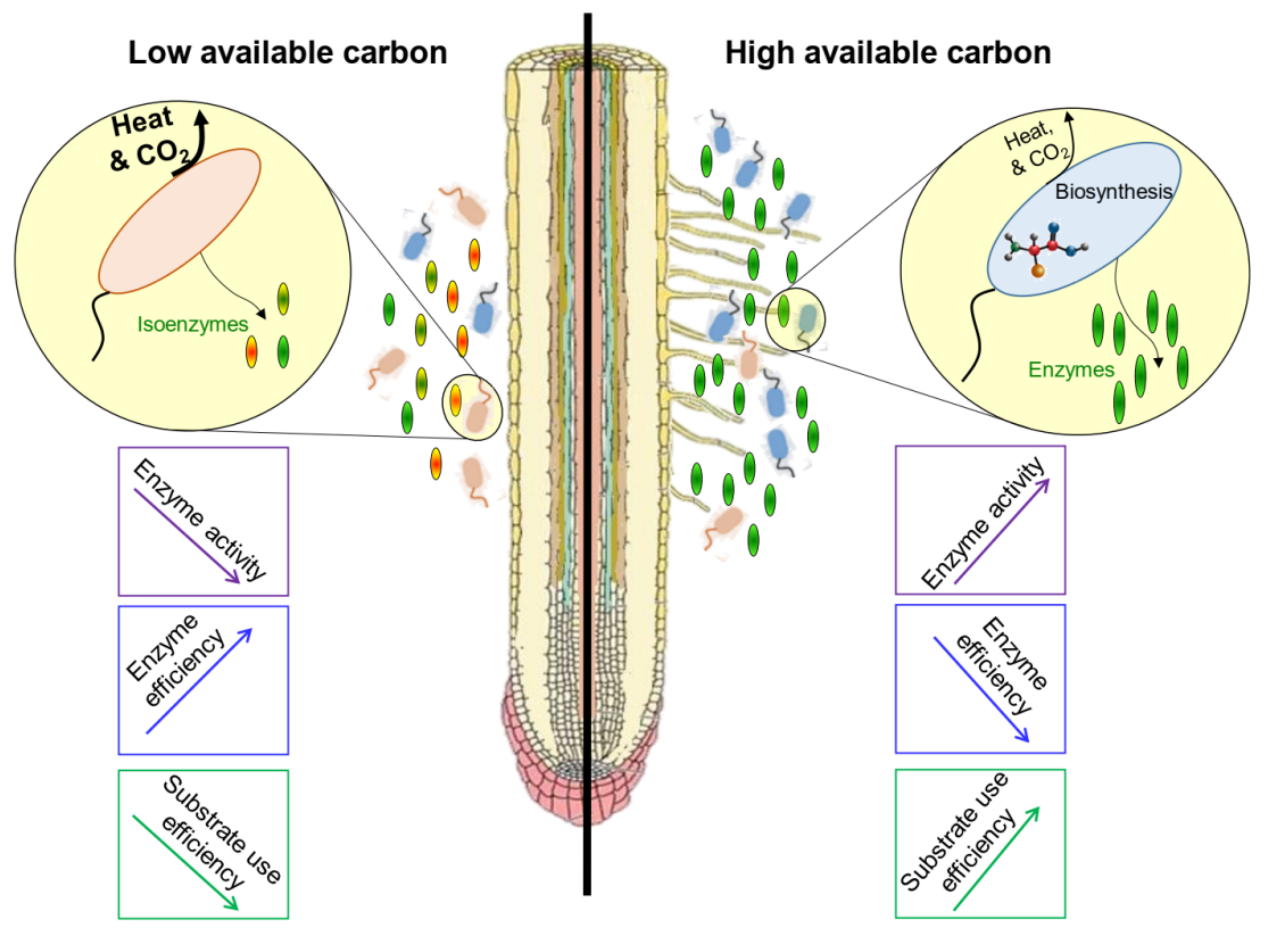

Fig. 1 Schematic microbial response to the input of root exudates in the rhizosphere. Substrate limitation shifts gene expression to the production of enzyme systems with a higher binding affinity. Production of multiple forms of key enzymes under low $\mathrm{C}$ availability reduces metabolic efficiency. This investment would impose a tradeoff by reducing the allocation of available energy to growth (left). Under high C input, however, microorganisms increase enzyme expression and maximize the fraction of resources for biosynthesis (right). Thus, the substrate availability as affected by root hair proliferation and warming may control the optimal strategy of thermoregulation.

Enzymes are crucial for almost all biological reactions (Burns et al., 2013). Efficient enzyme systems involve isoenzymes, which decrease the activation energy $\left(E_{a}\right)$ (Davidson and Janssens, 2006; Bradford, 2013; Razavi et al., 2016a) based on the Arrhenius equation (Marx et al., 2007; Razavi et al., 2017). Enzyme catalysis also releases energy mostly in the 
form of heat which can be quantified e.g. by microcalorimetry as net metabolic heat production. The calorespirometric ratio (i.e. heat production relative to $\mathrm{CO}_{2}$ emission) is an estimate of the efficiency of metabolic processes (an index of substrate use efficiency; Herrmann et al., 2014). Our knowledge is very limited on how root hair exudation affects enzyme systems, microbial growth strategy and microbial activity in microbial hotspots, especially under changing environmental conditions such as global warming.

Here, we coupled soil zymography — a method to visualize enzymatic activity (Spohn and Kuzyakov, 2014; Razavi et al., 2019) — with $\beta$-glucosidase kinetics, microbial growth and heat production to i) identify microbial hotspots in situ; and ii) assess how warming and root hairs affect microbial growth strategy and functionality in rhizosphere hotspots.

Two genotypes of maize (Zea mays L.) differing in root exudate quantity, a wild type with root hairs and the mutant $r t h 3$ without root hairs, were grown at 20 or $30{ }^{\circ} \mathrm{C}$ for 3 weeks. Given that $\beta$-glucosidase plays a central role in cellulose degradation (the most abundant plant polymer), and cleaves cellobiose into glucose monomers (Lammirato et al., 2010), it is the representative of C cycling enzymes (German et al., 2011; Moscatelli et al., 2012).

We hypothesized that i) warming and root hairs mutually increase root exudation, resulting in higher soil enzyme activities and higher abundance of $r$-strategists (based on faster specific growth rates, $\mu$ ); ii) microorganisms compensate lower amounts of exudation from hairless roots through the production of enzymes with higher efficiencies (lower $\mathrm{K}_{\mathrm{m}}$ and $\mathrm{E}_{\mathrm{a}}$; Somero, 1978); and iii) substrate use efficiencies, here studied by the calorespirometric ratio, decrease with warming and are regulated by root hairs and thus by $\mathrm{C}$ input.

\subsection{Materials and methods}

\subsubsection{Soil description and experimental setup}

The soil was collected from the 0 to $50 \mathrm{~cm}$ depth of a Haplic Phaeozem close to Schladebach in Saxony Anhalt. The soil properties were total C $8.5 \mathrm{~g} \mathrm{~kg}^{-1}$, total N $0.8 \mathrm{~g} \mathrm{~kg}^{-}$ 1, available P $39.7 \mathrm{mg} \mathrm{kg}{ }^{-1}$ and available $\mathrm{K} 38.5 \mathrm{mg} \mathrm{kg}^{-1}$, and $\mathrm{pH}$ 6.4. The soil was homogenized and passed through a $2 \mathrm{~mm}$ sieve before the experiment.

Two maize genotypes (Zea mays L.) - wild type (with root hairs) and mutant rth3 (without root hairs) - were germinated for 3 days. Each seedling was transplanted to a separate rhizobox with inner dimensions of $12.3 \times 12.5 \times 2.3 \mathrm{~cm}$. Two varieties with 3 replicates were incubated in a climate chamber at $20 \pm 1{ }^{\circ} \mathrm{C}$ or $30 \pm 1{ }^{\circ} \mathrm{C}$ for 3 weeks. The 
daily light period of that climate chamber was $12 \mathrm{~h}$ with a photosynthetically active radiation intensity of $350 \mu \mathrm{mol} \mathrm{m} \mathrm{m}^{-2} \mathrm{~s}^{-1}$ and the relative air humidity was $65 \%$. The temperatures used were chosen to reflect the moderate temperature for maize growth $\left(20^{\circ} \mathrm{C}\right)$ and the potential for higher peak summer temperatures $\left(30^{\circ} \mathrm{C}\right)$ in response to climate change. After 3 weeks of incubation, the maize was at the early growth stage with young and developed primarily and lateral roots, and reached the bottom of the rhizobox. During the growth period, these rhizoboxes were covered to avoid algal growth on the surface and kept inclined at an angle of $45^{\circ}$ to ensure that the roots grew along the lower wall. Each rhizobox was weighed and irrigated with distilled water to maintain the soil water content at $60 \%$ of the water holding capacity. Preliminary experiments showed that the two genotypes differ in the amount of root exudates (Bilyera et al., 2019).

\subsubsection{Soil zymography}

After 3 weeks incubation, one side of the rhizoboxes was opened and direct soil zymography for $\beta$-glucosidase activity was conducted and analyzed according to the protocol optimized by Razavi et al., 2016b, 2019. This involved saturating a polyamide membrane (0.45 $\mu \mathrm{m}$ pore size; $100 \mu \mathrm{m}$ thick, Tao Yuan, China) in $10 \mathrm{mM}$ 4-methylumbelliferyl- $\beta$-Dglucoside substrate solution and placing it on the soil surface. After $1 \mathrm{~h}$ incubation, the membranes (zymograms) were photographed under UV light with a Canon EOS 6D camera. The gray scale values were calculated to enzyme activity by calibrating a series of 4methylumbelliferone (MUF) concentrations $(0,0.01,0.2,0.5,1,2,4,6,10 \mathrm{mM})$. For the calibration, the membranes $(2 \mathrm{~cm} \times 2 \mathrm{~cm})$ were saturated with a known amount of MUF solution and then imaged under UV light. Finally, zymograms were used as a map to localize hotspot of $\beta$-glucosidase activity (Fig. 2). The criterium for hotspot identification is the gray scale values higher than mean +2 standard deviations (SD) (Razavi et al., 2019). The soil samples were collected from all the identified hotspots of each rhizobox and the mixed soils were split into 5 subsamples for further analysis ( 1 for enzyme kinetics, 2 for kinetics of substrate-induced respiration and 2 for heat production). 


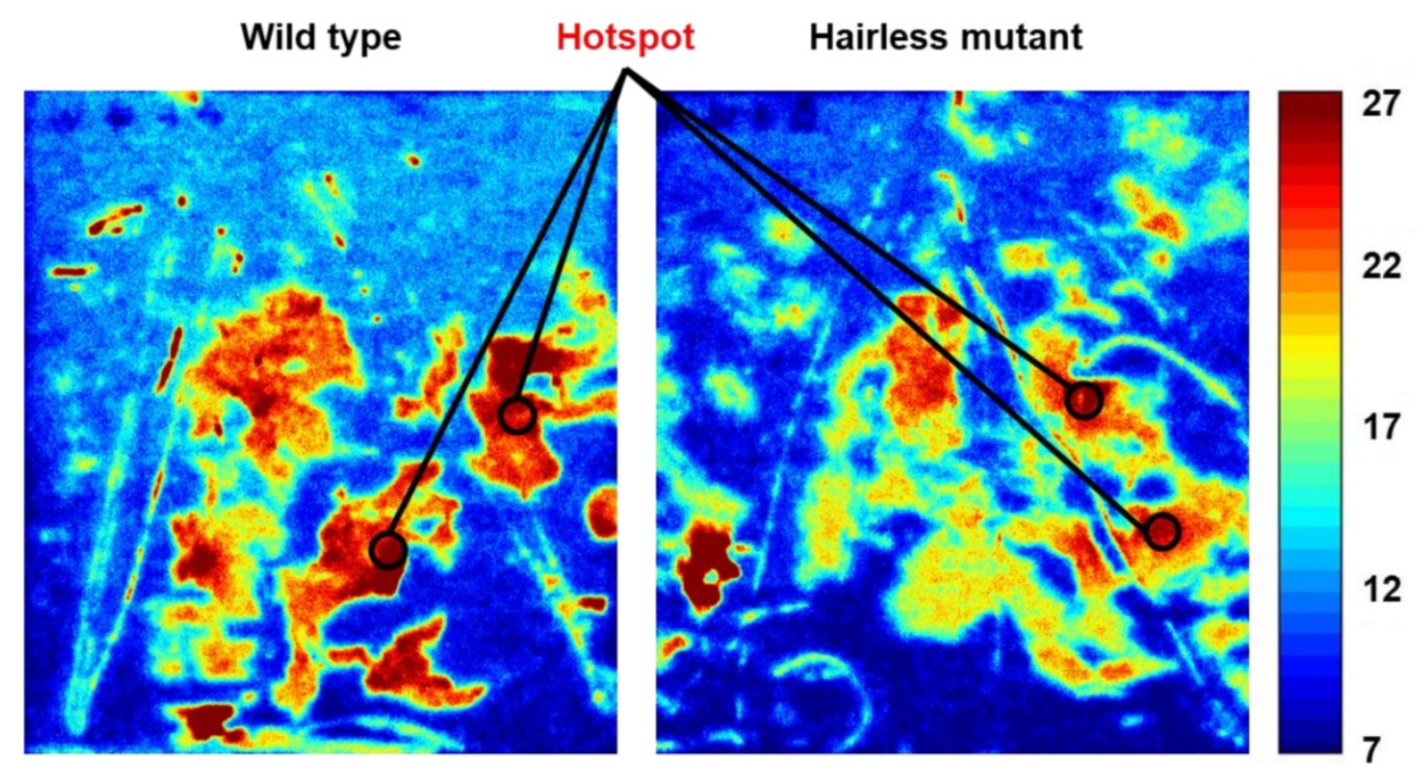

Fig. 2 Examples of soil sampling from hotspots of $\beta$-glucosidase activity $\left(\mathrm{nmol} \mathrm{cm} \mathrm{cm}^{-1}\right.$ ) for further analyses (enzyme kinetics (Fig. 3), kinetics of substrate-induced respiration (Fig. 4) and heat production (Fig. S1)). Small circles: the hotspot soil sampled for further analyses. Left: wild maize type; right: hairless mutant.

The images obtained from zymography were transformed into a 8-bit gray scale in ImageJ. The environmental background and camera noise were corrected by the images taken in the dark room without samples. Finally, the calibration line was used to convert gray scale values into enzyme activities.

\subsubsection{Kinetics of enzyme activity and activation energy}

The potential activity of $\beta$-glucosidase was measured using the same fluorogenic substrate for zymography (i.e. 4-methylumbelliferyl- $\beta$-D-glucoside). The concentrations for the kinetic measurement ranged from low to high $\left(0,5,10,20,50,100 \mu \mathrm{mol} \mathrm{L}^{-1}\right)$, whereby the saturation concentrations of fluorogenic substrates were obtained from preliminary experiments for this soil. Briefly, $0.5 \mathrm{~g}$ soil was mixed with $50 \mathrm{ml}$ sterile water. After $2 \mathrm{~min}$. low-energy sonification, $50 \mu \mathrm{l}$ soil suspension, $100 \mu \mathrm{l}$ substrate and $50 \mu \mathrm{l}$ MES buffer were added into a 96-well black microplate. The fluorescence was measured by a Victor 1420-050 Multi label counter (Perkin Elmer, USA) (Marx et al., 2001; German et al., 2011; Razavi et al., 2015). The Michaelis-Menten equation was used to determine $V_{\max }$ and $K_{m}$ :

$$
\mathrm{v}=\frac{\mathrm{V}_{\max } \times[\mathrm{S}]}{\mathrm{K}_{\mathrm{m}}+[\mathrm{S}]}
$$


where $\mathrm{V}$ is the reaction rate, $[\mathrm{S}]$ is the substrate concentration, $\mathrm{K}_{\mathrm{m}}$ is the substrate concentration at half-maximal rate, and $\mathrm{V}_{\max }$ is the maximum reaction rate at a given temperature.

The activation energy ( $\left.E_{a}\right)$ was calculated based on the Arrhenius equation (Eq. 2):

$$
\mathrm{K}=\mathrm{A} \times \exp \left(\frac{-\mathrm{E}_{\mathrm{a}}}{\mathrm{RT}}\right)
$$

where $\mathrm{k}$ is the reaction rate constant, $\mathrm{A}$ is the frequency of molecular collisions, $\mathrm{E}_{\mathrm{a}}$ is the required activation energy, $\mathrm{R}$ is the gas constant $\left(8.314 \mathrm{~J} \mathrm{~mol}^{-1} \mathrm{~K}^{-1}\right)$ and $\mathrm{T}$ is the temperature in Kelvin.

\subsubsection{Kinetics of the substrate-induced respiration}

Substrate Induced Growth Respiration (SIGR) is an approach to characterize functional soil microbial groups, and total and active (growing) microbial biomass (Panikov and Sizova, 1996; Blagodatskaya et al., 2014). Specifically, $0.5 \mathrm{~g}$ fresh soil in a tube was amended with a mixture containing glucose $\left(10 \mathrm{mg} \mathrm{g}^{-1}\right)$ and mineral salts $\left(1.9 \mathrm{mg} \mathrm{g}^{-1}\left(\mathrm{NH}_{4}\right)_{2} \mathrm{SO}_{4}, 2.25 \mathrm{mg}\right.$ $\mathrm{g}^{-1} \mathrm{~K}_{2} \mathrm{HPO}_{4}$, and $3.8 \mathrm{mg} \mathrm{g}^{-1} \mathrm{MgSO}_{4} \cdot 7 \mathrm{H}_{2} \mathrm{O}$ ) (Blagodatskaya et al., 2009), inducing unlimited growth. The samples amended with water instead of glucose were treated as the control. Soil samples were incubated in the modified rapid automated bacterial impedance technique (RABIT) system (don whitley scientific, UK) at 20 and $30^{\circ} \mathrm{C}$, respectively, and the $\mathrm{CO}_{2}$ production rate was monitored every $20 \mathrm{~min}$.

Equation (3) was used to estimate the specific growth rate $(\mu)$ of soil microorganisms:

$$
\mathrm{CO}_{2}=\mathrm{A}+\mathrm{B} \times \exp (\mu \mathrm{t})
$$

where $A$ is the initial respiration rate uncoupled from ATP production, $B$ is the initial rate of couple (growth) respiration, and $t$ is the time (Blagodatsky et al., 2000).

The total microbial biomass (TMB) and growing microbial biomass (GMB) at time zero were given by Eq. (4) and (5)

$$
\begin{aligned}
\mathrm{TMB} & =\frac{\mathrm{B}}{\mathrm{r}_{0} \mathrm{Q}} \\
\mathrm{GMB} & =\mathrm{TMB} \cdot \mathrm{r}_{0}
\end{aligned}
$$

where $r_{0}$ is the physiological state index of the microbial biomass (MB) before substrate addition and was calculated according to Eq. (6)

$$
r_{0}=\frac{B(1-\lambda)}{A+B(1-\lambda)}
$$


where $\lambda=0.9$, which has been accepted as a basic stoichiometric constant (Panikov and Sizova, 1996). Q is the total specific respiration activity:

$$
\mathrm{Q}=\frac{\mu}{\lambda \mathrm{YCO}_{2}}
$$

where $\mathrm{YCO}_{2}$ is the microbial yield per unit of glucose-C consumed, which was assumed to be a mean value of 0.6 (Panikov and Sizova, 1996). The theory of microbial growth kinetics has been presented in detail earlier (Panikov, 1995).

\subsubsection{Microbial energy response to substrates}

The approach - microcalorimetry - was used to monitor heat production. The measured heat production covers all metabolic processes (not only those leading to $\mathrm{CO}_{2}$ production), making them complementary to respiratory-based investigations (Harris et al., 2012; Hassan et al., 2014; Herrmann et al., 2014; Bölscher et al., 2016).

The heat production was estimated with separate sample sets. Briefly, $0.5 \mathrm{~g}$ soil was amended with the same nutrients and glucose/water as the SIGR described above in section 2.4. Sterile sand $\left(\mathrm{SiO}_{2}\right)$ was used as a reference for each sample. The sample and the reference should initially have the same heat capacity. All the samples containing soil or sand were placed into airtight glass containers and incubated at 20 and $30^{\circ} \mathrm{C}$, respectively, in the TAM Air Thermostat SN 548 (TA Instruments, Germany). Heat production was monitored continuously every $10 \mathrm{sec}$.

Microbial substrate use efficiency is a crucial property in SOM mineralization and helps strengthen our mechanistic understanding of the allocation of substrates towards energy losses and biosynthesis into microbial biomass in soils (Bölscher et al., 2017). The calorespirometric ratio $\left(\gamma, \mathrm{J} \mathrm{mol}^{-1} \mathrm{CO}_{2}\right.$ or $\left.\mathrm{mJ} \mu \mathrm{g}^{-1} \mathrm{CO}_{2}\right)$ is used as an indirect indicator of substrate use efficiency. It is the ratio of heat production and $\mathrm{CO}_{2}$ production (Hansen et al., 2004) and is calculated based on Eq. (8):

$$
\gamma=\frac{\mathrm{Q}}{\mathrm{CO}_{2}}
$$

where $\mathrm{Q}\left(\mathrm{J} \mathrm{g}^{-1}\right.$ soil $)$ is heat production and $\mathrm{CO}_{2}\left(\mathrm{~mol} \mathrm{CO} \mathrm{g}^{-1}\right.$ soil or $\mu \mathrm{g} \mathrm{CO}_{2}-\mathrm{C} \mathrm{g}^{-1}$ soil $)$ is the $\mathrm{CO}_{2}$ production over the period after substrate addition.

Substrate use efficiency is expected to decrease (e.g. higher calorespirometric ratio) with increasing temperature (Sinsabaugh et al., 2013; Wadsö and Hansen, 2015). This reflects changes in individuals, populations and/or community compositions (Barros et al., 2010; Schimel and Schaeffer, 2012). 


\subsubsection{Statistical analyses}

The significance of differences for maximal $\beta$-glucosidase activity, $K_{m}$, specific growth rate, total and growing microbial biomass, and the ratio of $\mathrm{Q} / \mathrm{CO}_{2}$ were analyzed by two-way ANOVA (i.e. maize genotypes and temperature are the two variables, and their interactions were also tested) using the software JMP, at $p<0.05$. Significance of differences of $E_{\mathrm{a}}$ for $\mathrm{V}_{\max }$ of $\beta$-glucosidase activity between the two maize genotypes were tested by the Student's $t$ test using the software JMP, at $p<0.05$.

\subsection{Results}

\subsubsection{Response of enzyme kinetics to the presence of root hairs and temperature}

$\beta$-glucosidase activities at $30{ }^{\circ} \mathrm{C}$ were $63 \%$ and $35 \%$ higher than at $20{ }^{\circ} \mathrm{C}$ in the soil from hotspots of root-hair wild type and root-hairless mutant maize, respectively. The maximum $\beta$-glucosidase activity in the soil from hotspots was not affected by root hairs at $20^{\circ} \mathrm{C}$. $\beta$ glucosidase activity in hotspot soil of maize with root hairs was $21 \%$ higher than that of the mutant at $30^{\circ} \mathrm{C}$ (Fig. 3a). The activation energy for $V_{\max }\left(E_{a}-V_{\max }\right)$ in hotspot soil of the wild type $\left(36.5 \mathrm{~kJ} \mathrm{~mol}^{-1}\right)$ was higher $(p=0.047)$ than that of the mutant $\left(21.9 \mathrm{~kJ} \mathrm{~mol}^{-1}\right)$ (Table 1$)$. $\mathrm{K}_{\mathrm{m}}$ values were also higher for the wild type than hairless mutant (Fig. 3b).

(a)

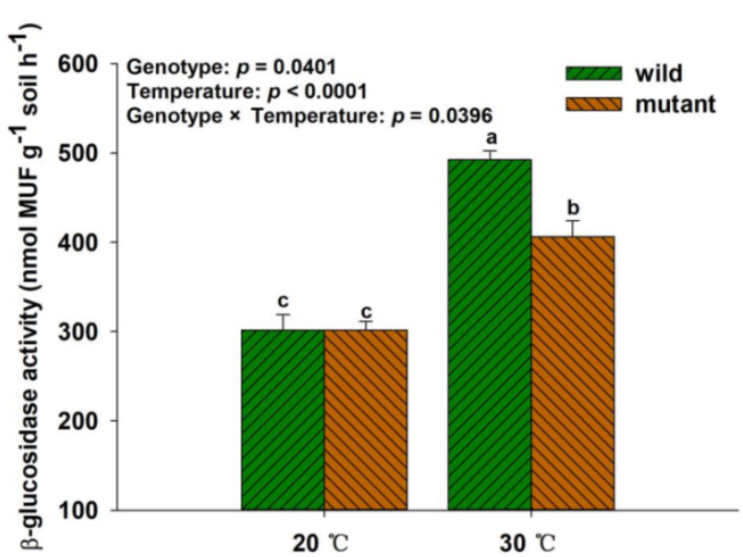

(b)

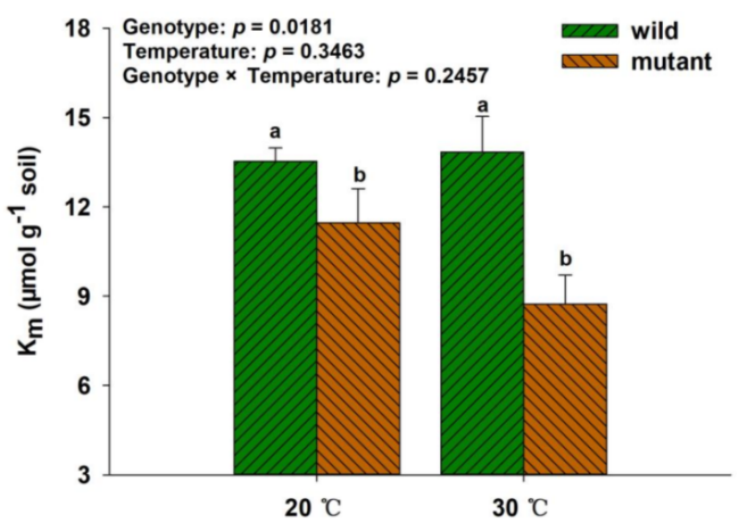

Fig. $3 \beta$-glucosidase activity parameters: $V_{\max }(\mathrm{a})$ and $\mathrm{K}_{\mathrm{m}}$ (b) at 20 and $30{ }^{\circ} \mathrm{C}$ of root-hair wild and root-hairless mutant maize. $p$ values were obtained after two-way ANOVA. Genotype: wild type and mutant maize; Temperature: 20 and $30^{\circ} \mathrm{C}$. Lower case letters in (a): significant differences after two-way ANOVA and Tukey's HSD test at $p<0.05$; Lower case letters in (b): significant differences between wild type and mutant maize after two-way ANOVA and Student's $t$ test at $p<0.05$. 
Table 1 The activation energy for $\beta$-glucosidase activity $\left(\mathrm{E}_{\mathrm{a}}-\mathrm{V}_{\max }\right)$ as obtained by fitting the Arrhenius equation (Eq. 2) based on the $\mathrm{V}_{\max }$ of $\beta$-glucosidase at 20 and $30{ }^{\circ} \mathrm{C}$. Small letters: significant differences after Student's $t$ test at $p<0.05$.

\begin{tabular}{ll}
\hline Maize genotype & $\mathrm{Ea}-\mathrm{V}_{\max }\left(\mathrm{kJ} \mathrm{mol}^{-1}\right)$ \\
\hline Wild & $36.5 \mathrm{a}$ \\
Mutant & $21.9 \mathrm{~b}$ \\
\hline
\end{tabular}

Thus, the enzyme kinetics $\left(\mathrm{V}_{\max }\right.$ and $\left.\mathrm{K}_{\mathrm{m}}\right)$ in soil hotspots for the two genotypes responded differently to temperature increase. The expected higher $\mathrm{K}_{\mathrm{m}}$ values in hotspot soil from the root-hair wild type at $30{ }^{\circ} \mathrm{C}$ than that at $20{ }^{\circ} \mathrm{C}$ indicated a change of the enzyme system to a lower efficiency. In contrast, an unexpected decrease in $K_{m}$ value in the hotspot soil of the root-hairless mutant showed a stronger substrate affinity of $\beta$-glucosidase to compensate the reduced release of root exudates.

\subsubsection{Response of substrate-induced respiration kinetics to the presence of root hairs and temperature}

The specific growth rates $(\mu)$ were about 2 times faster at $30{ }^{\circ} \mathrm{C}$ than $20^{\circ} \mathrm{C}(p<0.0001)$ in the hotspot soil of both genotypes (Fig. 4a). The specific growth rates of both genotypes were similar at $20^{\circ} \mathrm{C}$ (Fig. 4a). In contrast, the rate was $17.8 \%$ higher for the hotspot soil of root-hairless mutant versus root-hair wild type at $30{ }^{\circ} \mathrm{C}$ (Fig. 4a). Root hairs do not affect total soil microbial biomass (Table S1), but over doubled the growing microbial biomass and its portion in total microbial biomass compared to that of the mutant maize, independent of temperature (Fig. $4 \mathrm{~b}$ and $4 \mathrm{c}$ ). Thus, temperature caused a shift of the microbial growth strategy, while root hairs (i.e. C input) controlled the active portion of the microbial biomass.
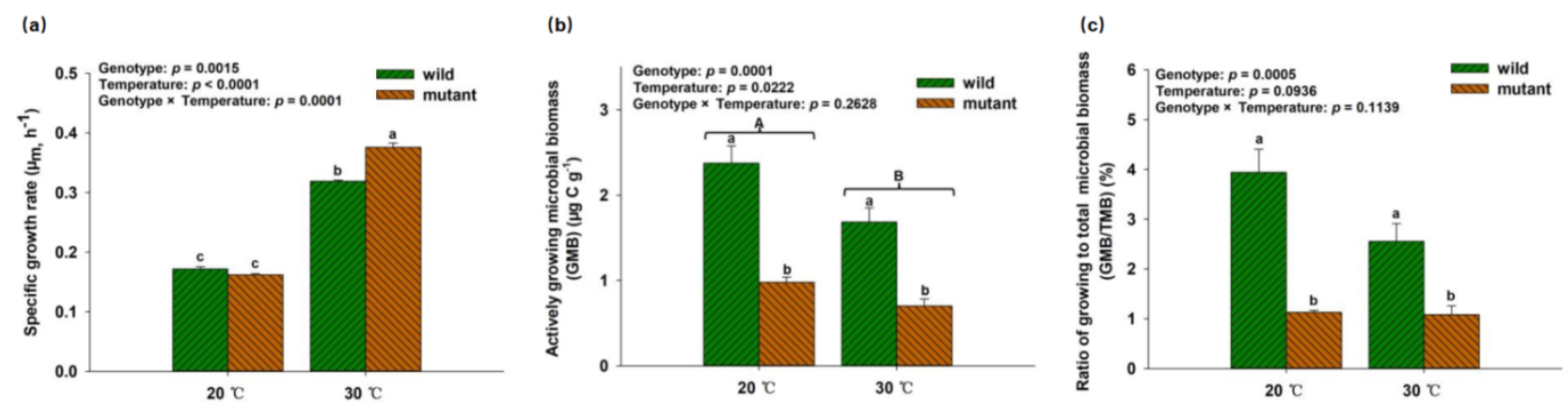

Fig. 4 Specific growth rates $(\mu)$ of soil microorganisms (a), actively growing microbial biomass (b), and the ratio of growing to total microbial biomass (c) during incubation at 20 and $30{ }^{\circ} \mathrm{C}$ for the two maize genotypes estimated by substrate-induced respiration. $p$ values were obtained after two-way ANOVA. Genotype: wild type and mutant maize; Temperature: 
20 and $30{ }^{\circ} \mathrm{C}$. Lower case letters in (a): significant differences after two-way ANOVA and Tukey's HSD test at $p<0.05$; Lower case letters in (b) and (c): significant differences between wild type and mutant maize after two-way ANOVA and Student's $t$ test at $p<0.05$; Upper case letters in (b): significant differences between 20 and $30{ }^{\circ} \mathrm{C}$ after two-way ANOVA and Student's $t$ test at $p<0.05$.

\subsubsection{Response of calorespirometric ratio to the presence of root hairs and temperature}

The effect of root hairs on heat production was negligible, whereas higher temperature increased the cumulative heat production (Fig. S1). The calorespirometric ratios after glucose addition to the hotspot soil of both maize genotypes and two temperatures ranged from 41.2 to $98.6 \mathrm{~mJ} \mathrm{\mu g}^{-1} \mathrm{CO}_{2}-\mathrm{C}$. The ratio at $20^{\circ} \mathrm{C}$ was lower than that at $30^{\circ} \mathrm{C}$, irrespective of maize genotype (Fig. 5), indicating a higher substrate use efficiency at lower temperature. The ratios increased with increasing temperature, and the root-hairless mutant maize exhibited the highest calorespirometric ratio at $30{ }^{\circ} \mathrm{C}$ (Fig. 5). Accordingly, the effect of root hairs on the calorespirometric ratio was irrespective of temperature, while temperature induced the conversion of more substrates to $\mathrm{CO}_{2}$ independent of root hairs.

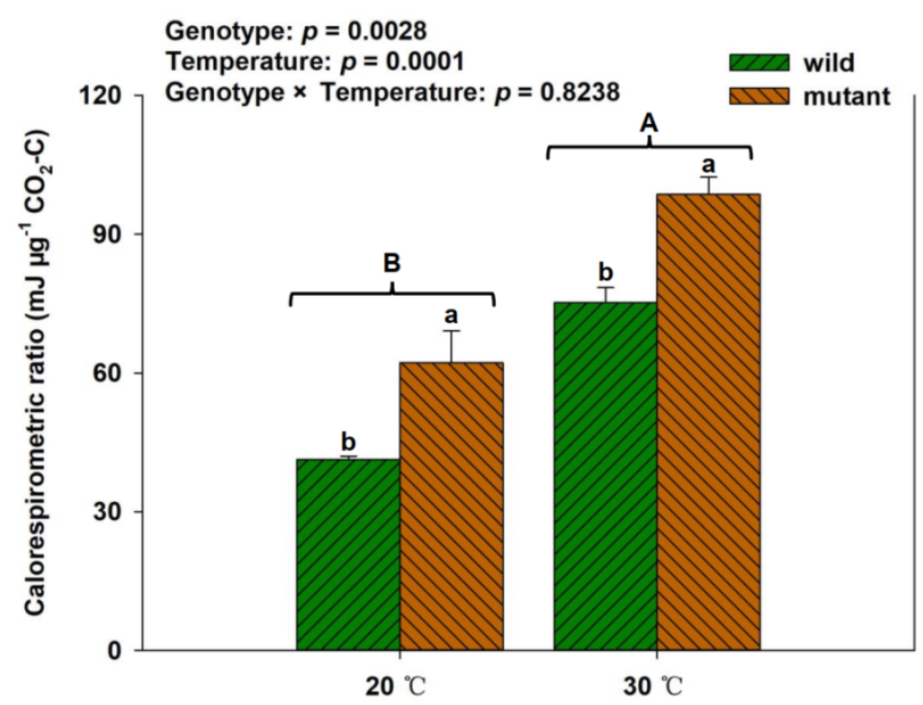

Fig. 5 Substrate use efficiency expressed as calorespirometric ratios obtained from the $24 \mathrm{~h}$ incubation of soil samples after glucose addition. $p$ values were obtained after two-way ANOVA. Genotype: wild type and mutant maize; Temperature: 20 and $30{ }^{\circ} \mathrm{C}$. Lower case letters: significant differences between wild type and mutant maize after two-way ANOVA and Student's $t$ test at $p<0.05$; Upper case letters: significant differences between 20 and $30{ }^{\circ} \mathrm{C}$ after two-way ANOVA and Student's $t$ test at $p<0.05$. 


\subsection{Discussion}

\subsubsection{The interactive effects of root hairs and temperature on enzyme activities, microbial growth strategy, and substrate use efficiency}

Elevated temperature caused higher $\beta$-glucosidase activity (Fig. 3a), which supported part of our first hypothesis. This increase was probably related to the higher root exudate release due to the effect of warming on the membrane permeability of root cells (Steinweg et al., 2008; Allison et al., 2010). More root exudates at warmer temperature stimulated microorganisms and thus boosted enzyme production (Ma et al., 2017). Importantly, the higher enzyme activities at 30 versus $20^{\circ} \mathrm{C}$ coincided with less growing microbial biomass (Fig. 4b), so that substrate allocation to microbial growth decreased due to higher maintenance demands with temperature (Steinweg et al., 2008; Wen et al., 2019). The higher enzyme production in warmer soils required more $\mathrm{C}$ and energy input at the cost of reducing the proportion of $\mathrm{C}$ to microbial growth (Cotrufo et al., 2013; Bölscher, 2016). The higher microbial demand for $\mathrm{C}$ at elevated temperature highlighted the role of root hairs. At $30{ }^{\circ} \mathrm{C}$, root hairs released large amounts of compounds (Badri and Vivanco, 2009; Jones et al., 2009; Holz et al., 2018), which increased growing microbial biomass and accelerated enzyme activities compared to the soil under the hairless mutant. In contrast, higher $\mathrm{K}_{\mathrm{m}}$ at $30^{\circ} \mathrm{C}$ (Fig. $3 b$ ) and higher $E_{a}$ (Table 1) in the hotspot soil of wild type maize confirmed the expression of low efficient enzymes (Razavi et al., 2017). This means that microorganisms in the hotspots of the wild type maintained a slow growth rate but maximized substrate use efficiency (Fierer et al., 2007). Accordingly, the increased $\beta$-glucosidase production in the presence of root hairs was sufficient to gain enough energy for microbial activity and proliferation. Higher substrate use efficiency combined with less efficient enzyme systems tended to be an evolutionary strategy to increase microbial biomass and probably maximize the fraction of resource uptake. Such a higher substrate supply is allocated to biosynthetic processes by investing in central metabolism and assimilatory pathways such as amino acid, nucleotide, and fatty acid synthesis to build cellular components and reduce SOM decomposition (Keiblinger et al., 2010; Wei et al., 2018) (Fig. 1). In contrast, the lower $K_{m}$ of $\beta$-glucosidase in the hotspots of root-hairless maize at higher temperature (Fig. 3b) could be attributed to isoenzyme expression (Razavi et al., 2017) by the same or different microbial groups. Such multiple isoenzyme expression will maintain the high efficiency and critical functions in the absence of abundant labile $C$. Lower $K_{m}$ supported hypothesis 2 on the efficient enzyme systems of the microbial communities inhabiting enzymatic hotspots of the root-hairless mutant to compensate for the lesser amount of exudate. These isoenzymes 
reduced the activation energy $\left(\mathrm{E}_{\mathrm{a}}-\mathrm{V}_{\max }\right)$ (Table 1) of their catalytic reactions compared with the wild type and thus ensured that the root-hairless-induced enzymes were faster and more efficient.

Interestingly, the effect of root hairs on microbial activity and functionality (e.g. enzyme kinetics, specific growth rate and heat production at moderate temperature) at $20{ }^{\circ} \mathrm{C}$ was negligible. This could be due to the insensitivity of hydrolytic enzymes to substrate concentrations at optimal temperature. This would represent a microbial acclimation mechanism (Ge et al., 2017). We detected no trends in enzyme-substrate affinity at $20{ }^{\circ} \mathrm{C}$ and therefore conclude that microorganisms adapted to moderate temperature in the studied soil used a similar set of isoenzymes at $20{ }^{\circ} \mathrm{C}$ (Razavi et al., 2016a). This also suggests that the processes at $20{ }^{\circ} \mathrm{C}$ were at a relatively stationary stage (Kuzyakov and Razavi, 2019), whereas warming caused extreme variability in microbiome activity and functionality. Accordingly, despite the high dynamics of life and processes in hotspots such as in the rhizosphere, roots may engineer the local microenvironment and optimize the conditions for their habitat (e.g. for better growth under specific soil conditions) (Kuzyakov and Razavi, 2019).

\subsubsection{What matters more: food or climate?}

We presented three mechanisms of how root hairs regulate microbial processes in hotspots in response to warming: i) alter enzyme systems (Fig. 3); ii) shift microbial growth strategies (Fig. 4) and iii) change substrate use efficiency (Fig. 5). Selecting enzymes with lower substrate affinity (i.e. higher $\mathrm{K}_{\mathrm{m}}$ ) in the presence of root hairs will restrain the enzymemediated reactions at higher temperature (Bradford et al., 2019). In contrast, substrate limitation due to the absence of root hairs shifted the expression of enzymes toward higher efficiency (i.e. lower $\mathrm{K}_{\mathrm{m}}$ and $\mathrm{E}_{\mathrm{a}}$ ) (Bradford, 2013). Such a shift is one way to maintain decomposition processes under warmer conditions. Consequently, the altered expression of hydrolytic enzymes mediated the response of the microbial decomposition of organic matter to sustained warming (Blagodatskaya et al., 2016). The higher relative abundance of slowgrowing microorganisms in the soil of maize with root hairs could induce a lower calorespirometric ratio compared with the hairless mutant (Fig. 5). Such a higher ratio of C incorporated into microbial biomass (Fig. 4c) meant higher SOM formation rates and retarded soil C losses (Bölscher, 2016; Bradford et al., 2019; Wen et al., 2019). In comparison, the higher abundance of fast-growing microorganisms in the soil of root-hairless maize at $30{ }^{\circ} \mathrm{C}$ responded faster to the available substrates and maximized their growth by increasing 
the calorespirometric ratio (Fig. 5) (Fierer et al., 2007), leading to a large energy loss as heat (Herrmann et al., 2014). In summary, changes in enzymatic properties and microbial functioning are likely to offset the exudate-induced increase of microbial activity in the presence of root hairs (wild type) and also compensate the reduced exudate effect in the absence of root hairs (mutant) in warmer conditions.

Overall, for the first time, our data on microbial efficiency and functionality (e.g. enzyme activity, growth rate, biomass and substrate use efficiency) confirmed the evolutionary theory on structure-function trade-offs of enzymes and thermal-substrate tradeoffs in response to warming at the resolution of soil hotspots (Fig. 6). The enzymatic responses we observed may involve individual and community adaptations (Treseder et al., 2012; Bradford, 2013; Bradford et al., 2019). Nonetheless, independent of the regulatory levels, the underlying biochemical mechanisms act through the tradeoffs between enzyme stability or flexibility and their facilitated functional rates (Bradford et al., 2019). We therefore conclude that root hairs affecting exudate quantity regulated enzyme expression, microbial growth strategies and thus substrate use efficiency, hence mediating the SOM stocks in response to warming.

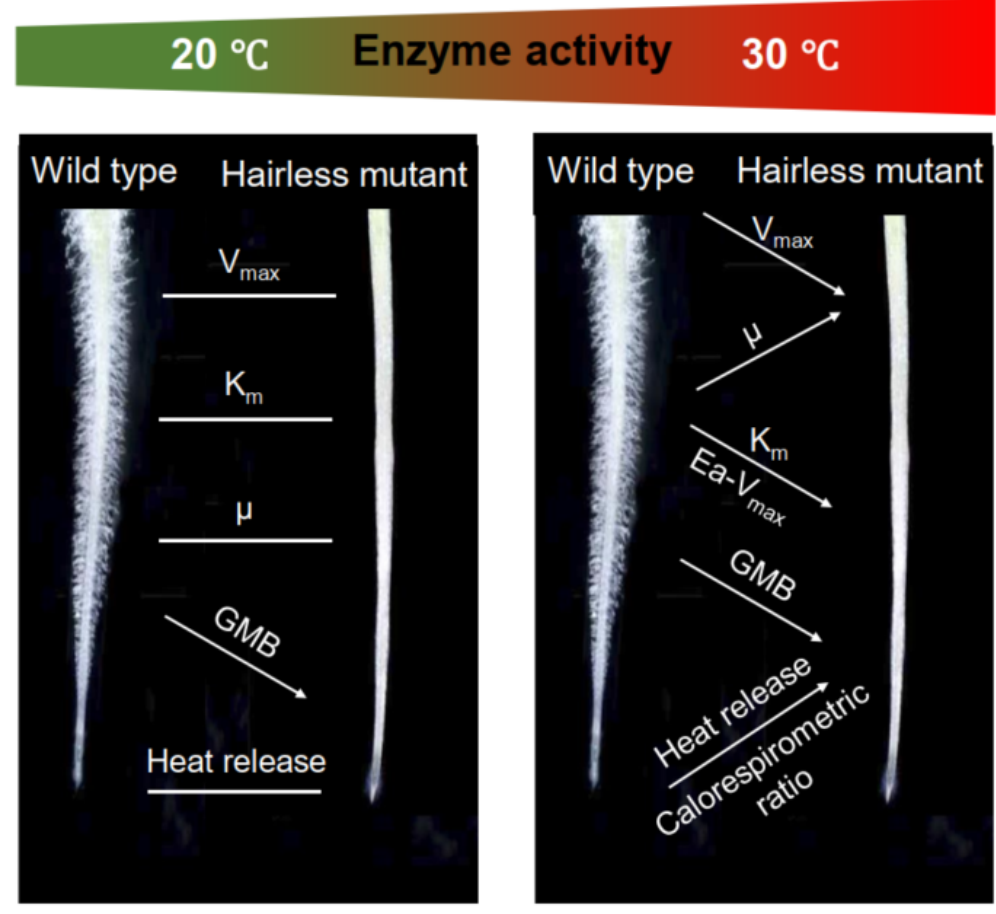

Fig. 6 Generalized effects of temperature and root hairs on microbial and enzyme activities. The effects of root hairs are more pronounced at higher temperature. Temperature shifted microbial growth strategy towards a higher abundance of fast-growing microorganisms. Root hairs induced higher enzyme activity and larger fraction of actively growing microbial biomass (GMB) under higher temperature, whereas was coincided with lower enzyme 
efficiency. Changes in enzymatic properties and in microbial functioning offset the exudateinduced promotion of microbial activities in the presence of root hairs (wild type) and could compensate for the reduced exudate effect in the absence of root hairs (mutant) in a warmer world. $V_{\max }$ : $\beta$-glucosidase activity; $E_{a}-V_{\max }$ : the activation energy for $\beta$-glucosidase activity; $\mu$ : specific growth rate; GMB: growing microbial biomass.

\section{Acknowledgments}

We gratefully acknowledge the China Scholarship Council (CSC) for financial support for Xuechen Zhang. This study was supported by the DFG grant RA-3062/3-1 and SP 943/61. We acknowledge Frank Hochholdinger, University of Bonn, for kindly providing maize seeds. The contribution of YK was supported by the Russian Science Foundation (project No. 18-14-00362). The authors would like to thank Callum C. Banfield for constructive criticism of the text.

\section{References}

Allison, S.D., Wallenstein, M.D., Bradford, M.A., 2010. Soil-carbon response to warming dependent on microbial physiology. Nature Geoscience 3, 336-340. doi:10.1038/ngeo846

Badri, D.V., Vivanco, J.M., 2009. Regulation and function of root exudates. Plant, Cell \& Environment 32, 666-681. doi:10.1111/j.1365-3040.2009.01926.x

Barros, N., Salgado, J., Rodríguez-Añón, J.A., Proupín, J., Villanueva, M., Hansen, L.D., 2010. Calorimetric approach to metabolic carbon conversion efficiency in soils: Comparison of experimental and theoretical models. Journal of Thermal Analysis and Calorimetry 99, 771-777. doi:10.1007/s10973-010-0673-4

Bates, T.R., Lynch, J.P., 2000. Plant growth and phosphorus accumulation of wild type and two root hair mutants of Arabidopsis thaliana (Brassicaceae). American Journal of Botany 87, 958-963. doi:10.2307/2656994

Bilyera, N., Zhang, X., Fan, L., Dippold, M., Kuzyakov, Y., Spielvogel, S., Razavi, B. S., 2019. Identification of spatial biochemical pattern in the rhizosphere by linkagebetween rhizodeposition and enzyme activities. EGU2019-1825

Blagodatskaya, E., Blagodatsky, S., Anderson, T.-H., Kuzyakov, Y., 2014. Microbial Growth and Carbon Use Efficiency in the Rhizosphere and Root-Free Soil. PLoS ONE 9, e93282. doi:10.1371/journal.pone.0093282

Blagodatskaya, E., Blagodatsky, S., Khomyakov, N., Myachina, O., Kuzyakov, Y., 2016. Temperature sensitivity and enzymatic mechanisms of soil organic matter decomposition along an altitudinal gradient on Mount Kilimanjaro. Scientific Reports 6. doi:10.1038/srep22240 
Blagodatskaya, E., Yuyukina, T., Blagodatsky, S., Kuzyakov, Y., 2011. Three-source-partitioning of microbial biomass and of $\mathrm{CO} 2$ efflux from soil to evaluate mechanisms of priming effects. Soil Biology and Biochemistry 43, 778-786. doi:10.1016/j.soilbio.2010.12.011

Blagodatskaya, E.V., Blagodatsky, S.A., Anderson, T.H., Kuzyakov, Y., 2009. Contrasting effects of glucose, living roots and maize straw on microbial growth kinetics and substrate availability in soil. European Journal of Soil Science 60, 186-197. doi:10.1111/j.1365-2389.2008.01103.x

Blagodatsky, S.A., Heinemeyer, O., Richter, J., 2000. Estimating the active and total soil microbial biomass by kinetic respiration analysis. Biology and Fertility of Soils 32, 73-81. doi:10.1007/s003740000219

Bölscher, T., 2016. Decomposition of Soil Organic Matter under a Changing Climate. Acta Universitatis Agriculturae Sueciae (1652-6880).

Bölscher, T., Paterson, E., Freitag, T., Thornton, B., Herrmann, A.M., 2017. Temperature sensitivity of substrate-use efficiency can result from altered microbial physiology without change to community composition. Soil Biology and Biochemistry 109, 59-69. doi:10.1016/j.soilbio.2017.02.005

Bölscher, T., Wadsö, L., Börjesson, G., Herrmann, A.M., 2016. Differences in substrate use efficiency: impacts of microbial community composition, land use management, and substrate complexity. Biology and Fertility of Soils 52, 547-559. doi:10.1007/s00374-016-1097-5

Bradford, M.A., 2013. Thermal adaptation of decomposer communities in warming soils. Frontiers in Microbiology 4. doi:10.3389/fmicb.2013.00333

Bradford, M.A., McCulley, R.L., Crowther, Thomas.W., Oldfield, E.E., Wood, S.A., Fierer, N., 2019. Cross-biome patterns in soil microbial respiration predictable from evolutionary theory on thermal adaptation. Nature Ecology \& Evolution 3, 223-231. doi:10.1038/s41559-018-0771-4

Burns, R.G., DeForest, J.L., Marxsen, J., Sinsabaugh, R.L., Stromberger, M.E., Wallenstein, M.D., Weintraub, M.N., Zoppini, A., 2013. Soil enzymes in a changing environment: Current knowledge and future directions. Soil Biology and Biochemistry 58, 216-234. doi:10.1016/j.soilbio.2012.11.009

Cotrufo, M.F., Wallenstein, M.D., Boot, C.M., Denef, K., Paul, E., 2013. The Microbial EfficiencyMatrix Stabilization (MEMS) framework integrates plant litter decomposition with soil organic matter stabilization: do labile plant inputs form stable soil organic matter? Global Change Biology 19, 988-995. doi:10.1111/gcb.12113

Crowther, T.W., Bradford, M.A., 2013. Thermal acclimation in widespread heterotrophic soil microbes. Ecology Letters 16, 469-477. doi:10.1111/ele.12069

Datta, S., Kim, C.M., Pernas, M., Pires, N.D., Proust, H., Tam, T., Vijayakumar, P., Dolan, L., 2011. Root hairs: development, growth and evolution at the plant-soil interface. Plant and Soil 346, 1-14. doi:10.1007/s11104-011-0845-4

Davidson, E.A., Janssens, I.A., 2006. Temperature sensitivity of soil carbon decomposition and feedbacks to climate change. Nature 440, 165-173. doi:10.1038/nature04514 
Fierer, N., Bradford, M.A., Jackson, R.B., 2007. Toward an Ecological Classification of Soil Bacteria. Ecology 88, 1354-1364.

Finkel, S.E., 2006. Long-term survival during stationary phase: evolution and the GASP phenotype. Nature Reviews Microbiology 4, 113-120. doi:10.1038/nrmicro1340

Ge, T., Wei, X., Razavi, B.S., Zhu, Z., Hu, Y., Kuzyakov, Y., Jones, D.L., Wu, J., 2017. Stability and dynamics of enzyme activity patterns in the rice rhizosphere: Effects of plant growth and temperature. Soil Biology \& Biochemistry 113, 108-115. doi:10.1016/j.soilbio.2017.06.005

German, D.P., Weintraub, M.N., Grandy, A.S., Lauber, C.L., Rinkes, Z.L., Allison, S.D., 2011. Optimization of hydrolytic and oxidative enzyme methods for ecosystem studies. Soil Biology and Biochemistry 43, 1387-1397. doi:10.1016/j.soilbio.2011.03.017

Hansen, L.D., Macfarlane, C., McKinnon, N., Smith, B.N., Criddle, R.S., 2004. Use of calorespirometric ratios, heat per $\mathrm{CO} 2$ and heat per $\mathrm{O} 2$, to quantify metabolic paths and energetics of growing cells. Thermochimica Acta 422, 55-61. doi:10.1016/j.tca.2004.05.033

Harris, J.A., Ritz, K., Coucheney, E., Grice, S.M., Lerch, T.Z., Pawlett, M., Herrmann, A.M., 2012. The thermodynamic efficiency of soil microbial communities subject to long-term stress is lower than those under conventional input regimes. Soil Biology and Biochemistry 47, 149-157. doi:10.1016/j.soilbio.2011.12.017

Hassan, W., Chen, W., Cai, P., Huang, Q., 2014. Estimation of enzymatic, microbial, and chemical properties in Brown soil by microcalorimetry. Journal of Thermal Analysis and Calorimetry 116, 969-988. doi:10.1007/s10973-013-3588-z

Herrmann, A.M., Coucheney, E., Nunan, N., 2014. Isothermal Microcalorimetry Provides New Insight into Terrestrial Carbon Cycling. Environmental Science \& Technology 48, 4344-4352. doi:10.1021/es403941h

Holz, M., Zarebanadkouki, M., Kuzyakov, Y., Pausch, J., Carminati, A., 2018. Root hairs increase rhizosphere extension and carbon input to soil. Ann Bot 121, 61-69. doi:10.1093/aob/mcx127

Jones, D.L., Nguyen, C., Finlay, R.D., 2009. Carbon flow in the rhizosphere: carbon trading at the soilroot interface. Plant and Soil 321, 5-33. doi:10.1007/s11104-009-9925-0

Keiblinger, K.M., Hall, E.K., Wanek, W., Szukics, U., Hämmerle, I., Ellersdorfer, G., Böck, S., Strauss, J., Sterflinger, K., Richter, A., Zechmeister-Boltenstern, S., 2010. The effect of resource quantity and resource stoichiometry on microbial carbon-use-efficiency: Resource quantity/quality drives microbial C-use-efficiency. FEMS Microbiology Ecology no-no. doi:10.1111/j.15746941.2010.00912.x

Kuzyakov, Y., 2010. Priming effects: Interactions between living and dead organic matter. Soil Biology and Biochemistry 42, 1363-1371. doi:10.1016/j.soilbio.2010.04.003

Kuzyakov, Y., Blagodatskaya, E., 2015. Microbial hotspots and hot moments in soil: Concept \& review. Soil Biology \& Biochemistry 83, 184-199. doi:10.1016/j.soilbio.2015.01.025 
Kuzyakov, Y., Razavi, B.S., 2019. Rhizosphere size and shape: Temporal dynamics and spatial stationarity. Soil Biology and Biochemistry 135, 343-360. doi:10.1016/j.soilbio.2019.05.011

Lammirato, C., Miltner, A., Wick, L.Y., Kästner, M., 2010. Hydrolysis of cellobiose by b-glucosidase in the presence of soil minerals - Interactions at solid - liquid interfaces and effects on enzyme activity levels. Soil Biology and Biochemistry 42, 2203-2210. doi: 10.1016/j.soilbio.2010.08.018

Ma, X., Razavi, B.S., Holz, M., Blagodatskaya, E., Kuzyakov, Y., 2017. Warming increases hotspot areas of enzyme activity and shortens the duration of hot moments in the root-detritusphere. Soil Biology and Biochemistry 107, 226-233. doi:10.1016/j.soilbio.2017.01.009

Marx, J.-C., Collins, T., D’Amico, S., Feller, G., Gerday, C., 2007. Cold-Adapted Enzymes from Marine Antarctic Microorganisms. Marine Biotechnology 9, 293-304. doi:10.1007/s10126-006-6103-8

Marx, M.-C., Wood, M., Jarvis, S.C., 2001. A microplate fluorimetric assay for the study of enzyme diversity in soils. Soil Biology and Biochemistry 33, 1633-1640. doi:10.1016/S00380717(01)00079-7

Mishra, B.S., Singh, M., Aggrawal, P., Laxmi, A., 2009. Glucose and Auxin Signaling Interaction in Controlling Arabidopsis thaliana Seedlings Root Growth and Development. PLoS ONE 4, e4502. doi:10.1371/journal.pone.0004502

Moscatelli, M.C., Lagomarsino, A., Garzillo, A.M.V., Pignataro, A., Grego, S., 2012. $\beta$-Glucosidase kinetic parameters as indicators of soil quality under conventional and organic cropping systems applying two analytical approaches. Ecological Indicators 13, 322-327. doi:10.1016/j.ecolind.2011.06.031

Panikov, N.S., 1995. Microbial growth kinetics. Chapman \& Hall Ltd, London.

Panikov, N.S., Sizova, M.V., 1996. A kinetic method for estimating the biomass of microbial functional groups in soil. Journal of Microbiological Methods 24, 219-230. doi:10.1016/01677012(95)00074-7

Paterson, E., Midwood, A.J., Millard, P., 2009. Through the eye of the needle: a review of isotope approaches to quantify microbial processes mediating soil carbon balance: Tansley review. New Phytologist 184, 19-33. doi:10.1111/j.1469-8137.2009.03001.x

Pausch, J., Loeppmann, S., Kühnel, A., Forbush, K., Kuzyakov, Y., Cheng, W., 2016. Rhizosphere priming of barley with and without root hairs. Soil Biology and Biochemistry 100, 74-82. doi:10.1016/j.soilbio.2016.05.009

Poirier, V., Roumet, C., Munson, A.D., 2018. The root of the matter: Linking root traits and soil organic matter stabilization processes. Soil Biology and Biochemistry 120, 246-259. doi:10.1016/j.soilbio.2018.02.016

Razavi, B.S., Blagodatskaya, E., Kuzyakov, Y., 2015. Nonlinear temperature sensitivity of enzyme kinetics explains canceling effect-a case study on loamy haplic Luvisol. Front Microbiol 6, 1126. doi:10.3389/fmicb.2015.01126 
Razavi, B. S., Blagodatskaya, E., Kuzyakov, Y., 2016a. Temperature selects for static soil enzyme systems to maintain high catalytic efficiency. Soil Biology and Biochemistry 97, 15-22. doi: 10.1016/j.soilbio.2016.02.018

Razavi, B.S., Liu, S., Kuzyakov, Y., 2017. Hot experience for cold-adapted microorganisms: Temperature sensitivity of soil enzymes. Soil Biology and Biochemistry 105, 236-243. doi:10.1016/j.soilbio.2016.11.026

Razavi, B.S., Zarebanadkouki, M., Blagodatskaya, E., Kuzyakov, Y., 2016b. Rhizosphere shape of lentil and maize: Spatial distribution of enzyme activities. Soil Biology and Biochemistry 96, 229-237. doi:10.1016/j.soilbio.2016.02.020

Razavi, B.S., Zhang, X., Bilyera, N., Guber, A., Zarebanadkouki, M., 2019. Soil zymography: Simple and reliable? Review of current knowledge and optimization of the method. Rhizosphere 100161. doi:10.1016/j.rhisph.2019.100161

Schimel, J.P., Schaeffer, S.M., 2012. Microbial control over carbon cycling in soil. Frontiers in Microbiology 3. doi:10.3389/fmicb.2012.00348

Sinsabaugh, R.L., Manzoni, S., Moorhead, D.L., Richter, A., 2013. Carbon use efficiency of microbial communities: stoichiometry, methodology and modelling. Ecol Lett 16, 930-9. doi:10.1111/ele.12113

Somero, G.N., 1978. Temperature Adaptation of Enzymes: Biological Optimization Through StructureFunction Compromises. Annual Review of Ecology and Systematics 9, 1-29. doi:10.1146/annurev.es.09.110178.000245

Spohn, M., Kuzyakov, Y., 2014. Spatial and temporal dynamics of hotspots of enzyme activity in soil as affected by living and dead roots—a soil zymography analysis. Plant and Soil 379, 67-77. doi:10.1007/s11104-014-2041-9

Steinweg, J.M., Plante, A.F., Conant, R.T., Paul, E.A., Tanaka, D.L., 2008. Patterns of substrate utilization during long-term incubations at different temperatures. Soil Biology and Biochemistry 40, 2722-2728. doi:10.1016/j.soilbio.2008.07.002

Tian, P., Razavi, B.S., Zhang, X., Wang, Q., Blagodatskaya, E., 2020. Microbial growth and enzyme kinetics in rhizosphere hotspots are modulated by soil organics and nutrient availability. Soil Biology and Biochemistry 141, 107662. doi:10.1016/j.soilbio.2019.107662

Treseder, K.K., Balser, T.C., Bradford, M.A., Brodie, E.L., Dubinsky, E.A., Eviner, V.T., Hofmockel, K.S., Lennon, J.T., Levine, U.Y., MacGregor, B.J., Pett-Ridge, J., Waldrop, M.P., 2012. Integrating microbial ecology into ecosystem models: challenges and priorities. Biogeochemistry 109, 7-18. doi:10.1007/s10533-011-9636-5

Wadsö, L., Hansen, L.D., 2015. Calorespirometry of terrestrial organisms and ecosystems. Methods 76, 11-19. doi:10.1016/j.ymeth.2014.10.024 
Wei, L., Razavi, B.S., Wang, W., Zhu, Z., Liu, S., Wu, J., Kuzyakov, Y., Ge, T., 2019. Labile carbon matters more than temperature for enzyme activity in paddy soil. Soil Biology and Biochemistry 135, 134-143. doi:10.1016/j.soilbio.2019.04.016

Wei, X., Ge, T., Zhu, Z., Hu, Y., Liu, S., Li, Y., Wu, J., Razavi, B.S., 2018. Expansion of rice enzymatic rhizosphere: temporal dynamics in response to phosphorus and cellulose application. Plant and Soil. doi:10.1007/s11104-018-03902-0

Wen, Y., Zang, H., Freeman, B., Musarika, S., Evans, C., Chadwick, D., Jones, D., 2019. Microbial utilization of low molecular weight organic carbon substrates in cultivated peats in response to warming and soil degradation. Soil Biology and Biochemistry. doi: 10.1016/j.soilbio.2019.107629

Zang, H., Blagodatskaya, E., Wen, Y., Shi, L., Cheng, F., Chen, H., Zhao, B., Zhang, F., Fan, M., Kuzyakov, Y., 2019. Temperature sensitivity of soil organic matter mineralization decreases with long-term $\mathrm{N}$ fertilization: Evidence from four Q10 estimation approaches. Land Degradation \& Development. doi: 10.1002/ldr.3496

Zhang, X., Dippold, M.A., Kuzyakov, Y., Razavi, B.S., 2019. Spatial pattern of enzyme activities depends on root exudate composition. Soil Biology and Biochemistry 133, 83-93. doi:10.1016/j.soilbio.2019.02.010

Zinser, E.R., Kolter, R., 1999. Mutations Enhancing Amino Acid Catabolism Confer a Growth Advantage in Stationary Phase. J. BACTERIOL. 181, 8. 


\section{Supplementary}

Table S1 Actively growing and total microbial biomass during incubation for substrateinduced respiration at 20 and $30^{\circ} \mathrm{C}$ for the two maize genotypes. Two-way ANOVA analysis of the influences of maize genotype, temperature and their interactions on microbial biomass.

\begin{tabular}{|c|c|c|c|c|}
\hline \multirow{2}{*}{$\begin{array}{l}\text { Temperature }\left({ }^{\circ}\right. \\
\text { C) }\end{array}$} & \multirow{2}{*}{$\begin{array}{l}\text { maize } \\
\text { genotype }\end{array}$} & \multicolumn{2}{|c|}{ microbial biomass (ug $\mathrm{Cg}^{-1}$ ) } & \multirow{2}{*}{$\begin{array}{l}\mathrm{GMB} / \mathrm{TMB} \\
\text { ratio }(\%)\end{array}$} \\
\hline & & growing (GMB) & total (TMB) & \\
\hline \multirow{2}{*}{20} & wild & 2.4 & 62.3 & 3.9 \\
\hline & mutant & 1.0 & 86.4 & 1.1 \\
\hline \multirow{2}{*}{30} & wild & 1.7 & 67.6 & 2.6 \\
\hline & mutant & 0.7 & 67.1 & 1.1 \\
\hline \multicolumn{5}{|l|}{ Source of variance } \\
\hline genotype & & 0.0001 & 0.1152 & 0.0005 \\
\hline temperature & & 0.0222 & 0.3244 & 0.0936 \\
\hline \multicolumn{2}{|c|}{ genotype $*$ temperature } & 0.2628 & 0.1039 & 0.1139 \\
\hline
\end{tabular}

Note: Significant values are shown in bold $(p<0.05)$.

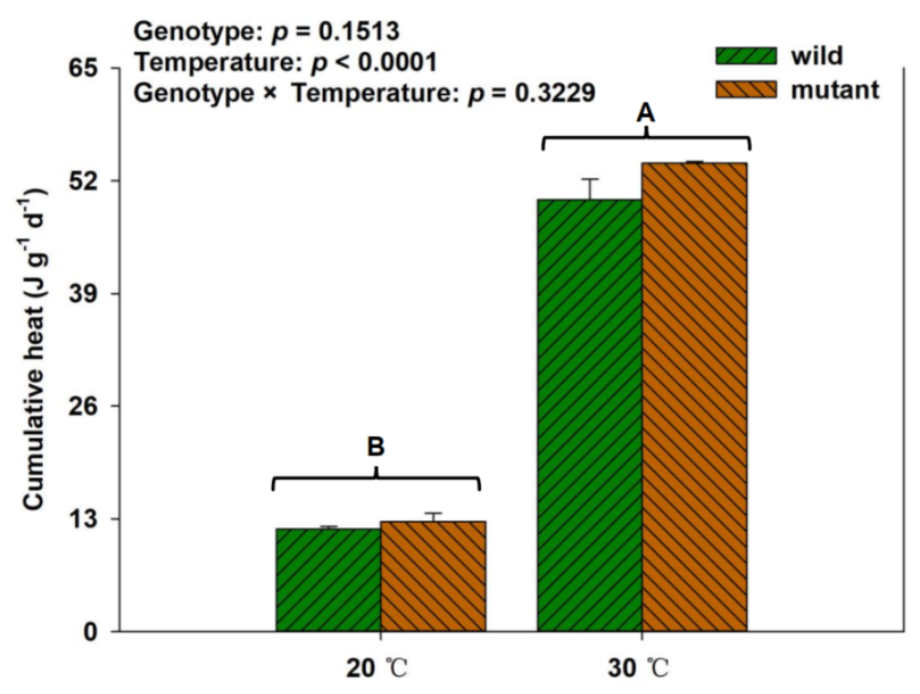

Fig. S1 Cumulative heat production after glucose addition subtract from no glucose addition with 3 replicates for the two maize genotypes at 20 and $30^{\circ} \mathrm{C}$, respectively. $p$ values were obtained after two-way ANOVA. Genotype: wild type and mutant maize; Temperature: 20 and $30{ }^{\circ} \mathrm{C}$. Upper case letters: significant differences between 20 and $30{ }^{\circ} \mathrm{C}$ after two-way ANOVA and Student's $t$ test at $p<0.05$. 


\title{
6 Study 6: Soil water content controls more than root exudation on the spatial distribution of $\beta$-glucosidase activities
}

Xuechen Zhang, ${ }^{\mathrm{a}, \mathrm{b}}$, Nataliya Bilyera ${ }^{\mathrm{a}, \mathrm{c}}$, Lichao Fan ${ }^{\mathrm{d}}$, Patrick Duddek ${ }^{\mathrm{e}, \mathrm{f}}$, Mutez A. Ahmed ${ }^{\mathrm{f}}$, Andrea Carminati ${ }^{\mathrm{f}}$, Anders Kaestner ${ }^{\mathrm{g}}$, Michaela A. Dippold ${ }^{\mathrm{b}}$, Sandra Spielvogel ${ }^{\mathrm{c}}$, Bahar S. Razavi $^{\text {a }}$

\section{Status: in preparation}

a Department of Soil and Plant microbiome, Institute of Phytopathology, Christian-Albrechts University of Kiel, Kiel, Germany

${ }^{b}$ Department of Biogeochemistry of Agroecosystems, University of Göttingen, Göttingen, Germany

${ }^{c}$ Department of Soil Science, Institute of Soil Science and Plant Nutrition, Christian-Albrechts University of Kiel, Kiel, Germany.

${ }^{d}$ Department of Soil Science of Temperate Ecosystems, University of Göttingen, Göttingen, Germany ${ }^{e}$ Department of Environmental Systems Science, Physics of Soils and Terrestrial Ecosystems, ETH Zürich, Switzerland

${ }^{f}$ Division of Soil Physics, Bayreuth Center of Ecology and Environmental Research (BayCEER), University of Bayreuth, Bayreuth, Germany

${ }^{g}$ Laboratory for Neutron Scattering and Imaging, Paul Scherrer Institute, 5232 Villigen, Switzerland

\begin{abstract}
Root hairs and soil water content play crucial roles in controlling the release of root exudates and shaping profiles of microbial activity in the rhizosphere. Understanding the photoassimilate allocation localization is crucial for characterizing the spatial distribution of enzyme activities in respond to drought. Three imaging techniques (soil zymography, ${ }^{14} \mathrm{C}$ imaging and neutron radiograph) were coupled to identity how root hairs and soil moisture regulate the spatial dependence of $\beta$-glucosidase activities on root exudates and soil water. To achieve this, we incubated two genotypes of maize (mutant $r$ th 3 with defective root hair prolongation and the corresponding wild type) at two soil water contents ( $70 \%$ and $30 \%$ of WHC).

Root hairs increased the input and diffusion of root exudates. This induced larger hotspot area and broader rhizosphere extent of $\beta$-glucosidase activities, as well as $27 \%-29 \%$ higher in potential $\beta$-glucosidase activities $\left(\mathrm{V}_{\max }\right)$ than that for mutant maize. Although, optimal soil moisture increased hotspot area and activities of $\beta$-glucosidase, drought widened the rhizosphere extent of root exudates and soil water. The effect size of soil moisture was higher than root hairs. Co-localization analysis showed that enzymatic hotspots is more co-localized with hotspots of root exudates under optimal water conditions; enzyme hotspots showed higher dependency on water hotspots under the scarcity of both water and root exudates. We conclude that both root hairs and soil moisture influenced spatial distribution of rhizosphere
\end{abstract}


biochemical properties and processes, but soil water availability was more important than root exudates when the soil is limited by both water and $\mathrm{C}$ sources.

Keywords: in-situ imaging techniques, spatial correlation, drought, root hairs, root exudates, enzyme activity

Correspondence author: Xueczhang@hotmail.com 


\subsection{Introduction}

The rhizosphere - a small volume of soil influnced by living roots - is a key hotspot of enzyme activities and plays an important role in carbon (C) cycling globally (Hinsinger et al., 2009; Kuzyakov and Razavi, 2019). The spatial distribution of the rhizosphere with regards to enzyme activities highly depends on soil and plant properties, including soil moisture, root morphology and metabolites released by roots (Ahmadi et al., 2018; Ge et al., 2017; Ma et al., 2018; Zhang et al., 2019).

Herbaceous plants release $20 \%$ and $50 \%$ of their photosynthesized $\mathrm{C}$ which are in the form of low or high molecular weight organic substances (Badri and Vivanco, 2009), through their roots into soil (Kuzyakov et al., 2003; Kuzyakov and Domanski, 2000) via various mechanisms including secretion, diffusion and cell lysis (Jones et al., 2009). Such a large input of C provides a significant energy source for microorganisms (Hinsinger et al., 2009), thus inducing higher microbial abundance and activities (Oburger et al., 2014) in the rhizosphere than in root-free zones of the soil (Burns, 1982). Detailed knowledge about the allocation and localization of photosynthetic $\mathrm{C}$ released from roots is an important prerequisite for understanding the complex interactions between plants and the rhizosphere microbiome.

The quantity, quality and spatial distribution of root exudates along the root and in the soil are strongly affected by root morphology (e.g. root hairs) (Datta et al., 2011; Nguyen, 2009; Poirier et al., 2018). Root hairs, an extension of the epidermal cells (Peterson and Farquhar, 1996), play a critical role in the resource exchange among soil, plants and soil microorganisms. The enlargement of root surface area by the extension of root hairs is a costeffective morphological strategy of plants to acquire water and nutrients (Cailloux, 1972; Carminati et al., 2017; Jungk, 2001). Because an important part of rhizodeposits may be released by root hairs, they act as a determinant of enzyme activity (Ma et al., 2018) and microbial functioning, e.g. nutrient mobilization. However, researchers have not revealed how strong enzyme activities and root exudates co-localize.

In addition to root hairs, drought - a sub consequence of climate change (Hasibeder et al., 2015) - commonly affects the quantity and alters partitioning of root exudates (Preece and Peñuelas, 2016). Drought, likely up-regulates the belowground allocation of assimilated $\mathrm{C}$ to compensate negative effects of drought (Preece and Peñuelas, 2016). For example, an increase in the release of mucilage, a gel exuded at the root tip, not only facilitate root water uptake but also ease the root movement in the dry soil (Ahmed et al., 2014; Holz et al., 2018b). 
However, the amount of root exudation are also projected to decline under severe drought, probably due to a lower $\mathrm{C}$ demand belowground or the $\mathrm{C}$ redirection to other vital processes (Gargallo-Garriga et al., 2018). The presence of root hairs (e.g. more root exudates) may magnify the uncertainty in our understanding how drought affects root exudation and microbial functionality (e.g. enzyme activities). Apart from alterations in root exudation caused by drought, water depletion directly imposes osmotic pressure on both root and microbial cells, disconnects enzymes from substrate as well as microorganisms from nutrients, which would lead to microbial death and thus impair enzyme activities (Holz et al., 2019a; Turner et al., 2003). This suggests that the spatial distribution of enzyme activities may also shift based on the pattern of water content, especially under drought. Therefore, a better understanding is urgently needed to identify the role of root exudates and water content in characterizing enzymatic distribution, especially at the root-soil interface. It is still unknown whether more root exudates can offset the direct negative impacts of water stress. Such knowledge is vital as it not only defines the soil volume actively used by plant and microorganisms, but also determine the soil volume where rhizosphere priming i.e. SOM decomposition as an important process in C cycling occurs (Kumar et al., 2018). Hence, as the enzymatic decomposition of SOM is the rate-limiting step in $\mathrm{C}$ and nutrient cycling, its spatial respond to the drought stress in a world with changing climate is essential (Kuzyakov and Razavi, 2019).

Due to the spatial and chemical heterogeneity of soil structure, complexity of root system architecture and rapid microbial incorporation of rhizodeposits, deciphering the spatial relation between enzyme activity and root exudation or water is highly challenging. Direct soil zymography - an in situ technique for two-dimensional (2D) imaging-allows to visualize and analyze the spatial distribution of extracellular enzymes (Razavi et al., 2016; Sanaullah et al., 2016; Zhang et al., 2019) at high resolution (Heitkötter and Marschner, 2018). The new development of ${ }^{14} \mathrm{C}$ imaging has been applied to visualize and quantify ${ }^{14} \mathrm{C}$ photosynthates in roots and soil at the microscale (Holz et al., 2019b; Pausch and Kuzyakov, 2011; Spohn and Kuzyakov, 2013). Neutron radiography offers an opportunity to quantitatively image the water distribution around roots (Esser et al., 2010; Moradi et al., 2009a; Zarebanadkouki et al., 2018).

Here for the first time, we combined three imaging techniques: soil zymography, radioisotope imaging $\left({ }^{14} \mathrm{C}\right.$ imaging) and neutron radiography to: 1$)$ estimate how root hairs and soil water content affect gradients of enzyme activities and photosynthates in the rhizosphere; 2) unravel whether the spatial linkage between enzyme activities and root 
exudates or water depends on soil moisture. To achieve these objectives, two maize genotypes - wild type with root hairs and $r$ th 3 root hair defective mutant - were grown under drought conditions (30\% of WHC) and at optimal water content (70\% of WHC) for 3 weeks. $\beta$-glucosidase was chosen as a phylogenetically conserved enzyme that plays an important role for soil microorganisms in moderating enzymatic diversity and function in environmentally dynamic niches. Due to the great importance of $\beta$-glucosidase in cellulose degradation, cleaving cellobiose into glucose molecules, it has always been selected as the representative of $\mathrm{C}$ cycling related enzymes (German et al., 2011; Zhang et al., 2020). We hypothesized that: 1) root hairs (i.e. C input) and optimal soil moisture widened the rhizosphere extent of root exudates and $\beta$-glucosidase activities. 2) the presence of root hairs buffers the negative impacts of drought on roots and microorganisms through the increased input of root exudation and thus induce higher enzyme activities. 3) the spatial pattern of enzyme activities is more closely co-localized with root exudates under optimal water content, while it is highly associated with water under drought.

\subsection{Material and methods}

\subsubsection{Soil description and experimental set up}

The loam soil substrate was collected from a Haplic Phaeozem close to Schladebach in Saxony Anhalt, Germany. The soil properties are described in detail in Vetterlein et al., (2020): organic C $8.5 \mathrm{~g} \mathrm{~kg}^{-1}$, total $\mathrm{N} 0.8 \mathrm{~g} \mathrm{~kg}^{-1}$, mineral N $1.4 \mathrm{mg} \mathrm{kg}^{-1}$, available P $32.7 \mathrm{mg}$ $\mathrm{kg}^{-1}$, available $\mathrm{K} 28.5 \mathrm{mg} \mathrm{kg}^{-1}, \mathrm{pH}\left(\mathrm{CaCl}_{2}\right)$ 6.4. Prior to plant transplantation into rhizoboxes, $\mathrm{NH}_{4} \mathrm{NO}_{3}-\mathrm{N}, \mathrm{K}_{2} \mathrm{SO}_{4}-\mathrm{K}$, and $\mathrm{MgCl}_{2} \cdot 6 \mathrm{H}_{2} \mathrm{O}$ as solution and $\mathrm{CaHPO}_{4}-\mathrm{P}$ as powder were added to the soil to reach the concentrations: $50 \mathrm{mg} \mathrm{N} \mathrm{kg}^{-1}$ soil, $50 \mathrm{mg} \mathrm{K} \mathrm{kg}^{-1}$ soil, $40 \mathrm{mg} \mathrm{P} \mathrm{kg}{ }^{-1}$ soil and $25 \mathrm{mg} \mathrm{Mg} \mathrm{kg}{ }^{-1}$ soil, respectively.

Two maize (Zea mays L.) genotypes, the root hair defective mutant $r$ th3 (showing root hair initiation but disturbed root hair elongation) (Hochholdinger et al., 2018, 2008), and the corresponding wild-type sibling were grown for 3 weeks in rhizoboxes with an inner size of $10 \times 21 \times 0.6 \mathrm{~cm}$. For a detailed description of the root hair defective mutant $r t h 3$, please refer to Hochholdinger et al., (2018) and (2008).

Before transplanting the plants to the rhizoboxes, seeds were germinated on filter paper for $72 \mathrm{~h}$. The rhizoboxes were kept at an angle of $45^{\circ}$ to make sure the roots grow along the lower side. The soil water content was maintained at 70\% water holding capacity (WHC) during the first two weeks. In the third week, the water content was kept at either $70 \%$ of WHC (optimal water content) or adjusted to $30 \%$ of WHC (drought). In total 12 rhizoboxes 
were planted: two genotypes of maize, two water content conditions, and 3 replicates for each treatment. All plants were grown under controlled conditions in a climate chamber with a constant temperature of $22 \pm 1^{\circ} \mathrm{C}$. The photoperiod was $12 \mathrm{~h}$ and the light intensity was $350 \mu \mathrm{M} \mathrm{m}^{-2} \mathrm{~s}^{-1}$.

\subsubsection{Plant labeling and ${ }^{14} \mathrm{C}$ imaging}

After 3 weeks of maize growth, each plant was labeled with $0.5 \mathrm{MBq}{ }^{14} \mathrm{CO}_{2}$ at a target $\mathrm{CO}_{2}$ concentration of $500 \mathrm{ppm}$, in an airtight chamber for 6 hours. For detailed description please refer to Kuzyakov et al., (2006). Briefly, before labeling, the $\mathrm{CO}_{2}$ inside the labeling chamber was reduced by cycling the air through $1 \mathrm{M} \mathrm{NaOH}$ for 8 hours with growth lights off. $\mathrm{NaOH}$ solution was then replaced by ${ }^{14} \mathrm{C}$ which was prepared as $3 \mathrm{MBq} \mathrm{Na}{ }_{2}{ }^{14} \mathrm{CO}_{3}$ solution $\left(0.5 \mathrm{MBq}^{*} 6\right.$ plants) dissolved by $10 \mathrm{ml}$ phosphoric acid $\left(1 \mathrm{M} \mathrm{H}_{3} \mathrm{PO}_{4}\right)$. The released ${ }^{14} \mathrm{CO}_{2}$ was pumped into the chamber for $6 \mathrm{~h}$. During the labeling, all plants were kept under a growth light $\left(350 \mu \mathrm{M} \mathrm{m}^{-2} \mathrm{~s}^{-1}\right)$ for highest photosynthetic activity. After labeling, the remaining ${ }^{14} \mathrm{CO}_{2}$ in the chamber was trapped with $1 \mathrm{M} \mathrm{NaOH}$ for $2 \mathrm{~h} .{ }^{14} \mathrm{C}$ activities were determined by liquid scintillation counting on a Hidex 300SL Automatic Liquid Scintillation Counter (Hidex, Turku, Finland). $0.5 \mathrm{ml}$ of $\mathrm{NaOH}$ was added to the $8 \mathrm{ml}$ scintillation cocktail Rotiszint Eco plus (Carl Roth, Karlsruhe, Germany) and kept in the dark for $24 \mathrm{~h}$ for chemiluminescence to cease.

Directly after labeling, the rhizoboxes were transferred to a dark room. The rooted soil surfaces were exposed to storage phosphor screens (BAS-IP MS 2040 E, GE Healthcare, U.S.A.). All screens were erased for $10 \mathrm{~min}$ under the strong bright light before use, and were protected from moisture by transparent plastic bags (polypropylene, $40 \mu \mathrm{m}$ thickness, density $0.95 \mathrm{~g} \mathrm{~cm}^{-3}$, MDF Verpackungen GmbH, Bergisch Gladbach, Germany). The plate with plastic bag was attached to the rooted soil surface for $20 \mathrm{~h}$ in a totally dark room. Thereafter, the plates were scanned with a laser scanner for phosphor-imaging (650 $\mathrm{nm}$ excitation, FLA7000, GE Healthcare, U.S.A.) with a spatial resolution of $25 \mu \mathrm{m}$ (Banfield et al., 2017).

\subsubsection{Direct soil zymography}

Soil zymography — an in situ technique for two-dimensional imaging of enzyme activity — was used to visualize the spatial distribution of $\beta$-glucosidase activity after ${ }^{14} \mathrm{C}$ imaging. The protocol we followed was referred to Razavi et al., (2019). Polyamide membranes (a pore size of $0.45 \mu \mathrm{m}$, Taoyuan, China) saturated with the 4-methylumbelliferyl - $\beta$-Dglucoside was applied to determine $\beta$-glucosidase activity on soil surfaces. The 4methylumbelliferyl- (MUF) containing substrates become fluorescent when hydrolyzed by a 
substrate-specific enzyme. 4-methylumbelliferyl- $\beta$-D-glucoside was dissolved in the universal MES buffer at $\mathrm{pH}$ 6.5. All the chemicals were purchased from Sigma-Aldrich (Germany). After $1 \mathrm{~h}$ of incubation, the saturated membranes were lifted off the soil surface and the soil particles attached to the membranes were carefully removed using a soft brush.

A standard calibration line is required to link the $\beta$-glucosidase activity to the gray values obtained from the zymograms. Briefly, 9 pieces of $2 \times 2 \mathrm{~cm}$ membranes were soaked in solutions of MUF with increasing concentrations (0, 0.01, 0.2, 0.5, 1, 2, 4, 6, and $10 \mathrm{mM})$. The amount of MUF needed for the saturation of each membrane pieces was based on a preliminary test. All the membranes used for rhizoboxes and calibration were placed in a dark room under UV lamps to be photographed.

\subsubsection{Neutron radiography}

Neutron radiography is a non-destructive method which is sensitive to hydrous materials (Ahmed et al., 2016; Moradi et al., 2009b), and thus can quantify present water distribution in the rhizosphere (Holz et al., 2018b; Zarebanadkouki et al., 2018). The experiments were conducted at the ICON beam line at the Paul Scherrer Institute (PSI) in Switzerland. We used a CCD camera detector with an array of 1260 by 1260 pixels, a field of view of $15.75 \mathrm{~cm}$ by $15.75 \mathrm{~cm}$, and a spatial resolution of $0.2 \mathrm{~mm} .4$ radiographs with marginal overlaps were scanned to cover the entire sample. The protocol for calculating water content from neutron radiography images were provided in earlier studies (Esser et al., 2010).

\subsubsection{Kinetics of enzyme activity}

Potential $\beta$-glucosidase activities for the soil sampled from the rhizosphere of wild type and $r$ th 3 mutant maize under drought and optimal water content were measured using the fluorometric microplate assay based on the 4-methylumbelliferyl- $\beta$-D-glucoside (Razavi et al., 2015; Zhang et al., 2020). $\beta$-glucosidase activities were determined at a range of substrate concentration from $0,5,10,20,50,100,200 \mu \mathrm{mol} \mathrm{L}^{-1} .0 .5 \mathrm{~g}$ soil was homogenously mixed with $50 \mathrm{~mL}$ sterile water using the low-energy sonication. $50 \mu \mathrm{L}$ soil suspension, $100 \mu \mathrm{L}$ substrate solution and $50 \mu \mathrm{L}$ MES buffer were added into a 96-well microplate. The fluorescence was measured using a Victor 1420-050 Multi label counter (PerkinElmer, USA) at $0,20 \mathrm{~min}, 1 \mathrm{~h}$ and $2 \mathrm{~h}$. Parameters of Michaelis-Menten kinetics for $\beta$-glucosidase activities were calculated with the following equation:

$$
v=\frac{V_{\max } \times[S]}{K_{m}+[S]}
$$


where $\mathrm{v}$ is the reaction rate, $\mathrm{V}_{\max }$ is the maximum enzyme activity, $[\mathrm{S}]$ is the substrate concentration, and $\mathrm{K}_{\mathrm{m}}$ is the substrate concentration at half-maximum rate.

\subsubsection{Image processing and analysis}

Images obtained by zymography, ${ }^{14} \mathrm{C}$ imaging and neutron radiography were processed in ImageJ. First, the projected signals of the images were transformed to gray values (8-bit) and modified by subtracting background gray values. The gravy values were then converted either to enzyme activity or to water content based on the corresponding calibration function.

To quantify the ${ }^{14} \mathrm{C}$ images, results were converted from a log into a linear system by applying the following equation:

$$
P S L=\left(\frac{R e S}{100}\right)^{2} \times \frac{4000}{S} \times 10^{L\left(\frac{Q L}{G}-\frac{1}{2}\right)}
$$

where PSL (photo stimulated luminescence) is the quantified value of the image in linear scale and is an arbitrary unit describing the absorbed and corrected energy on the imaging plate) (Thu Hoang et al., 2020). Res is the resolution of the image ( $\mu \mathrm{m}$; Res $=25 \mu \mathrm{m}), \mathrm{S}$ the sensitivity $(S=1000)$, $L$ the latitude $(L=5)$ and $G$ the gradation $(G=256)$.

We considered areas with gray values exceeding Mean +2 SD of the whole image as hotspots of $\beta$-glucosidase activity and ${ }^{14} \mathrm{C}$ activity and soil water content (Zhang et al., 2020).

Root segments that did not overlap with other roots were randomly selected to calculate bidirectional rhizosphere extent for enzyme activities $/{ }^{14} \mathrm{C}$ activities/water contents. Briefly, a vertical line was drawn through the root, and the gray values of this line were extracted. In total, around 20 lines were performed of each image. To determine the extent, the average gray values of these replicates were plotted against the distance in Sigmaplot 12.5. The distance at which the gray value increased from or dropped to the minimum asymptote was firstly visually taken as thresholds for bidirectional rhizosphere extent. Then we check the significant difference between the gray values of 5 points lower and 5 points higher than the visual threshold. If the difference was significant at $p<0.05$, we considered the visual thresholds as the real threshold.

The co-localization analysis between $\beta$-glucosidase activity and exudate hotspots or between $\beta$-glucosidase activity and water hotspots was performed by Just another colocalization plugin (JACoP) installed in Fiji (Bolte and Cordelières, 2006). Briefly, the images were adjusted to identical size. Then, the images were aligned/registered manually in Fiji using the plugin TrackEM2 (Cardona et al., 2012). After the registration, the aligned 
images were used to analyze Manders' coefficients (M1 and M2, Manders et al., 1993) in JACoP.

$$
\begin{aligned}
& M_{1}=\frac{\sum_{i} R_{i, c o l o c}}{\sum_{i} R_{i}} \\
& M_{2}=\frac{\sum_{i} G_{i, c o l o c}}{\sum_{i} G_{i}}
\end{aligned}
$$

where $R_{i}$ and $G_{i}$ are the grey values of each pixel of hotspot area of image $R$ and $G$, respectively. $\sum_{i} R_{i, c o l o c}$ and $\sum_{i} G_{i, c o l o c}$ are the total co-localized grey values over the threshold for image $\mathrm{R}$ and $\mathrm{G}$, respectively. $\sum_{\mathrm{i}} \mathrm{R}_{\mathrm{i}}$ and $\sum_{\mathrm{i}} \mathrm{G}_{\mathrm{i}}$ are the total grey values over the threshold for image $\mathrm{R}$ and $\mathrm{G}$, respectively.

\subsubsection{Statistical analysis}

The Shapiro-Wilk test and Levene tests were performed to check normality and homogeneity of variances, respectively. Statistical analyses were performed in JMP and the significance of differences was tested using two-way ANOVA at a probability level of $p<$ 0.05. If the effects of both genotype and water were significant, we calculated $\eta^{2}$ as a parameter to show the contribution of each factor to the total variation (effect size).

$$
\eta^{2}=\frac{S S_{A}}{S S_{\text {total }}}
$$

where $S S_{A}$ is the variance between treatments caused by factor A. $S S_{\text {total }}$ was the total sum of squares.

\subsection{Results}

\subsubsection{Spatial distribution and kinetics of $\beta$-glucosidase}

The spatial distribution of $\beta$-glucosidase activity was strongly affected not only by root hairs but also by soil moisture (Fig. 1). Root hairs and optimal water content increased the activity and hotspot area of $\beta$-glucosidase (Fig 1, 2a \& 3a). For both genotypes, the $\beta$ glucosidase hotspot area was mainly associated with roots (Fig. 1). The hotspot area of wild type was higher than that for mutant $r$ th 3 by $20 \%$ at optimal soil water content and by $49 \%$ at drought (Fig. 2a). Similarly, the percentage of hotspot area for both wild and mutant $r$ th 3 decreased under drought compared with optimum water content (Fig. 2a).

The rhizosphere extent of $\beta$-glucosidase varied between drought and optimum water content (Fig. 2b). It was $36.6 \%$ and $60.3 \%$ broader under optimal water content conditions than that under drought for wild type and mutant $r t h 3$, respectively. Additionally, the 
rhizosphere extent of $\beta$-glucosidase activity was wider in the soil for wild type maize than that for mutant maize irrespective of soil water content (Fig. 2b, $p=0.0039$ ). 


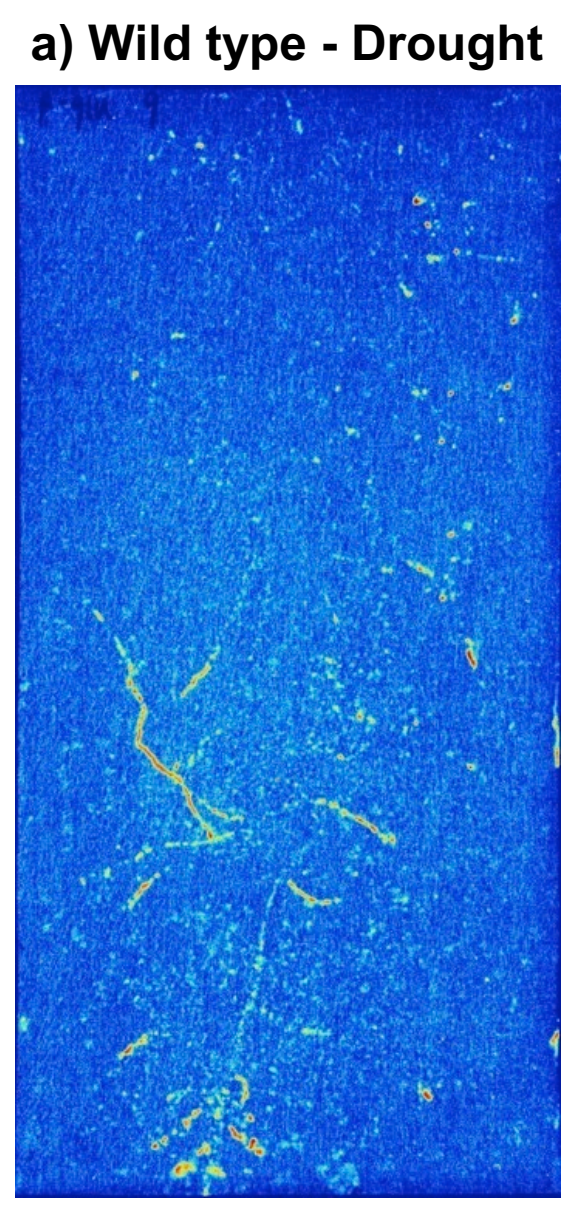
b) Mutant - Drought

c) Wild type-Optimum

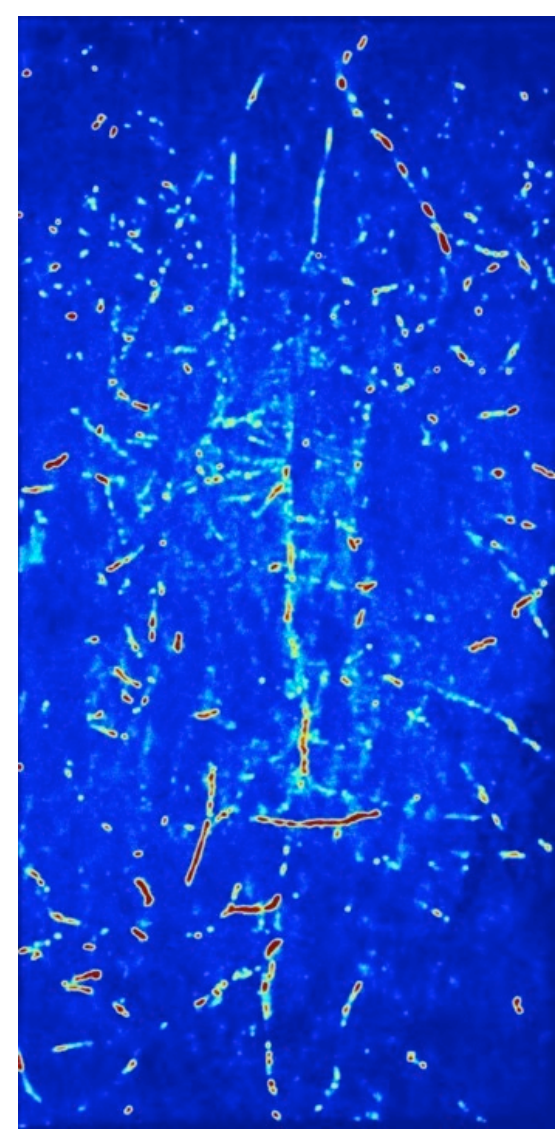

d) Mutant - Optimum

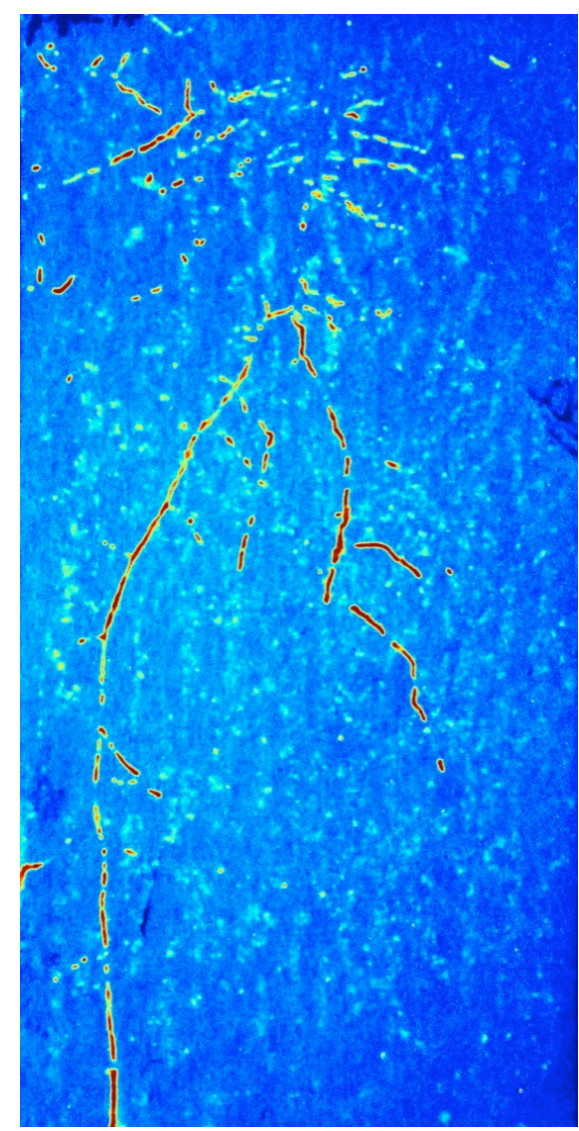

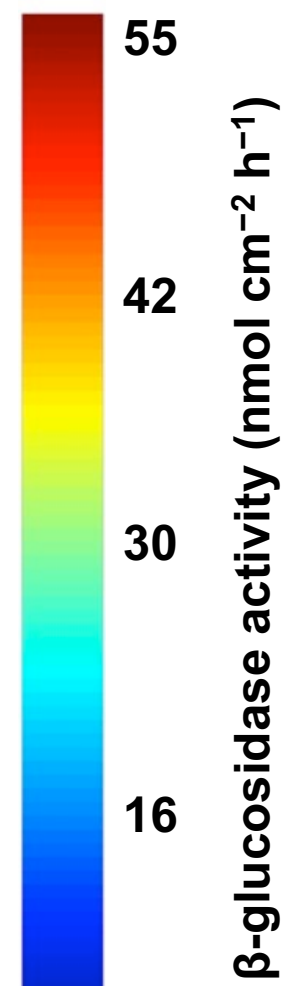

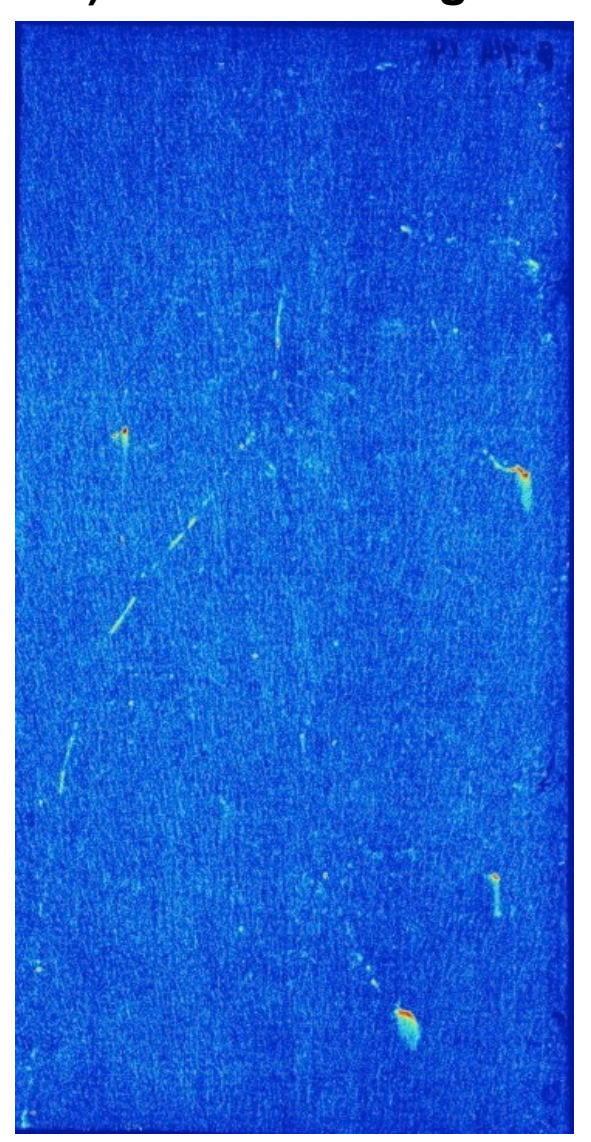


Fig. 1 Spatial distribution of $\beta$-glucosidase activity for two maize genotypes (wild type and mutant $r$ th3) under drought (a \& b) and optimal water content (c \& d). The color scale is proportional to $\beta$-glucosidase activity $\left(\mathrm{nmol} \mathrm{cm}^{-2} \mathrm{~h}^{-1}\right)$.
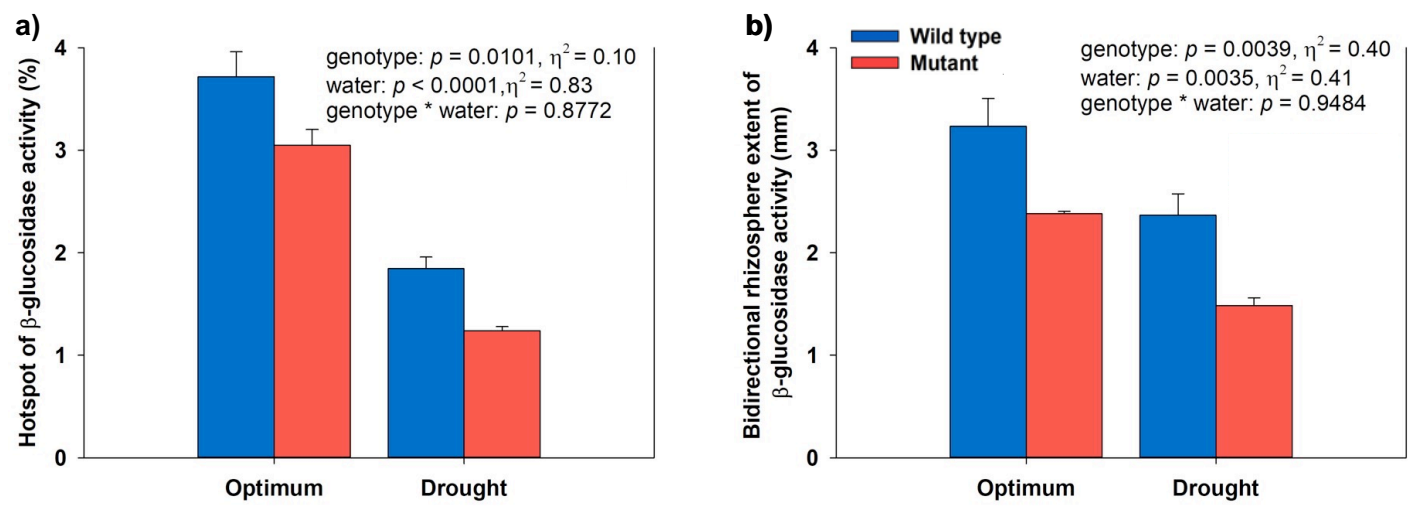

Fig. 2 (a) Hotspot (\%) and (b) bidirectional rhizosphere extent of $\beta$-glucosidase activity for two maize genotypes (wild type and mutant $r t h 3$ ) under drought and optimal water content. $p$ values were obtained after two-way ANOVA. genotype: wild type and mutant $r t h 3$; water: drought and optimal water content. Data is mean $(n=3)$ and error bars represent standard deviation (SD).

Compared to drought, optimal water content increased potential $\beta$-glucosidase activities $\left(\mathrm{V}_{\max }\right.$ ) by $55 \%$ and $57 \%$ for wild type and mutant maize, respectively (Fig. 3a). $\mathrm{V}_{\max }$ in the rhizosphere soil of wild type was $27 \%$ and $29 \%$ higher than that for mutant $r$ th 3 under optimal water content and drought, respectively (Fig. 3a). Similarly, water content and root hairs strongly increased both $\mathrm{V}_{\max }$ and $\mathrm{K}_{\mathrm{m}}$ of $\beta$-glucosidase activities (Fig. 3b). The effect size of water content $\left(\eta^{2}=0.74\right.$ for $V_{\max }$ and $\eta^{2}=0.56$ for $\left.K_{m}\right)$ was higher than that of genotype $\left(\eta^{2}=0.22\right.$ for $V_{\max }$ and $\eta^{2}=0.28$ for $\left.K_{m}\right)$ (Fig. 3).

Taken together, optimal water content contributed more to greater hotspot area, broader rhizosphere extension and higher activities of $\beta$-glucosidase than that of root hairs. 

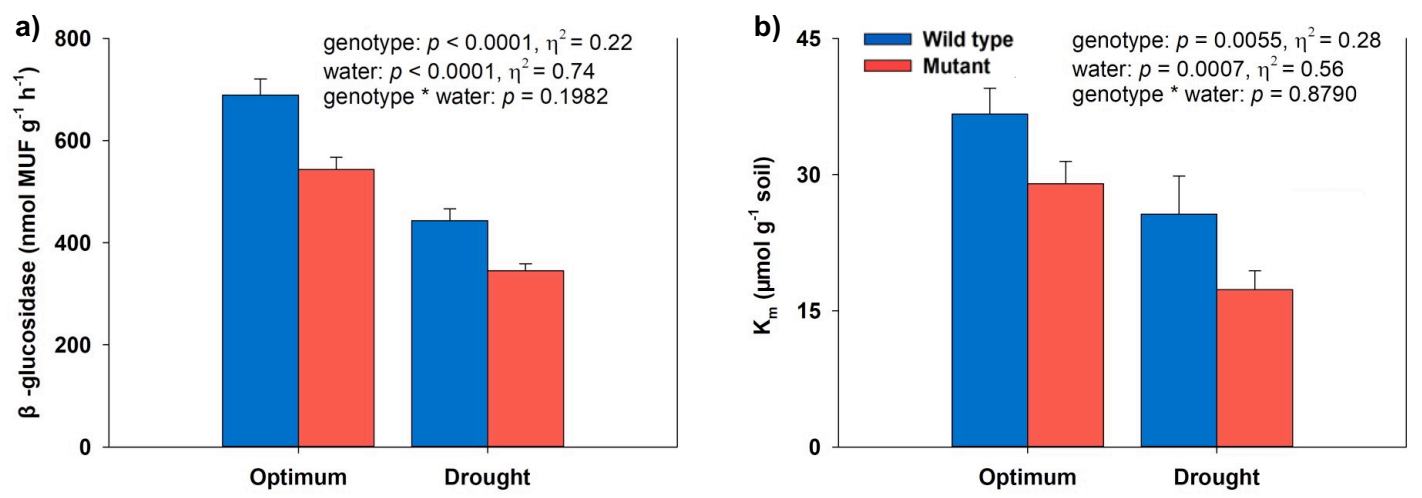

Fig. 3 Michaelis-Menten kinetic parameters, i.e. (a) $\mathrm{V}_{\max }\left(n m o l g^{-1} \mathrm{~h}^{-1}\right)$ and (b) $\mathrm{K}_{\mathrm{m}}\left(\mu \mathrm{mol} \mathrm{g}^{-}\right.$ ${ }^{1}$ soil), of rhizosphere soil for two maize genotypes (wild type and mutant $r t h 3$ ) under drought and optimal water content. Data is mean $(n=3)$ and error bars represent standard deviation (SD).

\subsubsection{Spatial distribution of ${ }^{14} \mathrm{C}$ exudates}

Similar to enzyme activity distributions, the distribution of photoassimilates showed root-associated pattern, and the ${ }^{14} \mathrm{C}$ activity was higher under optimum water content than under drought (Fig. 4). 
a) Wild type - Drought

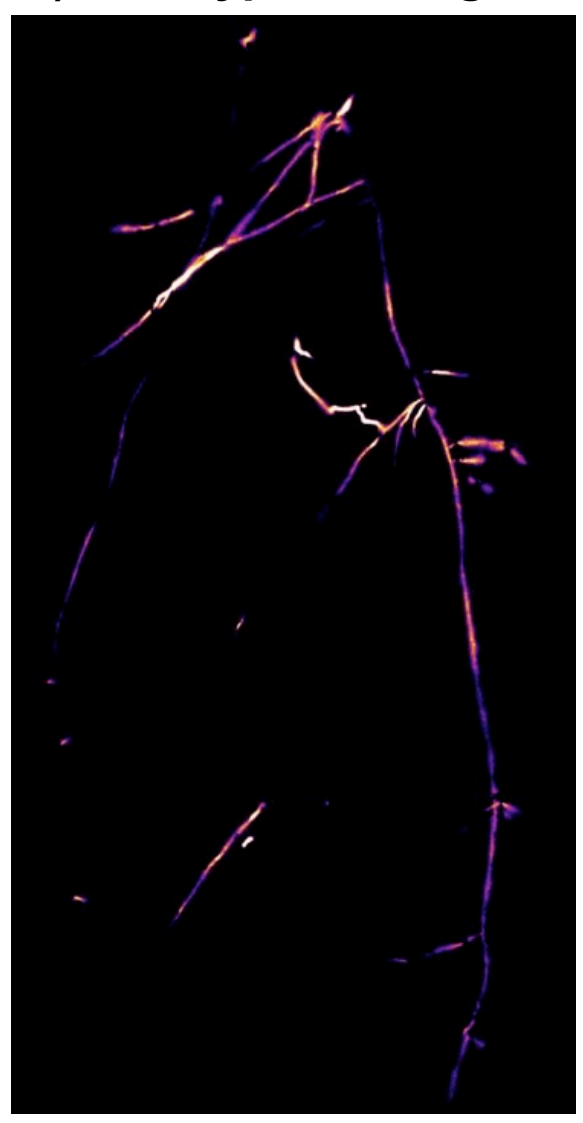

c) Wild type -Optimum

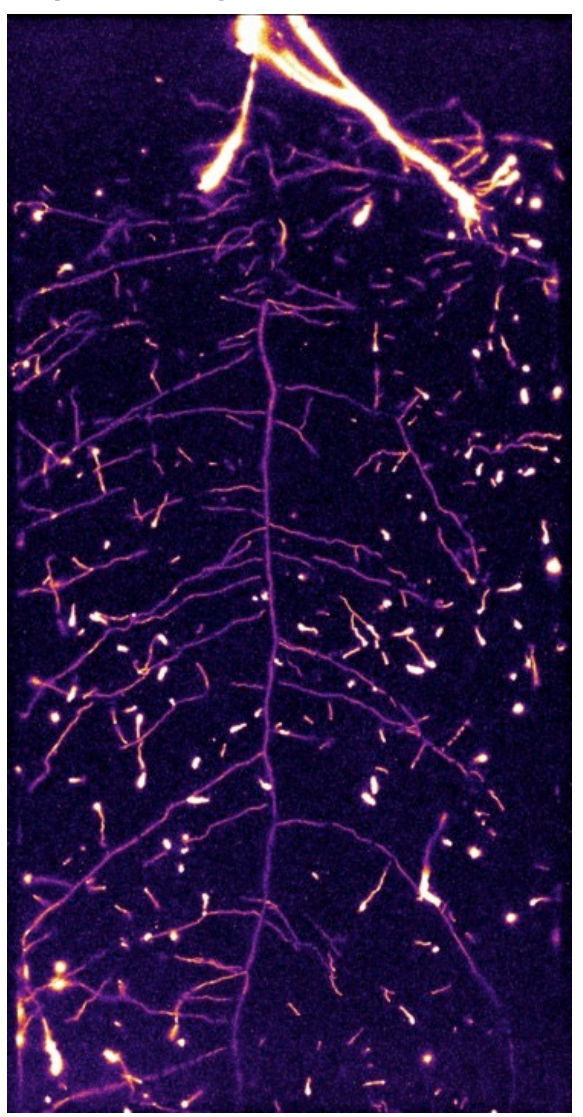

b) Mutant- Drought

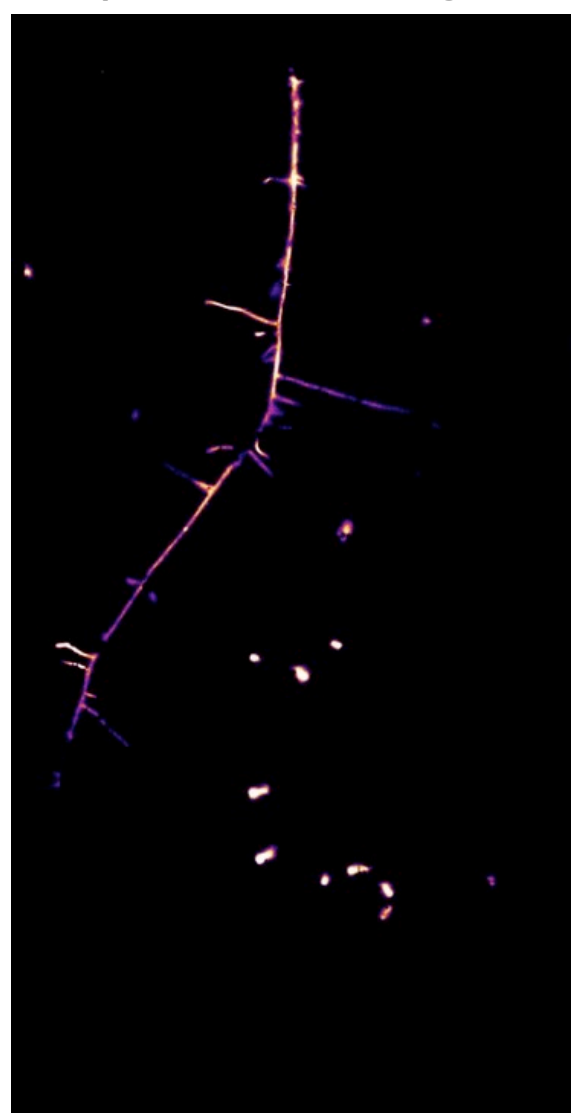

0.00194

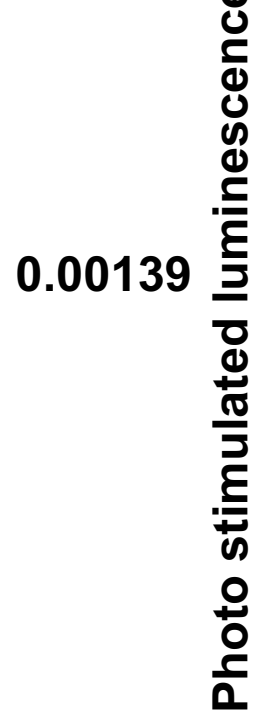

๘

$\underline{2}$

\$

0.00099

d) Mutant - Optimum

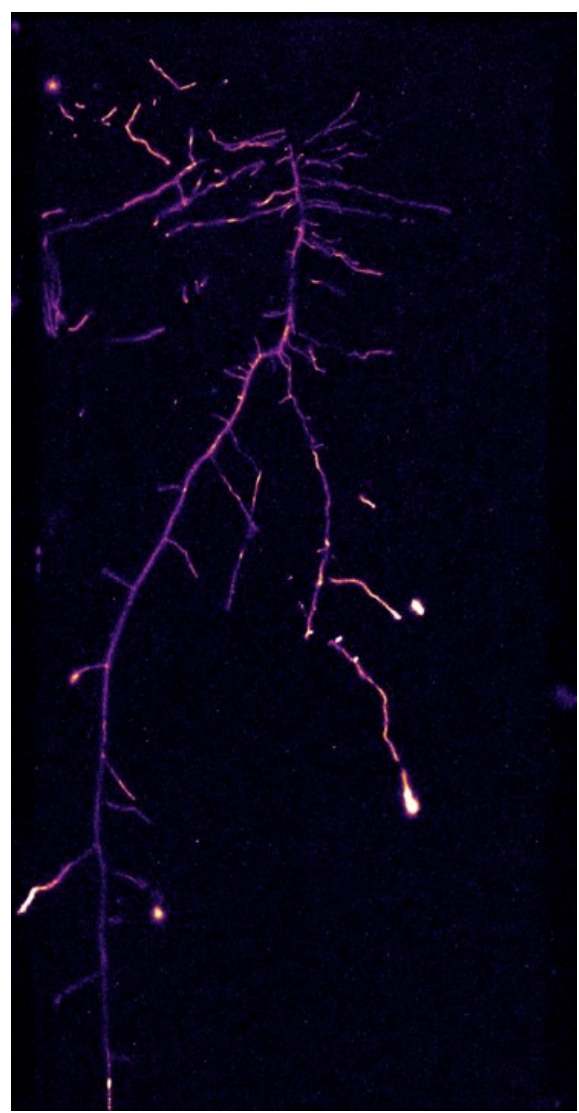

0.00598

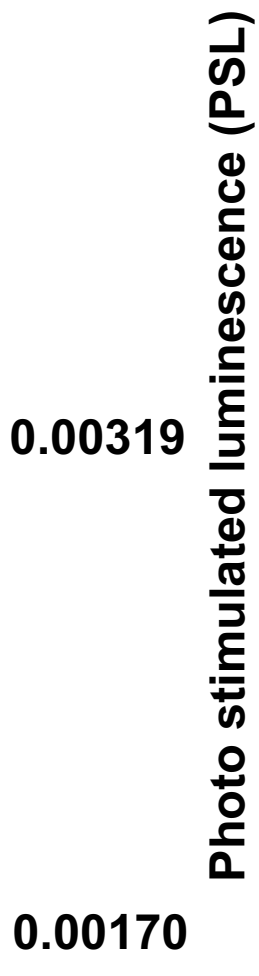


Fig. 4 Spatial distribution of root exudates for two maize genotypes (wild type and mutant rth3) under drought (a \& b) and optimal water content (c \& d).

Neither root hairs nor soil water content changed the hotspot area of ${ }^{14} \mathrm{C}$ activity $(p>$ 0.05 , Fig. 5a), but the trend was similar to $\beta$-glucosidase hotspots. The bidirectional rhizosphere extent of root exudates increased by $27 \%$ for both genotypes under drought compared with that under optimal water content (Fig. 5b, $p=0.0069)$. The rhizosphere extent of root exudates was broader for wild type $(2.6 \mathrm{~mm}$ under optimal soil moisture vs. $3.3 \mathrm{~mm}$ under drought condition) than that for mutant $r$ th3 $(2.1 \mathrm{~mm}$ under optimal soil moisture vs. $2.7 \mathrm{~mm}$ under drought condition) (Fig. 5b, $p=0.0013)$. The effect size of water $\left(\eta^{2}=0.42\right)$ was $10 \%$ higher than that of genotype $\left(\eta^{2}=0.32\right)$ (Fig. 5).
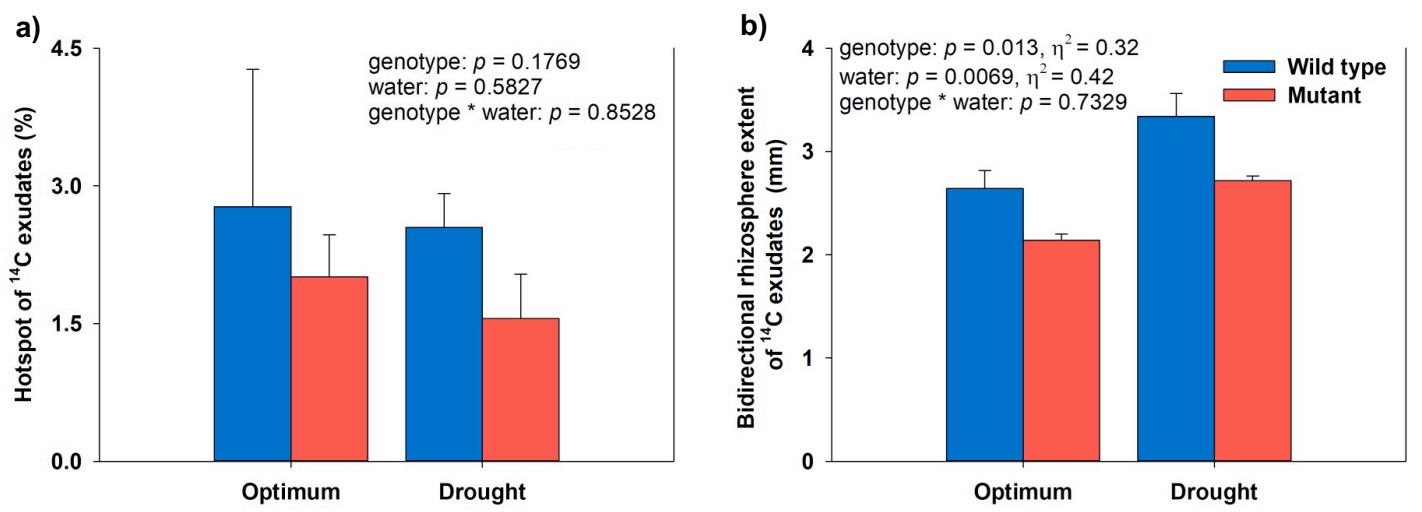

Fig. 5 (a) Percentage of hotspot and (b) bidirectional rhizosphere extent of root exudates for two maize genotypes (wild type and $r$ th 3 mutant) under drought and optimal water content. $p$ values were obtained after two-way ANOVA. $\eta^{2}$ : effect size; genotype: wild type and mutant $r t h 3$; water: drought and optimal water content. Data is mean $(\mathrm{n}=3)$ and error bars represent standard deviation (SD).

Remarkably, the distribution of exudates along the roots did not depend on the presence of root hairs and soil water content. In contrast, the activity of ${ }^{14} \mathrm{C}$ exudation hotspot was more affected by soil water content than by root hairs.

The water content was higher in the rhizosphere compared to that in bulk soil (Fig. 6). The water-rhizosphere extent was stimulated by both root hairs and soil moisture, while the effect size of water $\left(\eta^{2}=0.54\right)$ was much higher than that of genotype $\left(\eta^{2}=0.23\right)($ Fig. 7$)$. 
a) Wild type - Drought

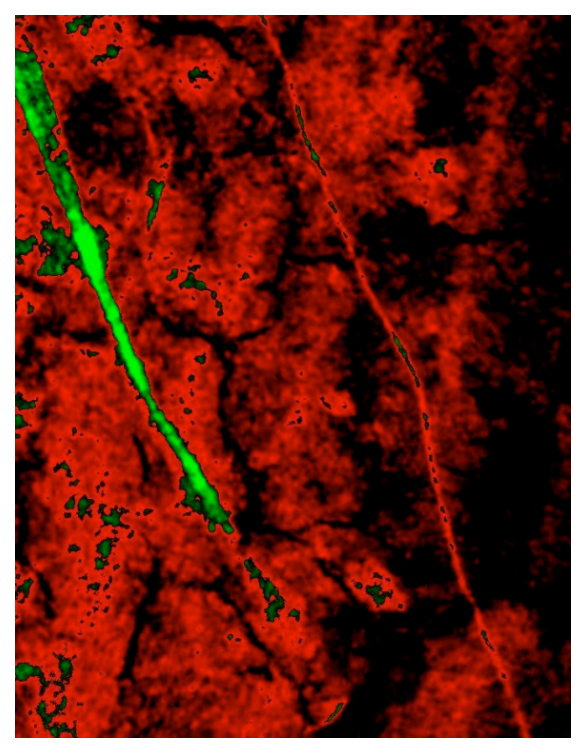

c) Wild type - Optimum

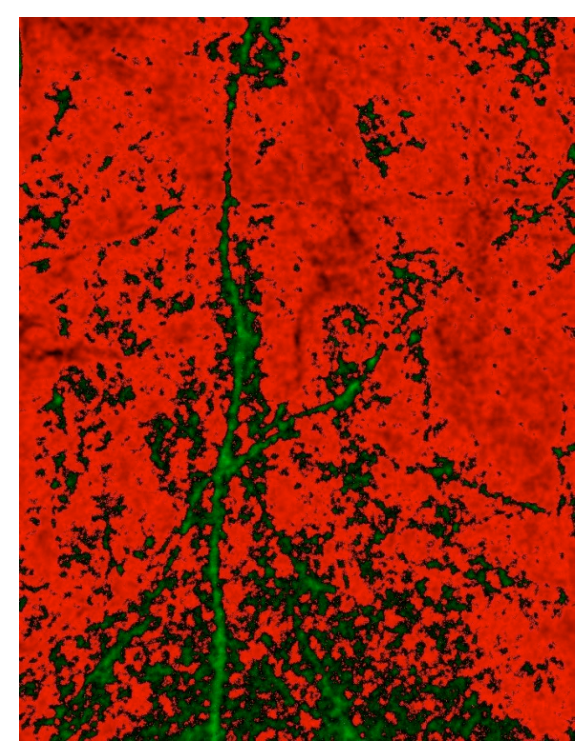

b) Mutant - Drought

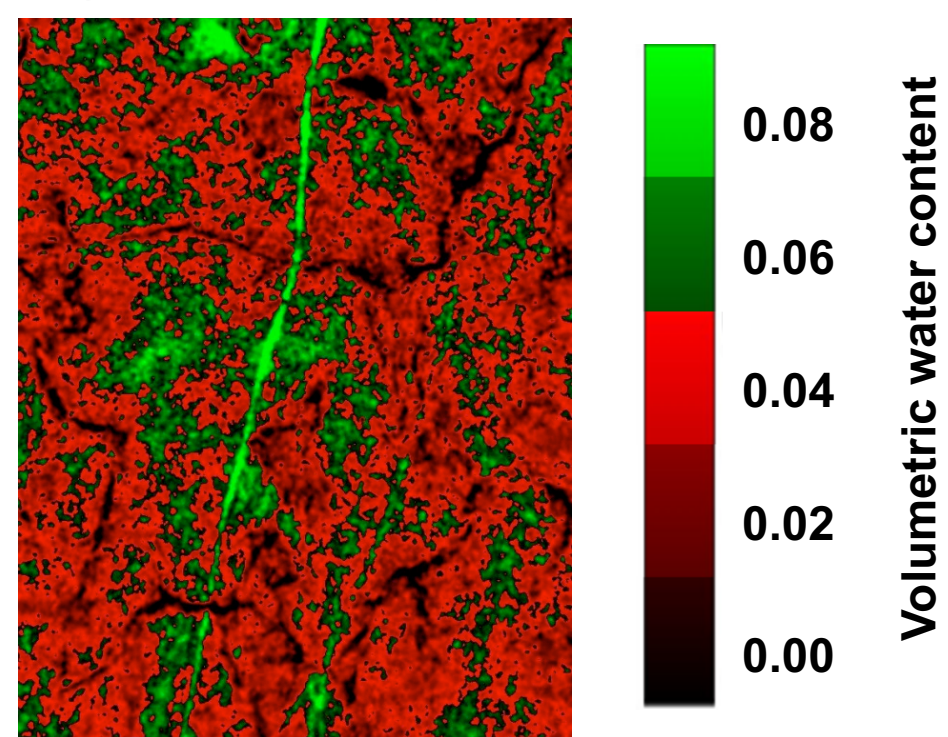

d) Mutant - Optimum
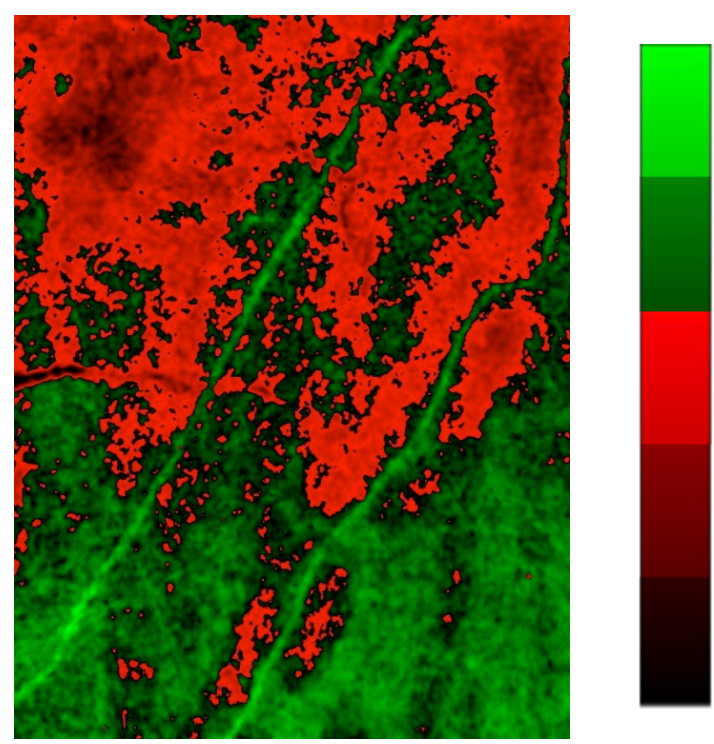

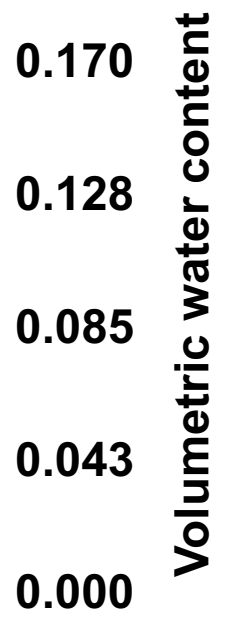

Fig. 6 Region of interest (ROIs) of soil water spatial distribution for two maize genotypes (wild type and mutant rth3) under drought (a \& b) and optimal water content (c \& d). Side color scale is proportional to volumetric water content. 


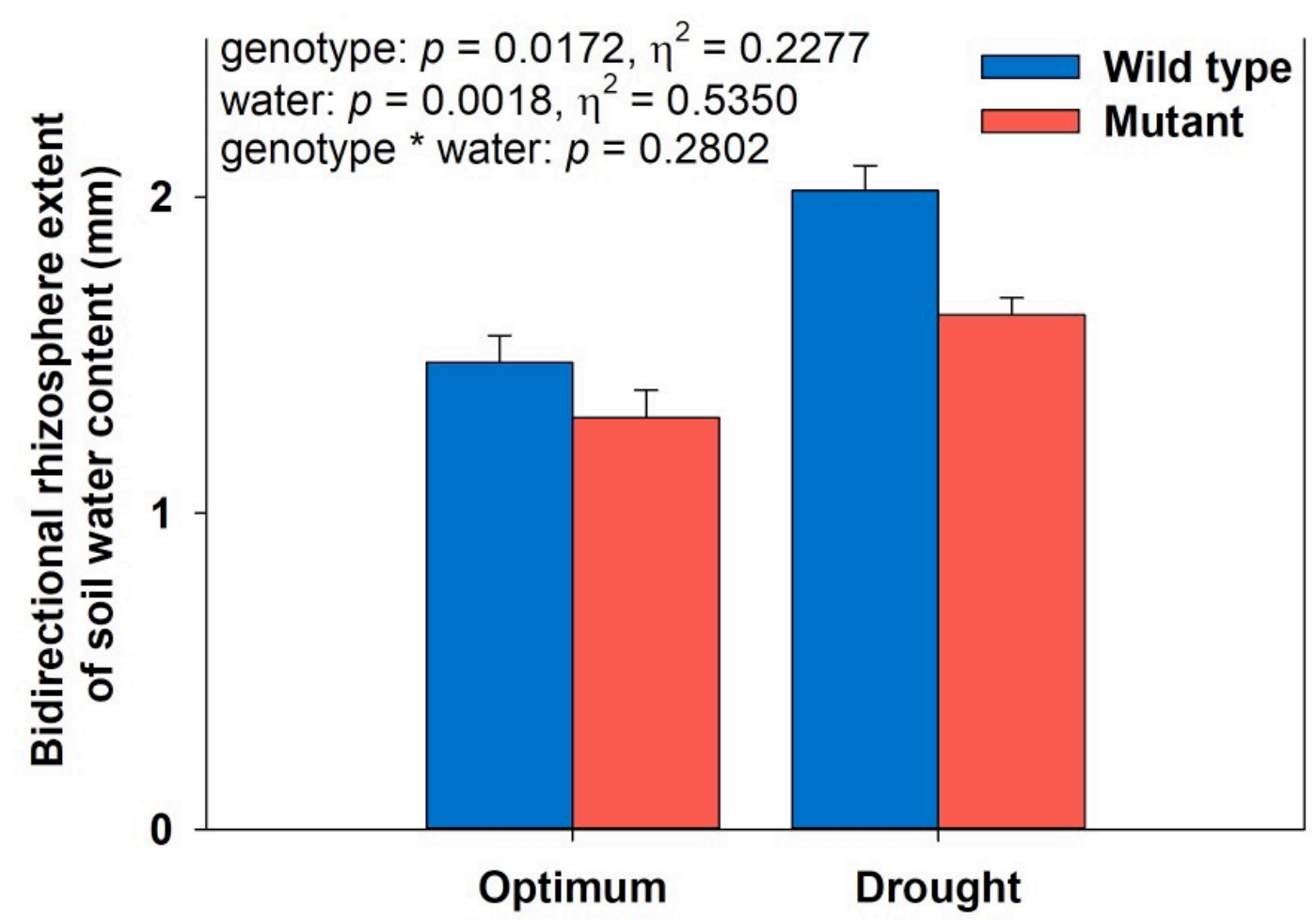

Fig. 7 Bidirectional rhizosphere extent of soil water content for two maize genotypes (wild type and mutant $r$ th3) under drought and optimal water content. $p$ values were obtained after two-way ANOVA. $\eta^{2}$ : effect size; genotype: wild type and mutant $r$ th 3 ; water: drought and optimal water content. Data is mean $(n=3)$ and error bars represent standard deviation (SD).

\subsubsection{Co-localization analysis}

The effect of root hairs was negligible with respect to the co-localization between hotspots of enzyme activity and root exudates (Fig. 8a). The fraction of enzyme hotspots overlapped with exudate hotspots was larger under optimal conditions that that under drought conditions $(p=0.0329$, Fig. 8a).

The interaction of soil moisture and genotypes affected the part of enzyme activity hotspots co-localized with hotspots of water hotspots ( $p=0.0077$, Fig. $8 \mathrm{~b})$. The fraction of enzyme hotspots co-localized with water was highest under drought conditions with mutant rth3.

Hotspots of root exudates or water colocalized strongly with hotspots of enzyme activities under optimal water content than under drought $(p<0.05)$ (Fig. 8). 
(a) Enzyme $\times$ Exudates

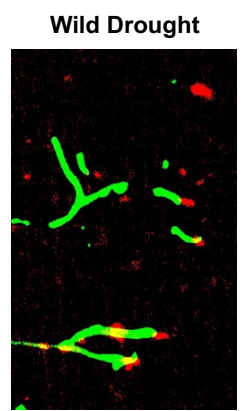

M1: 0.09B M2: 0.09b

Wild Drought

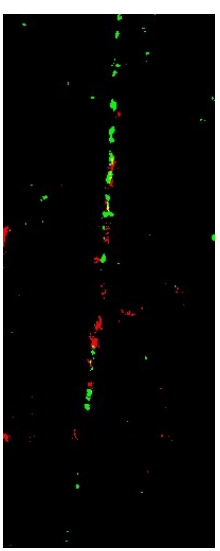

M1: 0.07B

M2: $0.04 b$

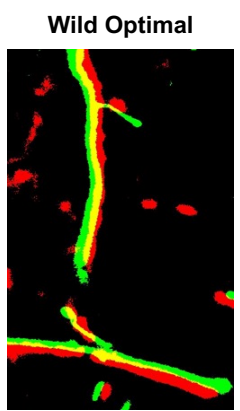

M1: 0.36A

M2: $0.44 a$

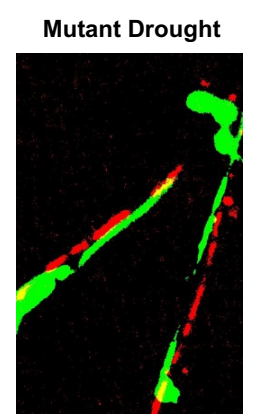

M1: 0.18B

M2: $0.08 \mathrm{~b}$

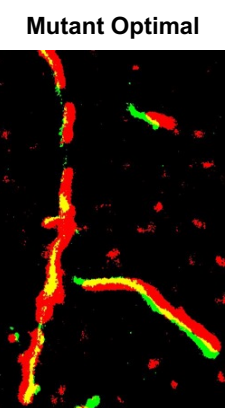

M1: 0.43A

M2: $0.52 a$
Two-way ANOVA for M1:

Genotype: $p=0.4768$

Water: $p=0.0329$

Genotype*Water: $p=0.9011$

Two-way ANOVA for M2:

Genotype: $p=0.5908$

Water: $p=0.0007$

Genotype*Water: $p=0.5647$

(b) Enzyme $\times$ Water

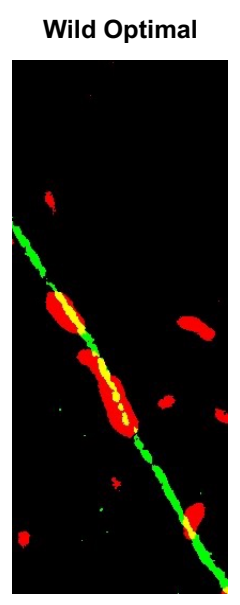

M1: 0.12B

M2: $0.29 a$

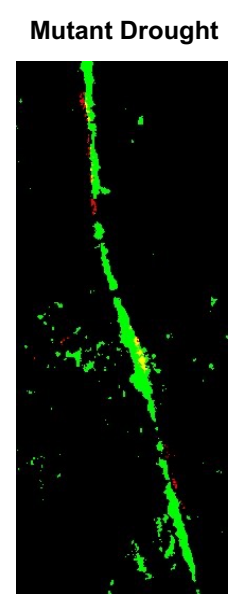

M1: 0.45A

M2: $0.04 b$

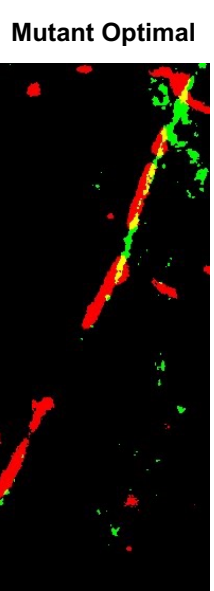

M1: 0.09B

M2: $0.23 a$
Two-way ANOVA for M1:

Genotype: $p=0.0170$

Drought: $p=0.0251$

Genotype*Drought: $p=0.0077$

Two-way ANOVA for M2:

Genotype: $p=0.5649$

Drought: $p=0.0032$

Genotype*Drought: $p=0.6018$

Fig. 8 Colocalization analysis for region of interest (ROIs) of (a) hotspots between $\beta$ glucosidase activity (Enzyme) and ${ }^{14} \mathrm{C}$ exudates (Exudates), or (b) hotspots between $\beta$ glucosidase activity (Enzyme) and water (Water). M1: Manders' coefficient, the fraction of Enzyme overlapping with Exudates or Water; M2: Manders' coefficient, the fraction of Exudates or Water overlapping with Enzyme; $p$ values were obtained after two-way ANOVA. genotype: wild type and mutant $r$ th3; water: drought and optimal water content. Upper case letters in (a): significant differences for M1 between optimal and drought conditions after two-way ANOVA and Student's t-test at $p<0.05$. Upper case letters in (b): significant differences for M1 among four treatments after two-way ANOVA analysis and Tukey's HSD test at $p<0.05$. Lower case letters in (a) and (b): significant differences for M2 between optimal and drought conditions after two-way ANOVA and Student's t-test at $p<0.05$. 


\subsection{Discussions}

\subsubsection{Effects of root hairs and soil water content on rhizosphere extent and hotspot of $\beta$ - glucosidase activities}

Higher $\beta$-glucosidase activities around roots (Fig. 1) occurred simultaneously with a higher allocation of photosynthesized $\mathrm{C}$ to the root and rhizosphere which was illuminated by ${ }^{14} \mathrm{C}$ imaging (Fig. 4). The activated and stimulated microbial activities induced by abundant labile $\mathrm{C}$ input (Wu et al., 2017) and the direct enzyme release from roots (Asmar et al., 1994) in the rhizosphere eventually drove the enzymatic hotspot there (Ma et al., 2018). The effect of available substrate on the hotspot formation were more pronounced with the presence of root hairs. Root hairs, which released more root exudates (Fig. 4, Pausch et al., 2016), enlarged the enzymatic hotspot area and extended the rhizosphere size (Fig. 1 and 2) as well as increased enzyme activities (Fig. 3a). In contrast, the substrate affinity was higher in the rhizosphere soil of the mutant $r$ th 3 (Fig. $3 \mathrm{~b}$ ) probably due to the isoenzyme expression to compensate for the absence of abundant root exudates (Zhang et al., 2020). Although root exudates directly relieved microbial $\mathrm{C}$ limitation, the importance of soil moisture outweighed root hairs in regulating the occurrence of enzyme hotspots. Drought reduced the hotspot area (Fig. 2a) and narrowed the rhizosphere extent of $\beta$-glucosidase activity (Fig. 2b). The larger hotspots area and wider rhizosphere extent of $\beta$-glucosidase activity were concurrent with optimal water content because the proper soil moisture is a prerequisite for higher root biomass. It has been strongly suggested as a compelling explanation for higher rhizodeposition (Preece and Peñuelas, 2016). Additionally, the optimal water content provides a suitable growth environment for microorganisms, and increased microbial access to nutrients and energy (Ahmed et al., 2018), as well as enhanced the diffusion of both enzymes and substrate (Holz et al., 2019a). Consequently, $\beta$-glucosidase activities in wet soil were most pronounced (Fig. 3a). Such higher $\beta$-glucosidase activities were enough to maintain microbial activities and crucial functions, and thus the enzyme systems in dry soil were more efficient (Fig. 3b). Accordingly, we conclude that the abiotic factors (e.g. soil moisture) is likely to contribute more than biotic factors (e.g. root hairs) in controlling enzymatic hotspot and distribution in the rhizosphere. Despite this, root hairs still play extremely important roles when plants facing drought. For example, root hairs tend to increase the hotspot area of root exudates, as well as significantly widened the rhizosphere extension of root exudates and water under drought (Fig. $5 \& 7$ ). These are likely to facilitate microbial activity and increase lubrication in the dry soil (Holz et al., 2018c; Preece and Peñuelas, 2016), and thus benefit enzyme activity (Fig. 2 and 3) and nutrient availability. 


\subsubsection{The spatial correlation between $\beta$-glucosidase activity and root exudation or soil water content}

Although the presence of root hairs showed positive effects on spatial distribution of $\beta$ glucosidase activity (Fig. $2 \& 3$ ), its effects on the dependency of $\beta$-glucosidase on root exudates was negligible ( $p=0.477$, Fig. 8a). The co-localization between enzymatic hotspot with root exudates was strongly influenced by soil moisture (M1 and M2, Fig. 8a), which was weaker under drought than under optimal soil water content (Fig. 8a). Such discordance in the spatial distribution of enzyme activity hotspots (Fig. 1) and the concentrated localization of root exudates (Fig. 4) under drought could be explained by: 1) a lower enzyme production. Drought suppressed microbial activities (Dijkstra et al., 2015; Huxman et al., 2004) due to osmotic stresses (Sanaullah et al., 2011; Turner et al., 2003) and the lower substrate mobility (Schimel et al., 2007). Thus, the released root exudates were likely to satisfy microbial living and maintenance but insufficient for enzyme production and expression. 2) the reduced translocation of easily available $C$ to the rhizosphere (Fig. 4) because of the lower belowground $\mathrm{C}$ demand and the alteration in the allocation of recent photosynthates (Fuchslueger et al., 2014; Hasibeder et al., 2015; Ruehr et al., 2009). Consequently, the lower enzyme production combined with a reduced release of root exudates probably impaired their link. 3) We assume that the large amount of enzyme which were independent on root exudates were those existing in the soil previously. Those enzymes functioned under drying probably because enzymes are small and favored of thinner water films and smaller water-filled pores induced by drought which facilitated their connection with substrates than do microorganisms (Schimel, 2018).

Nevertheless, the hotspot of $\beta$-glucosidase activity was overlapped strongly with water hotspot under drought planted with mutant $r$ th3 $(\mathrm{M} 1=0.0077)($ Fig. $8 b)$. The co-limitation of water and root exudates induced higher spatial dependency of enzymatic hotspots on water (Fig. 8b) but not on root exudates (Fig. 8a). This indicated that water availability is more important than root exudates in the area of enzymatic hotspots when occurrence of their colimitations. This can be supported by the higher fraction of soil water contributed to enzymatic hotspots under optimal soil moisture (values of M2, Fig. 8b). Drought constrains the diffusion rate of root exudates and imparts physiological stresses on microbial community activities (Bouskill et al., 2013). Therefore, many microorganisms were unable to thrive even though they inhabited in microsites with more $\mathrm{C}$ sources. Accordingly, root or/and microorganisms developed strategies to maintain water content in the rhizosphere under drought. For example, water limitation widened the rhizosphere extent of root exudates 
irrespective of root hairs (Fig. 5) to compensate for the negative effects of drought. This wider extent might be attributed to the increased quantity of gel-like substance - mucilage around the drought-stressed root (Sanaullah et al., 2012), which accounted for 2-12\% of total rhizodeposition (Dennis et al., 2010; Holz et al., 2018). Mucilage was shown to increase the water content at the root-soil interface during soil drying (Carminati et al., 2010; McCully and Boyer, 1997). The presence of mucilage probably widened water extent close to the root (Fig. 7) and thus induced faster diffusion rates of root exudate from root surface to soil (Kuzyakov and Razavi, 2019). Despite those beneficial microenvironments for rhizomicrobial growth, hotspots and rhizosphere extent of $\beta$-glucosidase activities were still lower than that in optimal water content (Fig. 2).

Consequently, although biotic factors (e.g. root exudates) play an important role in enzymatic distributions, the abiotic factors (e.g. soil moisture) contributed more to enzyme hotspot area and rhizosphere extent. More in detail, the combination of three imaging methods (zymography, ${ }^{14} \mathrm{C}$ imaging and neutron imaging) pointed out that the colocalization between enzymatic hotspots and root exudates were only pronounced under optimal soil moisture, while lower soil water availability limits the enzymatic hotspot areas when occurring co-limitation of available $\mathrm{C}$ and water.

\section{Acknowledgments}

We gratefully acknowledge the China Scholarship Council (CSC) for financial support for Xuechen Zhang. This project was carried out in the framework of the priority programme 2089 "Rhizosphere spatiotemporal organisation - a key to rhizosphere functions" funded by DFG (RA-3062/3-1 and SP 943/6-1). Seeds of the maize mutant rth3 were provided by Caroline Marcon and Frank Hochholdinger (University of Bonn).

\section{References}

Ahmadi, K., Razavi, B.S., Maharjan, M., Kuzyakov, Y., Kostka, S.J., Carminati, A., Zarebanadkouki, M., 2018. Effects of rhizosphere wettability on microbial biomass, enzyme activities and localization. Rhizosphere 7, 35-42. doi:10.1016/j.rhisph.2018.06.010

Ahmed, M.A., Kroener, E., Holz, M., Zarebanadkouki, M., Carminati, A., 2014. Mucilage exudation facilitates root water uptake in dry soils. Functional Plant Biology 41, 1129. doi:10.1071/FP13330

Ahmed, M.A., Sanaullah, M., Blagodatskaya, E., Mason-Jones, K., Jawad, H., Kuzyakov, Y., Dippold, M.A., 2018. Soil microorganisms exhibit enzymatic and priming response to root mucilage under drought. Soil Biology and Biochemistry 116, 410-418. doi:10.1016/j.soilbio.2017.10.041 
Ahmed, M.A., Zarebanadkouki, M., Kaestner, A., Carminati, A., 2016. Measurements of water uptake of maize roots: the key function of lateral roots. Plant and Soil 398, 59-77. doi:10.1007/s11104015-2639-6

Asmar, F., Eiland, F., Nielsen, N.E., 1994. Effect of extracellular-enzyme activities on solubilization rate of soil organic nitrogen. Biology and Fertility of Soils 17, 32-38. doi:10.1007/BF00418669

Badri, D.V., Vivanco, J.M., 2009. Regulation and function of root exudates. Plant, Cell \& Environment 32, 666-681. doi:10.1111/j.1365-3040.2009.01926.x

Banfield, C.C., Zarebanadkouki, M., Kopka, B., Kuzyakov, Y., 2017. Labelling plants in the Chernobyl way: A new $137 \mathrm{Cs}$ and $14 \mathrm{C}$ foliar application approach to investigate rhizodeposition and biopore reuse. Plant and Soil 417, 301-315. doi:10.1007/s11104-017-32607

Bolte, S., Cordelières, F.P., 2006. A guided tour into subcellular colocalization analysis in light microscopy. Journal of Microscopy 224, 213-232. doi:10.1111/j.1365-2818.2006.01706.x

Burns, R.G., 1982. Enzyme activity in soil: Location and a possible role in microbial ecology. Soil Biology and Biochemistry 14, 423-427. doi:10.1016/0038-0717(82)90099-2

Cailloux, M., 1972. Metabolism and the absorption of water by root hairs. Canadian Journal of Botany 50, 557-573. doi:10.1139/b72-069

Cardona, A., Saalfeld, S., Schindelin, J., Arganda-Carreras, I., Preibisch, S., Longair, M., Tomancak, P., Hartenstein, V., Douglas, R.J., 2012. TrakEM2 Software for Neural Circuit Reconstruction. PLOS ONE 7, e38011. doi:10.1371/journal.pone.0038011

Carminati, A., Moradi, A.B., Vetterlein, D., Vontobel, P., Lehmann, E., Weller, U., Vogel, H.-J., Oswald, S.E., 2010. Dynamics of soil water content in the rhizosphere. Plant and Soil 332, $163-$ 176. doi:10.1007/s11104-010-0283-8

Carminati, A., Passioura, J.B., Zarebanadkouki, M., Ahmed, M.A., Ryan, P.R., Watt, M., Delhaize, E., 2017. Root hairs enable high transpiration rates in drying soils. New Phytologist 216, 771-781. doi:https://doi.org/10.1111/nph.14715

Datta, S., Kim, C.M., Pernas, M., Pires, N.D., Proust, H., Tam, T., Vijayakumar, P., Dolan, L., 2011. Root hairs: development, growth and evolution at the plant-soil interface. Plant and Soil 346, 114. doi:10.1007/s11104-011-0845-4

Dennis, P.G., Miller, A.J., Hirsch, P.R., 2010. Are root exudates more important than other sources of rhizodeposits in structuring rhizosphere bacterial communities? FEMS Microbiology Ecology 72, 313-327. doi:10.1111/j.1574-6941.2010.00860.x

Dijkstra, F.A., He, M., Johansen, M.P., Harrison, J.J., Keitel, C., 2015. Plant and microbial uptake of nitrogen and phosphorus affected by drought using $15 \mathrm{~N}$ and 32P tracers. Soil Biology and Biochemistry 82, 135-142. doi:10.1016/j.soilbio.2014.12.021 
Esser, H.G., Carminati, A., Vontobel, P., Lehmann, E.H., Oswald, S.E., 2010. Neutron radiography and tomography of water distribution in the root zone. Journal of Plant Nutrition and Soil Science 173, 757-764. doi:10.1002/jpln.200900188

Fuchslueger, L., Bahn, M., Fritz, K., Hasibeder, R., Richter, A., 2014. Experimental drought reduces the transfer of recently fixed plant carbon to soil microbes and alters the bacterial community composition in a mountain meadow. New Phytologist 201, 916-927. doi:10.1111/nph.12569

Gargallo-Garriga, A., Preece, C., Sardans, J., Oravec, M., Urban, O., Peñuelas, J., 2018. Root exudate metabolomes change under drought and show limited capacity for recovery. Scientific Reports 8, 12696. doi:10.1038/s41598-018-30150-0

Ge, T., Wei, X., Razavi, B.S., Zhu, Z., Hu, Y., Kuzyakov, Y., Jones, D.L., Wu, J., 2017. Stability and dynamics of enzyme activity patterns in the rice rhizosphere: Effects of plant growth and temperature. Soil Biology \& Biochemistry 113, 108-115. doi:10.1016/j.soilbio.2017.06.005

German, D.P., Weintraub, M.N., Grandy, A.S., Lauber, C.L., Rinkes, Z.L., Allison, S.D., 2011. Optimization of hydrolytic and oxidative enzyme methods for ecosystem studies. Soil Biology and Biochemistry 43, 1387-1397. doi:10.1016/j.soilbio.2011.03.017

Hasibeder, R., Fuchslueger, L., Richter, A., Bahn, M., 2015. Summer drought alters carbon allocation to roots and root respiration in mountain grassland. New Phytologist 205, 1117-1127. doi:10.1111/nph.13146

Heitkötter, J., Marschner, B., 2018. Soil zymography as a powerful tool for exploring hotspots and substrate limitation in undisturbed subsoil. Soil Biology and Biochemistry 124, 210-217. doi:10.1016/j.soilbio.2018.06.021

Hinsinger, P., Bengough, A.G., Vetterlein, D., Young, I.M., 2009. Rhizosphere: biophysics, biogeochemistry and ecological relevance. Plant and Soil 321, 117-152. doi:10.1007/s11104008-9885-9

Hochholdinger, F., Wen, T.-J., Zimmermann, R., Chimot-Marolle, P., da Costa e Silva, O., Bruce, W., Lamkey, K.R., Wienand, U., Schnable, P.S., 2008. The maize (Zea mays L.) roothairless3 gene encodes a putative GPI-anchored, monocot-specific, COBRA-like protein that significantly affects grain yield. The Plant Journal 54, 888-898. doi:10.1111/j.1365-313X.2008.03459.x

Hochholdinger, F., Yu, P., Marcon, C., 2018. Genetic Control of Root System Development in Maize. Trends in Plant Science 23, 79-88. doi:10.1016/j.tplants.2017.10.004

Holz, M., Leue, M., Ahmed, M.A., Benard, P., Gerke, H.H., Carminati, A., 2018a. Spatial Distribution of Mucilage in the Rhizosphere Measured With Infrared Spectroscopy. Frontiers in Environmental Science 6. doi:10.3389/fenvs.2018.00087

Holz, M., Zarebanadkouki, M., Carminati, A., Hovind, J., Kaestner, A., Spohn, M., 2019a. Increased water retention in the rhizosphere allows for high phosphatase activity in drying soil. Plant and Soil 443, 259-271. doi:10.1007/s11104-019-04234-3 
Holz, M., Zarebanadkouki, M., Carminati, A., Kuzyakov, Y., 2019b. Visualization and quantification of root exudation using $14 \mathrm{C}$ imaging: challenges and uncertainties. Plant and Soil. doi:10.1007/s11104-019-03956-8

Holz, M., Zarebanadkouki, M., Kaestner, A., Kuzyakov, Y., Carminati, A., 2018b. Rhizodeposition under drought is controlled by root growth rate and rhizosphere water content. Plant Soil 423, 429-442. doi:10.1007/s11104-017-3522-4

Holz, M., Zarebanadkouki, M., Kuzyakov, Y., Pausch, J., Carminati, A., 2018c. Root hairs increase rhizosphere extension and carbon input to soil. Annals of Botany 121, 61-69. doi:10.1093/aob/mcx127

Huxman, T.E., Smith, M.D., Fay, P.A., Knapp, A.K., Shaw, M.R., Loik, M.E., Smith, S.D., Tissue, D.T., Zak, J.C., Weltzin, J.F., Pockman, W.T., Sala, O.E., Haddad, B.M., Harte, J., Koch, G.W., Schwinning, S., Small, E.E., Williams, D.G., 2004. Convergence across biomes to a common rain-use efficiency. Nature 429, 651-654. doi:10.1038/nature02561

Jones, D.L., Nguyen, C., Finlay, R.D., 2009. Carbon flow in the rhizosphere: carbon trading at the soil-root interface. Plant and Soil 321, 5-33. doi:10.1007/s11104-009-9925-0

Jungk, A., 2001. Root hairs and the acquisition of plant nutrients from soil. Journal of Plant Nutrition and Soil Science 164, 121-129. doi:10.1002/1522-2624(200104)164:2<121::AIDJPLN121>3.0.CO;2-6

Kumar, A., Shahbaz, M., Blagodatskaya, E., Kuzyakov, Y., Pausch, J., 2018. Maize phenology alters the distribution of enzyme activities in soil: Field estimates. Applied Soil Ecology. doi:10.1016/j.apsoil.2018.02.001

Kuzyakov, Y., Domanski, G., 2000. Carbon input by plants into the soil. Review. Journal of Plant Nutrition and Soil Science 163, 421-431. doi:10.1002/1522-2624(200008)163:4<421::AIDJPLN421>3.0.CO;2-R

Kuzyakov, Y., Raskatov, A., Kaupenjohann, M., 2003. Turnover and distribution of root exudates of Zea mays. Plant and Soil 254, 317-327.

Kuzyakov, Y., Razavi, B.S., 2019. Rhizosphere size and shape: Temporal dynamics and spatial stationarity. Soil Biology and Biochemistry S0038071719301452. doi:10.1016/j.soilbio.2019.05.011

Kuzyakov, Y., Shevtzova, E., Pustovoytov, K., 2006. Carbonate re-crystallization in soil revealed by 14C labeling: Experiment, model and significance for paleo-environmental reconstructions. Geoderma 131, 45-58. doi:10.1016/j.geoderma.2005.03.002

Ma, X., Zarebanadkouki, M., Kuzyakov, Y., Blagodatskaya, E., Pausch, J., Razavi, B.S., 2018. Spatial patterns of enzyme activities in the rhizosphere: Effects of root hairs and root radius. Soil Biology and Biochemistry 118, 69-78. doi:10.1016/j.soilbio.2017.12.009 
Manders, E.M.M., Verbeek, F.J., Aten, J.A., 1993. Measurement of co-localization of objects in dualcolour confocal images. Journal of Microscopy 169, 375-382. doi:10.1111/j.13652818.1993.tb03313.x

McCully, M.E., Boyer, J.S., 1997. The expansion of maize root-cap mucilage during hydration. 3. Changes in water potential and water content. Physiologia Plantarum 99, 169-177. doi:10.1111/j.1399-3054.1997.tb03445.x

Moradi, A.B., Conesa, H.M., Robinson, B., Lehmann, E., Kuehne, G., Kaestner, A., Oswald, S., Schulin, R., 2009a. Neutron radiography as a tool for revealing root development in soil: capabilities and limitations. Plant and Soil 318, 243-255. doi:10.1007/s11104-008-9834-7

Moradi, A.B., Conesa, H.M., Robinson, B., Lehmann, E., Kuehne, G., Kaestner, A., Oswald, S., Schulin, R., 2009b. Neutron radiography as a tool for revealing root development in soil: capabilities and limitations. Plant and Soil 318, 243-255. doi:10.1007/s11104-008-9834-7

Nguyen, C., 2009. Rhizodeposition of Organic C by Plant: Mechanisms and Controls, in: Lichtfouse, E., Navarrete, M., Debaeke, P., Véronique, S., Alberola, C. (Eds.), Sustainable Agriculture. Springer Netherlands, Dordrecht, pp. 97-123. doi:10.1007/978-90-481-2666-8_9

Oburger, E., Gruber, B., Schindlegger, Y., Schenkeveld, W.D.C., Hann, S., Kraemer, S.M., Wenzel, W.W., Puschenreiter, M., 2014. Root exudation of phytosiderophores from soil-grown wheat. New Phytologist 203, 1161-1174. doi:10.1111/nph.12868

Pausch, J., Kuzyakov, Y., 2011. Photoassimilate allocation and dynamics of hotspots in roots visualized by C-14 phosphor imaging. Journal of Plant Nutrition and Soil Science 174, 12-19. doi:10.1002/jpln.200900271

Pausch, J., Loeppmann, S., Kühnel, A., Forbush, K., Kuzyakov, Y., Cheng, W., 2016. Rhizosphere priming of barley with and without root hairs. Soil Biology and Biochemistry 100, 74-82. doi:10.1016/j.soilbio.2016.05.009

Peterson, R.L., Farquhar, M.L., 1996. Root hairs: Specialized tubular cells extending root surfaces. The Botanical Review 62, 1-40. doi:10.1007/BF02868919

Poirier, V., Roumet, C., Munson, A.D., 2018. The root of the matter: Linking root traits and soil organic matter stabilization processes. Soil Biology and Biochemistry 120, 246-259. doi:10.1016/j.soilbio.2018.02.016

Preece, C., Peñuelas, J., 2016. Rhizodeposition under drought and consequences for soil communities and ecosystem resilience. Plant and Soil 409, 1-17. doi:10.1007/s11104-016-3090-z

Razavi, B.S., Blagodatskaya, E., Kuzyakov, Y., 2015. Nonlinear temperature sensitivity of enzyme kinetics explains canceling effect-a case study on loamy haplic Luvisol. Front Microbiol 6, 1126. doi:10.3389/fmicb.2015.01126

Razavi, B.S., Zarebanadkouki, M., Blagodatskaya, E., Kuzyakov, Y., 2016. Rhizosphere shape of lentil and maize: Spatial distribution of enzyme activities. Soil Biology and Biochemistry 96, 229-237. doi:10.1016/j.soilbio.2016.02.020 
Razavi, B.S., Zhang, X., Bilyera, N., Guber, A., Zarebanadkouki, M., 2019. Soil zymography: Simple and reliable? Review of current knowledge and optimization of the method. Rhizosphere 100161. doi:10.1016/j.rhisph.2019.100161

Ruehr, N.K., Offermann, C.A., Gessler, A., Winkler, J.B., Ferrio, J.P., Buchmann, N., Barnard, R.L., 2009. Drought effects on allocation of recent carbon: from beech leaves to soil CO2 efflux. New Phytologist 184, 950-961. doi:10.1111/j.1469-8137.2009.03044.x

Sanaullah, M., Blagodatskaya, E., Chabbi, A., Rumpel, C., Kuzyakov, Y., 2011. Drought effects on microbial biomass and enzyme activities in the rhizosphere of grasses depend on plant community composition. Applied Soil Ecology 48, 38-44. doi:10.1016/j.apsoil.2011.02.004

Sanaullah, M., Chabbi, A., Rumpel, C., Kuzyakov, Y., 2012. Carbon allocation in grassland communities under drought stress followed by $14 \mathrm{C}$ pulse labeling. Soil Biology and Biochemistry 55, 132-139. doi:10.1016/j.soilbio.2012.06.004

Sanaullah, M., Razavi, B.S., Blagodatskaya, E., Kuzyakov, Y., 2016. Spatial distribution and catalytic mechanisms of $\beta$-glucosidase activity at the root-soil interface. Biology and Fertility of Soils 52 , 505-514. doi:10.1007/s00374-016-1094-8

Schimel, J., Balser, T.C., Wallenstein, M., 2007. Microbial Stress-Response Physiology and Its Implications for Ecosystem Function. Ecology 88, 1386-1394.

Spohn, M., Kuzyakov, Y., 2013. Distribution of microbial- and root-derived phosphatase activities in the rhizosphere depending on $\mathrm{P}$ availability and $\mathrm{C}$ allocation - Coupling soil zymography with 14C imaging. Soil Biology and Biochemistry 67, 106-113. doi:10.1016/j.soilbio.2013.08.015

Thu Hoang, D.T., Maranguit, D., Kuzyakov, Y., Razavi, B.S., 2020. Accelerated microbial activity, turnover and efficiency in the drilosphere is depth dependent. Soil Biology and Biochemistry 147, 107852. doi:10.1016/j.soilbio.2020.107852

Turner, B.L., Driessen, J.P., Haygarth, P.M., Mckelvie, I.D., 2003. Potential contribution of lysed bacterial cells to phosphorus solubilisation in two rewetted Australian pasture soils. Soil Biology and Biochemistry 35, 187-189. doi:10.1016/S0038-0717(02)00244-4

Vetterlein, D., Lippold, E., Schreiter, S., Phalempin, M., Fahrenkampf, T., Hochholdinger, F., Marcon, C., Tarkka, M., Oburger, E., Ahmed, M., Javaux, M., Schlüter, S., 2020. Experimental platforms for the investigation of spatiotemporal patterns in the rhizosphere-laboratory and field scale. Journal of Plant Nutrition and Soil Science 000, 1-16. doi:10.1002/jpln.202000079

Wu, X., Ge, T., Yan, W., Zhou, J., Wei, X., Chen, L., Chen, X., Nannipieri, P., Wu, J., 2017. Irrigation management and phosphorus addition alter the abundance of carbon dioxide-fixing autotrophs in phosphorus-limited paddy soil. FEMS Microbiology Ecology 93. doi:10.1093/femsec/fix154

Zarebanadkouki, M., Ahmed, M., Hedwig, C., Benard, P., Kostka, S.J., Kastner, A., Carminati, A., 2018. Rhizosphere hydrophobicity limits root water uptake after drying and subsequent rewetting. Plant and Soil 428, 265-277. doi:10.1007/s11104-018-3677-7 
Zhang, X., Dippold, M.A., Kuzyakov, Y., Razavi, B.S., 2019. Spatial pattern of enzyme activities depends on root exudate composition. Soil Biology and Biochemistry 133, 83-93. doi:10.1016/j.soilbio.2019.02.010

Zhang, X., Kuzyakov, Y., Zang, H., Dippold, M.A., Shi, L., Spielvogel, S., Razavi, B.S., 2020. Rhizosphere hotspots: Root hairs and warming control microbial efficiency, carbon utilization and energy production. Soil Biology and Biochemistry 107872. doi:10.1016/j.soilbio.2020.107872 


\title{
7 Study 7: Soil zymography: Simple and reliable? Review of current knowledge and optimization of the method
}

Bahar S. Razavi ${ }^{\mathrm{a},{ }^{*}}$, Xuechen Zhangb ${ }^{\mathrm{b}, \mathrm{c}}$, Nataliya Bilyera ${ }^{\mathrm{a}, \mathrm{d}}$, Andrey Guber ${ }^{\mathrm{e}}$, Mohsen Zarebanadkouki $^{\mathrm{f}}$

\section{Status: Published in Rhizosphere}

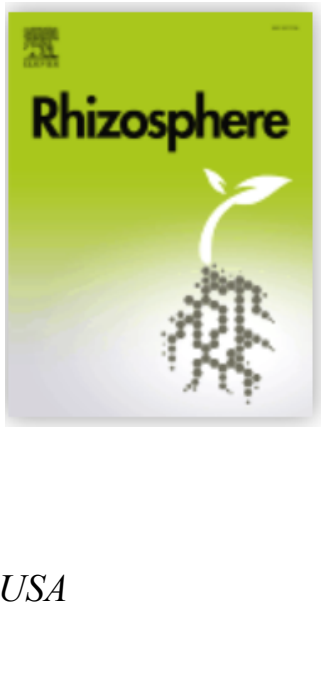

${ }^{a}$ Department of Soil and Plant Microbiome, Institute of Phytopathology, University of Kiel, Kiel, Germany

${ }^{b}$ Department of Biogeochemistry of Agroecosystems, University of Göttingen, Göttingen, Germany

${ }^{c}$ Department of Agricultural Soil Science, University of Göttingen, Göttingen, Germany

${ }^{d}$ Institute of Plant Nutrition and Soil Science, University of Kiel, Kiel, Germany

${ }^{e}$ Department of Plant, Soil, and Microbial Sciences, Michigan State University, USA

${ }^{f}$ Chair of Soil Physics, University of Bayreuth, Bayreuth, Germany

\begin{abstract}
Within just a few years, soil zymography has become accepted as an attractive and unique approach for 2D mapping of enzyme activities in intact soil samples. With zymography, enzymatic conversion of the substrate into a hydrolysis reaction product can literally be visualized. Soil zymography is, however, fraught with methodical difficulties due to: (i) membrane or gel attachment to the soil surface; (ii) diffusion of substrates through the membrane or gel and of reaction products back to the membrane; (iii) strong effect of imaging (photography) and image analysis on the results. In this review, we describe important procedural details of soil zymography and define the steps necessary to properly visualize enzyme activities in environmental samples. We make the following recommendations to improve zymography results 1) run soil background imaging prior to any soil zymography; 2) confirm that roots are in the soil and not on top of the soil surface; 3) perform soil zymography under the initial environmental conditions of the samples (temperature, water content, light intensity, etc); 4) examine whether membrane/gel attachment during the incubation is appropriate to properly measure enzyme activity; 5) find the right balance between saturating substrate concentration of soil and selected substrate concentration for zymography; 6) run proper standards to ensure that enzyme activity values can be accurately calculated; 7) fix camera settings and photography conditions; 8) ensure that images are properly analyzed. These steps should help to develop a unified visualization of enzyme activities in soil and ecosystem ecology. Finally, coupling of soil zymography with other imaging techniques and advanced analytical approaches will give insight into the net effect of multiple processes, such as root respiration, rhizodeposition, nutrient and metal(loid) dynamics, plant-mediated oxygen release, microbial respiration and reoxidation of reduced compounds in relation to the activities of enzymes released by plants or microbes.
\end{abstract}

Keywords: spatial pattern, enzyme distribution, imaging, microbial activity, hotspots *Corresponding author: brazavi@,phytomed.uni-kiel.de 


\subsection{Introduction}

\subsubsection{Current knowledge and relevance}

The term 'zymography' denotes the visualization of enzymatic activity by substrate conversion (essentially enzyme photography). The general biochemical reaction can be detected for either the appearance of the reaction product or the disappearance of the substrate (Vandooren et al., 2013; Spohn et al., 2013; Spohn and Kuzyakov, 2013). Zymography was first introduced in 1962, for detecting collagen degradation in tadpole tissue and described a matrix metalloproteinase (MMP) (Gross and Lapière, 1962; Vandooren et al., 2013). Development of zymography over five decades was mostly focused on the analysis of proteases and their inhibitors in various matrices and media besides soil (Hughes and Herr, 2010; Pan et al., 2011; Choi et al., 2009), for example, to gain insights into tumor formation (Kleiner and Stetlerstevenson, 1994; Nemori and Tachikawa, 1999; Wilkesman and Kurz, 2009).

Kurzbaum et al. (2010), proposed a novel approach to visualize dehydrogenase activity of plant roots by use of tetrazolium violet dye without destructive steps, allowing repeated observations of growing plants and the impact of inhibitors such as sodium azide and cycloheximide. However, this approach was not tested in soil specimens. Visualization of enzyme activities developed rapidly once fluorescently labeled substrates became widely applied in environmental samples. During the first attempt at visualization of enzyme activity in the soil matrix, the fluorescently labeled substrate was dissolved in agarose solution that was then directly poured onto the sample (Baldrian and Větrovský, 2012). The approach was successful in visualizing the spatial distribution of enzyme activity in soils and in biological specimens such as fungal cell colonies. However, due to the diffusion of the substrate in agar gel, the resolution of this enzyme mapping method was low. The same limitation was visible following the standard zymography assays for the detection of protease and amylase activity in electrophoresis gels (Spohn et al., 2013). The revolutionary optimization of the method started by integrating dissolved fluorescently labeled substrates in membrane filters instead of gels (Spohn and Kuzyakov, 2013; Sanaullah et al., 2016; Razavi et al., 2016).

Soil zymography techniques can be utilized for hydrolases or oxidases acting on any biological substrate such as proteins and peptides, oligosaccharides and polysaccharides, lipids and sugars (Kurzbaum et al., 2010; ; Spohn et al., 2013; Voothuluru et al., 2018).

To date soil zymography has been adapted for various applications such as studying the impact of plant species (Razavi et al., 2016), root morphology (Ma et al., 2018), pathogens 
(Razavi et al., 2017a), abiotic controls like temperature (Ge et al., 2017), drought (Guhr et al., 2015; Ahmadi et al., 2018), nutrient availability (Wei et al., 2018; Giles et al., 2018; Heitkötter and Marschner, 2018) and heavy metal pollution (Duan et al., 2018) on the activity of different enzymes in various spheres such as the rhizosphere (Spohn and Kuzyakov, 2013; Sanaullah et al., 2016), detritusphere (Spohn and Kuzyakov, 2014; Liu et al., 2017; Ma et al., 2017; Wei et al., 2019), and biopores (Hoang et al., 2016; Razavi et al., 2017b), in both lab and field studies (Razavi et al., 2017b). Benefiting from all of these developments, we can now test a larger array of hypotheses related to enzyme-based processes and their roles in biogeochemical cycling. Besides its potential application, the simple sample preparation procedure and relatively worldwide accessibility of all necessary chemicals and equipment have made soil zymography one of the most influential imaging techniques in soil.

Despite the widespread adoption of soil zymography, a comprehensive discussion of the details and pitfalls of the method is not available in the literature. In fact, a major motivation for writing this contribution is that the authors (and our colleagues) receive dozens of inquiries each year on the execution and interpretation of soil zymography. The prevalent use of high-throughput soil zymography methods has created the need for a comprehensive review of the current state of the art in ecosystem studies. The potential knowledge gap affects the quality and utility of contemporary soil zymography data; distort results or often resulting in relative activity levels that are incomparable among different studies, even though the same enzymes are studied. Methodological optimization will enable the soil and ecological community to perform larger scale meta-analyses, aiming to improve understanding of how plant and microbial enzymes drive ecosystem processes. For specific methodological studies regarding the preparation of calibration lines for soil zymography, and the sensitivity of enzyme activity measurements to exposure time during photography we refer readers to the recent works by Guber et al. (2018a) and Giles et al. (2018).

\subsection{Soil zymography and its expected outcomes}

Briefly, soil zymography involves visualizing fluorescent compounds produced when a substrate reacts with a substrate-specific enzyme. A membrane filter is soaked in a solution containing a known concentration of fluorescently labeled substrate. The uniformly saturated membrane will be placed in contact with the soil surface either directly (Razavi et al., 2016) or protected by a thin layer of gel (Spohn and Kuzyakov, 2013). The membrane will be incubated on the soil surface for a given period of time (see 6.4.2) and then will be removed 
and the imprint of the enzyme on the membrane will be imaged under UV light in dark (Fig. $1)$.

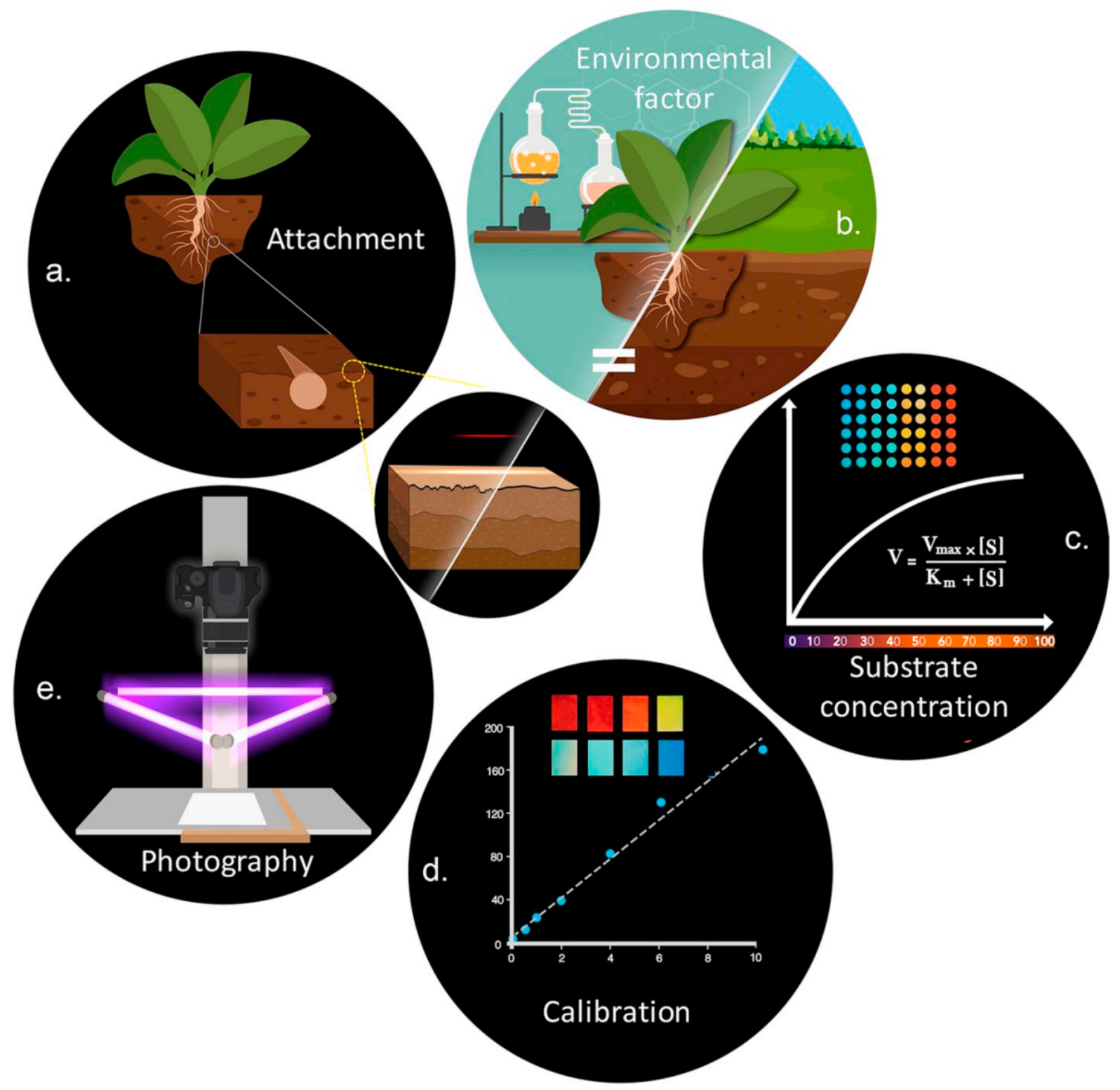

Fig. 1. Schematic illustration of soil zymography setup and its main steps: a. shows root position and membrane attachment. The inset shows laser scanning for soil surface topography; b. Performance of soil zymography under the initial environmental conditions of the samples; c. Balance between saturating substrate concentration of soil and selected substrate concentration; d. Proper calibration standards; e. Fixed camera settings and photography conditions. Art work: Tahoora Emam.

The result of zymography is a 2-D image obtained by a normal camera and is called a zymogram. The captured zymogram can be further quantified and related to the probability 
that a given enzyme reacts with the substrate and activates its fluorescent agent per unit of area and time. The fluorescent substrate is initially on the membrane and gets activated when it meets a specific enzyme located on the soil surface.

Theoretically, this activation process may occur by two contrasting diffusion-driven processes: i) once a membrane saturated by substrate is placed at the soil surface the substrate may diffuse (by Brownian motion) towards the soil surface. As the substrate meets a specific enzyme at the soil surface it gets activated. By the nature of diffusion, the now-fluorescent substrate may move back to the membrane, where its imprint will be visualized, ii) another alternative would be that the enzyme at the soil surface diffuses towards the membrane and activates the fluorescent agent of the substrate. Similarly, this process is also Brownian motion driven and may occur in both directions (i.e. the enzyme may return to the soil). After enough time, both processes will reach a steady state and the detected enzyme activity on the membrane will be constant. Although both processes are theoretically possible, the diffusion rates for substrate towards the soil and fluorescent product return is higher. The diffusion rate of a substance is inversely proportional to the square root of its molecular mass. Typically, enzymes have average molecular weights ranging from $10 \mathrm{kD}$ to 2,000 kD (Ogston, 1962; Wright, 1962), while the substrate used in zymography has a molecular weight of $176 \mathrm{D}$. This simple consideration would suggest that the probability that substrate diffuses towards the soil is surly more than 7.5 times higher than the enzyme towards the membrane (D $\propto \sqrt{1 / M}$, where $\mathrm{D}$ is the diffusion rate and $\mathrm{M}$ is the molecular weight). Thus, in soil zymography, while the membrane is placed on the soil surface it is very probable that the substrate diffuses from the membrane to the soil. This diffusion depends strongly on soil water content at the soil-membrane interface and the contact between soil and the membrane. A partially dried soil surface may adversely affect the results of enzyme activity (consider the case that only the first soil pore at the interface between membrane and soil are dry while the rest of the soil is wetter). In such cases, if the goal is to estimate potential enzyme activity -besides qualitative visualization- soil zymography could be coupled with classical enzyme assays (Hoang et al., 2016; Ma et al., 2017; Zhang et al., 2019).

One of the most important points to consider when performing soil zymography is that it is not a replacement for classical enzyme assays. Classical enzyme assays measure “maximum potential" enzymatic activity (Burns, 1978; Tabatabai and Dick, 2002; Wallenstein and Weintraub, 2008) in soil or litter. By its nature, soil zymography reflects enzyme activity associated with surfaces of a given sample rather than its entire volume (Baldrian and Větrovský, 2012). Based on experimental data and simulation it was shown 
that detected enzyme activity is only a small proportion, around $20-30 \%$, of the actual reactions that take place within the total soil volume (Ma et al., 2017; Guber et al., 2018b).

To ensure that estimations are accurate, several factors must be considered and procedures carried out before starting soil zymography in environmental samples: chemicals and materials, incubation conditions and duration, imaging conditions, sample preparation and image analysis. We will address each of these in turn with some examples of adaptations for specific conditions; however, for detail methodological descriptions of each hotsphere, in the lab and field, we refer the reader to original experimental studies (Hoang et al., 2016; Razavi et al., 2017b, Liu et al., 2017; Ge et al., 2017).

\subsection{Chemicals and materials}

\subsubsection{Substrate}

Current soil zymography has benefitted greatly from fluorescent dye-conjugated substrates [e.g., 4-methylumbelliferone (MUF), 7-amino-4-methylcoumarin (AMC); Marx et al., 2001; Saiya-Cork et al., 2002] for the detection of many hydrolytic enzymes. These fluorescence agents allow rapid and specific determination of the spatial distribution of enzyme activities involved in $\mathrm{C}, \mathrm{N}, \mathrm{P}$ and $\mathrm{S}$ cycling and, thus, provide the opportunity to answer questions related to the enzymatic hotspots on broader scales. Besides MUF- or AMC- conjugated substrates, 1-(3,7-dihydroxyphenoxazin-10-yl) ethanone, (OxiRed) and tetrazolium-dye substrates are also suitable for visualization of enzyme activities. OxiRed $\left(\mathrm{C}_{14} \mathrm{H}_{11} \mathrm{NO}_{4}\right)$, is a fluorogenic substrate that can be used to detect peroxidase activity (Table 1). The method is based on determination of a fluorescent signal developed from enzymatic oxidation of the substrate in the presence of peroxidase in the soil. In the presence of horseradish peroxidase (HRP), the OxiRed probe reacts in $1: 1$ stoichiometry with $\mathrm{H}_{2} \mathrm{O}_{2}$ to produce highly fluorescent resorufin. The substrates can be dissolved in $300 \mu 1$ dimethyl sulfoxide (DMSO) and later diluted with universal buffer to the desired concentration. OxiRed is sensitive to light and oxygen, which makes its application more limited than the other substrates. Tetrazolium violet-based dyes are qualitative redox indicators that enable visualization of dehydrogenase activity (Steponkus and Lanphear, 1967; Kurzbaum et al., 2010).

Table 1 Enzymes commonly imaged in environmental samples, and their organic matter constituents and substrates. 


\begin{tabular}{lll}
\hline Enzyme & Synthetic substrate & Organic matter constituent \\
\hline$\beta$-glucosidase & 4-MUF- $\beta$-D-glucopyranoside & Cellulose degradation products \\
$\beta$-cellobiosidase & 4-MUF- $\beta$-D-cellobioside & Cellulose degradation products \\
$\alpha$-glucosidase & 4-MUF- $\beta$-D-glucopyranoside & Starch degradation products \\
Xylanase & 4-MUF-b-D-xylopyranoside & Hemicellulose degradation products \\
Phosphatase & 4-MUF-Phosphate & Phytate \& Phosphodiester bond degrading \\
Leucine-aminopeptidase & 1-Leucine-7-amino-4-methylcoumarin & leucine and amino acids \\
Tyrosine-aminopeptidase & 1-Tyrosine-7-amido-4methylcoumarin & Tyrosine and amino acids \\
Chitinase & 4-MUF- N-Acetyl- $\beta$-D-glucosaminide & Chitin degradation products \\
Chitotriosidase & 4-Nitrophenyl beta-D-N,Nprime, triacetylchitotriose & Chitin degradation products \\
Peroxidase & 1-(3,7-Dihydroxyphenoxazin-10-yl)ethanone & Lignin polymerizing products \\
\hline (Modified after German et al., 2011) &
\end{tabular}

The substrate concentration normally suggested are $10 \mathrm{mM}$ (Spohn et al., 2014) or $10 \mu \mathrm{M}$ (Razavi et al., 2017b). However, these concentrations are not necessarily an optimum concentration for all soil types and, for many soils, concentrations much less than $10 \mathrm{mM}$ would be sufficient to reach saturating conditions for each hydrolytic enzyme. The saturated concentration can be inferred from Michaelis-Menten kinetics (Michaelis and Menten, 1913). Therefore, pre-testing is necessary to determine the appropriate substrate concentration for the soil prior to zymography. Application of inappropriate concentrations will complicate the interpretation of images, because obtained signals become insensitive to increments of concentration. This results in gray values that are out of the linear part of the calibration curve (over-saturating signals), (Razavi et al., 2016a; Guber et al., 2018a), (Fig. 2), (for more detail see section 6.6.1).
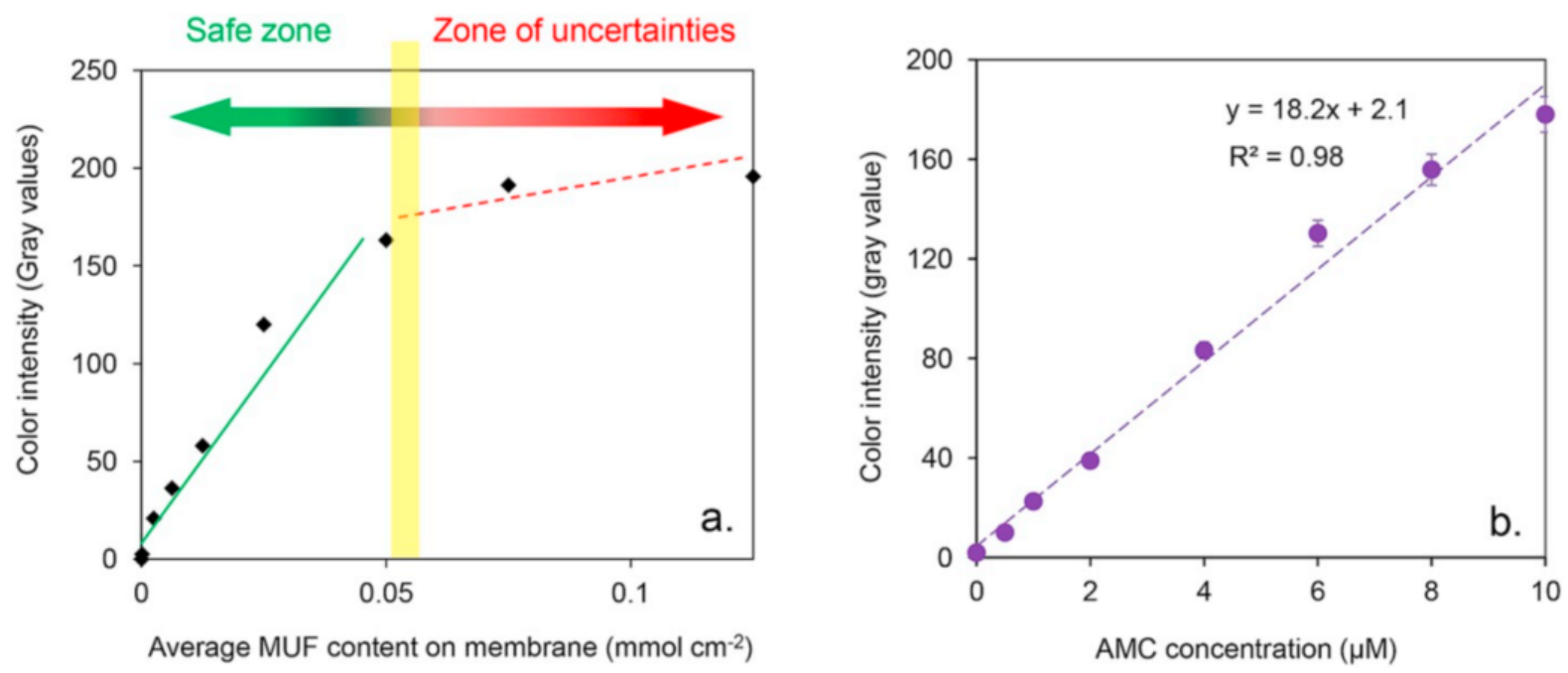

Fig. 2. Examples of calibration line: a) when the correlation of gray values and concentrations are linear; b) when the correlation is not linear. When the calibration line shows non-linear behavior, the safe zone of the curve according to the concentration and gray values should be identified. 


\subsection{2 pH}

Enzymes are sensitive to $\mathrm{pH}$ and display specific $\mathrm{pH}$ optima (Tabatabai, 1994; Turner, 2010). However, enzymes in soil may not be at their pH optimum (Burns, 1978). Unlike animal digestive tracts, for example, most microbes cannot control the environmental $\mathrm{pH}$ for their enzyme activity. Thus, in order to visualize enzyme activities in environmental samples, soil zymography should be run at the same $\mathrm{pH}$ as sample. Based on studies of soil enzymology it is known that some of the buffers may interfere with enzyme activity (Burns, 1978; Tabatabai, 1994; German et al., 2011; Sinsabaugh, 2010). For instance, phosphate buffer may interfere with the measurement of phosphatase activities, and is an inhibitor of glucosidase (Dahlqvist, 1968), while citrate can chelate iron (Essington et al., 2005), thereby inhibiting enzymes with iron-heme prosthetic groups (Sinsabaugh, 2010). Besides, MUF- or AMC-conjugated substrates fluoresce best at alkaline $\mathrm{pH}$ values ( $>9$; Mead et al., 1955). Since assays are typically conducted at a $\mathrm{pH}$ lower than $9, \mathrm{NaOH}$ is often added to raise the $\mathrm{pH}$ immediately before reading the samples in a fluorometer (German et al., 2011). Extreme alkalization compromised assay sensitivity because of variation (increase and decrease) in the fluorescence of the product/standard (German et al., 2011). Another issue regarding alkalization is that the fluorescence of MUF and AMC vary with time following the addition of $\mathrm{NaOH}$ (Fig. 3). MUF fluorescence increases until $\sim 20 \mathrm{~min}$ after $\mathrm{NaOH}$ addition, whereas AMC shows a decrease in fluorescence with time following the alkalization. In soil zymography, this would lead to exaggerated/elimination signals, which would be incorrectly, interpreted as high/low enzyme activities on the soil surface or a high/low percentage of hotspots (Fig. 3). It has even been suggested to omit any buffer for enzyme assays (German et al., 2011); however, $\mathrm{pH}$ fluctuation has been observed in assays performed in the absence of buffer (Fig. 3), (Burn, 1978), while, AMC fluorescence with TRIZMA buffer $\left[\mathrm{C}_{4} \mathrm{H}_{11} \mathrm{NO}_{3} \cdot \mathrm{HCl}, \mathrm{C}_{4} \mathrm{H}_{11} \mathrm{NO}_{3} ; \mathrm{pH}: 7.2\right]$ without $\mathrm{NaOH}$ addition showed temporal stationary pattern. Therefore, the substrates can be dissolved in any universal buffer that shows a static trend over time and no inhibitory effect on enzymes (Fig. 3). 


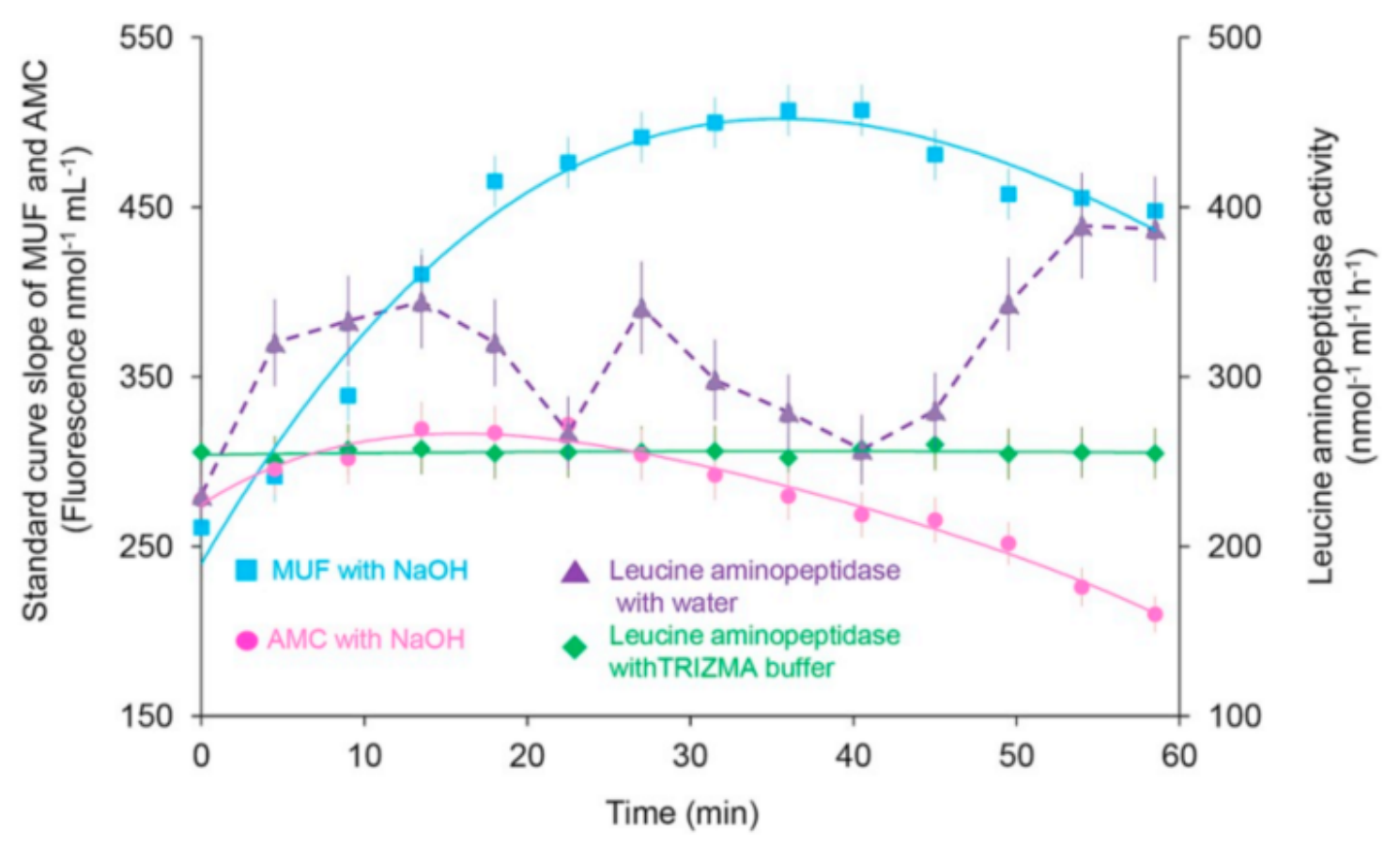

Fig. 3. Intensity of MUF and AMC standard curves with and without $\mathrm{NaOH}$, as well as trend of leucine aminopeptidase activity with and without buffer.

\subsubsection{Membranes}

Ideally, the thickness of the membrane filter should be reduced as much as possible to provide uniform vertical distribution of substrate in the membrane. However, thin membranes do not eliminate horizontal diffusion within the membrane, which creates an illusion of a growing area of enzyme activity over time. More specifically, by placing small drops of MUF/AMC with different concentrations in the middle of a membrane saturated with a buffer, followed by monitoring the area of the signal development under UV-light provides sufficient information for estimating the diffusion coefficients. The calculated diffusion coefficient of MUF on a dry membrane filter (Tao Yuan, China) was $5 \times 10^{-5} \mathrm{~mm}$ $\min ^{-1}$. Estimated diffusion coefficients can be used in calculations of expansion of enzyme activity (for example in the rhizosphere).

\subsection{Sample preparation}

\subsubsection{Root position and membrane attachment}

Proper contact between the soil surface and the membrane is crucial for achieving interpretable results. The interpretation of the fluorescent pattern on zymograms is based on the assumption that locations with high fluorescence reflect locations with high enzyme activities on the soil surface, while locations with no fluorescence correspond to locations on the soil surface without activity. However, the contact between the soil surface and 
membrane depends on the roughness and topology of the soil surface, which varies depending on soil particle size distribution and the positions of roots.

A lack of proper contact between soil surface and membrane may result in the absence of fluorescence signals on the zymograms and thus are interpreted as regions with no activity. To reduce the risk of misinterpretation, an initial evaluation of soil heterogeneity by taking and analyzing a photograph of the soil surface and, when possible, performing laser scanning to assess the roughness of the soil surface, is recommended. Laser scanning of the soil surface (e.g. using NextEngine, Inc., Santa Monica, California) prior to zymography could be reasonable for soil surface characterization and micro-topography (e.g. the areas of large and medium-sized soil pores at the surface as well as root distribution), (Guber et al., 2018b). The scanner uses a set of laser beams to hit the soil surface from different angles. Each point from the soil surface is automatically positioned by a laser-light sensor in a 3D coordinate system at a nominal resolution of $1.7 \mu \mathrm{m}$ (Uteau et al., 2013). While laser scanning provides a detailed soil surface map, it will not yield direct information on which portions of the surface will be in contact with the membrane after its placement on the surface. The general considerations are that the contact will take place at the areas which have the greatest height (peaks) in comparison with another regions of the soil surface, (Guber et al., 2018b).

The positions of roots on the soil surface is another critical factor that should be considered in performing soil zymography. Generally, there are 4 possible positions for root growth in a rhizobox or in field rhizotrons (root windows) (Fig. 4): Roots may be positioned: i) completely on top of the soil surface, ii) partly buried in soil and partly outside of the soil surface, iii) partly buried in soil and positioned at the same level as the soil surface, iv) completely buried in the soil. 

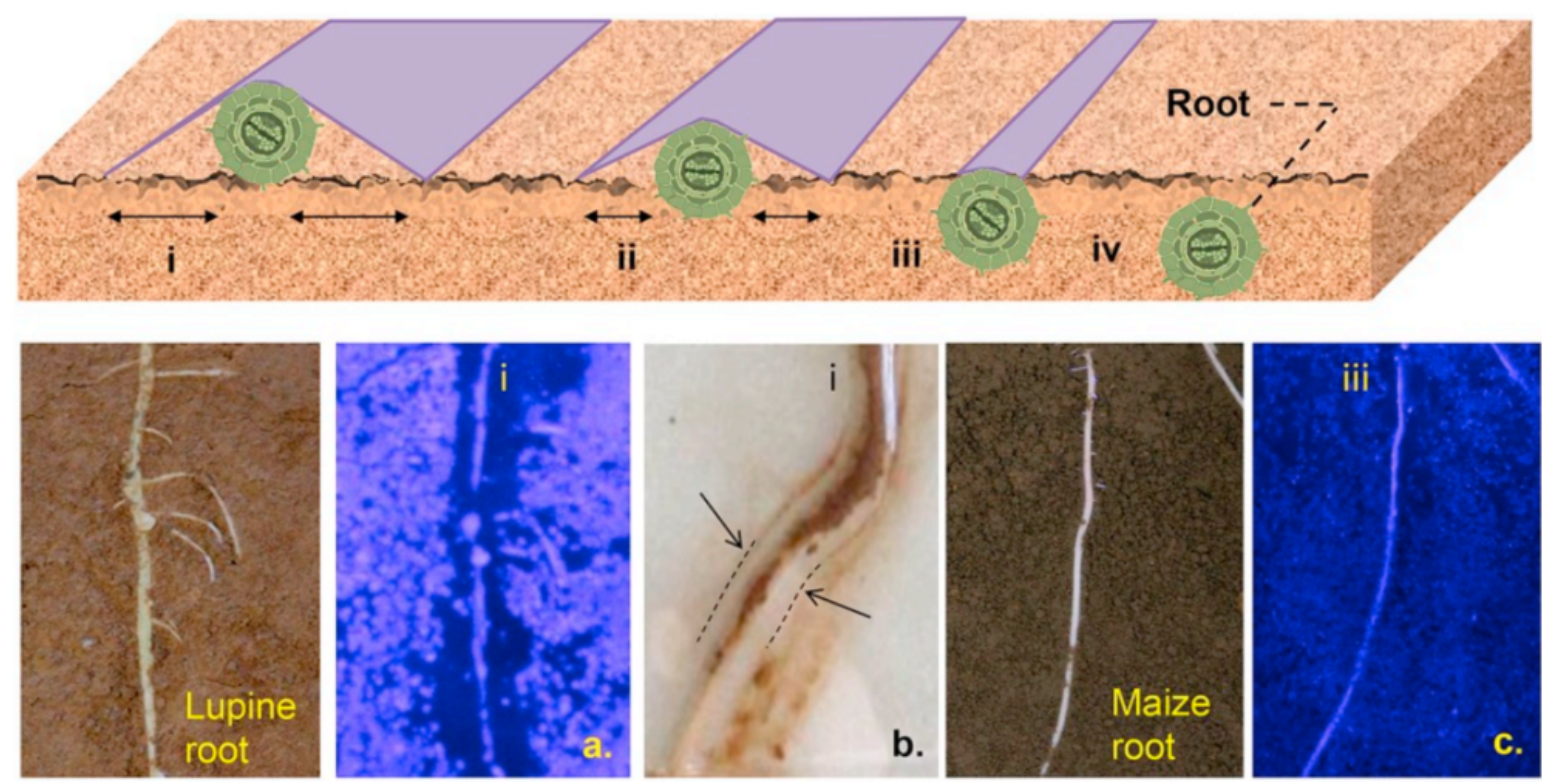

Fig. 4. Four possible positions of root in soil: i) completely out of the soil surface, ii) partly buried in soil and positioned partly outside of the soil surface, iii) partly buried in soil and positioned at the same level as the soil surface, iv) completely buried in the soil. The eliminated zones around the lupine root (a) corresponding to the similar root position as position (i). (b), shows eliminated zones around the maize root covered by $1 \mathrm{~mm}$ gel plate when the root is at a similar position as (i). A clear imprint of enzyme activity on the root and surrounding soil (c) corresponding to the similar root position as (iii). All images are in true color without image processing.

In the case that a root is in position (i), its footprint will be detected on the zymograms, but it should be kept in mind that the contact between the membrane and the surrounding soil will deteriorate depending on the thickness of the root: i.e. a thick root will prevent membrane contact across a larger region in its surroundings. For the case (ii), the imprint of the root will be detected on the zymograms, but the trail in the surrounding soil will be affected by the thickness of the root standing above the soil surface. Case (iii) is ideal for zymography (Fig. 4). The imprint of both roots and the surrounding soil will be detected safely on the zymograms. For the case that the root is in position (iii), its thickness will not have any effect on the contact between membrane and soil surface and its footprint on the zymogram will reflect its enzymatic activity. If roots are completely buried in the soil, (iv), the imprints may not be detected on the zymograms. In this case, the intensity of the detected signal mostly depends on the thickness of the soil layer between the root and membrane (Fig. 4). It should be noted that, if the root is located in position (i) or (ii), or the soil surface is not uniform, 
application of any intervening material e.g. filter paper, gel plate, would not improve the attachment and there will be a "blind spot" around the roots (Fig. 4, b). The same is valid for direct application of membrane, as we cannot fold the membrane (Fig. 4. a). Thus, confirmation of an appropriate root position is a critical step prior to any soil zymography analysis.

\subsubsection{Incubation conditions and duration}

In general, the incubation time depends on the temperature, soil texture, the activity of the tested enzyme in the soil and the soil water content. Soil water content (gravimetric or volumetric water content) and soil texture has a great impact on diffusion of enzyme (Burns et al., 2013). The drier is the soil the longer is the distance that any substrate should diffuse to/from the membrane (the overall chance of enzyme and substrate to diffuse decreases). However, theoretically, diffusion rate will increase at high water content and the probability that substrate would bind to enzyme (form enzyme-substrate complex) will be enhanced (Allison et al., 2011; Manzoni et al., 2012). Hence, the water content of samples should be constant. As the VW refers to the percentage of pores that are filled with water, it would represents the higher portion of enzymes if we assume that enzymes and microorganisms are active in the liquid phase (water-film or biofilms- biosynthesized polymeric substances exude by soil microbiome) (Ekschmitt et al., 2005; Or et al., 2007), or if we assume soil pores serve as conduits for water flow and chemical transport, as well as habitats for microorganisms, and thus play a key role in determining rates and magnitudes of most of soil chemical and biological processes (Kravchenko et al., 2015). Thus, soil water content has strong effect on results interpretation and accordingly, the incubation time should be long enough for diffusion to take place across the soil surface and the membrane. During this time, it is important to prevent evaporation from the membrane and ensure contact between the membrane and soil surface. To ensure such attachment one may put additional weight onto the membrane. However, different weights will greatly change the obtained signal on the zymograms (Fig. 5). If the load is necessary (for example in case of mapping enzymes around soil columns), then equal weight should be applied to all the samples. 

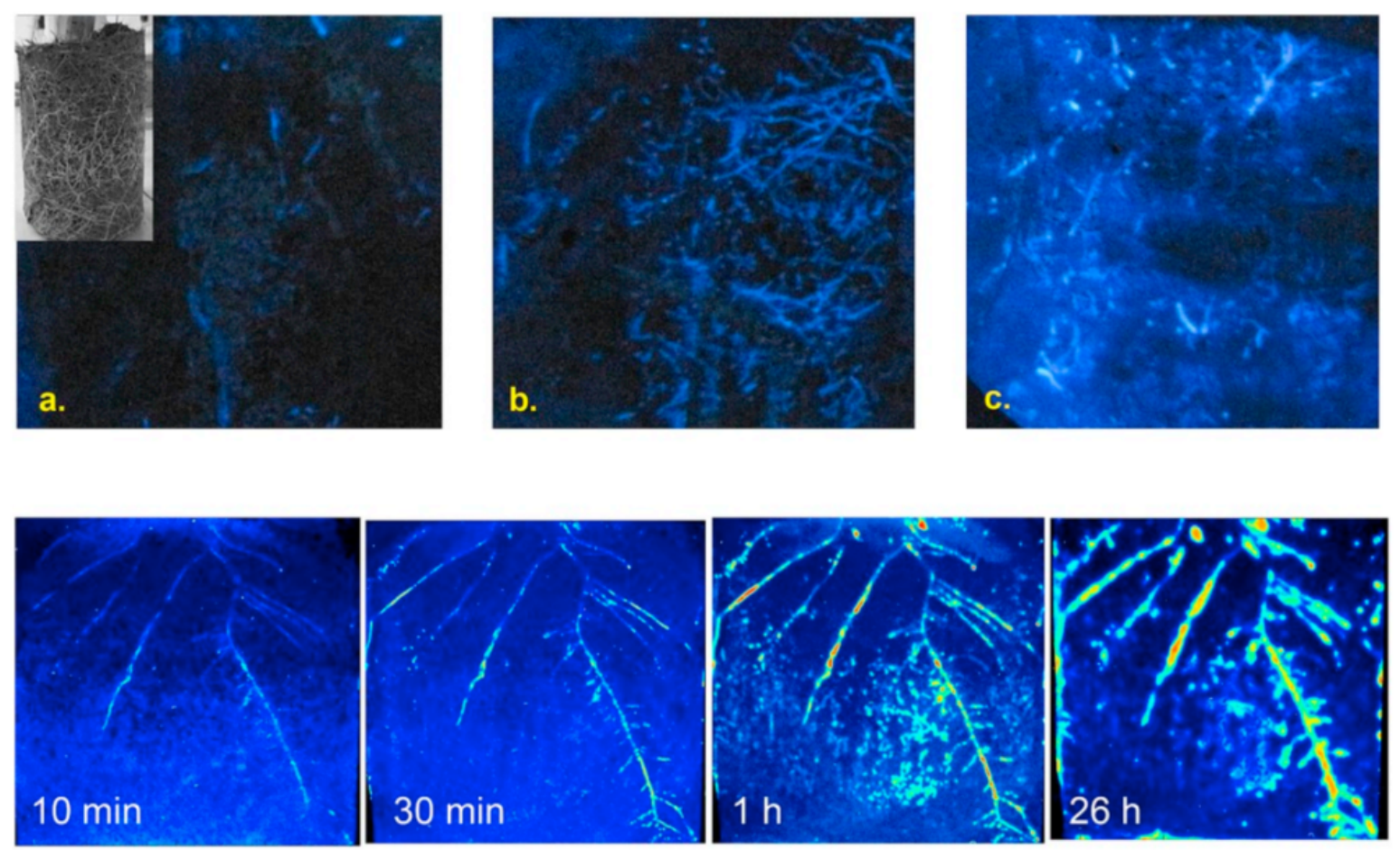

Fig. 5. Top: a, b and c presenting three different load levels around a soil column. The sub figure of a, shows real soil column. All images are in true color without image processing. Bottom: four incubation durations. The radial diffusion on the membrane after $26 \mathrm{~h}$ is clearly detectable.

The incubation time should not be too long, as this will cause oversaturation of the membrane. For a coarser soil with lower water content, a longer incubation time would be required than for a wet soil. One hour of incubation is normally selected based on preliminary experiments and previous studies (Dong et al., 2007). The criterion for appropriate incubation time is based on color intensity and diffusion rate: i) reaching the maximum intensity, ii) no detectable horizontal diffusion on the membrane (Fig. 5). After incubation, the membranes should be carefully lifted off the soil surface and any attached soil particles should be gently removed using tweezers. Another option is taking multiple images during the incubation on the soil surface at regular time intervals ( 2 to 5 minutes) and use the whole image sequence in calculations of enzyme activity.

\subsection{Imaging procedure}

\subsubsection{Camera setting}

The motivation behind this section is to highlight how strongly the imaging step, camera, and the lens models affect the quality of images as well as interpretation of results. 
Analyses of over 95 different full-frame models on the Canon EOS 6D - a randomly selected camera - showed the focal length ranged between $12 \mathrm{~mm}$ to $600 \mathrm{~mm}$. These tests revealed that, on average, about $45 \%$ of the resolution is lost due to lens defects. The data from DxOMark Image Labs shows that the EOS 6D camera is able to exceed maximum sharpness when paired with the right lens. It should be also taken into account that most digital cameras have internal settings to adjust their capturing properties depending on the intensity of the light received through the lens. In such cases, these settings should be disabled prior to any imaging.

Due to signal variation under different exposure times, the same camera settings should be used for zymograms and calibration standards. For more detailed methodological studies involving the sensitivity of measured enzyme activity to exposure time during photography we refer readers to (Waters, 2009; Guber et al., 2018a; Giles et al., 2018).

\subsubsection{Photography}

To obtain reliable results it is very important to perform zymography under the same conditions, such as temperature and selected incubation time. After/during incubation, the membranes will be placed under ultraviolet (UV) illumination with an excitation wavelength of $355 \mathrm{~nm}$ and an emission wavelength of $460 \mathrm{~nm}$, in a light-proof room or chamber. The UV light can be a single circular lamp, a rectangle or a square consisting of 3 or 4 similar lamps, with a wattage range of $18-22 \mathrm{~W}$. Important is that the sample will receive equal light intensity from all sides (Fig. 1).

The distance between the UV light sources, the camera and the samples (zymograms) should be fixed. This includes not only a fixed distance between zymogram, camera and UV light but also camera position, orientation, angle, image capture time and all camera settings. Any light or reflection will have a direct effect on the images and cause overestimation of color intensity. Zymograms should be corrected for the empty membrane ( $I_{e m}$, zymograms taken without any substrate) and the dark current $\left(I_{d c}\right.$, the signal recorded by the camera when there is no zymogram) according to (Eq. 1):

$$
I_{\text {norm }}=\frac{I-I_{d c}}{I_{e m}-I_{d c}}
$$

where $I_{\text {norm }}$ is the corrected image and $I$ is the original image. Thus, to correct for variations of the light intensity over the image area, background images from the uncoated membrane as well as background images without any membrane are needed (Eq. 1), (Menon et al., 2007). The scaled black flat field similar in all images should be considered as a reference object 
during whole image processing (Fig. S1). In addition, we strongly recommend a background test for each individual soil. This includes incubation of a water- or buffer-saturated membrane on the soil and imaging under UV light. This step is indispensable as many soil organic compounds can diffuse into the membrane, as can elements that can be detected as fluorescence under UV light: humic and a reduced quinone-like compounds (quinone compounds can be reduced by cellular reductases), (Watanabe et al., 2004) as well as some heavy metals can produce interfering signals (Fig. 6).
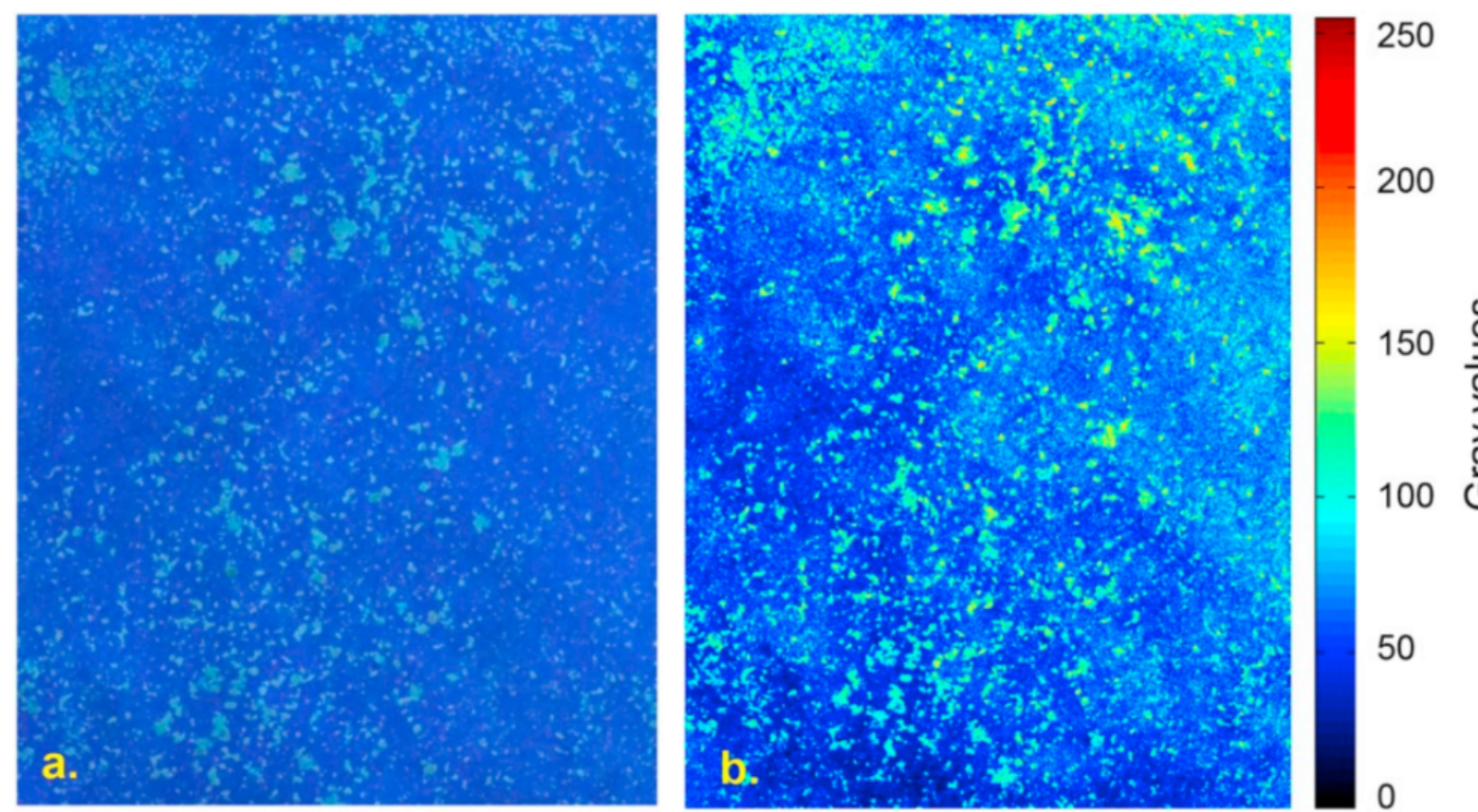

Fig. 6. Detected false signals on membrane saturated by sterile water under UV light. Not a single pixel refers to spot with enzyme activity. (a) Shows the original zymogram in true color and (b) shows the same zymogram after image processing.

\subsection{Image processing, quantification and analysis}

\subsubsection{Calibration line}

The amount of MUF, AMC or any other fluorogenic conjugate on an area basis can be calculated from the concentration and volume of the solution taken up by the membrane and its size. The membranes used for calibration should be imaged under UV light and analyzed in the same way as the samples (e.g. imaging and light conditions, the same incubation time and same camera settings).

There are two general approaches for calibration of soil zymograms. The simplest consists of saturating the membrane filters with standard MUF/AMC solutions and taking photographs of these filters using the same settings as for the zymography (Spohn and 
Kuzyakov, 2013, 2014). The image obtained with zero concentration of the fluorophore is subtracted from the images with known concentrations (background correction). The concentration of MUF/AMC per unit of area can be calculated for each membrane based on the applied concentration and volume of adsorbed solution. A linear regression with zero intercept is fitted to the obtained values of MUF/AMC (Fig. 2b). Normally, the correlation of fluorophore concentration and gray values results in an equation as (Eq. (2)) and is used to calculate enzyme activity per unit of area on zymograms:

$$
y=a x+b
$$

where $\mathrm{y}$ is enzyme activity, $\mathrm{x}$ is the gray value of the zymogram, and $\mathrm{a}$ is the slope of the fitted curve. The disadvantage of this approach lies in the deviation of the calibration curves from linearity due to membrane oversaturation at MUF/AMC content of approximately 12 $\mathrm{mM}$. Using the calibration beyond this concentration is therefore not reliable (Fig. 2, a).

The second approach applies a known volume of the standard MUF/ AMC solution to the membrane surface with continuous imaging. The disadvantage of this approach is the need for many different concentrations and volumes of the standard solutions and a relatively complicated algorithm of pixel-based calibration (Eq. (3)). The algorithm comprises two sections of linear regression:

$$
\left\{\begin{array}{lr}
\bar{M}_{\text {MUF/AMC }}=b_{1} \times \bar{G} ; & 0<\bar{G}<G^{*} \\
\bar{M}_{\text {MUF/AMC }}=a_{2}+b_{2} \times \bar{G} ; & G^{*}<\bar{G} \\
b_{2}=b_{1}-a_{2} / G^{*} &
\end{array}\right.
$$

where $M_{\mathrm{MUF} / \mathrm{AMC}}$ is an average MUF/AMC concentration in the membrane, $a_{2}, b_{1}$ and $b_{2}$ are parameters of the linear regression, $G^{*}$ is the grey value at the breakpoint (Fig. 2. yellow line), and $\bar{G}$ is the grey value averaged across the membrane. The advantage of the second approach is the possibility to extend the calibration curve to larger concentrations of MUF/AMC and overall more accurate calibration due to accounting for non-uniformity in MUF/AMC contents across the membrane (Guber et al., 2018a).

\subsubsection{Image processing}

Processing zymography images includes 5 steps: 1) transformation of signal (fluorescence) from the images to grayscale values, 2) background correction, 3) root segmentation, 4) root skeletonization, and 5) conversion of grayscale values to enzyme activity. 
The intensity of fluorescence is proportional to the activity of the enzyme. To obtain quantitative information, it is possible to process the zymograms using the image processing toolbox in Matlab (MATLAB, The MathWorks). Zymograms first should be transformed to grayscale images $(8,16$ or 32-bit) as matrices and corrected for light variations and camera noise (Eq. (1)) (Soille, 2003; Menon et al., 2007; Zarebanadkouki et al., 2012). Then, the zymograms will be referenced based on the grayscale value received from a reference object embedded in all the zymograms (or scaled black flat field). After referencing the gray values obtained from the zymograms of calibration lines at the concentration of zero can be calculated and then this value will be subtracted from all the zymograms. Note that the same membrane filters should be applied to all of the images, including both zymograms of the samples and the calibration line.

For further analysis, the roots can be easily segmented [cut off from the image by one or more points or lines], due to the strong contrast between the soil and roots. To detect the boundaries of the roots, threshold methods provided by Matlab can be used (Chaudhuri et al., 1989; Hoover et al., 2000). It should be noted that image segmentation is a crucial step in image processing, as it affects all subsequent image analyses (Schlüter et al., 2014). Locally adaptive segmentation methods (e.g. watershed algorithm; Beucher and Lantuejoul, 1979) calculate neighborhood statistics for a class assignment in order to smooth object boundaries, avoid noise objects, or compensate for local intensity changes. Due to the added flexibility, local segmentation methods often result in improved segmentation results (Iassonov et al., 2009; Wang et al., 2011). In addition, roots can be segmented and masked by multiplying the zymogram to the mask obtained from root segmentation using the Root-tracker 2D program (Fig. 7, an example Roottracker image). As the program segments the whole root system, the regions with high enzyme activity can be identified and the noise can be excluded from the analysis (Fig. 7).

To calculate enzyme activity as a function of distance along the root, the roots that are not overlapping and are entirely visible at the soil surface should be selected (Fig. 7). The images are then skeletonized with a thinning algorithm (Lam et al., 1992). The segmented roots, their lengths, and radii can be calculated using the Euclidean distance map function in Matlab (Menon et al., 2007; Moradi et al., 2011). For the processing of images using ImageJ, we refer readers to (Schlüter et al., 2014). 

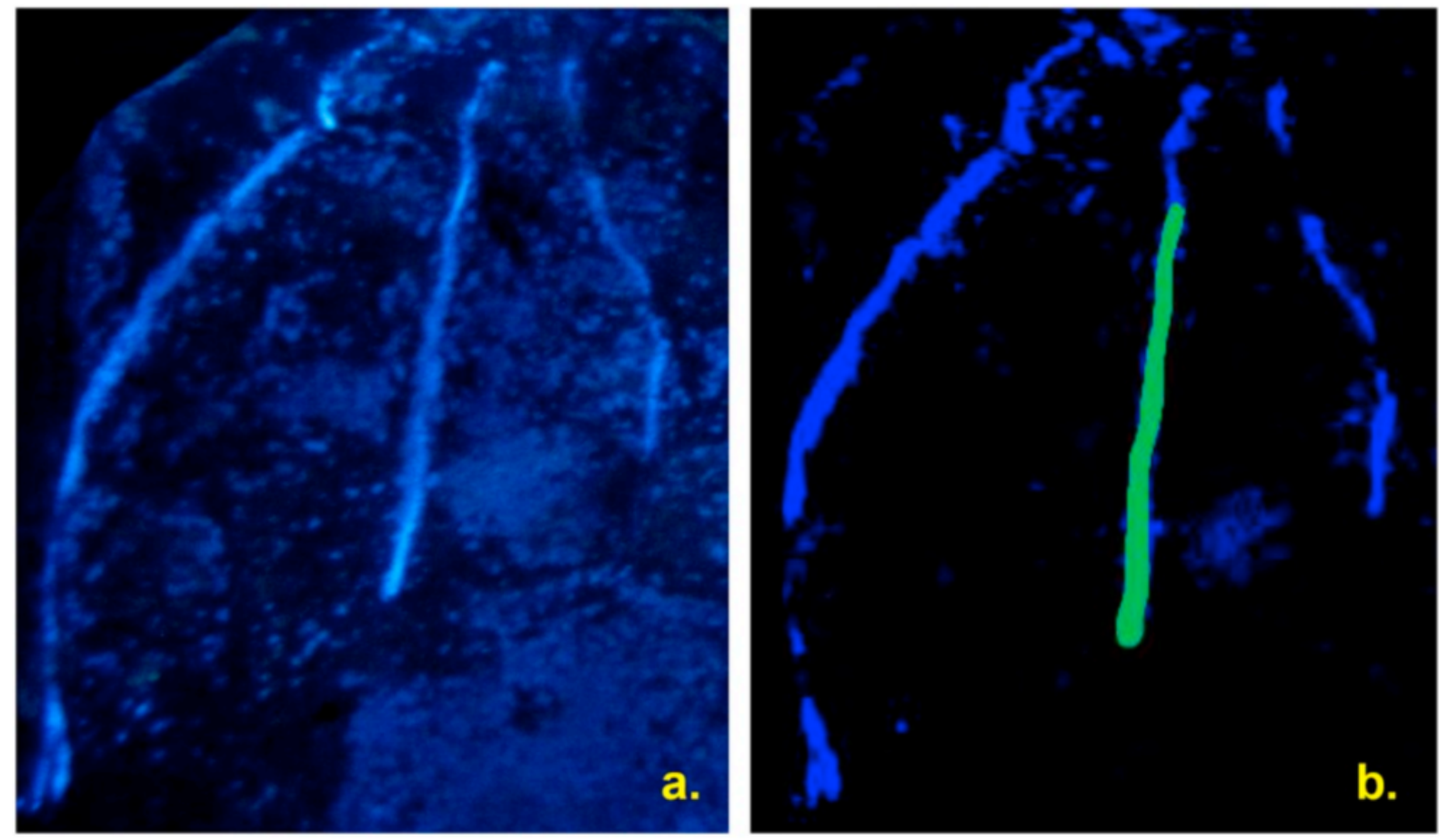

Fig. 7. (a) Example of zymogram (true color), and (b) shows segmented root in green, while blue is root and noise which should be excluded from the analysis (when the whole root is not visible or the contrast between root and background is not sufficient).

\subsection{Identification, quantification and localization of hotspots}

Main relevant biogeochemical processes are take place in the microsites, so called hotspots, (Kuzyakov and Blagodatskaya, 2015). Hotspots were defined as the small soil volumes with high process rates and very intensive interactions between pools and organisms (Kuzyakov and Blagodatskaya, 2015). Hotspots are often defined as a qualitative indicator. Precise definitions vary, with typically the highest $10-30 \%$ of gray values across the entire image considered as hotspots (Hoang et al., 2016; Liu et al., 2017; Ma et al., 2017; Zhang et al., 2019). Thus, hotspot percentage is an arbitrary value. However, it is valid for the comparison of treatments within one study, provided that the same threshold is applied to all analyses. In order to unify the calculation of hotspot percentage we recommend the following approach (Kuzyakov and Razavi, 2019): First, the mean gray value in the bulk soil and the standard deviation (SD) is calculated. This mean value in the bulk soil is taken as a reference $=1.0 \pm \mathrm{SD}$ (Helliwell et al., 2017). Then, moving from the bulk soil to the hotspot, the enzyme activity will increase. The hotspot boundary is accepted as the point at which enzyme activity exceeds +3 SD. The boundary of +3 SD is accepted because $99.7 \%$ of all bulk soil values are located within $\pm 3 \mathrm{SD}$. This approach may provide the most accurate estimation of hotspots according to its original definition (Kuzyakov and Blagodatskaya, 2015). 
In addition to hotspot identification, it is possible to classify different levels of activity (e.g. very low activity, low activity, moderate activity, and hotspots), (Fig. 8). The boundaries of each category can be confirmed by one way analysis of variance (ANOVA). ANOVA can assess the significant differences between independent variables (e.g. mean values of a specific number of adjacent pixels, for example equal to $0.1 \mathrm{~mm}$ ), (Fig. 8a).
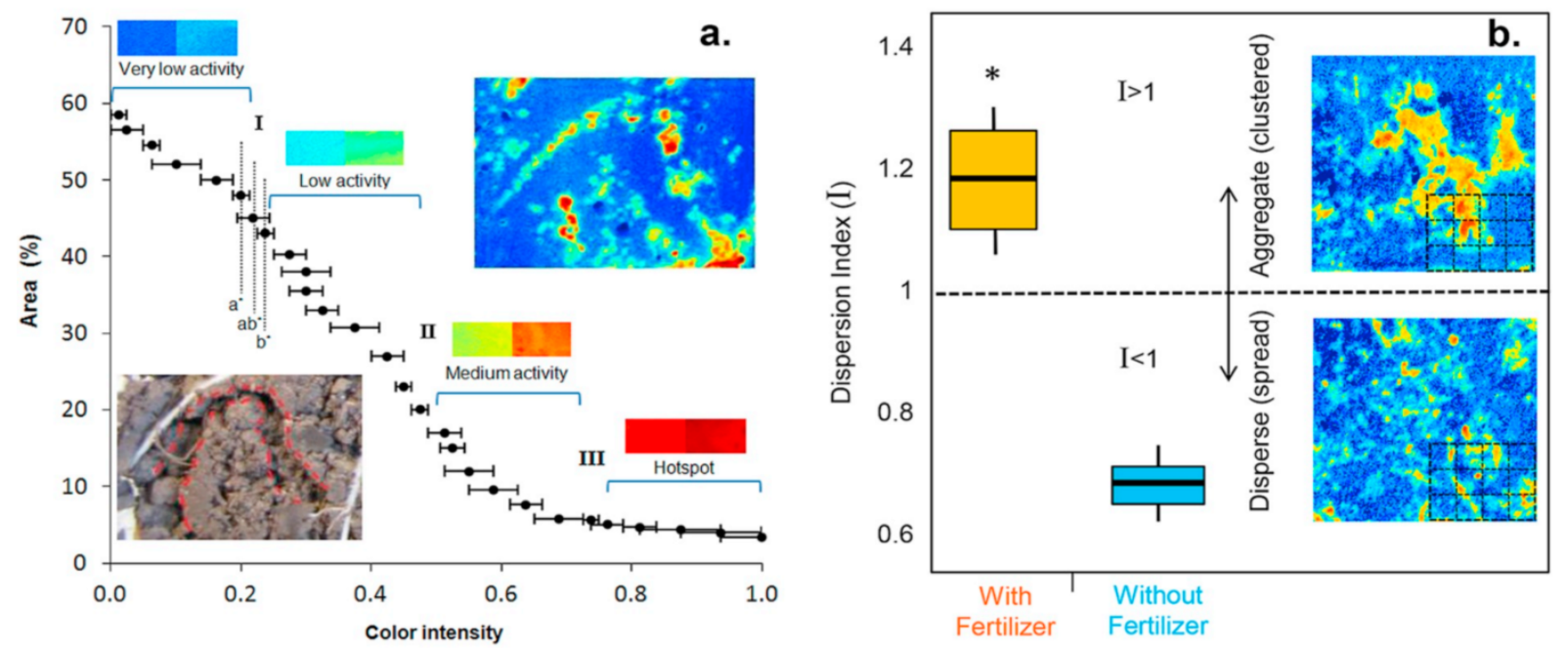

Fig. 8. a) Example of detecting the boundaries of different categories of enzyme activities in the specific gradient (biopores). Percentage of the area of MUF/AMC concentration in the total image is considered as a function of color intensity. Asterisks indicate significant differences between the mean values (modified from Hoang et al., 2016). b) Example of spatial distribution of hotspots in soil treated with and without fertilizer. Long-term $\mathrm{N}$ fertilization leads to formation of aggregate hotspots while no fertilization caused dispersed distribution of hotspots. The dotted quadrates represent symbolic applied quadrat counts method on images.

Besides, spatial pattern analysis quadrat methods (Diggle, 1983; Arnold et al., 1997) and calculation of dispersion index can illustrate whether the distribution of hotspots in space are aggregated or dispersed (Fig. 8b), (Hoang et al., 2016). Spatial point pattern analysis is a statistical method applied to obtain information about the spatial structure of the individual points (hotspots) within a study area (zymogram). There are a number of indices that could be used with the quadrat count method to detect a significant deviation from a Poisson distribution (Fisher et al., 1922). The most common one is dispersion index (I) and is defined as: 


$$
I=\frac{\mathrm{V}}{\overline{\mathrm{X}}}
$$

where $\mathrm{V}$ and $\mathrm{X}$ are the sample variance and the sample mean of the quadrat counts respectively. The method is based on fact that for randomly dispersed points, the variance of the number of points (hotspots) per quadrat is approximately the same as the average number of points per quadrat. Thus, the expected value of the index is I $>1$ for clustered distribution patterns and $\mathrm{I}<1$ for dispersed spatial distributions (Fig. 8b).

Application of spatial point pattern analysis quadrat methods can draw critical conclusions on spatial distribution of hotspots through whole soil profiles with different origins in response to various factors (temperature, time, light intensity, etc.) and promoters (C input, earthworm activities, etc.).

\subsection{Coupling zymography with other approaches}

Soil zymography provides information on the spatial distribution of enzyme activities, an important parameter that cannot be obtained with the classical enzyme assay. Soil zymography can be used to answer broader questions by coupling with classical enzyme assays (Hoang et al., 2016; Ma et al., 2017; Zhang et al., 2019) as well as other imaging approaches such as radioisotope imaging (e.g. ${ }^{14} \mathrm{C},{ }^{33} \mathrm{P},{ }^{35} \mathrm{~S}$ ), (Fig. 9), (Spohn and Kuzyakov, 2013; Hoang et al., 2017), planar optodes (e.g. $\mathrm{O}_{2}, \mathrm{CO}_{2}$, pH), (Fig. 9), FISH (Spohn et al., 2015), neutron radiography, gel-based approaches (e.g. diffusive gradients in thin films (DGT), diffusive equilibration in thin films (DET)), and also with $\mu \mathrm{CT}$ to illuminate spatial distributions of enzyme activities in three dimensions (Kravchenko et al., 2019). The relevance of soil zymography for soil and ecological sciences is highlighted by the observation that microorganisms use secreted or cell-membrane-bound digestive enzymes to degrade polymeric substances (e.g., cellulose, chitin) and rely on diffusion to access the degradation products (Burns, 1982; Sinsabaugh et al., 1991; Sinsabaugh, 1994). The products of enzymatic degradation (e.g., glucose, amino acids, phosphate) are then used by microorganisms for metabolism and growth. Soil zymography coupled with other imaging techniques as well as molecular approaches (e.g., qPCR) enables in situ mapping of all these processes in microsites (hotspots) and hotspheres. 

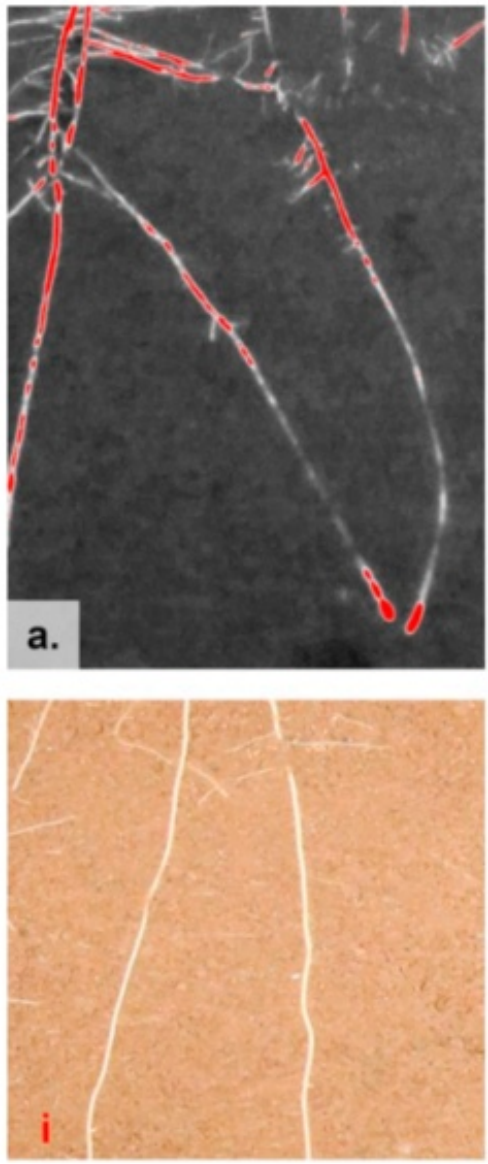
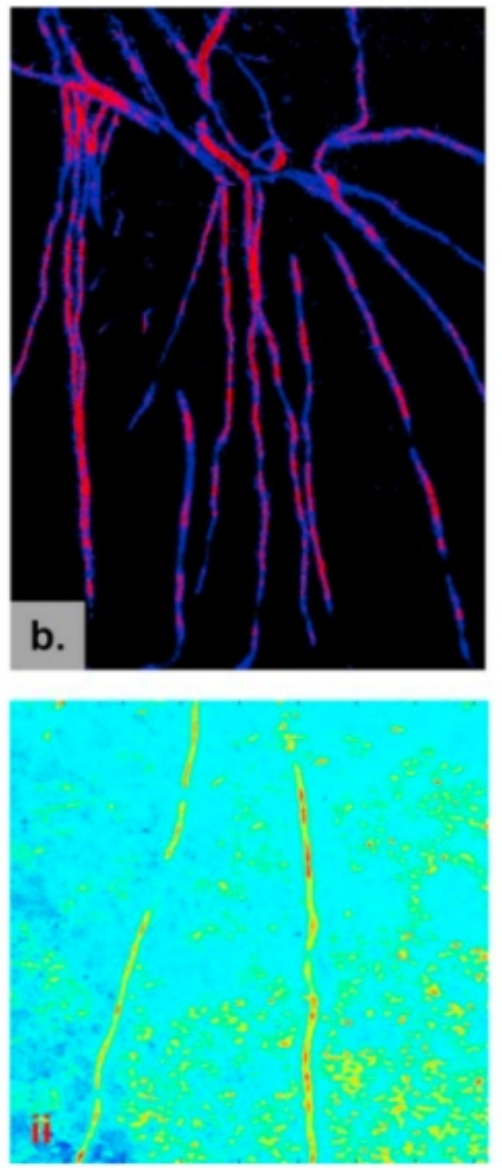
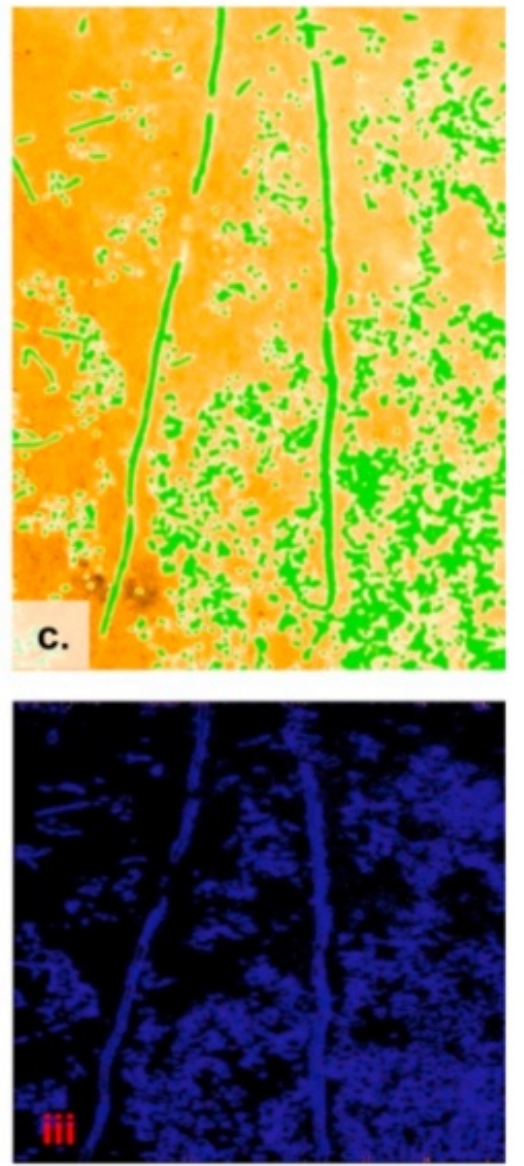

Fig. 9. a: an example of overlapped ${ }^{14} \mathrm{C}$ image and zymography. The red color corresponds to $\beta$-glucosidase activity and white represents ${ }^{14} \mathrm{C}$ release (root exudate). $\mathrm{b}$ : An illustrative example of phosphatase activity (blue) and changes of $\mathrm{pH}$ (red) along the maize root. In (a) and (b) background (soil) is converted to black to improve the visibility. c: an example of three overlapped images: real root, zymogram, and $\mathrm{CO}_{2}$ changes. The green color represents the area where leucine-aminopeptidase activity and $\mathrm{CO}_{2}$ release overlapped. Sub-figures shows: i. roots, ii. leucine-aminopeptidase imprint, and iii. $\mathrm{CO}_{2}$ release. There are areas where microbial respiration is visible while imprint of enzyme activity is not detectable (or the activity is low).

\subsection{Summary and moving forward}

Clearly, there are many challenges associated with the visualization of enzyme activities in soil and litter. Therefore, we summarized potential abiotic and biotic factors which may distort results (Table 2). In addition, we would like to conclude with a set of recommendations to improve soil zymography quality and facilitate the sharing of optimization procedures across laboratories: 
1) By incubation of water/buffer-saturated membrane on the soil and its photography under UV light (a background test of the soil) prior to any soil zymography, ensure that you are detecting enzyme activity not any other fluorescent compounds.

2) Identify the four possible positions for root growth in the rhizobox or in field rhizotrons and confirm that the roots are in the soil and not on top of the soil, prior to soil zymography.

3) Perform soil zymography under the initial environmental conditions of samples (e.g. keep exactly the same growth temperature, light intensity, water content, etc., while incubating the membrane).

4) Find the balance between saturating substrate concentrations of your soil and substrate concentration for soil zymography.

5) Examine whether attachment during the incubation is appropriate to properly map enzyme activity, and run laser scanning for soil surface topography in advance.

6) Run proper calibration standards to ensure that enzyme activity values are properly calculated.

7) Ensure that camera settings and photography conditions are the same for all samples as well as the measurement of calibration line.

8) Ensure that images are properly analyzed.

Table 2 Summary of abiotic and biotic factors which may distort results.

\begin{tabular}{lll}
\hline & Factor & Potential effect on result interpretation \\
\hline Abiotic & High/Low water content & High/Low enzyme activity \\
& Extra load on membrane & High enzyme activity \\
& Photography exposure time & High/low enzyme activity \\
& Not uniform topography & Disperse hotspot distribution \\
& Root position at soil surface & Localized hotspots around the root \\
& Inappropriate attachment & Aggregate hotspots distribution \\
& Incubation time & Expansion of rhizosphere or hotspots \\
& High/low temperature & High/low overall enzyme activity \\
& High substrate concentration & Outlier enzyme activity \\
Alkalization & High overall activity for MUF substrates; Low overall activity AMC substrates \\
& Pathogen infection & Expansion of rhizosphere; High total hotspots\% \\
& Fungus contamination & High total hotspots\% \\
& Algae contamination & High overall enzyme activity; High total hotspots\%
\end{tabular}

${ }^{*}$ Note that the effect of factors is called misinterpretation when they would differ between the initial and incubation conditions or vary between replicates or calibration membranes and zymograms.

If all of these steps are followed, then researchers can be more certain that their images are indeed reflective of the spatial distribution of enzymatic activity in their samples. 
Although great efforts have been made toward developing, quantifying and adapting soil zymography, we still have a long way to go. Standardized, user-friendly and correctly interpretable soil zymography tools for non-experts need to be developed and commercialized. The combination of mass spectrometry techniques and soil zymography will ultimately allow the exact trimming pattern of individual substrates by the enzyme (especially proteases) to be determined in situ and in vivo. Considering how the abiotic environment of the rhizosphere is controlled through a system of feedback loops between roots, microbes, and soil chemistry, in which the dynamics of the microbial community, root exudates, nutrient and elements, enzymes, $\mathrm{O}_{2}, \mathrm{pH}$, and $\mathrm{CO}_{2}$ play an essential role, it is clear that coupling soil zymography with other novel approaches will be beneficial. Soil zymography can be used as a mapping tool for localization of microbial hotspots and be coupled further with molecular and microbial analysis to identify the microbial community, or microbial growth and efficiency.

Scaling down the soil zymography on a micro-resolution scale or combining soil zymography and other approaches with different scales (for instance nanoSIM) is another untouched side of science that remains as the dark side of the moon to be discovered.

All of these steps will encourage better collaboration among researchers investigating the links between enzyme activities and decomposition. Furthermore, properly estimated enzyme activities may have even more meaning when used in conjunction with functional gene analysis, or emerging proteomic and genomic tools that are expanding our ability to understand microbial decomposers and the significant roles they play in ecosystems (Nannipieri, 2006; Wallenstein and Weintraub, 2008).

\section{Conflict of interest}

No conflict of interest.

\section{Acknowledgment}

BR thanks Prof. Xingliang $\mathrm{Xu}$ for the invitation to write this review. We gratefully acknowledge the German Research Foundation (DFG) for supporting the project: RA3062/3-1 within priority program 2089 and the highlighted importance of imaging approaches to overcome current knowledge gaps between soil, microbiome, and plant scientists. We would like to thank Prof. Yakov Kuzyakov for his valuable comments on the primarily version of the manuscript and Kyle Mason-Jones for the improvement of language and writing style. AG was supported by the National Science Foundation's Long-Term Ecological Research Program (DEB 1027253), by the National Science 
Foundation's Geobiology and Low-Temperature Geochemistry Program (Award no 1630399), by the Department of Energy Great Lakes Bioenergy Research Center (DOE O_ce of Science BER DE-FC02-07ER64494).

\section{References}

Ahmadi, K., Razavi, B.S., Maharjan, M., Kuzyakov, Y., Kostka, S.J., Carminati, A., Zarebanadkouki, M., 2018. Effects of rhizosphere wettability on microbial biomass, enzyme activities and localization. Rhizosphere 7, 35-42.

Allison, S.D., Weintraub, M.N., Gartner, T.B., Waldrop, M.P., 2011. Evolutionary economic principles as regulators of soil enzyme production and ecosystem function. Soil Enzymol. 229-243.

Arnold, S.E., Ruscheinsky, D.D., Han, L.Y., 1997. Further evidence of abnormal cytoarchitecture of the entorhinal cortex in schizophrenia using spatial point pattern analyses. Biol. Psychiatry 42, 639-647.

Baldrian, P., Větrovský, T., 2012. Scaling down the analysis of environmental processes: Monitoring enzyme activity in natural substrates on a millimeter resolution scale. Appl. Environ. Microbiol. https://doi.org/10.1128/AEM.07953-11.

Beucher, S., Lantuejoul, C., 1979. Use of watersheds. In: Contour Detection. International Workshop on Image Processing (Real-Time Edge and Motion Detection/Estimation), Rennes, France. Burns, R.G., 1978. Enzyme activity in soil: Some theoretical and practical considerations. In: Burns, R.G. (Ed.), Soil Enzymes. Academic Press, London, pp. 295-340.

Burns, R.G., 1982. Enzyme activity in soil: Location and a possible role in microbial ecology. Soil Biol. Biochem. 14, 423-427.

Burns, R.G., Deforest, J.L., Marxsen, J., Sinsabaugh, R.L., Stromberger, M.E., Wallenstein, M.D., Weintraub, M.N., Zoppini, A., 2013. Soil enzymes in a changing environment: Current knowledge and future directions. Soil Biol. Biochem. 58, 216-234.

Chaudhuri, S., Chatterjee, S., Katz, N., Nelson, N., Goldbaum, M., 1989. Detection of blood vessels in retinal images using two dimensional matched filters. IEEE Trans. Med. Imaging $8,263-269$.

Choi, N.S., Kim, B.H., Park, C.S., Han, Y.J., Lee, H.W., Choi, J.H., Lee, S.G., Song, J.J., 2009. Multiple-layer substrate zymography for detection of several enzymes in a single sodium dodecyl sulfate gel. Anal. Chem. 386, 121-122.

Dahlqvist, A., 1968. Assay of intestinal disaccharidases. Anal. Biochem. 22, 99-107.

Diggle, P.J., 1983. Statistical Analysis of Spatial Point Patterns. Academic Press, London.

Dong, S., Brooks, D., Jones, M.D., Grayston, S.J., 2007. A method for linking in situ activities of hydrolytic enzymes to associated organisms in forest soils. Soil Biol. Biochem. 39, 2414 2419. 
Duan, C., Fang, L., Yang, C., Chen, W., Cui, Y., Li, S., 2018. Reveal the response of enzyme activities to heavy metals through in situ zymography. Ecotoxicol. Environ. Saf. 156, 106115.

Essington, M.E., Nelson, J.B., Holden, W.L., 2005. Gibbsite and goethite solubility: The influence of 2-ketogluconate and citrate. Soil Sci. Soc. Am. J. 69, 996-1008.

Fisher, R.A., Thornton, H.G., Mackenzie, W.A., 1922. The accuracy of the plating method of estimating the density of bacterial populations, with particular reference to the use of Thornton's agar medium with soil samples. Ann. Appl. Biol. 9, 325-359.

Ge, T.D., Wei, X.M., Razavi, B.S., Zhu, Z.K., Hu, Y.J., Kuzyakov, Y., Jones, D.L., Wu, J.S., 2017. Stability and dynamics of enzyme activity patterns in the rice rhizosphere: Effects of plant growth and temperature. Soil Biol. Biochem. 113, 108-115.

German, D.P., Weintraub, M.N., Grandy, A.S., Lauber, C.L., Rinkes, Z.L., Allison, S.D., 2011. Optimization of hydrolytic and oxidative enzyme methods for ecosystem studies. Soil Biol. Biochem. 43, 1387-1397.

Giles, C.D., Dupuy, L., Boitt, G., Brown, L.K., Condron, L.M., Darch, T., Blackwell, M.S.A., Menezes-Blackburn, D., Shand, C.A., Stutter, M.I., Lumsdon, D.G., Wendler, R., Cooper, P., Wearing, C., Zhang, H., Haygarth, P.M., George, T.S., 2018. Root development impacts on the distribution of phosphatase activity: Improvements in quantification using soil zymography. Soil Biol. Biochem. 116, 158-166.

Gross, J., Lapiere, C.M., 1962. Proc. Natl. Acad. Sci. U. S. A 48, 1014.

Guber, A.K., Kravchenko, A.N., Razavi, B.S., Blagodatskaya, E., Kuzyakov, Y., 2018a. Calibration of 2-D soil zymography for correct analysis of enzyme distribution: Calibration of 2-D soil zymography. Eur. J. Soil Sci. https://doi.org/10.1111/ejss. 12744.

Guber, A., Kravchenko, A., Razavi, B.S., Uteau, D., Peth, S., Blagodatskaya, E., Kuzyakov, Y., 2018b. Quantitative soil zymography: Mechanisms, processes of substrate and enzyme diffusion in porous media. Soil Biol. Biochem. 127, 156-167.

Guhr, A., Borken, W., Spohn, M., Matzner, E., 2015. Redistribution of soil water by a saprotrophic fungus enhances carbon mineralization. Proc. Natl. Acad. Sci. Unit. States Am. $112,14647-14651$.

Heitkötter, J., Marschner, B., 2018. Soil zymography as a powerful tool for exploring hotspots and substrate limitation in undisturbed subsoil. Soil Biol. Biochem. 124, 210-217.

Helliwell, J.R., Sturrock, C.J., Mairhofer, S., Craigon, J., Ashton, R.W., Miller, A.J., Whalley, W.R., Mooney, S.J., 2017. The emergent rhizosphere: Imaging the development of the porous architecture at the root-soil interface. Sci. Rep. 7 14875, 1-10.

Hoang, D.T.T., Pausch, J., Razavi, B.S., Kuzyakova, I., Banfield, C.C., Kuzyakov, Y., 2016. Hotspots of microbial activity induced by earthworm burrows, old root channels, and their combination in subsoil. Biol. Fertil. Soils 52, 1105-1119. 
Hoang, D.T.T., Razavi, B.S., Kuzyakov, Y., 2017. Revealing hidden effect of earthworm on C distribution and enzyme activity. Geophys. Res. Abstr. 19 EGU2017-EGU13182-1.

Hoover, A., Kouznetsova, V., Goldbaum, M., 2000. Locating blood vessels in retinal images by piecewise threshold probing of a matched filter response. IEEE Trans. Med. Imaging 19, 203-210.

Hughes, A.J., Herr, A.E., 2010. Quantitative enzyme activity determination with zeptomole sensitivity by microfluidic gradient-gel zymography. Anal. Chem. 82, 3803-3811.

Iassonov, P., Gebrenegus, T., Tuller, M., 2009. Segmentation of X-ray computed tomography images of porous materials: A crucial step for characterization and quantitative analysis of pore structures. Water Resour. Res. 45. https://doi.org/10.1029/2009WR008087.

Kleiner, D.E., Stetlerstevenson, W.G., 1994. Quantitative zymography: Detection of picogram quantities of gelatinases. Anal. Biochem. 218, 325-329.

Kravchenko, A.N., Guber, A.K., Razavi, B.S., Koestel, J., Blagodatskaya, E.V., Dippold, M., Kuzyakov, Y., 2019. Spatial patterns of extracellular enzymes: combining X-ray computed micro-tomography and 2D zymography. Soil Biol. Biochem.

Kravchenko, A.N., Negassa, W.C., Guber, A.K., Rivers, M.L., 2015. Protection of soil carbon within macro-aggregates depends on intra-aggregate pore characteristics. Sci. Rep. 5.

Kurzbaum, E., Kirzhner, F., Armon, R., 2010. A simple method for dehydrogenase activity visualization of intact plant roots grown in soilless culture using tetrazolium violet. Plant Root 4, 12-16.

Kuzyakov, Y., Blagodatskaya, E., 2015. Microbial hotspots and hot moments in soil: Concept and review. Soil Biol. Biochem. 83, 184-199.

Kuzyakov, Y., Razavi, B.S., 2019. Rhizosphere size and shape: Temporal dynamics and spatial stationarity. Soil Biol. Biochem. https://doi.org/10.1016/j.soilbio.2019.05. 011.

Lam, L., Lee, S.-W., Suen, C.Y., 1992. Thinning methodologies-A comprehensive survey. IEEE Trans. Pattern Anal. Mach. Intell. 14, 855-869.

Liu, S., Razavi, B.S., Su, X., Maharjan, M., Zarebanadkouki, M., Blagodatskaya, E., Kuzyakov, Y., 2017. Spatio-temporal patterns of enzyme activities after manure application reflect mechanisms of niche differentiation between plants and microorganisms. Soil Biol. Biochem. $112,100-109$.

Ma, X., Razavi, B.S., Holz, M., Blagodatskaya, E., Kuzyakov, Y., 2017. Warming increases hotspot areas of enzyme activity and shortens the duration of hot moments in the rootdetritusphere. Soil Biol. Biochem. 107, 226-233.

Ma, X., Zarebanadkouki, M., Kuzyakov, Y., Blagodatskaya, E., Pausch, J., Razavi, B.S., 2018. Spatial patterns of enzyme activities in the rhizosphere: Effects of root hairs and root radius. Soil Biol. Biochem. 118, 69-78. 
Manzoni, S., Schimel, J.P., Porporato, A., 2012. Responses of soil microbial communities to water stress: results from a meta-analysis. Ecology 93, 930-938.

Marx, M.-C., Wood, M., Jarvis, S.C., 2001. A microplate fluorimetric assay for the study of enzyme diversity in soils. Soil Biol. Biochem. 33, 1633-1640.

Mead, J.A.R., Smith, J.N., Williams, R.T., 1955. Studies in detoxification. 67. Biosynthesis of the glucuronides of umbelliferone and 4-methylumbelliferone and their use in fluorimetric determination of b-glucuronidase. Biochem. J. 61, 569-574.

Menon, M., Robinson, B., Oswald, S.E., Kaestner, A., Abbaspour, K.C., Lehmann, E., Schulin, R., 2007. Visualization of root growth in heterogeneously contaminated soil using neutron radiography. Eur. J. Soil Sci. 58, 802-810

Michaelis, L., Menten, M.L., 1913. Biorhem 2 (49), 333-369.

Moradi, A.B., Carminati, A., Vetterlein, D., Vontobel, P., Lehmann, E., Weller, U., Hopmans, J.W., Vogel, H.J., Oswald, S.E., 2011. Three-dimensional visualization and quantification of water content in the rhizosphere. New Phytol. 192, 653-663.

Nannipieri, P., 2006. Role of stabilised enzymes in microbial ecology and enzyme extraction from soil with potential applications in soil proteomics. In: Nannipieri, P., Smalla, K. (Eds.), Nucleic Acids and Proteins in Soil. Springer, Berlin, pp. 75-94.

Nemori, R., Tachikawa, T.A., 1999. Review of in situ zymography: Method for localization of protease activities in a tissue. Tissue Cult Eng 25, 29-32.

Ogston, A.G., 1962. Molecular Weights of Enzymes. Nature 196, 171-172.

Or, D., Phutane, S., Dechesne, A., Ection, S.P.S., 2007. Extracellular polymeric substances affecting pore-scale hydrologic conditions for bacterial activity in unsaturated soils. Vadose Zone 6.

Pan, D., Hill, A.P., Kashou, A., Wilson, K.A., Tan-Wilson, A., 2011. Electrophoretic transfer protein zymography. Anal. Chem. 411, 277-283.

Razavi, B.S., Zarebanadkouki, M., Blagodatskaya, E., Kuzyakov, Y., 2016. Rhizosphere shape of lentil and maize: Spatial distribution of enzyme activities. Soil Biol. Biochem. 96, 229237.

Razavi, B.S., Hoang, D.T.T., Blagodatskaya, E., Kuzyakov, Y., 2017a. Mapping the footprint of nematodes in the rhizosphere: Cluster root formation and spatial distribution of enzyme activities. Soil Biol. Biochem. 115, 213-220.

Razavi, B.S., Hoang, D., Kuzyakov, Y., 2017b. Visualization of enzyme activities in earthworm biopores by in situ soil zymography. In: Wilkesman, J., Kurz, L. (Eds.), Zymography Methods and Protocols. Humana Press, New York, NY, USA, pp. 229-238.

Saiya-Cork, K.R., Sinsabaugh, R.L., Zak, D.R., 2002. The effects of long term nitrogen deposition on extracellular enzyme activity in an Acer saccharum forest soil. Soil Biol. Biochem. 34, 1309-1315. 
Sanaullah, M., Razavi, B.S., Blagodatskaya, E., Kuzyakov, Y., 2016. Spatial distribution and catalytic mechanisms of b-glucosidase activity at the root-soil interface. Biol. Fertil. Soils $52,505-514$.

Schlüter, S., Sheppard, A., Brown, K., Wildenschild, D., 2014. Image processing of multiphase images obtained via X-ray microtomography: A review. Water Resour. Res. 50, 3615-3639.

Sinsabaugh, R.L., 1994. Enzymatic analysis of microbial pattern and process. Biol. Fertil. Soils $17,69-74$.

Sinsabaugh, R.L., 2010. Phenol oxidase, peroxidase and organic matter dynamics of soil. Soil Biol. Biochem. 42, 391-404.

Sinsabaugh, R.L., Antibus, R.K., Linkins, A.E., 1991. An enzymic approach to the analysis of microbial activity during plant litter decomposition. Agric. Ecosyst. Environ. 34, 43-54.

Soille, P., 2003. Morphological Image Analysis: Principles and Applications, 2nd ed. SpringerVerlag, Berlin, Germany, pp. 391.

Spohn, M., Kuzyakov, Y., 2013. Distribution of microbial-and root-derived phosphatase activities in the rhizosphere depending on $\mathrm{P}$ availability and $\mathrm{C}$ allocation-Coupling soil zymography with $14 \mathrm{C}$ imaging. Soil Biol. Biochem. 67, 106-113.

Spohn, M., Kuzyakov, Y., 2014. Spatial and temporal dynamics of hotspots of enzyme activity as affected by living and dead roots - a soil zymography analysis. Plant Soil 79, 67-77.

Spohn, M., Carminati, A., Kuzyakov, Y., 2013. Soil zymography a novel in situ method for mapping distribution of enzyme activity in soil. Soil Biol. Biochem. 58, 275-280.

Spohn, M., Treichel, N.S., Cormann, M., Schloter, M., Fischer, D., 2015. Distribution of phosphatase activity and various bacterial phyla in the rhizosphere of Hordeum vulgare L. depending on P availability. Soil Biol. Biochem. 89, 44-51.

Steponkus, P.L., Lanphear, F.O., 1967. Refinement of the triphenyl tetrazolium chloride method of determining cold injury. Plant Physiol. 42, 1423-1426.

Tabatabai, M., 1994. Soil enzymes. In: Weaver, R.W., Angle, S., Bottomley, P. (Eds.), Methods of Soil Analysis Part 2: Microbiological and Biochemical Properties. Soil Science Society of America, Madison, pp. 775-833.

Tabatabai, M., Dick, W., 2002. Enzymes in soil: Research and developments in measuring activities. In: Burns, R.G., Dick, R.P. (Eds.), Enzymes in the Environment. Activity, Ecology and Applications. Marcel Dekker, NewYork, pp. 567-596.

Turner, B.L., 2010. Variation in pH optima of hydrolytic enzyme activities in tropical rain forest soils. Appl. Environ. Microbiol. 76, 6485-6493.

Uteau, D., Pagenkemper, S.K., Peth, S., Horn, R., 2013. Aggregate and soil clod volume measurement: A method comparison. Soil Sci. Soc. Am. J. 77, 60-63.

Vandooren, J., Geurts, N., Martens, E., Van den Steen, P.E., Opdenakker, G., 2013. Zymography methods for visualizing hydrolytic enzymes. Nat. Methods 10, 211-220.

Voothuluru, P., Braun, D.M., Boyer, J.S., 2018. An in vivo imaging assay detects spatial variability in glucose release from plant roots. Plant Physiol. 78, 1002-1010. 
Wallenstein, M.D., Weintraub, M.N., 2008. Emerging tools for measuring and modeling the in situ activity of soil extracellular enzymes. Soil Biol. Biochem. 40, 2098-2106.

Wang, L., Shi, F., Lin, W., Gilmore, J.H., Shen, D., 2011. Automatic segmentation of neonatal images using convex optimization and coupled level sets. Neuroimage 58, 805-817.

Watanabe, N., Dickinson, D.A., Liu, R.M., Forman, H.J., 2004. Quinones and glutathione metabolism. Methods Enzymol. 378, 319-340.

Waters, J.C., 2009. Accuracy and precision in quantitative fluorescence microscopy. J. Cell Biol. $185,1135-1148$.

Wei, X., Ge, T., Zhu, Z., Hu, Y., Liu, S., Li, Y., Wu, J., Razavi, B.S., 2018. Expansion of rice enzymatic rhizosphere: Temporal dynamics in response to phosphorus and cellulose application. Plant Soil. https://doi.org/10.1007/s11104-018-03902-0.

Wei, X., Razavi, B.S., Yajun Hu, Y., Shen, J., Wu, J., Ge, T., 2019. C/P stoichiometry of dying rice root defines the spatial distribution and dynamics of enzyme activities in root-detritusphere. Biol. Fertil. Soils 55, 251-263.

Wilkesman, J., Kurz, L., 2009. Protease analysis by zymography: A review on techniques and patents. Recent Pat. Biotechnol. 2009, 175-184.

Wright, S.T.C., 1962. An observation suggesting that the molecular weights of enzymes can be arranged in three geometric series. Nature 193, 334-337.

Zarebanadkouki, M., Kim, Y.X., Moradi, A.B., Vogel, H.-J., Kaestner, A., Carminati, A., 2012. Quantification and modeling of local root water uptake using neutron radiography and deuterated water. Vadose Zone J. https://doi.org/10.2136/vzj2011. 0196.

Zhang, X., Dippold, M.A., Kuzyakov, Y., Razavi, B.S., 2019. Spatial pattern of enzyme activities depends on root exudate composition. Soil Biol. Biochem. 133, 83-93. 


\section{Supplementary}
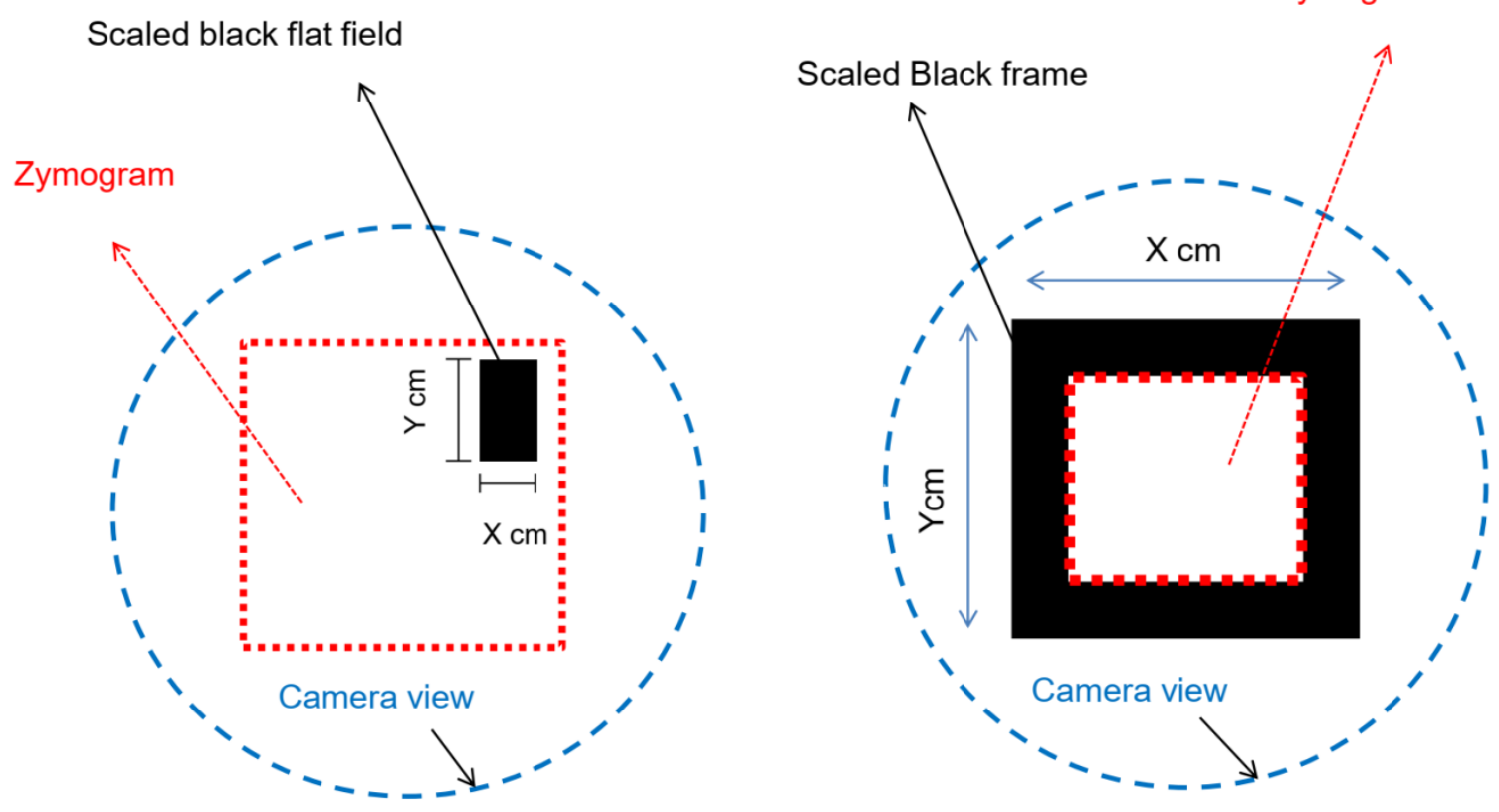


\title{
III Other studies
}

\section{Study 8: Croplands conversion to cash crops in dry regions: consequences of nitrogen losses and decreasing nitrogen use efficiency for food chain system}

Xuechen Zhang ${ }^{1,3,4}$, Bahar S. Razavi ${ }^{4}$, Jiaxin Liu ${ }^{1}$, Gui Wang ${ }^{1}$, Xucheng Zhang ${ }^{2}$, Ziyan Li $^{1,2^{*}}$, Bingnian Zhai ${ }^{1}$, Zhaohui Wang ${ }^{1}$, Kazem Zamanian ${ }^{3,5}$

\section{Status: Published in Land Degradation \& Development}

${ }^{I}$ College of Resources and Environment, Northwest A\&F University, Yangling, 712100, China

${ }^{2}$ Key Laboratory of High Water Utilization on Dryland of Gansu Province, Lanzhou, 730070, China

${ }^{3}$ Department of Biogeochemistry of Agroecosystems, University of Göttingen,

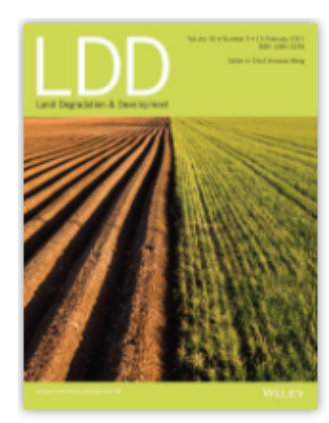
Göttingen, 37077, Germany

${ }^{4}$ Department of Soil and Plant Microbiome, University of Kiel, Kiel, Germany

${ }^{5}$ Soil Science of Temperate Ecosystems, University of Göttingen, 37077, Göttingen, Germany

\begin{abstract}
Understanding the effects of land-use change in drylands on nutrient use efficiencies and losses within food production-consumption system provides insights on nutrient management strategies and the effectiveness of land-use policies. Weibei dryland is considered as an example to use to evaluate changes in nitrogen $(\mathrm{N})$ flows through the food chain following conversion of croplands to apple orchards using the Nutrient flows in Food chains, Environment and Resources use (NUFER) model, and we also modeled the effects of $20 \%$ reduction in $\mathrm{N}$ fertilizers on apple yields to obtain a balanced fertilization strategy. The apple orchards area increased from $9.6 \times 10^{4}$ ha in 1978 to $72 \times 10^{4}$ ha in 2013 , while the area under cereals decreased from $186 \times 10^{4}$ ha in 1978 to $152 \times 10^{4}$ ha in 2013 . The increased income due to apple orchards led on-one-hand to more $\mathrm{N}$ fertilization to get a higher apple yield, and on-the-other-hand promoted the consumption of animal foods. Consequently, nitrogen use efficiency of crop production (NUEc) and the combination of crop and animal production (NUEc+a) decreased, but nitrogen use efficiency of animal production (NUEa) and N losses increased between 1978 and 2013. The modeled scenario of $20 \%$ reduction in $\mathrm{N}$ fertilization amounts will still keep optimum apple yield but will significantly decrease $\mathrm{N}$ losses from the apple orchards. We therefore, suggest that the key measures for improving nitrogen use efficiency and decreasing $\mathrm{N}$ losses after conversion to cash crops are: (a) reducing $\mathrm{N}$ fertilization as well as balancing various inorganic fertilizers; and (b) implying organic fertilizers.
\end{abstract}

Keywords: Apple orchards, fertilization management, land use change, nitrogen flow, nitrogen losses *Corresponding author: liziyan0161@,126.com 


\title{
Study 9: Plant flavones enrich rhizosphere Oxalobacteraceae to improve maize performance under nitrogen deprivation
}

Peng Yu $\mathrm{u}^{1,2,3,17}$, Xiaoming $\mathrm{He}^{1,2,3,17}$, Marcel Baer ${ }^{2}$, Stien Beirinckx ${ }^{4,5,6}$, Tian Tian ${ }^{7}$, Yudelsy A. T. Moya ${ }^{8}$, Xuechen Zhang ${ }^{9}$, Marion Deichmann ${ }^{10}$, Felix P. Frey ${ }^{2}$, Verena Bresgen ${ }^{2,3}$, Chunjian $\mathrm{Li}^{11}$, Bahar S. Razavi ${ }^{12}$, Gabriel Schaaf ${ }^{10}$, Nicolaus von Wirén ${ }^{8}$, Zhen $\mathrm{Su}^{7}$, Marcel Bucher $^{13,14}$, Kenichi Tsuda ${ }^{15,16}$, Sofie Goormachtig ${ }^{4,6}$, Xinping Chen ${ }^{1}$ and Frank Hochholdinger ${ }^{1,2}$

\section{Status: Published in Nature Plants}

${ }^{I}$ College of Resources and Environment, and Academy of Agricultural Sciences, Southwest University, Chongqing, China.

${ }^{2}$ Crop Functional Genomics, Institute of Crop Science and Resource Conservation, University of Bonn, Bonn, Germany.

${ }^{3}$ Emmy Noether Group Root Functional Biology, Institute of Crop Science and Resource Conservation, University of Bonn, Bonn, Germany.

${ }^{4}$ Department of Plant Biotechnology and Bioinformatics, Ghent University, Ghent, Belgium.

${ }^{5}$ Plant Sciences Unit, Flanders Research Institute for Agriculture Fisheries and Food, Merelbeke, Belgium.

${ }^{6}$ Center for Plant Systems Biology, VIB, Ghent, Belgium.

${ }^{7}$ State Key Laboratory of Plant Physiology and Biochemistry, College of Biological Sciences, China Agricultural University, Beijing, China.

${ }^{8}$ Molecular Plant Nutrition, Leibniz Institute of Plant Genetics and Crop Plant Research, Gatersleben, Germany.

${ }^{9}$ Department of Biogeochemistry of Agroecosystems, University of Göttingen, Göttingen, Germany.

${ }^{10}$ Plant Nutrition, Institute of Crop Science and Resource Conservation, University of Bonn, Bonn, Germany.

${ }^{11}$ Department of Plant Nutrition, College of Resources and Environmental Science, China Agricultural University, Beijing, China.

${ }^{12}$ Department of Soil and Plant Microbiome, Institute of Phytopathology, Christian-Albrecht University of Kiel, Kiel, Germany.

${ }^{13}$ Botanical Institute, Cologne Biocenter, University of Cologne, Cologne, Germany.

${ }^{14}$ Cluster of Excellence on Plant Sciences, University of Cologne, Cologne, Germany.

${ }^{15}$ State Key Laboratory of Agricultural Microbiology, College of Plant Science and Technology, Huazhong Agricultural University, Wuhan, China.

${ }^{16}$ Department of Plant Microbe Interactions, Max Planck Institute for Plant Breeding Research, Cologne, Germany.

\begin{abstract}
Beneficial interactions between plant roots and rhizosphere microorganisms are pivotal for plant fitness. Nevertheless, the molecular mechanisms controlling the feedback between root architecture and microbial community structure remain elusive in maize. Here, we demonstrate that transcriptomic gradients along the longitudinal root axis associate with specific shifts in rhizosphere microbial diversity. Moreover, we have established that rootderived flavones predominantly promote the enrichment of bacteria of the taxa Oxalobacteraceae in the rhizosphere, which in turn promote maize growth and nitrogen acquisition. Genetic experiments demonstrate that LRT1-mediated lateral root development coordinates the interactions of the root system with flavone-dependent Oxalobacteraceae
\end{abstract}


under nitrogen deprivation. In summary, these experiments reveal the genetic basis of the reciprocal interactions between root architecture and the composition and diversity of specific microbial taxa in the rhizosphere resulting in improved plant performance. These findings may open new avenues towards the breeding of high-yielding and nutrient-efficient crops by exploiting their interaction with beneficial soil microorganisms.

${ }^{17}$ These authors contributed equally: Peng Yu, Xiaoming He.

*Corresponding author: chenxp2017@swu.edu.cn; hochholdinger@uni-bonn.de 


\title{
Study 10: Root hairs and protein addition to soil promote leucine aminopeptidase activity of Hordeum vulgare $L$
}

Lucy M.Greenfield $^{\mathrm{a}}$, Bahar S.Razavi ${ }^{\mathrm{b}}$, Nataliya Bilyera ${ }^{\mathrm{b}, \mathrm{c}}$, Xuechen Zhang ${ }^{\mathrm{d}}$, Davey L.Jones ${ }^{\mathrm{a}, \mathrm{e}}$

\section{Status: Published in Rhizosphere}

${ }^{a}$ School of Natural Sciences, Bangor University, Gwynedd, LL57 2UW, UK

${ }^{b}$ Department of Soil and Plant Microbiome, Christian-Albrechts-University of Kiel, Kiel, Germany

${ }^{c}$ Department of Soil Science, Christian-Albrechts-University of Kiel, Kiel, Germany

${ }^{d}$ Department of Biogeochemistry of Agroecosystems, University of Göttingen, Göttingen, Germany

${ }^{e}$ School of Agriculture and Environment, The University of Western Australia, Perth, WA, 6009, Australia

\begin{abstract}
Protein typically represents the largest input of organic nitrogen $(\mathrm{N})$ into soil. Proteases subsequently make this protein available for use by both plants and microorganisms, however, the factors that regulate protein breakdown in the rhizosphere remain limited. Root exudation of carbon (C) and $\mathrm{N}$ into soil promotes microbial growth and thus enzyme production, which is further enhanced by root morphological traits such as root hairs. However, it is not clear how inputs of protein from external sources (e.g. necromass) affect enzyme activity in the rhizosphere. Insight into the interaction between protein addition and root morphology will enhance our knowledge of plant and microbial strategies for promoting $\mathrm{N}$ acquisition. Using soil zymography, we investigated the spatial distribution of leucine aminopeptidase activity in the rhizosphere of Hordeum vulgare L. (barley) with and without root hairs subject to localised protein addition. Seedlings of barley were grown for two weeks in rhizoboxes and soluble protein was applied $48 \mathrm{~h}$ before analysis of leucine aminopeptidase activity. In situ zymography was used to quantitatively visualise leucine aminopeptidase activity while ex situ sampling was used to determine its enzyme kinetics. In the zymograms, we found that mean and maximal leucine aminopeptidase activity was highest in the barley genotype with root hairs and in the presence of soil protein hotspots. This suggests that microorganisms and plant roots in the rhizosphere of genotypes with root hairs have a greater advantage in accessing protein hotspots in the soil. Leucine aminopeptidase activity did not follow the same trends when analysed by in situ zymography and ex situ sampling methods. Therefore, we recommend the use of in situ zymography to detect the spatial distribution of enzymatic hotspots and rhizosphere extent followed by ex situ sampling for assessing enzyme kinetics in the hotspot areas detected by in situ sampling. However, sampling biases must be considered to ensure enzyme activities are being interpreted as the true rhizosphere.
\end{abstract}

Keywords: Nitrogen mineralization, Enzyme activity, Soil zymography, Soil organic matter

*Corresponding author: 1.greenfield@bangor.ac.uk 


\title{
Study 11: The geographical scale dependence of diazotroph assembly and activity: Effect of a decade fertilization
}

Xiangtian Meng a,b,c, Hongkai Liao ${ }^{\text {d }}$, Haoxin Fan ${ }^{\mathrm{e}}$, Xuechen Zhang ${ }^{\mathrm{f}}$, Yaying Li ${ }^{\mathrm{a}, \mathrm{b}}$, Huaiying Yao a,b,e,*, Bahar S. Razavi ${ }^{\mathrm{g}}$

\section{Status: Published in Geoderma}

${ }^{a}$ Key Laboratory of Urban Environment and Health, Institute of Urban Environment, Chinese Academy of Sciences, Xiamen 361021, People's Republic of China

${ }^{b}$ Zhejiang Key Laboratory of Urban Environmental Processes and Pollution Control, Ningbo Urban Environment Observation and Research Station-NUEORS, Institute of Urban Environment, Chinese Academy of Sciences, Ningbo 315800, People's Republic of China

c University of Chinese Academy of Sciences, Beijing 100049, People's Republic of

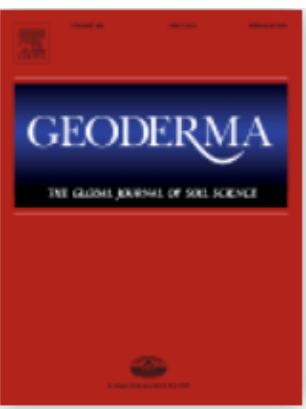
China

${ }^{d}$ Guizhou Provincial Key Laboratory of Mountain Environment, Guizhou Normal University, Guiyang 550001, People's Republic of China

e Research Center for Environmental Ecology and Engineering, School of Environmental Ecology and Biological Engineering, Wuhan Institute of Technology, Wuhan 430073, People's Republic of China

${ }^{f}$ Department of Biogeochemistry of Agroecosystems, University of Göttingen, Göttingen, Germany

${ }^{g}$ Department of Soil and Plant Microbiome, Institute of Phytopathology, Christian-Albrecht-University of Kiel, Kiel, Germany

\begin{abstract}
Biological nitrogen $(\mathrm{N})$ fixation is one of the most significant parts of the $\mathrm{N}$ cycle in terrestrial ecosystems, and this process is carried out by soil diazotrophs. However, knowledge of diazotroph assembly processes and activity in response to diverse fertilization strategies in agroecosystems across a large geographical scale is still lacking. Here, we selected nine agroecological experimental sites that covered a wide geographical distance $(\sim 3500 \mathrm{~km})$ at a continental scale, and investigated the diazotrophic communities, assembly processes, distance-decay patterns and $\mathrm{N}_{2}$ fixation activity in response to geographical factors and longterm fertilization strategies. The results showed that the dominant genera were Bradyrhizobium ( $\sim 30.5 \%)$ and Azospirillum ( 26.8\%) in all samples, and RDA analysis showed that the relative abundance of Bradyrhizobium was positive correlated with MAP while specific negatively correlated with soil $\mathrm{pH}$ and the relative abundance of Azospirillum. Geographical factors (location and climate) and fertilization collectively drive diazotroph assembly processes and determine diazotroph activity. Diazotroph assembly processes were influenced by both stochastic $(\sim 36.2 \%)$ and deterministic $(\sim 63.8 \%)$ processes simultaneously at large geographical scales and under various fertilization strategies. Moreover, fertilization increased the proportion of deterministic processes under various fertilization strategies. The $\mathrm{N}$ fixation rate was determined by local soil properties. Fertilization changes but does not always suppress nitrogen fixation activity. Both geographical factors and fertilization through the shift of diazotroph community composition and the changes in soil properties, indirectly affected the assembly process and $\mathrm{N}$ fixation rate. Among soil properties, $\mathrm{pH}$ was
\end{abstract}


the dominant factor and linearly related to diazotrophs assembly process, while $\mathrm{N}$ fixation rate reached peak at near-neutral $\mathrm{pH}$. These results elucidate the mechanism of soil diazotroph assembly process and activity shaped by both geographical factors and fertilization; thus, expand the current understanding of the diazotroph community affected by fertilization strategies across a large geographical scale.

Keywords: Long-term fertilization, Soil diazotroph, Community assembly, Nitrogen fixation rate, Spatial scale dependence

*Corresponding author: hyyao@iue.ac.cn 


\section{Study 12: Effects of plastic and straw mulching on soil microbial $P$ limitations in maize fields: Dependency on soil organic carbon demonstrated by ecoenzymatic stoichiometry}

Zizong Ma a , Xucheng Zhang ${ }^{b}$, Bangyu Zheng a , Shanchao Yue ${ }^{\text {a,d }}$, Xuechen Zhang e, Bingnian Zhai a, Zhaohui Wang ${ }^{\text {a, }}$ Wei Zheng ${ }^{\text {a,* }}$, Ziyan Li ${ }^{\text {a,c,d, }}$, Kazem Zamanian ${ }^{\mathrm{f}}$, Bahar S. Razavi e,f

\section{Status: Published in Geoderma}

${ }^{a}$ College of Resources and Environment, Northwest A\&F University, Yangling, 712100, China

${ }^{b}$ Key Laboratory of High Water Utilization on Dryland of Gansu Province, Lanzhou 730070, China

${ }^{c}$ Key Laboratory of Plant Nutrition and the Agri-environment in Northwest China, Ministry of Agriculture, Yangling, 712100, China

${ }^{d}$ State Key Laboratory of Soil Erosion and Dryland Farming on the Loess Plateau, Northwest A\&F University, Yangling, 712100, China

${ }^{e}$ Department of Biogeochemistry of Agroecosystems, University of Göttingen, Göttingen 37077, Germany

${ }^{f}$ Department of Soil Plant Microbiome, University of Kiel, Kiel, Germany

\section{Abstract}

Mulching rain-fed farmland ecosystems changes the soil physicochemical properties, especially soil organic carbon (SOC), but the metabolic limitations of soil microorganisms after these changes are unclear. We established a long-term experiment in 2012 with three treatments: no mulch (CK), straw mulch (SM), and plastic film mulch (FM). In 2019 the soil enzyme activities were measured in five maize growing periods: planting time, sixleaf period, silking period, milk period, and physiological maturity. Extracellular enzymatic stoichiometry models were used to examine microbial metabolic limitations. The vector length and angle were employed to determine the $\mathrm{C}$ and $\mathrm{N} / \mathrm{P}$ limitations of soil microorganisms. Compared with $\mathrm{CK}$, the average SOC and total nitrogen (TN) contents were 9.7\% and 7.8\% higher under SM, respectively, in each period. The SOC, TN, and total phosphorus (TP) contents were 5.6\%, 4.8\%, and 2.8\% lower under FM, respectively. Compared with $\mathrm{CK}$, the Cand $\mathrm{N}$-acquiring enzyme activities were $20.5 \%$ and $5.2 \%$ lower under FM, respectively. The alkaline phosphatase enzyme activities were $2.7 \%$ and $13.5 \%$ higher under SM and FM, respectively, than CK. Soil nutrients, $\mathrm{pH}$, and temperature influenced the $\mathrm{C}$ and $\mathrm{P}$ limitations of soil microorganisms. The different $\mathrm{P}$ limitation responses under SM and FM were mainly due to SOM. The decomposition of SOC was a key source of soil available P. The soil hydrothermal conditions under FM accelerated the decomposition of SOC in the early years, thereby increasing the P limitation. However, longterm SM increased the SOC due to the annual input of straw and its decomposition released available $\mathrm{P}$ to alleviate the $\mathrm{P}$ limitation for microorganisms. Thus, the temperature, water, $\mathrm{pH}$, and SOC affect the $\mathrm{P}$ limitation for microbes under mulching conditions, but the SOC content of alkaline soil in arid farmland is the main factor that leads to microbial P limitation.

Keywords: Ecoenzymatic stoichiometry, microbial metabolism, mulching measures, rain-fed agricultural ecosystem

*Corresponding author: zheng_wei@nwafu.edu.cn, liziyan0161@126.com 


\title{
Study 13: Changes in nutrient balance, environmental effects, and green development after returning farmland to forests: A case study in Ningxia, China
}

Ziyan Li ${ }^{\text {a,b,1, }}$ Xiting Sun ${ }^{\text {a,1 }}$, Zuhui Huang a , Xuechen Zhang ${ }^{\text {a }}$, Zhaohui Wang a , Shiqing Li

c, Wei Zheng ${ }^{\text {a,****, Bingnian Zhai }}{ }^{\text {a,*,**}}$

\section{Status: Published in Science of the Total Environment}

${ }^{a}$ College of Resources and Environment, Northwest A\&F University,

712100 Yangling, China

${ }^{b}$ Institute of Dryland Farming, Gansu Academy of Agricultural Sciences, Lanzhou 730000, China

${ }^{c}$ State Key Laboratory of Soil Erosion and Dryland Farming on the Loess Plateau, Northwest A\&F University, Yangling 712100, China

\begin{abstract}
Returning sloping farmland ( $>25^{\circ}$ ) to forest/grassland (RFTF) is an effective ecological measure for soil and water conservation. However, changes in nutrient cycles and green development are still unclear. Ningxia, in Northwestern China, began to implement RFTF in 2000. Here, we used the NUFER model to calculate the input and loss of nitrogen and phosphorus, utilization efficiency, production and consumption at food-chain scale in Ningxia for the period 1985-2015. Five aspects comprised the evaluation of green development: society, economy, resources, environment, and productivity. Results showed that forest coverage rate increased from $7.74 \%$ to $33.2 \%$, while cropping area decreased by $6.6 \% . \mathrm{NH}_{3}$ loss increased from 53,000 to 83,000 tons (56\%), $\mathrm{N}_{2} \mathrm{O}$ increased from 1200 to 2300 tons (92\%) and leaching loss from 18,000 to 62,000 tons (240\%). Phosphorus leaching loss increased from 13,000 to 35,000 tons (130\%). The environmental cost of food nitrogen per unit of production decreased from 8 to $6.7 \mathrm{~kg} / \mathrm{kg}(19.4 \%)$. Nitrogen and phosphorus use efficiencies decreased by $4.8 \%$ and $58 \%$ in crops-animal systems, respectively, but increased by $652 \%$ and $430 \%$ in animal husbandry systems. The proportion of animal protein production increased from $18.3 \%$ to $39.0 \%(113 \%)$. The major source of organic waste was livestock and poultry manure and urine (70\%). Indicators for achieving green development level increased from 14 to 18 (14.7\%). Improving the level of scientific and technological management of aquaculture system, increasing the proportion of organic matter returned to farmlands, and paying attention to the combination of planting and breeding will effectively promote future cycling efficiency of nitrogen and phosphorus in the food chain, and the sustainability of agriculture towards green development.
\end{abstract}

Keywords: Grain-for-green, Productivity, Nutrient flow, Nitrogen use efficiency

*Corresponding author: zheng_wei@nwafu.edu.cn, bingnianzhaitg@126.com 


\section{Declarations}

1. I, hereby, declare that this $\mathrm{Ph} . \mathrm{D}$. dissertation has not been presented to any other examining body either in its present or a similar form.

Furthermore, I also affirm that I have not applied for a Ph.D. at any other higher school of education.

Göttingen,

$$
\text { Xuechen zhang }
$$

(Signature)

2. I, hereby, solemnly declare that this dissertation was undertaken independently and without any unauthorized aid.

Göttingen,

$$
\text { Xuechen zhang }
$$

(Signature) 